ATTI

-1 - 



\title{
Humanity from African Naissance to Coming Millennia
}

\author{
Colloquia in Human Biology \\ and Palaeoanthropology
}

Editors

Phillip V. Tobias, Michael A. Raath, Jacopo Moggi-Cecchi and Gerald A. Doyle

assisted by Kevin L. Kuykendall and Himla Soodyall

Firenze University Press - 2001

Witwatersrand University Press - 2001 
Humanity from African Naissance to Coming Millennia : Colloquia in Human biology and Palaeonthropology / editors Phillip V. Tobias, Michael A. Raath, Jacopo Moggi-Cecchi and Gerald A. Doyle. - Firenze : Firenze University Press, 2001. (Atti ; 1).

ISBN 88-8453-003-2 (print)

ISBN 88-8453-003-2 (online PDF)

(C) 2001 Firenze University Press

Printed in Italy

The Dual Congress '98 symbol (by Nils Burwitz) is shown on the cover and its meaning is explained by the Artist: "In order to illustrate succinctly the motivations of a unique combined congress of palaeoanthropology and human biology, indeed to bring under one hat the opposites of 'making the Dead speak and the Living lecture', I made a skull face its vibrant mirror image: i.e. the profile of Sterkfontein specimen Sts 5 mirrors a set of chromosomes in the anaphase of mitosis, the last energetic burst of cell division, twisted into a three-dimensional shape. Both are gently wrapped up in strands of a section of the DNA double-helix, thus indirectly doffing our hat to Watson and Crick." 


\section{Foreword}

There was an air of excitement at Sun City, South Africa, in late June of 1998, as delegates started to arrive for the Dual Congress of the International Association of Human Biologists and the International Association for the Study of Human Palaeontology. For the conference organisers, under chairmanship of Professor Phillip V. Tobias, this was the culmination of four years of hard work and planning and, as Phillip remarked at the opening ceremony, it was also a symbolic homecoming to the continent of humanity's birth for people from all parts of the world. The delegates did indeed come from far and wide: they travelled from 70 countries and the registration list ran to 745 people, making this the most representative gathering of its kind ever held in Africa.

As a venue for the exchange of new information on the biology and ancestry of humankind, the Dual Congress provided ample scope. The programme was built around 18 Colloquia, in which 95 invited papers were delivered, and 11 Open Scientific Sections, covering a wide range of topics, discussed in 103 papers, as well as in 79 poster presentations. Nor were the contributions of South African pioneers in the field forgotten: the Raymond Dart Memorial Lecture was given by Sir Walter Bodmer while Professor Tobias delivered the Robert Broom Memorial Lecture, the text of which is reproduced in this volume, together with those of 38 invited papers presented in the Colloquia of the Dual Congress.

In addition to all this however, I believe that the occasion was a celebration for another important reason: it was a demonstration of South Africa's re-acceptance into the wide world of international science with respect to human biology and palaeontology. During the apartheid era, science in this country passed through a bleak period when people like myself had difficulty in travelling to many African countries on a South African passport and when the focus of public interest, with respect to human origins, shifted from this country, where the initial critical finds had been made, to East Africa, where spectacular fossils were coming to light. Such discoveries in lake-side and alluvial deposits certainly have the advantage of precise radiometric dating from associated volcanic ashbeds. But the palaeontological and cultural treasures from our South African caves should never be underestimated. They have yielded vital insights into human origins during the dark times of recent years and will continue to do so into a brighter future.

In all respects, the Dual Congress reflected in this volume, was a milestone occasion for South Africa and for international science at large. It was a privilege for me to have been associated with it

C. K. Brain

Honorary President, The Dual Congress Pretoria 


\section{Susan C. Antón', Fachroel Aziz \& Yahdi Zaim ${ }^{3}$}

\author{
${ }^{1}$ Department of Anthropology \\ University of Florida, Gainesville \\ FL 32611 USA
}

${ }^{2}$ Geological Research \& Development

Center, Bandung 40122, Indonesia

${ }^{3}$ Department of Geology

Institute of Technology

Bandung, 40132, Indonesia

Keywords: Homo erectus, biological invasions, energetics, diffusion coefficient, Indonesia, Africa

\section{Plio-Pleistocene Homo: Patterns and Determinants of Dispersal}

The first 2.5 million years of hominid history is characterized by limited dispersals similar to those of the living great apes whose home range sizes very little between years. Unlike our closest relative Pan, who are particulary vulnerable during dispersal because the distribution of their resources is highly habitat specific and predation takes a relatively higher toll than it does in r-selected animals, hominids are widely dispersed after 1.8 Ma. Hominid dispersal must have entailed either a shift in the types of resources exploited or a technological advance to ensure resource availability or both. Using data from ecology, geochronology, morphology, and paleontology we assess the initial hominid dispersal from Africa and the relationship to patterns of dispersal in nonhuman primates and large mammals of both 'widely dispersing' and 'non-dispersing' species. The dispersal rates of Plio/Pleistocene hominids differ from those of nonhuman primates and are typical of widely-dispersing large mammals. In fact, $H$. erectus first appears in Java almost immediately after its appearence in Africa, yet its first appearence in Java is contemporaneous with that of Colobus, Macaca, and Pongo that had already inhabited mainland Asia for millions of years. Although the timing of the first hominid dispersal pre-dates significant technological advances, the energy required by larger hominid body/brain sizes suggest a shift to exploitation of highprotein packages that, according to correlation between faunal and chronometric sequences, is itself dispersing. These data suggest that it is at the origin of $H$. erectus (sensu lato) that our uniquely human dispersal capabilities began to emerge and that this dispersal is not primarily due to the technological innovation of the Acheulean tradition.

\section{Introduction}

The global distribution of Homo sapiens contrasts with the restricted ranges of our closest living primate relative, Pan. Yet for some three million years after our lineages diverged, both were apparently exclusively African phenomena, as Pan remains today. These current biogeographic differences are reflected in home range (HR) sizes that are some 15 to 100 times greater in recent human huntergatherers than in Pan. (23 hectares in Pan, 330-2600 in humans; Leonard and Robertson, 2000). Although an extensive literature considers the significance of the behavioral repertoire that allows the final, relatively late, dispersal of Homo sapiens into Australasia, North and South America, and Siberia (e.g., Lindly \& Clark, 1990; Roberts et al., 1991; Davidson \& Noble, 1992; Jelinek, 1994; Waters et al., 1997), the origin of this difference in dispersal patterns is not well understood.

The original hominid dispersal from Africa has been viewed as a largely hominid (technologically) driven rather than ecologically driven phenomenon. Such scenarios are based on the idea that widely 
dispersed ex-African hominids are not found before 1.0 ma (Pope, 1983) or are not found before the development of the Acheulean (Wolpoff, 1999), and thus that there was a delay of nearly 1.0 my between the appearance of relatively large-brained/bodied hominids in Africa and their wide dispersal from Africa. This delay, or rather the acquisition of the ability to leave Africa, has been attributed to increasingly complex cognitive and technological capabilities typified by the Acheulean tradition (Wolpoff 1999:443) that likely signalled a shift in subsistence ecology (Klein, 1989:219). That is, technological and cognitive innovation allowed or sparked the original hominid dispersal from Africa.

Such a scenario has certain detractions including the fact that Acheulean type handaxes are rare or absent in East and Southeast Asian sites that form the earliest and geographically most distant exAfrican record (e.g. Movius, 1948; Beltwood, 1985; Keates, 1994) and that other mammals, including carnivores, megaherbivores, bovids, and equids dispersed between Africa and Asia without aid of Acheulean technology (Kurten, 1968; Antures, 1989; Opdyke, 1995). Likewise, hints from radiometric dating suggested that ex-African hominid sites existed in Southeast Asia much in excess of 1.0 Ma (Jacob \& Curtis, 1971).

Recent work in Java has confirmed not only the greatest age of 1.81 Ma for Mojokerto (Perning I), but has also shown that the main hominid bearing strata at Sangiran are all older than 1.0 Ma (Swisher et al., 1994; Swisher, 1996). Other Asian and West Asian sites have also been suggested to predate $1.0 \mathrm{Ma}$ including Longuppo (China, 1.8 Ma), Dmanisi (Georgia, 1.7 Ma), and Ubeidiya (Israel, 1.3-1.4 Ma; Tchernov 1987; Gabunia \& Vekua, 1995; Huang et al., 1995). For the purposes of dispersal pattern, however, it is the oldest and geographically most distant evidence that is of greatest importance (see below).

Although the Javan dates stand at odds with conventional wisdom, the data are numerous, internally and stratigraphically consistent and based on more reliable radiometric techniques (argon-argon) than previous temporal estimates (either fission-track or biostratigraphy; e.g., Sondaar, 1984; Watanabe \& Kadar, 1985). Likewise, the uncertainties surrounding the provenience of the Javanese fossil hominids have been grossly overstated; for some, provenience is unknown, but others, or portions of others, were found in situ (e.g, von Koenigswald, 1940; Anton \& Franzen, 1997), and for still others the purported find sites have been confirmed by chemical analysis (Matsu'ura, 1982). These data continue to place most of the Sangiran hominids in the Bapang (Kabuh) formation (as old as $1.5 \mathrm{Ma}$ ) and some hominids in the upper Sangiran (Pucangan) formation (1.66 Ma; Swisher et al., 1994; Swisher, 1996). In addition, fauna from the two formations exhibit significant preservational differences resulting from the compaction of bone by the black clays of the Sangiran formation. These differences are also present in the hominids from the Sangiran formation but not those from the Bapang formation. Thus mounting evidence suggests a much earlier exodus from Africa than originally conceived.

The timing of the earliest ex-African sites no longer supports the idea that a cognitive delay preceded the first hominid dispersal since the earliest hominids from Java predate or are coeval with the appearance of the first of the larger bodied/brained hominids in Africa (H. erectus, sensu lato) and with the earliest occurrence of the Acheulean (1.4-1.6 Ma; Asfaw et al., 1992). In addition, the first exAfrican areas occupied by $H$. erectus could be accessed via southern continental Asia without the substantial environmental shift required by the later, more northerly occupations by $H$. erectus. This eliminates an additional argument for why technological innovation needed to precede hominid dispersal. In short, the first dispersal was earlier than previously envisioned and apparently not preceded by Acheulean technology, it was also relatively sudden, and undertaken by a relatively large brained/large bodied hominid. Thus a solely technological impetus for hominid dispersal seems unlikely.

While technology may still be an important contributing factor in the dispersal, it is increasingly important to consider the ecological context of this first dispersal. We examine this first hominid dispersal in light of recent and ancient mammalian dispersals to elucidate the motivating ecological factors behind mammalian dispersals and to identify universal characteristics exhibited by widely dispersing species. There are two general approaches for considering dispersal capabilities, one recently 
presented by Leonard \& Robertson (2000) models HR size and diet quality in fossil hominds and other primates from body weight estimates, whereas we consider the characteristics of the first hominid dispersal using techniques developed to study extant biological invasions (see below).

\section{Universals of widely dispersing animals}

Widely dispersed extant and extinct species share certain characteristics. First, by definition, they cover a broad geographic range. Thus they tend to be animals with broad ecological tolerance (Lidicker and Stenseth, 1992a; Ehrlich, 1989). Related to this ranging behavior, widely dispersed species also tend to have large HR sizes, and thus body sizes for their group, and are often gregarious (Ehrlich, 1989). In addition, widely-dispersed species tend to be polytypic and to have a relatively long fossil record. For example, species with highly dispersing larvae persist twice as long in the geologic record as do nondispersing forms (Hansen, 1978).

The absolute area over which a species is dispersed and the yearly ranging behavior of its members are interrelated but not identical phenomena. Both relate to foraging strategy which in turn relates to energy requirements, body size, and group size. HR is positively correlated with diet quality, body size, and group size (McNab, 1963; Milton \& May, 1976; Leonard \& Robertson,2000). However, larger animals require differentially larger HR sizes, probably due both to differentially increased energetic needs for body maintenance and because HRs of larger animals are often more open, less productive, and encompass more non-productive lacunae than do smaller HRs (Harestad \& Bunnell, 1979). In addition, animals inhabiting more northern latitudes have differentially larger HR sizes than their tropical congeners, probably due to clinal increases in body size and decreases in environmental productivity with latitude (Bergmann, 1847; Allen, 1877)

Leonard \& Robertson (2000) have recently shown that in primates, including humans, HR size scales strongly positively allometrically with diet quality (DQ) and body size. Humans exhibit a significant qualitative shift in DQ and body size relative to great apes that is reflected in the vastly larger HR size of recent hunter-gatherers mentioned earlier (see below for more detail). Using fossil evidence, Leonard \& Robertson suggest that this significant shift in foraging strategy and diet quality in our lineage may coincide with the first hominid dispersal. To establish a causal link between this inferred change in foraging strategy and hominid dispersal, it is necessary to find a separate means of assessing the rate of the hominid dispersal relative to other mammals, especially other primates (see below).

\section{Issues faced by dispersing animals}

Dispersing animals face high fitness costs. These challenges differ somewhat between dispersals into areas previously uninhabited by the species in question and those into territories already inhabited by this or a closely related group. In the latter category, dispersal into another group of the same species may carry significant reproductive benefits for the disperser, whereas competition with conspecifics or congeners may significantly slow dispersal (Pusey, 1992; Waser, 1996). The ultimate success of dispersal also depends in part upon whether dispersal is attempted by an individual animal or by a group of animals. In gregarious species, dispersal by pairs or groups of individuals is often more successful than that by solitary individuals (Waser, 1996). The issues faced by dispersers into new, uninhabited territories are likely to be more similar to those faced by $H$. erectus during its original dispersal. Likewise, because no other hominids lived outside Africa, the first successful dispersal must have involved a group of hominids or several groups over time.

Dispersers into new, uninhabited territories must deal effectively with the so-called Allee or low density effects resulting from dispersal. These include increased predation (Isbell et al., 1990), difficulty in finding a mate (Stenseth \& Lidicker, 1992), difficulty in finding food/water (Waser \& Jones, 1983), and perhaps a change in parasite load due to differing environments (overviews in Stenseth \& Lidicker, 1992a,b; Williamson, 1996). The severity of these effects is in part related to the goodness of fit between 
the animal and the environment into which it is moving. Thus these effects are lessened in cases where animals move into a territory occupied by other groups of the same species, presumably because the ecological fit, as witnessed by the success of these other groups, is good. In all cases, dispersal increases mortality risk (Arnold, 1990; Waser, 1996). This increase is commonly viewed as the result of increased vulnerability to predators, but may also reflect resource stress or intraspecific competition. Field data from gregarious carnivores, including those of small body size, suggest that the increased mortality rate of animals which disperse into already occupied territories, either to join existing groups or to begin their own, is related to intraspecific aggression rather than increased predation (Waser, 1996). Additionally, although dispersers into existing groups may have difficulty finding a mate, in most cases the disperser is likely to be escaping either from reproductive suppression or inbreeding and thus, in effect, is in a potentially better breeding position than was the case prior to dispersal (Pusey, 1992; Waser, 1996).

Despite high fitness costs, animals do disperse into new territories and other groups, and thus correspondingly high rewards must exist. Unfortunately, there are very few universals regarding why animals disperse. Field studies and theoretical considerations suggest that animals disperse both when population size exceeds carrying capacity and when it does not (Grant, 1978; Stenseth \& Lidicker, 1992b), when the environment is stable and when it is vacillating (Hamilton \& May, 1977), when it is harsh and when it is not (Arnold, 1990; Lidicker \& Stenseth, 1992a), and when there is intraspecific or interspecific competition or aggression and when there is not (Pusey, 1992; Waser, 1996). And although most invasions into new territories are unsuccessful following the 'rule of 10s', in which only $10 \%$ of invasive species become established and only $10 \%$ of these become numerous enough to be pests, a good ecological match between disperser and environment can raise the success rate to $100 \%$ (Williamson, 1996). Thus the field studies of extant mammals offer good evidence of what the important obstacles to dispersal might have been for $H$. erectus, but they provide little guidance as to the likely causes of such dispersal.

\section{Recent dispersals: pattern and efficiency and the diffusion coefficient (D)}

The need to make predictions about recent biological invasions by pest species of plants and animals has instigated the careful study of extant dispersals and the development of methodologies to model these invasions (Drake et al., 1989; Williamson, 1996). The diffusion coefficient (D) considers the efficiency and speed with which a group invades a new region based on certain known variables:

1) $D^{1 / 2}=z /(t)\left(2 r^{1 / 2}\right)$

where $z$ is the square root of area invaded in kilometers, $t$ is the time over which invasion occurred in years, and $r$ is a life history variable, the intrinsic rate of natural increase of the species.

There are only a few extant mammals for which there are sufficiently good field data to reliably track $D$. All of these are relatively small bodied, northerly latitude mammals. They include the sea otter (Enhydra lutris) as it repopulated the California coastline, the muskrat (Ondatra zibethicus) invading central Europe, and the gray squirrel (Sciurus carolinensis) as it invades and competes with the red squirrel (Sciurus vulgaris) in England. Values of $D$ for these species vary between $0.4 \mathrm{~km}^{2}$ and $230 \mathrm{~km}^{2}$ per annum and exhibit great geographical variation within species (Williamson, 1996). This variation partly reflects the goodness of the ecological fit between species and new territory and whether the new territory is already occupied by a closely related, competitive species (see above). In particular, the interactions between gray and red squirrels in England have delayed the dispersal of the gray to $7.7 \mathrm{~km}^{2}$ per annum, and ultimately may eliminate the red squirrels since gray squirrels are behaviorally more plastic and ecologically more tolerant (Williamson, 1996). It should be noted that all of the animals for which we have data are located in more northerly latitudes with correspondingly larger HRs, as mentioned above, and that 
for these reasons their $D$ s are likely to be somewhat higher than if they were tropically located groups.

\section{Ancient Primate dispersals}

We have made gross calculations of $D$ for $H$. erectus and fossil macaques to compare between primate taxa and with the recent well documented dispersals described above. Only two primate dispersals are considered because very few primates offer a sufficient fossil record to attempt even a gross estimate of $D$. A similar geographic region is covered by both dispersals, although significantly greater time is covered by the macaque dispersal. We use the first appearance datum (FAD) of each group in the geographically most distant extents of their distribution to calculate $t$, and the square root of area between these FADs as $z$. Estimates of $r$ from closely related extant primates are used. Estimates of $z$ and $t$ were made that systematically favored higher estimates of $D$ for macaques and lower estimates of $D$ for $H$. erectus in order to be as generous as possible in our assessment of whether $D$ s for non-human primates and $H$. erectus might closely approximate one another on the basis of reasonable evidence from the fossil record. In addition, $D$ as calculated for Macaca is probably larger than it would be for a single fossil macaque species since several species may be represented across the original dispersal area. However, because of their generalized skeletal morphology and the difficulties of distinguishing macaque species, $D$ is calculated for the genus.

For macaques, $z$ is $4525 \mathrm{~km}, t$ is $1.5 \mathrm{Ma}$ as calculated from FADs of 5.3-5.5 Ma in eastern Spain (MN13, Casablanca-M; M. sp., Andrews et al., 1996), and 3.5-2.5 Ma in India (M. paleindica; Szalay \& Delson, 1979). However, an alternate shorter time of $0.5 \mathrm{Ma}$ to 10000 years is also used on the basis of two presumably macaque molars from the Yushe Basin, China (Delson, 1996) which, although currently unpublished, are from the upper Mahui Fm, which dates to between 6.0 and 5.0 Ma (Tedford et al., 1991) and whose upper layers are 5.5 to $5 \mathrm{Ma}$. An $r$ of $5.0 \%$ is used (Sade et al., 1977). Higher $r$ values would lower $D$ values. In addition, Macaca colonized Java by $c a$. $1.5 \mathrm{Ma}$ (M. sp; Bapang Formation, Sangiran; Swisher, chronology). These FADs suggest a variably slow, steady wave of macaque dispersal into Asia, the ultimate origin of which is suggested to be from N. Africa via the straits of Gibraltar, although this continues to be debated (Andrews et al., 1996).

A range of variables was used to estimate $D$ in $H$. erectus. In contrast to macaque estimates, every effort was made to be conservative regarding the speed and extent of the dispersal in H. erectus in order to ascertain whether a 'typical' primate model, given enough time, could account for the hominid dispersal as well. As such, the smallest area invaded was estimated as a narrow band beginning in East rather than South Africa and including only coastal India/East Asia (south of the Tibetan plateau) and island Southeast Asia as far as Java. Based on this, $z$ for H. erectus is $4382 \mathrm{~km}$. The time to occupy was estimated between a low, geologically unresolvable, 10000 years on the basis of the lack of difference between the earliest Javan and East African dates (FADs of $\sim 1.8$ Ma for each; Swisher et al., 1994; Howell, 1994) and 200000 years based on the difference between the oldest Sangiran dates (1.66 Ma) and those from East Africa. And $r$ values were based on a range from human hunter gatherers of between $1.0 \%$ and $1.5 \%$ per annum (Blurton-Jones, et al., 1992). Lower values for $r$ would raise estimates of $D$.

Based on the values provided above, $D$ ranges between 0.01 and $4.80 \mathrm{~km}^{2}$ per annum for $H$. erectus and $0.000045 \mathrm{~km}^{2}$ per annum for Macaca based on the early chronology, and 0.00041 to $1.0 \mathrm{~km}$ per annum based on the short chronology. The values for $H$. erectus are at the low end of the range for $D$ in dispersing extant mammals mentioned above and are clearly much higher than most of those for fossil macaques. Based on equivalently short time spans of 10000 years for dispersal, even the largest macaque $D$ values are nearly five times smaller than those of $H$. erectus. This difference between $H$. erectus and Macaca is not too surprising considering that for most primates in stable environmental conditions, group HR shifts little from year to year (Isbell et al., 1990), although individual animals, particularly males, may travel rather large distances to join other groups (Pusey \& Packer, 1987). Unlike Cachel \& Harris (1998), we do not see marked similarity between the dispersal patterns of Macaca and 
H. erectus, except perhaps in their ecological tolerance. However, we believe that it is only at the later periods of $H$. erectus that its ecological tolerance approaches the northerly tolerance of Macaca and thus we have limited our estimates of early dispersal area to only a narrow southerly route. Had we included more northerly areas (increasing $z$ ), making tolerance more like Macaca, differences in $D$ values between the two would have been even greater, re-emphasizing the difference in initial dispersal patterns between the two. And although the $H$. erectus values are at the low end of the recent mammal ranges, it is likely that this difference is exaggerated by comparing tropically adapted H. erectus with more northerly adapted recent mammals. That is, were we comparing $H$. erectus dispersal with that in tropically adapted mammals, the $D$ values would be more similar between the two groups. Differences may also be exaggerated by the much finer time scale allowed in the examination of modern versus ancient dispersals. It should be noted that none of these estimates is based on the size or morphology of fossil remains; that is, except for establishing the FADs in different locations, estimates of $D$, and therefore any implications drawn from them, are independent of fossil morphology.

\section{Ancient hyaenid dispersals}

We also consider the pattern of ancient dispersals in Crocuta crocuta and Pachycrocuta (Pliohyaena) brevirostris. These species are chosen because they have a well-documented fossil record providing reliable, widely distant FADs, because they cover a similar geographic range as $H$. erectus, and because they do not change species designations across this range. $D$ values for these ancient carnivores cannot be calculated because their FADs are synchronous across large parts of their ranges and thus the time interval $(t)$ of spread cannot be ascertained. For the same reason the directionality of the dispersals are disputed in both cases; although both species are present in Africa and Asia, there is debate as to their continent of origin (Kurten, 1968; Masini \& Torre, 1989; Savage, 1978; Savage \& Russell, 1983; Werdelin \& Solounias, 1991,1996).

Both hyaenids are found over a larger area in Africa and Asia and in more northerly latitudes than $H$. erectus ever occupied and, unlike H. erectus, they are also present in Europe (Kurten, 1968; Savage, 1978; Savage \& Russell, 1983; Werdelin \& Solounias, 1991). Thus the area invaded is quite a lot larger than that initially invaded by $H$. erectus. Both hyaenids appear throughout much of their ranges nearly instantaneously; C. crocuta first appears later in the Pliocene or early Pleistocene 'Makapanian' of Africa (Late Pliocene/Early Pleistocene at ?Hadar, Omo Shungura 6, Olduvai beds I and II, Sterkfontein Member 4, Swartkrans; Savage, 1978; Savage \& Russell, 1983 - although Werdelin \& Solounias [1996] suggest it first appeared in the Ruscinian = Early Pliocene, MN 14-15, ultimately from eastern Asia) and colonized Europe and Asia in the Plio-Pleistocene, whereas P. brevirostris exhibits a rapid spread throughout Europe and Asia when late Villafranchian associations were becoming established (e.g., Olivola and Nihewan, circa 1.5-2.0 Ma; Masini \& Torre, 1989) and is additionally found in island Southeast Asia as early as 1.5 Ma at Kedung Brubus (based on Swisher's chronology). In addition, P. brevirostris or a very closely related species occurs in the Plio-Pleistocene 'Makapanian' of East and South Africa, including at Kromdraai A, Sterkfontein, and Makapansgat among others, with its antecedants in S. Africa by the middle Pliocene (Howell \& Petter, 1980; Masini \& Torre, 1989). If the life histories of these hyaenids can be modeled on recent species, their $r$ s should be higher than those of $H$. sapiens. Taken together, if we were to estimate a short, geologically invisible, interval of say 10000 years for dispersal, $D$ values following equation (1) would be somewhat higher than in $H$. erectus. But the pattern seen in the fossil record, with nearly synchronous FADs over large areas, would be more similar between $H$. erectus and the hyaenids than that seen in Macaca, where a fairly clear wave of arrival from west to east can be documented (see above).

\section{$D$ for $H$. erectus suggests larger HRs and a shift in foraging strategy}

$D$ values for $H$. erectus, although not following primate patterns, are consistent with dispersal coefficients in extant mammals. Thus the virtually instantaneous appearance of H. erectus in Southeast 
Asia and Africa is not without precedent in the mammalian record.

However, $D$ as calculated for $H$. erectus suggests a dispersal pattern and thus a foraging strategy that is unlike fossil and recent primates (here and Leonard \& Robertson, 2000). These same Ds also suggest a similar if somewhat slower pattern of dispersal than is seen in (presumably) gregarious fossil carnivores. It should he noted again that every effort has been made to be conservative in the construction of $D$ for $H$. erectus; larger areas or smaller $r$ values would only raise $D$ values. However, longer time intervals would lower these values. The time interval needed for $H$. erectus to approach the macaque values is 2 million years at an $r$ of $1.5 \%$ per year $(D=0.00008)$. Even earlier estimates of delayed dispersal did not suggest such an extended dispersal time.

Given the comparison of $D \mathrm{~s}, H$. erectus patterns suggest larger HRs and a concomitant shift in foraging behavior, and following Leonard \& Robertson (in press), an increase in diet quality. Despite the similarity in pattern to gregarious carnivores, additional data for other types of foragers, particularly herbivores, are necessary before specific conclusions regarding foraging niche can be drawn from $D$ values alone. It should again be noted that $D$ values are not dependent upon fossil morphology.

\section{Is $\boldsymbol{H}$. erectus morphology consistent with large $\mathrm{HRs}$ and a change in foraging strategy?}

HR size, energetic requirements, and ultimately foraging strategies can also be estimated from the fossil remains themselves. Numerous authors have recognized the high metabolic cost of brain tissue and explored this in relation to the brain and body size changes seen at the origin of H. erectus compared with conditions in early Homo and Australopithecus (e.g., Foley \& Lee, 1991; Leonard \& Robertson, 1992, 1994, 1996; Aiello \& Wheeler, 1995). Leonard \& Robertson (1997) have recently examined total energy expenditure (TEE) in H. erectus and used postcranial measures from various fossil hominids to estimate body weight and HR size in order to predict diet quality (Leonard \& Robertson, 2000). Based on a sample of 47 non-human primate taxa and 6 human groups, they suggest that, regardless of the model used to estimate body weight, there was an 8- to 10-fold increase in the HR size of $H$. erectus compared with that of $H$. hahilis and Australopithecus, which share similar HR sizes and, by implication, foraging strategies. These results are consistent with but independent of the results from the mammalian dispersal comparisons for HR and foraging strategy

\section{A model for hominid dispersal from Africa}

Taken together, these independent lines of evidence converge on the conclusion that it is at the origin of $H$. erectus that a shift occurred in HR size, energy requirements, and foraging strategy that allowed ex-African dispersal (here and Leonard \& Robertson, 2000). This has implications for why dispersal occurred when it did, rather than requiring technological breakthroughs.

In order for a species to disperse (expand its range) it must be able to do so both geographically and physiologically. The Sahara desert might be an obvious geographic barrier to ex-African dispersal and may well have been important in later Pleistocene hominid dispersals (Foley, this congress). However, paleoenvironmental reconstructions suggest that such a desert was not an inhibiting factor prior to or during the time of the initial hominid dispersal. Models suggest that a desert was established in the western Sahara by 2.6 Ma, but not before, and that expansions and shifts in its range increased in the Pleistocene (deMenocal \& Bloemendal, 1995). However, projections also suggest that this desert was much less extensive in the Pliocene than is the recent Sahara and that a large corridor of savanna extended from eastern Africa into Israel (Prism project, 1995). Thus the presence of an impassable desert is not likely to be responsible for the limited hominid dispersal prior to the origin of $H$. erectus.

In the physiological realm, prior to the emergence of the longer limbed, larger brained H. erectus, energy requirements and by inference ranging behavior do not imply large shifts in HR size (Leonard \& Robertson, 2000). However, body and brain size dramatically increase in H. erectus, raising TEE by 
some 45\% (Leonard \& Robertson, 1997) and thus demanding a higher quality of diet for survival. This occurrence slightly postdates extensive expansion of the African savanna in which the bovid biomass increases substantially (Vrba, 1995; Beherensmeyer, 1997). Because of increasing TEE, the larger number of bovids would prove a compelling resource if hominids could access them either by hunting or scavenging (Leonard \& Robertson, 2000). And there is some evidence, inferred from the pathological condition of KNM-ER 1808, that animal protein of some sort may have been available to these hominids (Walker et al., 1982 but contra Skinner, 1991). In addition, there is a growing body of data suggesting other significant biological shifts at the origin of $H$. erectus that are consistent with, and perhaps correlated to, increasing TEE requirements (e.g., Walker \& Leakey, 1993; Wood \& Collard, 1999 for a synthesis). These changes include increases in brain and, particularly, body size, changes in developmental pattern (e.g., Smith, 1993) and perhaps the insertion of an adolescent growth spurt similar to that seen in modern humans (Tardieu, 1998; Antón, in press; contra Bogin \& Smith, 1996). In addition, the African archaeological record becomes increasingly complex beginning just after the appearance of $H$. erectus at $1.8 \mathrm{Ma}$ (Cachel \& Harris, 1998).

However, animals do not always disperse even given both geographic and physiological capabilities to do so (Woodburne \& Swisher, 1995). There is often a delay between FADs in two regions even when both the above criteria are met, thus suggesting that an additional catalyst may be necessary. In the case of $H$. erectus, in addition to lacking both geographic and physiological barriers to dispersal, during the Plio-Pleistocene there is significant faunal interchange between Africa, Europe, and Asia, particularly of bovids (Kurtén, 1963; Opdyke, 1995; Vrba, 1995). Thus if there was an increased intimacy between hominids and bovids, and if bovids were dispersing, we might have the answer to the alleviation of some of the Allee effects. That is, by following the protein source, the difficulty of finding food and water is obviated in a way not possible for an animal reliant upon patchy, seasonal or ephemeral resources that are more difficult to locate without great familiarity with the environment (e.g. Milton, 1980; Jolly, 1985).

Thus from an evolutionary perspective first the protein biomass increased in response to increasing niche opportunities on the African Savanna (approximately 2.5-1.8 Ma; Behrensmeyer et al., 1997) following which hominids of slightly larger body and brain size took advantage of this new resource, either by hunting or scavenging, and in so doing differentially increased their own reproductive success (see Leonard and Robertson, 1997). Thus ecological changes (increases in bovids, and savanna environments, decreases of forests) provide an opportunity for favoring increases in body and brain size that correlates with increases in energy requirements, changes in foraging strategy, and increases in HR size, and thus the ability to disperse. Likewise, the dispersing bovids provide not only a dietary resource, but also a dispersing impetus, and an alleviation of some of the Allee effects.

Despite the overwhelmingly ecological tone of this scenario, it is not entirely atechnological in origin. Cultural intervention (stone tools?) was probably critical in facilitating access to the protein sources and may have been critical to predation control during dispersal, perhaps by means of fire, although evidence of the latter is scant in the archaeological record (controlled? fire is present as early as 1.6 Ma in East Africa; Bellomo, 1994 and perhaps slightly earlier in South Africa, 1.5-1.8 Ma. Brain \& Sillen, 1988). The strength of this scenario rests in its positioning of early hominids within an ecological context and its incorporation of independent lines of evidence to identify the origin of the shift in foraging strategy necessary for HR size increase and thus the ability to disperse widely. These data suggest that it is at the origin of H. erectus (sensu lato) that our uniquely human dispersal capabilities began to emerge.

\section{Acknowledgments}

We are grateful to Dr. B. Wood for the invitation to participate in the 1998 Dual Congress. Drs. M. Collard, W.R. Leonard, H. Schwarcz, and C.C. Swisher, III provided valuable discussion. 


\section{References}

Aiello, L.C. \& Wheeler, P. (1995). The expensive-tissue hypothesis: The brain and digestive system in human and primate evolution. Curr. Anthropol., 36,199-221.

Allen, J.A. (1877). The influence of physical conditions on the genesis of species. Radiol. Rev., 1, 108-40.

Andrews, P., Harrison, T., Delson, E., Bernor, R.L. \& Martin, L. (1996). Distribution and biochronology of European and Southwest Asian Miocene catarrhines. In: The Evolution of Western Eurasian Neogene Mammal Faunas, ed. R.L. Bernor, V. Fahlbusch, \& H-W. Mittman, pp.168-207. New York: Columbia University Press.

Antón, S.C. (In press 1999). Cranial Growth in Homo erectus. In: Human Evolution Through Developmental Change, ed. N. Minugh-Purvis \& K. McNamara. Baltimore: Johns Hopkins University Press.

Antón, S.C. \& Franzen, J.L. (1997). The occipital torus and developmental age of Sangiran-3. J. Hum. Evol., 33, 599-610.

Antunes, M.T. (1989). The proboscideans data, age and paleogeography: evidence from the Miocene of Lisbon. In: European Neogene Mammal Chronology, ed. E.H. Lindsay, V. Fahlbusch, \& P. Mein, pp. 253-63. New York: Plenum Press.

Arnold, W. (1990). The evolution of marmot sociality: I - why disperse late? Behav. Ecol. Sociobiol., 27, 229-37.

Asfaw, B., Beyene, Y., Suwa, G., Walter, R., White, T., WoldeGabriel, G. \& Yemane, T. (1992). The earliest Acheulean from Konso-Gardula. Nature, 360, 732-35.

Behrensmeyer, A.K., Todd, N.E., Potts, R. \& McBrinn, G.E. (1997). Late Pliocene faunal turnover in the Turkana basin, Kenya and Ethiopia. Science, 278, 1589-94.

Bellomo, R.V. (1994). Methods of determining early hominid behavioral activities associated with the controlled use of fire at FxJj 20 Main, Koobi Fora, Kenya. J. Hum. Evol., 27, 173-95.

Bellwood, P. (1985). Prehistory of the Indo-Malaysian Archipelago. New York: Academic Press.

Bergmann, C. (1847). Über die verhaltnisse der warmeokonomie der tiere zu ihrer grosse. Göttingen Studien, 1, 595-708.

Blurton-Jones, N.G., Smith, L.C., O'Connell, J.F., Hawkes, K. \& Kamuzora, C.L. (1992). Demography of the Hadza, and increasing and high density population of savanna foragers. Amer. J. Phys. Anthropol., 89,159-81.

Bogin, B.\& Smith, B.H. (1996). Evolution of the human life cycle. Amer. J. Hum. Biol. 8, 703-16

Brain, C.K. \& Sillen, A. (1988). Evidence from the Swartkrans cave for the earliest use of fire. Nature, 336, 464-66.

Cachel, S. \& Harris, J.W.K. (1995). Ranging patterns, land-use and subsistence in Homo erectus from the perspective of evolutionary ecology. In: Evolution and Ecology of Homo erectus. eds., Bower, J.R.F. \& S. Sartono, pp. 51-66. Leiden: Pithecanthropus Centennial Foundation.

Cachel, S. \& Harris, J.W.K. (1998). The lifeways of Homo erectus inferred from archaeology and evolutionary ecology: a perspective from East Africa. In: Early Human Behaviour in Global Context: The rise and diversity of the lower paleolithic record, eds., M.D. Petraglia \& R. Korisettar, pp.108-132. New York: Routledge.

Davidson, I. \& Noble, W. (1992). Why the first colonisation of the Australian region is the earliest evidence of modern human behavior. Persp. Hum. Biol. Archaeo1. Oceania, 27, 113-19.

Delson, E. (1996). The oldest monkeys in Asia. In: Abstracts, International Symposium: Evolution of Asian Primates. ed, O. Takenaka, p. 40 (abstract). Inuyama, Japan. Primate Research Institute.

deMenocal, P.B. \& Bloemendal, J. (1995). Plio-Pleistocene climatic variability in subtropical Africa and the paleoenvironment of hominid evolution: a combined data-model approach. In: Paleoclimate and Evolution, with Emphasis on Human Origins, ed. E.S. Vrba, G.M. Denton, T.C. Partridge \& L.M. Burkle, pp: 262-88. New Haven: Yale University Press.

Drake, J.A., Mooney, H.A., Castri, F. di, Groves, R.H., Kruger, F.J., Rejmanek, M. \& Williamson, M. (eds) (1989). Biological Invasions: A global perspective. New York: John Wiley and Sons.

Ehrlich, P.R. (1989). Attributes of invaders and the invading process: vertebrates. In: Biological Invasions: A global perspective, ed. J.A. Drake, H.A. Mooney, F. di Castri, R.H. Groves, F.J. Kruger, M. Rejmanek, \& M. Williamson, pp. 315-28. New York: John Wiley and Sons.

Foley, R.A. \& Lee, P.C. (1991). Ecology and energetics of encephalization in hominid evolution. Philos. Trans. R. Soc. London, B, 334, 223-32.

Gabunia, L. \& Vekua, A. (1995). A Plio-Pleistocene hominid from Dmanisi, East Georgia, Caucasus. Nature, 373, 509-12.

Gasaway, W.C., Dubois, S.D., Preston, D.J. \& Reed, D.J. (1985). Home range formation and dispersal of subadult moose in interior Alaska. Alaska Dept. Fish Game, Final report, Project W-22-2, Job 1.26R.

Grant, P.R. (1978). Dispersal in relation to carrying capacity. Proc. Nat. Acad. Sci., 75, 2854-58. 
Hamilton, W.D. \& May, R.M. (1977). Dispersal in stable habitats. Nature, 269, 578-81.

Hansen, T.A. (1978). Larval dispersal and species longevity in lower Tertiary gastropods. Science, 199, 885-87.

Harestad, A.S. \& Bunnell, F.L. (1979). Home range and body weight: a re-evaluation. Ecology, 60, 389-402.

Huang, W., Ciochon, R., Yumin, G., Larick, R., Qiren, F., Schwarcz, H., Yonge, C., de Vos, J. \& Rink, W. (1995). Early Homo and associated artefacts from Asia. Nature, 378, 275-78.

Howell, F.C. (1994). A chronostratigraphic and taxonomic framework of the origins of Modern Humans. In: Origins of Anatomically Modern Humans, ed. M.H. Nitecki \& D.V. Nitecki, pp. 243-320. New York: Plenum Press.

Howell, F.C. \& Petter, G. (1980). The Pachycrocuta and Hyaena lineages (Plio-Pleistocene and extant species of the Hyaenidae). Their relationships with Miocene ictitheres: Palhyaena and Hyaenictitherium. Geobios, 13, 579-623.

Isbell, L.A., Cheney, D.L. \& Seyfarth, R.M. (1990). Costs and benefits of home range shifts among vervet monkeys (Cercopithecus aethiops) in Amboseli National Park, Kenya. Behav. Ecol. Sociobiol., 27, 229-37.

Jacob, T. \& Curtis, G.H. (1971). Preliminary potassium-argon dating of early man in Java. University of California, Berkeley, Archaeological Research Facility, Contributions, 12, 50.

Jelinek, A.J. (1994). Hominids, energy, environment, and behavior in the late Pleistocene. In: Origins of Anatomically Modern Humans, ed, M.H. Nitecki \& D.V. Nitecki, pp. 67-92. New York: Plenum Press.

Jolly, A. (1985). The Evolution of Primate Behavior, 2nd edition. New York: MacMillan.

Keates, S.G. (1994). Archaeological evidence of hominid behavior in Pleistocene China. In: 100 Years of Pithecanthropus, the Homo erectus problem. ed. J.L. Franzen, pp. 33-46 Courier Forschungsinstitut Senckenberg, vol. 171.

Klein, R.G. (1989). The Human Career: human biological and cultural origins. Chicago: University of Chicago Press.

Kurtén, B. (1968). Pleistocene Mammals of Europe. Chicago: Aldine Publ. Co.

Koenigswald, G.H.R. von (1940). Neue Pithecanthropus-Funde 1936-1938, Ein Beitrag zur Kenntnis der Praehominiden. Wetenschappelijke Mededeelingen, 28, 7-14.

Leonard, W.R. \& Robertson, M.L. (1992). Nutritional requirements and human evolution: a bioenergetics model. Amer. J. Hum. Biol., 4, 179-95.

Leonard, W.R. \& Robertson, M.L. (1994). Evolutionary perspectives on human nutrition: the influence of brain and body size on diet and metabolism. Amer. J. Hum. Biol., 6, 77-88.

Leonard, W.R. \& Robertson, M.L. (1996). On diet, energy metabolism and brain size in human evolution. Curr. Anthropol., 37, 125-29.

Leonard, W.R. \& Robertson, M.L. (1997). Comparative primate energetics and hominid evolution. Amer. J. Phys. Anthropol., 102, 265-81.

Leonard, W.R. \& Robertson, M.L. (2000). Ecological correlates of home range variation in primates: implications for hominid evolution. In: On the Move: How and Why Animals Travel in Groups, ed. S. Boinski \& P. Garber, pp. 628-648 Chicago: Univ. Chicago Press.

Lidicker, W.Z. \& Stenseth, N.C. (1992). To disperse or not to disperse: who does it and why? In: Animal Dispersal: Small Mammals as a Model, ed. W.Z. Lidicker \& N.C. Stenseth, pp. 21-36. New York: Chapman Hall.

Lindly, J.M. \& Clark, G.A. (1990). Symbolism and modern human origins. Curr. Anthropol., 31, 233-61.

Masini, F. \& Torre, D. (1989). Large mammal dispersal events at the beginning of the late Villafranchian. In: European Neogene Mammal Chronology, ed. E.H. Lindsay, V. Fahlbusch \& P. Mein, pp.131-38. New York: Plenum Press.

Matsu'ura, S. (1982). A chronological framing for the Sangiran hominids: fundamental study by the fluorine dating method. Bull. Natl. Sci. Mus. Tokyo, Ser. D 8, 1-53.

McNab, B.K. (1963). Bioenergetics and the determination of home range size. Amer. Nat., 97, 133-40.

Milton, K. (1980). The Foraging Strategy of Howler Monkeys. New York: Columbia University Press.

Milton, K. \& May, M.L. (1976). Body weight, diet and home range in primates. Nature, 259, 459-62.

Movius, H.L. (1948). The lower Paleolithic cultures of southern and eastern Asia. Trans. Amer. Phil. Soc., new series, 38, 329-420.

Opdyke, N.D. (1995). Mammalian migration and climate over the last seven million years. In: Paleoclimate and Evolution, with Emphasis on Human Origins, ed. E.S. Vrba, G.M. Denton, T.C. Partridge \& L.M. Burkle, pp:109-14. New Haven: Yale University Press.

Pope, G.G. (1983). Evidence on the age of the Asian Hominidae. Proc. Ntl Acad. Sci., 80, 4988-92. 
PRISM Project Members (1995). Middle Pliocene paleoenvironments of the Northern Hemisphere. In: Paleoclimate and Evolution, with Emphasis on Human Origins, ed. E.S. Vrba, G.M. Denton, T.C. Partridge \& L.M. Burkle, pp: 197-212. New Haven: Yale University Press.

Pusey, A.E. (1992). The primate perspective on dispersal. In: Animal Dispersal: Small Mammals as a Model, ed. W.Z. Lidicker \& N.C. Stenseth, pp.243-59. New York: Chapman Hall.

Pusey, A.E. \& Packer, C. (1987). Dispersal and philopatry. In: Primate Societies, ed. B.B. Smuts, D.L. Cheney, R.M. Seyfarth, R.W. Wrangham \& T.T. Struhsaker, pp. 250-66. Chicago. University of Chicago Press.

Roberts, R.G., Jones, R. \& Smith, M.A. (1991). Thermoluminescence dating of a 50,000 year old human occupation site in northern Australia. Nature, 345, 153-56.

Sade, D.S., Schneider, J. M., Figueroa, A., Kaplan, J.R., Chepko-Sade, B.D., Cushing, K., Cushing, P., Dunaif, J., Morse, T., Rhodes, D. \& Stewart, M. (1977). Population dynamics in relation to social structure on Cayo Santiago. Yearbook of Physical Anthropology, 20, 253-62.

Savage, R.J.G., (1978). Carnivora. In: Evolution of African Mammals, ed. V.J. Maglio \& H.B.S. Cooke, pp. $249-67$. Cambridge (Mass.): Harvard University Press.

Savage, D.E. \& Russell, D.E. (1983). Mammalian Paleofaunas of the World. Reading: Addison-Wesley.

Skinner, M. (1991). Bee brood consumption: an alternative explanation for hypervitaminosis A in KNM-ER 1808 (Homo erectus) from Koobi Fora, Kenya. J. Hum. Evol., 20, 493-503.

Smith, B.H. (1993). The physiological age of KNM-WT 15000. In: The Nariokotome Homo erectus skeleton, eds., A. Walker \& R. Leakey, pp.195-220. Cambridge (Mass.): Harvard University Press.

Sondaar, P.Y. (1984). Faunal evolution and the mammalian biostratigraphy of Java. Cour. Forsch. Inst. Senckenberg, 69, 219-35.

Stenseth, N.C. \& Lidicker, W.Z. (1992a). The study of dispersal: a conceptual guide. In: Animal Dispersal: Small Mammals as a Model, ed. W.Z. Lidicker \& N.C. Stenseth, pp.5-20. New York: Chapman Hall.

Stenseth, N.C. \& Lidicker, W.Z. (1992b). Pre saturation and saturation dispersal 15 years later: some theoretical considerations. In: Animal Dispersal: Small Mammals as a Model, ed. W.Z. Lidicker \& N.C. Stenseth, pp.199224. New York: Chapman Hall.

Swisher, C.C., Curtis, G.H., Jacob, T., Getty, A.G., Suprijo, A. \& Widiasmoro, (1994). Age of the earliest known hominids in Java, Indonesia. Science, 263, 1118-21.

Swisher, C.C. (1996). Toward a revised geochronology for the hominid-bearing stratigraphy of Java, Indonesia (abstract). Paleoanthropology Society Annual Meetings, New Orleans.

Szalay, F. \& Delson, E. (1979). Evolutionary History of the Primates. New York: Academic Press.

Tardieu, C. (1998). Short adolescence in early hominids: infantile and adolescent growth of the human femur. Amer. J. Phys. Anthropol. 107, 163-78.

Tedford, R.H., Flynn, L.J., Zhanxiang, Q, Opdyke, N.D. \& Downs, W.R. (1991). Yushe Basin, China; Paleomagnetically calibrated mammalian biostratigraphic standard for the late Neogene of eastern Asia. J. Vert. Paleo., 11, 519-26.

Tchernov, E. (1987). The age of the 'Ubeidiya Formation, an early Pleistocene hominid site in the Jordan Valley, Israel. Israel Journal Earth Sciences, 36, 3-30.

Vrba, E.S. (1995). The fossil record of African antelopes (Mammalia, Bovidae) in relation to human evolution. In: Paleoclimate and Evolution, with Emphasis on Human Origins, ed. E.S. Vrba, G.M. Denton, T.C. Partridge \& L.M. Burkle, pp: 385-424. New Haven: Yale University Press

Walker, A. \& Leakey, R. (eds). (1993). The Nariokotome Homo erectus skeleton. Cambridge (Mass.): Harvard University Press.

Walker, A., Zimmerman, M. \& Leakey, R. (1982). A possible case of hypervitaminosis A in Homo erectus. Nature, 296, 248-50.

Waser, P.M. (1996). Patterns and consequences of dispersal in gregarious carnivores. In: Carnivore Behavior, Ecology, and Evolution, vol. 2. pp. 267-95. Ithaca: Cornell Univ. Press.

Watanabe, N. \& Kadar, D. (eds) (1985). Quaternary Geology of the Hominid Fossil Bearing Formations in Java. Geological Research and Development Center, Bandung, Indonesia. Special Publications no. 4.

Waters, M.R., Forman, S.L. \& Pierson, J.M. (1997). Diring Yriakh: a lower Paleolithic site in central Siberia. Science, 275, 1281-84.

Werdelin, L. \& Solounias, N. (1991). The Hyaenidae: taxonomy, systematics and evolution. Fossils \& Strata, 30, 1104.

Werdelin, L. \& Solounias, N. (1996). The evolutionary history of hyaenas in Europe and West Asia during the 
Miocene. In: The Evolution of Western Eurasian Neogene Mammal Faunas, ed. R.L. Bernor, V. Fahlbusch \& HW. Mittman, pp. 290-306. New York: Columbia University Press.

Williamson, M. (1996). Biological Invasions. New York: Chapman Hall.

Wolpoff, M.H. (1999). Paleoanthropology, 2nd edition. San Francisco: McGraw-Hill.

Wood, B. \& Collard, M. (1999). The human genus. Science, 284, 65-71.

Woodburne, M.O. \& Swisher, C.C. (1995). Land mammal high-resolution geochronology, intercontinental overland dispersals, sea level, climate, and vicariance. In: Geochronology, Time Scales and Global Stratigraphic Correlations, SEPM Special Publication, 54, 335-64. 


\section{List of Contributors}

\section{Francisco Aboitiz}

Instituto de Ciencas Biomedicas

Universidad de Chile

Independencia Avenida \#1027,

P O Box 70079, Santiago 7, Chile

faboitiz@machi.med.uchile.cl

\section{Tatyana I. Alexeeva}

Institute and Museum of Anthropology,

Moscow State University

\section{Susan Anton}

Department of Anthropology,

University of Florida,

Gainesville, FL 32611 USA

anton@nervm.nerdc.ufl.edu

\section{Juan-Luis Arsuaga}

Dept. Paleontologia, Universidad Complutense,

Ciudad Universitaria,

Madrid 28040, Spain

azara@eucmax.sim.ucm.es

\section{Fachroel Aziz}

Geological Research \& Development Center, Bandung 40122, Indonesia

\section{Jean-Pierre Bocquet-Appel}

EP 1781, Musée de l'Homme, 17, place du Trocadéro,

75116 Paris, France

bocquet@mnhn.fr

\section{Charles Brain}

Transvaal Museum,

P O Box 413,

Pretoria 0001, South Africa

brain@tm.up.ac.za

\section{Günter Bräuer}

Institute of Human Biology,

University of Hamburg,

Allende-Platz 2,

20146 Hamburg, Germany

\section{D.C. Broadfield}

Dept. of Anthropology,

City University of New York,

NY, NY 10036, USA

\section{Leigh Broadhurst}

1315 Harding Lane,
Silver Spring MD 20905-4007, USA

cleigh@cais.com

\section{Michel Brunet}

Laboratoire Paleontologie Humaine,

Université de Poitiers, Faculté des Sciences,

40 Avenue Recteur Pineau,

Poitiers - Cedex 86022, France

michel.brunet@cri.univ-poitiers.fr

\section{Camilo Cela-Conde}

Department of Philosophy,

Universidad de las Islas Baleares,

07071 Palma de Mallorca, Spain.

cela@atlas-iap.es

\section{Philip Chase}

Museum of Archaeology \& Anthropology,

University of Pennsylvania,

Philadelphia PA 19104-6324, USA

pchase@sas.upenn.edu

\section{Mark Collard}

Department of Anthropology,

University College London,

Gower Street, London,

WC1 6BT UK

m.collard@ucl.ac.uk

John Czelusniak,

Wayne State University School of Medicine, Department of Anatomy and Cell Biology,

540 E. Canfield Avenue,

Detroit, Michigan 48201, USA

\section{Sergio U. Dani}

Laboratory of Gerontogenetics and Gene Therapy, Medical School,

University of São Paulo Ribeirão Preto,Brazil udani@nodel.com.br

\section{Hilary Deacon}

Department of Archaeology,

University of Stellenbosch,

Private Bag X1, Matieland 7602,

South Africa

hjd@akad.sun.ac.za

\section{Simon Easteal}

Human Genetics Group,

John Curtin School of Medical Research,

The Australian National University,

Canberra, ACT 0200, Australia 


\section{Morris Goodman}

Dept. of Anatomy \& Cell Biology,

Wayne State University School of Medicine 540 E. Canfield Avenue,

Detroit MI 48201 USA

mg@tree.roc.wayne.edu

\section{Frederick Grine}

Department of Anthropology,

State University of New York,

Stony Brook NY 11794-4364 USA

fgrine@epo.som.sunysb.edu

\section{Colin Groves}

Department of Archaeology,

Australian National University,

Canberra, ACT 0200 Australia

groves@anu.edu.au

\section{Ralph Holloway}

Department of Anthropology,

Columbia University,116th \& Broadway,

New York NY 10027, USA

rlh2@columbia.edu

\section{Jan Jelinek}

Moravske Museum, Zelny trh 6, Brno 65937,

Czech Republic

anthrop@mzm.anet.cz

\section{Harry Jerison}

Department of Psychiatry,

University of California 503 W. Rustic Road, Santa Monica CA 90402-1115, USA

hjerison@ucla.edu

\section{Rhys Jones}

Archaeology \& Natural History Division, Australian National University Research

School of Pacific \& Asian Studies,

Canberra 0200 Australia

rhys@coombs.anu.edu.au

\section{Kenneth A. R. Kennedy}

Ecology \& Systematics,

Cornell University Corson Hall,

Ithaca NY 14853 USA

kak10@cornell.edu

\section{Julia A. Lee-Thorp}

Archaeometry Research Unit,

Department of Archaeology,

University of Cape Town,

Private Bag, Rondebosch 7701, South Africa jlt@beattie.uct.ac.za

\section{Giorgio Manzi}

Dipartimento Biologia animale e dell' Uomo, Università di Roma "La Sapienza",

P. Aldo Moro 5, Rome 00185, Italy

G.Manzi@, caspur.it

\section{Carla M. Meireles}

Wayne State University School of Medicine, Department of Anatomy and Cell Biology, 540 E. Canfield Avenue, Detroit, Michigan 48201, USA

\section{Virendra Misra}

Post-Graduate \& Research Institute, Deccan College, Pune 411006, India deccan.college@gems.vsnl.net.in

\section{Jacopo Moggi-Cecchi}

Istituto di Antropologia, Università di Firenze,

Via del Proconsolo 12, Firenze 50122, Italy jacopo@unifi.it.

\section{Scott Page}

Wayne State University School of Medicine, Department of Anatomy and Cell Biology, 540 E. Canfield Avenue, Detroit, Michigan 48201, USA

\section{John Parkington}

Department of Archaeology,

University of Cape Town, Rondebosch 7701, South Africa

jep@beattie.uct.ac.za

\section{David Penny}

Institute of Molecular BioSciences

Massey University, Palmerston North

New Zealand

\section{Carlo Peretto}

Dipartimento di Scienze Geologiche e

Paleontologiche,

Università degli Studi di Ferrara,

Corso Ercole I d'Este, 32, 44100

Ferrara, Italyme4@dns.unife.it

\section{Janusz Piontek}

Institute of Anthropology,

University of Poznan, PL 61-701 Poznan,

Poland, Fredry 10

Piontek@main.amu.edu.pl. 
Marcia S. Ponce de León

Anthropological Institute,

University of Zurich

Winterthurerstrasse 190, Zurich 8057,

Switzerland

marcia@ifi.unizh.ch

\section{G. Philip Rightmire}

Department of Anthropology,

State University of New York at Binghamton,

Binghamton NY 13902, USA

gpright@bingvmb.cc.binghamton.edu

\section{Richard G. Roberts}

Department of Earth Sciences,

La Trobe University, Melbourne, VIC 3083,

Australia

\section{Henry P. Schwarcz}

School of Geography \& Geology,

McMaster University, Hamilton,

Ontario L8S 4M1, Canada

schwarcz@mcmaster.ca

\section{Daniel Sellen}

Departments of Anthropology \& International

Health,

Emory University,

Geosciences Building, 1557 Pierce Drive,

NE, Atlanta, GA 30322, USA

dsellen@emory.edu

\section{Guanjun Shen}

Dept. Chemistry, Guishou University, Guiyang Ghuizhou 550025, China (address for correspondence: Institute for Coastal and Quaternary Studies, Nanjing Normal University, Nanjing 210097, P. R. China)

gishen@chem.gzu.edu.sn

\section{Andrew Sillen}

Department of Archaeology

University of Cape Town Rondebosch 7701

South Africa

sillen@beattie.uct.ac.za

\section{Anna Siniarska}

Department of Human Ecology:

Institute of Ecology,

Polish Academy of Sciences, Warsaw, Poland and CINVESTAV, Merida, Mexico

\section{Naoyuki Takahata}

Biosystems Science,

Graduate University for Advanced Studies,

Hayama Kanagawa 240-0193, Japan

takahata@soken.ac.jp

\section{Mark Teaford}

Dept. of Cell Biology \& Anatomy,

Johns Hopkins University,

725 N. Wolfe Street, Baltimore,

MD 21205, USA

mteaford@welchlink.welch.jhu.edu

Phillip V. Tobias F.R.S.

Department of Anatomical Sciences,

University of the Witwatersrand

Medical School 7 York Road,

Parktown 2193, South Africa

055pvts@chiron.wits.ac.za

\section{Peter Ungar}

Department of Anthropology,

University of Arkansas, Old Main 330,

Fayetteville AR 72701, USA

pungar@comp.uark.edu

\section{John Vogel}

QUADRU, c/o Environmentek, CSIR

P O Box 395, Pretoria 0001, South Africa

\section{Elizabeth Watson}

Institute of Molecular Biosciences,

Massey University, Palmerston North,

New Zealand

e.watson@massey.ac.nz

\section{Napoleon Wolanski}

Department of Human Ecology,

Polish Academy of Sciences, Nowy Swiat 72,

Warsaw 00330, Poland

and CINVESTAV, Merida, Mexico

hanzar@plearn.edu.pl

\section{Bernard Wood}

Department of Anthropology,

George Washington University,

2110 G Street NW, Washington DC 20052,

USA bwood@qwis2.circ.gwa.edu

\section{S. Yuan}

Department of Anthropology,

Columbia University 116th \& Broadway,

New York, NY 10027, USA

\section{Yahdi Zaim}

Department of Geology, Institute of Technology, Bandung, 40132, Indonesia

\section{Christoph Zollikofer}

Anthropological Institute, University of

Zurich, Winterthurerstrasse 190, Zurich 8057 ,

Switzerland

zolli@ifi.unizh.ch 


\section{Phillip V. Tobias \\ OMSG, FRS, NAS}

Department of Anatomical Sciences, University of the Witwatersrand, Johannesburg

Keywords: Australopithecus, acceptance, rejection, conversion

\section{Conversion in Palaeo-Anthropology: The Role of Robert Broom, Sterkfontein and other Factors in Australopithecine Acceptance}

\author{
$8^{\text {th }}$ Robert Broom Memorial Lecture
}

(By permission of the Transvaal Museum of Natural History, this lecture was delivered as part of the Dual Congress programme at Sun City, South Africa on 29 June 1998. It was repeated at the Transvaal Museum, Pretoria, on 19 October 1998.)

This lecture deals with the question of why some new discoveries and new hypotheses in science are sometimes rejected -or ignoredfor long periods, before they gain ultimate acceptance, whilst others are avidly accepted immediately. In the field of human origins, a classical example is that of Raymond Dart's claims in 1925 for the little child skull found the previous year at Taung not far from Kimberley. He called it Australopithecus africanus and claimed that it was an African ape which had taken decisive steps in a human direction: it was, he suggested, a "missing link". The world, with few exceptions, rejected Dart's claims for over twenty years. Yet the claims, like the fossil itself, did not simply go away. After the second World War, several prominent scientists, such as Sir Wilfred LeGros Clark of Oxford, came to accept the validity of Dart's earlier idea. Tobias speaks of their conversion to belated acceptance of the human-like affinities of Australopithecus, and states that the concept of conversion can be applied in scientific research just as in theology and ideology. He then goes on to examine the factors that were responsible for this particular conversion. He shows that Broom's monograph on the australopithecine fossils from Taung, Sterkfontein and Kromdraai played a crucial role in turning the tide and in converting many scholars. Tobias's analysis brings to light that three or four kinds of factors were instrumental in this delayed conversion: people - most notably Broom and LeGros Clark; new discoveries - such as more and more australopithecine fossils, of different ages, genders, species and geological epochs; the overturning of deterrents - fixed ideas such as the Asian origin of humankind, that had hindered people from accepting Australopithecus; and new facts - such as the information freshly recorded on great apes. Three factors stand out as having been mainly responsible for effecting the conversion. The first was Sterkfontein and its amazing wealth of hominid fossils, providing the possibility, for the first time, to study not merely individual fossils but fossil populations. The second was Broom, a remarkably energetic and productive scientist who demonstrated, through his discoveries a Kromdraai, and those he made with John Robinson at Swartkrans, that southern Africa had been populated by a variety of apemen, not all of whom were ancestors of later hominids; and the third was LeGros Clark whose meticulous, comparative studies did more than anything else to convince human palaeontologists that the australopithecines were hominids. In the history of science and discovery, acceptance, rejection and conversion are critical factors.

There are many ways to convert an audience or one's colleagues to a viewpoint previously rejected. One way I shall never forget: as an Honours student, I listened to Robert Broom expounding his views on human evolution at the University of the Witwatersrand Medical School. On the chalkboard, he 


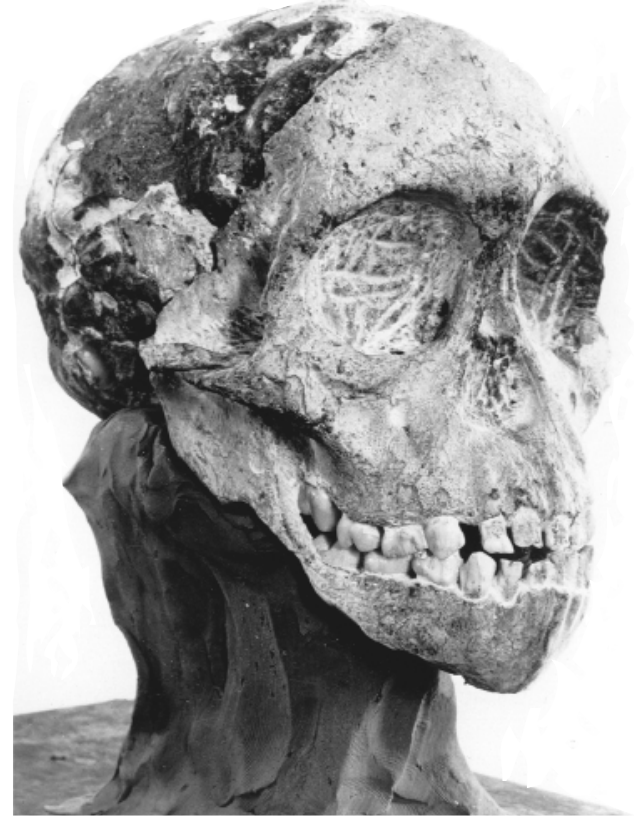

Figure 1. Three-quarter view of the skull of the Taung child, type specimen of Australopithecus africanus, mounted on a plasticine plinth. This photograph was taken early in 1925 before Dart had cut through the narrow connection between the right ramus and the right corpus of the mandible, the connection being shown here as a narrow isthmus.

rapidly sketched three different family trees of mankind: one was his own, one was that of Sir Arthur Keith and, if my memory serves me aright, the third was that of sir Frederic Wood Jones. All three were different. "You can accept," said Broom, "that, since they are all talking about the same thing, they cannot all be correct".

"For practical purposes, you can disregard this one - it's hopelessly wrong!" - and he vigorously erased Keith's tree. "Don't give any thought to this one; it's quite out of date" - and he proceeded to liquidate poor Wood Jones with great sweeps of the blackboard duster - "and that leaves just Broom's tree, which must be correct!"

How many of the 600 members of his audience he converted to the Broomian interpretation I am not sure, but he moved great numbers to amusement and adoration of the speaker. As a 21 year-old, I think I learned more about the fey and puckish personality of Robert Broom than I did about human evolution.

Just 53 years since I first sat at Broom's knee as an undergraduate medical science student and since he first took me and my fellow-students to Sterkfontein and Kromdraai, it is an honour to deliver this $8^{\text {th }}$ Robert Broom Memorial Lecture

\section{Delayed acceptance in scientific discovery}

When one examines the history of palaeo-anthropology in the $20^{\text {th }}$ century, one is struck by the lengthy delays that sometimes followed new discoveries before they were generally accepted. For years I have been examining this question. I wondered why Dart's claim that Australopithecus stood on the threshold of humanity took such a long time to be accepted (Figures 1, $2 \& 3$ ). Although he published the claim in 1925, it was not until the early 1950s that the nod of approval was received from the anthropological establishment. Was this case unique?, I pondered.

Then, I found myself involved in another instance of the same sort. In 1964 Louis Leakey, John Napier and I published in Nature our claim that some remains which had been found by members of the 


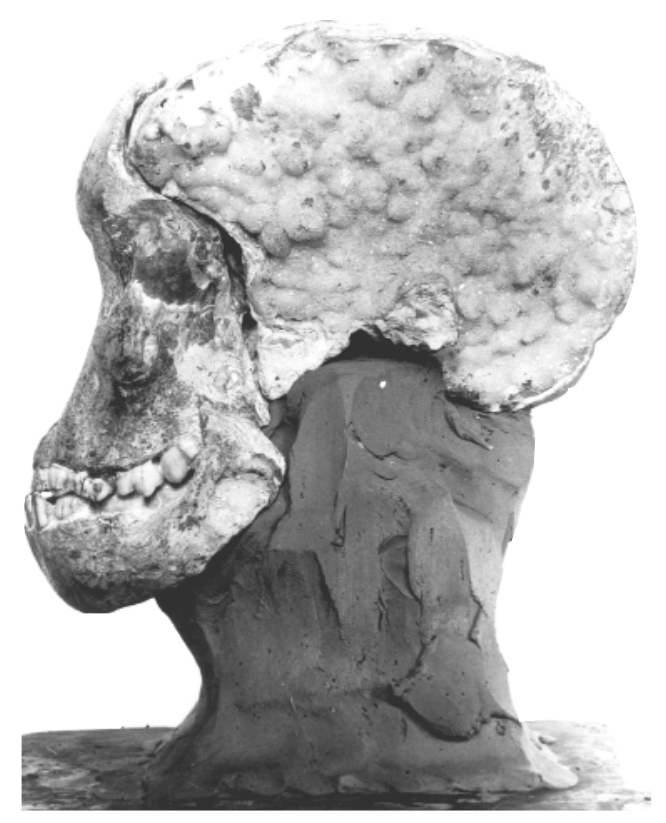

Figure 2. The left lateral view of the Taung skull, photographed in 1925. It shows the encrustation of calcite on the left face of the endocranial cast, and an artificial mandibular prognathism due to the anterior displacement of the mandible vis-à-vis the cranium.

Leakey family at Olduvai Gorge, Tanzania, belonged to a new species: we had the temerity to place it in the genus Homo. Thus was born the species Homo habilis. This claim, like Dart's of 1925, was spurned and derided by such eminent colleagues as Sir Wilfrid LeGros Clark, David Pilbeam, Kenneth Oakley, Bernard Campbell, Tadeusz Bielicki, Elwyn Simons, Clark Howell and John Robinson. It took close on twenty years before the concept of the species Homo habilis gained general acceptance (Tobias, 1992a).

A third example was my conclusion in 1973 that the endocranial casts of Homo habilis showed bulges corresponding to the speech areas of Broca and Wernicke (Tobias, 1975). Then followed my claim in 1980 (the centenary of the death of Paul Broca) that Homo habilis was the first speaking primate. This was rejected or ignored by most of one's colleagues for a number of years. Only recently a groundswell of support for the claim has become evident, and even some erstwhile opponents now accept that the evidence and the concept are valid (Falk, 1983; Eccles, 1989; Andrews \& Stringer, 1993; Deacon, 1994; Wilkins \& Wakefield, 1995; Lieberman, 1995).

My mind thus became focussed on the broad issues of rejection and acceptance in scientific discovery. I wondered whether the phenomenon of delayed acceptance was confined to the field of human evolution. Was there something about those who take up this study that leads to delayed acceptance? The Finnish palaeontologist, Björn Kurtén, went so far as to declare, “... practically all of the epoch-making discoveries of new kinds of fossil hominids have been received with doubts and opposition from most contemporary anthropologists" (1972). Kurtén did not explain the phenomenon and his readers might have inferred that palaeo-anthropologists constituted a species of scientist who were especially critical and cautious. Yet this did not seem to agree with the common impression.

Another line of thinking was suggested in 1976 by John Maddox, the editor of Nature. I had taken to him the manuscript by Alun Hughes and myself on the first skull of early Homo, probably Homo habilis, from Sterkfontein (Hughes \& Tobias, 1977). In his office during a chat about human evolution, Maddox turned to me and, with the authority that invests the editorial chair of Nature, said "It seems to 


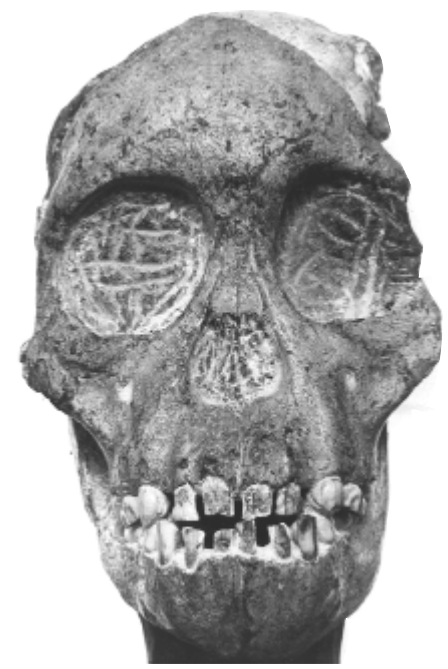

Figure 3. Facial view of the Taung skull, soon after Dart had liberated it from the matrix in which it had been entombed.

me that palaeo-anthropologists are a rather quarrelsome crowd!" This was a man who, more than most others, was able to weigh up the temperament of communities of scholars. I remember wondering whether astrophysicists have fewer arguments than palaeo-anthropologists! Was this a reason for delays in the acceptance of palaeo-anthropological discoveries?

Looking further afield, I soon found that delayed acceptance was not by any means confined to the field of human evolution (Tobias, 1992a, 1996). Other examples were -

- There was the well-known 35 years' delay before Mendel's laws of inheritance were adopted.

- Sixty years after John Frere claimed that flint objects from Hoxne in Suffolk, England, were tools fabricated and used by people at a very remote period, his deduction was accepted.

- For a century the concept of continental drift was ridiculed or disregarded.

- There was a 14 years' delay in the recognition of Chagas' Disease, the malady from which Charles Darwin probably suffered after the voyage of the Beagle.

- Ten years elapsed between Fleming's discovery of penicillin and its application by Florey and Cheyne.

- After Avery, McLeod and McCarty proved that DNA was the basic hereditary substance in 1944, it took six or eight years for this seminal discovery to be appreciated.

- Even the double helix structure of DNA, published by Watson and Crick in 1953, took over twenty-five years, according to Francis Crick, "for our model of DNA to go from being only rather plausible, to being very plausible (as a result of the detailed work on DNA fibres), and from [then] to being virtually certainly correct [in the early 1980s]...".

- An example suggested to me by Ernst Mayr was the delay before Darwin's and Wallace's concept of Natural Selection was supported.

We live in an age when scientific knowledge is said to grow exponentially. In the light of this, the delays I have spoken of, ranging in the 20th century from eight to thirty years, are extraordinary phenomena. They are not a general feature of scientific discoveries and I had to search long and hard to find even a dozen examples.

Puzzled by the DNA example, Gunther Stent proposed that "a discovery is premature if its implications cannot be connected by a series of simple logical steps to canonical, or generally accepted, knowledge" (Stent, 1972, p. 84). 
The palaeo-anthropological case histories cited do exemplify premature discoveries in Stent's usage (Tobias, 1996). However, there are at least four other categories of deterrents that I have identified as delaying factors in the acceptance of discoveries - and I have classified these as linguistic, political, theological and personal. I believe it is important to recognise the phenomenon and to understand the network of causal factors that may be involved.

\section{Conversion in science}

The other side of the coin is the question of conversion in science. One may speak of conversion in science as validly as conversion in religion, ideology and politics.

W. C. Jordan of Princeton University has recently spoken of conversion as "the range of processes by which individuals and groups come to accept or engage beliefs, ideas, rituals, or social and material practices [which are] often radically different from those with which they began". Jordan's Center for Historical Studies (the Shelby Cullom Davis Center) planned to devote two academic years to the study of Conversion: Sacred and Profane. Clearly this is a valid field of historical and philosophical study. I am convinced we cannot escape it in the discourse of anthropology and archaeology.

This brings me to my main question: what were the principal factors that ultimately led to the acceptance of Australopithecus after so many years of rejection? What was responsible for this conversion?

\section{Australopithecus africanus a premature discovery}

What Dart claimed from 1925 onwards and the implications of those claims have been often examined (Figures $4 \& 5$ ). Elsewhere I have defined the principal tenets of the paradigm that prevailed in 1925 (Tobias, 1996). It was clear that the implications of Dart's claims for the Taung child could not be connected by simple, logical steps to the generally accepted knowledge of 1925 . Thus I was able to show that Australopithecus africanus was a premature discovery, on Stent's definition. Not only did many aspects of the 1925 mind-set deter scientists from adopting Dart's claims, but there were nonscientific objections, such as linguistic, theological, political and personal obstacles. If ever Australopithecus was to gain approval, it was necessary for every one of the tenets of the 1925 mindset, as well as for these para-scientific hindrances, to be addressed, revised or replaced.

Let me dwell for a few moments on the "para-scientific" obstacles to the early adoption of Dart's claims.

One of these fell into my category of Personal Factors. Dart was considered too young and inexperienced: he was 31 when he received the Taung skull and he turned 32 only three days before his famous article appeared in Nature (Figure 6). According to the outspoken and biting Broom (1950), it was unpalatable to the scientists in England that the young colonial upstart had presumed to describe the skull himself, instead of submitting it to his elders and betters. Moreover, Dart had already revealed a penchant for scientific heresies (Dart \& Craig, 1959; Tobias, 1984): how could anyone believe such a man?

A linguistic objection was raised by Bather (1925): the first half of the word Australopithecus was Latin, the second half Greek. A man who could perpetrate such a barbarism was no scholar - or so it was implied! Yet there are many graeco-latinisms already in the English language - such as palaeospecies, archduke, palaeocerebellum, neoclassical, archistriatum and palaeotemperature - which were overlooked by the censorious contributor to Nature. Fifty years later, one of the last of the enemies of Dart and Australopithecus, Lord Solly Zuckerman (1974), called Australopithecus "an unauthorized confusion of Latin and Greek". The memory of this was behind the greeting sent to Dart on his $90^{\text {th }}$ birthday by the leading American anthropologist, Sherwood Washburn (1983, cited by Tobias, 1984: 41): "Anthropologists honor your discoveries of Australopithecus and rejoice in the combination of Greek and Latin roots."

Another deterrent was the school of thought known as creationism: while Dart was claiming that his child came closer to bridging the gap between human and non-human than anything yet discovered, the 


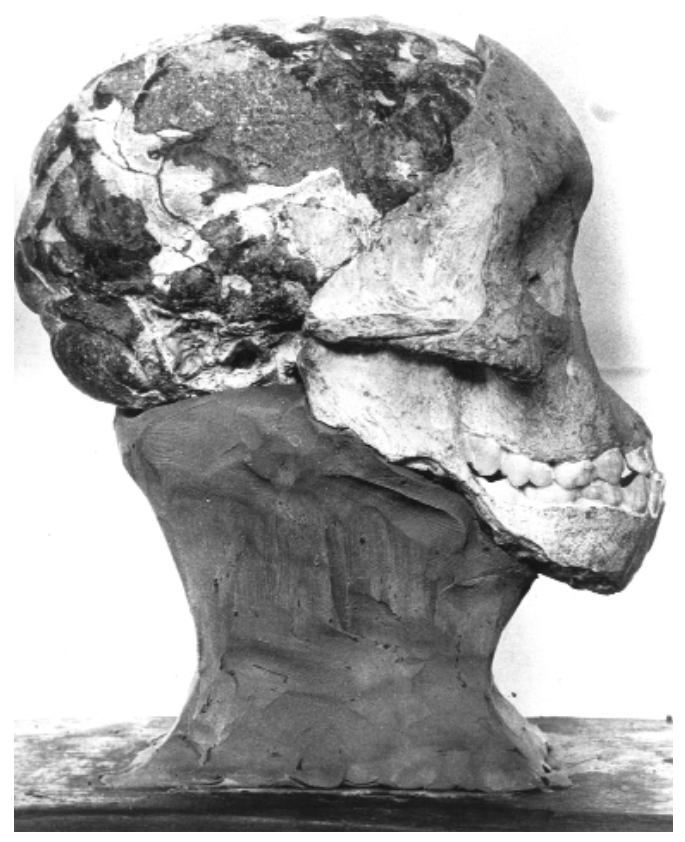

Figure 4. Right lateral view of the skull of the Taung child. The isthmus of bone connecting the right ramus and right corpus of the mandible is clearly apparent, as is the artificial or taphonomic forward displacement of the lower jaw in relation to the maxillary teeth. At this stage there were traces of the tabula interna on the right surface of the endocast. The impression of the cerebrum and that of the cerebellum are clearly seen.

creationists would not accept any evolutionary link between humans and non-human animals, or the very idea of evolution. No wonder Dart received letters telling him that he would "roast in the quenchless fires of hell"; expressing the hope that "you will be placed in an institution for the feebleminded"; accusing him of being a priest of Baal; and naming him as "the active agent of Satan and his ready tool" (Dart \& Craig, 1959).

Today we may confidently assert that the Taung discovery and what Dart made of it wrought a revolution in our thinking about human evolution and will be remembered as the most fundamental breakthrough in the history of palaeo-anthropology.

Dart had given the world Australopithecus. It was not, however, his destiny to convert the world. What factors produced the conversion about the middle of the 20th century?

\section{Conversion: the role of Robert Broom}

Let us first examine the role of Robert Broom (Figure 7). Among the objections to Dart's claim for the Taung skull was that it had belonged to a child. How could one infer what would be the nature of the adult?

Fossil baboons or monkeys were recovered from Sterkfontein, in Gauteng Province, by three of Dart's students, Trevor Rubidge Jones in 1935 and G.W.H. Schepers and W.H. Le Riche in 1936. Broom was taken to the site by Schepers and Le Riche in August 1936. Within eight days, Broom had parts of the first adult australopithecine specimen in his hands. Essentially it confirmed for the adult what Dart had claimed for the child. Broom was an ardent splitter in the matter of classifying fossils. Thus he at first placed the Sterkfontein specimens in a new species of the same genus: he named it Australopithecus transvaalensis. His description is racy and to the point:

“... I immediately visited these caves in [the] company [of these students]. 


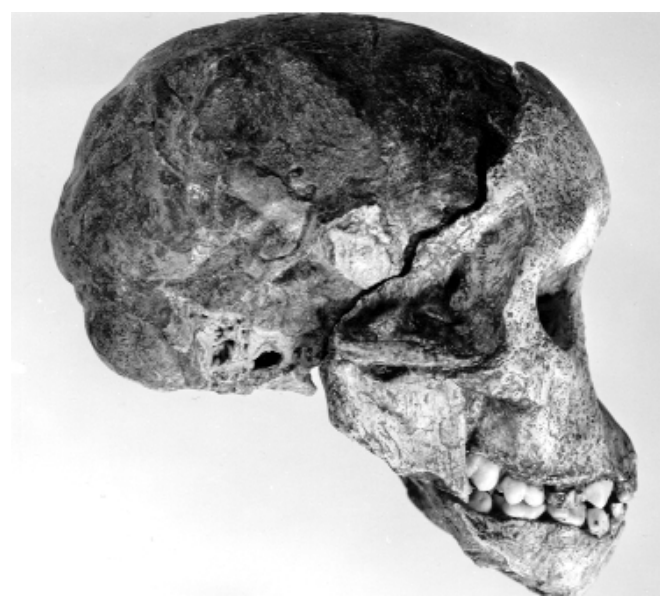

Figure 5. Right lateral view of the Taung skull: a recent photograph which differs from Figure 4 in two important respects. It will be seen that the isthmus connecting the right ramus and right corpus of the mandible had been cut through: Dart carried this out in 1929 in order to enable him to look down upon the occlusal surfaces of the maxillary and mandibular teeth. The severance of the link permitted the corpus of the mandible with its mandibular teeth to be occluded correctly and the mandibular prognathism is no longer apparent. To this day the right ramus lies attached to the cranium posterior to the maxillary tuberosity, its condylar process being slightly displaced anteriorly in relation to the mandibular fossa. A second difference is that the fragments of tabula interna which were formerly attached to the surface of the endocast had been removed by G.W.H. Schepers, when Dart gave him the endocast for study in 1945-1946. By removing those endocranial fragments shown in Figure 4, a clearer picture was obtained of the pattern of gyri and sulci and Schepers' description of the sulcal and gyral pattern appeared as part of Robert Broom's famous 1946 monograph, the book which this author believes played a crucial role in converting Sir Arthur Keith and other opponents of Australopithecus to an acceptance of it.

There I found a rich deposit of fossil bones, and the manager of the limeworks, Mr. G.W. Barlow, afforded me every help. He had in the little refreshment room at the caves, skulls and teeth of quite a variety of animals - the little baboon, the extinct horse Equus capensis, ... some arm bones of what I thought might belong to a giant baboon I had found at Schurveberg and a lot of indeterminable bones. Mr. Barlow had for years worked at Taung[s], and he informed me that he believed dozens of adult skeletons and skulls of the Taung[s] ape were thrown into the lime kilns there and burnt. No one seemed to worry. I impressed on Mr. Barlow the importance of keeping his eyes open for any signs of anything like the Taung[s] ape. I again visited the caves three days later, when Mr. Barlow gave me three nice little baboon heads and part of the skull of a large carnivore.... Five days later I again visited the caves, when Mr. Barlow gave me much of a brain cast of what appeared to be an anthropoid ape. A hunt for some hours failed to discover any parts of the skull except the cast of the top of the skull on the side of the cave wall. I returned the following day with a fairly large party, including Mr. Herbert Lang, who photographed the cave, showing the exact spot where the skull had lain. A long and careful search resulted in the finding of the base of the skull, and many parts of the cranial vault." (Broom, 1937)

Thus did the first adult specimen come into Broom's hands. He added an interesting note to this 1937 paper: "Among the bones collected by Mr. Barlow at another cave near by are most of the bones of the hind leg of what is almost certainly another skeleton of the same anthropoid, and a number of metacarpals. The arm, that I thought might be that of the giant baboon is probably also the arm of the anthropoid. Unfortunately, some visitor to the caves has removed it and so far I have been unable to trace it." As these bones are said to have come from another cave close by, it is possible that they had been removed from what we later named Silberberg Grotto, in a deep part of the Sterkfontein cave system (Tobias, 1979). We had removed bone-bearing breccia from Silberberg Grotto in 1978-1980 and David 


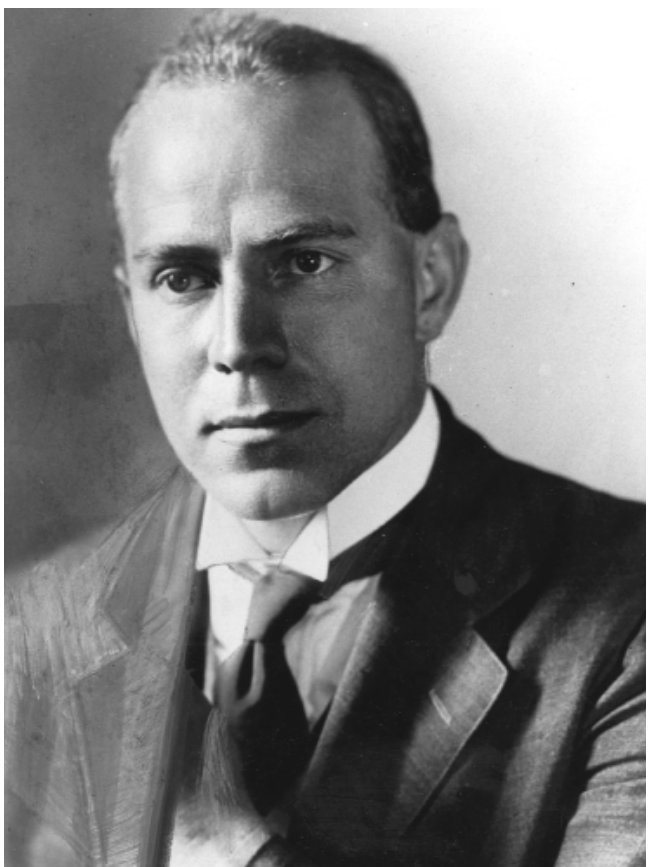

Figure 6. Professor Raymond Arthur Dart photographed shortly after the announcement of the discovery of the Taung skull in 1925 . He was then 32 years of age and had been Head of the Department of Anatomy at the University of the Witwatersrand Medical School for just over 2 years.

Molepolle in 1980 extracted some small foot-bones from this breccia. Fourteen years later, in 1994, Dr. Ronald Clarke recognised these articulating foot-bones as hominid. He and I nicknamed it 'Little Foot' and demonstrated that it possessed a mélange of ape-like and human-like features (Clarke \& Tobias, 1995). It is tempting to ask whether Barlow's leg-bones of 1936 were indeed from the Silberberg Grotto and if so whether they belonged to the same hind limb as did the bones of 'Little Foot'. I hope Dr. Clarke will follow up this suggestion. [The discovery by R.J. Clarke (1998), S. Motsumi and N. Molefe of the leg-bones to which the 'Little Foot' bones belonged, and much of the rest of the virtually complete hominid skeleton in situ within the Silberberg Grotto, would seem to have eliminated this possibility.]

A little while after Broom (1936a) obtained the first adult cranium, the discovery of a canine tooth led him to believe that the Sterkfontein apeman was very different from that of Taung. So he erected a new genus, Plesianthropus, to accommodate the Sterkfontein specimens (Broom, 1936b). From this proposed generic name the colloquial abbreviation 'Ples' is derived, as in the affectionate sobriquets, 'Mrs. Ples' and 'Mr. Ples' . Later, Robinson (1954) lumped the Sterkfontein form into the same species as that at Taung, but as a different subspecies - Australopithecus africanus transvaalensis. In a major lumping exercise, Robinson reacted to Broom's splitting propensity, and rearranged Broom's three genera containing five species into two genera with one species each.

From 1936 until 1939 Broom recovered more specimens from Sterkfontein. The first robust australopithecine came to light at Kromdraai in 1938. Broom made it the type of a new genus and species, Paranthropus robustus (Broom, 1938a, 1938b). It was later lumped into the genus Australopithecus by G.G. Simpson, Washburn, Patterson, Dart, LeGros Clark, Oakley, Campbell, Howell and myself. In 1964, Leakey, Tobias and Napier proposed that (Paranthropus) and (Zinjanthropus) be accepted as sub-genera of Australopithecus. To this day, opinion remains divided among at least three viewpoints, that Paranthropus was a good genus, that (Paranthropus) formed a sub- 


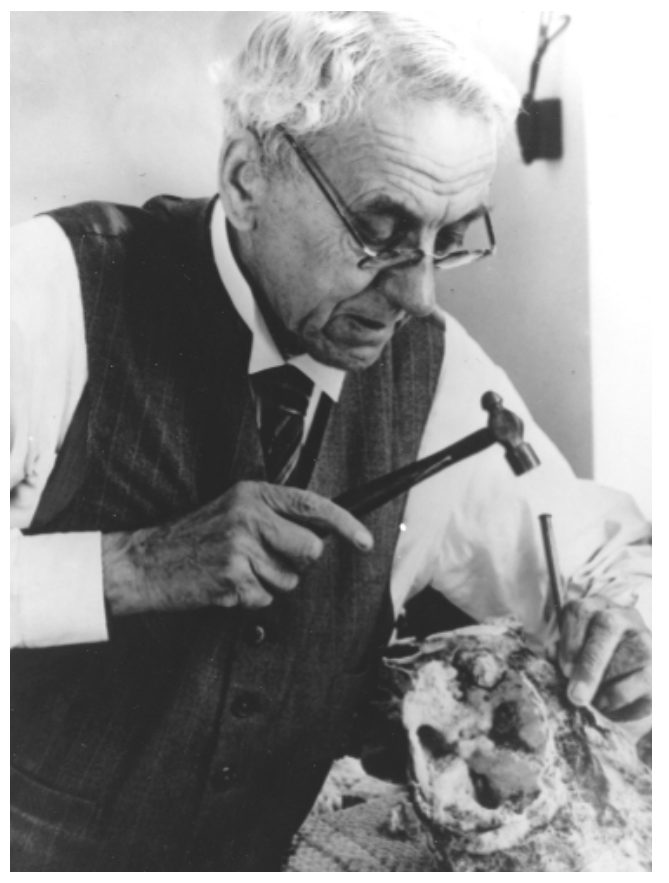

Figure 7. Dr. Robert Broom FRS soon after the discovery in 1947 of a very complete cranium of an Australopithecus africanus (earlier called by him Plesianthropus transvaalensis) from Member 4 of the Sterkfontein Formation. The picture shows Broom chipping away at the matrix around the base of the cranium seen from above. The anterior and middle cranial fossae are clearly seen, as well as the hypophyseal fossa and the petrous pyramids of the temporal bones. This cranium was affectionately dubbed "Mrs. Ples"

genus, and that the robust ape-men comprised one or more species of Australopithecus.

Broom and the Sterkfontein Valley had shown that there had lived in South Africa at least two populations of erect, bipedal hominids with absolutely and relatively small brain sizes. However, only some short papers by Dart, Broom, Sollas, and a few others, had been published when the Second World War broke out in 1939.

So the world knew little and accepted less by the time such pursuits as palaeo-anthropology were shelved during the mighty turmoil that followed.

By the end of World War II, there were small-brained ape-man remains from Taung, Sterkfontein and Kromdraai. The time was ripe for an overall appraisal of what had been found. Broom undertook this. In 1946, there appeared the first of that marvellous series of Transvaal Museum Memoirs, "The South African Fossil Ape-men, the Australopithecinae". The work was dated $31^{\text {st }}$ January 1946. Its authors were Broom, who described the fossil bones and teeth, and G.W.H. Schepers, a student of Dart's, who described and evaluated the endocranial casts. [Broom had initially invited Dart to tackle the endocasts, but as he was beset with many other duties, Dart suggested that Schepers undertake the task. Schepers had already devoted papers to the anatomy and physiology of the brain and was working on the evolution of the forebrain for his doctorate of science.]

There is no doubt that Broom's description and appraisal in that volume of the hominids from Taung, Sterkfontein and Kromdraai played a critical part in beginning the process of conversion.

\section{The conversion of Sir Arthur Keith}

Among those to whom Broom sent a copy of the monograph was his inveterate opponent, Sir Arthur Keith. Both men were sons of Scotland and both had been born in 1866, Keith close to Aberdeen on the east coast on $5^{\text {th }}$ February, Broom at Paisley close to the west coast on $30^{\text {th }}$ November. So Keith was ten 
months senior to Broom. In 1946, when Keith received the Broom and Schepers memoir, he was already 80 years of age (Keith, 1950). The Memoir made a great impact on Keith.

Fifteen years earlier, following acrimonious exchanges in Nature, Keith had devoted no fewer than six chapters to Taung, in the 1931 edition of his work, "New Discoveries Relating to the Antiquity of Man". The 80 pages on Taung comprised one-sixth of that book. It constituted the most detailed account of Australopithecus africanus that had yet appeared - although Keith had studied only the cast of the skull and Dart's, Broom's and a few other published articles. Dart had written a 300-page memoir on the Taung child, and submitted it to the Royal Society of London. Keith's book had however pipped Dart at the post, and the Royal Society declined to publish Dart's monograph, save for the section on the child's teeth. Dart was not willing to break up the treatise and it remained unpublished. When I became a fulltime member of Dart's academic staff at the beginning of 1951, I re-discovered the monograph in my new office, which had just been vacated by L.H. Wells. The latter had just left the Witwatersrand University to take up a position in the Anatomy Department at Edinburgh University, Scotland, under George Romanes. Later, in 1956, Wells became head of the Anatomy Department at the University of Cape Town. The bulky manuscript I found in my office was Dart's unpublished memoir of twenty years earlier. Realising its historical value, I discussed it with Professor Dart and offered to edit it for him with a view to its belated publication. Dart declined my offer because (i) much of the content was out of date; (ii) he had used the dental section in his article in Folia Anatomica Japonica in 1934; and (iii) he had included large sections of the manuscript in other articles (Tobias, 1993).

To return to Keith: in his 1931 book, he had concluded that Australopithecus africanus was essentially an anthropoid ape, but one in which some human characters had evolved. As Broom pointed out in "Finding the Missing Link", "Keith was handicapped by having to work on casts that were not very satisfactory. For example, he could not have given the unsatisfactory account of the teeth had he had the actual specimens to work on." (Broom, 1950, page 60). Keith's view - that the australopithecines had no bearing on the origin of mankind - remained unchanged from 1925 (when he called Dart's claims "preposterous") until 1946. He was for Broom a constant irritant, a running sore. Because of Keith's eminence and international reputation, his opposition to the acceptance of Australopithecus was a major hindrance to conversion on the part of others.

When the Broom/Schepers (1946) book arrived on Keith's desk by the end of February 1946, it came as a bolt from the blue. In An Autobiography published by Keith a few years later (1950), he calls the book "an important monograph in which there was convincing evidence that the extinct anthropoids of South Africa had in truth all the human qualities which Professor Dart and he [Broom] had ascribed to them." (Keith, 1950, page 691). As soon as he had digested the monograph, Keith wrote to Broom on 12 $2^{\text {th }}$ March 1946: "Whatever theory one holds of human evolution, man as we know him, must have passed through such a stage as is represented by the Australopets! I agree they (may) be direct descendants of such a stage." (Broom, 1950, page 60). In another letter to Broom, he states, "No doubt the South African anthropoids are much more human than I had originally supposed".

So, as a direct result of the Transvaal Museum monograph, Keith made his peace with Broom. But he had yet to make his peace with Dart. In the Autobiography Keith spoke of Raymond Dart as "another of J.T. Wilson's brilliant Australian pupils" (Keith, 1950, page 480). He recorded that he, Keith, had been one of three selectors (with G. Elliot Smith and J.T. Wilson) who had interviewed Dart and Claude Stump, in London, when the University of the Witwatersrand was seeking a professor of anatomy in 1922 to succeed the first incumbent, E.P. Stibbe. Keith tells us:

"I was one of those who recommended [Dart] for the post, but I did so, I am now free to confess, with a certain degree of trepidation. Of his knowledge, his power of intellect, and of imagination there could be no question; what rather frightened me was his flightiness, his scorn for accepted opinion, the unorthodoxy of his outlook."

So Dart was recommended to The University of the Witwatersrand ('Wits') and Claude Stump took 
the chair at Bangkok. Wits offered the post to Dart, only after its first choice, Robert Black Thomson, had withdrawn his application. Dart filled the chair of anatomy at Wits with lustre for 36 years. Thus it was into Dart's hands, and not those of Stump, Thomson or M.R. Drennan, that the Taung skull came in November 1924. How differently the story might have turned out, if it had been another person, perhaps a more cautious scientist than Dart, lacking his flair, imagination and courage, whose lot it befell to reveal Australopithecus to the world!

How did Keith offer the olive branch to Dart? In his Autobiography there appears this entry, "During 1947 I wrote a few minor articles..." (op.cit., page 698). One of these was a letter which appeared in Nature in 1947:

"When Professor Dart...announced in Nature the discovery of a juvenile Australopithecus and claimed for it a human kinship, I was one of those who took the point of view that when the adult form was discovered it would prove to be nearer akin to the living African anthropoids - the gorilla and chimpanzee. Like Professor Le Gros Clark I am now convinced on the evidence submitted by Dr. Robert Broom that Professor Dart was right and I was wrong. The Australopithecinae are in or near the line which culminated in the human form"

Then in a quaint and droll fashion, Keith made further amends for those decades of hostility to Dart. His note to Nature continued:

"My only complaint now is the length of the name which the extinct anthropoid of South Africa must forever bear. Seeing that Professor Dart not only discovered them but also so rightly perceived their true nature, I have ventured, when writing of the Australopithecinae, to call them by the colloquial name of Dartians thereby saving much expenditure of ink and of print. The Dartians, are ground-living anthropoids, human in posture, gait and dentition, but still anthropoid in facial physiognomy and size of brain. It is much easier to say that there was a "Dartian" phase in man's evolution than to speak of one which was Australopithecine". (Keith, 1947).

Dart's charming and frolicsome response to Keith's 'Dartian' proposal is still in the Keith papers in the Royal College of Surgeons, London. As far as I know, Kurtén was the only prominent palaeontologist who adopted the name Dartians (Kurtén, 1972).

Seen in historical perspective, Broom's discovery of adult ape-men at Sterkfontein and of another kind at Kromdraai, and above all, his monograph on all of the South African ape-man remains, played a crucial part in Keith's Damascus road conversion - and that of others. It seems it was important whom one converted: for Keith had maintained the most sustained and vocal opposition. Charles Darwin was well aware that it was important who was converted. On $13^{\text {th }}$ November 1859 , eleven days before The Origin of Species was published, Darwin wrote: "If I can convert [ Thomas Henry] Huxley I shall be content."

The impact of the Broom/Schepers monograph was immense. As one earnest of its significance, it was awarded the Daniel Giraud Medal of the U.S. National Academy of Sciences for the "most important biological work published in that year".

The monograph did not convince everybody. For instance, Wood Jones (1947) wrote to Nature suggesting that Plesianthropus was "a primitive and generalized anthropoid ape that has not attained to all the specializations characteristic of the modern apes, and is therefore nearer to the basal stock of the Primates from which man arose". In a letter to Wood Jones in 1949, William Straus of Johns Hopkins University wrote, "I do object to the prematureness with which the posture and zoological affinities - not to mention the social life - of the australopithecines have been determined. In my opinion, a great deal of additional, careful study is indicated" (Straus to Wood Jones, $10^{\text {th }}$ March 1949). Straus reiterated these views to me seven years later when I visited him at Johns Hopkins University, Baltimore, in January 1956.

\section{'Mrs. Ples' and the conversion of Professor LeGros Clark}

Sir Wilfrid LeGros Clark was another example of outright conversion to the acceptance of Australopithecus. His interest was doubtless kindled by Broom's monograph and Keith's recantation, 
although already in 1946 Clark had published an article in Nature on the Australopithecinae. For a time his views had been somewhat similar to those of Keith. Before his visit to study the ape-man remains for himself, another event occurred which undoubtedly played a major role in the process of conversion.

In the first part of 1947, Broom was involved in a bitter and very public altercation with the South African Historical Monuments Commission (later called the National Monuments Council). It banned him from carrying out further work at Sterkfontein because, it said, his work was unsystematic and he paid no heed to stratigraphy. While he was excluded from Sterkfontein, Broom worked at Kromdraai for the first three months of 1947. Then, helped by his new assistant, John Talbot Robinson, Broom returned to Sterkfontein.

On $18^{\text {th }}$ April 1947, "a blast broke open a large block of what had appeared to be rather barren bone breccia, and in this was found the perfect skull of a middle-aged or elderly female, Plesianthropus, but without the mandible". Thus did Broom, Robinson \& Schepers (1950) record it in another masterful memoir of the Transvaal Museum. The specimen, catalogued as Sts 5, was the most complete cranium of the Sterkfontein ape-man discovered up till then, lacking only the teeth and the mandible. Broom placed it in the genus Plesianthropus and, as he and Robinson saw it as female, it became known as 'Mrs. Ples'. This fossil is one of the crowning possessions of the Transvaal Museum. It and its nickname were publicised widely by Dr. Francis Thackeray in 1997, the fiftieth anniversary of the discovery by Broom and Robinson.

Until then, apart from the Taung child, all australopithecine fossils were incomplete: it was exceptional to have a cranium which was not only perfectly complete save for its teeth, but also neither crushed nor distorted. Broom joyously revealed the new find in the pages of Nature (1947).

LeGros Clark, the professor of anatomy at Oxford University, was planning to attend the first PanAfrican Congress on Prehistory which Louis Leakey and Sonia Cole were organising in Nairobi, Kenya. Clark travelled to South Africa before the Nairobi meeting. He studied the original australopithecine fossils in Pretoria and Johannesburg. He applied craniometric techniques and indices to the remains and the hard evidence of the fossils converted Clark. Shortly afterwards, at the Pan-African Congress in Nairobi in August 1947, he rose to his feet to declare that he was now convinced that the australopithecines were hominids and not anthropoid apes (Clark, 1947).

If Keith had been convinced by the facts enshrined in the monograph of 1946, LeGros Clark was converted by the sheer weight of morphological evidence presented by the fossils themselves and, above all, by the cranium of 'Mrs. Ples'. Clark's fine morphological analyses published between 1947 and 1952, in turn, converted many others. So, the convert became the converter. Although Clark's conclusion that the australopithecines were indisputably hominid was bitterly opposed by Zuckerman, many were convinced by these studies.

Thus, one of the earlier deterrents - that Dart was the wrong man - had fallen away, for no-one dared assert that of either Keith or LeGros Clark! The concerns that Africa was the wrong continent for hominid ancestry, that the Taung child represented too young an individual to throw any light on its affinities, that the dating of the South African deposits was geologically too young to have a bearing on human origins, were being whittled away one by one.

There remained the Piltdown enigma, which for some investigators had been a serious obstacle to the acceptance of Australopithecus.

\section{Piltdown and Australopithecus}

In the first part of the century, it had been thought that cerebral precocity - geologically early enlargement and structural hominisation of the brain - must have been a dominant feature of hominid evolution. Yet no fossils that unequivocally supported this view had been found. The Piltdown forgery was an attempt to fabricate a hominid 'missing link' of this kind. The counterfeit skull had the large brain case of a modern human and an ape-like mandible and teeth. It lay in a deposit which, by being seeded 
with genuine fossilised animal bones and stone artefacts, had been made to seem very old - and ostensibly older than any hominid fossil that had yet come out of Europe, the oldest then being the Mauer mandible from Heidelberg, Germany. The Piltdown chimera, apparently showing very ancient hominisation of the brain, accompanied by archaic jaws and teeth, was precisely what some theoreticians had predicted. If it was a true model of the morphology of early human ancestors, then the Taung child and the others from South Africa, with brains scarcely bigger than those of chimpanzees, could not have been on the hominid lineage. Australopithecus then would not have been a model for human evolution - just a great ape that had somewhere taken a wrong turning.

So, for those who accepted that the Piltdown specimens were genuine, they remained a real deterrent to the acceptance of Australopithecus. That was where matters stood in the late 1940s. When Keith, Clark and others accepted Australopithecus as hominid, the Piltdown remains became more of a mystery than ever. They deserved another long, hard look!

In 1953, a re-examination by Joseph Weiner of Oxford and London, and formerly of the Wits Anatomy Department, Kenneth Oakley of the Natural History Museum, London, and Wilfrid LeGros Clark of the University of Oxford Anatomy Department, revealed the tell-tale signs of a deliberate forgery. Mixed up in the Piltdown gravel were a modern human cranium, a modern ape (orang-utan) mandible, genuine ancient, non-hominid faunal remains and supposed early stone tools. Further evidence published in 1955 showed that all the remains from three sites in the Piltdown area had been pointedly selected, doctored and stained, and salted into several deposits (Weiner, Oakley \& Clark, 1953, 1955). One purpose was to create the illusion that the oldest fossil hominid in Europe came from England. A second object was, it seems, to provide hard evidence to support the brain-first theory. As Piltdown had been the only shred of supposed evidence favouring brain precocity, the expunging of Piltdown from the human fossil record in 1953-1955 removed a major obstacle to the acceptance of Australopithecus (Spencer, 1990; Tobias, 1991, 1992b, 1992c).

\section{Mosaic evolution as a deterrent}

As part of the pre-australopithecine paradigm, it had been assumed by many scholars that hominisation of various parts of the body had been more or less uniform. The Taung skull, with its small brain-size (an apish trait) and small canine teeth (a human feature), was at variance with this concept. By the 1950s, much work had been done on the tempo of evolution and on different rates of evolution (e.g. Simpson, 1944, 1953). There was now a tendency to accept that during evolution varying rates of change could have applied to different parts of the body. Such mosaic evolution was illustrated by the Taung child. So this deterrent had largely withered away.

\section{Liquidation of some other prejudices}

The geographic bias favouring Asia was overridden by the sheer weight of fossil discoveries in Africa. Moreover, from 1959 onwards, the new dating evidence suggested that some African fossil hominids were older than the most ancient in Asia. This remains true on the present fossil record with well-established dates. Claims are made from time to time about very ancient hominid remains in China and India, but the Pliocene dates claimed have not been widely accepted. One must of course keep an open mind on the matter. As I have often said, tomorrow's new, well-dated hominid discovery from Asia may lead us to revise earlier ideas on the pattern and placement of hominid phylogeny. We should never be afraid to face up to a change of paradigm. I can think of nothing that may have a healthier and more rejuvenating effect on the devotees of our science than periodic changes of paradigms - even on so basic a question as the continent in which hominids arose. However, as present evidence points overwhelmingly to an African origin of the hominids, inter-continental bias no longer impedes the acceptance of Australopithecus.

The anti-Africa and anti-African prejudice to which Bowler (1986) drew attention was a by-product 
of past eras of slavery, colonialism and racial prejudice. In the 20th century there has been much agonising over the relations between science, medicine and ethics. Science without an ethic has in the recent past given us negative eugenics such as sterilisation and even extermination of the 'unfit', biological and chemical warfare, nuclear weapons. Science without ethos has allowed or even produced aberrations like racism (and its political expressions like Nazism, lynching, apartheid, genocide and the latest horror, 'ethnic cleansing').

It was earlier held that scientific research should be pursued wherever it might lead - without heed to the ethical consequences of its discoveries. This view went up in smoke, when in August 1945, atomic bombs were detonated over Japan.

In the 50 years since the atomic bombs were dropped on Hiroshima and Nagasaki, it has been realised that science cannot and should not be neutral. Scientists are morally obliged to take heed of where their work may lead and what might happen to their discoveries. The role of science has been dramatically remoulded and will never again be the same. Thus, in my lifetime, the very faith of scientists has changed.

Is this remote from the bias against Africa, to which Bowler alerted us? We human biologists and palaeo-anthropologists need the critical scrutiny of the philosopher and the historian to point out that climates of opinion and prevailing prejudices may play a part in the acceptance or rejection of new discoveries. Their influence may be subtle, unsuspected - but no ideas are free-floating in a vacuum.

Let us hope that also this anti-African hindrance to australopithecine acceptance has withered away with the efflux of time.

Another powerful mind-set militating against the acceptance of Dart's and Broom's claims was prejudice against evolution. One of those fascinating coincidences with which the history of science is peppered occurred in 1925. That was the year in which Australopithecus was launched on its Odyssey, but it was also the year of the Scopes 'monkey trial' in Dayton, Tennessee, USA. John Thomas Scopes, a teacher of science in Rhea High School, had been teaching evolution. In Tennessee this was against the law. The legislature of the state of Tennessee had passed the anti-evolution law earlier that same year. It was signed by the governor on $13^{\text {th }}$ March, 1925. That was only 38 days after the sensational news of the discovery of Australopithecus and Dart's claims for it had first been published in The Star of Johannesburg and been telegraphed around the world. It was only 34 days after Dart's article had appeared in Nature on $7^{\text {th }}$ February, 1925. It is tempting to suspect that there was a link between the hasty passage of the Tennessee legislation and the debut of the South African ape-man. Perhaps Broom had this in mind when, in his article in Natural History in the latter part of 1925, he wrote, "... if the discovery [of Australopithecus] results in the universal acceptance of the belief in man's evolution from the lower forms, the discovery of Australopithecus may have nearly as great an influence on human progress as the publication of Darwin's Origin of Species" (page 417). Scopes was found guilty and fined \$100: on appeal the verdict was set aside on a technicality. In South Africa the teaching of evolution in primary and high schools was prohibited until only a few years ago - and this, in the very country which gave the world its first 'missing link'!

\section{Conversion consummated}

From 1947, the tide began to turn. After long decades of isolation and rejection, Dart found himself gaining belated recognition. The change of the paradigm did not occur suddenly, as though by one of Thomas Kuhn's (1970) scientific revolutions. It took another ten years and longer before it was generally accepted that the australopithecines were hominids.

As late as 1957, in the first English translation of the great French work, Les Hommes Fossiles by Marcellin Boule and Henri V. Vallois, we find this summing up of what they considered to be the widespread viewpoint at that time:

"The majority of palaeontologists subscribe to a theory that ... the Australopithecinae are a group of Anthropoids [apes or pongids] in the process of evolving towards humanity, but which never 


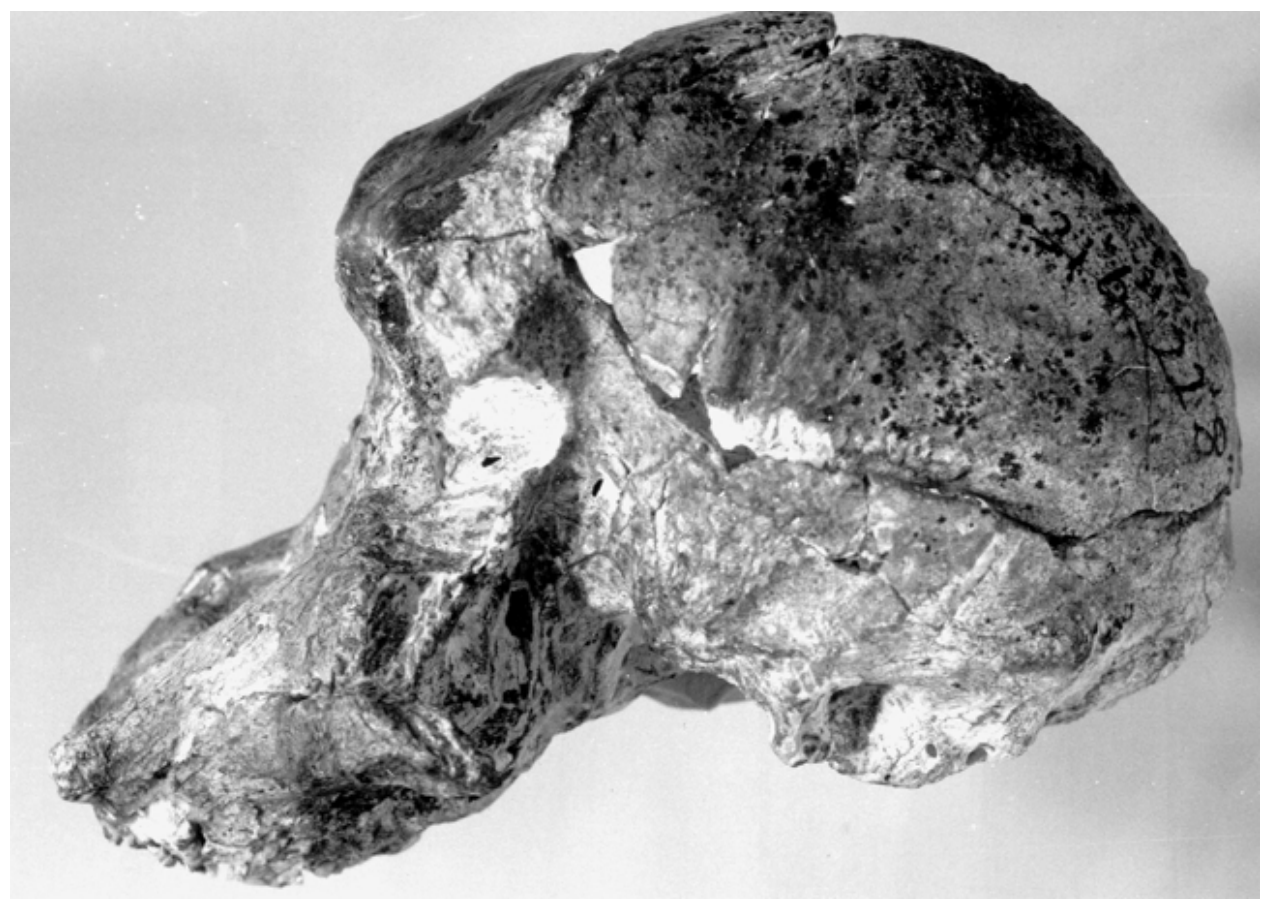

Figure 8. A fine male cranium of Australopithecus found in situ in Member 4 of the Sterkfontein Formation by Alun R. Hughes and the author in 1989. This specimen is catalogued Stw 505 and has been affectionately dubbed "Mr. Ples"! It has recently been shown to have an endocranial capacity of about $515 \mathrm{~cm}^{3}$, the biggest of the 7 endocranial capacity values available for the sample of Australopithecus africanus.

crossed the 'threshold' to this condition and vanished without having become truly human. It cannot be denied that the fundamental human characteristic, that is the great development of the brain, the basis of all our psychological evolution, was never fulfilled in them. Human as they are in their dentition and posture, the Australopithecinae are none the less apes in terms of their brain." (Boule \& Vallois, 1957, page 92).

Even later a few scientists remained unconverted. Resistance lingered on, at the hands of Zuckerman (1974, 1978), Oxnard (1975) and a few others, as late as the 1970s. By that time virtually all of the tenets of the old canonical knowledge had been replaced and a new paradigm had emerged.

In summing it all up, we see that three or four categories of factors were ultimately responsible for australopithecine acceptance: people - such as Broom and LeGros Clark; discoveries - such as more and more australopithecines, of different ages, genders and species; the removal of deterrents, fixed ideas that had hindered people from accepting Australopithecus; and factual data - such as the information which Ashton and Zuckerman $(1950,1951,1952,1954)$ recorded on the morphology of the great apes - for it was as important to know what was an ape as to know what was not!

Among all these factors, three stand out as having been primarily responsible for effecting the conversion. The first was Sterkfontein and its amazing wealth of hominid fossils (Figure 8), providing the possibility, for the first time, to study not merely individual fossils but fossil populations. The second was Robert Broom, a remarkably energetic and productive scientist whose list of publications ran to 456 
items and who demonstrated, through his discoveries at Kromdraai, and those he made with Robinson at Swartkrans, that southern Africa had been populated by a variety of ape-men, not all of whom were ancestors of later hominids. The third was Wilfrid LeGros Clark whose meticulous, comparative studies $(1947,1950,1952,1955)$ did more than anything else to convince human palaeontologists that the australopithecines were hominids.

\section{Last thoughts on Robert Broom}

This lecture is named in honour of Robert Broom. Let me close by reverting to him. Not long before he died in 1951, Robinson, his brilliant young assistant, made an historical find at Swartkrans. He showed that, along with the robust apeman, that cave held remains of a more advanced kind of hominid, which Broom \& Robinson (1949) named Telanthropus capensis. It was later re-classified by Robinson (1961) in the Transvaal Museum and by Simonetta (1957) in Italy as Homo erectus. This was the first known instance of early Homo contemporary with late-surviving, small-brained, apeman remains. Later studies by R.J. Clarke (1977, 1985) suggested that the Swartkrans early Homo might lie somewhere between Homo habilis and Homo erectus. Still more recently he has opined that it might have belonged to another species, Homo ergaster (Clarke, 1994).

In the last five years of Broom's life, jointly with Robinson and Schepers, he produced a series of detailed memoirs on the Australopithecinae. These publications of the Transvaal Museum appeared in 1946 and 1950 and, posthumously, in 1952. Collectively they played a vital role in persuading opponents of Dart and Broom to accept their claims for the ape-men.

Broom was a sparkling personality, an individualist who loved a good fight and a good joke (especially at someone else's expense!). He delighted in surprising and shocking his colleagues, the press and the public, and was no respecter of persons. He was a bit of a rascal and had a roving eye all his life. Once, when Mrs. Margaret Oakley asked him, "To what do you attribute your energy?", he placed his hand on her knees and twinkled, "Always in love, my dear" (K.P. Oakley, 1968, page 36). Kenneth Oakley, the husband, published that anecdote - otherwise I don't think I would have dared to tell it! Like Raymond Dart and Louis Leakey, Broom was a renaissance man of enormous breadth and depth. He had a strong philosophical and religious streak, but was not free of vanity, egotism and ambition - as his biographer, George Findlay (1972), makes clear. An accurate freehand artist and a rapid writer, he possessed a prodigious memory and an unorthodox style. His letters were dashed off by hand at speed and were besprinkled with sketches of his latest finds. He was a physician, palaeontologist, physical anthropologist, geologist, comparative anatomist, embryologist, but left a mark in many other areas: he was a connoisseur and collector of art, a philatelist (with a probably unrivalled collection of 'Old Transvaals'), a chess player of repute, to name but some of them.

He received recognition and honours from many parts of the world. Among some he prized most highly, he was the Croonian Lecturer of the Royal Society of London in 1913 and received its Royal Medal in 1928. In 1949 he was given the Wollaston Medal of the Geological Society of London.

Broom touched the imagination of many students and younger colleagues with whom he came into contact. I shall always be grateful to him for first setting my feet on the path of field-work and palaeoanthropological research. I remember with appreciation his inspirational effect on me when I was a bachelor of science and an honours student, sitting at the knee of the master in the last five years of his life. As a young, founder-president of the Science Students' Council at Wits, I organised an $80^{\text {th }}$ birthday party for Dr. Broom in 1947 (a few months after the birth date). I think that, apart from organising the first all-student expedition to Makapansgat in 1945, this tea-party for Dr. Broom (with Dart as the principal speaker) was the most memorable achievement of the Science Students' Council! Four years later, in April 1951, as a young lecturer on Dart's staff, I was bringing a party of my students back to Johannesburg after one of our fossil-collecting trips to Makapansgat. At $15 \mathrm{~h} 00$ we drew up at the roadside and stood by the car with heads bowed for a minute - Dr. Broom was being buried in Pretoria at that moment. 
Broom's unique monument is a bust executed by Elsa Dziomba, one copy of which stands in the Transvaal Museum, while the other is to be found in the amphitheatre of the Sterkfontein caves, the scene of so many of his important discoveries.

\section{Acknowledgements}

My appreciation is extended to the Transvaal Museum and, in particular to the Director, Dr. Naas Rautenbach, and the head of the Department of Palaeontology, Dr. Francis Thackeray; to the organisers of the scientific programme of the Dual Congress, Dr. Kevin Kuykendall and Dr. Himla Soodyall; to my long-time and most patient personal assistant, Mrs. Heather White; to Professor Beverley Kramer, head of the Wits Department of Anatomical Sciences; to Dr. Lee R. Berger, leader, and to Dr. Ronald J. Clarke, senior research officer, of the Palaeo-Anthropology Research Group. Financial support for these researches has come from the Foundation for Research Development, the PAST Fund, the Wits University Research Committee, the Wenner-Gren Foundation for Anthropological Research, the Department of Arts, Culture, Science and Technology, the Standard Bank, the Ann Barry - San Francisco Foundation, the Chairman's Fund of the Anglo-American and De Beers Corporation.

\section{References}

Andrews, P. \& Stringer, C. (1993). The primates' progress. In: The Book of Life, ed. S.J. Gould, pp. 219-51. New York: Ebury Hutchinson.

Ashton, E.H. \& Zuckerman, S. (1950). Some quantitative dental characteristics of the chimpanzee, gorilla and orang-utang. Philosophical Transactions of the Royal Society of London, B, 234, 471-84.

Ashton, E.H. \& Zuckerman, S. (1951). Some cranial indices of Plesianthropus and other Primates. American Journal of Physical Anthropology, 9, 283-96.

Ashton, E.H. \& Zuckerman, S. (1952). Age changes in the position of the occipital condyles in the chimpanzee and gorilla. American Journal of Physical Anthropology, 10, 277-88.

Ashton, E.H. \& Zuckerman, S. (1954). The anatomy of the articular fossa (fossa mandibularis) in man and apes. American Journal of Physical Anthropology, 12, 29-61.

Avery, O. T., McLeod, C. \& McCarty, M. (1944). Studies on the chemical nature of the substance inducing transformation of pneumococcal types. Journal of Experimental Medicine, 79, 137-57.

Bather, F.A. (1925). Letter to Nature. The word Australopithecus and others. Nature, 115, 947.

Boule, M. \& Vallois, H.V. (1957). Fossil Men. New York: The Dryden Press.

Bowler, P.J. (1986). Theories of Human Evolution: A Century of Debate, 1844-1944. Baltimore: Johns Hopkins University Press/Oxford: Basil Blackwell.

Broom, R. (1925). On the newly discovered South African man-ape. Natural History, 25, 409-18.

Broom, R. (1936a). A new fossil anthropoid skull from South Africa. Nature, 138, 486-88.

Broom, R. (1936b). The dentition of Australopithecus. Nature, 138, 719.

Broom, R. (1937). The Sterkfontein ape. Nature, 139, 326.

Broom, R. (1938a). The Pleistocene anthropoid apes of South Africa. Nature, 142, 377-79.

Broom, R. (1938b). Further evidence on the structure of the South African Pleistocene anthropoids. Nature, 142, $897-99$.

Broom, R. (1947). Discovery of a new skull of the South African ape-man, Plesianthropus. Nature, 159, 672.

Broom, R. (1950). Finding the Missing Link. London: Watts.

Broom, R. \& Robinson, J.T. (1949). A new type of fossil man. Nature, 164, 322-23.

Broom, R. \& Robinson, J.T. (1952). Swartkrans ape-man, Paranthropus crassidens. Pretoria: Transvaal Museum Memoirs, 6.

Broom, R., Robinson, J.T. \& Schepers, G.W.H. (1950). Sterkfontein ape-man, Plesianthropus. Pretoria. Transvaal Museum Memoirs, 4.

Broom, R. \& Schepers, G.W.H. (1946). The South African Fossil Ape-men, the Australopithecinae. Transvaal Museum Memoirs, 2.

Clark, W.E. Le Gros (1946). Significance of the Australopithecinae. Nature, 157, 863-65.

Clark, W.E. Le Gros (1947). Observations on the anatomy of the fossil Australopithecinae. Journal of Anatomy, 81, $300-33$. 
Clark, W.E. Le Gros (1950). South African fossil hominoids. Nature, 165, 893-94.

Clark, W.E. Le Gros (1952). A note on certain cranial indices of the Sterkfontein skull No. 5. American Journal of Physical Anthropology, 10, 119-21.

Clark, W.E. Le Gros (1955). The Fossil Evidence for Human Evolution. Chicago: University of Chicago Press.

Clarke, R.J. (1977). The cranium of the Swartkrans hominid SK 847 and its relevance to human origins. Unpubl. $\mathrm{PhD}$ thesis, Department of Anatomy, University of the Witwatersrand, Johannesburg.

Clarke, R.J. (1985). Australopithecus and early Homo in Southern Africa. In: Ancestors: The Hard Evidence, ed. E, Delson, pp. 171-77. New York: Alan R. Liss Inc.

Clarke, R.J. (1994). The significance of the Swartkrans Homo and the Homo erectus problem. In: 100 Years of Pithecanthropus. The Homo erectus Problem, ed. J.L. Franzen, pp. 185-93, Courier Forschungsinstitut Senckenberg, Vol. 171.

Clarke, R.J. (1998). First ever discovery of a well-preserved skull and associated skeleton of Australopithecus. South African Journal of Science, 94, 460-63.

Clarke, R.J. \& Tobias, P.V. (1995). Sterkfontein Member 2 foot bones of the oldest South African hominid. Science, $269,521-24$.

Crick, F.H.C. (1988). What mad pursuit: a personal view of scientific discovery. New York: Basic Books.

Dart, R.A. (1925). Australopithecus africanus: the man-ape of South Africa. Nature, 115, 195-99.

Dart, R.A. (1934). Dentition of Australopithecus africanus. Folia Anatomica Japonica, 12, 207-21.

Dart, R.A. \& Craig, D. (1959). Adventures with the Missing Link. New York: Harper and Brothers.

Deacon, T. (1994). Interview cited in R. Caird, Ape Man: the Story of Human Evolution. London: Boxtree, pp. 99-101.

Eccles, J.C. (1989). Evolution of the Brain: Creation of the Self. London and New York: Routledge.

Falk, D. (1983). Cerebral cortices of East African early hominids. Science, 222, 1072-74.

Findlay, G. (1972). Dr. Robert Broom, Palaeontologist and Physician, 1866-1951. Cape Town: A.A. Balkema.

Hughes, A. R. \& Tobias, P.V. (1977). A fossil skull probably of the genus Homo from Sterkfontein, Transvaal. Nature, 265, 310-12.

Jones, F.W. (1947). The Plesianthropus skull. Nature, 159, 883.

Keith, A. (1931). New Discoveries Relating to the Antiquity of Man. London: Williams and Norgate.

Keith, A. (1947). Australopithecine or Dartians. Nature, 159, 377.

Keith, A. (1950). An Autobiography. London: Watts/New York.

Kuhn, T. (1970). The Structure of Scientific Revolutions. Chicago: University of Chicago Press.

Kurtén, B. (1972). Not from the Apes: Man's Origins and evolution. London: Victor Gollancz.

Leakey, L.S.B., Tobias, P.V. \& Napier, J.R. (1964). A new species of the genus Homo from Olduvai Gorge. Nature, 202, pp. 7-9.

Lieberman, P. (1995). Manual versus speech motor control and the evolution of language. Behavioural and Brain Sciences, 18, 197-98.

Oakley, K.P. (1968). An appreciation of Dr. Robert Broom, F.R.S. South African Archaeological Bulletin, 23, 3536.

Oxnard, C.E. (1975). The place of the australopithecines in human evolution: grounds for doubt? Nature, 258, 389-95.

Robinson, J.T. (1954). The genera and species of the Australopithecinae. American Journal of Physical Anthropology, 12, 181-200.

Robinson, J.T. (1961). The australopithecines and their bearing on the origin of man and of toolmaking. South African Journal of Science, 57, 3-13.

Simonetta, A. (1957). Catalogo e sinonimia annotata degli ominoidi fossili ed attuali (1758-1955). Atti della Società Toscana Scienze Naturali, B, 64, pp. 53-112.

Simpson, G.G. (1944). Tempo and Mode in Evolution. New York: Columbia University Press.

Simpson, G.G. (1953). The Major Features of Evolution. New York: Columbia University Press.

Spencer, F. (1990). Piltdown: A Scientific Forgery. London and New York: Natural History Museum Publications and Oxford University Press.

Stent, G. (1972). Prematurity and uniqueness in scientific discovery. Scientific American, 227, 84-93.

Tobias, P.V. (1975). Brain evolution in the Hominoidea. In: Primate Functional Morphology and Evolution, ed. R.H. Tuttle, pp. 353-92. The Hague: Mouton.

Tobias, P.V. (1979). The Silberberg Grotto, Sterkfontein, Transvaal, and its importance in palaeo-anthropological 
researches. South African Journal of Science, 75, 161-64.

Tobias, P.V. (1980). L'évolution du cerveau humain. La Recherche, 11, 282-92.

Tobias, P.V. (1984). Dart, Taung and the 'Missing Link'. Johannesburg: Witwatersrand University Press for The Institute for the Study of Man in Africa.

Tobias, P.V. (1991). The Piltdown skull forgery and Taung: rejection and acceptance in science - and new revelations on the identity of the forger (Part I ). Adler Museum Bulletin, 17, 4-14.

Tobias, P.V. (1992a). The species Homo habilis: example of a premature discovery. Annales Zoologici Fennici, 28, $371-80$.

Tobias, P.V. (1992b). The Piltdown skull forgery and Taung: rejection and acceptance in science - and new revelations on the identity of the forger (Part II). Adler Museum Bulletin, 18, 9-26.

Tobias, P.V. (1992c). Piltdown: an appraisal of the case against Sir Arthur Keith. Current Anthropology, 33, 243-93.

Tobias, P.V. (1993). Raymond Dart's unpublished memoir on Taung. South African Journal of Science, 89, 311-12.

Tobias, P.V. (1996). Premature discoveries in science with especial reference to Australopithecus and Homo habilis. Proceedings of the American Philosophical Society, 140, 49-64.

Watson, J.D. \& Crick, F.H.C. (1953). A structure for deoxyribose nucleic acid. Nature, 171, 737-38.

Weiner, J.S., Oakley, K.P. \& Clark, W.E. Legros. (1953). The solution to the Piltdown problem. Bulletin of the British Museum of Natural History (Geology), 2, 141-146.

Weiner, J.S., Oakley, K.P. \& Clark, W.E. Legros. (1955). Further contributions to the solution of the Piltdown problem. Bulletin of the British Museum of Natural History (Geology), 2, 225-287.

Wilkins, W.K. \& Wakefield, J. (1995). Brain evolution and neurolinguistic preconditions. Behavioral and Brain Sciences, 18, 161-226.

Zuckerman, S. (1974). Choosing one's ancestors. Engineering and Science (Caltech), 2-5 May, pp. 22-23.

Zuckerman, S. (1978). From Apes to Warlords 1904-1946: An Autobiography. London: Hamish Hamilton. 


\section{Tatyana I. Alexeeva}

Institute and Museum of Anthropology, Moscow State University

Keywords: population ecology, adaptation, high altitudes, Mongolian populations

\section{Anthropo-ecological Investigation of Central Asia}

The territory of Central Asia is a good choice for anthropological investigations because the original populations have much in common racially and genetically. Thus, a natural experiment in Central Asia which had been prepared by history and nature might be a very successful opportunity for us as we have a rare opportunity to study representatives of genetically close anthropological types in a variety of ecosystems.

Our studies of the mountain-dwelling populations of Altai-Sayany discovered that the nature of morpho-physiological parameters of populations living in severe continental climatic conditions had many specific features. To begin with, they reflect several adaptations to the influence of cold stress -e.g. brachymorphy, characterised by relatively shortened lower limbs, relatively heavy mass, a large amount of body fat, and a rather high level of cholesterol in the blood serum. The morphological status of Mongolian populations demonstrates features not only of continental type but also high-altitudes of 2000-3000 $\mathrm{m}$ above sea level. The morphophysiological status of the Gobi populations compared with the Khangai populations is characterised by clearer manifestations of continental adaptive type. The Gobi populations are more brachymorphic, with greater developed fat skin folds. Adaptive types of taiga and steppe were discovered also, but the most characteristic feature of Mongolian populations is adaptation to high altitudes.

The demographic structure of Central Asia populations is greatly variable, although it has many common features. In general Central Asian populations are characterised by a low tempo and age dynamics. One can observe prolonged skeletal maturation and biological age lagging behind chronological age. These features are peculiar for the longevity of the population. The low length of life characteristic of some Central Asian groups is connected with unfavourable social factors.

Anthropo-ecological investigations in Central Asia began in 1976, covering the territories of the Altai-Sayany mountains and Mongolia, where studies were conducted from 1986 to 1991. During 16 field seasons approximately 6000 individuals of both sexes were examined, 2500 of them children aged from 7 to 17 years.

The program included the study of body build, metabolic rates, genetic markers and demographic structures. Different groups of Tuvins, Khakass, Mountain and Abakan Shortsys, Altai-Kijis, Telengits, Teleuts, Kazakhs, several groups of Mongols and Khotons were studied (see Fig. 1).

Territorially, Central Asia was a good choice for anthropo-ecological investigations because the original populations have much in common racially and genetically. Thus a natural experiment in Central Asia, as a result of historical circumstances, provided a rare opportunity to study representatives of genetically close anthropological types in various ecosystems.

The identical nature of their economic and cultural types, and the consequent similarity of their diets and nutrition, facilitated the investigation, making it possible to identify laws of climatic and 


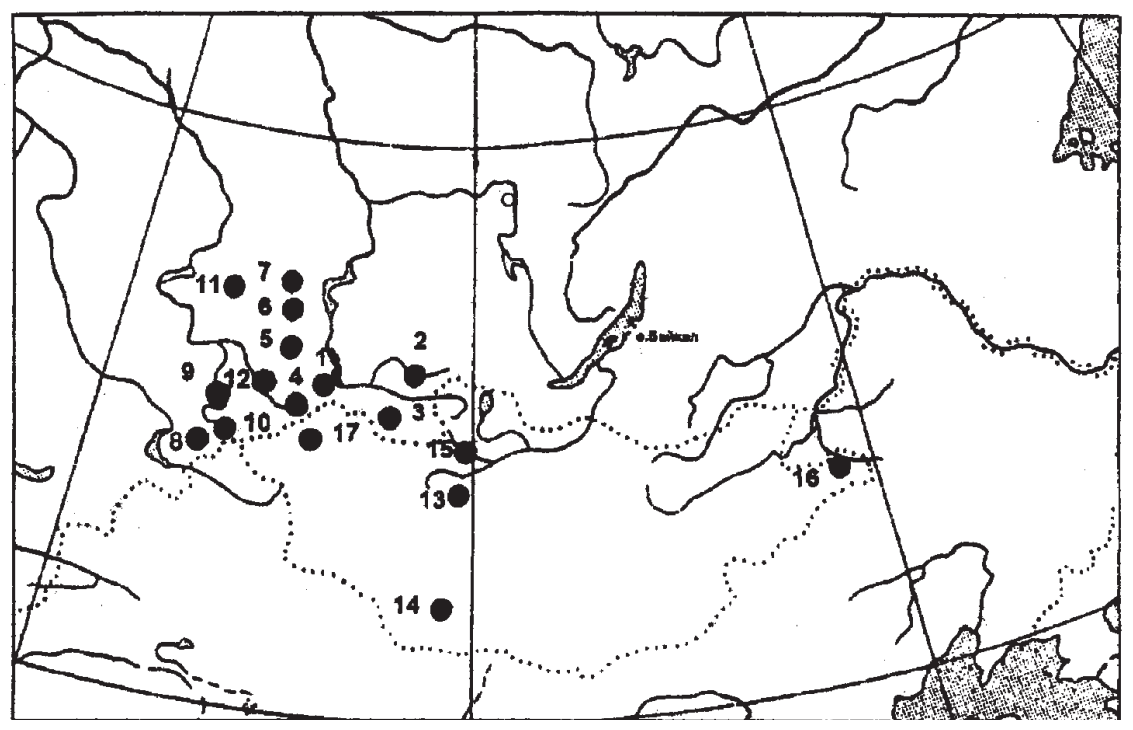

Figure 1. Location of the populations studied.

1 Tuvins of the Dzun-Khemchiksy region; 2 Tuvins-Todjins; 3 Tuvins of the Erzinsky region; 4 Tuvins of the Mongun-Taiginsky region; 5 Khakass-Sagaits; 6 Khakass-Kysyls; 7 Khakass-Kachins; 8 Alatai-Kijis; 9 Mountain Shortsys; 10 Chuisk Kazakhs and Telengits; 11 Teleuts; 12 Abakan Shortsys; 13 Khalkha-Mongols of Bat-Ulzy and Burd somons; 14 Khalkha-Mongols of Bayan-Lig somon; 15 Khalkha-Mongols of Jhargalan somon; 16 KhalkhaMongols of Khalkhgol somon; 17 Khotons and Derbets of Tarialan somon.

geomorphological influences on human individuals, as well as some other biological parameters of the human populations.

In the Altai-Sayany Plateau the following groups were studied:

In the mountain-taiga area - Tuvins (Mongunsky-Taiginsky region; $2300 \mathrm{~m}$ above sea level); TuvinsTodjins (Todjinsky region; 800-1200 m above sea level); Altai-Kiji (Ust-Kansky region; 2000-2200 m); Mountain Shortsy (Tashtagolsky region; 1400-1500 m); Abakan Shortsy (Tashtypsky region; 700-850 m).

In the mountain-steppe area Telengits and Kazakhs (Kosh-Agachsky region; 1750-2200 m) were studied; in the steppe and desert-steppe area - Tuvins (Dzun-Khemchiksky region; 500-1000 m) and Teleuts (Belovsky Village Centre of Kemerovskaya region; 500 m); Tuvins (Erzinsky region; 1000-1100 m).

The following groups live in the forest-steppe area: Khakass-Kachints (Shirinsky region; 500-1000 m); Khakass-Sagaits (Askizsky region; 500-1000 m); Khakass-Kysyls (Shirinsky region; 500-1000 m).

In Mongolia, in the mountain-taiga zone Khalkha-Mongols of the somons Bat-Ulzyi, Burd and Zhargalang were studied; in the desert zone, Khalkha-Mongols of the somons Bayan-Lig and Bogd (altitudes ranging from 1700 to $1850 \mathrm{~m}$ above sea level). In the steppe zone Khalkha-Mongols of the somon Khalkhgol; Khalkha-Mongols, Derbets and Khotons of the somon Tarialan were studied (altitudes ranging from 750 to $940 \mathrm{~m}$ above sea level).

Our studies of Altai-Sayany mountain populations revealed that the morpho-physiological parameters of populations living in severe continental climatic conditions show many specific features, including several adaptations to cold stress (Alexeeva, 1984; Alexeeva, Batsevich, Yasina \& Tumen, 1998a,b; Klevtsova, 1987). 


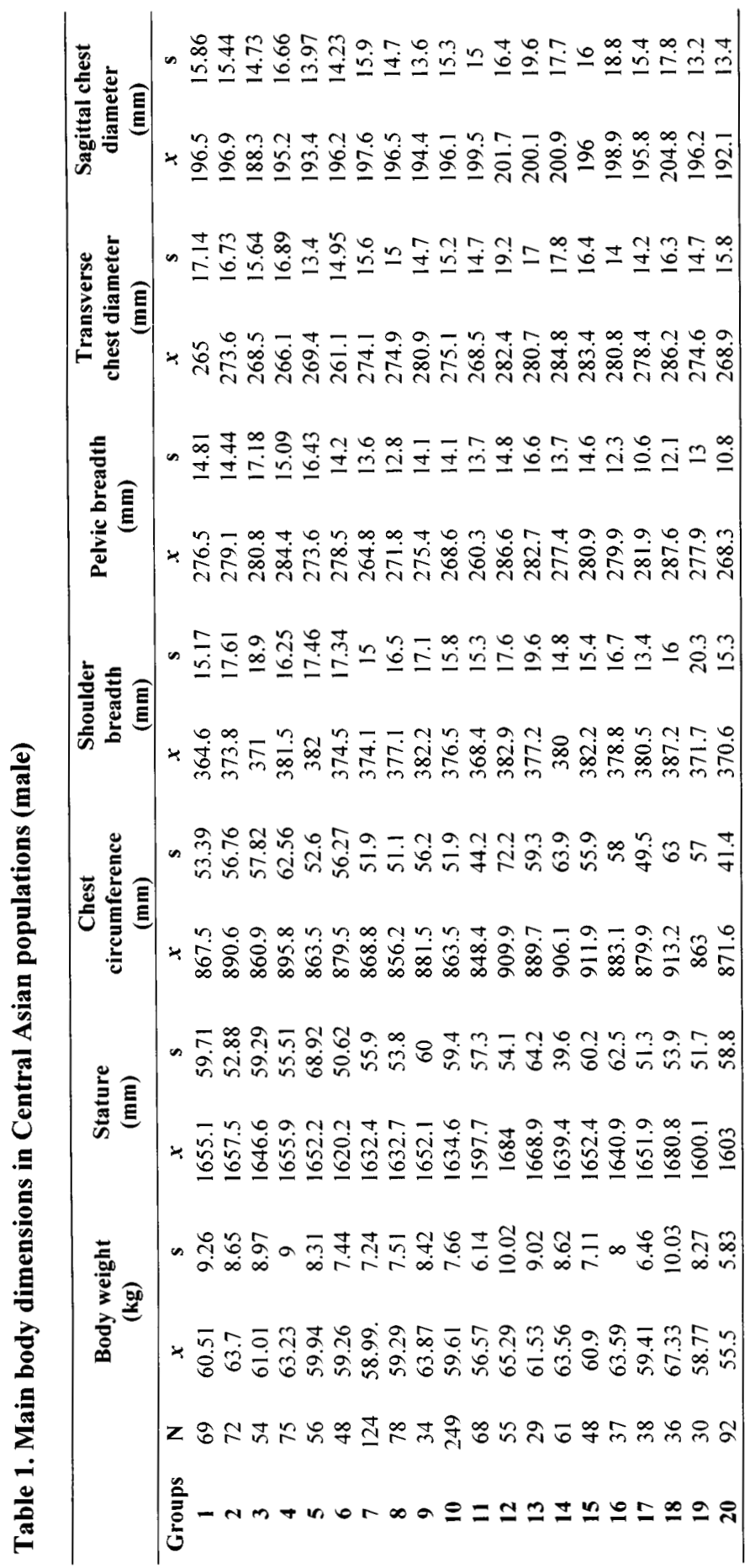



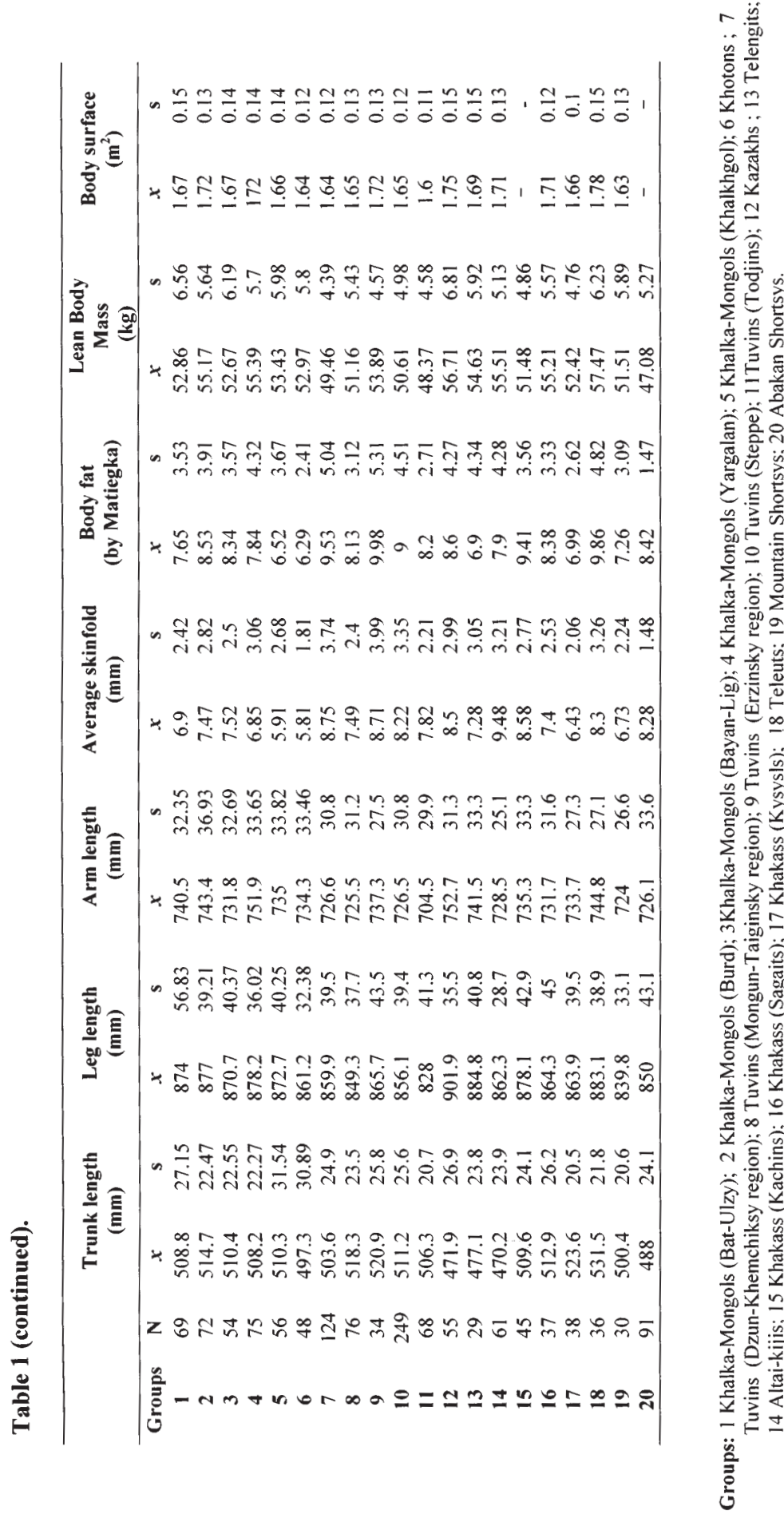
I shall deal first with a brachymorphic type which is characterized by relatively shortened lower limbs, relatively great weight, large amounts of body fat and relatively high serum cholesterol levels. This combination of morphological and functional parameters is interpreted as a reaction to cold-stress and is referred to as the continental adaptive type (Alexeeva, 1977).

Application of canonical analysis to evaluate the morphological traits of Central Asian populations revealed that taxonomically the most valuable features are: stature, leg length, transverse and sagittal chest diameters, pelvic breadth, ankle breadth, body weight and average skinfold thickness. This analysis showed the existence of two clearly expressed morphological types in the area studied: the first type - of massive body-build with high body weight, large chest, wide pelvis and well developed skeleton, and high levels of body fat; the second type - more gracile, with shorter body lengths, flatter chest, less developed skeleton, and low levels of body fat.

The majority of Central Asian populations studied fall into the first morphological type. They are concentrated in the steppe zone, while the gracile type is more common in taiga regions (Chikisheva, 1986). The most typical representatives among the latter are Tuvins-Todjins and Mountain Shortsys.

It is difficult to explain such morphological differentiation at the present time. The territory of Central Asia is characterised by a single subsistence type - nomadic and seminomadic pastoralism in the arid zone. The only exceptions are the Mountain Shortsys, who until recently were hunters, fishermen and gatherers (Andrianov \& Cheboxarov, 1972). The diet of Central Asian peoples is rich in protein and fatty foods which have a high caloric value. Hence, nutrition alone can hardly explain the differences in body build among the native populations of Central Asia.

Similarly, somatic differentiation cannot be explained by different genetic origins. Despite slight anthropological differences (e.g. the peoples of Altai are more Europoid, while the peoples of Sakha and Mongolia are more Mongoloid), the morphological base of them all is rather similar (Alexeev \& Gokhman, 1984). Thus, the suggestion that the massive and gracile types may be of different genetic origin should be rejected.

It seems that the reason for the differences must be purely ecological, though there is no direct evidence for it. In the anthropological literature there are some references to a link between gracile forms and a deficiency of bone forming mineral elements in acid forest soils (Alexeeva, 1979; Dobrovolskaya, 1984). This may also be the case in our study.

Ecological differentiation of the Altai-Sayany peoples and Mongolian peoples cannot be explained in terms of differences between steppe and taiga versions. In the framework of the 'continental type', some traits of high altitude adaptation can be traced which are expressed morphologically in terms of enlarged medullary canal and chest dimensions. It is especially expressed in the populations of Khangai living at altitudes of 2000-3000 $\mathrm{m}$ above sea level.

The morphophysiological status of the Gobi populations compared with the Kangai populations is characterized by a clearer manifestation of the continental adaptive type. The Gobi populations are more brachymorphic, with thicker skinfolds.

Adaptive types characteristic of taiga and steppe were also identified, but the most characteristic feature of Mongolian populations is adaptation to high altitudes.

The demographic structure of Central Asian populations is greatly variable, although there are many common features. In general, Central Asian populations are characterized by low tempos of age dynamics. One can observe prolonged skeletal maturation and biological age lagging behind chronological age; these features have important implications for longevity in the populations concerned.

The shorter life expectancy characteristic of some Central Asian groups is connected with unfavourable social factors. Analysis of growth curves and growth rates reveals differences among children living in different geographical regions of Central Asia. The longest period of growth is typical of desert inhabitants; the most intensive growth is characteristic of those inhabiting the steppe zone. These morphological characteristics typical of inhabitants of the different ecological niches of Central 


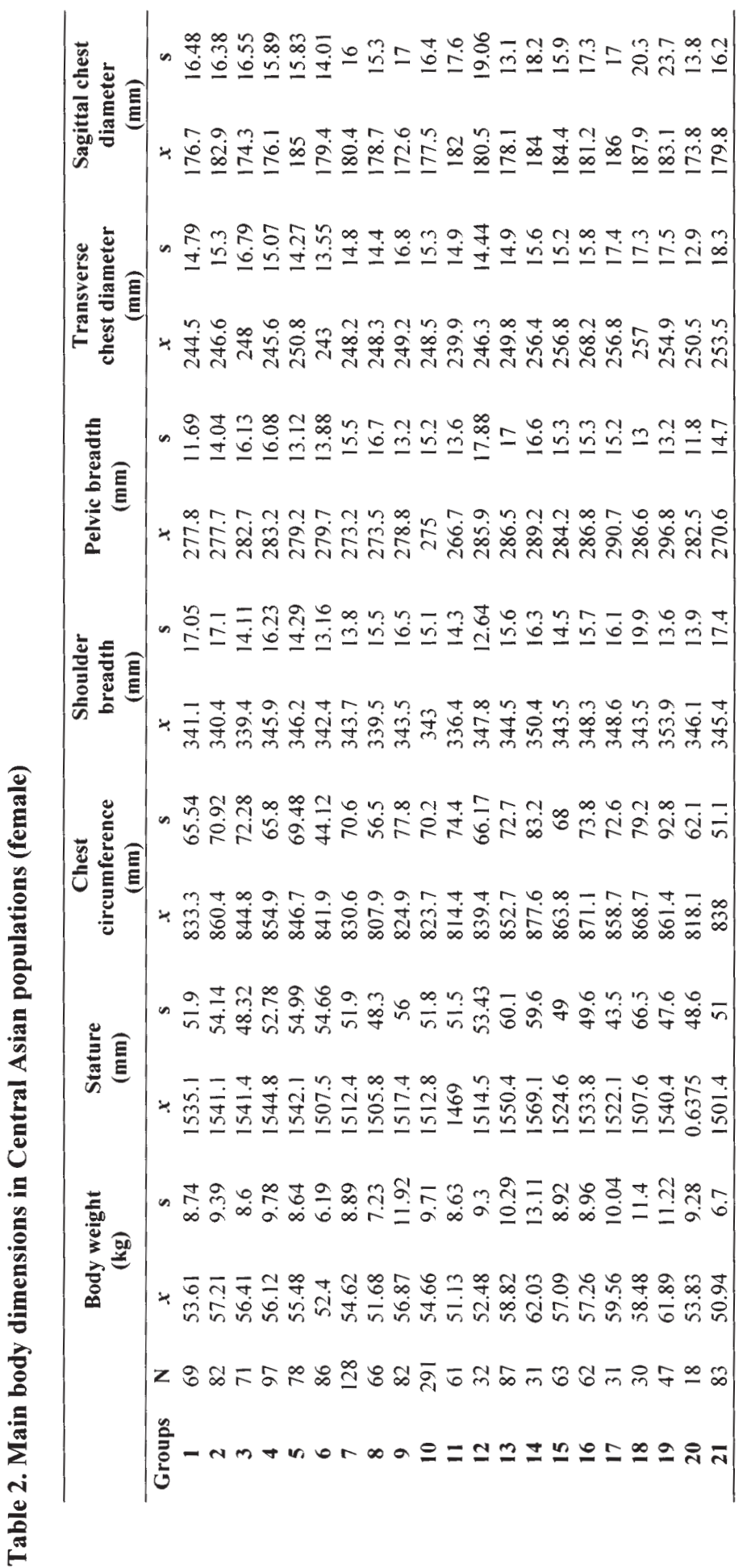



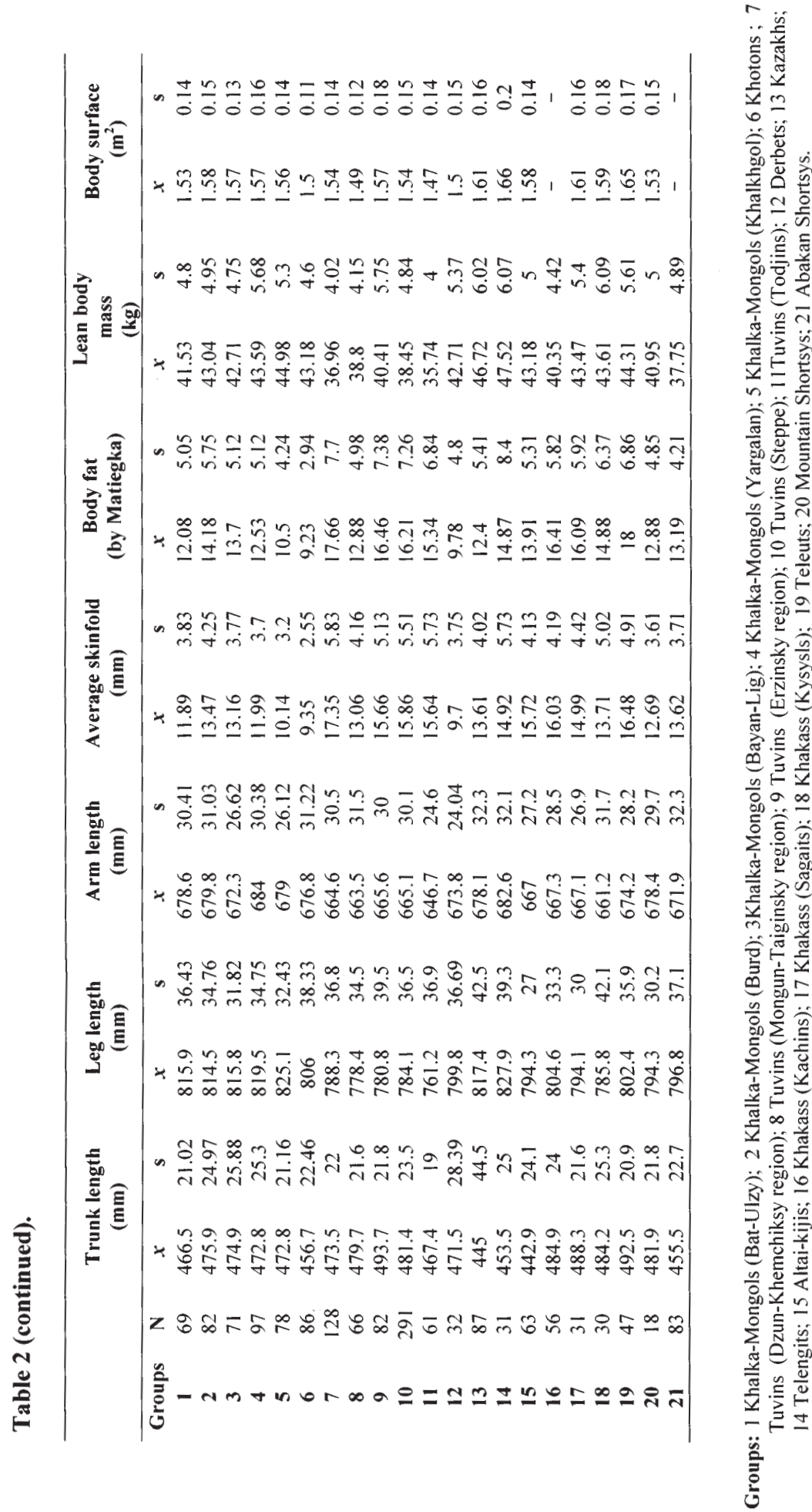
Asia are observable even in the children.

The most important results of our Central Asian studies are the identification of several versions of adaptive variability: in the framework of well-defined continental features that are more clearly expressed in the population of the Gobi region, some traits of steppe, taiga and high altitude adaptations have been traced.

The similarity of subsistence patterns, and hence of diet, in Central Asian populations, as well as their genetic affinity, support the suggestion that the morpho-functional characters of those populations reflect adaptations to specific geographical environmental conditions.

\section{References}

Alexeev, V.P. \& Ghokhman, I.I. (1984). Anthropology of the Asian Part of the USSR. M., Nauka (In Russian).

Alexeeva, T.I. (1977). Geographical Environment and Human Biology. M., Mysl. (In Russian).

Alexeeva, T.I. (1979). Biogeochemistry and problems of anthropology. In: Sovremennye zadachi i problemy biogeochimii, 17. M., Nauka (In Russian).

Alexeeva, T.I. (Ed). (1984). Anthropoecological investigations in Tuva. M., Nauka. (In Russian).

Alexeeva, T.I., Batsevich, V.A., Yasina, O.V. \& Tumen, D. (1998a). Anthropology of Central Asia (Ethnogenesis, Ecology). In: Narody Rossii. Antropologiya. Chast 1.

M., Stary Sad (In Russian).

Alexeeva, T.I., Batsevich, V.A., Yasina, O.V. \& Tumen, D. (1998b). Processes of growth and development in children of Central Asia. In: Narody Rossii. Antropologiya. Chast 1. M., Stary Sad (In Russian).

Andrianov, B.V. \& Cheboksarov, N.N. (1972). Subsistence types and the problems of their mapping. Sovetskaya Etnographiya, 2 (In Russian).

Chikisheva, T.A. (1986). Problems of Anthropology of Ancient and Modern Population of Soviet Asia. Novosibirsk, Nauka (In Russian).

Dobrovolskaya, M.V. (1984). Quantitative evaluation of microelements in human skeleton (on the materials of ancient burials). Voprosy antropologii, 74 (In Russian).

Klevtsova, N.I. (1993). Materials to characteristics of native population of Altai-Sayany plateau. Voprosi antropologii, 87 (In Russian). 


\section{Janusz Piontek}

Institute of Anthropology,

University of Poznan,

PL 61-701 Poznan,

Poland, Fredry 10

Keywords: Culture, human ecology, Central Europe, Upper Paleolithic, Neolithic, industrialization, body size, body shape, secular trends

\section{Culture as a Human Adaptive System: Human Ecology and Culture}

\begin{abstract}
A hypothesis is formulated that changes in the structure of the socio-economic system between the Upper Paleolithic and Neolithic Age, and in the transition to industrialization, resulted in new possibilities for natural selection to operate through differential fertility. The changes in morphological structure of human populations in these transitions (to agriculture and industrialization), as described by a number of authors, are shaped simultaneously by two biocultural factors. The main one is natural selection: the process of genetic adaptation to a new lifestyle (i.e. a new cultural adaptive strategy). The second factor is the process of change in adaptability as an adjustment to different biocultural situations: disease, nutrition, work demand, settlement pattern, industrialization, urbanization, etc. The relationships between changes in adaptive strategy and biological structure of human populations in Central Europe in (a) the transition to agriculture and (b) the transition to industrialization in Central Europe are analysed.
\end{abstract}

\section{Introduction}

Human ecology is understood in terms of (a) a physical interpretation - the energetics of living systems; (b) an economic interpretation - the economy of biosocial systems; (c) a biological interpretation - adaptation and the adaptability of biological systems. We postulate a multi-faceted interpretation and define human ecology as a science investigating the relationships between the biological structure of human populations and: (a) its economic structure, (b) the human environment (abiotic, biotic, and cultural), (c) its social structure, and (d) its ideological control subsystem. In the human system, as opposed to non-human populations, a cultural adaptive strategy is generated. This adaptive strategy we understand as a pattern of adaptation or adjustment to the environmental conditions in a biological and/or cultural way (Wolanski, 1990), because if the human system is a class of elements (e.g. population, human environment, economic, social structure and ideology), then the adaptive strategy comprises a pattern of the arrangement of these elements.

If culture is an important element of the human adaptive system, then ideology should be defined more precisely. This is a social pattern of the world, defining the human status within it and the utilitarian value of human activities. Of course, the ideology characteristic of hunters and gatherers would be completely different from that characteristic of agricultural populations and modern human populations (Wierciński, 1978).

We advance the hypothesis that, at successive stages of biocultural development of human populations (e.g. Upper Paleolithic, Neolithic and modern human populations in the transition to industrialization), these factors interacted at different levels of significance, and that significant factors displayed different adaptive strategies.

This hypothesis is here verified for two types of adaptive strategies - that in the transition to agriculture, and that in the transition to industrialization, in Central Europe. 


\section{The transition to agriculture \\ Hypothesis}

Changes in the relations of essential elements of the human system in the period between the Upper Paleolithic and Neolithic times gave rise to new possibilities of natural selection operating through differential fertility. A new life-style promoted a high general fertility rate, which has been emphasized in models describing the transition to agriculture (Hassan, 1985; Ammerman, 1989). Also, studies of the fertility rate in modern traditional agricultural and non-agricultural populations indicate that higher fertility is associated primarily with the intensification of agriculture ( Bentley et al., 1993a,b).

In the Neolithic adaptive strategy, there was a preference for high general fertility and natural selection could operate through a differential fertility rate of earlier and later maturing individuals. In this situation, the individuals maturing earlier (i.e. those who start to reproduce earlier) would have had a better chance to produce more offspring than those individuals starting their reproduction later, while mortality rate would be similar for both groups. This adaptive strategy is characteristic of the $r$ selection model elaborated by Pianka (1970). In this model natural selection favors early maturation of individuals, early reproduction, higher general fertility rate, as well as small body size.

To explain the differences between the Upper Paleolithic and Neolithic populations with regard to their physique (long bones, body size, proportions of long bones, sexual dimorphism, reduction in body shape), we advanced the hypothesis that in Neolithic populations in which cultural factors shaped a new fertility pattern, natural selection could operate through the differential fertility of earlier and later maturing individuals, favoring a new pattern of growth (early maturation).

To test this hypothesis, we analysed parameters of the long bones describing body size, body shape and long bone proportions. Our choice was based on the fact that, according to numerous previous investigations, study of the morphology of the postcranial skeleton can provide important information on the biological and ecological traits of human groups living in various social and economic systems (Frayer 1980, 1981, 1984; Henke, 1988; Vančata, 1988).

The size and shape of long bones, their sexual differences, their robusticity, and temporal changes in these traits, seem also to be the most important indicators of a basic adaptive and ecological pattern in human microevolution, as well as good indicators of adaptive strategy in different cultural periods.

On the basis of comparative analysis of variability in long bone traits from Upper Paleolithic and Mesolithic archaeological sites (data collected by several authors), we compared long bone morphology in these populations with data for two Neolithic population types: one typical of agriculture - the Band Pottery Culture (BPC) from the Elbe-Saale Basin and the other representing populations that are not typically agricultural (mixed economy) - the Corded Ware Culture (CWC) from the Elbe-Saale Basin.

Data for European Upper Paleolithic material were taken from the works of Frayer (1981), Jacobs (1985) and Vančata (1993 - individual data and arithmetic means were drawn from a data base provided by this latter author). Comparison of the three sets of data showed that Frayer's (1981) data can be located somewhat between the other two which is why they were chosen for further comparison.

Data for European material of Mesolithic times were drawn from Frayer (1981) and Jacobs (1985), and four collective groups were compared. This showed that the data set collected by Jacobs (1985) for Post-glacial specimens (POG) occupies a position intermediate between the other data sets.

In the case of Neolithic populations from Central Europe, the collections from various archaeological sites in the Elbe-Saale Basin of Germany are well documented (numbers of skeletons, number of studied characteristics, archaeological description of findings) (Bach et al., 1975; Bach 1978).

\section{Skeletal adaptation in the transition to agriculture}

Figures 1-7 present summaries of the long bone characteristics studied in this investigation covering the Upper Paleolithic, Mesolithic and Neolithic. On the basis of these data we can draw the following conclusions: 


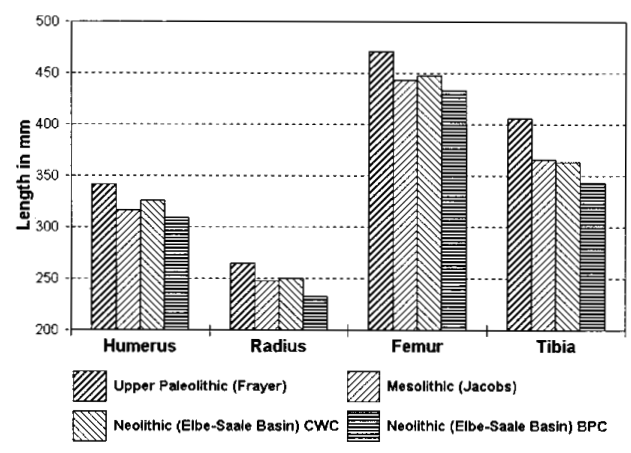

Figure 1. Upper Paleolithic/Neolithic Transition Length of long bones - Males

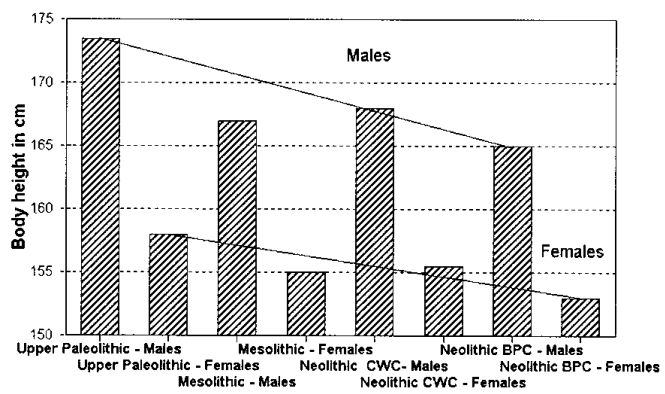

Figure 3. Upper Paleolithic/Neolithic Transition Body height

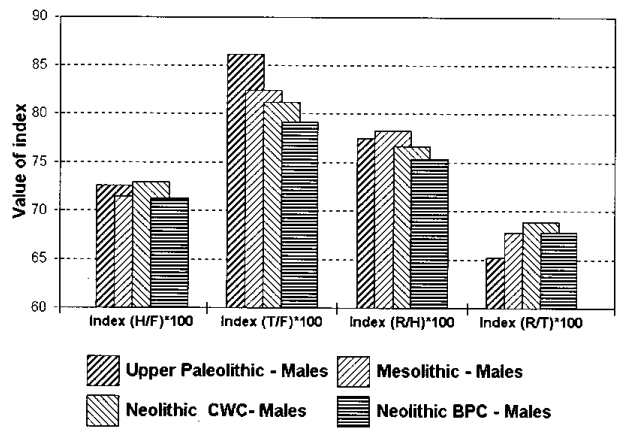

Figure 5. Upper Paleolithic/Neolithic Transition Proportions of long bones (Males)

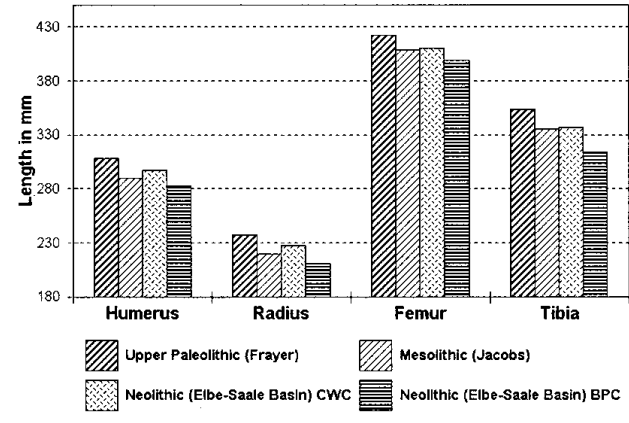

Figure 2. Upper Paleolithic/Neolithic Transition Length of long bones - Females

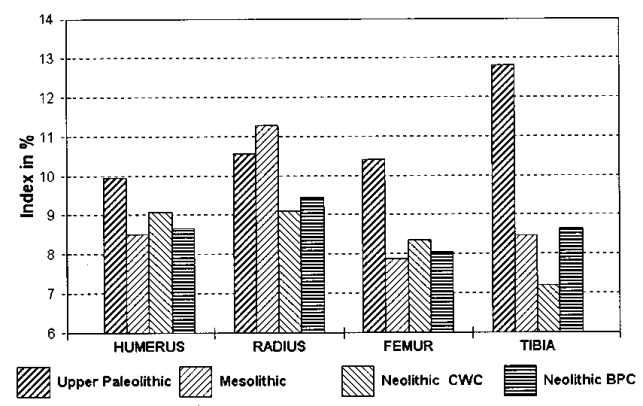

Figure 4. Upper Paleolithic/Neolithic Transition Sexual dimorphism of long bones

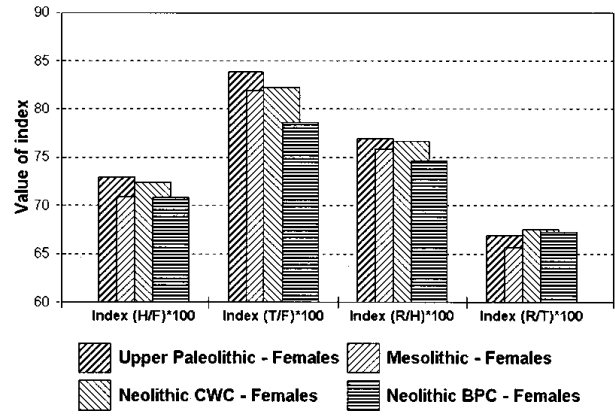

Figure 6. Upper Paleolithic/Neolithic Transition Proportions of long bones (Females) 


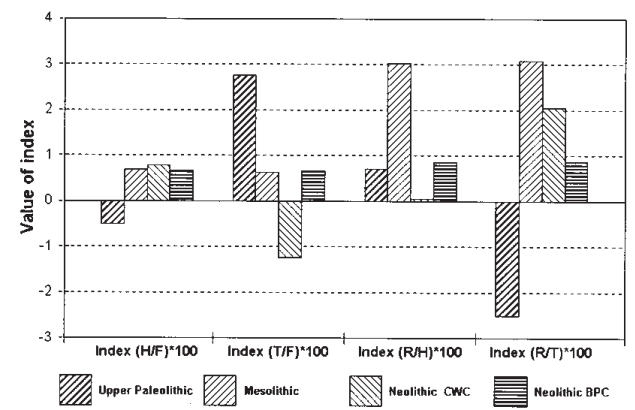

Figure 7. Upper Paleolithic/Neolithic Transition Proportions of long bones (dimorphism)

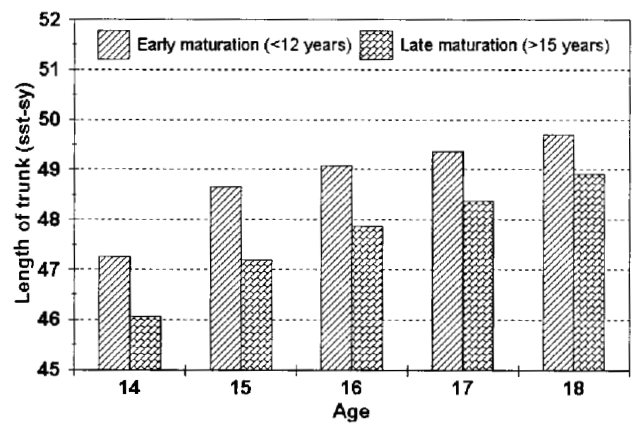

Figure 9. Length of trunk (sst-sy) - girls Poznan region- Poland ( 1960-1964)

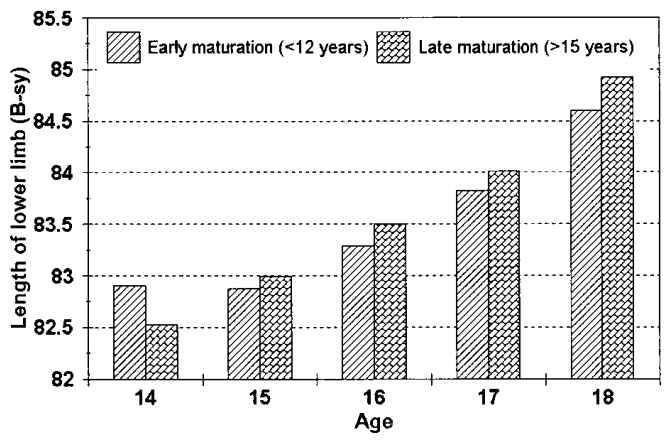

Figure 8. Length of lower limb (B-sy) - girls Poznan region- Poland (1960-1964)

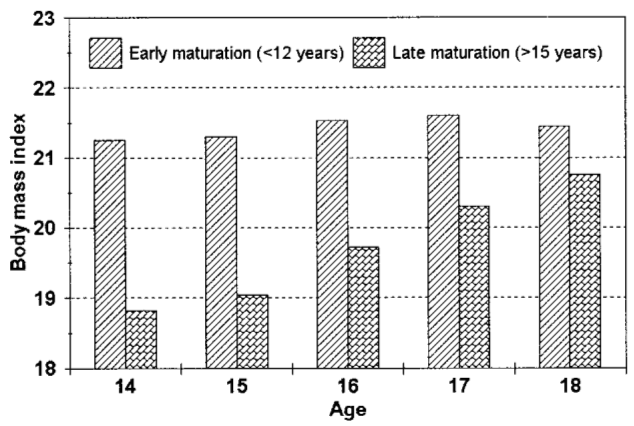

Figure 10. Body mass Index - girls Poznan region- Poland ( 1960-1964)

(a) three different morphological patterns of long bones - corresponding to the Upper Paleolithic, Mesolithic and Neolithic - probably existed during microevolution of Homo sapiens in the Upper Paleolithic/Neolithic transitional period;

(b) the morphology of long bones of the Mesolithic populations was of a transitional character, and the non typical agricultural populations of the Corded Ware Cultures showed some traits similar to those of the Mesolithic populations;

(c) the morphology of Neolithic populations from two types of archaeological cultures (BPC and CWC) seems to be of a different character. The CWC populations are in some respects similar to the Mesolithic populations, while the BPC populations show an extremely different pattern of long bone morphology compared with that of the Upper Paleolithic populations.

\section{Discussion}

The pattern of development seen in populations of Neolithic farmers involves reduction in the growth of long bones, changes in their size, shape and proportions, and changes in their sexual dimorphism. Figure 8 attempts to explain these changes. It depicts a model of skeletal adaptation in which the role of genetics and the process of morphological adaptability changes. This model assumes 


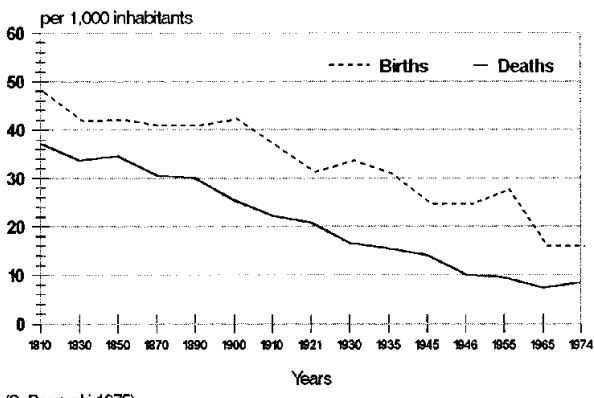

(S. Borowskj 1975)

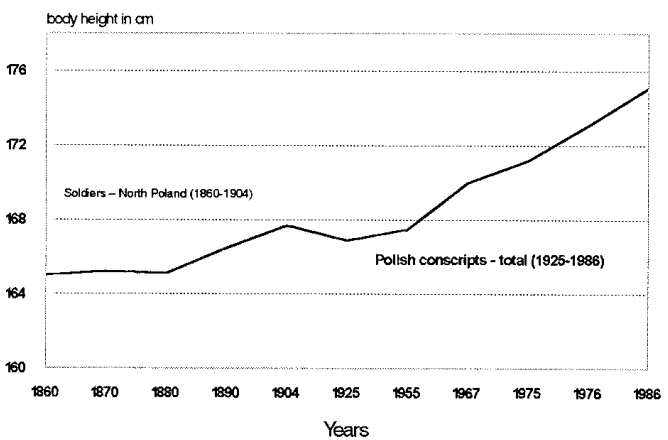

Figure 12. Secular Trends in Body Height in the Polish territories (1860-1986)

Figure 11. Natural Movements in the Pol
(Births, Deaths per 1,000 Inhabitants)

that the principal factor shaping the new pattern was differential reproduction in two different patterns of ontogenetic development: a pattern of fast growth (early maturation) and a pattern of slower growth.

According to the hypothesis we propose, and the model based on it, the changes in long bone morphology are most evident in 'typical' populations of farmers B that is, in the Band Pottery Culture. These were the populations in which agriculture constituted the main economic activity.

The CWC populations, whose cultural system, according to the archaeological data, was much more differentiated than that of the BPC populations, followed a different adaptive model. In this model, decisive importance can be attributed to economic and technological cultural factors, which made it possible to differentiate economic activities to a certain degree while simultaneously allowing for the exploitation of more varied parts of the environment.

The differences between BPC and CWC populations relating to body size reduction and length and proportions of long bones may be explained in terms of different patterns of individual development characterizing the BPC populations.

Changes in long bone morphology in the transition from Upper Paleolithic/ Mesolithic to Neolithic agricultural populations are caused by socio-economic factors, and from the biological point of view they may be regarded as of a microevolutionary character. These changes are not caused by natural environmental factors but by a new socio-economic structure which came into existence after the transition to agriculture (i.e. a new social structure and a new pattern of fertility).

\section{In summary:}

(1) The Neolithic type of adaptive strategy created new possibilities for the operation of natural selection. The adaptive strategy of the Band Pottery Cultures promoted a high fertility rate and the operation of natural selection through differential fertility as a result of slower and faster development of individuals;

(2) Natural selection favors fast development, early maturation and early reproduction. Alteration of the pattern of growth in the Neolithic agricultural populations resulted in a new morphological pattern of long bones: very short length, different proportions (short radius and tibia), minor sexual dimorphism;

(3) The reduced length of long bones in the Neolithic agricultural populations was caused by two types of biological factors: the primary factor was natural selection (genetic adaptation to a new lifestyle and new cultural adaptive strategies), and the secondary factors included changes in adaptability to 
different biocultural situations e.g. disease, food, work demand, settlement pattern etc.

\section{Verification of the hypothesis: contemporary data}

The hypothesis on differences in body build in early and late maturing individuals has been tested on the basis of contemporary semi-longitudinal data of 1100 girls aged from 14 to 18 years from the Poznan region, Poland ( Malinowski \& Stolarczyk, 1996).

This study shows (Figures 8-10) that early maturation is linked with a longer trunk and shorter lower limbs, while late maturing individuals have a shorter trunk and longer lower limbs. Similar differences have been described for the transition from the Upper Paleolithic to the Neolithic in Europe.

\section{The transition to industrialization: morphological reactions or a new adaptive strategy?}

It has been shown that the transition to agriculture was related to a change in fertility rate. This demographic transition resulted in a population increase and a change in the mode of operation of natural selection, which could now operate via differential fertility. The biological effects of this demographic transition were reflected in a succession of skeletal adaptations.

If the agricultural demographic transition triggered the skeletal adaptations described, then the question arises: were similar biological changes induced by the industrial demographic transition? The latter transition was caused by a drop in mortality rate, and subsequently in fertility rate (Figure 11). It also changed the opportunities for natural selection through differential mortality and fertility.

The biological changes related to the industrial demographic transition are similar in character to those changes generated by the agricultural demographic transition, but they progress in a different direction (Figure 12). Models explaining the biological consequences of the transition to industrialization put too much emphasis on the processes of adaptability. A commonly advanced hypothesis is that upon the transition to industrialization the improvement in living conditions triggered adaptability reactions which entailed an increase in body size and changes in body proportions.

One may venture a competing hypothesis that, upon the transition to industrialization, the proportion of early maturing to late maturing individuals changed as a result of the demographic transition (drop in mortality rate and fertility rate).

Therefore, we propose that in Upper Paleolithic times a pattern of growth involving late maturation prevailed, in Neolithic and post-Neolithic times the prevalent pattern of growth involved early maturation, and in the industrialization period both of these patterns occurred simultaneously and with equal intensity.

\section{Conclusions}

In physical anthropology certain controversies exist concerning the role of natural selection in the changes of the biological structure of human populations. Attempts to describe the adaptive significance of different morphological traits are still incomplete.

The key to understanding morphological changes in adult individuals is the analysis of ontogenetic processes, and recognition of the role of natural selection in the shaping of the pattern of human ontogeny.

The changes in morphological structure of human populations in the transition to agriculture and to industrialization were in our opinion shaped simultaneously by two biocultural factors: the main factor was natural selection B the process of genetic adaptation to a new lifestyle, that is, a new cultural adaptive strategy; the secondary factor was a process of adjustment to different biocultural situations B such as disease, nutrition, work demand, settlement pattern, industrialization processes, urbanization processes, etc. 


\section{References}

Ammerman, A.J. (1989). Population Studies and the Archaeologist. Norw. Arch. Rev., 22, 65-87.

Bach, A. (1978). Neolithische Populationen im Mittelelbe-Saale-Gebiet. Zur Anthropologie des Neolithikums unter besonderer Berücksichtigung der Bandkeramiker. Weimarer Monographien zur Ur- und Frühgeschichte, Weimar.

Bach, A., Bach, H., Gall, W., Feustel, R. \& Teichert, M. (1975). Beiträge zur Kultur und Anthropologie der Mitteldeutschen Schnurkeramiker II. Alt-Thüringen, 13, 43-107.

Bentley, R.G., Goldberg, T. \& Jasienska, G. (1993a). The fertility of agricultural and non-agricultural traditional societies. Population Studies, 47, 269-81.

Bentley, R.G., Jasienska, G. \& Goldberg, T. (1993b). Is the fertility of agriculturalists higher than that of nonagriculturalists? Current Anthropology, 34, 778-85.

Bielicki, T., Welon, Z. \& Zukowski, W. (1988). Social-class differences in physique and physiological fitness (in Polish). Materialy i Prace Antropologiczne, 109, 123-40.

Borowski, S. (1975). Population growth in the Polish territories. In: The Population of Poland, Series C.I.C.R.E.D., World Population Year, Polish Academy of Sciences, 1-17.P

Frayer, D.W. (1980). Sexual dimorphism and cultural evolution in the Late Pleistocene and Holocene of Europe. Journal of Human Evolution, 9, 399-415.

Frayer, D.W. (1981). Body size, weapon use, and natural selection in the European Upper Paleolithic and Mesolithic. American Anthropologist, 83, 57-73.

Frayer, D.W. (1984). Biological and cultural change in the European Late Pleistocene and Early Holocene. In: The Origins of Modern Humans: A World Survey of the Fossil Evidence, ed. F.H. Smith \& F. Spencer, pp. 211-50. Alan R. Liss, Inc.

Górny, S. \& Dobrzanska, A. (1981). Physique of conscripts and changes in nutrition. Polish Anthropological Review, 47, 145-150.

Hassan, F.A. (1981). Demographic Archaeology. New York, Academic Press.

Henke, W. (1988). Die Menschen der letzten Eiszeit. Zur Frage der Differenzierung der endpleistozaenen Hominiden Europas. Anthropologische Anzeiger, 46, 289-316.

Jacobs, K. (1985). Evolution in the postcranial skeleton of Late Glacial and early Postglacial European hominids. Zeitschrift für Morphologie und Anthropologie, 75, 307-26.

Malinowski, A. \& Stalarczyk, H. (1996). Traits of somatic structure of girls according to age of menarche (in Polish). In: Antropologia a medycyna i promocja zdrowia, ed. A. Malinowski, B. Luczak, J. Grabowska, pp.258-275. Wydawnictwo Uniwersytetu Lódzkiego, Lódz.

Mydlarski, J. (1933). Budowa fizyczna mlodziezy meskiej roczników 1906 do 1909 swietle materialów komisji poborowych. Lekarz Wojskowy, 22, 14-27.

Pianka, E.R. (1970). On $r$ - and $K$-Selection. American Naturalist, 104, 592-97.

Piontek, J. (1971). Ocena stanu rozwoju fizycznego poborowych powiatów Inowroclaw i Tuchola, urodzonych w drugiej polowie XIX wieku, w porównaniu z wspólćzesna mlodziea z Pomorza i Kujaw. Wydawnictwo Uniwersytetu im. Adama Mickiewicza w Poznaniu, seria antropologia, 1, 71-75.

Vancata, V. (1988). Ecological aspects of skeletal sexual dimorphism in microevolution of Homo sapiens. Anthropologie (Brno), 26, 83-92.

Wiercinski, A. (1978). The meaning and scope of anthropology. Collegium Antropologicum, 2, 10-16.

Wolanski, N. (1990). Glossary of Terms and Annotated Bibliography for Human Ecology. Warsaw: Polish Academy of Sciences.

Wolanski N. (1991) Human ecology, medicine and anthropology. Collegium Antropologicum, 15, 7-26. 


\section{Daniel W. Sellen}

Departments of Anthropology \& International Health

Emory University,

Geosciences Building, 1557 Pierce Drive, NE, Atlanta, GA 30322, USA

Keywords: bio-demography, fertility, mortality, subsistence

\section{Relationships between Fertility, Mortality and Subsistence: Results of Recent Phylogenetic Analyses}

\begin{abstract}
The results of recent tests of the hypothesis that measures of fertility rates and sub-adult mortality rates in natural fertility populations are associated with subsistence practices in selected cross-cultural samples are discussed in a behavioral ecological perspective. When phylogenetic comparative methods are used to take account of the general likelihood of cultural similarities between genetically closely related societies in stepwise multiple regression procedures, the estimate of percent dietary dependence on agriculture is retained as the best positive correlate of fertility rate reported for a culture. Among phylogenetic 'sister' cultures, increases in agricultural dependence are associated with linear increases in fertility across cultures. Dependence on extractive modes of subsistence (hunting, gathering and fishing) is a significant positive correlate of total child mortality $\left({ }_{15} \mathrm{q}_{0}\right)$, even after controlling for distance from the equator. There is little association with infant mortality $\left({ }_{1} \mathrm{q}_{0}\right)$. Implications for understanding the demographic changes that accompany subsistence transitions in both modern and prehistoric human populations are discussed.
\end{abstract}

\section{Introduction}

There have been many debates recently over the extent to which rates of fertility and mortality were dependent on the mode of subsistence in traditional and archaeological populations. Questions about demographic differences between anatomically modern humans adopting a wide range of ecological adaptations are inevitable if we are to understand the processes by which our species has populated its environments and the precise relationship between subsistence and population growth. There are many problems with reconstructing the demography of ancient populations (Armelagos et al., 1991; Bentley, 1996; Cohen, 1989; Hammel, 1996; Handwerker, 1983). The validity of these reconstructions can be strengthened using theoretical insights gained from observations of modern traditional peoples (Blurton Jones et al., 1992; Handwerker, 1986; Hill \& Hurtado, 1996; Howell, 1979). However, teasing apart the complex inter-relationships between culture, demography and resource base among modern preindustrial populations represents a considerable challenge.

Various hypotheses about the demographic impact and evolutionary significance of systematic differences in food availability and work patterns between the major modes of subsistence have been put forth. A consensus exists that fertility is higher among agriculturists, and that sub-adult mortality is higher among nomads. However, the mechanisms are unclear and the independent influence of cultural factors such as technology, the organisation of labour, marriage systems and social institutions is poorly understood. This paper summarises recent results of tests of these hypotheses using real demographic data from extant human populations while attempting to control for the non-independence of societies 
Table 1. Total fertility rates by mode of subsistence

\begin{tabular}{lcccc}
\hline & $\begin{array}{c}\text { Campbell \& } \\
\text { Wood (1988) }\end{array}$ & Hewlett (1991) & $\begin{array}{c}\text { Borgerhoff Mulder } \\
(1992)\end{array}$ & $\begin{array}{c}\text { Bentley, Jasienska \& } \\
\text { Goldberg (1992) }\end{array}$ \\
\hline Foragers & $65.7(10)$ & $5.5(37)$ & - & $5.6(2)$ \\
Horticulturalists & $65.9(26)$ & $6.1(10)$ & - & $5.4(14)$ \\
Agriculturalists & $66.3(34)$ & - & - & $6.6(31)$ \\
Pastoralists & - & $6.2(5)$ & $5.9(14)$ & - \\
Conclusion: & no differences & no differences & great variation & differences \\
\hline
\end{tabular}

Numbers in parentheses represent numbers of societies sampled in each group

(Sellen \& Mace, 1997; 1999). and discusses their implications for understanding the demogrphic changes that accompany subsistence transitions.

\section{Demography and Subsistence}

Several recent meta-analyses have compared Total Fertility Rate among pre-demographic transition populations categorised as practising various types of subsistence (Table 1). In a germinal study, Campbell \& Wood (1988) presented data from 70 societies indicating that no significant differences in mean total fertility rates existed among foragers, horticulturists and agriculturists, and that the variation shown within each subsistence grouping was large. Hewlett (1991) also found that basic forager and farmer-herder demographic structures were similar, and that mean differences in total fertility rates were small. In contrast, Borgerhoff Mulder (1992) and Bentley et al. (1993a) marshalled cross-cultural data showing large variation in fertility within single subsistence types. All sorts of factors may confound these comparisons. For example, most studies suggest at least a tendency for mean fertility rates to be higher among agriculturists. When Bentley et al. (1993b) applied stringent exclusion criteria to populations with high rates of primary sterility, evidence of subsistence transition and unreliable measures, the remaining data indicated that the mean fertility of agriculturists, but not horticulturists, was significantly higher than that of non-agriculturists.

Data on infant and child mortality rates in pre-demographic transition populations are harder to find but also show wide variation (Table 2). Can we account for this? Two analyses of slightly overlapping cross-cultural samples by Hewlett (1991) and Pennington (1996) indicate that sub-adult mortality rates do not vary consistently between populations grouped categorically by principal mode of subsistence. They attribute the variaton to other factors.

\section{Problems with Previous Studies}

It may be that previous comparisons have yielded equivocal results due to methodological limitations. One may be a lack of adequate control for Galton's problem of the non-independence of societies (Ember Guglielmo et al., 1995; Mace \& Pagel, 1994; but see Cashdan \& Rogers, 1997). Societies practising a particular form of subsistence are likely to have similar marriage, child-care and other practices known to influence fertility and sub-adult mortality by descent from a common cultural ancestor and are not statistically independent units of analysis. Therefore it is possible that any reported cross-cultural associations do not result from the co-evolution of demography and subsistence but are an artefact of pseudo-replication of chance ancestral associations among groups of related societies (Figure 1). Conversely, it is possible that lack of control for history will obscure real associations. A final problem is that many pre-industrial populations were not pure foragers, farmers or herders, but dependant to some extent on a variety of subsistence techniques. Useful information is lost when comparisons do not capture this variation and instead adopt a mutually exclusive categorical approach in defining subsistence dependency. 
Table 2. Sub-adult mortality rates by mode of subsistence

\begin{tabular}{llccc}
\hline & \multicolumn{2}{c}{ After Hewlett (1991) } & \multicolumn{2}{c}{ After Pennington (1996) } \\
\hline & $1 \mathrm{q}_{0}$ & $15 \mathrm{q}_{0}$ & $1 \mathrm{q}_{0}$ & ${ }^{\mathrm{q}} \mathrm{q}_{1}$ \\
Foragers & $0.20(14)$ & $0.43(12)$ & $0.17(4)$ & $0.21(4)$ \\
Horticulturists & $0.21(10)$ & $0.39(10)$ & $0.18(4)$ & $0.20(4)$ \\
Agriculturists & - & - & $0.21(2)$ & $0.18(2)$ \\
Pastoralists & $0.21(5)$ & $0.34(3)$ & $0.12(8)$ & $0.10(8)$ \\
Conclusions: & \multicolumn{2}{c}{ no differences } & \multicolumn{2}{c}{ great variation } \\
\hline
\end{tabular}

Numbers in parentheses represent numbers of societies sampled in each group

\section{Methods}

Recently, Mace and I performed some fresh analyses designed to minimise any cultural 'phylogenetic' effects on the distribution of the data and to remain sensitive to diverse subsistence strategies. We collected demographic estimates on populations for which comparable quantitative measures of subsistence dependency and mortality were available, and for which historical relationships could be estimated using published genetic phylogenies of human populations. The procedure involved several steps. First, we developed a base sample of estimates of total fertility rate (the number of live births to the average woman), infant mortality rate (the proportion of children dying in the interval between birth and one year of age, ${ }_{1} \mathrm{q}_{0}$ ) and total childhood mortality rate (the proportion of children dying in the interval between birth and 15 years of age, ${ }_{15} \mathrm{q}_{0}$ ) for 'natural fertility' populations representative of as many societies as possible. We expanded the samples of previous workers by literature search, and included data only for populations for which there was no evidence of demographic or epidemiological transition.

Next, we mapped as many of these societies as possible on to the genetic phylogeny for human populations recently published by Cavalli-Sforza and associates on the basis of their analysis of the global distribution of human genetic polymorphism (Cavalli-Sforza et al., 1994). We then selected for analysis those populations for which we could calculate estimates of the percentage importance of hunting, gathering, fishing, herding and agriculture for the whole diet and economy. We derived these estimates from the quantitative subsistence codes available for 1267 societies in the World Ethnographic Sample. Matching of populations from the three disparate data sets was achieved by paying special attention to geographic location and ethnic names or synonyms. Finally, we compared only the differences in fertility and subsistence among cultural sister populations using the method of Harvey \& Pagel (1991) of calculating independent contrasts between pairs of branches and nodes on a diagram of cultural similarity estimated from genetic distances Purvis 1999. Examining the variance in these phylogenetically unbiased sets of contrasts, rather than variance in the raw values of the variables, assessed the significance of the unbiased associations between subsistence and fertility. The use of quantitative measures of all variables allowed us to use a multiple regression approach and to control for a variety of confounds.

\section{Results}

The final samples consisted of only those societies for which demographic, genetic and standardised ethnographic data could be obtained. Data on fertility were obtained for 102 populations. We were able to collate fertility and other data for 69 societies, of which 48 had been included in previous nonphylogenetic analyses by other investigators (see Sellen \& Mace, 1997, for details and data used). Data on sub-adult mortality were obtained for 72 populations. We were able to use data on infant mortality for 34 societies and data on childhood mortality for 18 cultures (see Sellen \& Mace, 1999, for details and data used). The final samples had a fairly wide geographic distribution, and a wide range of subsistence modes was represented. 


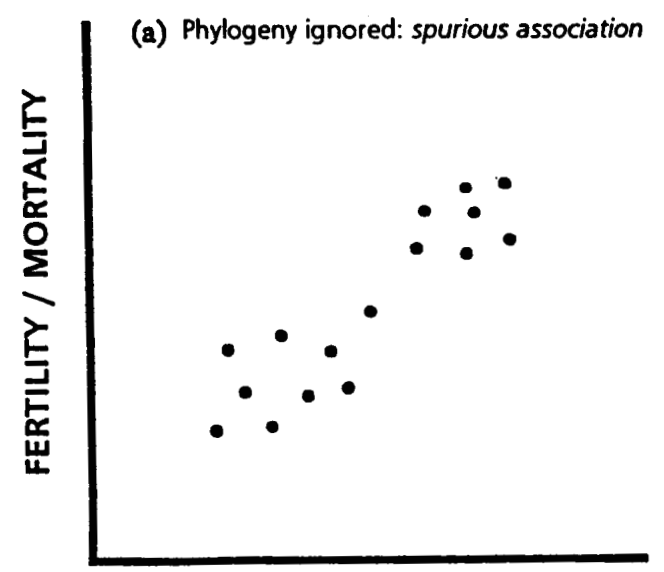

AGRICULTURE / FORAGING

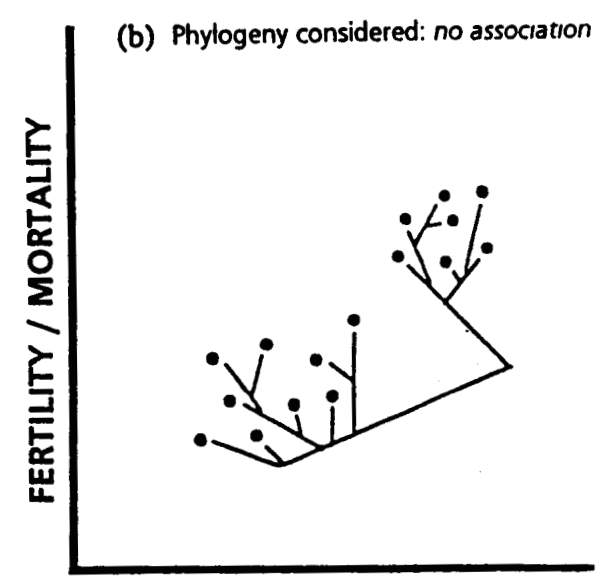

AGRICULTURE / FORAGING

Figure 1. Relevance of Galton's problem to the study of the relationship between demography and subsistence.

\section{Subsistence and Fertility}

Figure 2 summarises the cross-cultural pattern of association between total fertility rates and dependence on agriculture for our sample. The 69 societies included in the analysis are labelled in the centre of the diagram. For analysis these 'cultures' were defined as distinct units on ethno-geographic grounds. On the left hand side is a branching diagram representing the genetic similarities and thus probably the general cultural evolutionary relationships among these cultures. The shading of the branches gives a rough indication of the extent to which each society was dependent on agriculture for production of dietary and economic resources. On the right hand side is the same phylogeny, except that here the shading indicates whether the populations taken as representative of each society showed generally high, low or intermediate total fertility levels. Low fertility is defined as fewer than five live births per woman, and high fertility is defined as more than seven live births per woman.

In analysis we used the actual continuous estimates of demographic and subsistence measures, for ease of presentation in the diagram low agricultural dependence is defined as less than $15 \%$ of subsistence returns, and high agricultural dependence as greater than $55 \%$ of subsistence returns.

It is clear that although both dependence on agriculture and levels of fertility vary quite widely among historically related cultures, there was a tendency for high levels of fertility to cluster in the same branches of the phylogeny as high dependence on agriculture. Since data from closely related societies may not represent independent instances of a correspondence between high fertility and agriculture, phylogenetic control is desirable.

We therfore examined the bivariate associations between phylogenetically independent contrasts in percent dependence on each mode of subsistence and in fertility (Table 3). Unsurprisingly, differences in dependence on agriculture and on hunting and gathering among sister societies in our sample were negatively correlated because foraging tends to substitute for farming. Differences in dependence on hunting and gathering were positively correlated because these two modes of subsistence tend to be adopted together. Increased dependence on fishing substituted only marginally for dependence on all other forms of subsistence, while dependence on livestock substitutes for hunting and gathering. For further analysis, dependence on hunting gathering and fishing was therefore combined into a single 


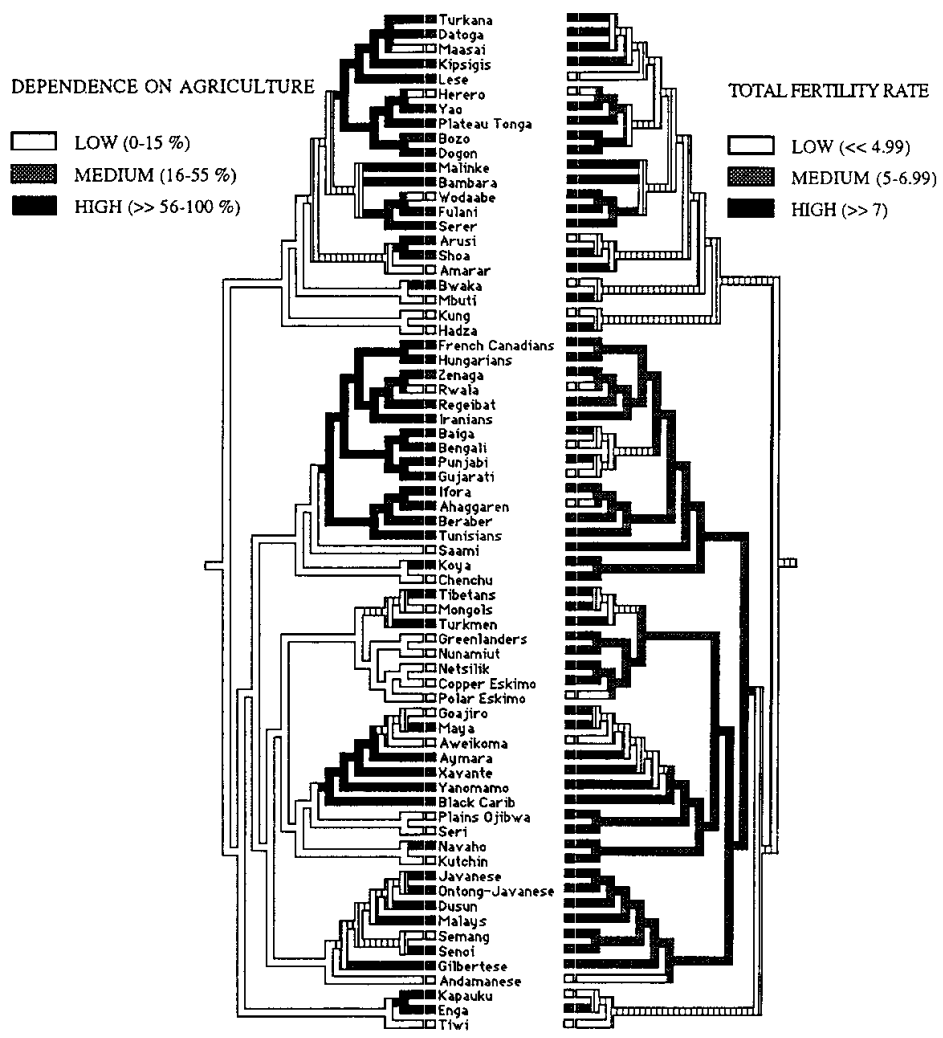

Figure 2. Genetic phylogeny of 69 cultures for which subsistence and total fertility data were collated.

estimate of dependence on extracted resources.

When phylogenetically independent contrasts in percent dependence on the major types of subsistence were compared with independent contrasts in fertility using multiple regression through the origin, the only variable showing an independent association with fertility was dependence on agriculture (Table 4). The model with all variables forced in explains about $10 \%$ of the variance in fertility. In stepwise deletion procedures beginning with the model containing all subsistence practices, dependence on agriculture was always retained as the only significant predictor of fertility rates (Table 5). Using a cultural phylogeny based on genetic similarity, a $10 \%$ difference in dependence on agriculture between sister societies was associated in this sample with a mean total fertility difference of approximately 0.2 live births per woman (Figure 3).

The validity of this apparent association might be called into question because the data on fertility and subsistence did not always coincide in time. However these time lags in the data seem to have weakened the power of the tests rather than created a spurious association. The relationship appeared stronger in the sub-sample of 16 societies for which the demographic data were collected within 20 years of the ethnographic observations upon which the subsistence codes were based (Table 5). Fertility was estimated to increase on average by approximately 0.4 births per woman with each $10 \%$ increase in agricultural dependence between sister cultures.

The power of the phylogenetic method is weakened when one has the wrong phylogeny for the entities being compared. When a language phylogeny based on Ruhlen's (1991) classification of world 
Table 3. Correlation between contrasts in subsistence dependence $(n=66)$

\begin{tabular}{lllll}
\hline & Hunting & Gathering & Fishing & Animal Husbandry \\
\hline Agriculture & -0.5542 & -0.4744 & -0.0759 & -0.1105 \\
& $\mathrm{p}<0.001$ & $\mathrm{p}<0.001$ & $\mathrm{p}=0.544$ & $\mathrm{p}=0.377$ \\
Hunting & & 0.3159 & -0.1896 & -0.3042 \\
& & $\mathrm{p}=0.010$ & $\mathrm{p}=0.127$ & $\mathrm{p}=0.013$ \\
Gathering & & -0.1275 & -0.4452 \\
& & & $\mathrm{p}=0.303$ & $\mathrm{p}<0.001$ \\
Fishing & & & -0.4533 \\
& & & $\mathrm{p}<0.001$ \\
\hline
\end{tabular}

Table 4. Relationship between contrasts in total fertility rate and subsistence practices

\begin{tabular}{lllll}
\hline Variables in regression model: & & B & t & $p$ \\
\hline \% dependence on agriculture & & 0.3749 & 3.059 & 0.003 \\
\% dependence on animal husbandry & & -0.1219 & -0.975 & 0.3334 \\
\% dependence on extracted resources & & -0.1201 & 0.98 & $0.3308^{*}$ \\
Analysis of Variance: & Sum of Squares & Mean Square & $\mathrm{F}_{2,64}$ & 0.0127 \\
Regression & 5.936 & 2.968 & 4.6813 & \\
Residual & 40.579 & 0.634 & & \\
Model adjusted $\mathrm{R}^{2}=$ & 0.1004 & & \\
* "model-in" value & & &
\end{tabular}

languages was used to structure the independent comparisons, the estimated relationship was almost identical to that derived using a genetic phylogeny (Table 5). The language tree had fewer deep branches than the genetic tree, because linguists have been reluctant to group major language families into larger clusters. However the pattern at the tips, which defines sister cultures, was very similar. Thus, the finding of a positive association between fertility and agricultural dependence does not appear to be an artefact of the type of phylogeny used.

There is a debate over whether the process of settlement itself results in demographic shifts, which may not necessarily be associated with differences in subsistence or a switch to agriculture (Randall, 1994; Roth, 1981). In order to tease out any effects of settlement, the sample was divided into those societies that were permanently settled and those that had some degree of mobility. Using the genetic phylogeny, clear association between fertility and agriculture was found among the non-permanently settled societies (Table 6). However, among the permanently settled (sedentary) groups, many of which were dependent to a high degree on agriculture, variance in fertility was not associated with dependence on agriculture, foraging or herding. Similarly, there was no relationship between fertility and subsistence when we looked at 'non-foragers' (a category which excludes foragers and fishers, but includes pastoralists) or 'agriculturists' (a category which excludes pastoralists and foragers). Importantly, these and other observations (see Sellen \& Mace, 1997, for more details) suggest that there is a threshold level of dependence on agriculture above which differences in fertility among pre-industrial populations are associated with factors other than the proportion of the diet provided by agriculture. 


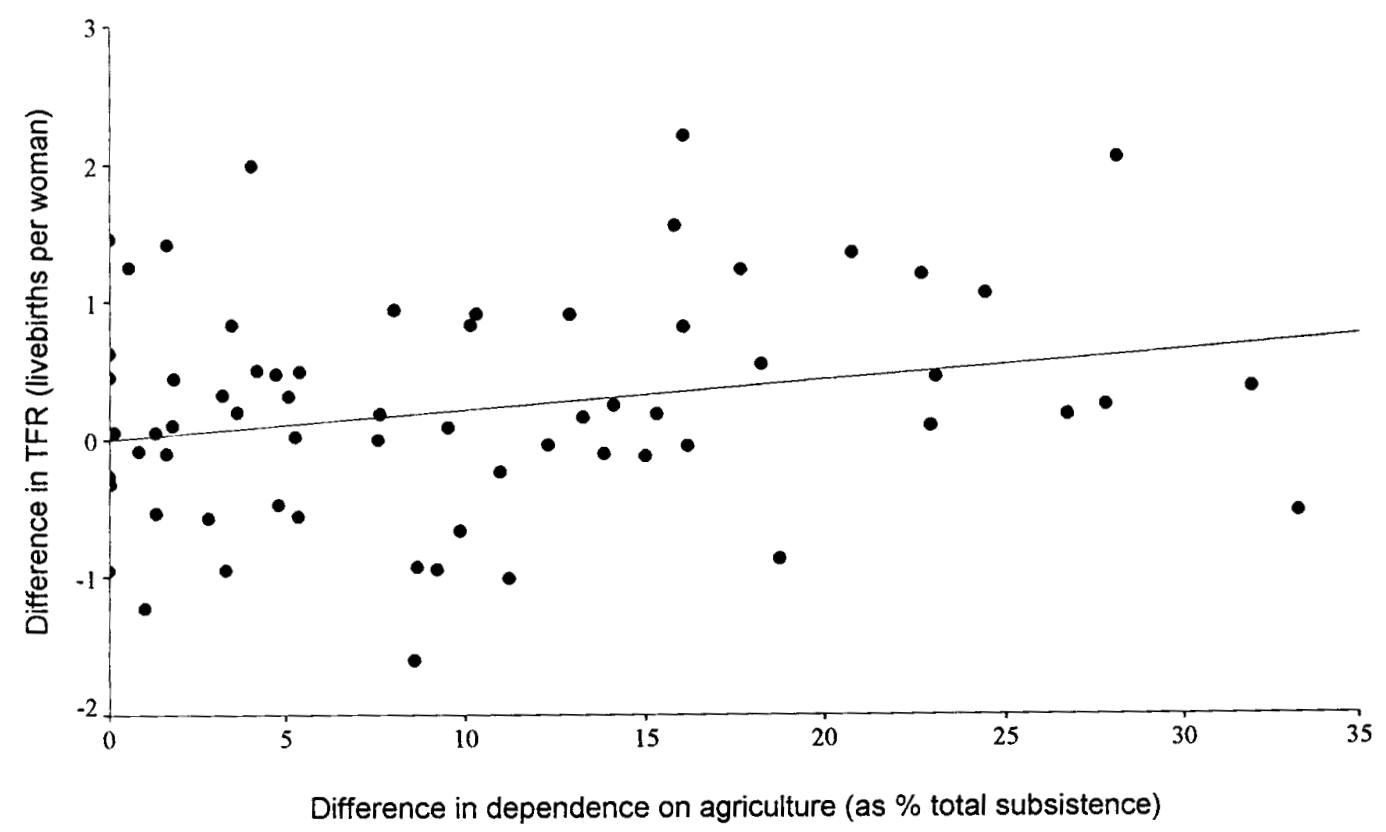

Figure 3. Relationship between fertility and agricultural dependence.

\section{Subsistence and Sub-adult Mortality}

Figure 4 summarises the cross-cultural pattern of association between infant mortality rates and dependence on foraged resources for our sample. Once again, the societies for which data could be found are listed in the centre of the diagram and the genetic phylogeny indicating their evolutionary relationships is drawn on either side. The shading of the branches on the left gives a rough indication of the extent to which each society was dependent on resource extraction (hunting, gathering and fishing) for production of dietary and economic resources. Purely for presentation, low foraging dependence is defined as less than $25 \%$ of total subsistence returns, and high foraging dependence as greater than $75 \%$ of subsistence returns. The shading on the right hand side indicates whether the populations taken as representative of each society showed generally high, low or intermediate levels of infant mortality. Low infant mortality is defined as less than 150 deaths per thousand, and high infant mortality is defined as more than 250 deaths per thousand. Although there appears to be some correspondence between high dependence on foraging and high infant mortality, the association is not striking when viewed in this categorical manner.

Figure 5 summarises the cross-cultural pattern of association between childhood mortality rates and dependence on foraged resources. Here the shading on the right hand side indicates whether populations from each society showed generally high, low or intermediate levels of childhood mortality, or deaths in the first fifteen years. For presentation, low total childhood mortality is defined as less than 300 deaths per thousand, and high childhood mortality is defined as more than 500 deaths per thousand. This sample is drawn onto the earlier phylogeny, but one can see from the hatched lines on the right that data are missing for many societies and that this is a smaller sample. The correspondence between high dependence on foraging and high childhood mortality looks stronger, but the clustering of high and low 


\section{Table 5. Relationship between contrasts in total fertility rate and dependence on agriculture}

\begin{tabular}{|c|c|c|c|c|c|}
\hline & $\begin{array}{c}n \text { contrasts compared, } \\
k \text { societies used }\end{array}$ & $\begin{array}{c}\text { Best } \\
\text { predictor }\end{array}$ & b & $\mathbf{p}$ & Adjusted $R^{2}$ \\
\hline \multicolumn{6}{|c|}{ a) using a genetic phylogeny (Cavalli-Sforza et al., 1994): } \\
\hline Whole sample & 66,69 & Agriculture & +0.0212 & 0.0051 & 0.101 \\
\hline \multicolumn{6}{|c|}{ Excluding societies with a greater than } \\
\hline \multicolumn{6}{|c|}{20 year interval between demographic } \\
\hline and subsistence data & 15,16 & Agriculture & +0.0430 & 0.0043 & 0.413 \\
\hline \multicolumn{6}{|c|}{ b) linguistic phylogeny (Ruhlen, 1991): } \\
\hline & 28,46 & Agriculture & +.0263 & 0.0295 & 0.133 \\
\hline
\end{tabular}

\section{Table 6. Effects of settlement}

\begin{tabular}{lccccc}
\hline $\begin{array}{l}\text { Using a genetic phylogeny } \\
\text { (Cavalli-Sforza } \text { et } \boldsymbol{a l} \text {., 1994): }\end{array}$ & $\begin{array}{l}\boldsymbol{n} \text { contrasts compared, } \\
\boldsymbol{k} \text { societies used }\end{array}$ & Best predictor & $\mathbf{b}$ & p & Adjusted R $^{2}$ \\
\hline Non-permanently settled only & 39,41 & Agriculture & 0.031 & 0 & 0.191 \\
Permanently settled only & 26,30 & None & - & n.s. & 0.136 \\
'Non-foragers' only & 49,51 & None & - & n.s. & 0.061 \\
'Agriculturalists' only & 34,35 & None & - & n.s. & 0.176 \\
\hline
\end{tabular}

values of both variables in certain branches of the tree cautions against an uncontrolled interpretation.

Table 7 shows the results of multiple regression analysis of phylogenetically independent contrasts in sub-adult mortality rates and subsistence. The overall model was not predictive of infant mortality rates. Although positive contrasts in infant mortality were positively correlated with contrasts in dependence on hunting and negatively correlated with contrasts in dependence on all other forms of subsistence and distance from the equator, the partial significance of hunting within the model disappeared after removal of a single outlier. Despite the great variation in infant mortality in the raw data, none of the test variables were retained as significant predictors of contrasts in infant mortality rates among phylogenetic sister societies in stepwise removal procedures. No improvement in predictive power was observed when distance from the equator, a crude proxy for disease exposure, was included in the model.

Contrasts in childhood mortality were associated with contrasts in dependence on hunting, gathering and fishing, and also with distance from the equator (Table 8). Contrasts in dependence on hunting and gathering were retained as significant independent positive predictors of contrasts in childhood mortality rates in stepwise removal procedures beginning with all variables entered. There was on average a difference in childhood mortality of approximately 20 deaths per thousand associated with a $10 \%$ difference in dependence on gathering and a difference in childhood mortality of approximately 30 deaths per thousand associated with a $10 \%$ difference in dependence on hunting. The data were reanalyzed after combining measures of dependence on hunting, gathering and fishing into a single estimate of dependence on extracted resources (see Sellen \& Mace, 1999, for details). Figure 6 shows the relationship between childhood mortality and dependence on extracted resources after partialling out some of the effects of phylogeny and geographic location. 


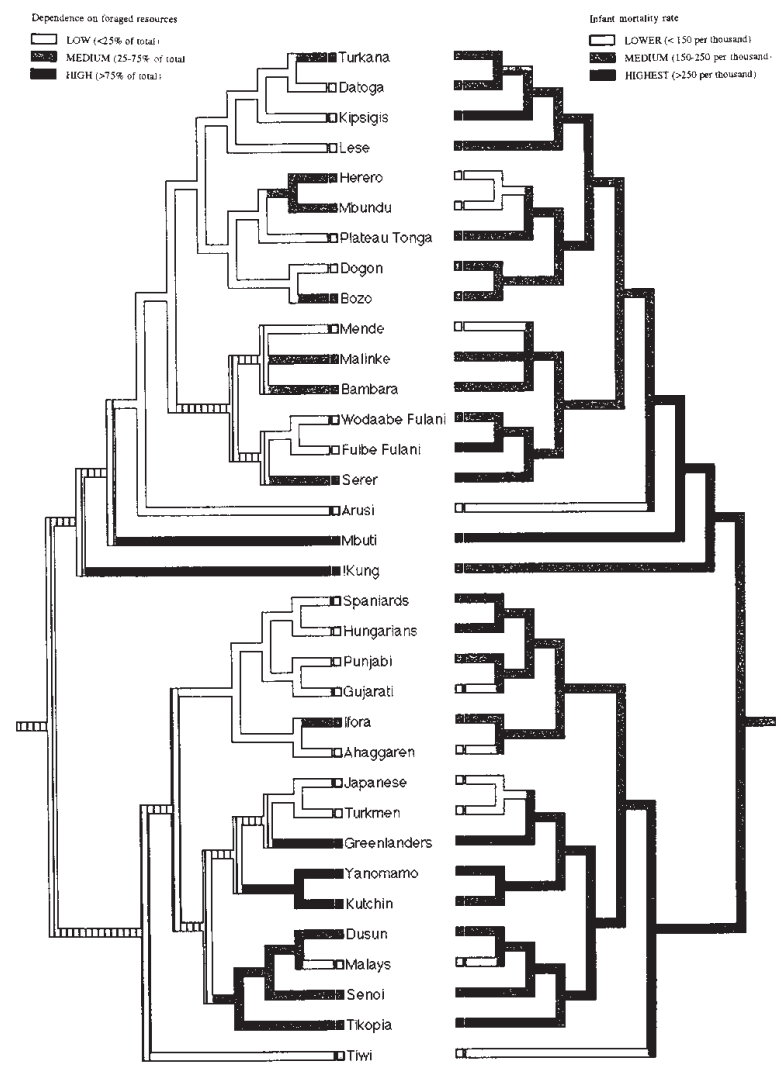

Figure 4. Genetic phylogeny of 34 cultures for which subsistence and infant mortality $\left({ }_{1} \mathrm{q}_{0}\right)$ data were collated.

\section{Discussion}

It would be helpful to anthropologists working in several areas to quantify any demographic concomitants of subsistence. These include behavioural ecological anthropologists interested in whether subsistence transitions are related to the reproductive strategies of individuals, and archaeologists trying to understand the origins of agriculture. In our sample of pre-industrial, natural fertility populations measured soon after contact, differences in dependence on agriculture were strong predictors of differences in fertility between closely related cultures. Differences in dependence on extracted resources agriculture were strong predictors of difference in mortality rates in the first 15 years of life between closely related cultures. The finding of a positive relationship between agricultural dependence and fertility corroborates previous reports that increased dependence on agriculture is associated with increased fertility across human populations. In contrast to previous studies, we can also suggest that this relationship is not simply due to the general tendency for clusters of historically related societies to share similarities. Using a cultural phylogeny based on genetic similarity, we have also been able to quantify a linear relationship. A $10 \%$ difference in dependence on agriculture between sister societies was associated in this sample with a mean total fertility difference of approximately 0.2 live births per woman (Figure 3).

The finding of a positive relationship between foraging activity and childhood mortality also lends 
Table 7. Contrasts in infant mortality rate and subsistence

\begin{tabular}{|c|c|c|c|c|}
\hline $1 q 0$ & & B & $\mathbf{T}$ & p \\
\hline Dependence on hunting (\%) & & +2.115 & 2.64 & 0.014 \\
\hline gathering $(\%)$ & & -0.555 & -0.58 & 0.564 \\
\hline fishing $(\%)$ & & -0.191 & -0.25 & 0.809 \\
\hline herding $(\%)$ & & -0.824 & -1.28 & 0.212 \\
\hline agriculture $(\%)$ & & -0.484 & -2.89 & $0.009 *$ \\
\hline Distance from the equator (degrees latitude) & & -0.612 & -0.62 & 0.550 \\
\hline ANOVA: & $\mathrm{SS}$ & MS & $\mathrm{F}_{5,11}$ & $p$ \\
\hline Regression & 6208.7 & 1241.7 & 1.91 & 0.125 \\
\hline Residual & 17530.8 & 649.3 & & \\
\hline Model adjusted $\mathrm{R}^{2}=$ & 0.125 & & & \\
\hline
\end{tabular}

Table 8. Contrasts in child mortality rate and subsistence

\begin{tabular}{|c|c|c|c|c|}
\hline $15 q 0$ & & B & $\mathbf{T}$ & $p$ \\
\hline Dependence on hunting (\%) & & +3.300 & 3.89 & 0.003 \\
\hline gathering $(\%)$ & & +2.740 & 3.82 & 0.001 \\
\hline fishing $(\%)$ & & +2.730 & 2.49 & 0.030 \\
\hline herding $(\%)$ & & +0.398 & 0.46 & 0.656 \\
\hline agriculture (\%) & & -0.285 & -0.94 & $0.370 *$ \\
\hline \multicolumn{5}{|l|}{ Distance from the equator } \\
\hline (degrees latitude) - & & 3.524 & -3.05 & 0.011 \\
\hline ANOVA: & SS & MS & $\mathrm{F}_{5,11}$ & $p$ \\
\hline Regression & 18379.2 & 3675.8 & 7.42 & 0.003 \\
\hline Residual & 5447.8 & 495.3 & & \\
\hline Model adjusted $\mathrm{R}^{2}=$ & 0.667 & & & \\
\hline
\end{tabular}

* "model-in" value

support to previous suggestions that such a relationship exists. On average a $10 \%$ increase in dependence on extracted resources between sister societies on the phylogeny is associated with an increase in childhood mortality of just under 30 deaths per thousand (Figure 6). Our results contribute to the scant literature on the relationships between mode of subsistence and rates of child survival. We can also suggest that this relationship is not simply due to geographic variation in background population attributable risk of infection since childhood mortality rates were independently associated with both dependence on extracted resources and proximity to the equator.

Two major issues arise from the results. The first concerns the validity of the phylogenetic method, which has been widely debated elsewhere by evolutionary biologists and anthropologists. Here it is worth making several points. First, while it is not known to what extent Galton's problem confounds cross-cultural analyses of particular aspects of human cultural variation, or what the best method for 
removing such confounding may be, some attempt to do so is logically desirable. If patterns identified in raw comparisons are robust to phylogenetic controls, then we have further evidence that they are not random and may have some biological significance. Second, it is still not entirely clear whether the use of genetic, linguistic or other cultural markers in constructing cultural phylogenies makes a difference (Pocklington, 1997). To date most studies suggest good agreement between phylogenies constructed using any of these markers (Cavalli-Sforza et al., 1988; Cavalli-Sforza et al., 1992; Guglielmo et al., 1995), so that the researcher is advised to use the data that is most rigorously collected and produces more highly resolved phylogenies. Our current inability to quantify the degree of divergence or cultural separation among societies - that is, to estimate 'branch lengths' - and our current inability to distinguish derived and convergent cultural components, may have biased the results presented here to an unknown degree. Third, the use of populations or societies as bounded units of analysis is potentially highly problematic, particularly for many types of anthropological question about individual actions and interactions. It almost certainly has some utility or heuristic value when one is trying to identify broad socio-ecological patterns and associations. Problems are that explanations that seem compelling at one level of analysis may be ecological fallacies, and that a cross-cultura approach may throw little light on the mechanisms generating the observed patterns.

This brings us to the second major issue, which concerns strategies to identify the underlying causes of demographic concomitants of subsistence. These remain under-theorised by anthropologists and archaeologists. We must conclude that most of the variance in infant mortality rates among related societies was associated with factors other than subsistence. This makes biological sense because in
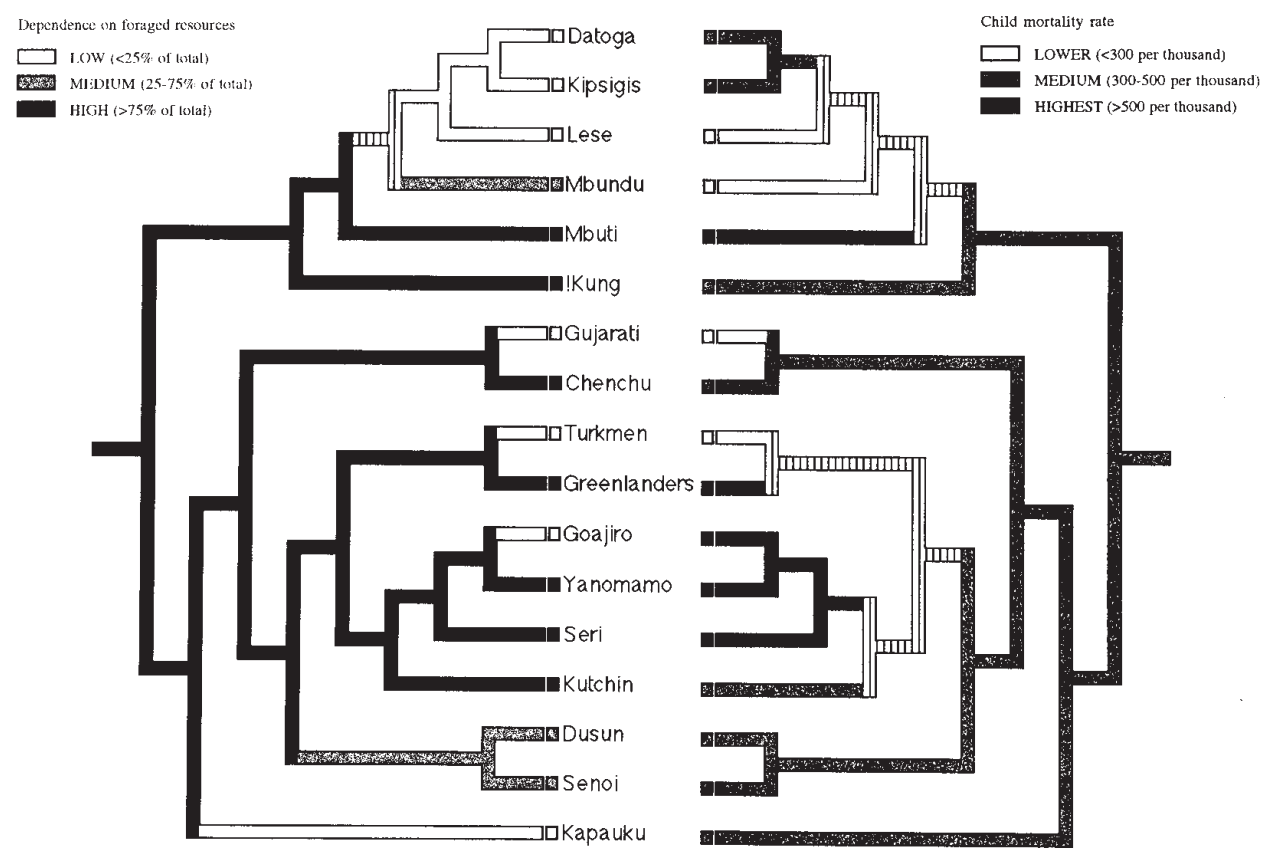

Figure 5. Genetic phylogeny of 18 cultures for which subsistence and childhood mortality $\left({ }_{15} \mathrm{q}_{0}\right)$ data were collated. 


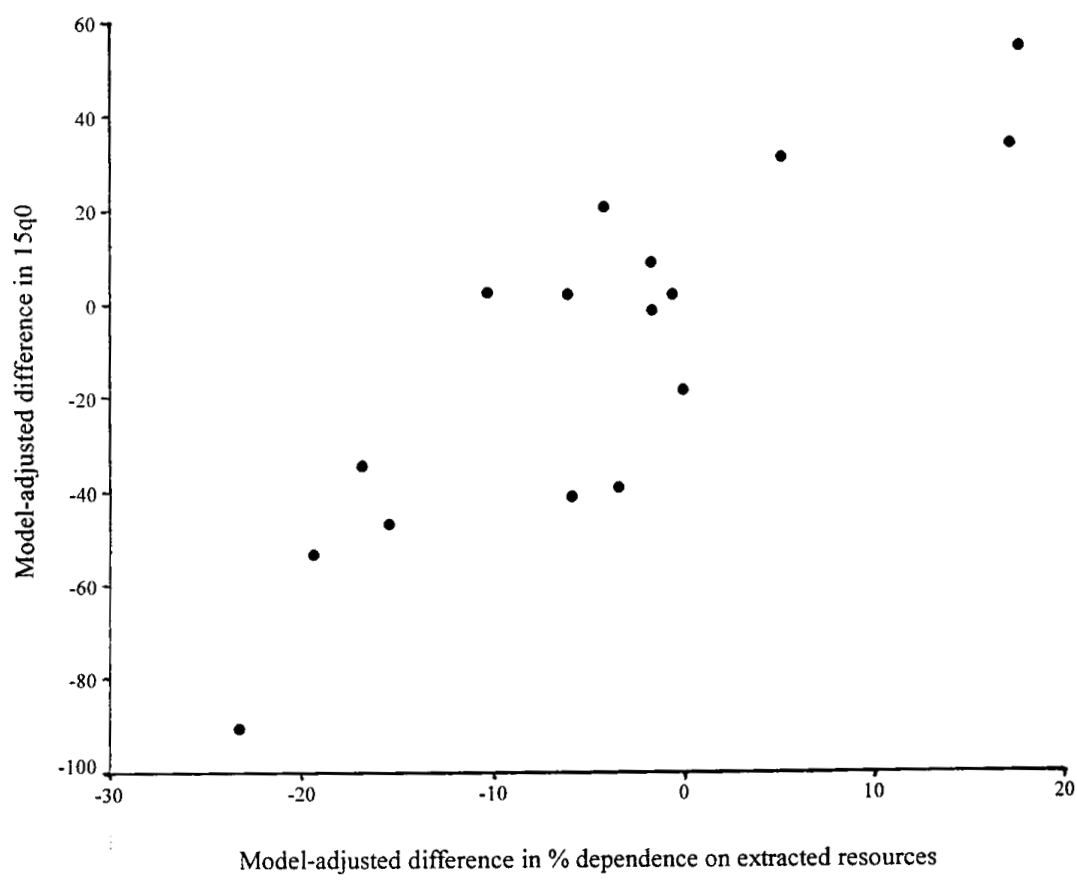

Figure 6. Relationship between contrasts in childhood mortality and contrasts in dependence on extracted resources after partialling out the association with distance from the equator.

most of these societies children would be breast fed and closely nurtured for much of the first year of life, even when mothers were engaged in food-producing activities. This probably conferred a similar degree of protection from infection and physical dangers irrespective of the principal mode of subsistence practised. What mechanisms could result in higher fertility among agriculturists and lower childhood mortality among non-foragers?

It is possible that the nature of women's work in agricultural societies tends to result in separation of mothers and their offspring for longer periods at earlier ages than in other types of society. This would result in earlier weaning, whether or not weaning foodstuffs were available or adequate. However, it might also result in higher childhood mortality among agriculturists. We do not find evidence for this and there was no relationship between fertility rates and infant or child mortality rates in our sample. Another hypothesis is that better availability of weaning foods shortens inter-birth intervals in agricultural populations. If this mechanism could be shown to operate in natural fertility populations it would be consistent with many archaeological explanations for Neolithic population increase. The apparent reduction in childhood mortality among sister cultures more strongly involved in agriculture or pastoral production may provide insights into the shifts in subsistence observed in the archaeological record in many regions. While much evidence indicates such shifts entailed a reduction in health and nutritional status for both adults and children (Armelagos et al., 1991), our data on traditional societies suggests this may have involved a net reduction in child mortality because of reduced physical dangers or social vulnerability of children. 
There is a need to understand the importance of weaning diets in shaping the demography of anatomically modern humans and to investigate the behavioral mechanisms that link subsistence work, child survival and fertility in pre-industrial societies. Further empirical tests of the demographic differences between recently observed pre-industrial societies may help us develop a better theory of the reproductive trade-offs inherent in subsistence transitions during human prehistory. However, the paucity of data on populations that remained marginal to the modern world system long enough to be observed before a demographic transition took place places stringent and insurmountable limits on such an approach.

\section{Conclusions}

Cross-cultural comparisons suggest that, across traditional human populations, fertility is positively associated with dependence on agriculture, corroborating earlier claims. Infant mortality rates do not appear to vary with subsistence mode. Childhood mortality rates (deaths among children under 15 years of age) increase with dependence on extracted resources. The available data therefore indicate that among recent human populations the practice of particular modes of subsistence in particular cultures, such as high dependence on agriculture or foraging, entailed clear demographic consequences. I suggest that high fertility rates and lowered child mortality rates contribute to the persistence of agriculture as a fitness-maximising strategy under conditions where it can be practised.

\section{Acknowledgements}

Gillian Bentley and Patrick Gray shared ideas and data, and Rob Poh assisted with graphics. The Leverhulme Trust and Emory University provided financial support.

\section{References}

Armelagos, G., Goodman, A.. \& Jacobs, K. (1991). The origins of agriculture: Population growth during a period of declining health. Population and Environment, 13, 9-22.

Bentley, G. (1996). How did prehistoric women bear Man the hunter? Reconstructing fertility from the archaeological record. In: Gender and Archaeology, ed. R. Wright. pp. 23-51. Philadelphia: University of Philadelphia Press.

Bentley, G., Goldberg, A. \& Jasienska, G. (1993a). The fertility of agricultural and non-agricultural traditional societies. Pop. Stud., 47, 269-81.

Bentley, G., Jasienska, G. \& Goldberg, A. (1993b). Is the fertility of agriculturalists higher than that of nonagriculturalists? Current Anthropology, 35(5), 778-85.

Blurton Jones, N., Smith, L., O'Connell, J., Hawkes, K. \& Kamuzora, C. (1992). Demography of the Hadza, an increasing and high density population of savanna foragers. American Journal Physical Anthropology, 89, 159-81.

Borgerhoff Mulder, M. (1992). Demography of pastoralists: Preliminary data on the Datoga of Tanzania. Hum. Ecology, 20(4), 383-405.

Campbell, K. \& Wood, J. (1988). Fertility in traditional societies. In: Natural Human Fertility: Social and Biological Mechanisms, ed. P. Diggory, S. Teper \& M. Potts. pp. 39-69. London: Macmillan.

Cashdan, E. \& Rogers, A. (1997). Review of Human Nature: A Critical Reader. Evolution and Human Behavior, 18, $279-83$.

Cavalli-Sforza, L., Menozzi, P. \& Piazza, A. (1994). The History and Geography of Human Genes. Princeton: Princeton University Press.

Cavalli-Sforza, L., Menozzi, P., Piazza, A. \& Mountain, J. (1988). Reconstruction of human evolution: bringing together genetic, archaeological and linguistic data. Proceedings of the National Academy of Sciences, USA, 85, $6002-06$.

Cavalli-Sforza, L., Minch, E. \& Mountain, J. (1992). Coevolution of genes and languages revisited. Proceedings of the National Academy of Sciences, USA, 89, 5620-24.

Cohen, M. (1989). Health and the Rise of Civilization. New Haven: Yale University Press.

Ember M. (1971). An empirical test of Galton's problem. Ethnology 10, 98-106.

Guglielmo, C., Viganotti, C., Hewlett, B. \& Cavalli-Sforza, L. (1995). Cultural variation in Africa: Role of mechanisms of transmisssion and adaptation. Proceedings of the National Academy of Sciences, USA, 92, 7585-89. 
Hammel, E. (1996). Demographic constraints on population growth of early humans. Human Nature, 7(3), 217-55. Handwerker, P. (1983). The first demographic transition: An analysis of subsistence choices and reproductive consequences. American Anthropologist, 85, 5-27.

Handwerker, W. (1986). The modern demographic transition: An analysis of subsistence choices and reproductive consequences. American Anthropologist, 88, 400-17.

Harvey, P. \& Pagel, M. (1991). The Comparative Method in Evolutionary Biology. Oxford: Oxford University Press.

Hewlett, B. (1991). Demography and childcare in preindustrial societies. Journal of Anthropological Research, 47(1), 1-37.

Hill, K. \& Hurtado, M. (1996). Ache Life History: The Ecology and Demography of a Foraging People. New York: Aldine de Gruyter.

Howell, N. (1979). Demography of the Dobe !Kung. New York: Academic Press.

Mace, R. \& Pagel, M. (1994). The comparative method in anthropology: a phylogenetic approach. Current Anthropology, 35, 540-64.

Pennington, R. (1996). Causes of early human population growth. American Journal of Physical Anthropology, 99(2), 259-74.

Purvis, A. \& A. J. Webster (1999). Phylogenetically independent comparisons and primate phylogeny. In Comparative Primate Socioecology. Ed. P.C. Lee, pp. 44-68. Cambridge Studies in Biological Anthropology, Vol. 22. Cambridge: Cambridge University Press.

Randall, S. (1994). Pastoralists demographically different from sedentary agriculturalists? In: Environment and Population change, ed. B. Zaba \& J. Clarke. pp. 325-47. Liege, Belgium: Ordina Editions/IUSSP.

Roth, E. (1981). Sedentism and changing fertility patterns in a Northern Athapascan isolate. Journal of Human Evolution, 10, 413-25.

Ruhlen, M. (1991). A Guide to the World's Languages. Volume, 1: Classification. Second Edition. London: Edward Arnold.

Sellen, D. W. \& Mace, R. (1997). A phylogenetic analysis of the relationship between fertility and mode of subsistence. Current Anthropology, 38(5), 878-89.

Sellen, D. \& Mace, R. (1999). A phylogenetic analysis of the relationship between sub-adult mortality and mode of subsistence. Journal of Biosocial Science, 31(1), 1-16. 


\section{Napoleon Wolański}

Department of Human Ecology, Polish Academy of Sciences, Warsaw, Poland and CINVESTAV, Merida, Mexico

Keywords: niche, migration, ecosensitivity, adaptability, genetic adaptation, environmental adjustments

\section{How Human Populations Adapt: Their Niches in Time and Space}

This paper presents a concept of the origin and development of human niches in a time and space perspective as an effect of adaptation. The term 'niche' is understood here as: the 'nest' of a subject in an environment, and of a population in nature; habitat and a form of its exploitation; n-dimensional space in a population (society) and an environment created by function and place (job, dwelling, etc.), which determines access to natural resources, use of the technological environment, and biological and social fitness (contribution and satisfaction). In space, human niches follow the diversity of the natural environment. Cultural links of human populations with the environment in time increasingly dominate the biological connections.

\section{Introduction}

Living organisms are related to the habitat by their needs and form of exploitation of the environment. The concept of the 'niche' embraces a 'nest' of interrelationships of a subject with an environment and population in nature.

The niche of humans is n-dimensional space in a population (society) and an environment created by function and place (job, dwelling, etc.), which determines access to natural resources, use of a technology, and biological and social fitness (contribution and satisfaction). The term includes the biological, social and cultural connections of humans with their environment.

Human ecology considers human populations and their cultures as components of ecosystems. It considers two-way interactions: human pressure on the environment and changes occurring in organisms or human populations as a result of environmental effects. Important here are feedback and the side-effects of changes caused by humans in nature and in their closest surroundings. The 'niche' expresses all these interactions between subjects and their environment.

Since humans are the only species which inhabits all kinds of ecosystems or landscapes present on the globe, it is important to understand to what degree they are adapted to them. This is related to the time when man spread into these ecosystems.

\section{Origin and proliferation of human species}

Humans probably derive from the tropics of Africa, and they are likely to be best adapted genetically to an African climate, particularly in terms of their thermoregulation. However, at least 100000 years ago, humans started colonizing other lands of our globe (Foley, 1987). First, they arrived in Europe through the Near East (ca 40000 years ago). Europe has thus been inhabited by modern humans for at least 30000 years, which means that about 1200 generations have been born and have died in this region. As a result of changes occurring between the generations, humans have evolved adaptations to these new environmental conditions, related in the first instance to climatic differences.

About 40 thousand years ago modern humans arrived in Asia and from there they colonized Australia. Because of glaciation, larger areas of dry land areas were exposed, as a result of which Asia and North America were connected by a land bridge. Using this route, humans from Siberia reached the present Alaska about 20000 years ago, after which they spread over the whole continent, colonizing it probably at least 10000 years ago. 
Thus, human populations have been adapting to new conditions over thousands of generations (Fig. 1). Even the tribes that arrived in America are likely to have lived within this time period and on them too the processes of natural selection acted through differential fertility and survival, childbearing and mortality being very high at that time. This was biological adaptation acting through the genetic pathway.

Humans were subject also to socio-cultural evolution. By organizing social institutions and creating material culture they could migrate to areas to which they were not biologically adapted. Without cultural forms of adaptation they would not have survived there. Thus, social and cultural patterns (behavior) which protected them against cold and permitted them to find food accounted for the fact that they could inhabit cold lands.

Cultural evolution had another expression: human groups stopped moving from place to place in search of food; instead, they settled, produced food locally, and stored it. Thus was born the economic system known as agriculture. Based on it, with time, people started building settlements. But the duration of this phase of the process was much shorter than the preceding phases - the oldest towns were built no more than a few thousand years ago, that is, involving merely 150-200 generations, and in that

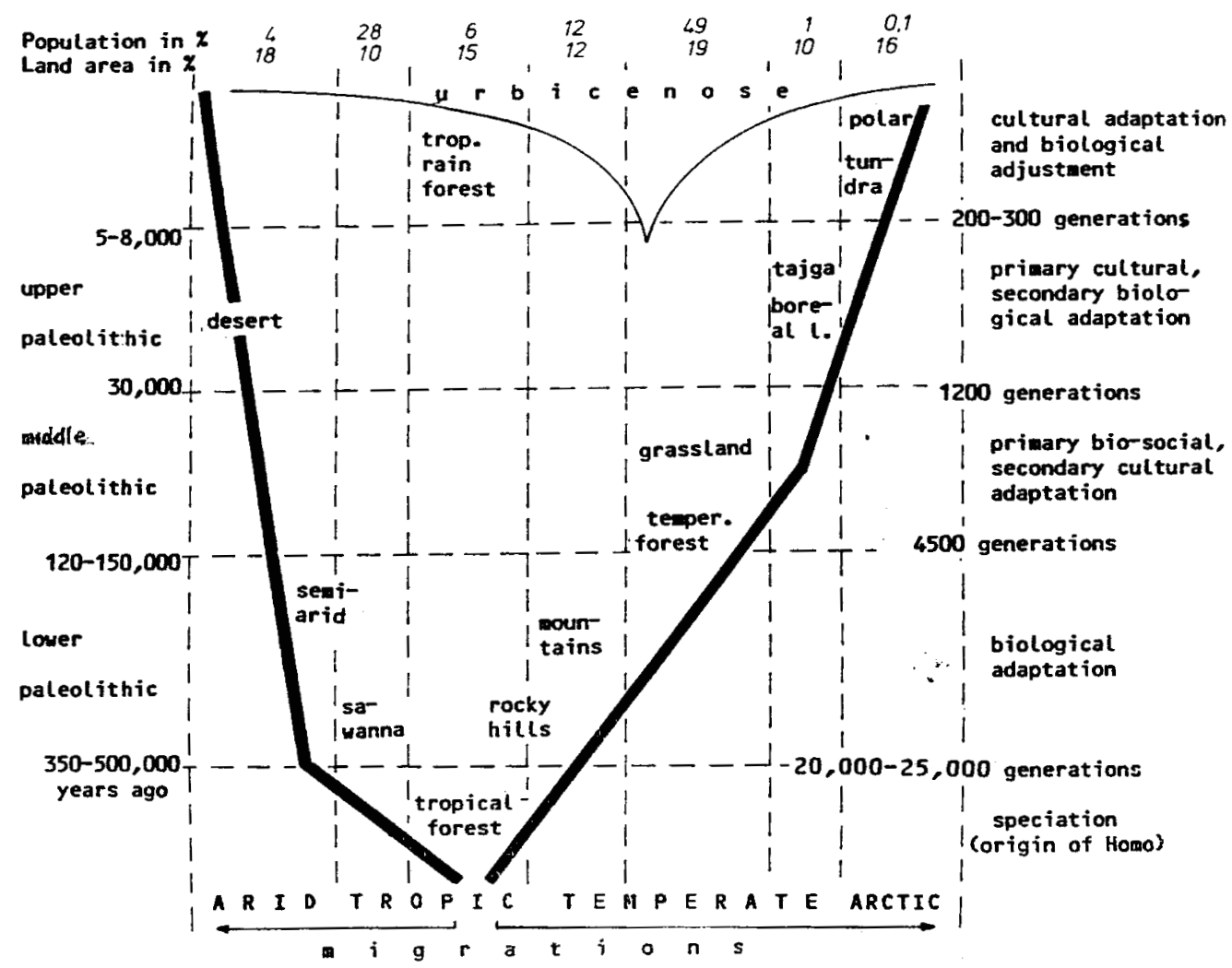

Figure 1. Proliferation of the genus Homo in various ecosystems, including the creation of urbicenoses. Left thousands of years of evolution and cultural periods; right - number of generations and the form of adaptational changes (Wolański, 1989). 
short time there was no chance for genetic adaptation to urbicenoses. Besides, there was no such need because culture protected human life. It provided opportunities for survival and transmission of information to new generations, which resulted in rapid development of civilization. The niches of contemporary humans are dominated by cultural links.

Differences in the rate of development of civilization may have been related to variation in generation time. In areas where puberty occurred at an earlier age, motherhood was also earlier and generation time shorter. Since each generation is a potential carrier of at least one innovation per person, a higher number of innovations could arise in temperate-Mediterranean climatic zones where maturation was earlier and population density higher. This could also be related to higher food resources that are growing or produced in these areas, and consequently to the consumption of foods having more protein and a higher caloric value.

\section{Sources of variation in human traits - genetic adaptation and environmental adjustments}

Although modern humans have a common socio-cultural background, they are characterized by marked variation in appearance and function. Even the similarity of progeny to the parents is not equal to genetic chance (expected coefficient of correlation $=0.5$; in fact it varies between 0.3 and 0.6 in various populations). This happens not only because of genetic variation but also as a result of phenotypic adjustments to different conditions.

Four groups of factors determine our traits: genetic, paragenetic, mode of life, and environmental conditions (Table 1). Variation in human traits depends on the interaction of each of these factors with the others.

Summing up the argument outlined above, it can be said that humans adapted biologically to variable environmental conditions, and where biological adaptation was insufficient, they used socio-cultural pathways (Fig. 2). Migration into areas which enabled survival was a safety-valve, and nomadic movements still occur in some parts of the globe.

\section{Ecosensitivity and adaptability}

Environmental adaptations depend not only on the character and strength of the environmental stimulus but also on the responsiveness of particular individuals, that is, on their sensitivity to environmental factors and also on the functional and structural adaptive capacity of their bodies.

Ecosensitivity is genetically determined, but it is modified by the experience of an individual (Fig. 3). Sufficiently strong and prolonged environmental stimulus overcomes defensive barriers of individuals, and causes changes in them. Each environmental stimulus that overcomes a barrier of tolerance is transformed into the organism. The type of adaptive changes will depend on individual predisposition called adaptability. Adaptability depends on the genetic make-up and on earlier experience, but also on individual unconditioned reflexes and aspirations (Fig. 3). Aspirations are understood here as typically human motivations. Animals run as long as the biological organism permits; a man who is physically exhausted, and whose biological mechanisms oppose his continuing to run, will keep running through the sheer power of his will.

It should be noted that changes occurring in an organism under specified conditions depend not only on the environment but also on the reactivity (ecosensitivity and adaptability) of the organism concerned. We should consider not only the biological processes, but also cultural adaptive behaviour (adjustments).

\section{Regulatory, acclimatory and developmental adjustments}

The biological adaptation of an organism involves a number of stages (Fig. 4). Responses to changes of short duration are regulatory in character and are aimed at repelling the stimulus, without deeper changes in the organism.

The response to more prolonged or recurring factors typically involves functional and structural 
Table 1. Four main factors of human development and variation

\begin{tabular}{|c|c|c|}
\hline & & heterogeneity \\
\hline & & sex differences \\
\hline & genetic & metabolic type and rate \\
\hline & (endogenous) & growth rate \\
\hline & & size control \\
\hline & & etc \\
\hline Main Sources of & & 'Genetic resonance' \\
\hline Variation of & paragenetic & Parental age \\
\hline Human & (maternal) & Parity \\
\hline Quantitative & & etc \\
\hline Traits & & \\
\hline & & $\begin{array}{l}\text { type of professional activity, and physical and } \\
\text { mental load }\end{array}$ \\
\hline & & sports, recreation (type and load) \\
\hline & life style & sleep habits \\
\hline & & smoking habits, alcohol, drugs, etc \\
\hline & & etc \\
\hline & & natural \\
\hline & environmental & socio-economic \\
\hline & (exogenous) & cultural, technical, man-made \\
\hline
\end{tabular}

adaptive changes. These acclimatory changes, also called habitual, can be exemplified by adjustment of the mode of respiration, changes in blood morphology under conditions of hypoxia, muscular hypertrophy in the case of intensive physical activity, or hypertrophy of adipose tissue as a result of excessive feeding.

If particular environmental conditions persist for a long time, especially in childhood, they may account for permanent developmental adjustments. If environmental stressors are very strong, an individual will die. If this happens before reproduction, those genes will not be transmitted to the next generation.

An example of acclimatory (habitual) adjustment is respiratory-circulatory adaptation and blood adaptation to different climatic and living conditions in Poland (Fig. 5). If values of different indices for 


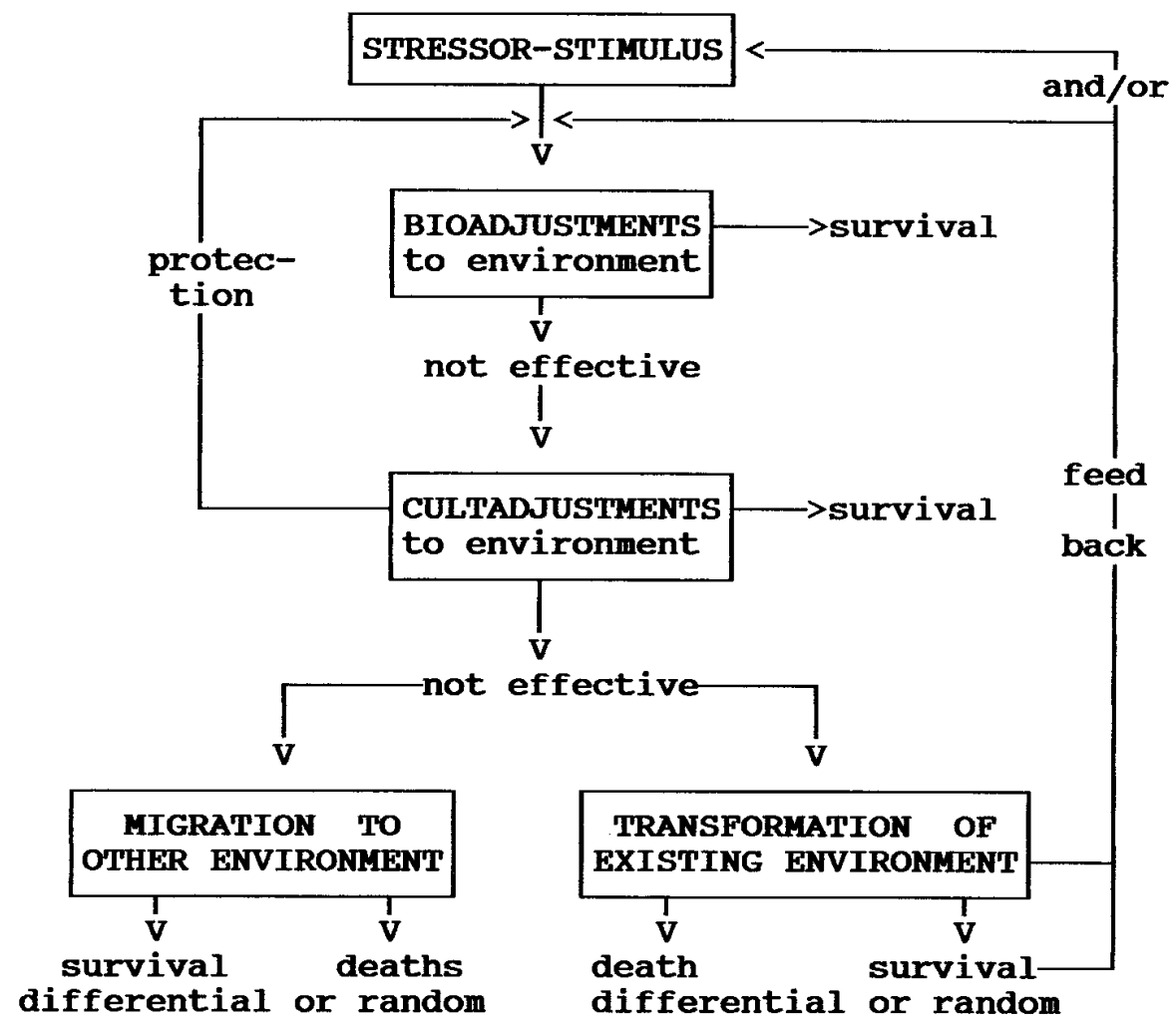

Figure 2. The general model of adaptative strategies

young inhabitants of Warsaw are taken as $100 \%$, then the inhabitants of low mountains (Pieniny Mt.) will have an increased vital lung capacity (VC), haemoglobin concentration ( $\mathrm{Hb})$, heart rate (HR) and cardiac output (Q), but decreased lung ventilation (VE) and blood pressure (BP). The opposite adjustments are seen in inhabitants of the coast (Hel Peninsula). The population of highly industrialized and dust-polluted Silesia (Katowice) shows all these indices to be increased. All these adjustments are aimed at securing appropriate amounts of oxygen in the tissues. Adjustments observed in inhabitants of mountain and coastal areas are of a compensatory character (e.g. small lung ventilation versus high haemoglobin concentration and rapid circulation, or vice versa). In an emergency, one of the low (reserve) characters can be increased. But in areas with heavy dust pollution we observe overadjustments of almost all traits and the disappearance of the adaptive reserves.

An example of developmental adjustments might be body height in the people of Asia - short body height in the children of India, China, or Japan as compared with children in the USA. However, Japanese children born and raised in the USA are much taller, close to the height of the permanent population of this country (Wolański, 1993a).

Another example is provided by a comparison of the body height of children from villages and towns. Until about 1915 (the period of World War I) village children in most European countries for which data are available, were taller and heavier than children from the towns. This was presumably 


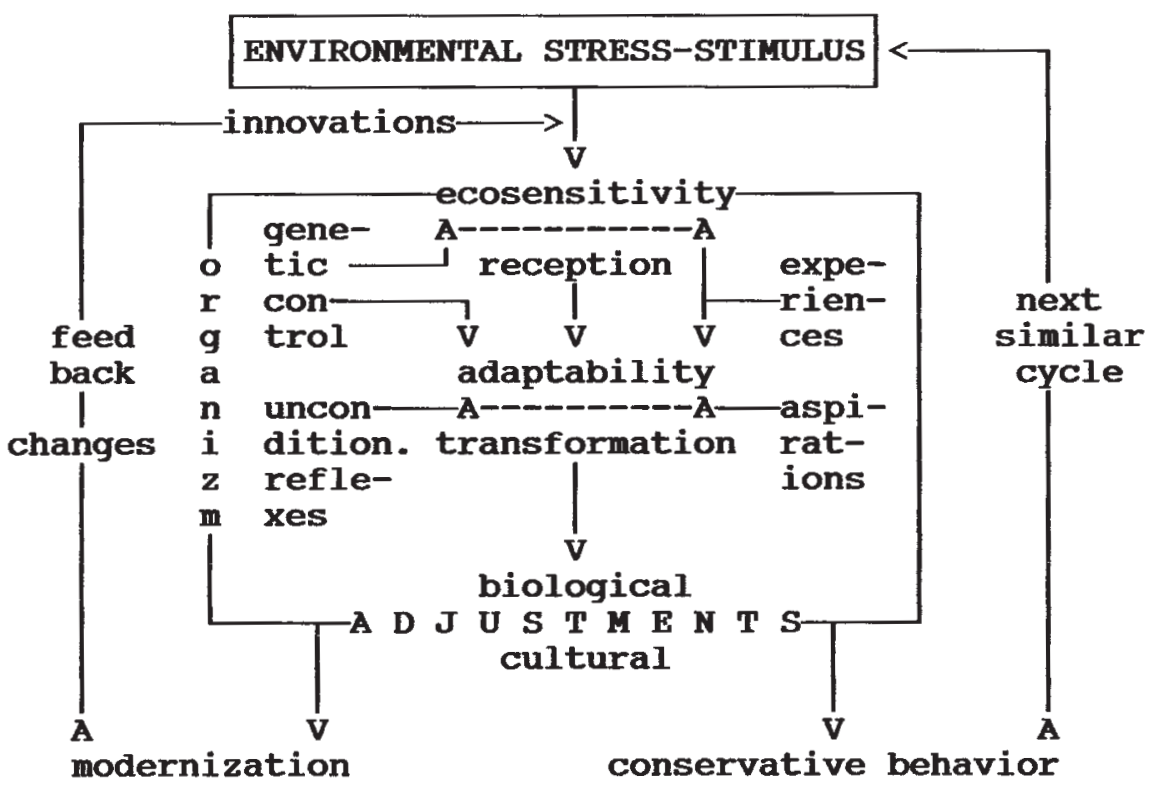

Figure 3. Model of ecosensitivity and adaptability of the organism to environmental stimuli (stressors).

related to the difficult living conditions of the urban working class. With the changes that have taken place in these conditions since about 1920, the body height and weight of town children are greater than those of village children. But during the German occupation of Polish Pomerania in the period 1939-45, children in villages were again taller than in towns (Wolański, 1990). Over that period shortage of food was much more severe in towns than in villages where food was produced.

Probably a decrease of body height in Maya Indians, which has been observed for the last three thousand years (Fig. 6), is affected by the increasing size of this population, the degradation of soil fertility caused by its intensive exploitation, and consequent food shortages, especially for children (Siniarska \& Wolański, 1999).

The phenomenon of 'secular trend' is observable over the last century in most countries of the world, that is, an increase in body weight, acceleration of the age at menarche, etc. from generation to generation. But this is not a linear process. There are periods of increase and periods of decrease in the stature of children. It is suggested that this process is related to the improvement of general living conditions (nutrition, hygiene, etc.) of the populations. Decreases in body height have occurred in periods of war (1914-18, 1939-45) and economic crisis (1929-31).

A very interesting phenomenon is the change in foot arch occurring with age, as measured by the slope of tendo Achillis. Foot arch at the time of the initiation of walking (in the second year of life) is similar for children from villages and towns. From then, until the period of menarche, the foot becomes flattened in typically unshod children from villages, whereas foot arching increases in urban children who wear shoes and use urban means of transportation. It is important to note that, when the juveniles reach maturity and with the more common wearing of shoes by both these groups, these differences largely disappear (Wolański, 1966). 


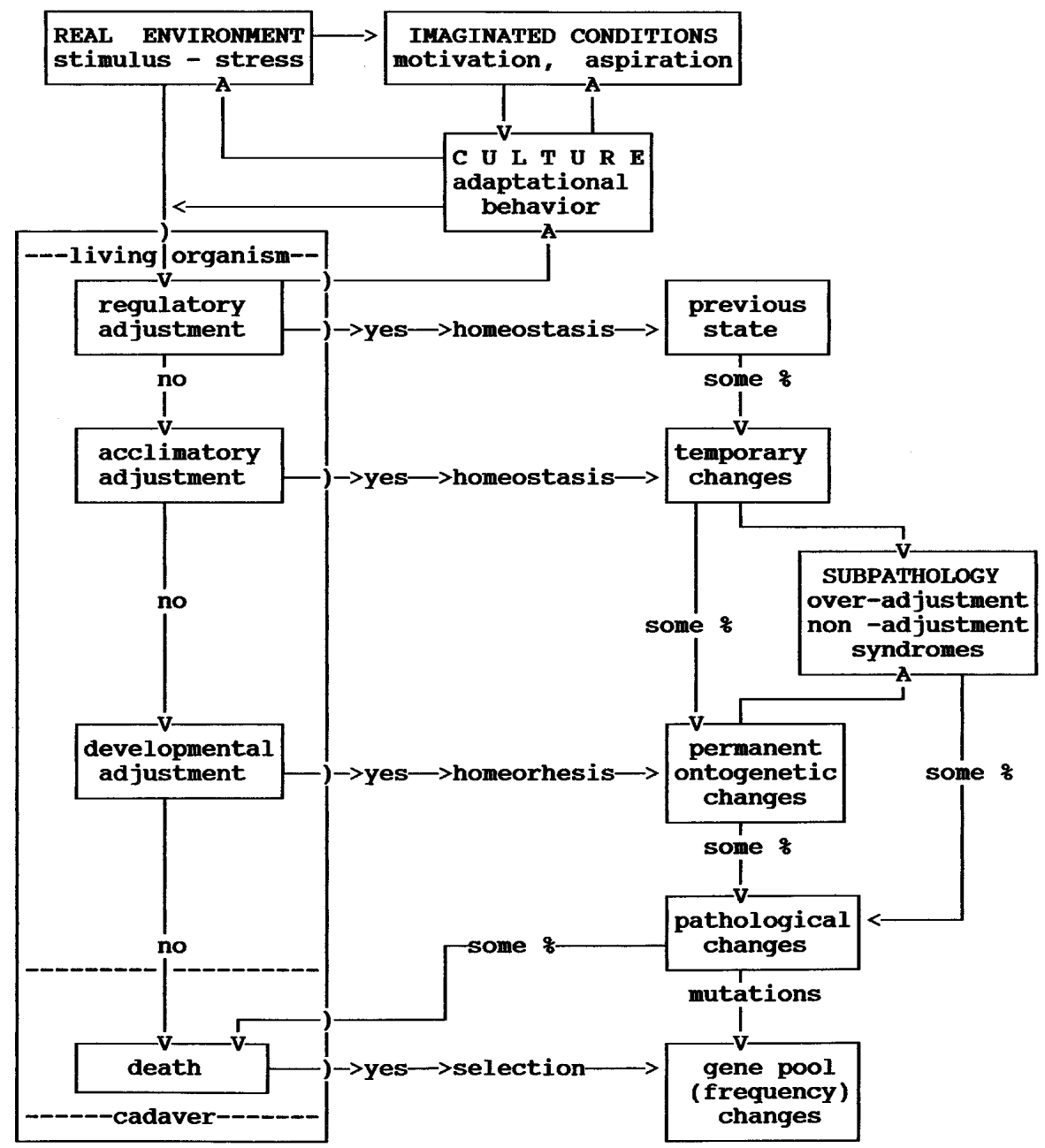

Figure 4. Model of adaptative changes of the organism as an effect of environmental stress (bio-adjustments) (Wolanski, 1993a).

The sequence of some developmental processes called stages of ontogenetic development is very conservative. This is particularly so in the case of the sequence of tooth eruption. In the long processes of phylogeny there is a tendency for the appearance of the molars at a later age than that of other teeth. In contemporary Polish populations, the first permanent molar (M1) appears earlier than the first permanent incisor (I1) for the majority of people. This is the case in $92 \%$ of the rural population, but in only $86 \%$ of the urban population. In about $50 \%$ of American children, M1 appears earlier and in another $50 \%$ I1 appears earlier, but in 57\% of Japanese children M1 appears later than I1 (Wolański, 1993a). This is probably connected with the living standards and diet characteristic of industrial civilization.

The rate of maturation, measured, for example, as the age at menarche in women, is a good example 


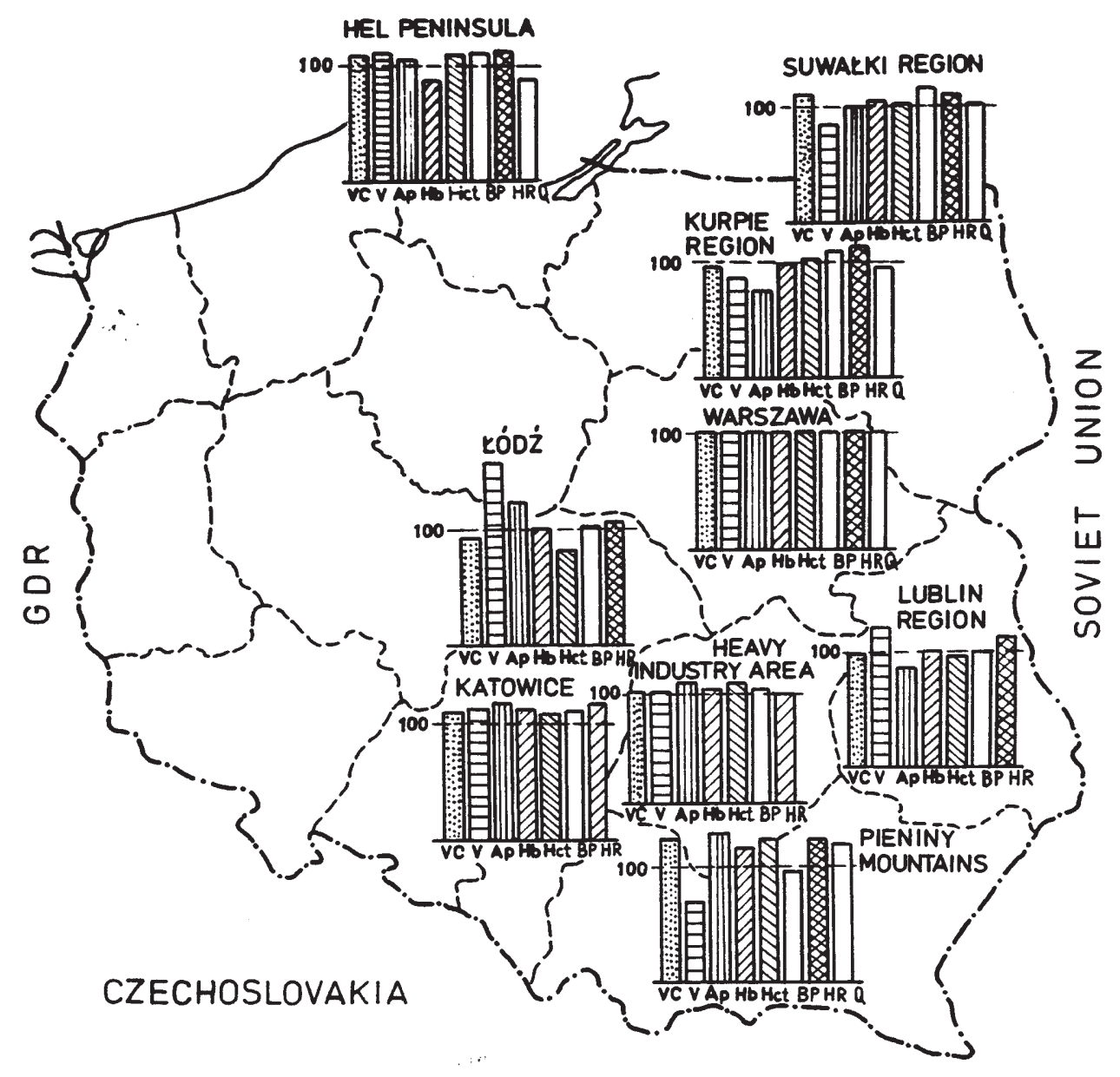

Figure 5. Adaptive changes of respiratory-circulatory functions of man in various climatic and altitudinal conditions, including those changed by industrialization and urbanization (especially air pollution).

Abbreviations: $\mathrm{VC}=$ vital capacity of lungs, $\mathrm{V}(\mathrm{VE})=$ lung ventilation at rest per minute, $\mathrm{Ap}=$ apnea, time without breath, $\mathrm{Hb}=$ haemoglobin concentration in blood, $\mathrm{Hct}=$ blood cells as percentage of blood volume, $\mathrm{BP}=$ arterial blood pressure, $\mathrm{HR}=$ heart rate at rest, $\mathrm{Q}=$ minute heart volume at rest (cardiac output). Data of Pyzuk \& Wolański (1972) and Koziol \& Wolański (1982).

of the effect of living conditions on the rate of development. Typically, earlier maturation is observed in well-fed girls from families with higher education and higher income. This pattern is observed in both towns and villages. But if we compare the age at menarche for urban and rural girls, even if these two groups have similar diet and derive from similar families, urban girls mature at an earlier age (Charzewska et al., 1976). Presumably, emotional stress is among the factors accelerating maturation: an urban girl may encounter as many unknown people in a day as a girl from a remote village might encounter over a whole year or even her entire life. Each new person may be a potential stressing factor, 


\section{Secular changes of stature in Maya populations} in pre-, early and late classic, and postclassic periods

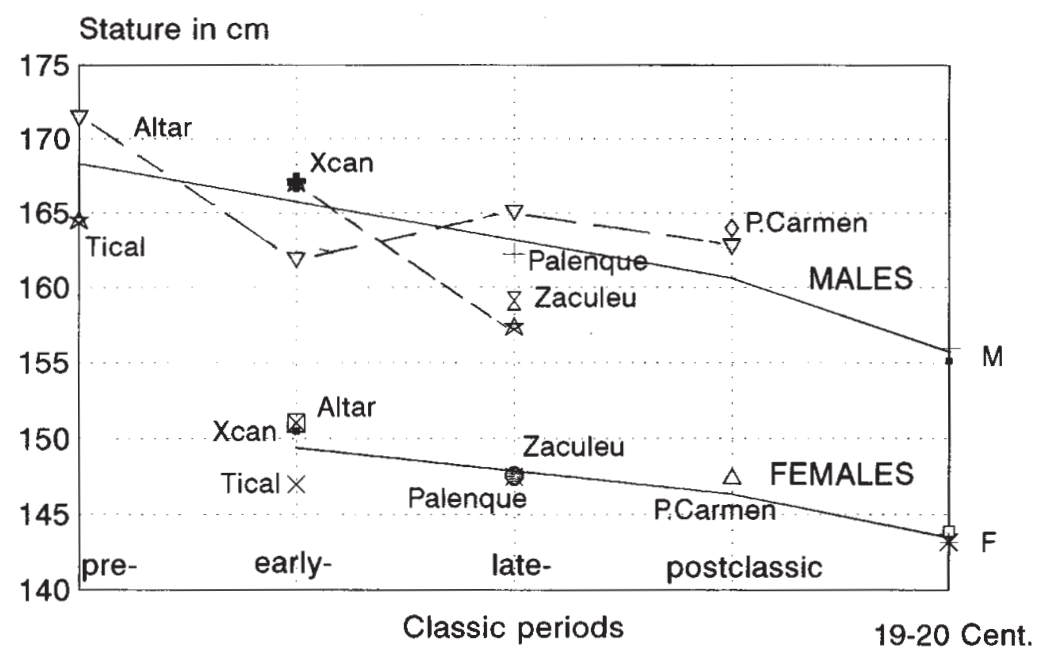

Data: Genovese 1970, Saul 1972, Marquez et al.1982, McCullough 1982, Morfin et al 1982

\section{Secular changes of stature in Yucatan populations} Inhabitants born in 1860-1976, in comparison with ancient Maya

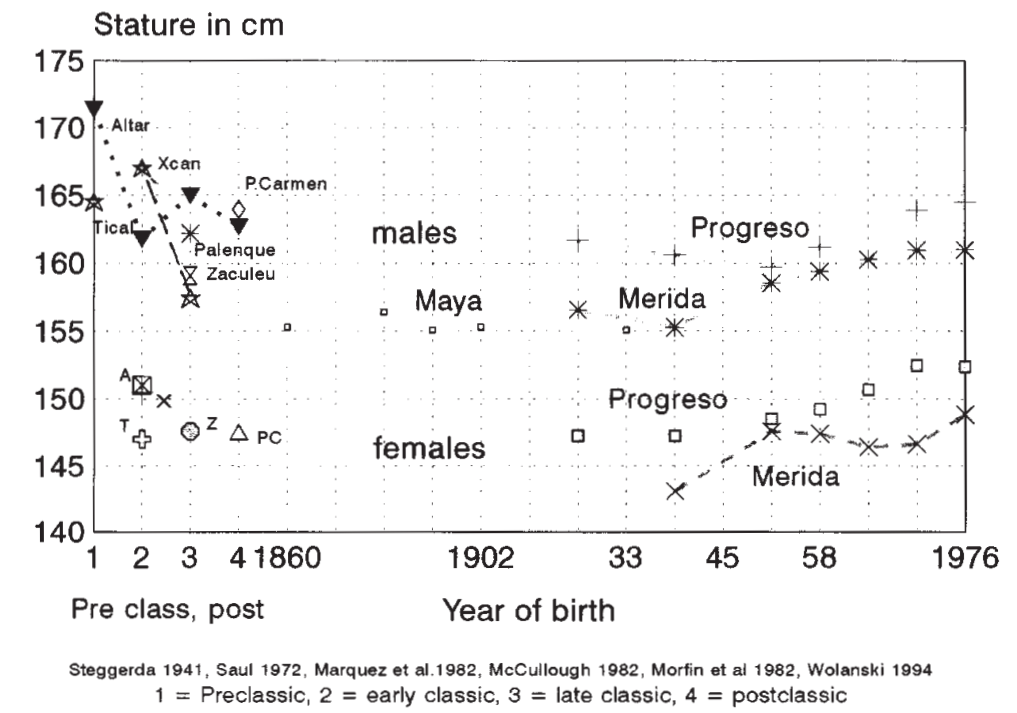

Figure 6. Changes of stature in (a) Maya skeletal populations in pre-, early-, late- and post-classic periods and (b) in adult subjects born between 1860 and 1976, in comparison with ancient Maya Indians (Siniarska \& Wolański, 1998). 


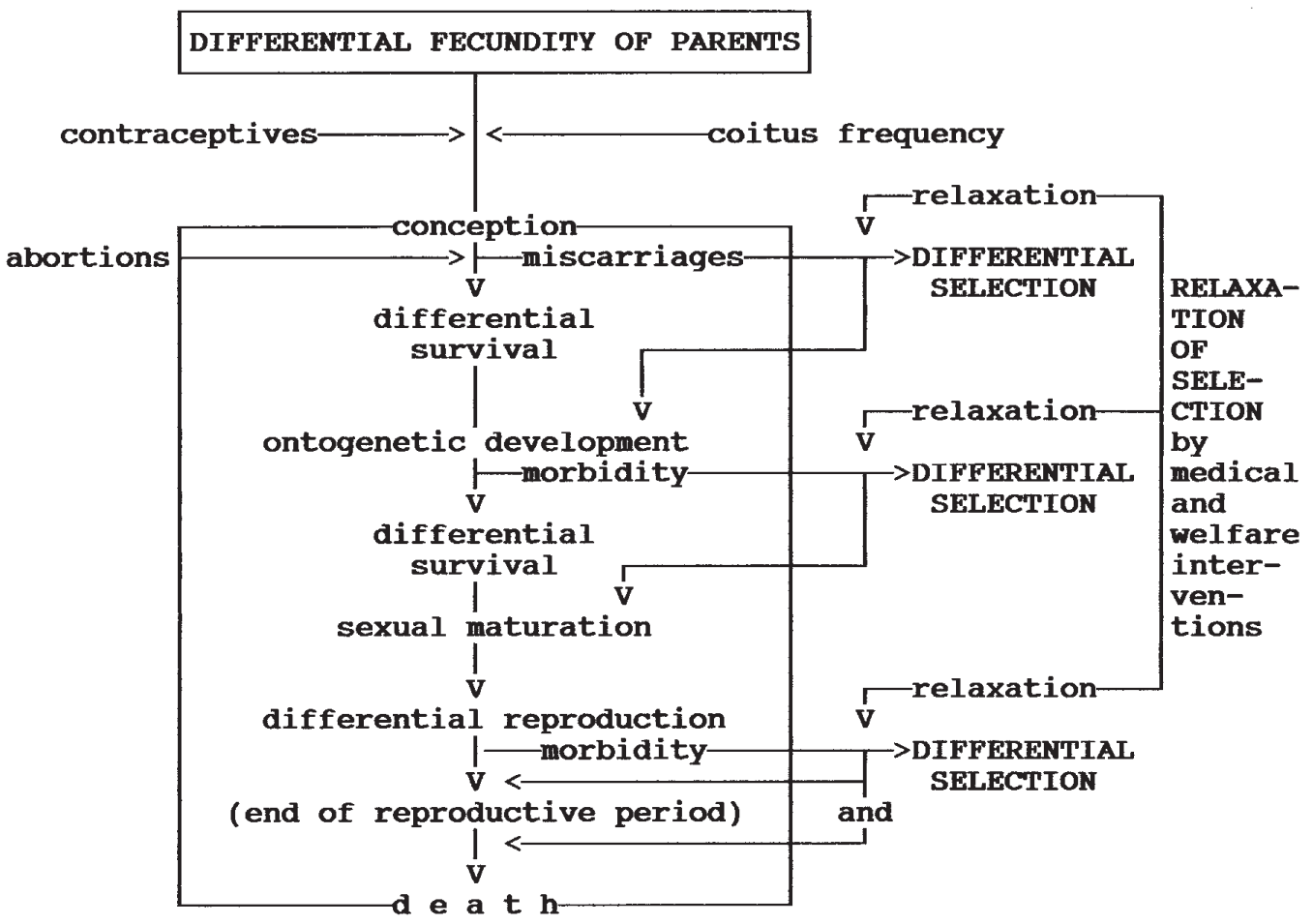

Figure 7. Genetic adaptation by differential fertility and mortality (selection), and the role of relaxation of selection.

\section{$\rightarrow$ TENDENCY TOWARD THE ARITHMETIC MEAN -}

theoretically expected stature of offspring with both parents:

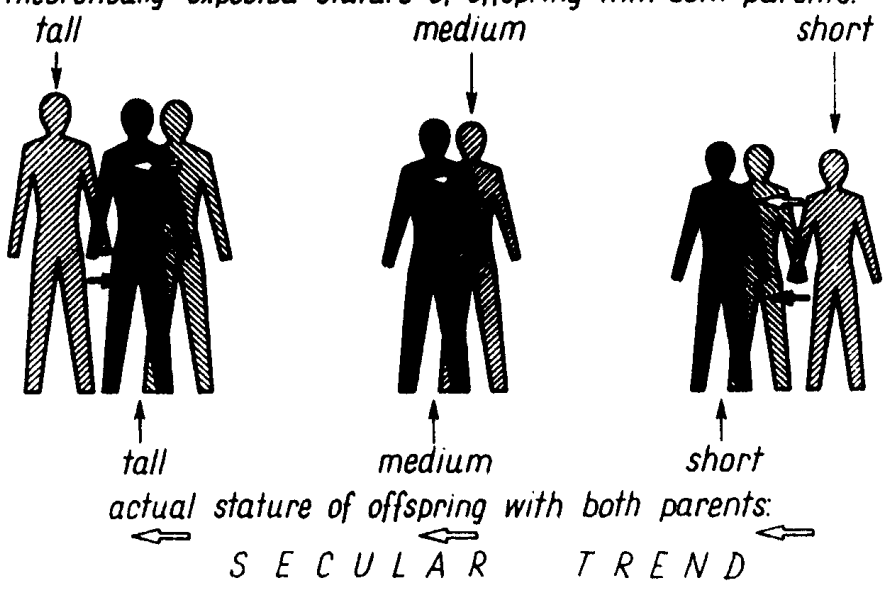

Figure 8. Schematic picture of stature in offspring of two tall, medium and short parents, showing a conjoint effect of the tendency toward arithmetic mean and secular changes. 
and this may stimulate earlier maturation in urban girls.

This hypothesis supports an observation that in some families living in stressing conditions, sexual maturation is accelerated, even if there is scarcity of food - which generally retards maturation (Kowalska et al., 1963, Hulanicka, 1986, Prokopec et al., 1987).

\section{Adaptation at the population level}

As the earlier model shows, there are also strong stimuli that disturb the functioning of an organism permanently. Such is the environmental source of diseases. In extreme cases these stimuli or factors can lead to the death of an individual. Death is itself a selective response - what one person can survive, another cannot. Consequently, survival is differentiated. Since fecundity also is differentiated, the transmission of genes from generation to generation is not random (Fig. 7).

In contemporary populations especially, there is a 'relaxation of selection' arising from the fact that individuals who are 'condemned to death' by nature are 'saved' by medicine and social care; if they survive to reproductive age, their 'unfit' genes can be transmitted to future generations.

\section{Self-regulation}

Reference has already been made to the 'evolutionary' phenomenon of 'secular trend', observed also in contemporary populations. This refers to changes in body weight and proportions, age at menarche, etc., occurring from generation to generation. These are multifactorial changes: they may be caused by variation in gene frequency and increased sensitivity of heterogeneous individuals in the face of the growing frequency of couples with different genomes, but the main factor seems to be changes in diet and mode of life.

There are also some mechanisms for the 'self-regulation' of the magnitude of changes. Well known is the tendency towards so called 'golden mean' - e.g. while individuals at the two extremes may die, those from the middle of the distribution curve tend to survive; very tall couples have children shorter than the mean height of the parents, whereas short parents have taller children than expected on the basis of the stature of the parents. As a result the stature varies within certain limits from generation to generation (Fig. 8).

It has been observed that the breadth of the head and face differ more between populations living close to one another than between distant populations. This was first noted in Micronesia (Hunt), and we found it also in Poland (Siniarska, 1984).

It has been found also that differences in body height between the various social strata in

towns are smaller than those between inhabitants of adjacent villages with differentiated living conditions (Fig. 9).

Martorell \& Habicht (1986) have suggested that differences in body height between social strata are greater than those between the upper social strata of various ethnic groups. They concluded that "the variation that can be attributed to the environment is several times greater than that which can be attributed to genetics". This may well be true, as genetic variation stabilized through evolution is subject to selection, whereas especially in modern civilizations, differences that arise from living conditions are substantial and the threat of negative selection is limited by medical science. We suspect that some mechanism of regulation of the changes is involved, but the nature of this mechanism has not been recognized as yet. It may be related to the tendency to limit intragroup variation.

\section{Sociocultural adaptation}

Earlier we referred to the effects of culture on the processes of fecundity and selection. Cultural evolution is related to biological evolution, and there is a two-way interaction.

Cultural evolution in terms of the progress of civilization has generally been viewed in a positive sense. However, the question arises whether progress is always safe - as at present, when many 
unfavourable changes are occurring in our environment (Fig. 10). As progress cannot and should not be stopped, the problem of sustainable development is arising.

But is it really true that progress cannot be stopped, or rather that it is not an advantageous, or profitable, option? Satisfaction with existing conditions is transient in human beings. Biological adjustment and mental attunement to a particular situation after a time weaken the sense of satisfaction, as man's longing for change gradually turns into a determination to flesh out his aspirations. New conditions are then created, which differ from the former state, but the sense of satisfaction fades again only to be replaced by the recurrent desire for yet another measure of adjustment and accommodation. The consecutive gyrations of the spiral move towards the destination referred to as 'advancement' (Figure 11). When these changes become more rapid and occur on a larger scale, it is not only their intended effects which grow, but also the unintentional side-effects. Typically, these side-effects are unfavourable, often difficult to perceive, and thus are not controlled.

These changes are concentrated in towns, which some people consider as urban ecosystems, although some others agree to call them only urbicenoses. A particularly high concentration of unfavourable changes occurs in the central parts of towns.

Urban niches were constructed to facilitate, improve and prolong human life. However, analysis of contemporary urban populations shows that life expectancy in towns nowadays is no greater than in villages. This is the case in Polish towns and villages analyzed here as an example of temporal variation (Wolański, 1991), and it also applies worldwide.

\section{Civilization as a form of sociocultural adaptation}

The city is the top achievement of urban-industrial civilization. Interrelations among various components of civilization (Fig. 12), such as ideological superstructure, social institutions, techno-

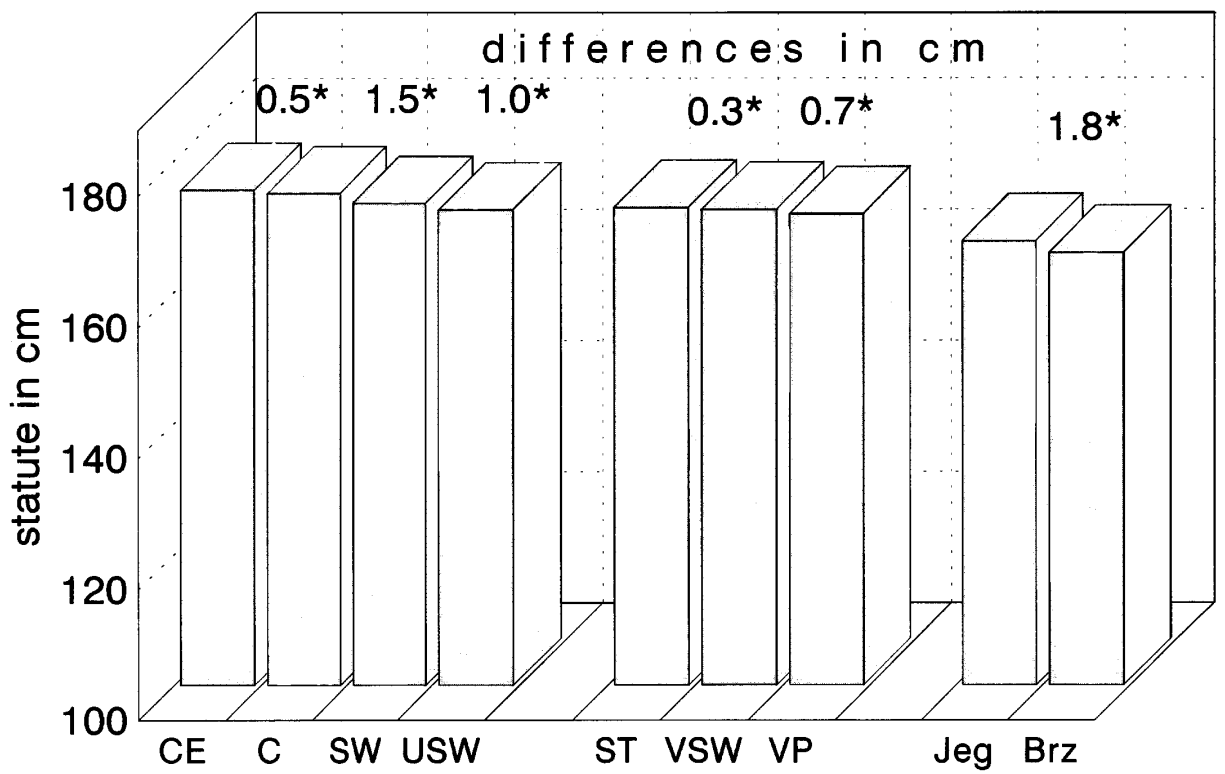

Figure 9. Stature in adult males from various social strata in towns, small towns and villages, and in two Kurpie villages, Jeglijowiec and Brzozowka in Poland (data from Bielicki \& Welon, 1982, Szemik, 1986, Bielicki \& Waliszko, 1991). 
economic level, and cultural practices have different consequences for the biological condition of the population, depending on local environmental conditions (ecosystems in a sense), and on the developmental stage of mankind.

Religions are an ideological basis of civilization (Wolański,1993b). Infant mortality, which is a sensitive index of the biological condition, can be used as evidence. It has been shown that in typically Catholic Christian countries, infant mortality is higher than in typically Protestant countries (Fig. 13). Catholicism promotes poverty as a virtue, and, consequently, it does not stimulate material progress - "It is easier for a camel to pass through the eye of a needle than for a rich man to enter the Kingdom of God". Protestantism, on the other hand, says that wealth is a gift of God; resourcefulness and enterprise are rewarded.

It may be that, as a result of such distinct ideologies, Protestant countries are richer and their economies and medicine are better developed (Marcuzzi, 1998). This has consequences for the biological condition of life. Niche differences due to civilization are expressed also in the biology of human populations.

We are proud of the fact that, although many species of plants and animals have become extinct, the human species persists. But this is a relative truth. In fact, man has become 'extinct' many times already if he is identified with specific civilizations. At least twenty important civilizations disappeared before modern times. For this reason it is important to preserve the diversity of mankind in terms of cultures and civilizations. If urban-industrial civilization were to spread over the entire globe, its crisis, already noticeable in some countries and societies, would threaten the existence of mankind all over the world.

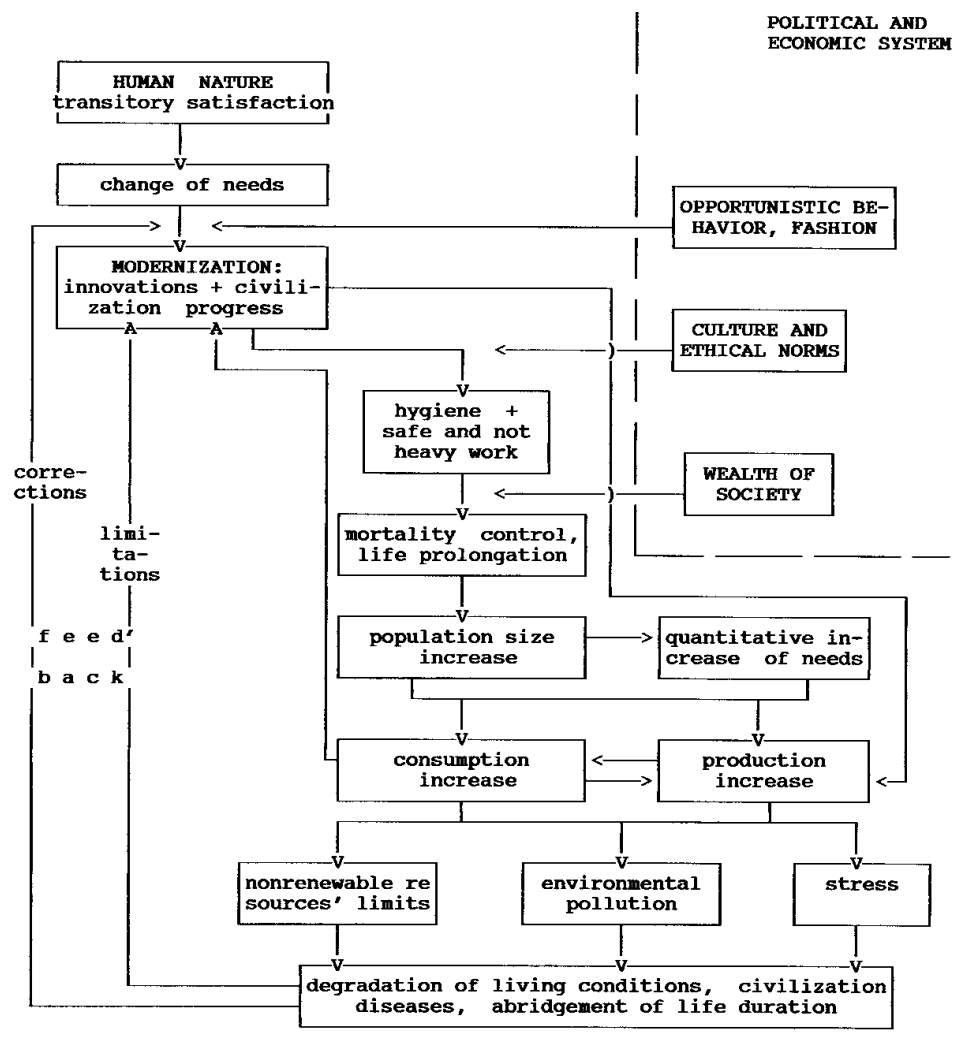

Figure 10. Model of adaptative behaviour in the form of modernization of contacts with the natural environment and the political/economic environment (cult-adjustments). 


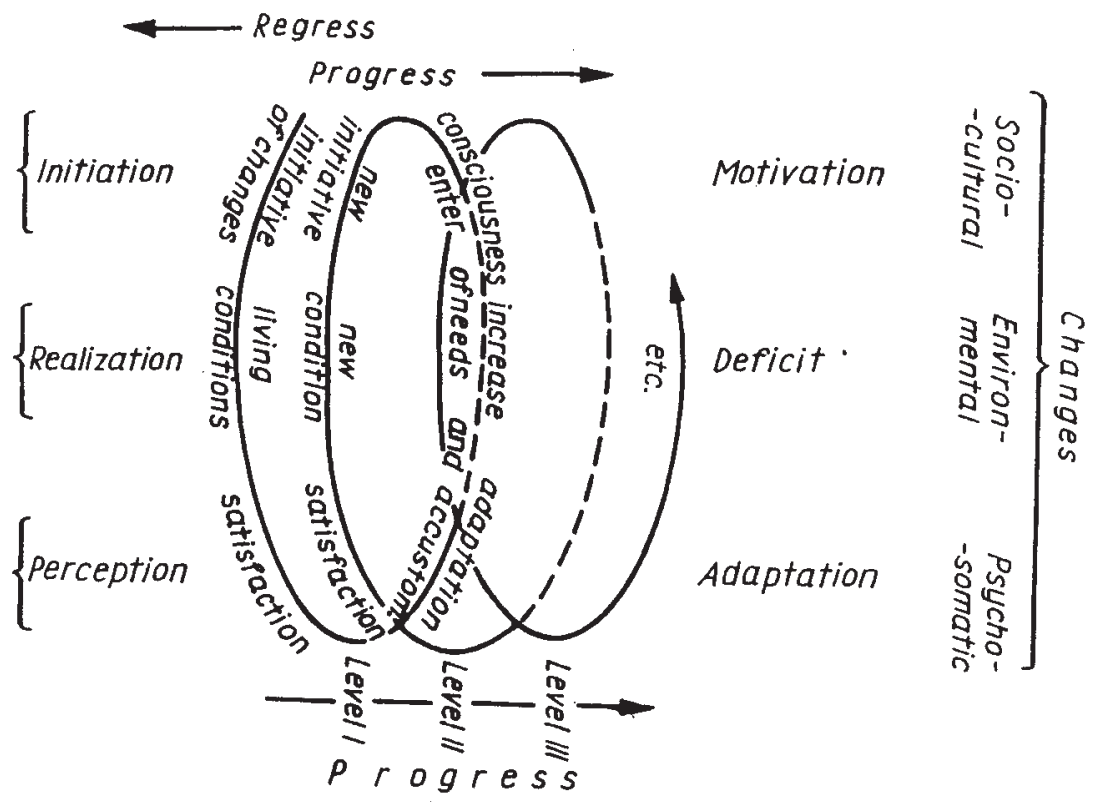

Figure 11. A typical attribute of humans is a loss over time of satisfaction with existing living conditions. This is the source of inspiration to create new changes in the environment, and is an everlasting process accounting for a so called 'spiral of progress', which is an immanent feature of human nature. The spiral of changes, Is the inevitable consequence of man's psychological and biological features. The cultural progress of humans is an inherent feature of this species (Wolański, 1989).

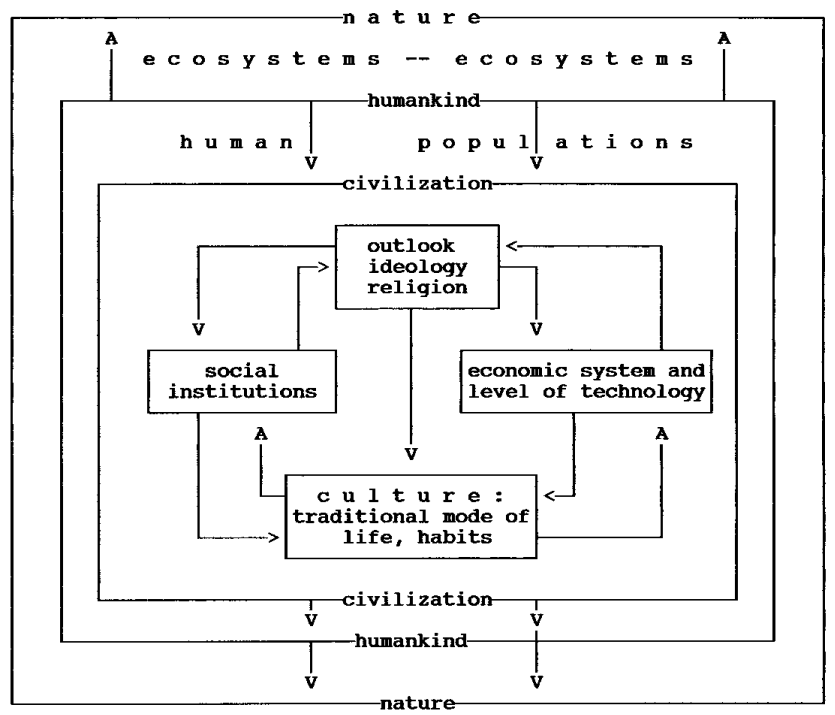

Figure 12. Model of complex forms of social existence, cultural expressions of socio-political organization of society adequate to the environment (ecosystem in wide sense) (Wolanski \& Bogin, 1996). 
Infant mortality per 1000 live births in European countries in 1935-1975

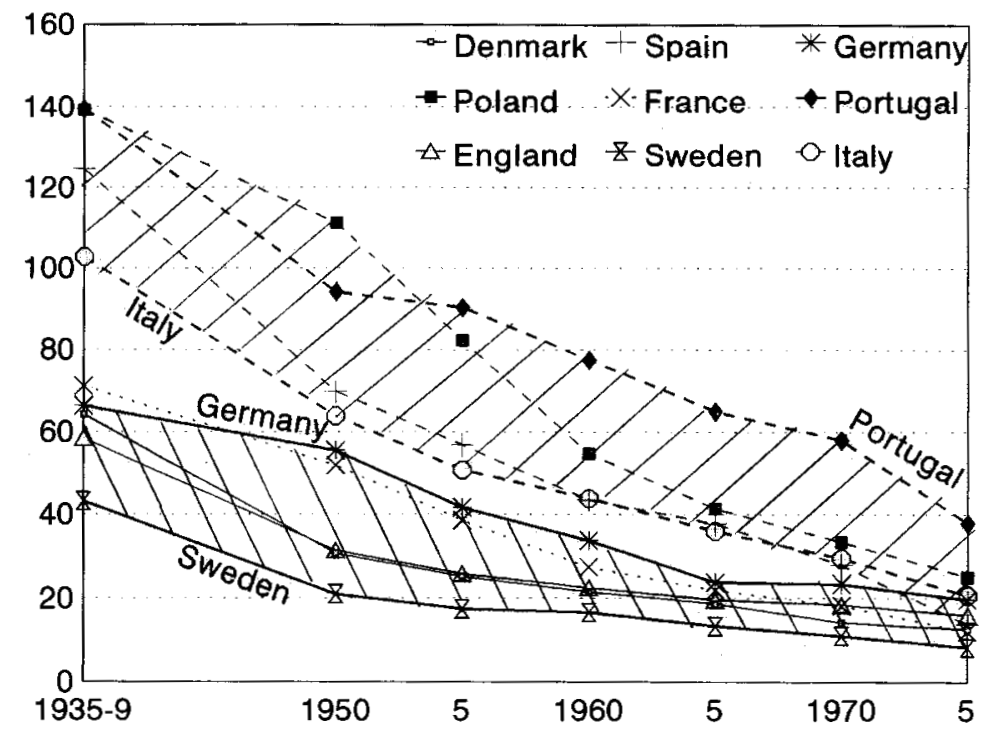

Infant mortality per 1000 live births in European countries in 1975-1996

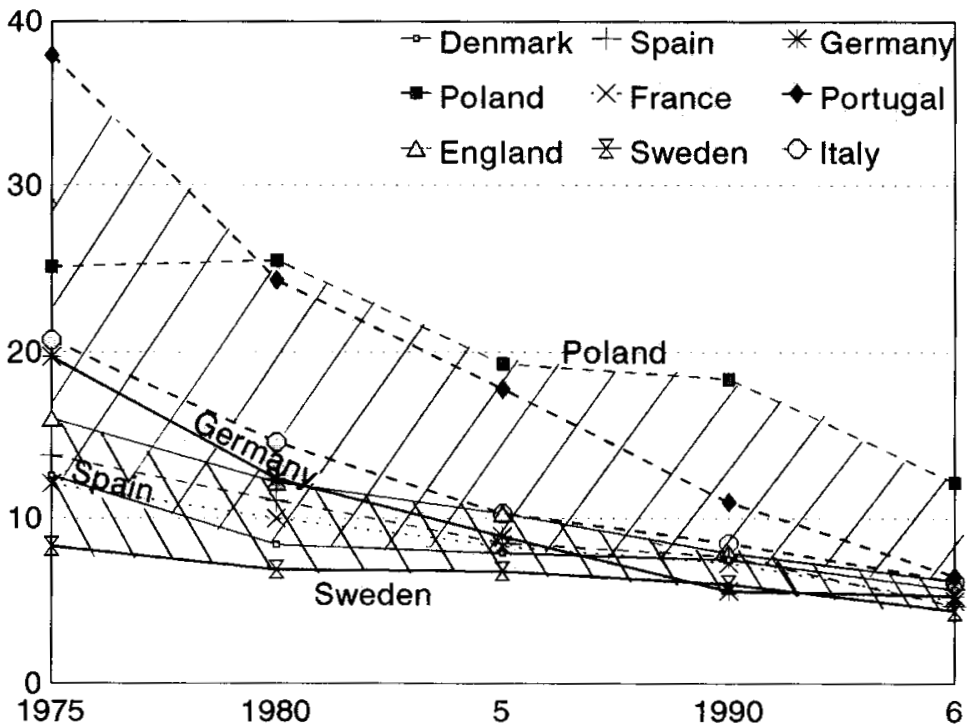

Figure 13. Infant mortality in European countries in the years 1935-1996. The trend of changes is shown for four typical Catholic Christian countries (Portugal, Poland, Spain and Italy) and four typical reformed Christian countries (Germany, Great Britain, Denmark and Sweden). 


\section{Acknowledgments}

Data used in this paper was supported in part by Mexican CONACyT grants No. 1324-1325-S9206 and $26469 \mathrm{H}$.

\section{References}

Bielicki, T. \& Waliszko, H. (1991). Urbanization-dependent gradients in stature among Polish conscripts in 1976 and 1986. Amer. J. Human Biology, 3, 419-24.

Bielicki, T. \& Welon, Z. (1982). Growth data as indicator of social inequalities: The case of Poland. Yearbook of Physical Anthropology, 25, 153-67.

Charzewska, J., Ziemlanski, S. \& Lasecka, E. (1976). Menarcheal age, nutrition and socio-economic environment. Studies in Phys. Anthrop., 2, 47-51.

Foley, R.A. (1987). Another Unique Species. Harlow Essex: Longman

Hulanicka, B. (1986). Effect of psychologic and emotional factors on age at menarche. Materialy i Prace Antropolog., 107, 45-80.

Kowalska, I., Valsik, J.A. \& Wolański, N. (1963). Season of the year in which menstruation begins in relation to age and social and geographical environment. Prace i Materialy Nauk. IMD, 1, 81-108.

Koziol, R. \& Wolański, N. (1982). Respiratory and cardiovascular system in population from areas of different degree of industrialization. In: Ekologia Populacji Ludzkich, pp.397-438, Wroclaw: Ossolineum.

Marcuzzi, G. (1998). The reformation and its diffusion: An ethnological problem. Conference AEA, Bucuresti (Abstract).

Martorell, R. \& Habicht, JP. (1986). Growth in early childhood in developing countries. In: Human Growth, ed. F. Falkner \& J.M. Tanner, vol. 3, pp.241-262, New York: Plenum Press

Prokopec, M., Dutkova, L. \& Vignerova, J. (1987). End of secular trend in the age at menarche in Czech girls. Proceedings of 8th Intern. Anthrop. Poster Conference, Zagreb, pp. 28-31.

Pyzuk, M. \& Wolański, N. (1972). Respiratory and cardiovascular system in children in different environmental conditions. Warszawa: PWN.

Siniarska, A. (1984). Interpopulational and interfamilial differences in some somatic, physiological and psychomotor traits. Studies in Human Ecology, 5, 195-221.

Siniarska, A. \& Wolański, N. (1999). Secular changes and economic transformations in Yucatan, Mexico. Perspectives in Human Biology. 4(2): 189-201.

Szemik, M. (1986). Changes in somatic development of inhabitants of two neighboring villages in Kurpie region (Poland) between 1961-1981. Studies in Human Ecology, 7, 65-93.

Wolański, N. (1966). Environmental modification of human form and function. Annals of New York Academy of Sciences, 134(2), 826-40.

Wolański, N. (1989). Human life and culture: dynamic components of ecosystems. Zygon, Journal of Religion and Science, 24(4), 401- 27.

Wolański, N. (1990). Human population as bioindicator of environmental conditions (environmental factors in biological status of population of Poland). Studies in Human Ecology, 9, 295-321.

Wolański, N. (1991). Human ecology and problems of demography. Collegium Antropologicum, 15(1), 27-43.

Wolański, N. (1993a). Selected problems of human ecology related to town planning. Acta Oecologie Hominis, 2, 1-194.

Wolański, N. (1993b). Poverty, wealth, pollution and human health. Collegium Antropologicum, 17(2), 199-207.

Wolański, N. \& Bogin, B. (eds) (1996). The family as an environment for human development. Delhi: Kamla-Raj Enterprises. 


\section{Anna Siniarska \& Napoleon Wolanski}

\author{
Department of Human Ecology \\ Institute of Ecology, \\ Polish Academy of Sciences, Warsaw, Poland \\ and \\ CINVESTAV, Merida, Mexico
}

Keywords: human ecology, family structure, human development

\section{The Family as the Environment of Human Development}

The study sample comprised 9030 Polish, 578 Japanese, 265 Korean and 629 Mexican offspring ranging in age from 2 to 48 years, and their parents. Studies were conducted in 1975-1993. The analyzed variables included stature of offspring, parental stature, their education and age at birth of the children and some family characteristics such as family size, apartment size, and income. The results of multiple regression of offspring stature on family factors revealed that in Poland and Mexico the best child development is observed in families with high parental education and income and with income divided among a small number of family members. In Japan and South Korea this is true in families with a large number of family members even if there is a low level of education and income. But the effect is most noticeable when parents are tall. These results suggest that in Mexico and Poland economics and education are the most important factors for proper child development. However, in Japan and South Korea the best child development takes place in large and traditional families even if income and education are below the national level. This most probably shows that in societies with high economic levels, which have been sustained for at least two generations, the decisive role for child biological development is played by factors other than good economic conditions only. These factors are likely to be related to culture and tradition.

\section{Introduction}

The human family is often recognized as a social rather than a biological unit. But, the family is also a biosocial environment, and is the most important ecological factor, which controls external influences on family members (Karsaevskaya, 1996; Muhsam, 1996; Wang et. al, 1996; Siniarska, 1996; Wolański, 1996a). The main aim of the present study, which concerns families in different ethnic groups, economic systems and civilizations, was to evaluate the biological development of children in terms of their body height within these families and to find out which family factors are the most responsible for child growth and development. The questions, which arise in our research, include: How does family environment influence the biological development of children in different countries? To what extent does biological development depend on genetic factors and on economic conditions? How do parental education and family size impact on development? Do cultural habits and customs play an important role in the biological development of children? There are very few such studies in the literature (IYF, 1995), and the main base for us is our own research.

\section{Materials and Methods}

The material of this paper comprises studies on stature of offspring and living conditions of their families conducted in Poland, Mexico, South Korea and Japan, in 1975 - 1993 (Wolański et al., 1994a,b,c; Wolański, 1996a; Wolański and Zaremba 1996). The material details concerning each country are presented in Table 1 . The family environment was described by ten characteristics: mother's and 
father's stature, parental education, parents' ages at the birth of their children, family size (number of persons), the number of family members working outside of the home, size of the house or apartment (number of rooms), and the family income.

Two statistical methods were used. Principal Component Analysis with varimax rotation was applied to all 10 family characteristics to find out the independent factors correlated with certain characteristics. These factors were next subjected to multiple regression analysis as independent variables to evaluate their influence on the dependent variable, which is stature of offspring.

Additionally, separate analysis of the offspring stature distribution (males only) was performed according to different family types. The family types were mostly established on the base of four family factors and these factors were characterized by two digits: 1 (below the median) and 2 (above the median). The idea was to compare two types of families, with the most extreme differences in factor scores, and the most extreme differences in child stature. For Poland only, six family factors were used, and 11-year-old boys were included in this analysis. For Mexico, South Korea and Japan the offspring stature is presented in T scores.

\section{Results}

The results of Principal Component Analysis show that there are four factors named according to family characteristics mostly associated with each factor (Table 2). Those are: education and income, parental age at childbirth, family size and the genetic factor, which is represented by stature of both parents. There are important differences in the variance of studied family characteristics in these four countries. In Mexico, Poland and South Korea the total variance of all characteristics is explained mostly

Table 1. The general characteristics of the offspring samples from different countries.

\begin{tabular}{|c|c|c|c|c|c|c|}
\hline \multirow[t]{2}{*}{ Country } & \multicolumn{3}{|c|}{ No of offspring } & \multirow{2}{*}{$\begin{array}{l}\text { Age of offspring } \\
\quad \text { (in years) }\end{array}$} & \multirow{2}{*}{ No of families } & \multirow{2}{*}{$\begin{array}{c}\text { Years of } \\
\text { investigations }\end{array}$} \\
\hline & Total & Males & Females & & & \\
\hline Poland (town) & 5851 & 2930 & 2921 & $2-27$ & 2287 & $1975-92$ \\
\hline Poland (villages) & 2937 & 1467 & 1470 & $2-27$ & 2287 & $1975-92$ \\
\hline $\begin{array}{l}\text { Mexico } \\
\text { (towns: Merida and Progreso, } \\
\text { Yucatan State) }\end{array}$ & 623 & 311 & 312 & $2-27$ & 300 & 1993 \\
\hline $\begin{array}{l}\text { Korea } \\
\text { (rural Chung Cheong province) }\end{array}$ & 672 & 338 & 334 & $2-44$ & 265 & 1988 \\
\hline $\begin{array}{l}\text { Japan } \\
\text { (rural, mountain Akita province) }\end{array}$ & 1219 & 607 & 612 & $2-44$ & 578 & 1988 \\
\hline
\end{tabular}

Table 2. Results of Principal Component Analysis with Varimax Rotation. F1 to F4 - factors; PEV - percent of explained variance.

\begin{tabular}{|c|c|c|c|c|c|c|c|c|c|c|}
\hline & Poland - towns & PEV (\%) & Poland villages & PEV (\%) & Mexico & PEV (\%) & Korea & PEV (\%) & Japan & PEV $(\%)$ \\
\hline F1 & Education & 23.9 & Education & 23.7 & $\begin{array}{l}\text { Education and } \\
\text { income }\end{array}$ & 26.2 & $\begin{array}{l}\text { Education and } \\
\text { income }\end{array}$ & 23.5 & Parental age & 19.3 \\
\hline F2 & Parental age & 17.9 & Parental age & 18.2 & Parental age & 19.0 & Parental age & 18.8 & $\begin{array}{l}\text { Education and } \\
\text { income }\end{array}$ & 17.4 \\
\hline F3 & $\begin{array}{l}\text { Family size and } \\
\text { income }\end{array}$ & 15.1 & $\begin{array}{c}\text { Family size and } \\
\text { income }\end{array}$ & 13.2 & Genetic factor & 13.0 & Family size & 16.5 & Family size & 16.0 \\
\hline \multirow[t]{2}{*}{ F4 } & Genetic factor & 10.9 & Genetic factor & 10.9 & Family size & 83. & Genetic factor & 11.1 & Genetic factor & 10.7 \\
\hline & $\Sigma=$ & 67.5 & $\Sigma=$ & 66.0 & $\Sigma=$ & 66.5 & $\Sigma=$ & 69.9 & $\Sigma=$ & 63.4 \\
\hline
\end{tabular}


by education. In Mexico and South Korea, education is associated with income. However, in Poland education is not correlated with income. Only in more recent years has such a correlation in Poland been observed. Rather, there is observed an association between income and family size in Polish families, which suggests that more numerous families have higher income (more people work). In Japan the factor "parental age at child birth" explains the highest percent of variance of all family characteristics.

Regression analysis of children's stature on family factors shows that the genetic factor plays the most important role, explaining the highest percent of the stature variance (Figure 1). In Poland, education is in second place, followed by parental age. In Mexico, South Korea and Japan family size is second. However, what is very interesting, is that in Mexico taller children are observed in the smaller families, whereas in the Asian countries the same phenomenon takes place in larger (more numerous) families.

The above results suggested a closer look, following the distribution of offspring stature in different types of families. In Poland, the tallest children are in families characterized by higher education and income where only father works, family size is small, apartment size is small (at the time of our investigations, smaller apartments were better than bigger ones, because they were more modern with better equipment), and parents are taller (Figure 2). The shortest children are in families having lower education and income where both parents work, with larger family, big apartment, short parents. The question arises as to which factors react the most effectively to decrease or increase the body height of children. It was found that the most important factors associated with short stature are lower education, lower income, and shorter parents. The most important factors associated with tall stature are a lower number of workers outside the home (when mother stays home and takes care of a family) and taller mothers.

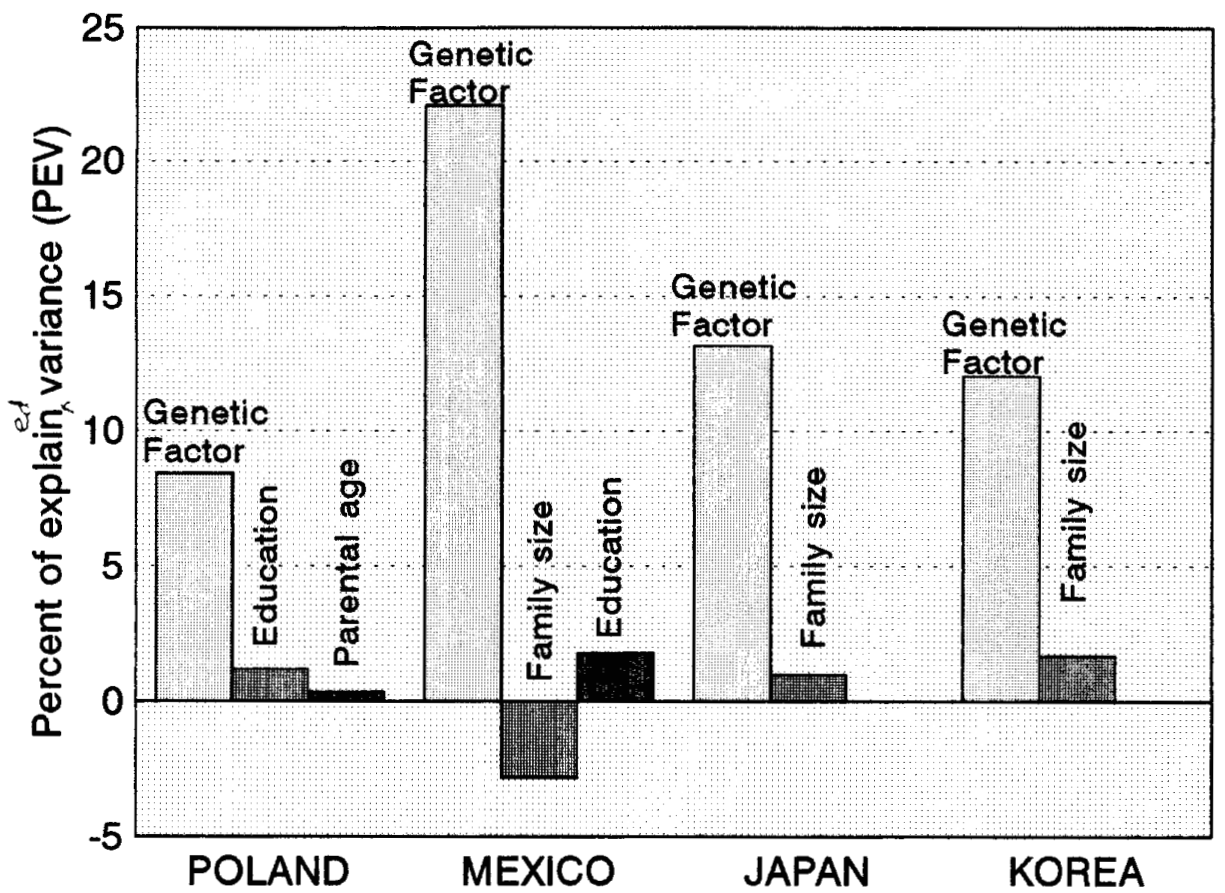

Figure 1. Factors which significantly explain the variance of children's body height (mean for boys and girls). 
In Mexico, the tallest children are in families characterized by higher education and income, younger and taller parents, and smaller families (Figure 3). In contrast, the shortest children are in the families having lower education and income, older parents, shorter parents and larger families. The decisive factors lowering offspring stature are lower education and income, and shorter parents. By contrast, smaller family and taller parents increase the offspring stature the most effectively.

In South Korea, the tallest children are in families characterized by lower education and income, younger parents, larger families and taller parents (Figure 4), while the shortest children are in families characterized by higher education and income, older parents, smaller families and shorter parents. The factors, which mostly decrease the offspring stature, are higher education and income, and smaller family size. The increasing factors are larger family even with lower education and income.

In Japan, the tallest children exist in families characterized by younger parents, lower education and income, larger families and taller parents (Figure 5) while the shortest children are in the families having older parents, higher education and income, smaller families and shorter parents. The decreasing factors are shorter parents and higher education and income. The increasing factors are taller parents and lower education and income.

\section{Discussion}

The countries taken for this analysis reveal very different levels of socio-economic development, style of life, nutritional habits as well as various cultural traditions. Mexico, at the time of the present

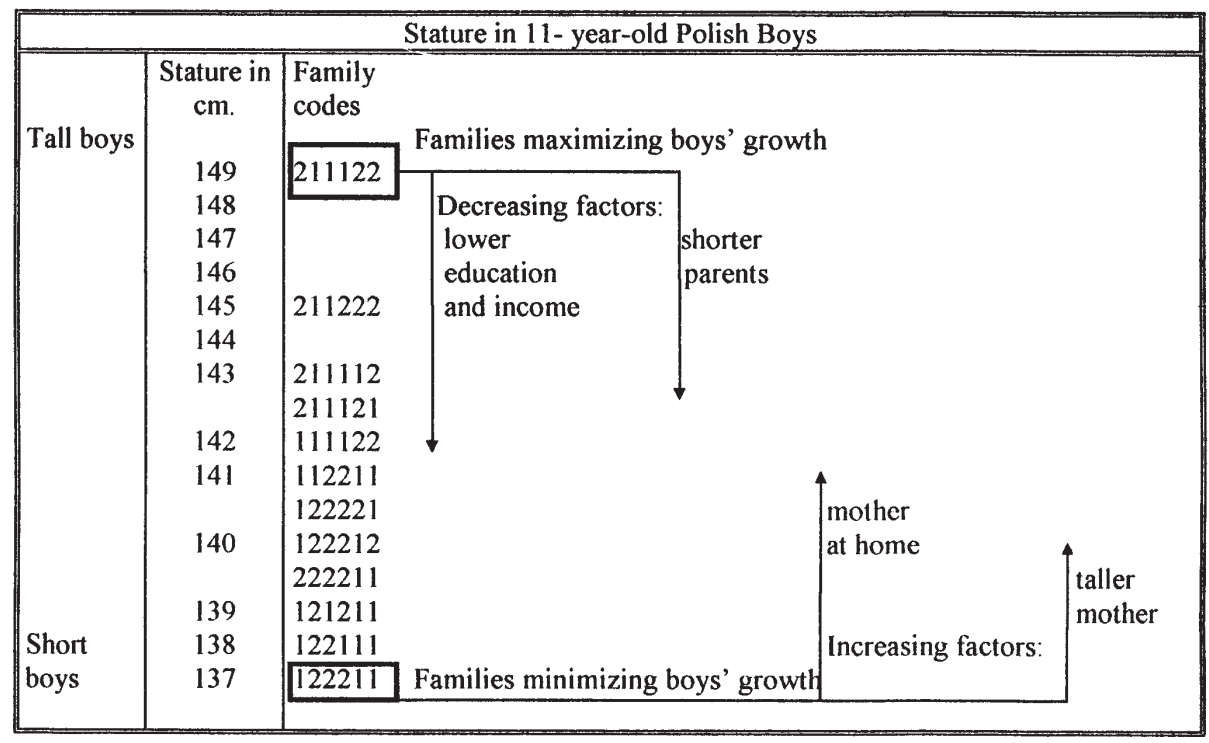

Figure 2. Stature of 11-year-old sons in various types of Polish families.

Family codes: the first digit - education and income (1 - below, 2 - over average).

The second digit - number of employees ( 1 - only father, 2 - more than two)

The third digit - family size ( 1 - smaller, 2 - larger $)$

The fourth digit - apartment size ( 1 - smaller, 2 - bigger $)$

The fifth digit - maternal genetic factor (1 - shorter, 2 - taller)

The sixth digit - father genetic factor (1- shorter, 2 - taller) 
study, was under an intensive economic development. Poland was under a socialist economic system, with very low values of GNP. In both countries, symptoms such as an unstable economy and inflation, made the life of people rather stressful. South Korea and especially Japan belong to economically developed countries, where cultural traditions are very different from those in European countries and in Mexico.

The results presented show rather well marked similarities between Poland and Mexico, and between South Korea and Japan. However, the differences between these two groups (Poland and Mexico versus the Asian countries) are even more marked. The explanation lies probably in the level of economy and differences in cultural tradition. There is a lot of poverty both in Mexico and Poland. Because of this, the income of most families in these countries equals, or is even below, the social minimum. By contrast, in South Korea and Japan, after so many years of progressive economic development, income of the average family exceeds the social minimum, and the social and economic needs (in the wide spectrum) should be easily reached by all types of families.

It is rather hard to explain the results observed in Asian countries, showing that children are taller in families with parents of lower education than when parents are better educated. However, this definitely means that education in the highly economically developed countries does not play such an important role in biological development of children as in the less developed countries. Education, as used in our research, does not equate with intelligence. Rather, it reflects the level of knowledge parents received at home and during their years of schooling. But, even more important is the cultural tradition of the

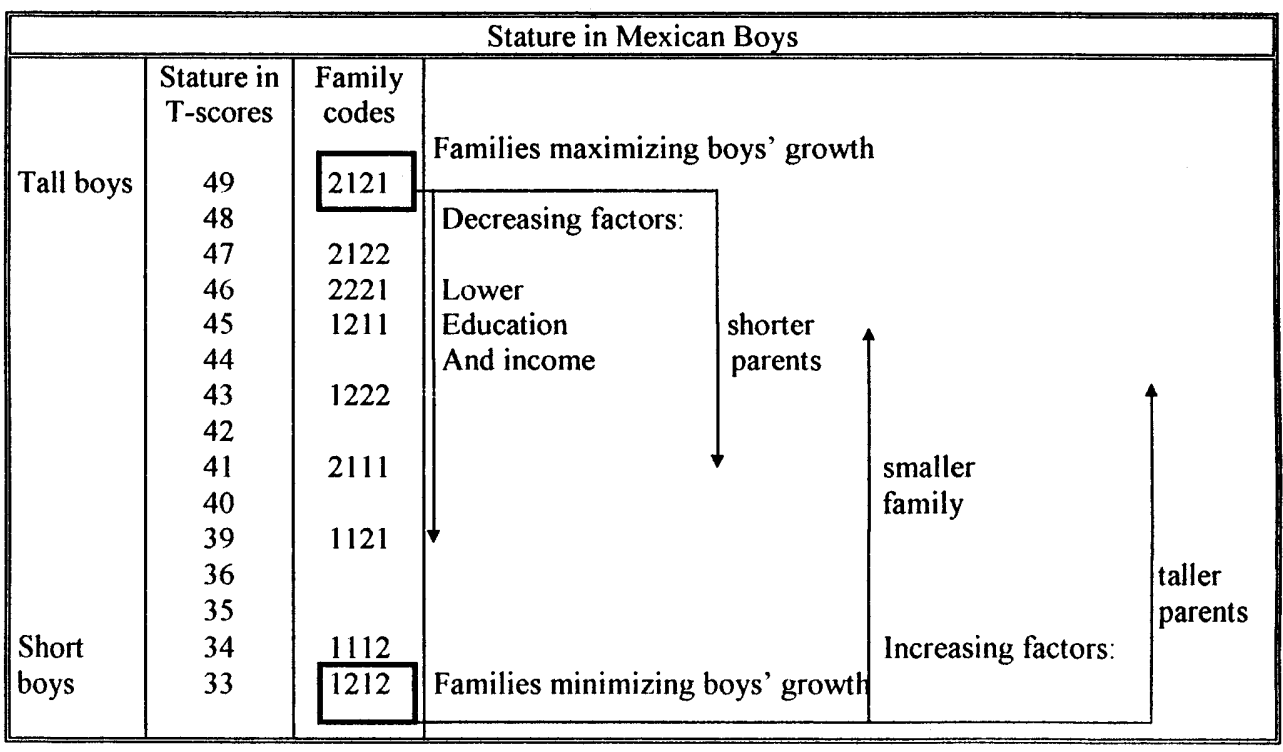

Figure 3. Stature of sons (in age independent values) in different types of Mexican families.

Family codes: the first digit - education and income (1 - below, 2 - over average).

The second digit - parental age at child birth (1 - younger, 2 - older parents)

The third digit - genetic factor ( 1 - shorter, 2 - taller parents)

The fourth digit - family and apartment size (1 - smaller, 2 - larger). 


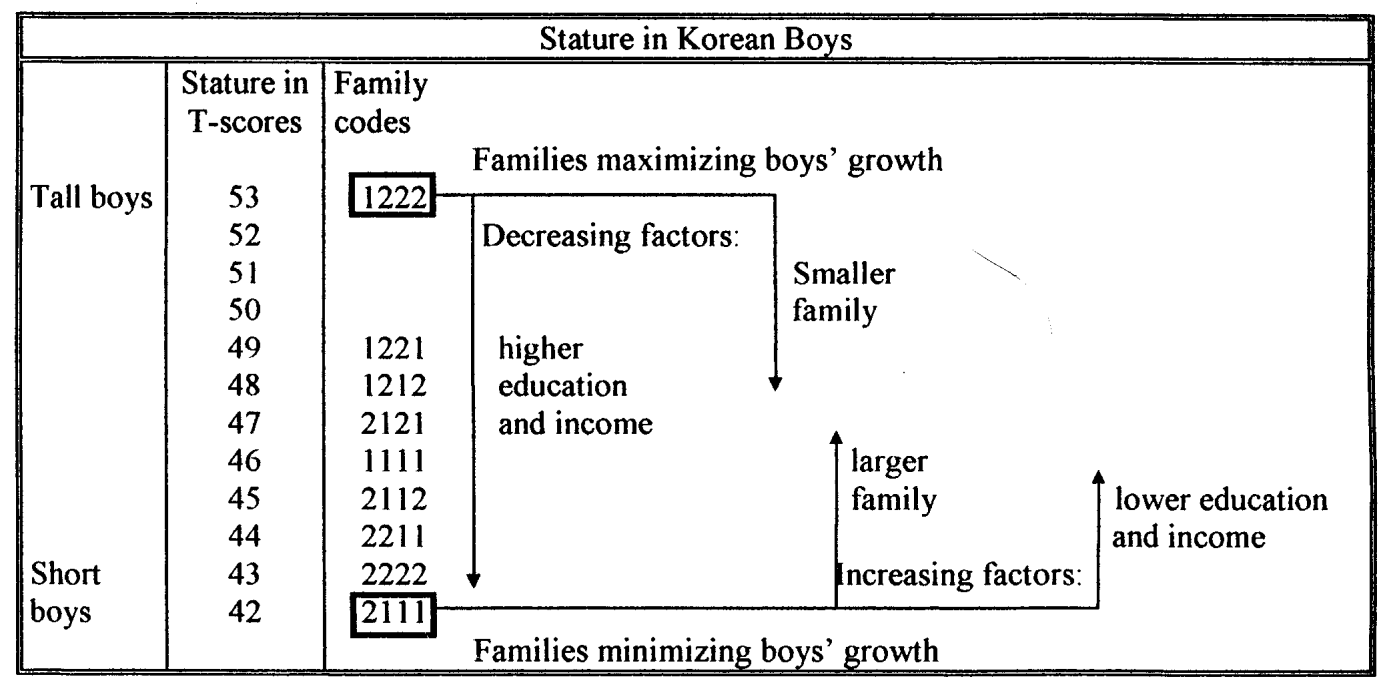

Figure 4. Stature of sons (in age independent values) in different types of South Korean families.

Family codes: the first digit - education and income (1 - below, 2 - over average).

The second digit - parental age at child birth (1 - younger, 2 - older parents)

The third digit - family and apartment size (1 - smaller, 2 - larger $)$.

The fourth digit - genetic factor ( 1 - shorter, 2 - taller parents)

families. It may be true that all parents' knowledge (both higher and lower educated) is sufficient to provide all children with a good biological development. In both types of families there is a sufficient economic level to gather all types of food, and knowledge of which food is the best and how children should be raised. The difference between these families (well and less educated) may be based on their professional activities. Well-educated parents may have been professionally more occupied, have fewer children and less time to take care of them than in families of less educated parents. If so, one may conclude that modernization, which can lead to smaller families of better educated parents, gives no benefits in biological development to their children.

The differences concerning family size depend probably on tradition, which in the Asian countries favours a large family. Consistently, economic prosperity promotes larger families. Studies of Leonetti (1976) on American families of European and Japanese origin revealed that the basis for existence in families of European origin is "an individual effort of the man", whereas for Japanese families, the family is the productive unit. It is also worth noting the results for Polish families which show that if a mother does not work and stays home taking care of children, the biological development of children is better than in families where both parents work. The best developed children were found in families where mothers were better educated but did not work and fathers had higher income, even with lower education. 


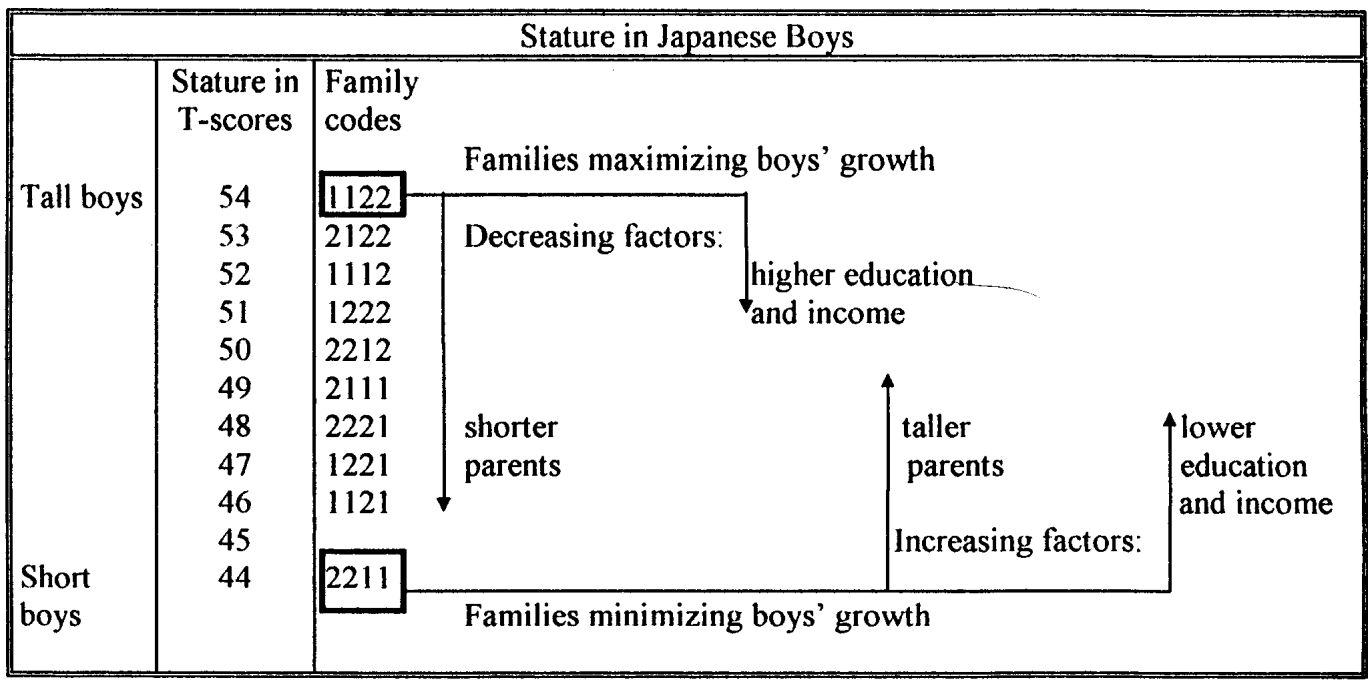

Figure 5. Stature of sons (in age independent values) in different types of Japanese families.

Family codes: the first digit - parental age at child birth ( 1 - below, 2 - over average).

The second digit - education and income (1 - younger, 2 - older parents)

The third digit - family and apartment size $(1-$ smaller, 2 - larger $)$.

The fourth digit - genetic factor $(1$ - shorter, 2 - taller parents $)$

\section{Conclusions}

In the highly economically developed countries, the education and income of parents play a less important role in the biological development of children than in the less economically developed countries.

In countries where tradition plays an important role in upbringing and education of children, the factors which are important for the biological development of children may be of a different order and may even play a different role than in the countries where the style of life is less stressful.

In Japan and South Korea, in the big and traditional families even with lower education and income, the biological development of children is better than in the small families with higher parental education and income.

In Poland and Mexico better education and income divided among a small number of family members are decisive for better biological development of children.

\section{Acknowledgments}

Grants No 1324 and 1325-S9306 from the Mexican CONACyT, and the editorial assistance of Dr. Barry Bogin are gratefully acknowledged.

\section{References}

IYF (1995). International Directory of IYF (1994 - International year of the family) Research Activities. Australian Institute of Family Studies, p. 127. Melbourne, Impact Printing.

Leonetti, D.L. (1976). Fertility in transition: An analysis of the reproductive experiences of an urban Japanese 
American population. Unpublished Ph.D. Dissertation, University of Washington.

Karsaevskaya T.V. (1996). Family in today's Russia: Civilizational aspect. In: The Family as an Environment for Human Development, ed. N. Wolański \& B. Bogin, pp. 89-99. Delhi: Kamla-Raj Enterprises.

Muhsam H.V. (1996). The family as a social response to biological constraints. In: The Family as an Environment for Human Development, ed. N. Wolański \& B. Bogin, pp. 67-74. Delhi: Kamla-Raj Enterprises.

Siniarska, A. (1996). Family environment, parents constitutional characteristics and biological development of children. In: The Family as an Environment for Human Development, ed. N. Wolański \& B. Bogin, pp. 145183. Delhi: Kamla-Raj Enterprises.

Wang R., Niu T., Shi Y. (1996). Family transition and its human ecological implications in China. In: The Family as an Environment for Human Development, ed. N. Wolański \& B. Bogin, pp. 101-111. Delhi: Kamla-Raj Enterprises.

Wolański, N. (1996a). Somatic traits of offspring and family factors in populations. In: Studies in Human Biology, ed. B.É. Bodzsár \& C. Susanne, pp. 379-386. Budapest: Eötvös Univ. Press.

Wolański, N. (1996b). The family and child growth (Cross cultural studies in Poland, Japan, South Korea and Mexico). In: The Family as an Environment for Human Development, ed. N. Wolanski \& B. Bogin, pp. 185199. Delhi: Kamla-Raj Enterprises.

Wolański, N., Czarzasta, T., Chung, S., Tomonari, K., Tsushima, S., Seiwa, H. (1994a). Family characteristics and offspring growth in various countries. II. Stature of offspring in various families in Japan and Korea. Studies in Human Ecology, 11, 13-22.

Wolański, N., Chung, S., Czarzasta, T., Dickinson, F., Harada, S., Liocheva, V., Seiwa, H., Tomonari, K., Tsushima, S. (1994b). Family characteristics and offspring growth in various countries. I. Frequency of various family types in Bulgaria, Japan, Korea, Mexico and Poland. Studies in Human Ecology, 11, 5-11.

Wolański, N., Chung, S., Tsushima, S., Tomonari, K., Czarzasta, T. (1994c). Family characteristics and offspring growth in various countries. III. Regression of offspring's stature in relation to parents' and family's factors in Japan and Korea. Studies in Human Ecology, Poland, 11, 23-29.

Wolański, N., Zaremba H. (1996). Regression of offspring morphology to socio-economic and genetic family factors in rural and urban populations of Poland. Coll. Antropol., 20(1), 37-62 


\section{Preface}

Humanity from African Naissance to Coming Millennia arises out of the Dual Congress that was held at Sun City, South Africa, from $28^{\text {th }}$ June to $4^{\text {th }}$ July 1998. As the idea of a "Dual Congress" is a new one, a word of explanation is needed.

Two international bodies, with partially overlapping spheres of interest, chose South Africa as the host country for their respective meetings. One of the bodies is the International Association for the Study of Human Palaeontology, which Professor Henry de Lumley had set up at an inaugural congress in Nice, France, in 1981. At the III International Congress of IASHP in Jerusalem in 1992, Dr. Francis Thackeray of the Transvaal Museum, Pretoria, extended an invitation on behalf of human palaeontologists of South Africa for the IV Congress to be held in South Africa. This was accepted by the Permanent Council and General Assembly of IASHP. Originally the meeting was intended to be held in 1997, but for various reasons it was necessary to defer it to 1998 .

Independently, the Executive Committee and Council of the International Association of Human Biologists (IAHB) had invited me to organise a meeting in South Africa within my term of office as its President.

It would have been difficult to organise two major international meetings in the same area within a short time of each other. Moreover, it seemed to me that there would be great intellectual benefits if the two bodies were to meet in a single integrated congress: such a Dual Congress would stimulate a healthy cross-fertilisation of ideas between those whose work is predominantly in the field of human evolution and investigators of recent and living mankind. The idea was put to the two organisations and their governing bodies welcomed the proposal.

The Dual Congress was held in a lavish conference centre at Sun City about $200 \mathrm{~km}$ north-west of Johannesburg. Approximately 600 participants from 70 countries attended and 300 papers were presented, 100 as invited addresses in colloquia and 200 as free or contributed papers. Eighteen colloquia were an important feature of the Congress. Wherever possible, a colloquium comprised speakers on the evolutionary aspects and others on the living populations and where applicable two chairpersons per colloquium were appointed by the Scientific Programme Committee. Thus students of the Living and the Dead were brought together in a novel way.

Colloquia were devoted to Human Growth and Secular Trend (presided over by N. Cameron and J. Moggi-Cecchi); Human Ecology, Past and Present (E.S. Vrba and N. Wolanski); Food and Humanity, Past and Present (A. Sillen and J. Lee-Thorp); The Demography of Hominids, Past and Present (A. Mann and S. Dani); The Human Genome Diversity Project (Sir Walter Bodmer); The Human Dimension in Biodiversity (G. Häuser); Towards a Revised Systematics of the Hominids (G. Groves); Advances in Dating of the Past (G. Curtis and C. Swisher); The Earliest Emergence of the Hominidae (T. White and B. Asfaw); Australopithecine Diversity in South, East, and West Africa (M. Leakey); Hominid and NonHominid Primate Behaviour and Lifestyles (H. Roche); The Diversity of Early Homo (B. Wood); The Emergence and Evolution of the Human Brain (R. Martin); Human Biological and Cultural Diversity in the Middle and Later Pleistocene (G. Giacobini); Pleistocene Gateways to Europe and Asia (G. Manzi); The Current Dispute on the Origin of Modern Humans (F. Smith); Archaeological Perspectives on the Origin of Modern Humans (H. Deacon); Palaeo-Anthropology during the Twentieth Century (F. Spencer).

This volume includes refereed papers from these 18 colloquia. The contributions have here been reclassified in eight parts, which deal respectively with Human Biology, Emerging Homo, Evolving Homo, Early Modern Humans, Dating, Taxonomy and Systematics, Diet, and Brain. At the request of the Director of the International Institute for the Study of Man, Professor B. Chiarelli, the $8^{\text {th }}$ Robert Broom Memorial Lecture by P.V. Tobias is included in this volume, with the approval of the Director of the Transvaal Museum under whose auspices the Robert Broom Lecture is delivered. In 1998, the lecture 
was presented at the Dual Congress on $29^{\text {th }}$ June and repeated at the Transvaal Museum on $19^{\text {th }}$ October 1998. We should have liked to publish the other special lecture, the Raymond Dart Memorial Lecture by Sir Walter Bodmer F.R.S., in this book, but we did not receive a manuscript of this Lecture-which was devoted to Genetic Diversity and Disease Susceptibility. Dr. C.K. ("Bob”) Brain kindly furnished the Foreword.

As Organiser-in-Chief and President of the Dual Congress, I thank all the scores of people who supported us - the Patrons led by Patron-in-Chief Nelson Mandela, the Principal Sponsors - The Standard Bank Group, Anne Barry - San Francisco Foundation, an anonymous donor and the Department of Arts, Culture, Science and Technology of the South African Government, 28 other sponsors, the Organising Committee and many sub-committees, the Student Volunteers - and those who graciously took on the tasks of organising and chairing the Colloquia and Sectional Meetings, the referees who unselfishly adjudicated upon the articles in this book, and the cheerfulness and cooperative spirit which everyone concerned showed at all times. We owe an immense volume of thanks to the Department of Anatomical Sciences and its Head, Professor Beverley Kramer, and the Transvaal Museum and its Director, Dr. Ignatius Rautenbach.

I write this on behalf of my co-editors - Michael Raath, Jacopo Moggi-Cecchi and Gerald Doyle, as well as the assistant editors, Kevin Kuykendall and Himla Soodyall, to all of whom my appreciation is expressed. If I may single out one for special mention, my deepest gratitude goes to Mike Raath who bore the lion's share of editing work with efficiency and generous outlay of his time, experience, computer skills and monumental energy. All of us deeply appreciate the invaluable master-minding and editorial and managerial skills of Brunetto Chiarelli.

The work depended heavily upon the insightful help of Melanie Smith and, in earlier days, 'Sfiso Mthembu, the wise financial council and guidance of Neil McCormick, and the backing and experience of Heather White.

This book goes out to the world of human biology and palaeo-anthropology from the continent which gave birth to humanity, its African Naissance, at the turn of the millennium, after five thousand millennia of humanity as we stand poised before many more Coming Millennia.

\author{
Phillip V. Tobias \\ Department of Anatomical Sciences \\ University of the Witwatersrand, \\ Johannesburg \\ South Africa
}

$1^{\text {st }}$ January 2000 


\section{Michel Brunet}

Université de Poitiers - EP 1596 du CNRS Lab. de Géobiologie, Biochronologie et Paléontologie humaine

40 av. du Recteur Pineau

82022 Poitiers Cedex-France

Keywords: West Africa, Pliocene

Biochronology, Palaeoecology

\section{Chadian Australopithecines: Biochronology and Environmental Context}

\begin{abstract}
Five palaeontological and geological field missions carried out in the Djourab Desert (Northern Chad) by the French-Chadian Paleoanthropological Mission (MPFT) have resulted in the discovery of about one hundred continental Mio-Plio-Pleistocene vertebrates sites. Until now three areas have been intensively collected: Koro Toro (KT), Kollé (KL) and Kossom Bougoudi (KB). All the fossils come from poorly consolidated subhorizontal sandstone levels that outcrop sporadically amid dunes and sand. Two hominid localities have already been discovered (Brunet et al., 1995 and 1997). One of them has yielded the first australopithecine known from west of the Rift Valley, Australopithecus bahrelghazali Brunet et al., 1996: a new species characterized by several unique features including a shortened face. In spite of biases associated with preliminary collections and some distinct provincialism, the faunas indicate a biochronological age of between 3 and $3.5 \mathrm{Ma}$ for the two hominid sites, between 4 and $5 \mathrm{Ma}$ for Kollé and older than $5 \mathrm{Ma}$ for Kossom Bougoudi. These faunas are representative of mosaic landscapes including fresh water, wooded savannah and grassland. The diverse faunas indicate a closed environment for $\mathrm{KB}$, a more open environment for KL and still more open for KT. Chadian faunas dated between 3 and $6 \mathrm{Ma}$ are critical to an understanding of the evolution of early hominids and their environments. Already the Chadian australopithecines show us that the hominid story is pan-African at least until 3.5 Ma.
\end{abstract}

\section{Introduction}

Five paleontological collection trips carried out in the Djurab desert (northern Chad: $15-18^{\circ} \mathrm{N}, 16^{\circ}$ $20^{\circ} \mathrm{E}$ ) by the French-Chadian Paleoanthropological Mission (French acronym: MPFT) have resulted in the discovery of about one hundred continental Mio-Plio-Pleistocene vertebrate sites. Two hominid localities in the Koro Toro region (KT 12 and KT 13) have already been discussed (Brunet et al., 1995, 1997). One of them (KT 12) has yielded the first australopithecine known from west of the Rift Valley: Australopithecus bahrelghazali Brunet et al., 1996.

These discoveries have taken the MPFT to older sedimentary levels. Faunas from two new sites have been described ; the Kollé (KL) sites about $30 \mathrm{~km} \mathrm{NNE}$ of the hominid sites (Brunet et al., 1998) and the Kossom Bougoudi (KB) sites about $30 \mathrm{~km}$ West of Kollé (Brunet \& MPFT, submitted). This entire region, called 'Pays Bas' ('low country'), is very flat and outcrop of the sedimentary deposits is patchy because they are overlain by dunes and windblown sand of variable thickness. Despite this, few rare and very small outcrops (no more than 1,5 m high) indicate repetitive successions of sandstones and pelitic clays with or without interstratified diatomites.

\section{Biochronology and Biogeography}

Almost all the fossils come from these poorly consolidated sandstone levels that outcrop 
Table 1 : Chadian Suinae

\begin{tabular}{lllll}
\hline & \multicolumn{4}{c}{ Localities } \\
Taxa & KB & KL & KT 12 & KT 13 \\
\hline Kolpochoerus afarensis & & & + & + \\
Notochoerus euilus & & & & + \\
Nyanzachoerus jaegeri & + & & & \\
Nyanzachoerus kanamensis & + & + & & \\
\hline
\end{tabular}

sporadically amid the dunes and sand.

Thus far, almost four thousand fossil specimens have been collected and about one hundred taxa have been determined (flora 1; insects 3; fishes 13; reptiles 8; birds 6; mammals 67). Among the mammals, two groups are particularly significant from a biochronological point of view: Suidae and Proboscidea (Tables 1, 2).

We have recovered Stegodon kaisensis 'warwire' (also known from Uganda), from the Warwire Zone, which is dated to 3-3.5 Mya (Tassy, 1994); Loxodonta exoptata, as known from Laetoli and Hadar (Beden, 1985); and the Kolpochoerus afarensis-Notochoerus euilus association known also from Hadar (Cooke, 1985). Their presence in the faunas of the hominid sites KT 12-13 point to a biochronological age between 3 and 3.5 My (Brunet et al., 1995, 1997).

In the Kollé fauna the Proboscidea (Loxodonta n. sp., Stegodon kaisensis 'warwire', Anancus kenyensis 'petrochii') and the suid association Nyanzachoerus kanamensis-N. jaegeri suggest an age between 4 and 5 My (Brunet et al., 1998). In the KB fauna the more primitive Proboscidea Anancus kenyensis 'kenyensis', Stegodon kaisensis 'nkondo', and the sole primitive tetraconodontine Nyanzachoerus kanamensis indicate an age older than Kollé around the Mio-Pliocene boundary (Brunet \& MPFT, submitted).

This first West African biochronological sequence is very important, first because it overlaps a critical period in the earliest hominid story, and secondly because its oldest fauna (KB) comes from near the Mio-Pliocene boundary. Sites of this age and of early Pliocene age are not numerous in Africa: Sahabi and Langebaanweg in North and South Africa respectively, and Middle Awash, Lukeino, Manonga Valley and Lothagam in East Africa.

The singularity of the Chadian faunas is evidenced by the presence of about ten per cent of new species, and by the fact that some known taxa, like Stegodon, are very common as in Uganda, although rare in Ethiopia and absent in Kenya (Tassy, 1994). This reflects marked provincialism.

It is clear that the Mio-Pliocene Chadian faunas will henceforth be critically important for a proper understanding of the environments of the first hominids in Africa.

\section{Palaeoenvironment}

All the fossiliferous levels belong to repetitive sedimentary sequences of sandstones, clays, and diatomites, representing a succession of fluviatile and lacustrine environments in a relatively humid period. Moreover, in all the localities, the non-hominid fauna includes aquatic taxa such as siluriform and perciform (Lates niloticus) fish, and water-dependent taxa such as turtles (Trionyx), crocodiles (Tomistoma or Euthecodon), snakes (Python aff. sebae), water monitor lizards (Varanus cf. niloticus), aquatic birds (e.g. Anatidae), and several species of Hippopotamidae among the mammals. These taxa all indicate long-term stable freshwater environments.

On the other hand suids, Giraffa, Bovini and proboscideans suggest a wooded savannah environment, while equids, Sivatherium and Reduncini (Kobus) suggest an open environment like 
Table 2 : Chadian Proboscidea

\begin{tabular}{lcccc}
\hline & & & Localities & \\
Taxa & KB & KL & KT 12 & KT 13 \\
\hline $\begin{array}{l}\text { Loxodonta exoptata } \\
\text { cf. Loxodonta nov. sp. (primitive form) }\end{array}$ & & & + & + aff. \\
$\begin{array}{l}\text { Primelephas aff. gomphotheroides } \\
\text { Stegotetrabelodon sp. }\end{array}$ & + & & & \\
$\begin{array}{l}\text { Elephantidae stegomorph indet. } \\
\text { Stegodon kaisensis 'warwire' }\end{array}$ & + & + & \\
Stegodon kaisensis 'nkondo' & + & + & & \\
Anancus kenyensis 'petrochii' & & & & \\
Anancus kenyensis 'kenyensis & + & + & & \\
\hline
\end{tabular}

grassland. But in the mosaic of these environments, there are several important differences which show a progressively humid trend from KT to KL to KB. For example, the fish and aquatic bird diversity in $\mathrm{KB}$ is greater than in the other sites. The same applies to the frequency of occurrence of aquatic reptiles and Hippopotamidae. Among crocodiles, Euthecodon cf. nitriae, basically an ichthyophage, is very well represented from KB and KL, but is unknown from KT. Among rhinocerotids, the grazer Ceratotherium praecox from $\mathrm{KT}$ and $\mathrm{KL}$ is unknown from $\mathrm{KB}$, which yielded the folivorous Diceros. The diverse faunas indicate a closed environment for $\mathrm{KB}$, a more open environment for $\mathrm{KL}$ and a still more open one for the KT hominid sites.

These observations are confirmed by biogeochemical analysis of the tooth enamel of the herbivores (Bocherens et al., 1996). To date about 75 fragments of tooth enamel from 15 species have been treated. The ${ }^{13} \mathrm{C}$ means are higher in $\mathrm{KT}(-0,1 \pm 1,9)$ and decrease from $\mathrm{KL}(-2,0 \pm 2,1)$ to $\mathrm{KB}(-2,9 \pm 3,2)$ (Bocherens et al., submitted).

This independent approach confirms the opening up of the environment in the period from the MioPliocene boundary (KB), through KL (5-4 Mya), to KT around 3.5-3.0 Mya.

All these preliminary results indicate that the Chadian faunas between 6 and 3 Mya are critically important to our understanding of the environmental evolution of early hominids. Already Chadian australopithecines show that the hominid story is pan-African at least until 3.5 Mya.

\section{Acknowledgments}

We thank the Chad authorities (Ministère de l'Education Nationale de l'Enseignement Supérieur et de la Recherche). We extend gratitude for their support to the French Ministères de l'Enseignement Supérieur, de la Recherche et de la Technologie (CNRS and Université de Poitiers) and Affaires Etrangères (Coopération: MCAC N'Djaména), to the Région Poitou-Charente, Département de la Vienne, Groupe Elf, and the Association pour le Prix scientifique Philip Morris, and also to the Armée française and all the soldiers of MAM and to Epervier, which, by their logistical support, have contributed with the members of MPFT to successful field programs. We are most grateful to Ghislaine Florent for administrative guidance of MPFT and to Sabine Riffaut for draughting the drawings.

\section{References}

Beden, M. (1985). Les Proboscidiens des grands gisements à Hominidés Plio-Pléistocènes d'Afrique Orientale. In: l'Environnement des Hominidés au Plio-Pléistocène, pp. 21-44. Fondation Singer-Polignac, Masson ed. Paris. Bocherens, H., Koch, P.L., Mariotti, A., Geraads, D. \& Jaeger, J.J. (1996). Isotopic biogeochemistry $\left({ }^{13} \mathrm{C},{ }^{18} \mathrm{O}\right)$ of 
mammal enamel from African Pleistocene hominid sites: implications for the preservation of paleoclimatic isotopic signals. Palaios, 11, 306-18.

Brunet, M., Beauvilain, A., Coppens, Y., Heintz, E., Moutaye, A.H.E. \& Pilbeam. D. (1995). The first australopithecine 2,500 kilometers west of the Rift Valley (Chad). Nature, 378, 273-75.

Brunet, M., Beauvilain, A., Coppens, Y., Heintz, E., Moutaye, A.H.E. \& Pilbeam, D. (1996). Australopithecus bahrelghazali, une nouvelle espèce d'Hominidé ancien de la région de Koro Toro (Tchad). Comptes Rendus de l’ Académie des Sciences, Paris, 322, 907-13.

Brunet, M., Beauvilain, A., Geraads, D., Guy, F., Kasser, M., Mackaye, H.T., MacLatchy, L., Mouchelin, G., Sudre, J., \& Vignaud, P. (1997). Tchad: un nouveau site à Hominidés Pliocène. Comptes Rendus de l'Académie des Sciences, Paris, 324, 341-45.

Brunet, M., Beauvilain, A., Geraads, D., Guy, F., Kasser, M., Mackaye, H.T., MacLatchy, L., Mouchelin, G., Sudre, J. \&Vignaud, P. (1998). Tchad: découverte d'une faune de Mammifères du Pliocène inférieur. Comptes Rendus de l'Académie des Sciences, Paris, 326, 153-58.

Cooke, H.B.S. (1985). Plio-Pleistocene Suidae in relation to African Hominid deposits. In: l'Environnement des Hominidés au Plio-Pléistocène, pp. 101-117. Fondation Singer-Polignac, Masson ed., Paris.

Tassy, P. (1994). Les proboscidiens (Mammalia) fossiles du Rift Occidental, Ouganda. In: Geology and Palaeobiology of the Albertine Rift Valley, Uganda-Zaire, eds B. Senut \& M. Pickford, Vol.II: Palaeobiology, pp. 217-57. CIFEG Occasional Publication, 1994/29, Orléans. 


\section{Frederick E. Grine}

Departments of Anthropology and Anatomical Sciences

State University of New York

Stony Brook, NY 11794-4364 USA

Keywords: Cranium, Homo habilis, Homo erectus, Swartkrans, Sterkfontein, Taxonomy

\section{Implications of Morphological Diversity in Early Homo Crania from Eastern and Southern Africa}

\begin{abstract}
Morphometric analyses of crania from the African PlloPleistocene have intimated that the closest phenetic affinities of specimens from the South African sites of Sterkfontein (Stw 53) and Swartkrans (SK 847) lie with fossils from eastern Africa that are attributed to Homo habilis sensu stricto, but that the South African crania may represent a species not sampled in eastern Africa. Examination of a number of discrete morphological features reveals that SK 847 differs from $H$. erectus crania in a number of traits that are distinctive for that species, and that SK 847 is not unusual among $H$. habilis specimens. However, SK 847 and Stw 53 differ from East African H. habilis crania in several features, which may reinforce suggestions of their taxonomic distinctiveness.
\end{abstract}

\section{Introduction}

The species of Homo that can be recognized among the Late Pliocene and Early Pleistocene fossils of Africa, and the attribution of individual specimens to these taxa are major points of inquiry in hominid palaeontology (Stringer, 1986; Chamberlain, 1987, 1989; Lieberman et al., 1988; Groves, 1989; Rightmire, 1990, 1993; Wood, 1991, 1992, 1993; Tobias, 1991; Miller, 1991, 1993; Grine et al., 1993, 1996). Fossils from between about 2.5 and $1.8 \mathrm{Myr}$ have been referred to a variety of species, including $H$. habilis, $H$. rudolfensis, $H$. ergaster and $H$. erectus. While it has been cogently argued that our genus was quite speciose in the Plio-Pleistocene, there is a lack of consensus concerning the number of taxa and their hypodigms.

Recent morphometric analyses (Grine et al., 1993, 1996) have provided evidence of a close phenetic relationship between Homo crania from Swartkrans Member 1 (SK 847) and Sterkfontein Member 5 (Stw 53), and emphasized their differences from crania attributed to early $H$. erectus, or H. ergaster (KNM-ER 3733 and KNM-WT 15000). In addition, Grine et al. (1996) concluded that at least two, and possibly three taxonomic sets exist within the hypodigm of Homo habilis sensu lato (i.e., KNM-ER 1813, KNMER 1470, OH 24, SK 847 and Stw 53). All of these specimens are clearly distinct from H. erectus crania, but there are quite marked morphometric differences among them. Most notably, KNM-ER 1470 differs from the other four principally by virtue of its size, whereas there are significant shape differences between the smaller specimens from South Africa (SK 847 and Stw 53) and those from East Africa (OH 24 and KNM-ER 1813). Although the conclusions of Grine et al. $(1993,1996)$ differ from those of Walker (1981) and Clarke (1985), who drew attention to what they regarded as the striking overall similarity of SK 847 and the KNM-ER $3733 \mathrm{H}$. erectus cranium, they tend to corroborate the findings of Bilsborough \& Wood (1988) on the affinities of SK 847. Their morphometric study led them to align SK 847 with the smaller early Homo crania from eastern Africa (KNM-ER 1813 and OH 24), although similarities with KNM-ER 1470 were also noted. In particular, they found that SK 847 differed from H. erectus (e.g., KNM-ER 3733), and that while it resembled H. habilis crania, the similarities were not consistent. Their 
results suggested that SK 847 possesses a "distinct pattern of facial morphology."

The taxonomic affinities of SK 847 have been the subject of numerous and varied opinions. The specimen was recovered in several pieces of Swartkrans Member 1 'Hanging Remnant' breccia in 1949 and 1950 by R. Broom and J.T. Robinson. The three largest fragments comprised a maxilla (originally catalogued as SK 80), part of the left side of the face (SK 847), and part of a left temporal (SK 846b). Robinson (1953) observed that the maxilla differed from Paranthropus homologues in subnasal morphology, and attributed it to Telanthropus capensis, a taxon subsequently considered a subjective junior synonym of $H$. erectus (Robinson, 1961). Subsequently, the facial and temporal pieces were found to join with the SK 80 maxilla to form a partial cranium, SK 847, that Clarke et al. (1970) confirmed to be a specimen of early Homo. They noted that although SK 847 has "some resemblances" to $H$. erectus, it is preferable to treat the fossil as Homo sp. indet.

Clarke \& Howell (1972) subsequently drew favorable comparisons with OH 16 in the morphology of its supraorbital torus and supratoral sulcus, and with $\mathrm{OH} 24$ in its degree of post-orbital constriction, although they noted differences between SK 847 and OH 24 in the supra-orbital tori and nasal bones. Clarke \& Howell (1972: 333) concluded that SK 847 and "the other 'Telanthropus' fossils may ultimately prove to be conspecific with $\mathrm{OH}$ 13," which was attributed to H. habilis. Indeed, Leakey et al. (1964: 9) had earlier noted that "the specimens originally described by Broom and Robinson as Telanthropus capensis ... may well prove, on closer comparative investigation, to belong to Homo habilis." Oakley \& Campbell (1964) were quick to comment on the nomenclatural significance of this possibility.

Although Groves \& Mazak (1975) regarded the Swartkrans fossils as Homo incertae sedis, they noted similarities in dental measurements with $H$. ergaster specimens, and concluded that no important differences in dental morphology or mandibular structure "are apparent when $H$. ergaster is compared to the so-called 'Telanthropus' from Swartkrans. The two could therefore belong to the same taxon..." (1975: 244-245). Of course, the hypodigm of $H$. ergaster established by them was comprised solely by mandibles with the exception of KNM-ER 1805, which they suggested "seems" to belong to that taxon. Clarke (1977: 289) noted that "there are certain points that would lend support to the placement of SK 847 and the SK 45 [mandible] in the taxon Homo habilis." However, he also opined that despite the differences in temporal bone morphology and general cranial robusticity between SK 847 and specimens of $H$. erectus, SK 847 could still be attributed to that species. Clarke (1977) did not consider H. ergaster to have been established as a valid taxon.

Howell (1978) attributed SK 847, together with SK 27, SK 45 and SK 2635 to H. habilis. He also noted that the craniofacial morphology and teeth of Stw 53 resemble other specimens, including SK 847, attributed by him to that species. He allocated SK 15 and SK 18 from Swartkrans Member 2 to $H$. erectus. Tobias (1978) noted similarities in the teeth and maxillae of SK 847 and Stw 53, and differences between them in supraorbital morphology, with Stw 53 resembling some H. habilis crania (i.e., OH 16 and $\mathrm{OH} 24$ ), and SK 847 being more reminiscent of H. erectus. Tobias (1991) later referred Stw 53 and SK 847 to $H$. habilis and $H$. erectus, respectively.

As noted above, Walker (1981) drew attention to the overall similarity between KNM-ER 3733 (which he attributed to $H$. erectus) and SK 847, an observation with which Clarke (1985) concurred. Later, however, Clarke $(1990,1994)$ assigned all of the Swartkrans Homo fossils and some East African fossils commonly attributed to H. erectus (i.e., OH 9, KNM-ER 3733, KNM-ER 3883, KNM-ER 992 and KNM-ER 730), to H. leakeyi Heberer, 1963. Heberer (1963) designated OH 9 the type of that taxon, and while Wood $(1984,1994)$ and Stringer $(1984,1986)$, amongst others, have questioned the allocation of the earlier African fossils (e.g., KNM-ER 3733, KNM-ER 3883 and KNM-ER 992) to H. erectus, there has been some unanimity that $\mathrm{OH} 9$ does belong to that species.

Rightmire (1990) referred the SK 15 mandible from Swartkrans Member 2 to H. erectus, but was more cautious about the assignment of SK 847. Most recently, Kimbel et al. (1997: 239) assigned the SK 847 cranium to $H$. erectus, observing that it "exhibits more derived states in the degree of nasal 
bridge projection, the conformation of the supraorbital torus and the basal morphology of the temporal bone than does H. habilis." They included KNM-ER 1805, KNM-ER 1813, OH 13, OH 16, OH 24, OH 62 and Stw 53 in the hypodigm of the latter species.

Wood (1991, 1992) has accepted OH 62 from Bed I, Olduvai Gorge, as a representative of Homo habilis sensu stricto. This is presumably because of the specimen's geographic and stratigraphic context, as all of the other 'gracile' fossils from Beds I and II comprise part of his hypodigm of that species. However, as pointed out by Wood (1991), the initial attribution of OH 62 to H. habilis (Johanson et al., 1987) was largely circuitous, since in nearly every comparison that was made with Homo habilis, Stw 53 was the principal focus of similarity. The latter has yet to be subjected to a detailed comparative analysis relating to its own taxonomic affinities.

In the initial description of Stw 53, Hughes \& Tobias (1977: 312) cited five features that were thought to provide "convincing evidence that [it] belonged to the genus Homo and either to H. habilis or to a form closely related (H. aff. habilis)." These features included temporal line configuration, brow ridge thickness and protuberance, and subnasal facial morphology. Tobias $(1978,1980)$ also drew attention to the helicoidal wear plane of Stw 53, which he likened to $\mathrm{OH} \mathrm{13,} \mathrm{OH} 16$ and $\mathrm{OH} 24$, and which Wallace (1972) had noted in SK 45 and SK 847. The taxonomic validity of this trait, however, has been disputed (Ward, 1981; Smith, 1986). A reconstruction of Stw 53 was undertaken by Clarke (1985), who noted it to be "almost identical" to $\mathrm{OH} 24$, which he had also reconstructed. On this basis he attributed Stw 53 to H. habilis. Tobias (1991) accepted Stw 53 as a specimen of H. habilis, and this appears to be based primarily on its resemblances to $\mathrm{OH} 24$ in lateral craniograms, occipital condyle size, superior facial height, palatal and dental arcade breadth, the nasal index, and the helicoidal plane of wear.

In sum, controversy has surrounded the specific attribution of SK 847, and it has been suggested recently that SK 847 and Stw 53 may represent a species of early Homo that is not known in eastern Africa (Grine et al., 1993, 1996). Because Grine et al. (1993, 1996) concluded that SK 847 has closest affinities with $H$. habilis, it is necessary to ascertain the effect that inclusion of SK 847 in the hypodigm of that species has on its degree of morphological heterogeneity. It is also necessary to examine SK 847 with reference to those features that are considered to be distinctive of $H$. erectus.

\section{Cranial variability in Homo habilis sensu stricto}

In their cladistic analysis of early hominid relationships, Strait et al. (1997) observed that Australopithecus africanus and Homo habilis presented the greatest morphological variability among the species considered by them. The latter evinced variable states in 11 of the 60 characters coded by Strait et al. (1997). Their H. habilis hypodigm included the SK 847 and SK 27 crania from Swartkrans Member 1, as well as the SK 15 and 45 mandibles from Swartkrans Members 1 and 2. It also included Stw 53 from Sterkfontein Member 5, Sts 19 from Sterkfontein, following Kimbel \& Rak (1993), and a number of eastern African specimens (e.g., OH 7, 13, 24, 62; KNM-ER 1805, 1813) attributed by Wood (1992) to H. habilis sensu stricto.

Does the inclusion of SK 847 (and/or the inclusion of Stw 53) in H. habilis account for the level of intraspecific variability observed by Strait et al. (1997)? The character state distribution for the 11 variable features in $H$. habilis is depicted in Fig. 1. In addition to the crania and mandibles included by Strait et al. (1997) in H. habilis, this figure incorporates the AL 666-1 palate, which has been attributed to that species by Kimbel et al. (1997). It is apparent that SK 847 is not responsible for the variability in the H. habilis hypodigm. There are differences between SK 847 and Stw 53 in two or possibly three characters, but this is no greater than that between $\mathrm{OH} 24$ and $\mathrm{OH} \mathrm{62,} \mathrm{and} \mathrm{it} \mathrm{is} \mathrm{notably} \mathrm{less} \mathrm{than} \mathrm{that}$ between KNM-ER 1805 and either KNM-ER 1813 or OH 24. The SK 847 cranium exhibits derived (i.e., $H$. erectus-like) morphology in perhaps six of eight characters, but in each instance there are other specimens in the hypodigm that display the same derived state, and both OH 24 and KNM-ER 1813 display about the same proportion of apomorphic to plesiomorphic states as SK 847. It is perhaps 
noteworthy that the single variable mandibular character varies within the Swartkrans sample; SK 45 (Member 1) displays the primitive state, while SK 15 (Member 2) evinces the derived state in common with the Olduvai Gorge jaws.

\section{Distinctive features of Homo erectus}

Tobias (1978) and Kimbel et al. (1997) have alluded to differences in supraorbital morphology between Stw 53 and SK 847, with the former resembling H. habilis and the latter resembling H. erectus. One diagnostic feature that distinguishes the supraorbital torus of $H$. erectus from that of earlier species of Homo is its vertical thickness (Rightmire, 1990). This dimension in SK 847 is compared with those for $H$. habilis, $H$. rudolfensis and $H$. erectus crania in Fig. 2. H. habilis brows tend to be thinner than those of H. erectus. The supraorbital torus of Stw 53 is noticeably thinner than that of SK 847 but, by the same token, it is thinner than that of any other hominid cranium on record. The SK 847 torus falls comfortably within the observed H. habilis sample range, and below the lower end of the H. erectus (and H. rudolfensis) range.

Another feature that clearly distinguishes $H$. erectus from earlier species of the genus is its wide pyriform aperture (Fig. 3). Stw 53 and SK 847 are comparable to one another in this dimension, and these dimensions fall within the lower part of the observed $H$. habilis sample range. The SK 847 and Stw 53 noses are particularly distinct from the wider apertures of penecontemporaneous African H. erectus crania.

\section{Character State Distribution Among Putative Homo habilis Specimens}

\begin{tabular}{|c|c|c|c|c|c|c|c|c|}
\hline \multicolumn{9}{|c|}{ CRANIAL } \\
\hline character \# & AL 666-1 & $\mathrm{OH} 24$ & $\mathrm{OH} 62$ & ER 1805 & ER 1813 & Sts 19 & Stw 53 & SK 847 \\
\hline 4 & absent & absent & present & present & absent & & present & absent \\
\hline 7 & stepped & stepped & smooth & smooth & stepped & & smooth & stepped \\
\hline 12 & deep & shallow & deep & ? shallow & shallow & & deep & deep \\
\hline 19 & & weak & & & weak & & moderate & moderate \\
\hline 22 & & absent & & present & absent & & absent & absent \\
\hline 25 & & no & & yes & & & no & \\
\hline 33 & & small / fused & & small / fused & small / fused & inter / fused & small / fused & small/fused \\
\hline 35 & & lateral & & lateral & lateral & medial & c. lateral & ? medial \\
\hline 36 & & small & & small & smali & moderate & small & \\
\hline 41 & & posterior? & & anterior & at line & at line & at line & \\
\hline \multicolumn{9}{|c|}{ MANDIBULAR } \\
\hline character \# & $\mathrm{OH} 7$ & $\mathrm{OH} 13$ & & SK 15 & SK 45 & & & \\
\hline 48 & narrow & narrow & & narrow & wide & & & \\
\hline
\end{tabular}

Figure 1. The character numbers are the same as those employed by Strait et al. (1997). Bold italics indicate the derived state shared with $H$. erectus. Character $4=$ anterior pillars; $7=$ nasal cavity entrance; $12=$ anterior palatal depth; $19=$ anteromedial incursion of the superior temporal lines; $22=$ asterionic notch; $25=$ lateral inflation of mastoid process relative to the supramastoid crest; $33=$ size and position of the postglenoid process; $35=$ mediolateral position of the external auditory meatus; $36=$ vaginal process of the tympanic; $41=$ position of the foramen magnum relative to the bitympanic line; $48=$ mandibular extramolar sulcus. 
As noted by Kimbel et al. (1997: 248), "the palates usually attributed to $H$. erectus are deeper than those of H. habilis..." They also illustrated a striking separation of $H$. habilis and $H$. erectus palates using a bivariate plot of palatal depth against a palatal shape (breadth vs. length) index (Kimbel et al.,1997: fig. 7). Because palatal length cannot be determined for SK 847, that specimen was not incorporated in their illustration. However, it is possible to determine palatal breadth for SK 847 (Clarke, 1977). A bivariate plot that employs palatal breadth and depth (Fig. 4) illustrates a clear separation in depth between $H$. erectus and East African H. habilis specimens. The SK 847 and Stw 53 palates are shallow (13.0 and $13.5 \mathrm{~mm}$ respectively); these values fall within the observed $H$. habilis sample range and well below the two $H$. erectus (Sangiran 4 and KNM-ER 3733) values. Moreover, while the narrowest $H$. erectus (KNM-ER 3733) and H. habilis (KNM-ER 1813, OH 24) palates are of similar breadth, Stw 53 and especially SK 847 are noticeably the narrowest early Homo specimens on record. Thus, in palatal breadth and depth, the South African crania are clearly distinct from $H$. erectus, and they are distinguishable even from East African H. habilis homologues (Fig. 4).

\section{Discussion}

Consideration of a number of morphological variables reveals that the Swartkrans Member 1 cranium (SK 847) is not unusual among specimens from eastern and southern Africa that have been attributed to Homo habilis sensu stricto by other workers (Wood, 1991; Tobias, 1991; Kimbel et al.,

\begin{tabular}{|c|c|c|c|c|c|c|}
\hline \multicolumn{7}{|c|}{ Vertical Thickness of Supraorbital Torus } \\
\hline South African Homo & Homo ha & bilis & Homo rudc & Ifensis & Homo erec & \\
\hline $\begin{array}{ll}\text { SK } 847 & 7.2 \\
\text { Stw } 53 & 4.0\end{array}$ & $\begin{array}{l}\text { ER } 1813 \\
\text { OH } 24 \\
\text { OH } 16\end{array}$ & $\begin{array}{l}9.5 \\
6.0 \\
8.3\end{array}$ & $\begin{array}{l}\text { ER } 1470 \\
\text { ER } 3632\end{array}$ & $\begin{array}{r}11.5 \\
8.0\end{array}$ & $\begin{array}{l}\text { ER } 3733 \\
\text { ER } 3883 \\
\text { WT } 15000 \\
\text { Danakil UA31 } \\
\text { Sangiran } 17 \\
\text { Sangiran } 10 \\
\text { Zhou I } \\
\text { Zhou III } \\
\text { Zhou X } \\
\text { Zhou XI } \\
\text { Zhou XII }\end{array}$ & $\begin{array}{c}8.5 \\
13.0 \\
10.4 \\
17.0 \\
18.0 \\
19.0 \\
17.4 \\
12.1 \\
16.5 \\
13.6 \\
14.6\end{array}$ \\
\hline
\end{tabular}

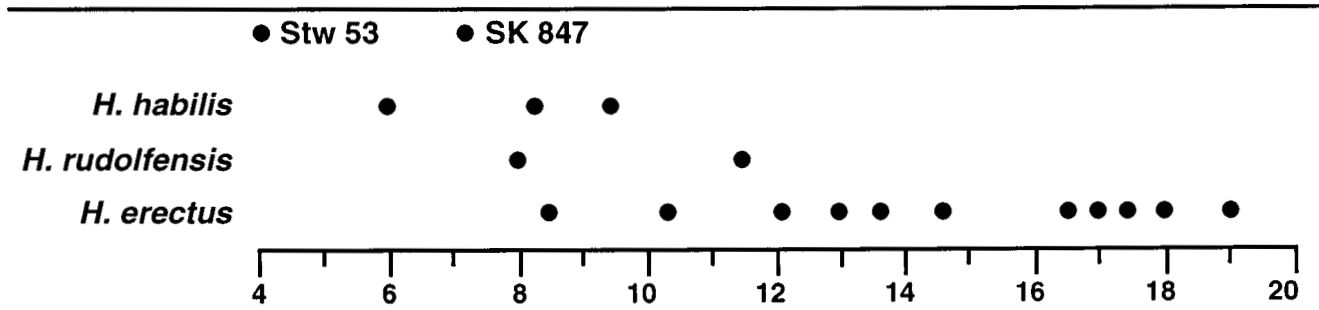

Figure 2. Data are from Weidenreich (1943; table IIB) for the Zhoukoudian crania; Jacob (1973) for Sangiran 10; Wood (1991; reference table 8, variable 62) for KNM-ER 1470, 1813, 3732, 3733, 3883, Sangiran 17; Tobias (1991) for OH 16, OH 24, SK 847, Stw 53; Walker \& Leakey (1993: 75) for KNM-WT 15000; Abbate et al. (1998: 460) for Danakil UA 31. 


\section{Pyriform Aperture Width}

\begin{tabular}{cccccccc}
\multicolumn{2}{c}{ South African Homo } & \multicolumn{2}{c}{ Homo habilis } & Homo rudolfensis & \multicolumn{2}{c}{ Homo erectus } \\
\hline SK 847 23.2 & ER 1805 & 27.6 & ER 1470 & 26.0 & ER 3733 & 34.3 \\
Stw 53 24.0 & ER 1813 & 22.8 & & & WT 15000 & 34.7 \\
& & AL 666-1 & 24.0 & & & Sangiran 4 & 32.4 \\
& & OH 24 & 23.4 & & & Sangiran 17 & 32.0 \\
& & OH 62 & 28.0 & & & \\
\hline
\end{tabular}

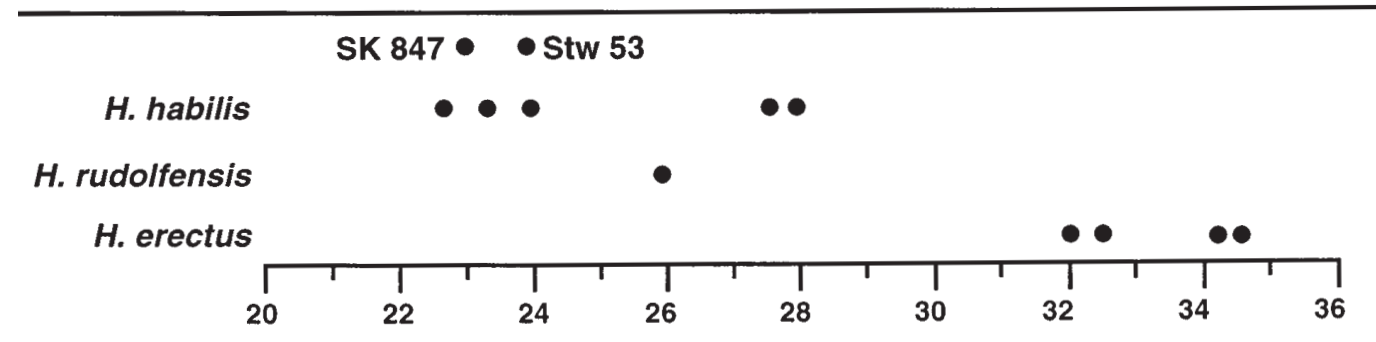

Figure 3. Data are from casts of Sangiran 4 and 17; Walker \& Leakey (1993: 65) for KNM-WT 15000; Kimbel et al. (1997: 240) for AL 666-1; Kimbel (pers. comm) for all other specimens.

1997). Furthermore, SK 847 is clearly distinguished from $H$. erectus homologues in several features that are distinctive for that species in relation to other early Homo taxa. These morphological and morphometric characters lend support to conclusions reached by Grine et al. $(1993,1996)$ and by earlier studies (e.g., Howell, 1978; Bilsborough \& Wood, 1988) that the affinities of SK 847 are with H. habilis rather than with $H$. erectus. These characters also tend to support suggestions (Grine et al., 1993, 1996) that the closest affinities of SK 847 are with the Sterkfontein Member 5 cranium (Stw 53), which itself has been attributed to $H$. habilis.

However, SK 847 and Stw 53 differ from other H. habilis crania in several features (e.g., they share a primitively moderate incursion of the superior temporal lines, comparatively thin supraorbital tori, and very narrow palates). This may reinforce suggestions that these South African crania are taxonomically distinct from penecontemporaneous congeners in East Africa. Moreover, if Homo specimens from the terminal Pliocene and early Pleistocene of eastern and southern Africa are attributable to more than one species, it is reasonable to question the taxonomic homogeneity of the Homo fossils from Swartkrans. This sample derives from at least two (and possibly four) distinct lithostratigraphic units. Whereas the Paranthropus fossils from the different Swartkrans members appear to represent a single species (Grine, 1993), the Swartkrans Homo remains have yet to be examined in this light. Previous studies have noted differences in the mandibular corpora of SK 15 and SK 45 (Clarke, 1977; Strait et al., 1997), but these specimens have not been subjected to detailed study. The taxonomic affinities of the early Homo fossils from South Africa await a comprehensive comparative analysis of all relevant morphological characters, including details of dental morphology (for which the sample is considerably larger).

\section{Summary}

The results of this study lend support to suggestions that the affinities of SK 847 are with Homo habilis sensu stricto rather than $H$. erectus, and that there may be a distinction not only among early Homo crania from eastern Africa (Wood, 1992, 1993), but also between South and East African 


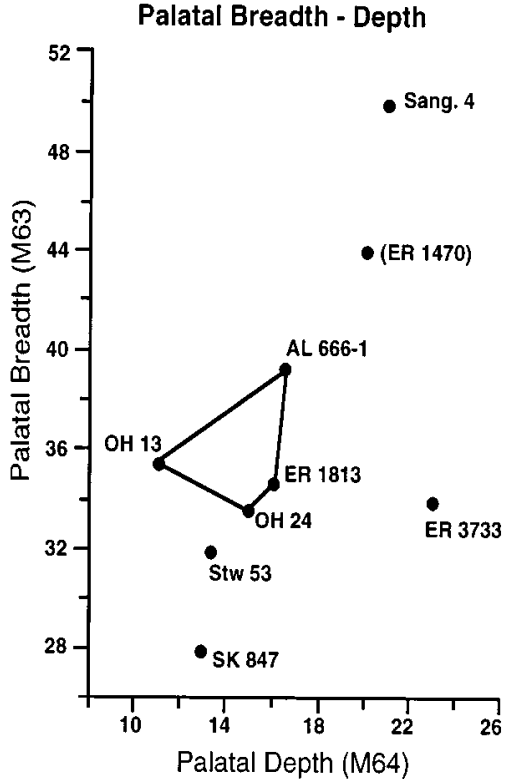

Figure 4. Data for Palatal Breadth (Martin number 63) are from a cast of KNM-ER 1470 (estimated); Clarke (1977) for SK 847; Tobias (1991) for OH 13, Stw 53; Walker \& Leakey (1993) for KNM-ER 3733; Kimbel et al. (1997) for KNM-ER 1813, AL 666-1, Sangiran 4 ; and average of the values recorded by Tobias (1991) and Kimbel et al. (1997) for OH 24. Data for Palatal Depth (Martin number 64) are from a cast of KNM-ER 1470 (estimated using ectomolare opposite $\mathrm{M}^{1}$ as a guide to alveolar height); Clarke (1977) for SK 847; Kimbel (pers. comm.) for Stw 53, KNM-ER 1813, OH 24, KNM-ER 3733, Sangiran 4; Tobias (1991) for OH 13; Kimbel et al. (1997) for AL-666-1.

specimens that have been attributed to H. habilis (Grine et al., 1993, 1996). This study has provided some additional evidence for taxonomic diversity within the sample of Homo crania from the PlioPleistocene of eastern and southern Africa.

\section{Acknowledgements}

I thank B.A. Wood and P.V. Tobias for the invitation to participate in Colloquium 12 of the Dual Congress, and the Organizing Committee and Sponsoring Bodies of the Dual Congress, and the Holt Foundation for financial support. I thank W.H. Kimbel for sharing data on early Homo fossils, and J.F. Thackeray (Transvaal Museum), P.V. Tobias and L. Berger (University of the Witwatersrand), and M. Leakey (Kenya National Museum) for permission to examine the fossils in their care and for generous hospitality. I thank L. Betti-Nash for the illustrations.

\section{References}

Abbate, E., Albianelli, A., Azzaroli, A., Benvenuti, M., Tesfamariam, B., Bruni, P., Cipriani, N., Clarke, R.J., Ficcarelli, G., Macchiarelli, R., Napoleone, G., Papini, M., Rook, L., Sagri, M., Tecle, T.M., Torre, D. \& Villa, I. (1998). A one-million-year-old Homo cranium from the Danakil (Afar) Depression of Eritrea. Nature, 393, 458-60.

Bilsborough, A. \& Wood, B.A. (1988). Cranial morphometry of early hominids: facial region. Am. J. Phys. Anthrop., 76, 61-86.

Chamberlain, A.T. (1987). A taxonomic review and phylogenetic analysis of Homo habilis. Unpubl. Ph.D. Thesis, University of Liverpool.

Chamberlain, A.T. (1989). Variations within Homo habilis. In: Hominidae. Proc. 2nd Int. Cong. Human Paleont., ed. G. Giacobini, pp. 175-81. Milan: Jaca Books.

Clarke, R.J. (1977). The cranium of the Swartkrans hominid SK 847 and its relevance to human origins. Unpubl. Ph.D. Thesis, University of the Witwatersrand, Johannesburg.

Clarke, R.J. (1985). Australopithecus and early Homo in southern Africa. In: Ancestors: the Hard Evidence, ed. E. Delson, pp. 171-77. New York: Alan R. Liss. 
Clarke, R.J. (1990). The Ndutu cranium and the origin of Homo sapiens. J. Human Evol., 19, 699-736.

Clarke, R.J. (1994). The significance of the Swartkrans Homo to the Homo erectus problem. Cour. Forschungsinstitut Senckenberg, 171, 185-93.

Clarke, R.J. \& Howell, F.C. (1972). Affinities of the Swartkrans SK 847 hominid cranium. Am. J. Phys. Anthrop., 37, 319-36.

Clarke, R.J., Howell, F.C. \& Brain, C.K. (1970). More evidence of an advanced hominid at Swartkrans. Nature, 225 , 1219-22.

Grine, F.E. (1993). Description and preliminary analysis of new hominid craniodental fossils from the Swartkrans Formation. In: Swartkrans: a Cave's Chronicle of Early Man, ed. C.K. Brain, pp. 75-116. Transvaal Museum Monograph 8.

Grine, F.E. \& Strait, D.S. (1994). New hominid fossils from Member 1 "Hanging Remnant", Swartkrans Formation, South Africa. J. Human Evol., 26, 57-75.

Grine, F.E., Demes, B., Jungers, W.L.\& Cole, T.M. (1993). Taxonomic affinity of the early Homo cranium from Swartkrans, South Africa. Am. J. Phys. Anthrop., 92, 411-26.

Grine, F.E., Jungers, W.L. \& Schultz, J. (1996). Phenetic affinities among early Homo crania from East and South Africa. J. Human Evol., 30, 189-225.

Groves, C.P. \& Mazak, V. (1975). An approach to the taxonomy of the Hominidae: gracile Villafranchian hominids of Africa. Caspos Mineral. Geol., 20, 225-47.

Heberer, G. (1963). Über einen neuen archanthropinen Typus aus der Oldoway-Schlucht. Z. Morph. Anthrop., 53, 17177.

Howell, F.C. (1978). Hominidae. In: Evolution of African Mammals, ed. V.J. Maglio \& H.B.S. Cooke, pp. $154-248$. Cambridge (Mass.): Harvard University Press.

Hughes, A.R. \& Tobias, P.V. (1977). A fossil skull probably of the genus Homo from Sterkfontein, Transvaal. Nature, $265,310-12$.

Jacob, T. (1973). Palaeoanthropological discoveries in Indonesia with special reference to the finds of the last two decades. J. Human Evol., 2, 473-85.

Johanson, D.C., Masao, F.T., Eck, G.C., White, T.D., Walter, R.C., Kimbel, W.H., Asfaw, B., Manega, P., Ndessokia, P. \& Suwa, G. (1987). New partial skeleton of Homo habilis from Olduvai Gorge, Tanzania. Nature, 327, $205-08$.

Kimbel, W.H. \& Rak, Y (1993). The importance of species taxa in paleoanthropology and an argument for the phylogenetic concept of the species category. In: Species, Species Concepts, and Primate Evolution, ed. W.H. Kimbel \& L.B. Martin, pp. 461-85. New York: Plenum.

Kimbel, W.H., Johanson, D.C. \& Rak, Y. (1997). Systematic assessment of a maxilla of Homo from Hadar Ethiopia. Am. J. Phys. Anthrop., 103, 235-62.

Leakey, L.S.B., Tobias, P.V. \& Napier, J.R. (1964). A new species of the genus Homo from Olduvai Gorge. Nature, 202, 7-9.

Lieberman, D.E., Pilbeam, D.R. \& Wood, B.A. (1988). A probabilistic approach to the problem of sexual dimorphism in Homo habilis: a comparison of KNM-ER 1470 and KNM-ER 1813. J. Human Evol., 17, 503-12.

Miller, J.M.A. (1991). Does brain size variability provide evidence of multiple species in Homo habilis? Am. J. Phys. Anthrop., 84, 385-98.

Miller, J.M.A. (1994). Homo habilis: is the degree of craniofacial variation excessive? Am. J. Phys. Anthrop., suppl. $18,147$.

Oakley, K.P. \& Campbell, B.G. (1964). Newly described Olduvai hominid. Nature, 202, 732.

Rightmire, G.P. (1990). The Evolution of Homo erectus. Cambridge: Cambridge University Press.

Rightmire, G.P. (1993). Variation among early Homo crania from Olduvai Gorge and the Koobi Fora region. Am. J. Phys. Anthrop., 90, 1-33.

Robinson, J.T. (1953). Telanthropus and its phylogenetic significance. Am. J. Phys. Anthrop., 11, 445-501.

Robinson, J.T. (1961). The australopithecines and their bearing on the origin of Man and of stone tool making. S. Afr. J. Sci., 57, 3-16.

Smith, B.H. (1986). Development and evolution of the helicoidal plane of dental occlusion. Am. J. Phys. Anthrop., 69, 21-35.

Strait, D.S., Grine, F.E. \& Moniz, M.A. (1997). A reappraisal of early hominid phylogeny. J. Human Evol., $32,17-82$.

Stringer, C.B. (1984). The definition of Homo erectus and the existence of the species in Africa and Europe. Cour. Forschungsintitut Senckenberg, 69, 131-43. 
Stringer, C.B. (1986). The credibility of Homo habilis. In: Major Topics in Primate and Human Evolution, ed. B.A. Wood, L.B. Martin \& P. Andrews, pp. 266-94. New York: Alan R. Liss.

Tobias, P.V. (1978). The earliest Transvaal members of the genus Homo with another look at some problems of hominid taxonomy and systematics. Z. Morph. Anthrop., 69, 225-65.

Tobias, P.V. (1980). The natural history of the helicoidal occlusal plane and its evolution in early Homo. Am. J. Phys. Anthrop., 53, 173-87.

Tobias, P.V. (1991). The Skulls, Endocasts and Teeth of Homo habilis. Olduvai Gorge, Vol. 4. Cambridge: Cambridge Univ. Press.

Walker, A. (1981). The Koobi Fora hominids and their bearing on the origins of the genus Homo. In: Homo erectus: Papers in Honor of Davidson Black, ed. B.A. Sigmon \& J.S. Cybulski, pp. 193-215. Toronto: University of Toronto Press.

Walker, A. \& Leakey, R.E.F. (1993). The skull. In: The Nariokotome Homo erectus Skeleton, ed. A. Walker \& R.E.F. Leakey, pp. 63-94. Cambridge (Mass.): Harvard University Press.

Wallace, J.S. (1972). The dentition of the South African early hominids: a study of form and function. Unpubl. Ph.D. Thesis, University of the Witwatersrand, Johannesburg.

Ward, S.C. (1981). The role of axial molar angulation in mediating helicoidal wear in Miocene apes, Pliocene hominids, and early Homo. Am. J. Phys. Anthrop., 54, 288.

Weidenreich, F. (1943). The skull of Sinanthropus pekinensis; a comparative study on a primitive hominid skull. Palaeont. Sin., New Series D, 10, 1-484.

Wood, B.A. (1984). The origin of Homo erectus. Cour. Forschungsinstitut Senckenberg, 69, 99-111.

Wood, B.A. (1991). Hominid Cranial Remains. Koobi Fora Research Project, Vol. 4. Oxford: Clarendon Press.

Wood, B.A. (1992). Origin and evolution of the genus Homo. Nature, 355, 783-90.

Wood, B.A. (1993). Early Homo: how many species? In: Species, Species Concepts, and Primate Evolution, ed. W.H. Kimbel \& L.B. Martin, pp. 485-522. New York: Plenum.

Wood, B.A. (1994). Taxonomy and evolutionary relationships of Homo erectus. Cour. Forschungsinstitut Senckenberg, 171, 159-65. 


\section{Giorgio Manzi}

Dipartimento di Biologia Animale e dell'Uomo

Università di Roma "La Sapienza"

P. le Aldo Moro 5, I-00185

Roma (Italy).

Keywords: Homo, Paleogeography, evolutionary scenarios

\section{The Earliest Diffusion of the Genus Homo Toward Asia and Europe: a Brief Overview}

\begin{abstract}
During the last decade a growing amount of evidence has focused the attention of paleoanthropologists on the earliest diffusion of the genus Homo into Eurasia. Sub-Saharan Africa is the most probable area where our ancestry emerged: the problem is 'when' 'why', and which hominid/s diffused into the rest of the continent as well as toward Asia and Europe. New sites at the Pliocene/Pleistocene boundary and re-dating of known localities (particularly in Asia), together with new fossil evidence and reappraisal of former discoveries (everywhere in Eurasia) call for a global reconsideration of the entire issue. This should involve not only dating techniques, paleoenvironmental analyses, and skeletal morphology, but also the extant paradigms regarding biology, taxonomy, phylogeny, behaviour, and adaptive strategies of our genus.
\end{abstract}

\section{Introduction}

In the Scienza Nuova, while trying to find invariable rules for the interpretation of human history, Giovanbattista Vico, well-known Italian philosopher (1668-1744), claimed that it is characterised by a turnover of facts and conditions according to his theory of the "repetition of historical phenomena". The history of human paleontology seems to be no exception. Scientific and popular interest has been discontinuously attracted by different stages of our evolution. As indicated in the Vico theory, there is a precise relationship between a declining interest in one topic and a growing attraction of the next - in such a way that the cycle is repeated each time at a deeper level of analysis and comprehension.

For example, following a period of enthusiasm during the 1970s for the earliest hominids and their origins (e.g., Johanson \& White, 1979), the last fifteen years have seen a deep involvement of many scholars in the debate on the appearance and dispersal of modern humans late in the Pleistocene (see, e.g., Manzi et al., 1994). Recently, the general focus has been drawn once more to the recognition of the original stem of the Hominidae early in the Pliocene (e.g., White et al., 1994; Leakey et al., 1995).

An issue chronologically intermediate between these two extremes that has periodically held the attention of paleoanthropologists relates to the origin of the genus Homo and its earliest 'world-wide' diffusion, with the obvious exclusion of Australia, northern Eurasia, and the Americas. One century after the first discovery of an 'ape-man' in Java - echoing the hypothetical existence of Pithecanthropus alalus predicted by Ernst Haeckel - the spotlight of our enquiry into human evolution has focused once more upon early Homo in Africa, as well as on the earlier inhabitants of Eurasia, their phenotype, their biology and ecology, and their routes of diffusion (e.g., Tattersall, 1997; Wood \& Turner, 1995).

This is not simply a matter of fashion, or an intrinsic process entirely ruled by Vico's theory. Such a turn-over of scientific and popular interest about different stages of human evolution is also driven by the emergence of new and sometimes unexpected discoveries.

\section{Atapuerca and Ceprano}

In 1995, Roebroeks and Van Kolfschoten conclusively published in the proceedings of the ESF 
workshop (Tautavel, 1993) their claims concerning the earliest occupation of Europe. In that volume, the so-called European 'short chronology' (Dennel, 1983; Roberts et al., 1994; Roebroeks \& van Kolfschoten, 1994) - versus the 'long chronology' (e.g., de Lumley et al., 1988; Peretto et al., 1998; Rolland, 1992) or even the 'very long' chronologies' (e.g., Bonifay \& Vandermeersch, 1991; Gibert, 1992 ) - is approached dialectically from various thematic and regional perspectives. It is conceded that "the question of the earliest occupation of Eurasia is far from solved and highly controversial" (from the introduction, p. 4), but a certain consensus is reported that the earliest permanent presence of humans in Europe is not firmly attested earlier than about 500-600 ka.

However recent and unambiguous discoveries of human remains in both Italy (Ceprano) and Spain (Atapuerca-TD6) refute that claim. The European short chronology hypothesis has been shortly reconsidered in this light, and different timings in the respective occupation of southern and northcentral European regions have been assumed (Dennel \& Roebroeks, 1996).

The calvaria from Ceprano in south-central Italy could be the most ancient human fossil found so far in Europe, according to the interpretation of the geological deposit given by Ascenzi et al. (1996):"An unconformity separates the hominid skull, which is included in a sterile clay layer with no volcanism [where, probably, the fossil hominid was brought secondarily from an older destroyed layer], from the upper $700 \mathrm{kyr}$ [K-Ar] dated layers". Thus, the cranium "is considered, geologically, to pertain to the lower Cromer, i.e. to about 800-900 kyr of age", associated with sediments that contain Mammutus trogontherii and pre-Acheulean artifacts (Ascenzi \& Segre, 1998, p. 37). On this basis, the human specimen from Ceprano should antedate the beginning of the Middle Pleistocene, and approach the richer and well dated fossil material discovered at the Gran Dolina site in the Sierra de Atapeurca, near Burgos in Spain (Carbonell et al., 1995; Bermúdez de Castro et al., 1997).

Ceprano reopens the long-running debate about the presence of Homo erectus in Europe (e.g., Stringer, 1984). Affinities are observed between the Italian specimen, the eastern African OH-9 from Olduvai, and the morphological pattern displayed by Asian H. erectus. According to the description recently given by Ascenzi \& Segre (1998) on the basis of an ongoing new reconstruction of the calvaria (compare Ascenzi et al., 1996), Ceprano is a very heavily built specimen, with massive supraorbital and occipito-temporal superstructures, very high bone thickness (reaching values around $20 \mathrm{~mm}$ ), and a relatively small endocranial volume (round $1100 \mathrm{ml}$ ). The supraorbital region is characterised by a very robust and horizontal torus, followed by a post-orbital constriction and an extended supratoral sulcus. The cranial vault is low (inion coincident with opisthocranion and not at the same level as endinion); it shows angled parietal bones, maximum cranial breadth at the level of the well developed supramastoid crests, and presence of an angular torus. The rear part of the skull presents the occipital torus, with maximum development in the mid-sagittal plane and sharp bending between the two scales of the occipital bone. The profile appear asymmetric in posterior view.

Unfortunately, there are no valid comparisons at present between this and other fossil specimens in Europe, even taking into account the sample from Gran Dolina (TD6 level, 'Aurora' layer) referred to about 800 ka (Parés \& Pérez-Gonzalez, 1995). Indeed, of the nearly 80 human fossils which have been found so far at Atapuerca-TD6, including neurocranial, facial, mandibular, dental and postcranial material (Carbonell et al., 1995; Bermúdez de Castro et al., 1997), not one is directly or adequately comparable with Ceprano, at least in terms of completeness (as for some temporal bone fragments) or age at death (as in the case of the juvenile frontal TD6-15).

In any case, the description given by Ascenzi and co-workers (1996), suggests a general difference in human morphology between Italy and Spain in the late Early Pleistocene. While Ceprano is referred to $H$. erectus, The hominids represented at Atapeurca-TD6 appears to be phylogenetically closer to the ancestral African $H$. erectus morphotype or H. ergaster (as known from the Turkana basin), and, do not show affinities with Asian H. erectus, (Carbonell et al., 1995). Thus, as argued by Bermùdez de Castro el al. (1997, P. 1395), the available data could indicate "the coexistence of two different hominid species 
in Europe" in the late Early Pleistocene, raising intriguing speculative scenarios about both their respective origins and the possible bio-cultural relationships between them.

The fossil record from Atapuerca-TD6 is interpreted as the first evidence (unique at present) of a new species, $H$. antecessor, that should fit in the taxonomic and phylogenetic void between $H$. ergaster / erectus and the Neandertals on the one hand, and modern humans on the other (Bermùdez de Castro et al., 1997), postulating the existence of a possible last common ancestor at about $800 \mathrm{ka}$. At the same time, with unpredictable synchrony and consistency, the results of the first successful attempt to recover and analyse ancient DNA material from the Neandertal type specimen (Krings et al., 1997) support and strengthen this point of view, indicating a date in the early Middle Pleistocene for the divergence of the lineages that ultimately led to the Neandertals in Europe (e.g., Arsuaga et al., 1997) and modern $H$. sapiens, probably in Africa (e.g., Bräuer, 1992).

\section{A glimpse into the general issue}

It is beyond the scope of this review to examine whether and how the first occupation of Europe is intimately linked with the subsequent evolution of the genus Homo, (as it probably was) in the more general framework of both the origin and dispersal of the hominines out of Africa. However, I would like to briefly consider a few points which touch on these questions.

\section{Datings}

The dating of the first settlement of hominids outside Africa is obviously of central importance. New chronological data have accumulated in recent years, especially from sites at the eastern edge: e.g., Mojokerto and Sangiran in Java; Longgupo Cave in China; Riwat and Pabbi Hills in Pakistan; from the Middle East (Ubeidiya in Israel; Sukhne in Jordan; Dmanisi in Georgia); and from Europe (Fuentenueva 3 and other controversial sites near Orce, south-eastern Spain, and Atapuerca-TD6, in the north; Le Vallonet in southern France; Monte Poggiolo and Ceprano in Italy) (Fig. 1).

These results are the outcome of improvements in dating techniques (paleomagnetism, ESR, ${ }^{40} \mathrm{Ar} /{ }^{39} \mathrm{Ar}$ ), combined with a careful multidisciplinary approach to the lithic assemblages and to both the faunal and the human remains, when present, and they hold out the promise of confirming or refuting their inherent implications in the near future. Taken as a whole, they consistently indicate a very ancient dispersal of the genus Homo out of Africa toward Asia between 2 and 1.5 Ma (Swisher et al., 1994; Huang et al., 1995; Dennel et al., 1988), and toward Europe between 1.5 and $1 \mathrm{Ma}$ (Tchernov, 1989; Gabunia \& Vekua, 1995).

\section{Gateways}

The question of the gateways crossed by representatives of the genus Homo in their earliest diffusion toward Asia and Europe is interrelated with a number of other questions: the dating of this first multicontinental diffusion; the global climatic trends during the time; the diversification of environments; the routes of dispersal followed by other mammalian species; and both the ecology and the subsistence strategies of those archaic humans (e.g., Tchernov, 1992; Turner, 1994; Gamble, 1995; Larick \& Ciochon, 1996).

Given the present distribution of land and sea inlets, the most obvious passage from Africa into the eastern and the western peripheries of Eurasia is across the Near East. Other corridors can be also hypothesised toward Asia - for instance, throughout the present Bab-el-Mandab district, along the south-eastern edge of the Arabian Peninsula, reaching the Persian Gulf (possibly via Hormuz), the western side of the Indian sub-continent, and eventually to the Far East.

About the gateway/s toward Europe, the hypothesis of a passage directly from north Africa - both at Gibraltar or through Sicily (Alimen, 1975) - should be cautiously reconsidered, in addition to the more obvious eastern gates across the Bosphorus and, possibly, the Caucasus region. The former possibility also involves the unproven assumption that short sea inlets could be crossed by humans at this precocious stage of bio-cultural evolution. The presence of pre-Acheulean assemblages in Sicily, 


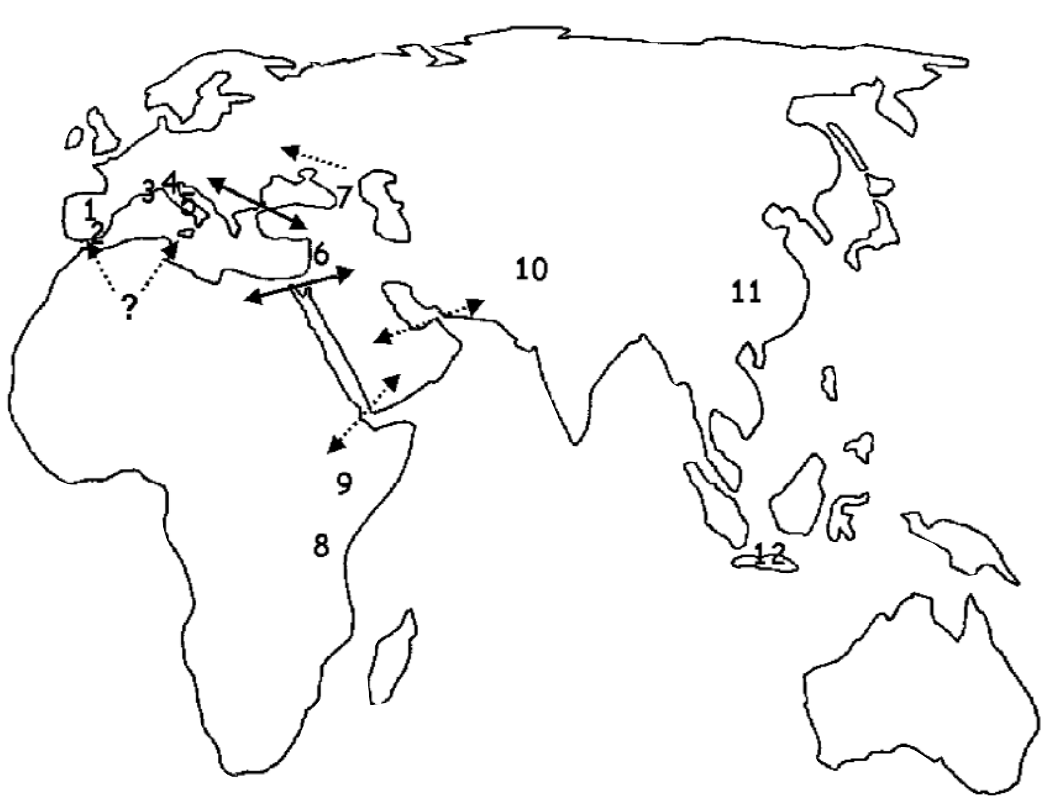

Figure 1. Distribution of sites mentioned in the text (datings are all in the range of the Early Pleistocene): 1. Atapuerca, Gran Dolina (Spain); 2. region of Orce (Spain); 3. Vallonet (France); 4. Monte Poggiolo (Italy); 5. Ceprano (Italy); 6. Ubeidiya, (Israel) and Sukhne (Jordan); 7. Dmanisi (Georgia); 8. Olduvai (Tanzania); 9 . Turkana basin (Kenya); 10. Riwat and Pabbi Hills (Pakistan); 11. Longgupo (China); 12. Mojokerto and Sangiran (Java). Possible gateways toward Asia and Europe are also indicated.

from sites in the areas of Agrigento, Catania and Ragusa, prompted reconsideration of the possibility of human occupation of the island during the Pleistocene (e.g., Piperno, 1992), in association with the hypothetical existence of a passage from Africa. A crossable chain of smaller and larger islands (most notably the present Banco Avventura) probably emerged during marine regressions in the canal between Sicily and Tunisia. This geomorphologic argument and the paleogeography of macro-mammals (e.g., Bonfiglio \& Burgio, 1992) indicate that such a corridor is plausible. It is conceivable that it was used during the Pleistocene by animals and humans in both directions. Even in this case, however, the deeply irregular geomorphology of the present region of Calabria - the southwestern peninsular extremity of Italy - possibly represents a further obstacle for an effective connection between Africa and Europe, throughout Sicily and the Italian peninsula.

\section{Hominids}

The morphological features of the earliest inhabitants of Eurasia, their phylogenetic affinities, and their taxonomic position are also issues in the debate about the earliest diffusion and the first settlements outside Africa.

Over the last few decades it has come to be considered plausible that more than one human species was present on earth at various chronological intervals between, say, $2 \mathrm{Ma}$ and $30 \mathrm{ka}$. In a seminal paper, Tattersall (1986) suggested that there has been a tendency to underestimate the number of species in the hominid fossil record. He stated also that "it would be better for the comprehensiveness of our understanding of the human fossil record that, if err we must, we err ... on the side of recognizing too 


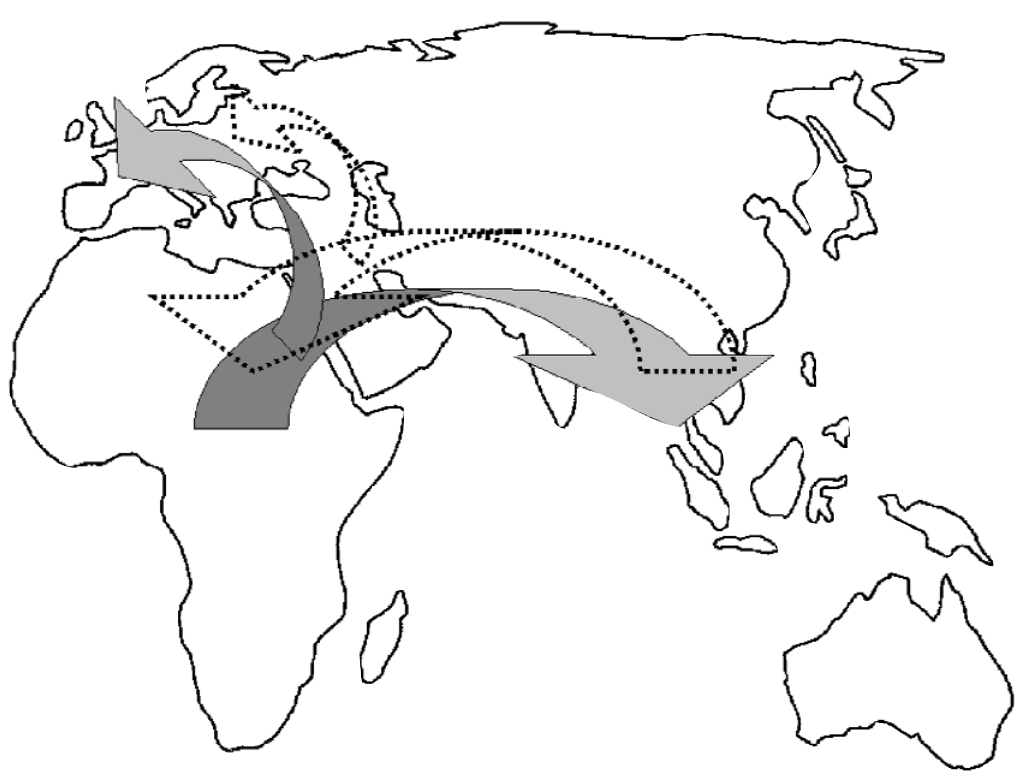

Figure 2. Scenario for the earliest diffusion of the genus Homo (see text). Note that the position of the arrows is merely suggestive.

many rather than ... too few species units"(Tattersall, 1986: 168). This suggestion was followed - more or less explicitly - by a number of authors, although a consensus has not yet been reached among the workers about the number, the attributes, the phylogenetic significance and the nomina of these various hypothetical species to be included in the natural history and taxonomy of our own genus.

Whether the appearance of the genus Homo itself in the African savannahs was a phenomenon of interspecific diversification (H. rudolfensis, H. habilis, H. ergaster; Wood, 1991), it is reasonable to expect that humans would have undergone a greater degree of diversification when far more distant regions were reached. The debate is still open about the distinction at the species level between $H$. ergaster, as the more generalised African form, and H. erectus, as the typical Asian clade (e.g., Andrews, 1984; Bräuer \& Mbua, 1992; Wood, 1994). It can be also considered the hypothesis that an older species, (ancestral to both of them), left Africa round $2 \mathrm{Ma}$, according to the possible causal relationship between diversification and dispersal of early Homo in terms of bio-cultural (Larick \& Ciochon, 1996) and/or eco-physiological (Aiello \& Wheeler, 1995) adaptations.

\section{Scenarios}

Understanding the last phylogenetic point is crucial in trying to depict a plausible scenario, which starts with the earliest diffusion of the genus Homo and follows its subsequent evolutionary history until the origin of modern humans.

In this perspective (see Fig. 2), after and in consequence of the original dispersal of humans outside Africa, in the Early Pleistocene there were at least two distinct areas of human settlement - one in Africa and the other in Asia. According to Wood \& Turner (1995), it seems reasonable that, from that time on, these two centres acted discontinuously as a double source of variation and diffusion, at least in terms of gene flow. While H. ergaster, or another more archaic hominid of African origin, was probably 
responsible for the earliest diffusion outside Africa into Asia, (and more hypothetically into Europe), $H$. erectus can be regarded as the indigenous result of human evolution in the Far East. Given the existence outside Asia of specimens displaying affinities with $H$. erectus, it can be assumed that, subsequent to its evolution in Asia, this species spread back toward Africa and Europe or influenced by gene flow the variability of human populations westwards.

Any scenario dealing with human evolution in the Early and Middle Pleistocene shold take this argument into account. It might be helpful in interpreting the erectus-like features encountered in African (OH.9) and European (Ceprano) hominids of this time period, apparently coexisting with specimens that exhibit ergaster-like features - as the cranium from the Danakil formation, in Eritrea (Abbate et al., 1998) - and/or advanced traits, (Atapuerca-TD6). At the same time, this framework is consistent with the long-standing maintenance of non-Acheulean industries in the Far East.

It can be readily understood - that the effective development of scenarios as complex and highly hypothetical as this one is not only a matter of dating techniques, paleoenvironmental analyses, or skeletal morphology It calls for a review of the extant paradigms regarding biology, taxonomy, phylogeny, behaviour, and adaptive strategies of our genus.

\section{Acknowledgements}

I would like to thank the organisers of the Dual Congress 1998 - particularly Professor Phillip V. Tobias - for suggesting the idea of a colloquium on Pleistocene gateways to Europe and Asia: the earliest hominines in those continents and their diffusion, and for inviting me to organise and chair such a meeting. Discussions on this topic, with Juan Luis Arsuaga, Carlo Peretto and Aldo G. Segre, have been very fruitful. I'm also grateful to Giacomo Giacobini for his support and advices. Mike Raath arranged for the original manuscript to be reviewed, and kindly helped with the written English.

\section{Note}

When this paper was already in press, the discovery of two new fossil crania from the site of Dmanisi (Georgia) have been officially announced and exhibited in the meeting "Les premiers habitants de l'Europe" (Tautavel, April 2000). The two specimens are the amazing validation of hypotheses reported in this brief overview. Their morphology is apparently consistent with both their chronology (approximately $1.7 \mathrm{Ma}$ ) and geographic position (southern Caucasus), representing a "missing link" between the availabale fossil record from Africa (including Australopithecus and "early Homo") and Eastern Asia (Java) at the boundary between Pliocene and Pleistocene. Their position in the northern part of the Levant is also a clear signal that hominids were at the gates of Europe at that time. Were the gates open...?

\section{References}

Abbate, E., Albianelli, A., Azzaroli, A., Benvenuti, M., Tesfamariam, B., Bruni, P., Cipriani, N., Clarke, R.J., Ficcarelli, G., Macchiarelli, R., Napoleone, G., Papini, M., Rook, L., Sagri, M., Tecle, T.M., Torre, D. \& Villa, I. (1998). A one-million-year-old Homo cranium from the Danakil (Afar) depression of Eritrea. Nature, 393, 458-60.

Aiello, L. \& Wheeler, P. (1995). The expensive-tissue hypothesis. The brain and the digestive system in human and Primate evolution. Curr. Anthropol., 36, 199-221.

Alimen, M-H. (1975). Les "isthmes" hispano-marocain et siculo-tunisien aux temps acheuléens. L'Anthropologie, 79, 399-436.

Andrews, P. (1984). An alternative interpretation of the characters used to define Homo erectus. Cour. ForschungsInst. Senckenberg, 69, 167-75.

Arsuaga, J. L., Martínez, I., Garcia, A. \& Lorenzo, C. (1997). The Sima de los Huesos crania (Sierra de Atapuerca, Spain). A comparative study. J. Human Evol., 33, 219-81.

Ascenzi, A., Biddittu, I., Cassoli, P.F., Segre, A.G. \& Segre, N. E. (1996). A calvarium of late Homo erectus from Ceprano, Italy. J. Human Evol., 31, 409-23. 
Ascenzi, A. \& Segre, A.G. (1998). The fossil calvarium of Homo erectus from Ceprano, central Italy. In: Internat. Symp. "The Origin of Humankind"; pp. 37-38 (abstract). Venezia: Ist. Veneto Sc. Lett. Arti.

Bermúdez de Castro, J. M., Arsuaga, J. L., Carbonell, E., Rosas, A., Martínez, I. \& Mosquera, M. (1997). A hominid from the lower Pleistocene of Atapuerca: possible ancestor to Neandertals and modern humans. Science, 276, 1392-95.

Bonfiglio, L. \& Burgio, E. (1992). Significato paleoambientale e cronologico delle mammalofaune pleistoceniche della Sicilia in relazione all'evoluzione paleogeografica. Il Quaternario, 5, 223-34.

Bonifay, E. \& Vandermeersch, B. (1991). Les Premiers Européens. Paris: Editions du C.T.H.S.

Bräuer, G. (1992). Africa's place in the evolution of Homo sapiens. In: Continuity or Replacement. Controversies in Homo sapiens Evolution, ed. G. Bräuer \& F.H. Smith, pp. 83-98. Rotterdam: Balkema.

Bräuer, G. \& Mbua, E. (1992). Homo erectus features used in cladistics and their variability in Asian and African hominids. J. Human Evol., 22, 79-108.

Carbonell, E., Bermúdez de Castro, J. M., Arsuaga, J. L., Díez, J.C., Rosas, A., Cuenca-Bescós, G., Sala, R., Mosquera, M. \& Rodríguez, X.P. (1995). Lower Pleistocene hominids and artifacts from Atapuerca-TD6 (Spain). Science, 269, 826-29

Dennel, R.W. (1983). European Economic Prehistory: A New Approach. London: Academic Press.

Dennel, R.W., Rendell, H. \& Hailwood, E. (1988). Early tool-making in Asia: two-million-year-old artefacts in Pakistan. Antiquity, 62, 98-106.

Dennel, R.W. \& Roebroeks, W. (1996). The earliest colonisation of Europe: the short chronology revisited. Antiquity, $70,535-42$.

Gabunia, L. \& Vekua, A. (1995). A Plio-Pleistocene hominid from Dmanisi, East Georgia, Caucasus. Nature, 373, 509-12.

Gamble, C.S. (1995). The earliest occupation of Europe: the environmental background. Anal. Praehist. Leidensia, 27, 279-95.

Gibert, J. (ed.) (1992). Proyecto Orce - Cueva Victoria (1988-1992): Presencia Humana en el Pleistoceno Inferior de Granada y Murcia. Orce (Granada): Museo de Prehistoria "J. Gibert".

Huang, W., Ciochon, R., Gu, Y., Larick, R., Fang, Q., Schwarcz, H., Yonge, C., de Vos, J. \& Rink, W. (1995). Early Homo and associated artefacts from Asia. Nature, 378, 275-78.

Johanson, D.C. \& White, T.D. (1979). A systematic assessment of early African hominids. Science, 203, 321-30.

Krings, M., Stone, A., Schmitz, R.W., Krainitzki, H., Stoneking, M. \& Pääbo, S. (1997). Neandertal DNA sequences and the origin of modern humans. Cell, 90, 19-30.

Larick, R. \& Ciochon, R.L. (1996). The African emergence and early Asian dispersals of the genus Homo. Am. Scientist, 84 (6).

Leakey, M.G., Feibel, C.S., McDougall, I. \& Walker, A. (1995). New four-million-year-old hominid species from Kanapoi and Allia Bay, Kenya. Nature, 376, 565-71.

Lumley, H. de, Fournier, A., Krzepkowska, J. \& Echassoux, A. (1988). L'industrie du Pléistocène inférieur de la grotte du Vallonet, Roquebrune-Cap-Martin, Alpes Maritimes. L'Anthropologie, 92, 501-614.

Manzi, G., Grimaldi, S. \& Destro-Bisol, G. (1994). Modern human origin/s: fossil, genetic and archaeological evidence. State of the art. Riv. Antropol., 72, 243-69.

Parés, J.M. \& Pérez-González, A. (1995). Paleomagnetic age for hominid fossils at Atapuerca archaeological site, Spain. Science, 269, 830-32.

Peretto, C. et al. (in press1998). L'industrie lithique de Ca' Belvedere di Monte Poggiolo: stratigraphie, matière première, typologie, remontages et traces d'utilisation. L'Anthropologie.

Piperno, M. (1992). Il Paleolitico Inferiore. In: L'Italia Preistorica, ed. A. Guidi \& M. Piperno, pp. 139-69. Bari: Laterza.

Roberts, M.B., Stringer, C.B. \& Parfitt, S.A. (1994). A hominid tibia from Middle Pleistocene sediments at Boxgrove, U.K. Nature, 369, 311-13.

Roebroeks, W. \& van Kolfschoten, T. (1994). The earliest occupation of Europe: a short chronology. Antiquity, 68, 489-503.

Roebroeks, W. \& van Kolfschoten, T. (1995). The Tautavel workshop: an introduction. Anal. Praehist. Leidensia, 27, 1-6.

Rolland, N. (1992). The paleolithic colonization of Europe: an archaeological and biogeographic perspective. Trabajos Prehist., 49, 69-111. 
Stringer, C.B. (1984). The definition of Homo erectus and the existence of this species in Africa and Europe. Cour. Forschungs-Inst. Senckenberg, 69, 131-43.

Swisher, C.C., Curtis, G.H., Jacob, T., Getty, A.G., Suprijo, A. \& Widiasmoro (1994). Age of the earliest known hominids in Java, Indonesia. Science, 263, 1118-21.

Tattersall, I. (1986). Species recognition in human paleontology. J. Human Evol., 15, 165-75.

Tattersall, I. (1997). Out of Africa again... and again? Scient. American, 276, 4, 60-67.

Tchernov, E. (1989). The age of the Ubeidiya formation. Israeli J. Earth Sc., 36, 3-30.

Tchernov, E. (1992). Mammalian migration and dispersal events in the Quaternary. Cour. Forschungs-Inst. Senckenberg, 153, 103-23.

Turner, A. (1994). Evolution and dispersion of larger mammals in Europe during the time span of Homo erectus. Cour. Forschungs-Inst. Senckenberg, 171, 241-47.

White, T.D., Suwa, G. \& Asfaw, B. (1994). Australopithecus ramidus, a new species of early hominid from Aramis, Ethiopia. Nature, 371, 306-12.

Wood, B. (1991). Koobi Fora Research Project (4) - Hominid Cranial Remains. Oxford: Clarendon.

Wood, B. (1994). Taxonomy and evolutionary relationships of Homo erectus. Cour. Forschungs-Inst. Senckenberg, $171,159-65$.

Wood, B. \& Turner, A. (1995). Out of Africa and into Asia. Nature, 378, 339-40. 


\section{Jacopo Moggi-Cecchi}

\author{
University of the Witwatersrand \\ Johannesburg, Sudafrica \\ and \\ Istituto di Antropologia \\ Università di Firenze \\ Italy
}

Keywords: dental development, early Homo, Australopithecus

\section{Patterns of Dental Development of Australopithecus africanus, with Some Inferences on Their Evolution with the Origin of the Genus Homo}

The study of the dental developmental patterns of early hominids has received much attention during the last ten years. Some authors have suggested a unique pattern of development for each of the main groups of Australopithecines (namely Australopithecus on one hand and Paranthropus on the other), these differing from those of great apes and of modern humans. Other students point out the large variability in the dental developmental patterns of human populations, so that what can be observed in early hominids could very well be accommodated within the range of modern human patterns of dental development. In recent study of the fossil hominids from South African sites, it has been possible to identify at least 23 juvenile specimens of Australopithecus africanus, with at least three developing permanent teeth that can be examined directly or through X rays or CT scanning. A preliminary analysis of the variability in the dental developmental patterns was carried out following the methods proposed by Smith (1994). The range of variability of the dental developmental patterns (as expressed by the coefficients of variation) of A.africanus only partially overlaps that of modern humans, from one side, and apes, from the other, reinforcing the hypothesis of a dental developmental pattern of these early hominids different from both humans and apes. How the increase in brain size, the hallmark of the origin of the genus Homo, affected the growth and development of the individuals? In a series of papers aimed at the description of the developmental patterns of fossil hominids, Smith noticed that the children of Homo erectus possessed developmental features different from Australopithecus (and Paranthropus) and more similar to modern humans. The developmental features of the few specimens attributed to early Homo (H. habilis), on the other side, seem to show stronger similarities with Australopithecus rather than with H. erectus. A major shift in the process of growth and development, that is an extension of the growth period, seems to have occurred only in the transition from early Homo to Homo erectus. This condition, if confirmed on other specimens, will add a new element to the definition of the earliest species of the genus Homo, but at the same time poses a number of questions. What is the reason for this ? And also, from a taxonomic standpoint how much emphasis should we put on the evidence deriving from the study of the developmental features of fossil hominids?

\section{Introduction}

The dental developmental patterns of fossil hominids, as observed from juvenile specimens, have received much attention during the last 15 years. In the light of the fact that dental developmental patterns can provide indications of overall somatic maturity, the similarities described between dental developmental patterns of australopithecines and modern humans (Mann, 1975) were interpreted to 
indicate that a typically human extended growth period of somatic maturation had already evolved in these early hominids. In the 'eighties, several authors suggested that early hominids had distinct features of dental development, differing not only from modern humans, but also from one early hominid group to another, namely between Australopithecus and Paranthropus (Bromage \& Dean, 1985; Smith, 1986; Beynon \& Dean, 1988; Conroy \& Kuykendall, 1995). A brief review is presented here of the kind of information we can derive from study of dental developmental patterns of fossil children, together with some new data on Australopithecus africanus.

\section{Variability in the patterns of dental development of Australopithecus africanus}

The developing dentition - mainly the process of formation of the permanent teeth - is considered to be one of the best indicators of individual maturation, less sensitive than skeletal growth to external influences, and thus less variable in its expression (Lewis \& Garn, 1960). Studies on skeletal remains from archaeological sites usually rely on the stages of development of the permanent teeth to assess the biological age of juvenile individuals within the sample. Also, in humans and in primates in general, the development of specific teeth acts as a marker of growth in the life of an individual. In primates the eruption of the first permanent molar marks the end of the infantile period (childhood) and the eruption of the third permanent molar - the so called 'wisdom tooth' - marks the end of the juvenile period.
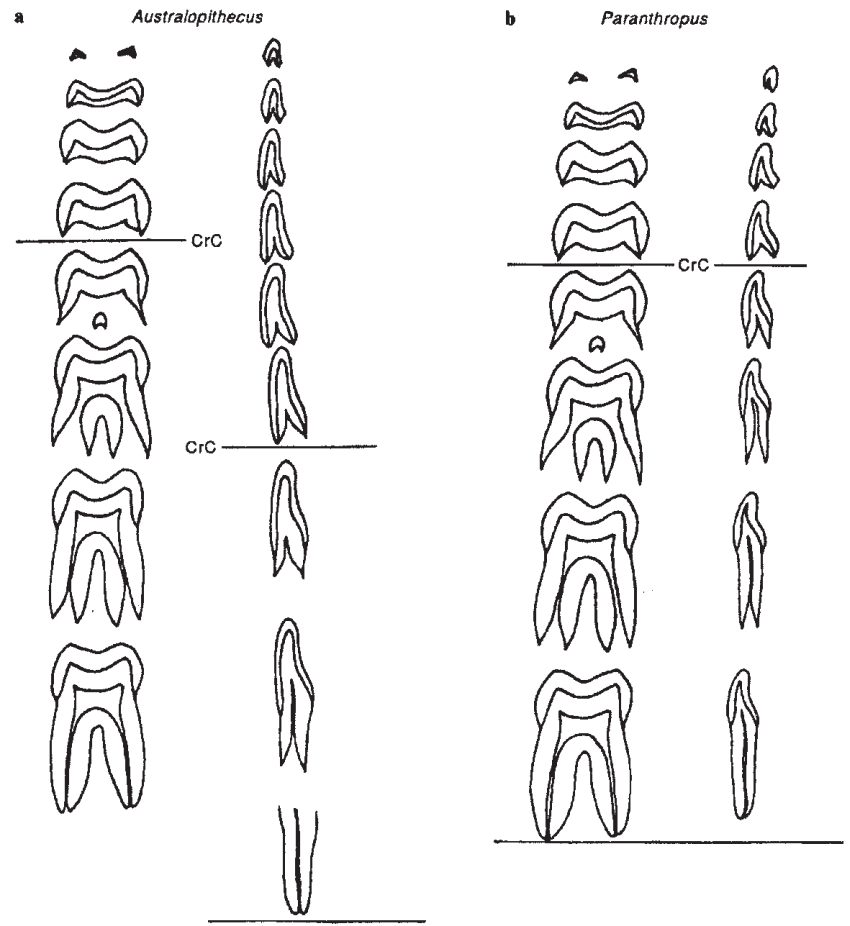

Figure 1. Stages of dental formation in comparison for the first molar and the first incisor in specimens of Australopithecus (a) and Paranthropus (b) (modified after Aiello \& Dean, 1990). See text for explanations. 
Table 1. List of the individual infant/juvenile specimens attributed to $A$. africanus, arranged by age, as estimated from the relative development of the available teeth. A + sign indicates that the developmental stage of a tooth can be assessed by visual inspection, through x-ray analysis or CT scanning images. "a" indicates that antimeres are present. $\mathrm{mx}=$ maxillary; $\mathrm{md}=$ mandibular.

\begin{tabular}{|c|c|c|c|c|c|c|c|c|c|c|c|c|c|c|}
\hline \multirow[b]{2}{*}{ Specimen } & \multicolumn{6}{|c|}{ Deciduous teeth } & \multicolumn{8}{|c|}{ Permanent teeth } \\
\hline & Jaw & i1 & i2 & c & m1 & m2 & I1 & I2 & C & P3 & $\mathbf{P 4}$ & M1 & M2 & M3 \\
\hline Sts 2 & $m x$ & & & + & $+a$ & $+a$ & & & + & + & + & + & & \\
\hline Sts 24a & $\mathrm{mx}$ & & & + & $+a$ & $+a$ & $+a$ & $+a$ & + & $+a$ & $+\mathrm{a}$ & + & & \\
\hline Sts 24 & md & + & $+\mathrm{a}$ & $+a$ & $+a$ & + & + & $+a$ & & $+a$ & + & + & & \\
\hline Stw 75 & $\mathbf{m x}$ & & & & & & + & + & + & + & & & & \\
\hline Stw 412 & md & & & & & & + & & + & & + & & $+a$ & \\
\hline Stw 420 & md & & & & & & & + & & $+a$ & & $+a$ & + & \\
\hline Stw 296 & md & & & & + & + & $+a$ & + & & & & ta & + & \\
\hline Sts 18/Stw 48 & md & & & & + & $+a$ & & & & + & + & $+\mathbf{a}$ & + & \\
\hline Taung & $\mathrm{mx}$ & $+\mathbf{a}$ & $+a$ & $+\mathbf{a}$ & $+a$ & $+\mathbf{a}$ & $+a$ & $+\mathbf{a}$ & $+\mathbf{a}$ & $+a$ & $+a$ & $+a$ & $+\mathbf{a}$ & \\
\hline Taung & md & $+a$ & $+a$ & $+\mathbf{a}$ & $\mathrm{ta}$ & $+a$ & $+a$ & $+a$ & $+a$ & $+a$ & $+a$ & $+a$ & $+a$ & \\
\hline Stw 59 & $\mathrm{mx}$ & & & & & + & + & + & & + & + & + & + & \\
\hline MLD 11/30 & $\mathrm{mx}$ & & & & & & & + & + & + & + & + & & \\
\hline Stw 151 & $\mathrm{mx}$ & & & $+\mathbf{a}$ & $+a$ & $+a$ & $+a$ & ta & + & $+a$ & + & $+a$ & $+a$ & \\
\hline Stw 151 & md & & & + & $+a$ & $+a$ & $+\mathbf{a}$ & $+a$ & $+a$ & + & $+a$ & $+a$ & + & \\
\hline Sts 51 & md & & & & + & + & & & + & + & + & & & \\
\hline MLD 2 & md & & & & & + & & & $+a$ & ta & $+\mathbf{a}$ & $+\mathbf{a}$ & $+\mathbf{a}$ & \\
\hline Stw 104 & md & & & & + & + & & & + & + & + & & & \\
\hline Sts 57 & $\mathrm{mx}$ & & & & & & & & & + & + & + & + & \\
\hline Sts 8 & $\mathbf{m x}$ & & & & & & & & & & & + & + & + \\
\hline Stw 327 & md & & & & & & & & & & + & + & + & + \\
\hline Stw 183 & $\operatorname{mx}$ & & & & & & + & $+a$ & ta & + & & + & + & + \\
\hline Stw 116 & md & & & & & & + & $+a$ & + & & & & + & \\
\hline Stw 269 & md & & & & & & + & $+\mathbf{a}$ & ta & & + & + & $+\mathbf{a}$ & + \\
\hline Stw 252 & $\mathrm{mx}$ & & & & & & $+a$ & $+\mathbf{a}$ & $+\mathbf{a}$ & $+\mathbf{a}$ & ta & $+a$ & $+a$ & $+a$ \\
\hline Stw 277 & $\mathrm{mx}$ & & & & & & & & & + & $+a$ & + & + & + \\
\hline Stw 560 & md & & & & & & & & & & & + & $+a$ & $+a$ \\
\hline
\end{tabular}

On these bases, the study of the dental development of fossil hominids can provide information on their growth process. One way of addressing the issue is to study the dental developmental patterns, that is, the relative sequence of formation of the teeth. Not all of the permanent teeth develop at the same time, and not all take the same amount of time to form. The relative development of one tooth (e.g. first molar - M1) as compared to another (e.g. central incisor - I1), has been used as a marker of a specific developmental sequence. Figure 1 shows the comparative stages of dental formation for the first molar and 
the first incisor in specimens of Australopithecus and Paranthropus. In the incisors of Australopithecus the tooth crown is completed relatively later than the first molar, whereas in Paranthropus the two occur at approximately the same time. That is, as far as patterns of dental development are concerned, Australopithecus recalls a situation similar to that observable in living apes, whereas Paranthropus shows patterns of development in some respects similar to those of modern humans. In both groups, however, the chronology of dental development appears to have been shorter than that of modern humans, and more similar to modern apes, with some differences between the two groups.

Although these conclusions are consistent, even when different methods of approaching the problem are used, some students have pointed out that the extent of variability in the dental developmental patterns of modern humans is so broad that australopithecines can easily be accommodated within this range (Mann, Lampl \& Monge, 1990). The issue of variability of dental developmental patterns within a single fossil species is thus of crucial importance if we wish to provide a basis for understanding the differences between taxa in terms of life history parameters. To date very few studies have specifically addressed this issue. Conroy \& Kuykendall (1995) examined six immature specimens of $A$. (Paranthropus) robustus and seven of $A$. africanus from South Africa with the aid of CT scanning. Their conclusions show, for $A$. robustus, a unique pattern of dental development, only superficially similar to that of humans, whereas for $A$. africanus the overall pattern of dental development turned out to be similar to that observed in chimpanzees.

Studying the south African fossils, I noted that there are 23 infant or juvenile specimens of $A$. africanus from the sites of Sterkfontein, Makapansgat and Taung with at least three developing permanent teeth that can be examined directly or via X-rays or CT scanning. In particular, among the more recent finds from Sterkfontein (labelled Stw), it has been possible to recognise 14 juveniles, represented by isolated teeth or groups of teeth that can reasonably be assigned to individual specimens. Table 1 presents a list of the individual infant/juvenile specimens attributed to $A$. africanus, arranged by age, as estimated from the relative development of the available teeth. In an attempt to use these specimens to study the intraspecific variability in dental developmental patterns, I have applied one of the methods of analysis recently suggested by Smith (1994), with the relevant computer program. She devised a method to compute 'developmental distances', an interesting way of quantifying similarities and differences between humans and chimpanzees. In this method (Figure 2) each developing tooth of a juvenile specimen is scored by its stage of development (following Smith, 1994 after Moorrees, Fanning \& Hunt, 1963) and afterwards "a dental age is assigned to each developing tooth of an individual from average standards of human development" (Smith, 1994). A mean individual age is then calculated, with its standard deviation and also a coefficient of variation (CV). This CV expresses, in a single value, to what extent the dental developmental pattern of each fossil specimen is consistent or inconsistent with the human standard. The sampling criteria necessary to include fossil specimens in this kind of analysis require a fairly complete dentition to be present, and for this reason among the $23 \mathrm{~A}$. africanus juveniles, it was possible to include only six: the Taung specimen, Sts 24, and three other specimens (Stw 412, Stw 183, MLD 11/30) with at least one tooth per class (i.e. incisors, canines, premolars and molars. In this way the contribution of each tooth type to the variability can be taken into account). MLD 2 has also been included, because, although it lacks incisors, it provides data on all the other teeth.

Figure 3 presents the results of the analysis that I have carried out on these juvenile specimens of $A$. africanus together with data for humans, African apes (from Smith, 1994) and A. robustus (data from Conroy \& Vannier, 1991). The human sample $(n=174)$ tends to have lower CV values, ranging from 4 to 22 , with a median value of 11 ; that is, obviously, humans are closer to human standards. The ape sample $(n=37)$ shows higher values of $C V$, from 14 to 46 , median value 31 . The range for the six specimens of $A$. africanus is 10 to 32 with a median of 23 . The values for $A$. robustus fall close to the median value for the modern human sample, reflecting the observations by several authors that $A$. robustus shows a superficially human-like pattern of dental development, at least when examined at this 


\begin{tabular}{l|cccccc} 
teeth : & I1 & I2 & C & P3 & P4 & M1 \\
\hline $\begin{array}{l}\text { stage of development : } \\
\begin{array}{l}\mathrm{C}=\text { crown; } \mathrm{R}=\text { root; } \\
\text { the numeric values are percentages of formation }\end{array}\end{array}$ & $\mathrm{C} \mathrm{95}$ & $\mathrm{C} 95$ & $\mathrm{C} 75$ & $\mathrm{C} 75$ & $\mathrm{C} 75$ & $\mathrm{R} 75$ \\
age : & 3.4 & 3.7 & 3.1 & 4.3 & 5.5 & 6.0
\end{tabular}

number of teeth :

mean age :

coefficient of variation :

Figure 2. The method of Smith (1994) to compute 'developmental distances', as applied to the Taung child specimen (A. africanus). See text for explanations.

level of resolution.

The position of the $A$. africanus specimen Stw 183 is peculiar. It falls far apart from the other $A$. africanus specimens, in a position more similar to the three $A$. robustus specimens. Perhaps this simply confirms the expectation of variation in dental development in fossil hominids, and that $A$. africanus, though variable, is intermediate between apes and humans. However, in a recent discussion of the systematic position of Stw 183 (Lockwood, 1997; Lockwood \& Moggi-Cecchi, 1998), a number of morphological differences have been described in this specimen that clearly separate it from other $A$. africanus specimens, making it more similar to robust australopithecines. The dental developmental data seem to support the morphological observations suggesting that Stw 183 may represent a taxon at Sterkfontein other than A. africanus, more derived towards a 'robust' condition. Thus, if we exclude Stw 183 from the $A$. africanus sample, three points may be made:

1. The range of variability of $A$. africanus only partially overlaps that of modern humans, indicating that dental developmental patterns of $A$. africanus cannot all be accommodated within those of modern humans;

2. The range of $A$. africanus variability also overlaps that of apes;

3. There is no overlap between the range of variability of $A$. africanus and that of A. robustus.

Thus, the data on A. africanus indicate a species whose pattern of dental development is slightly more similar to the patterns of apes than of humans. These results, together with the data on the absolute chronology of formation of the teeth, have been interpreted to suggest that somatic maturation may have been comparable to that of apes, and, in turn, that in this species no evidence seems to exist of a shift towards an extended growth period typical of the human species. This represents a major breakthrough in the interpretation of the biology of these early hominids, since it adds to the growing list of primitive features known to characterise the species A. africanus relative to Homo. 


\section{CV of dental ages - summary score on human standards}

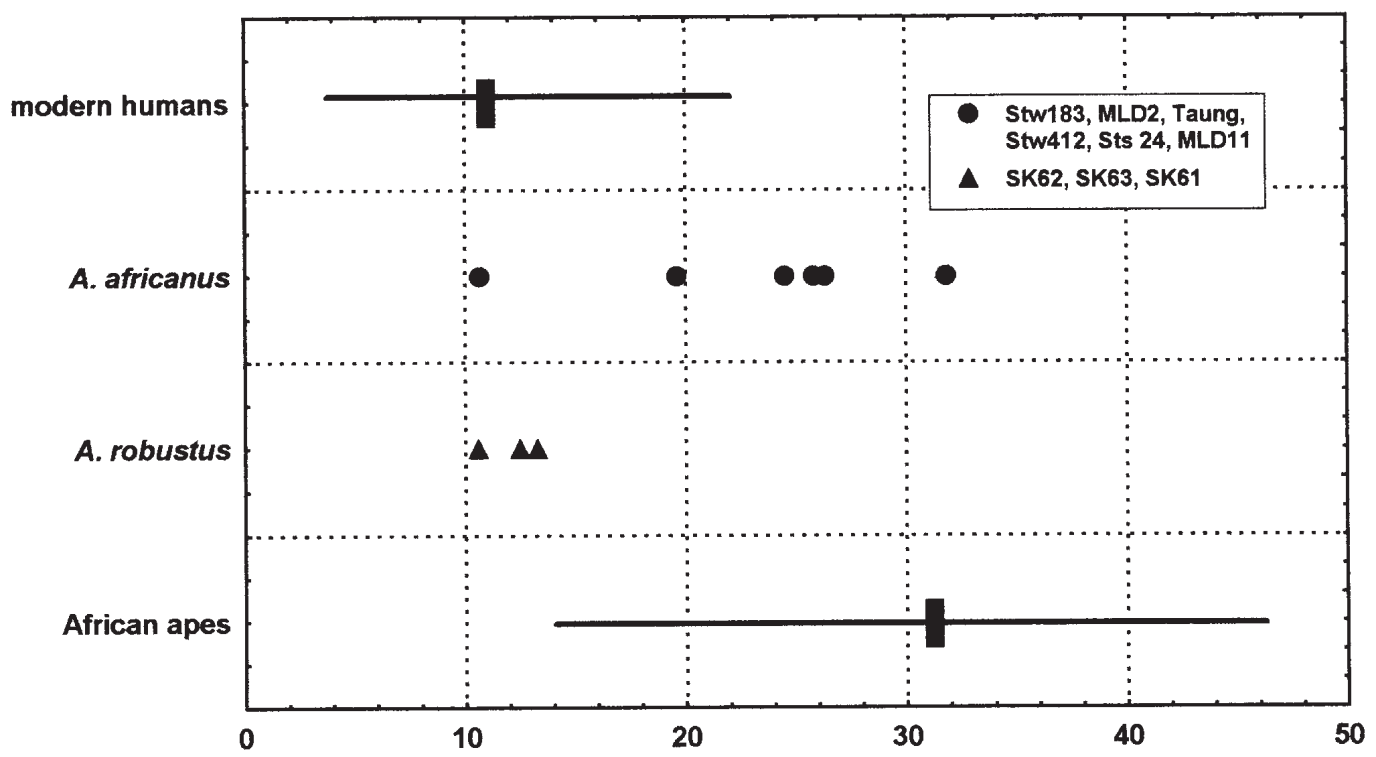

Figure 3. Coefficient of variation of dental ages ('developmental distances') for A. africanus, and A. robustus (data from Conroy \& Vannier, 1991), as compared to modern humans and African apes (data from Smith, 1994).

\section{Patterns of dental development of early Homo}

The next step has been the analysis of specimens belonging to species of early Homo. This was done in order to address questions such as: How did the increase in brain size, the hallmark of the origin of the genus Homo, affect the growth and development of individuals? Was it associated with changes in the developmental patterns as evident in the dentition of juvenile specimens? For this purpose, I have here considered the two species Homo habilis and Homo erectus. Homo habilis includes specimens considered by some authors to belong to a different species of early Homo, namely Homo rudolfensis (Wood, 1992, 1993). Similarly, Homo erectus includes Homo ergaster, the African form of Homo erectus, considered by some authors to be a different species from its Asian counterpart (Wood, 1992, 1993).

There are a few relatively complete juvenile specimens of these early hominids where the dental developmental patterns can be studied. The early Homo specimens examined here are: KNM-ER 1590, a specimen from Koobi Fora, in Kenya; OH6 from Olduvai, in Tanzania (in which, although a canine is not present, data are available for the other tooth classes). Among the Homo erectus specimens, there are two from Kenya (KNM-ER 820, WT 15000) and one from the Zhoukoudian site in China. Data on the dental developmental stages of KNM-ER 1590, ER 820, WT 15000 and Zhou-I are from Smith (1994). Data on OH6 derive from Tobias (1991).

The results of the analysis of the developing dentition of these specimens are presented in Figure 4 using the method of 'developmental distances'. Together with the two Homo habilis specimens, I have added a specimen from Sterkfontein, South Africa (Stw 151), which, although not formally attributed to early Homo, shows a number of features closely allying it with other early Homo specimens (MoggiCecchi, Tobias \& Beynon, 1998). The two early Homo specimens, plus Stw 151, seem to fall at the lower end of the range for A. africanus (Stw 183 removed), whereas the three Homo erectus specimens are 


\section{CV of dental ages - summary score on human standards}

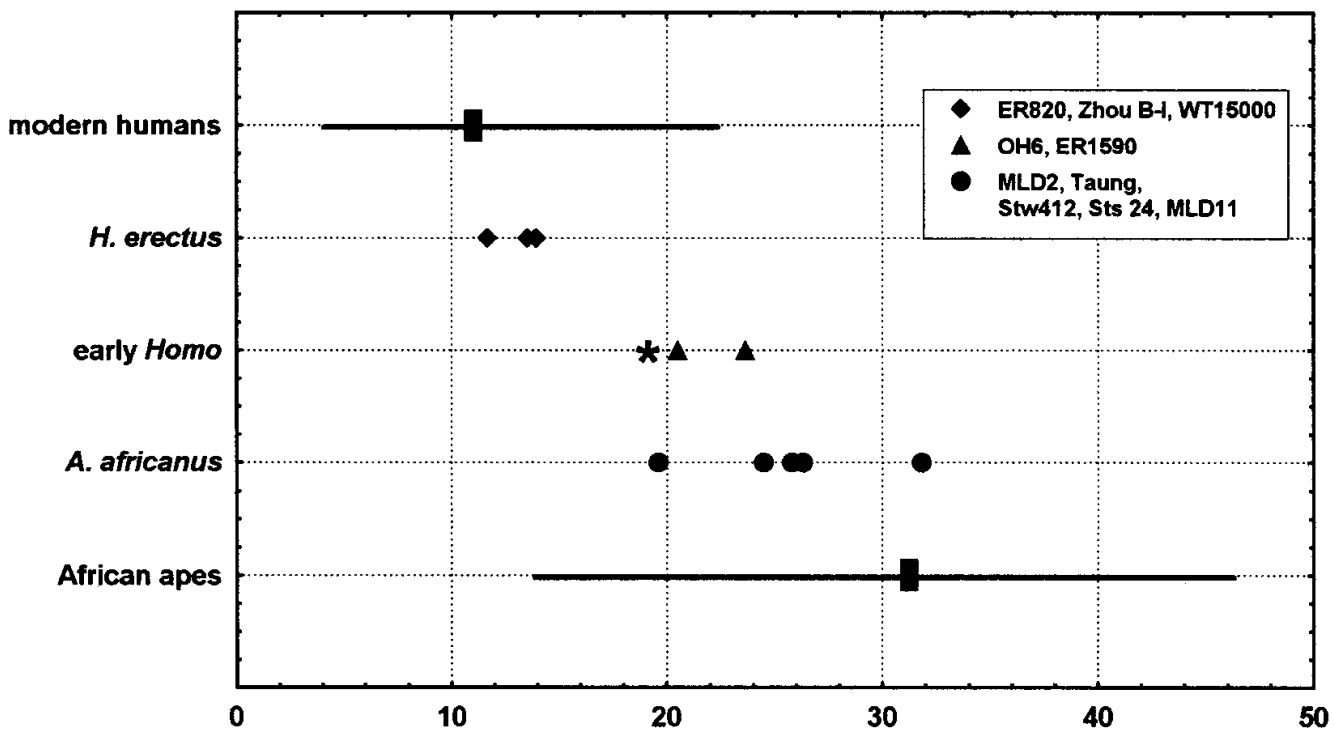

Figure 4. Coefficient of variation of dental ages ('developmental distances') for five specimens of $A$. africanus, two of early Homo (data from Smith, 1994; Tobias, 1991) plus Stw 151 (*) and three of Homo erectus, as compared to modern humans and African apes (data from Smith, 1994).

closer to the central part of the range for modern humans. Also, the two Homo habilis, plus Stw 151, and the three Homo erectus cluster separately, with no overlap between the two series of points. This difference in the distribution between the Homo habilis and the Homo erectus specimens may simply be due to the small number of specimens analyzed, that is, with a larger number of children available, the results may differ. However, as we have seen above, this kind of analysis has proved itself fairly accurate, for example, in isolating specimens of $A$. africanus from a possibly different kind of hominid - Stw 183 .

On the assumption that the specimens examined are representative of the dental developmental patterns of the species they belong to, we may suggest that Homo habilis still seems to show a condition more similar to Australopithecus, whereas Homo erectus seems to show more affinities with a modern human pattern of dental development. These data seem to suggest that the marked increase in brain size (which is among the key anatomical features considered to characterize the early members of the genus Homo) and acquisition of a more humanlike pattern of dental development did not occur at the same time of the evolution of the genus Homo as currently recognised. Thus, it seems that the data on the dental developmental pattern may be added to the list of features which are known to distinguish Homo habilis from Homo erectus.

These results can also be examined in the light of the hypothesis proposed by Martin (1983) to explain the increase in brain size through human evolution in relation to the extended growth period typical of the human species. Following Martin's hypothesis, the marked increase in brain size as evident in Homo habilis could have occurred simply by lengthening the foetal stage of growth, thus giving birth to a baby with a larger brain, with no substantial modifications of the postnatal growth process as compared to australopithecines. The neonatal brain size did not yet represent a constraint on the birth canal and birth process; it was only with progressive encephalization, when adult cranial 
capacity reached about $850 \mathrm{cc}$. (which is approximately the mean cranial capacity for Homo erectus) that foetal brain size reached the physical limit for the size of the pelvic inlet. At that point, when an Australopithecus mode of growth could no longer accommodate neonatal brain size in the pelvic inlet, a radically different ontogenetic mechanism evolved, with foetal growth rate continuing in the first year of postnatal life, which is the condition seen in modern humans, and a subsequent extension of the growth period typical of the human species, as can be described by the dental developmental patterns.

It will be necessary, however, to add other kinds of information before a more accurate picture of the developmental correlates of the increase in brain size will be fully understood.

\section{Possible implications for the systematics of Homo habilis}

As a final point I would like to consider the possible taxonomic implication of these results. In terms of developmental features, Homo habilis can be described as a relatively primitive hominid, in this respect more similar to Australopithecus than to Homo erectus. What implications might this have for our understanding of the systematics of H. habilis?

Since the original description of Homo habilis was published (Leakey, Tobias \& Napier, 1964), new discoveries and a reinterpretation of the available evidence have indicated that there are traits for which Homo habilis retains a more primitive morphology, such as, for example, limb proportions (HartwigScherer \& Martin, 1991) which are known to be more similar to apes than to humans; similarly, data on rates of dental root formation, as reported by Dean (1995) for the H. habilis specimen OH 16, indicate strong similarities with extant great apes. The issue is rendered more complex since some authors have suggested that the Homo habilis sample could very well comprise more than one species, each of which is characterized by some derived and some primitive features in different areas of the skull and the postcranial skeleton (Wood, 1992, 1993).

How should we interpret the data on dental development? A major shift in the process of growth and development seems to have occurred in the transition from Homo habilis to Homo erectus, in which $H$. habilis may be the last representative of an australopithecine-like mode of growth, whereas Homo erectus marks the appearance of a basically new mode of growth in hominid evolution. The evidence of dental development does not represent a morphological feature, such as brain size or dental reduction, or a series of functionally related structures; rather it is evidence of a process, the growth process itself and, as such, should be given greater weight in the interpretation of any fossil species. In this respect, in their analysis of the dental developmental features of australopithecines, Beynon \& Dean (1988) described a marked distinction between the so-called 'gracile' and 'robust' australopithecines, and concluded that these differences are beyond those typically observed within a single hominoid genus, thus supporting the proposal that robust australopithecines should be granted a separate generic status, namely Paranthropus. In the case of the genus Homo, the evidence of the dental developmental patterns raises new questions on the systematics of Homo habilis.

\section{Acknowledgements}

I thank Prof. P.V. Tobias, for inviting me to the Dual Congress where this paper was presented, and also for continuous support and encouragement. Special thanks to C. Lockwood for innumerable comments and careful revision of earlier drafts. Thanks are also due to J. Masters, M. Del Pero and G. Manzi for comments. Research discussed in this paper was made possible through a grant from PARG, University of the Witwatersrand, whose support, in the person of the Leader, Lee Berger, is gratefully acknowledged. 


\section{References}

Aiello, L., \& Dean, M.C. (1990). An Introduction to Human Evolutionary Anatomy. London: Academic Press.

Beynon, A.D. \& Dean, M.C. (1988). Distinct dental development patterns in early fossil hominids. Nature, 335, 509-14.

Bromage, T.G. \& Dean, M.C. (1985). Re-evaluation of age at death of immature fossil hominids. Nature, 317, 525-27.

Conroy, G.C. \& Kuykendall, K. (1995). Paleopediatrics: or when did human infants really become human? American Journal of Physical Anthropology, 98, 121-31.

Conroy, G.C. \& Vannier, M.W. (1991). Dental development in South African australopithecines. Part II: Dental stage assessment. American Journal of Physical Anthropology, 86, 137-56.

Dean, M.C. (1995). The nature and periodicity of incremental lines in primate dentine and their relationship to periradicular bands in $\mathrm{OH} 16$ (Homo habilis). In: Aspects of Dental Biology: Palaeontology, Anthropology and Evolution, ed. J Moggi-Cecchi, pp. 239-66. Florence: International Institute for the Study of Man.

Hartwig-Scherer, S. \& Martin, R.D. (1991). Was "Lucy" more human than her "child"? Journal of Human Evolution, 21, 439-49.

Leakey, L.S.B., Tobias, P.V. \& Napier, J. (1964). A new species of the genus Homo from Olduvai Gorge. Nature, 202, 7-9.

Lewis, A.B. \& Garn, S.M. (1960). The relationship between tooth formation and other maturational factors. Angle Orthodontist, 30, 70-77.

Lockwood, C.A. (1997). Variation in the Face of Australopithecus africanus and other African Hominoids. Unpubl. $\mathrm{PhD}$ Thesis, University of the Witwatersrand, Johannesburg.

Lockwood, C.A. \& Moggi Cecchi, J. (1998). The systematic position of Stw 183, an adolescent maxilla from Sterkfontein. American Journal of Physical Anthropology, Suppl. 26, 151-52.

Mann, A.E. (1975). Some Paleodemographic Aspects of the South African Australopithecines. Philadelphia, University of Pennsylvania Press.

Mann, A., Lampl, M. \& Monge, J (1990). Patterns of ontogeny in human evolution: evidence from dental development. Yearbook of Physical Anthropology, 33, 111-50.

Martin, R.D. (1983). Human brain evolution in an ecological context. Fifty-second James Arthur Lecture on the Evolution of the Human Brain. New York: American Museum of Natural History.

Moggi Cecchi, J., Tobias, P.V. \& Beynon, A.D. (1998). The mixed dentition and associated skull fragments of a juvenile fossil hominid from Sterkfontein, South Africa. American Journal of Physical Anthropology, 106, 425-65.

Moorrees, C.F.A., Fanning, E.A. \& Hunt, E.E. (1963). Age variation of formation stages for ten permanent teeth. Journal of Dental Research, 42, 1490-502.

Smith, B.H. (1986). Dental development in Australopithecus and early Homo. Nature, 323, 327-30.

Smith, B.H. (1994). Patterns of dental development in Homo, Australopithecus, Pan and Gorilla. American Journal of Physical Anthropology, 94, 307-25.

Tobias, P.V. (1991). Olduvai Gorge vols. 4A and 4B. The skulls, Endocasts and Teeth of Homo habilis. Cambridge: Cambridge University Press.

Wood, B.A. (1992). Origin and evolution of the genus Homo. Nature, 355, 783-90.

Wood, B.A. (1993). Early Homo: how many species? In: Species, Species Concepts, and Primate Evolution, ed. W.H. Kimbel \& L.B. Martin, pp. 485-522. New York: Plenum Press. 


\section{G. Philip Rightmire}

Department of Anthropology

State University of New York at Binghamton, Binghamton, NY 13902-6000, U.S.A.

Keywords: Bodo, Homo erectus, Homo heidelbergensis, phylogeny, speciation

\section{Morphological Diversity in Middle Pleistocene Homo}

\begin{abstract}
Hominid usually identified as Homo erectus dispersed from Africa into Eurasia well before 1.0 million years ago. These groups persisted in Java and China until late in the Middle Pleistocene, well after the time when the species can be documented in the West. The cranium from Bodo (Middle Awash, Ethiopia) is thought to mark one of the first appearances of people distinct from Homo erectus. This well preserved specimen reveals many aspects of the morphology of the face and braincase. Bodo is like Homo erectus in some of its features, but endocranial volume, frontal proportions, shape of the temporal bone, and details of the nose and palate resemble recent Homo. In these respects, Bodo is similar to other fossils from Broken Hill (Kabwe), Elandsfontein and Ndutu in Africa and hominids including Arago and Petralona from Europe. This evidence is in keeping with an episode of speciation occurring in the midQuaternary and giving rise to people that are more modern anatomically. Such populations have frequently been described as "archaic" Homo sapiens. This situation is unsatisfactory for several reasons, and it can be argued that the new species is more appropriately called Homo heidelbergensis. This taxon may be the stem from which both Neanderthals and modern humans are derived. The latter probably evolved in Africa, as suggested by fossils such as Omo 1, Laetoli 18 and Jebel Irhoud.
\end{abstract}

\section{Introduction}

In their well-known 1975 volume After the Australopithecines, Karl Butzer and Glynn Isaac listed many uncertainties surrounding human evolution in the Middle Pleistocene (Butzer \& Isaac, 1975). Some of these questions have been answered. But the 'muddle in the middle' is still evident, particularly in respect of the systematics of earlier Middle Pleistocene hominids. Specimens from Africa and Eurasia have most frequently been described as 'archaic' representatives of our own species. However, this situation is unsatisfactory for several reasons. The fossils retain a number of (primitive) erectus-like characters, and this anatomy sets them apart from recent humans. Simply lumping diverse ancient groups with living populations obscures these differences. Some authors have argued for a system of grades based on morphology and dating, but neither this scheme nor others designating subspecies of Homo sapiens have solved the problem. I will argue that distinct lineages (species level taxa) should be recognized.

\section{Dispersals of Homo erectus}

A first point concerns the role played by Homo erectus, which is the taxon usually considered to be ancestral to Middle Pleistocene humans. This species has been a focus of controversy, and of course there are questions about taxonomy. Nevertheless, most workers would concede that populations resembling Homo erectus dispersed from Africa into Eurasia, well before 1.0 million years ago. Probably these movements occurred over a long period of time. Indeed, the hominids may have made 
repeated sorties, introducing crude chopping tools and stone flakes into different regions (Bar-Yosef, 1995). Evidence documenting this dispersal comes from several sites, including Dmanisi in Georgia and Ubeidiya in Israel. Representatives of Homo erectus also flourished in the East Asian tropics, before moving into more temperate regions.

The picture emerging is one of Homo erectus as a widespread, polytypic species, with groups persisting longer in some regions than in others. The pattern documented in China and especially in Java contrasts with that in the West, where Homo erectus seems to disappear from the record at a relatively early date (Groves, 1994; Dean \& Delson, 1995). Also, the Asian populations apparently became more specialized. Skulls from Sangiran and Ngandong in Java and Zhoukoudian in China exhibit a higher incidence of characters associated with cranial robusticity. This may signal a different evolutionary fate. There is no reason to suppose that all demes of Homo erectus evolved further, and the evidence is consistent with extinction of some (or all) populations in the Far East. A less specialized branch of the species may have given rise to later humans (Rightmire, 1990; Harrison, 1993). This budding of a daughter lineage from Homo erectus must have occurred very early in the Middle Pleistocene, if not before. Africa or western Asia are the areas in which these more advanced people probably originated. Indeed, an African locus is consistent with findings from archaeology, environmental reconstruction, and patterns of animal dispersal (Foley \& Lahr, 1997).

\section{The first humans of modern aspect}

Figure 1 illustrates the relationship of Homo erectus to later species. The tree has a geographic component, and there is a time scale to one side. Several splitting events (marked with an S) are indicated. The one of interest, producing the first populations different from $H$. erectus, took place in Africa. Evidence in this regard comes from several key localities. These include Bodo in the Middle Awash region of Ethiopia. The Bodo cranium, and later a broken parietal from a second individual, were found with Acheulean artifacts. The face and front of the braincase are reasonably complete, and Bodo is like Homo erectus in some of its features. In other respects, the cranium is more advanced in its anatomy. Brain size (close to $1300 \mathrm{cc}$ ) is greater than expected for Homo erectus. Frontal bone proportions, the squamous temporal, the cranial base and the face show resemblances to recent Homo (Rightmire, 1996).

This mix of characters suggests that the Middle Awash individuals are 'intermediate' in their morphology. However, several of the similarities to Homo erectus are plesiomorphies that cannot be considered diagnostic. It is clear that the cranium shares other apomorphic features with populations that are more modern. Bodo can be grouped with the famous fossil from Broken Hill (Kabwe) in Zambia. This hominid was found by miners in 1921, and it is one of the treasures of prehistory. The face and braincase are remarkably well preserved. Comparable specimens are known from Elandsfontein in South Africa, Lake Ndutu in Tanzania, and probably Eyasi. All of these localities are Middle Pleistocene in age. For Bodo, new radiometric dates along with the evidence from animal bones and archaeology point to an age of about 600,000 years (Clark et al., 1994).

As has been recognized before, the African hominids are similar to other, roughly contemporary people known from Europe. Like Broken Hill, the cranium from Petralona in Greece is very complete. Although there is doubt about both its original provenience within the cave and its association with an extinct fauna, this individual is of Middle Pleistocene antiquity (Cook et al., 1982; Grün, 1996). Petralona and Broken Hill differ only slightly in orbit size, frontal proportions, and prominence of the torus crossing the occipital bone. In general they are remarkably alike. Resemblances are apparent in the height, breadth and massive construction of the upper face and cheek, several measures of facial projection, configuration of the brows, and many aspects of vault shape.

Multivariate studies of skull form have been carried out by several workers. For example, Van Vark (1995) has used 17 dimensions of the face and braincase to construct a measure of generalized distance 


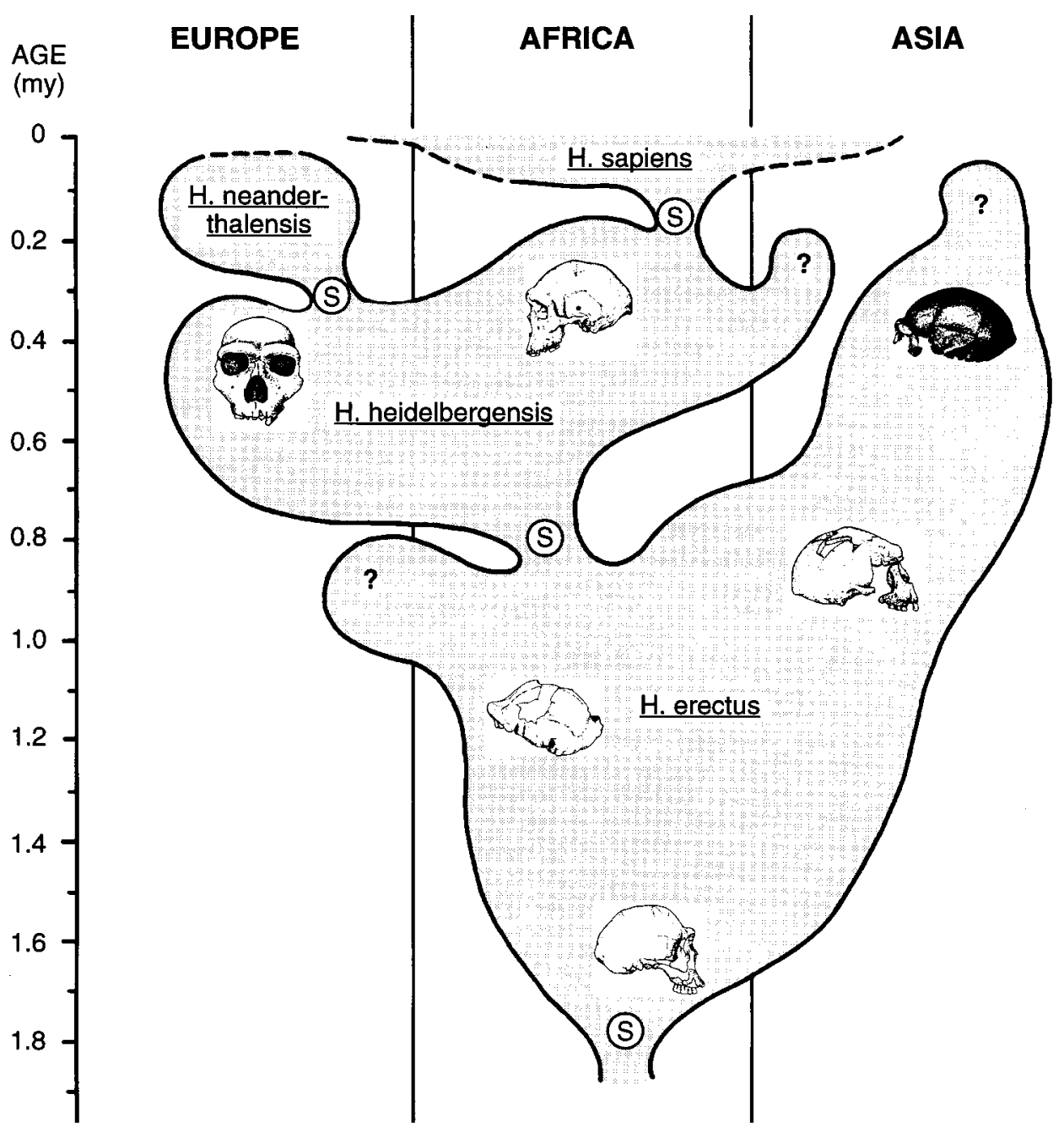

Figure 1. Tree illustrating the evolution and geographic distribution of Homo in the Pleistocene. Homo erectus is assumed to originate in Africa and then spread quickly to Asia and probably to Europe. Homo heidelbergensis is distributed from Africa into Eurasia during the Middle Pleistocene. Whether this species reached the Far East is still a question. European Homo heidelbergensis gives rise to the Neanderthals, while an African branch of Homo heidelbergensis is ancestral to modern humans. Altogether, four speciation events (S) are depicted.

$\left(D^{2}\right)$. This shows Broken Hill and Petralona to differ less from one another than is the case for Upper Paleolithic and recent humans. When a reconstruction of the partial cranium from Arago Cave in France is included in this analysis, it also falls close to Broken Hill, and there seem to be good phenetic grounds for lumping these hominids together. Ancient finds from Germany and Hungary are generally more fragmentary. But if the Mauer mandible is grouped with other specimens from Europe and Africa, then 
the entire assemblage can be referred to Homo heidelbergensis (Rightmire, 1990; Stringer, 1993; Groves \& Lahr, 1994).

This species was named by Otto Schoetensack in 1908, to accommodate the jaw found near Heidelberg. Schoetensack was impressed with the primitive character of his fossil, but he recognized that it must be human. Later (in 1960), Clark Howell noted that the specimen can be distinguished by its ramus breadth, anterior depth of the corpus, and moderate size of the dentition, both from Far Eastern Homo erectus and from the Ternifine people. Howell left open the relationship of Mauer to European groups, including the Neanderthals. While there are still obvious difficulties with linking the mandible to individuals such as Petralona (for which there is no lower jaw), the fossil is usually lumped with earlier Middle Pleistocene humans in the way that I have outlined. As defined on this basis, Homo heidelbergensis retains a number of archaic characters. It may be the stem from which both Neanderthals and modern people are derived.

\section{Continuing questions}

I recognize that this point is controversial, and there are questions about the make-up of Homo heidelbergensis. It can be argued that the European and African specimens should be set apart, as representatives of distinct lineages. Even the oldest Middle Pleistocene Europeans may exhibit apomorphic traits that align them (only) with Neanderthals (Vandermeersch, 1985; Arsuaga et al., 1993; Hublin, 1996; Dean et al., 1998). In this reading of the evidence, Mauer and Arago Cave, Petralona, Bilzingsleben, Vertesszöllös and Swanscombe document a single line evolving toward the populations at Steinheim in Germany and Atapuerca in Spain. These assemblages can be referred to Homo heidelbergensis, but there seems to be no clear separation of this group from early Neanderthals (or even "classic" Neanderthals of the Late Pleistocene).

Certainly, parts of this scenario are reasonable. It is easy enough to track the Neanderthals back to Steinheim or even to Swanscombe. Earlier in the Middle Pleistocene, however, Neanderthal roots are more difficult to find. Some authors have pointed to Vertesszöllös or Bilzingsleben as documenting continuity, but this material is fragmentary. The Mauer jaw is complete but shows few if any specific links to later European populations. More important here are the crania from Arago and Petralona. The question is whether there are clear signs of Neanderthal morphology, especially in the facial region.

The cranium from Arago has a face that is largely complete but unfortunately damaged. The frontal bone, interorbital pillar, nose and cheeks show numerous cracks, and localized crushing is apparent. In spite of these problems, some workers see definite resemblances to Neanderthals. The infraorbital surface of the maxilla seems flattened or slightly convex, and the cheek bones are obliquely oriented (Hublin, 1996). Also, there is much forward protrusion of the face at subspinale (in the midline, just below the nasal opening).

These observations are suggestive, but in fact it is difficult to assess key aspects of morphology. The wall of the Arago maxilla is generally flattened in the manner of Neanderthals, but there is slight hollowing laterally, below the orbit. Also, it is not clear that the zygomatic bone is swept back (obliquely oriented) so noticeably as in later populations. In facial forwardness at subspinale, Arago is in the Neanderthal range, and Petralona shows almost as much protrusion. But Broken Hill is similar, and a low zygomaxillary angle does not necessarily align Arago or Petralona with Neanderthals rather than with other Middle Pleistocene humans.

Given this level of doubt concerning specific Neanderthal affinities of Arago or Petralona, perhaps it is premature to disassociate these specimens from contemporary Africans. In my view, all of the earlier Middle Pleistocene hominids share both erectus-like features and a suite of derived traits common to later humans. It is hard to find any morphological basis for restricting Homo heidelbergensis to Europe. 


\section{The evolutionary role of Homo heidelbergensis}

If this taxon evolved in Africa, then it may be closely related not only to Neanderthals but also modern humans. Speciation to Homo sapiens probably took place later in the Middle Pleistocene, as depicted in the scenario of Figure 1. This event is documented by fossils such as Florisbad, Laetoli, the Omo material, and Jebel Irhoud. Especially the cranium from Laetoli in Tanzania is less archaic than Broken Hill or Bodo and shows features that link it to more recent populations. The brow is only moderately projecting, and the parietal bones are large and strongly curved. The back of the vault is rounded and not flexed. More evidence for continuity comes from Late Pleistocene sites such as Klasies River Mouth in South Africa, along with Skhul and Qafzeh in Israel. Here the picture is quite convincing, as Klasies and the Levantine caves were occupied by anatomically 'close-to-modern' people during the Last Interglaciation.

Of course there is still uncertainty about the course of human evolution in the Middle Pleistocene, and not everyone will agree that the 'muddle' alluded to by Butzer and Isaac has been clarified. There is much additional material to consider, including the important new finds from Gran Dolina (Bermudez de Castro et al., 1997) and other localities in Europe (Ascenzi et al., 1996). South Asia continues to pose questions, although the Narmada assemblage points to a human presence in India, perhaps early in the Middle Pleistocene (Sonakia \& Biswas, 1998). In China, sites such as Dali and Jinniushan have yielded 'archaic' crania that are more advanced than Homo erectus (Wu \& Poirier, 1995). These Far Eastern individuals possess some of the same derived features as do the hominids from Africa and Europe, although their facial morphology may differ from that of Homo heidelbergensis. Fitting these diverse fossils into our family tree will be a challenge.

\section{Acknowledgements}

For the invitation to attend the Dual Congress 1998 and present this paper in Colloquium 12, I am most grateful to Bernard Wood and Phillip V. Tobias. The L.S.B. Leakey Foundation and the Boise Fund supported much of the research on which this contribution is based.

\section{References}

Arsuaga, J.-L., Martinez, I., Gracia, A., Carretero, J.M. \& Carbonell, E. (1993). Three new human skulls from the Sima de los Huesos Middle Pleistocene site in Sierra de Atapuerca, Spain. Nature, 362, 534-37.

Ascenzi, A., Biddittu, I., Cassoli, P.F., Segre, A.G. \& Segre-Naldini, E. (1996). A calvarium of late Homo erectus from Ceprano, Italy. Journal of Human Evolution, 31, 409-23.

Bar-Yosef, O. (1995). The role of climate in the interpretation of human movements and cultural transformations in western Asia. In: Paleoclimate and Evolution with Emphasis on Human Origins, ed. E.S. Vrba, G.H. Denton

T.C. Partridge, \& L.H. Burckle, pp. 507-23. New Haven: Yale University Press.

Bermudez de Castro, J.M., Arsuaga, J.L., Carbonell, E., Rosas, A., Martinez, I. \& Mosquera, M. (1997). A hominid from the Lower Pleistocene of Atapuerca, Spain: possible ancestor to Neandertals and modern humans. Science, 276, 1392-95.

Butzer, K.W. \& Isaac, G.L., (eds). (1975). After the Australopithecines. The Hague: Mouton.

Clark, J.D., de Heinzelin, J., Schick, K.D., Hart, W.K., White, T.D., WoldeGabriel, G., Walter, R.C., Suwa, G., Asfaw, B., Vrba, E. \& H.-Selassie, Y. (1994). African Homo erectus: old radiometric ages and young Oldowan assemblages in the Middle Awash valley, Ethiopia. Science, 264, 1907-10.

Cook, J., Stringer, C.B., Currant, A.P., Schwarcz, H.P. \& Wintle, A.G. (1982). A review of the chronology of the European Middle Pleistocene hominid record. Yearbook of Physical Anthropology, 25, 19-65.

Dean, D. \& Delson, E. (1995). Homo at the gates of Europe. Nature, 373, 472-73.

Dean, D., Hublin, J.-J., Holloway, R.L. \& Ziegler, R. (1998). On the phylogenetic position of the pre-Neandertal specimen from Reilingen, Germany. Journal of Human Evolution, 34, 485-508.

Foley, R. \& Lahr, M.M. (1997). Mode 3 technologies and the evolution of modern humans. Cambridge Archaeological Journal, 7, 3-36.

Groves, C.P. (1994). The origin of modern humans. Interdisciplinary Science Reviews, 19, 23-34. 
Groves, C.P. \& Lahr, M.M. (1994). A bush not a ladder: speciation and replacement in human evolution. Perspectives in Human Biology, 4, 1-11.

Grün, R. (1996). A re-analysis of electron-spin resonance dating results associated with the Petralona hominid. Journal of Human Evolution, 30, 227-41.

Harrison, T. (1993). Cladistic concepts and the species problem in hominoid evolution. In: Species, Species Concepts and Primate Evolution, ed. W.H. Kimbel, \& L.B. Martin, pp. 345-71. New York: Plenum Press.

Howell, F.C. (1960). European and northwest African Middle Pleistocene hominids. Current Anthropology, 1, 195232.

Hublin, J.-J. (1996). The first Europeans. Archaeology, 49, 36-44.

Rightmire, G.P. (1990). The Evolution of Homo erectus. Comparative Anatomical Studies of an Extinct Human Species. Cambridge: Cambridge University Press.

Rightmire, G.P. (1996). The human cranium from Bodo, Ethiopia: evidence for speciation in the Middle Pleistocene? Journal of Human Evolution, 31, 21-39.

Schoetensack, O. (1908). Der Unterkiefer des Homo heidelbergensis aus den Sanden von Mauer bei Heidelberg. Ein Beitrag zur Paläontologie des Menschen, pp. 1-67. Leipzig: Engelmann.

Sonakia, A. \& Biswas, S. (1998). Antiquity of the Narmada Homo erectus, the early man of India. Current Science, 75, 391-93.

Stringer, C.B. (1993). New views on modern human origins. In: The Origin and Evolution of Humans and Humanness, ed. D.T. Rasmussen, pp. 75-94. Boston: Jones and Bartlett.

Vandermeersch, B. (1985). The origin of the Neandertals. In: Ancestors: the Hard Evidence, ed. E. Delson, pp. 306309. New York: Alan R. Liss.

Van Vark, G.N. (1995). The study of hominid skeletal remains by means of statistical methods. In: Biological Anthropology: the State of the Art, ed. N.T. Boaz \& G.D. Wolfe, pp. 71-90. Corvallis: Oregon State University Press.

Wu, X.Z. \& Poirier, F.E. (1995). Human Evolution in China. A Metric Description of the Fossils and a Review of the Sites. New York: Oxford University Press. 


\section{Bernard Wood ${ }^{1} \&$ Mark Collard ${ }^{2}$}

\author{
${ }^{1}$ Department of Anthropology \\ George Washington University \\ 2110 G St. NW, Washington DC 20052, USA \\ ${ }^{2}$ Department of Anthropology \\ University College London, WC1E 6DB, UK
}

Keywords: Homo, Genus, grade, clade

\section{Evolving Interpretations of Homo}

\begin{abstract}
The criteria for the inclusion of species within the genus Homo have changed over the years. The tendency has been for a stepwise relaxation of these criteria, yet it has been more than thirty years since the most recent, and most radical, revision of the boundaries of the genus. There is no widely accepted definition of a genus, but we suggest that genera should be both a clade and a grade. In other words a genus should be both a monophyletic group and a group of species that share a common adaptive regime. We have examined the available evidence relating to locomotion, diet, encephalization and body shape, and conclude that if Homo habilis sensu stricto and Homo rudolfensis are included in Homo that genus fails both the 'grade' and 'clade' tests. We suggest that Homo can only be defined both cladistically and adaptively if its membership, among the hominids of the late Pliocene/early Pleistocene, is limited to early African Homo erectus/homo ergaster. Even then, there are substantial differences in absolute and relative brain size between $H$. ergaster and temporally-later Homo species.
\end{abstract}

\section{Introduction}

When the genus Homo was introduced in 1758 by Carolus Linnaeus it embraced two extant species: One, Homo troglodytes, also known as Homo sylvestris, is now known to have been based partly on the orangutan, and partly on myth. The other was Homo sapiens, the species to which all modern human populations belong. In the course of the $c$. 250 years since its introduction, our understanding of Homo has been changed by the addition of fossil species. This has resulted in the step-by-step relaxation of the criteria for the inclusion of species into the genus Homo. This paper traces this trend towards inclusivity, and sets out how it has affected the way Homo is defined. We will also demonstrate that some of the criteria that have been suggested are difficult, if not impossible, to determine from the fossil record. We conclude with a proposal for a revised definition of Homo that would result in the exclusion of two of the species, Homo habilis and Homo rudolfensis, that are presently included in the genus.

\section{Relaxing the criteria - the major steps}

It was the absorption of four fossil species, Homo neanderthalensis, Homo heidelbergensis, Homo erectus and Homo habilis, over the course of exactly a century, that brought about the most significant changes in our interpretation of the genus Homo. This section will explore in more detail the implications of each of these additions to the genus.

\section{Homo neanderthalensis King, 1864}

The type specimen of $H$. neanderthalensis consists of a single, adult, partial skeleton recovered from the Feldhofer Cave in the Neander Valley in Germany in 1856. With hindsight this was not the first evidence of Neanderthals to come to light, for a child's skull found in 1829, at a site in Belgium called Engis, and a cranium recovered in 1848, from Forbes' Quarry in Gibraltar, also display the distinctive 
Neanderthal morphology. It was just less than thirty years after the recovery of the type specimen that the next Neanderthal discovery was made in Moravia (Sipka, 1880). Thereafter came discoveries from Belgium (Spy, 1886), Croatia (Krapina, 1899-1906), Germany (Ehringsdorf, 1908), France (Le Moustier, 1908 and 1914; La Chapelle-aux-Saints, 1908; La Ferrassie, 1909, 1910 and 1912, and La Quina, 1911) and in the adjacent Channel Islands (St. Brelade, 1911). Notwithstanding the range of taxa these remains were initially attributed to, all of them share the characteristic Neanderthal morphology. In 1924-26 the first Neanderthal was found outside of Europe at Kiik Koba in the Crimea. Thereafter came discoveries at Tabun Cave on Mt. Carmel (1929), and then in Asia, at Teshik Tash (1938). In the meantime, two more sites in Italy, Saccopastore (1929-35) and Guattari/Circeo (1939), had yielded the remains of Neanderthals. Further evidence was added after the 1939-45 war, first from Shanidar, Iraq (1953 and 1957-60), and then from Amud (1961, 1964 and thereafter) and Kebara (1964 and thereafter) in Israel, and more recently from sites in France and Spain (e.g. St. Cesaire, 1979 and Zafarraya, 1983 and 1992). Thus, Neanderthal remains have been found throughout Europe, with the exception of Scandinavia, as well as in the Near East, the Levant and Western Asia.

The inclusion of the Neanderthals within Homo resulted in modifications to the range of both the cranial and postcranial morphology within the genus. The Neanderthal cranium typically has discrete and rounded supraorbital ridges, a face which projects anteriorly in the midline, laterally-projecting and rounded parietal bones, a rounded, posteriorly-projecting occipital bone, large incisor teeth, and postcanine teeth with large root canals. The postcranial peculiarities include limb bones with stout shafts and relatively large joint surfaces, especially well-marked areas for the attachment of a muscle that helps to control the shoulder and an elongated pubic ramus of the pelvis. Despite the peculiarity of the pubis there is no indication that the Neanderthals were anything other than upright, obligate, long-range, bipeds. Estimates of their brain size suggest that their brains were as large as, if not larger than, the brains of living Homo sapiens.

\section{Homo heidelbergensis Schoetensack, 1908}

This species nomen was introduced for a hominin mandible found in 1907 during excavations to extract sand from a quarry at Mauer, near Heidelberg, Germany. The mandible has no chin and the corpus is a good deal larger than those of the mandibles of modern humans living in Europe today. The next evidence within Europe of fossil remains that showed equivalently archaic features came from Petralona (Greece), where in 1959 a cranium was recovered from a cave. Thereafter came evidence from Montmaurin (1949) and Arago (1964-9) in France, Vertesszöllös (1965) in Hungary, Bilzingsleben (1972-7, 1983 and thereafter) in Germany, and most recently from the Gran Dolina (1994-1996), at Atapuerca in Spain (but see Bermúdez de Castro et al., 1997, for an alternative classification).

The first African evidence for 'archaic' H. sapiens came in 1921 with the recovery of a cranium from a cave in the Broken Hill Mine at Kabwe, in what is now Zambia. Other morphologically comparable remains have been found from the same time range at Florisbad (1932), Eyasi (1935) and Rabat (1933), Jebel Irhoud (1961 and 1963) in southern, East and North Africa, respectively. The earliest evidence of this African 'archaic' group comes from Bodo (1976), which is dated at c. $600 \mathrm{Kyr}$, and specimens intermediate in age (c. $400 \mathrm{Kyr}$ ) include crania from Hopefield/Elandsfontein (1953), Ndutu (1973), Sale (1971), and Thomas Quarry (1969 and 1972). Asian evidence comes from Ngandong, (1931-33) in Indonesia, Dali (1978), Mapa (1958), and Yunxian (1989 and 1990) in China, and Hathnora (1982) in India.

If there is to be a single species name to cover the archaic material from Europe, Africa and Asia, then $H$. heidelbergensis Schoetensack, 1908 has priority. If there was compelling evidence that the latter two regions sampled equally good species, then the name for the African species would be $H$. helmei Dreyer, 1935, and if the Ngandong material is not to be included in H. erectus (see below), the appropriate species name for the Asian species would be H. soloensis Oppenoorth, 1932. 
What sets this material apart from $H$. sapiens and $H$. neanderthalensis is the morphology of the cranium. The brain cases are often, but not always, smaller than those of modern humans and the Neanderthals. They are always more robustly built, with large ridges above the orbits and a thickened occipital region. They have some, but not all, of the features of H. erectus crania (see below), but they lack the derived features of Neanderthal crania. Postcranially the shapes of the limb bones are much like those of $H$. sapiens, except that the shafts of the long bones are generally more robust.

\section{Homo erectus (Dubois, 1892) and Homo ergaster Groves and Mazák, 1975}

In 1890 Eugene Dubois found a mandible fragment in Java at a site called Kedung Brubus. Less than a year later, in 1891, at excavations on the banks of the Solo river at Trinil, workers unearthed the skull cap that was to become the type specimen of a new, and significantly more primitive, species of fossil hominid. Initially Dubois placed the skull cap in the genus Anthropopithecus, but two years later he changed the generic designation to Pithecanthropus. The focus for the next phase of field research in Java was the Plio-Pleistocene sediments of what is called the Sangiran Dome. It was here that in 1937 a German palaeontologist, Ralph von Koenigswald, recovered a cranium, Sangiran 2, that resembled the distinctive shape of the Trinil skull cap, but which had a brain smaller $\left(c .800 \mathrm{~cm}^{3}\right)$ than that of the Trinil calotte.

In the meantime the Swedish palaeontologist, Gunnar Andersson, together with a junior colleague from Austria, Otto Zdansky, had spent two seasons in 1921 and 1923 excavating a cave at Choukoutien (now Zhoukoudian), near Peking (Beijing), in China. Two teeth, an upper molar and a lower premolar, originally identified as being ape-like, were judged to be hominid. Together with a left permanent first molar (Ckn. A.1.1) found in 1927, the three specimens were referred to a new genus and species, Sinanthropus pekinensis Black, 1927. Cranial fragments were found at Locus B in 1928, the first calvaria at Locus D in 1929, and excavations continued at Zhoukoudian until their interruption by World War 2 (1939-45).

The morphology of the fossils recovered from Locality 1 at Zhoukoudian resembled that seen in the Pithecanthropus erectus remains from Java. Since then similar-looking material has been found at sites which include Lantian (1963-4), also in China, at Swartkrans (1949 and thereafter) in southern Africa, and at Olduvai, (1960 and thereafter), West and East Turkana (1970 and thereafter), Melka Kunturé (1973 and thereafter) and most recently at Buia (1995-1997) in Eritrea, in East Africa, and from Tighenif (19545 ) in North Africa. Many consider that the remains from Ngandong, Indonesia (see above), should be included in this hypodigm. Recent discoveries at Dmanisi, Georgia, have been referred to Homo ergaster.

Despite the relatively large numbers of crania recovered from Java and China, relatively little was known about the postcranial morphology of this group of taxa, and it was discoveries from East African sites that provided the crucial evidence. This came in the form of a pelvis and femur from Olduvai Gorge (OH 28), two fragmentary partial skeletons from East Turkana (KNM-ER 803 and 1800), and the unusually well-preserved skeleton from West Turkana (KNM-WT 15000).

The crania of these remains all have a low vault, with the greatest width towards the base. There is a substantial, essentially continuous, torus above the orbits, behind which there is a sulcus. There is usually a sagittal torus, and an angular torus that runs towards the mastoid process. The occipital region is sharply angulated, with a well-marked supratoral sulcus. The inner and outer tables of the cranial vault are thickened and the cranial capacity is less than that seen in H. heidelbergensis. The roots of the premolar teeth tend to be more complex than in the latter taxon. The cortical bone of the postcranial skeleton is generally thick, the long bones are robust, and the shafts of the femur and the tibia are relatively flattened from front to back relative to those of other Homo species; this is referred to as platymeria and platycnemia, respectively.

Until the taxonomy was rationalized, the two main subsets of what is now the hypodigm of $H$. erectus were attributed to four genera, Pithecanthropus and Meganthropus in Java, Sinanthropus in China, with the fourth genus, Atlanthropus, being used for the North African material. In 1943 Franz 
Weidenreich formally sank Sinanthropus into Pithecanthropus, and in 1964 Le Gros Clark supported the Mayr (1944) proposal that Pithecanthropus and Atlanthropus be sunk into Homo. This, of course, had the effect of changing the definition of Homo so that it could accommodate the relatively primitive remains that are included in the hypodigm of $H$. erectus. In particular this meant that the genus Homo now included a much wider range of cranial shape, brain size and mandible shape and size. It was the incorporation of this material into Homo that resulted in the change in diagnosis between the 1955 and 1964 editions of Le Gros Clark's Fossil Evidence for Human Evolution. The incorporation of the hypodigm of $H$. ergaster into this group extended the range of dental and mandibular morphology to include teeth with more complex crowns and roots and mandibles with robust corpora, and it confirmed the inclusion within Homo of individuals with endocranial volumes that barely exceed $800 \mathrm{~cm}^{3}$.

\section{Homo habilis Leakey, Tobias and Napier, 1964}

A year after a new genus and species, Zinjanthropus boisei Leakey, 1959 (now referred to Australopithecus or Paranthropus) had been created for the $\mathrm{OH} 5$ cranium, the Leakeys found more hominid fossil evidence in the form of substantial parts of both parietal bones, much of a mandible and at least 13 hand bones of a juvenile skeleton $(\mathrm{OH} 7)$. In the next year or so, further evidence of a 'nonrobust' hominid was unearthed in Bed I of Olduvai Gorge (OH 4 and 6 - skull fragments and teeth; $\mathrm{OH}$ 8 - an adult foot; $\mathrm{OH} 14$ - juvenile cranial fragments, and $\mathrm{OH} 16$ - the fragmented cranial vault and maxillary dentition of a young adult) as well as in Bed II (OH 13 - the incomplete skull of an adolescent).

In 1964 Louis Leakey and two colleagues set out the case for recognizing a new species for the 'gracile' hominid remains from Olduvai, and they also proposed that the new species should be accommodated within the genus Homo, as Homo habilis Leakey, Tobias and Napier, 1964. The addition of H. habilis to the genus Homo meant that Le Gros Clark's 1955 diagnosis of the latter needed to be amended. This involved relaxing some criteria, such as brain size, so that the relatively small-brained (c. $600-700 \mathrm{~cm}^{3}$ ) crania from Olduvai could be included. Leakey and his colleagues claimed that other criteria, such as dexterity, an erect posture and a bipedal gait, did not need to be changed because their interpretation of the capabilities of the H. habilis remains from Olduvai was consistent with these functional criteria.

In due course important additional specimens from Olduvai (e.g. OH 24 and $\mathrm{OH}$ 62) were added to the hypodigm. Fossils attributed to 'early Homo', or H. habilis sensu lato, had also been found at Koobi Fora, Members $\mathrm{G}$ and $\mathrm{H}$ of the Shungura Formation, Member 5 at Sterkfontein, and Member 1 at Swartkrans. This material displays a spectrum of cranial morphology, with endocranial volumes ranging from just less than $500 \mathrm{~cm}^{3}$ to $c .850 \mathrm{~cm}^{3}$. The mandibles also vary in size, the larger ones having robust bodies and premolar teeth with complex crowns and roots. Our knowledge of the postcranial skeleton has traditionally come from the remains from Bed I at Olduvai Gorge (e.g. OH 7, 8 and 35), but although these were allocated to $H$. habilis, it is by no means certain that one can exclude their allocation to $P$. boisei. The only postcranial evidence from Olduvai Gorge which can, with confidence, be allocated to H. habilis and not to P. boisei, is the associated skeleton $\mathrm{OH}$ 62. Unfortunately, very little useful morphology is preserved, but it is possible to determine the relative lengths of the segments of the upper and lower limbs, and these show that the skeleton had longer arms relative to leg length than is the case in any other species within Homo. If $\mathrm{OH} 62$ does belong to H. habilis, then its inclusion in the genus would mean that the postcranial skeleton of at least one species of Homo cannot be distinguished from that of Australopithecus and Paranthropus.

Some researchers expressed the view that $H$. habilis was simply too variable to make a plausible single species. Views are polarized, with some researchers supporting the retention of a single taxon, $H$. habilis sensu lato, for this material, and others supporting a 'two-taxon' solution. This debate has been reviewed elsewhere (Wood, 1996). 


\section{Homo after $\boldsymbol{H}$. habilis}

Whatever the detailed morphological criteria for allocating individual fossils to species, in practice three of the four commonly used criteria for allocating those species to Homo are inferences about performance, or technical competence. The only one to be based directly on morphological evidence is absolute brain size, but even this has been shown to be of questionable biological significance (Martin, 1983).

The three inferred criteria related to performance are language competence (Tobias, 1991), the ability to manufacture stone tools, and the related possession of a modern human-like precision grip (Leakey et al. 1964; Tobias, 1991). There is evidence that these criteria are either impossible to operate within the constraints of the hominid fossil record, or that the competencies they refer to can no longer be confidently restricted to Homo. For example, there is good evidence that language function cannot be reliably inferred from the gross appearance of endocasts, and that the language-related parts of the brain are not as well localized as earlier studies had implied (e.g. Galaburda \& Pandya, 1982; Gannon et al., 1998).

The connection between stone-tool manufacture and Homo is a long-standing one, which Kenneth Oakley made explicit in the content and the title of his book Man the Tool-Maker (Oakley, 1949). Although for five years Zinjanthropus was credited with being "the oldest yet discovered maker of stone tools" (Leakey, 1959, p.493), the mantle was soon passed to H. habilis (Leakey et al., 1964). Thereafter, the link between stone-tools and Homo has been maintained (e.g. Hill et al., 1992; Kimbel et al., 1996). However, since there is now overwhelming evidence that for much of the Pliocene in East Africa hominid species were both synchronic and sympatric, the link between Homo and stone-tool manufacture is difficult to substantiate. For example, the earliest stone artifacts were almost certainly contemporaneous with both Homo and Paranthropus (Kibunjia et al., 1992; Kibunjia, 1994; Wood et al., 1994; Semaw et al., 1997). There is also evidence that the type of dexterity needed for the manufacture of relatively crude stone artifacts is most likely not restricted to Homo (Susman, 1994; Marzke, 1997).

\section{Defining Homo: an alternative proposal and its implications}

There must first be agreement about the general criteria for defining a genus, then specific criteria for Homo need to be generated. We have proposed elsewhere that a genus should be both a clade and a grade and thus can be defined as "a species, or monophylum, whose members occupy a single adaptive zone" (Wood \& Collard, 1999). Thus, in the case of Homo this means that the species within it should be more closely related to the type species, H. sapiens, than they are to australopithecine genera. Furthermore, their adaptive strategies should be more similar to those used by H. sapiens than to the strategies used by the various australopithecine genera. The first of these criteria can be investigated using cladistic analysis, the second by objective methods designed to generate reliable inferences about adaptation from the fossil record.

Investigations using both traditional qualitative characters and characters generated from quantitative data suggest that the only fossil species that form a robust clade with $H$. sapiens are $H$. neanderthalensis, $H$. heidelbergensis, $H$. erectus, and H. ergaster. Likewise, when evidence about body size, body shape, and development is combined with inferences about locomotion and diet, it is clear that these are also the only Homo taxa whose adaptations are closer to those of H. sapiens than they are to the australopithecines; the relative brain size of $H$. ergaster does not align it so strongly with $H$. sapiens. Thus, according to cladistic and gradistic criteria, H. habilis sensu lato, or H. habilis sensu stricto and H. rudolfensis, are closer to australopithecines than they are to Homo. Consequently, they need either to be transferred to an existing australopithecine genus, or allocated to a new genus, or genera. We explored the taxonomic implications of the results of this analysis elsewhere (Wood and Collard, 1999). 


\section{Acknowledgments}

We thank Professor Phillip Tobias for the opportunity to participate in this Colloquium of the Dual Congress, and the Organizing Committee and the sponsoring bodies for their support. Research reported in this contribution was supported by the Leverhulme Trust, the Henry Luce Foundation, and the Wellcome Trust. We thank all the Institutions and Curators of the collections for permission to examine and analyze the fossils in their care.

\section{References}

Bermúdez de Castro, J.M., Arsuaga, J.L., Carbonell, E., Rosas, A., Martinez, I., \& Mosquera, M. (1997). A hominid from the lower Pleistocene of Atapuerca, Spain: Possible ancestor to Neandertals and Modern Humans. Science, 276, 1392-95.

Galaburda, A.M. \& Pandya, D.N. (1982). Role of architectonics and connections in the study of primate brain evolution. In: Primate Brain Evolution, ed. E. Armstrong \& D. Falk, pp. 203-16. New York: Plenum.

Gannon, P.J., Holloway, R.L., Broadfield, D.C. \& Braun, A.R. (1998). Asymmetry of chimpanzee planum temporale: humanlike pattern of Wernicke's brain language area homology. Science, 279, 220-22.

Hill, A., Ward, S., Deino, A., Curtis, G. \& Drake, R. (1992). Earliest Homo. Nature, 355, 719-22.

Kibunjia, M., Roche, H., Brown, F.H. \& Leakey, R.E.F. (1992). Pliocene and Pleistocene archaeological sites west of Lake Turkana, Kenya. J. Human Evol., 23, 431-38.

Kimbel, W.H., Walter, R.C., Johanson, J.L., Assefa, Z., Marean, C., Eck, G.G., Bobe, R., Hovers, E., Rak, Y., Vondra, C., Yemane, T., York, D., Chen, Y., Evensen, N.M., \& Smith, P.E. (1996). Late Pliocene Homo and Oldowan tools from the Hadar Formation (Kada Hadar Member), Ethiopia. J. Human Evol., 31, 549-61.

Leakey, L.S.B. (1959). A new fossil skull from Olduvai. Nature, 184, 491-93.

Leakey, L.S.B., Tobias, P.V., \& Napier, J.R. (1964). A new species of the genus Homo from Olduvai Gorge. Nature, 202, 7-9.

Martin, R.D. (1983). Human Brain Evolution in an Ecological Context. New York: American Museum of Natural History.

Marzke, M.W. (1997). Precision grips, hand morphology, and tools. Am. J. Phys. Anthrop., 102, 91-110.

Mayr, E. (1944). On the concepts and terminology of vertical subspecies and species. Natl. Research Council Committee on Common Problems of Genetics, Paleontology and Systematics, Bull. No. 2., 11-16.

Oakley, K.P. (1949). Man the Tool-Maker. London: British Museum (Natural History).

Semaw, S., Renne, P., Harris, J.W.K, Feibel, C.S., Bernor, R.L., Fesseha, N., \& Mowbray, K. (1997). 2.5-millionyear-old stone tools from Gona, Ethiopia. Nature, 385, 333-36.

Susman, R.L. (1994). Fossil evidence for early hominid tool use. Science, 265, 1570-73.

Tobias, P.V. (1991). The skulls, endocasts and teeth of Homo habilis. Olduvai Gorge: Vol. 4, pp. 1-921. Cambridge: Cambridge Univ. Press.

Wood, B.A. (1996). Origin and evolution of the genus Homo. In: Contemporary Issues in Human Evolution, Memoir 21. ed. W.E. Meickle, F.C. Howell \& N.G. Jablonski, pp. 105-14. San Francisco: California Acad. of Science. Wood, B.A \& Collard, M. (1999). The Human Genus. Science, 284, 65-71.

Wood, B.A, Wood, C.W. \& Konigsberg, L.W. (1994). Paranthropus boisei - an example of evolutionary stasis? Am. J. Phys. Anthrop., 95, 117-36. 
Jean-Pierre

Bocquet-Appel $^{1}$

and

Juan-Luis Arsuaga ${ }^{2}$

'UPR 2147, CNRS, 44 rue Amiral Mouchez, 75014 Paris, France

${ }^{2}$ Dpto. Paleontología. Fac. CC. Geológicas, Universidad Complutense de Madrid.

Ciudad Universitaria. 28040 Madrid. Spain

Keywords: Atapuerca hominid, Krapina hominid, Archaic human, catastrophe mortality, palaeodemography

\section{Probable Catastrophic Mortality of the Atapuerca (SH) and Krapina Hominid Samples}

\begin{abstract}
The Atapuerca $\mathrm{SH}(\mathrm{N}=32)$ and Krapina $(\mathrm{N}=23.5)$ observed age distributions are examined by testing two alternative mortality hypotheses: the catastrophe and the attritional pattern. The observed age distributions in both hominid sample are tested against the values typically observed of the variable $x_{1}$ (= number of skeletons aged from 5 to 9 years / number aged from 10-14 years) and $x_{2}$ (= number of skeleton aged from 5 to 14 years / number aged from 15 to 24 years) in pre-Jennerian modern human and chimpazee populations, for the two sides of population dynamics: in the living (the age pyramid) and in the corresponding dead, which represent the catastrophic and attritional mortality patterns, respectively. Three out of six statistical tests point in the same direction: the $\mathrm{SH}$ and Krapina age distributions come from the age pyramid. The curious age distribution of both hominid samples might be the result of a demographic crisis of a local group for a meta-population, caused by a severe enviromental fluctuation.
\end{abstract}

\section{Introduction}

In this paper we re-examine the observed age distributions of the Atapuerca (Sima de los Huesos, $\mathrm{SH})$ and Krapina hominid samples in the light of two alternative mortality hypotheses: the catastrophic or the attritional pattern (Craig \& Oertal, 1966; Hallam, 1972; Lyman, 1994). In the former, the age distribution represents that of a living population, whereas the latter represents a distribution of individuals that have died under normal circumstances, the important point being that attritional profiles are quite different from those of living populations. We test the two hypotheses of catastrophic-vsattritional mortality using parameter-values representing the two models, typically observed in modern human populations before 1796 (i.e. pre-Jenner and the use of vaccine). Do the death distributions of Atapuerca (SH) and Krapina fit a catastrophic mortality model statistically and qualitatively, or are they in better agreement with other published models under the attritional hypothesis, such as predation by carnivores, or as would be expected in a sample from an ancient cemetery?

Apart from the particular problem of the origin of the Atapuerca and Krapina human samples, the samples could offer an example of a demographic catastrophe of the kind which would have occurred on a regional scale in small human populations in the Pleistocene, as predicted theoretically (Royama, 1992; Mangel \& Tier, 1993).

\section{Paleontological sample data and estimated age distributions}

For the Atapuerca site ( $\mathrm{SH})$ we have used the age distribution data of Bermúdez de Castro \& Díez (1995; minimum number of individuals $(\mathrm{MNI})=32$ ), and for Krapina the data of White \& Toth (personal communication; average MNI for the age distribution: 23 maxillas +24 mandibles $=23.5$ ), 
rather than age distributions which were not based on MNI (Wolpoff, 1979). Estimates of ages-at-death for SH and Krapina were based on modern human patterns of dental eruption/formation for immature individuals. In the SH sample, radiographic observations were made for those individuals in which the teeth did not move freely. For adult individuals, Bermúdez de Castro (1995), Bermúdez de Castro \& Díez (1995) and Bermúdez de Castro et al. (1995), followed Miles (1963). It should be remembered that the Miles technique furnishes a calibration (rate of wear = linear relationship of age at death) based on the individuals of a sample whose dentitions are incompletely developed. This calibration is then extended to the adults. At first sight the method seems reasonably accurate for immature individuals and young adults, which seem to represent nearly all of both paleontological samples studied. The estimated age distributions at death of the SH and Krapina samples are given in Table 1.

\section{Statistical parameters and demographic reference populations}

The meaning of the observed age distributions in both hominid samples can be interpreted using the values typically observed of variables $x_{1}$ (= number of skeletons aged from 5 to 9 years / number aged from 10-14 years) and $x_{2}$ (= number of skeletons aged from 5 to 14 years / number aged from 15 to 24 years) in pre-Jennerian populations, for the two aspects of population dynamics: the living (i.e. the age pyramid), and the corresponding dead; these in turn represent catastrophic and attritional mortality patterns, respectively. These values are readily derived from life-tables. The choice of modern human samples from the literature to include in the reference population was based on three criteria: the health status of the individuals, the care taken in obtaining the age estimates, and the production of demographic data without passing through an intermediate model life-table. Ideally, the sample demographic parameters should be derived from a population of Neanderthal foragers, but a first biological as well as cultural approximation is to use ethnographic data from samples of modern human foragers. However, most of the published studies have used the life-table models of Coale \& Demeny (1966) to estimate the ages of individuals from populations with no written record. This approach superimposes a modern mortality pattern on the ethnographic data. We will rather use data of archaic mortality based on historical populations sampled as early as possible before Jenner, or modern

Table 1. Estimated age distribution for Atapuerca (SH), Krapina, and the pooled Neanderthal sample.

\begin{tabular}{ccccc}
\hline Age class & Krapina (1) & Atapuerca (2) & Both & Pooled Neanderthals (3) \\
\hline $0-4$ & 2.0 & 0.0 & 2.0 & 37.0 \\
$5-9$ & 3.5 & 2.0 & 5.5 & 26.0 \\
$10-14$ & 3.5 & 6.0 & 9.5 & 13.5 \\
$15-19$ & 8.0 & 11.0 & 19.0 & 13.5 \\
$20-24$ & 3.5 & 4.0 & 7.5 & \\
$25-29$ & 2.5 & 7.0 & 9.5 & 93.0 \\
$30+$ & 0.5 & 2.0 & 2.5 & \\
Total & $\mathbf{2 3 . 5}$ & $\mathbf{3 2 . 0}$ & $\mathbf{5 5 . 5}$ & $\mathbf{1 8 3 . 0}$ \\
\hline
\end{tabular}

(1) White \& Toth (pers. comm.) Average estimate from mandibles and maxillae.

(2) Bermúdez de Castro \& Díez (1995) average estimate.

(3) Trinkaus (1995), Krapina substracted The frequency of the age-class 10-14 years was obtained by dividing the frequency of the age-class 10-19 years by two. 
populations with no access to immunization programs (Table 2). The values for $x_{1}$ are well grouped without a noticeable influence of the chronology, geographic location or economic status of the samples. The errors of the age estimates based on physical examinations, for both the skeletal samples and the living, are probably much smaller for the children and adolescents than for the adults.

Table 3 presents the values observed at SH and Krapina, separately and together, and the $x_{1}$ value for the pooled Neanderthal sample (Trinkaus, 1995). The age-class subdivision, $x_{2}$, is not computable for the latter.

Compared to the values of $x_{1}$ (i.e. values for the dead), the values of $x_{2}$ are more scattered (Table 2). In order to equally weight each geographic continent (weight $=1$ ), the two European life-tables have been grouped. The averages of each variable will be used as parametric values in the models tested below. For the $x_{1}$ variable, these values are approximately the same as in the living $(c 5-9 / c 10-14=$ 1.09 and 1.06) and in the dead $(d 5-9 / d 10-14=2.27$ and 2.04) distribution for modern humans and chimpanzees respectively, where $c$ is the corresponding age-class in the age-pyramid. But this is not true for $x_{2}$; in the death distribution of chimpanzees its value is approximately half that of humans ( $d$ 5-14 / $d$ 15-24 $=2.04$ for modern humans, but 1.03 for chimpanzee). This is certainly due to the influence of the potential maximum longevity (PML) which for the chimpanzee is approximately half that of the human (55 years for chimpanzees vs. 110 years for humans). The PML is the upper limit for the survival function which is well expressed in both species by the universal 'bathtub' (U) shape (Anson, 1991), although the chimpanzee range is half that of the human.

What is the PML of pre-Neanderthals and Neanderthals? In a sample of 63 species of primates, Cutler (1975) observed a strong correlation between brain weight, body weight and PML (for a recent review of Cutler's results, see Allman et al., 1993). Cutler gives a PML estimate of 93 years for Neanderthals, i. e. a value practically equalling that of modern human ( 94 years), estimated by the same author. By analogy of estimated longevity, we take the expected value of the variable $x_{2}$ for the fossil samples to be approximately the same as that for modern humans.

\section{Testing the two alternative hypotheses}

Let $x$ be the ratio of two-age classes, distributed approximately normally in two alternative hypotheses. One hypothesis, $\mathrm{H}_{0}$, represents the catastrophic mortality model of a population, the other, $\mathrm{H}_{1}$, represents the alternative hypothesis of an attritional mortality model. Each hypothesis is characterized by coupled parameters - for $\mathrm{H}_{0}:\left(\mu_{0}, \sigma_{0}\right)$, and for $\mathrm{H}_{1}:\left(\mu_{1}, \sigma_{1}\right)$, where $\mu=\mathrm{E}(\underline{x} \mid \underline{H}) \sigma=\sqrt{ }$ var $(\underline{x} \mid \underline{H})$, representing respectively the expectation and the standard deviation for $x$ in hypothesis $\mathrm{H}$.

From which of the two alternative distributions, characterizing $\mathrm{H}_{0}$ or $\mathrm{H}_{1}$, do the observed values of $x_{1}$ and $x_{2}$ derive for the $\mathrm{SH}$ and Krapina samples? The statistical approach consists of applying a two decision rule:

Accept $\mathrm{H}_{0}$ if $x$ is located:

i) in the acceptance region for the hypothesis, at the level $1-\alpha=0.95(\alpha=0.05$ is the type I error), determined by $\mathrm{Q}=1$-Prob $\left(x^{\prime}>x \mid \mathrm{H}_{0}\right)<0.95$;

ii) and in the rejection region for $\mathrm{H}_{1}$ at the level $\beta=0.05$, determined by $\mathrm{P}=\operatorname{Prob}\left(x^{\prime} \leq x \mid \mathrm{H}_{1}\right) \leq \beta$.

Alternatively, accept $\mathrm{H}_{1}$ if $x$ is located:

i) in the rejection region for $\mathrm{H}_{0}$, determined by $1-\mathrm{Q} \leq \alpha$;

ii) and in the acceptance region for $\mathrm{H}_{1}$, determined by $1-\mathrm{P}>\beta$.

If conditions (i) and (ii) are not fulfilled for either of the hypotheses, $x$ is located in the indetermination region where $\mathrm{H}_{0}$ and $\mathrm{H}_{1}$ overlap. Thus, no decision can be reached given the sample sizes. That statistical approach is equivalent to the Neyman-Pearson theorem when the critical region has been fixed for $\beta=0.05$. 


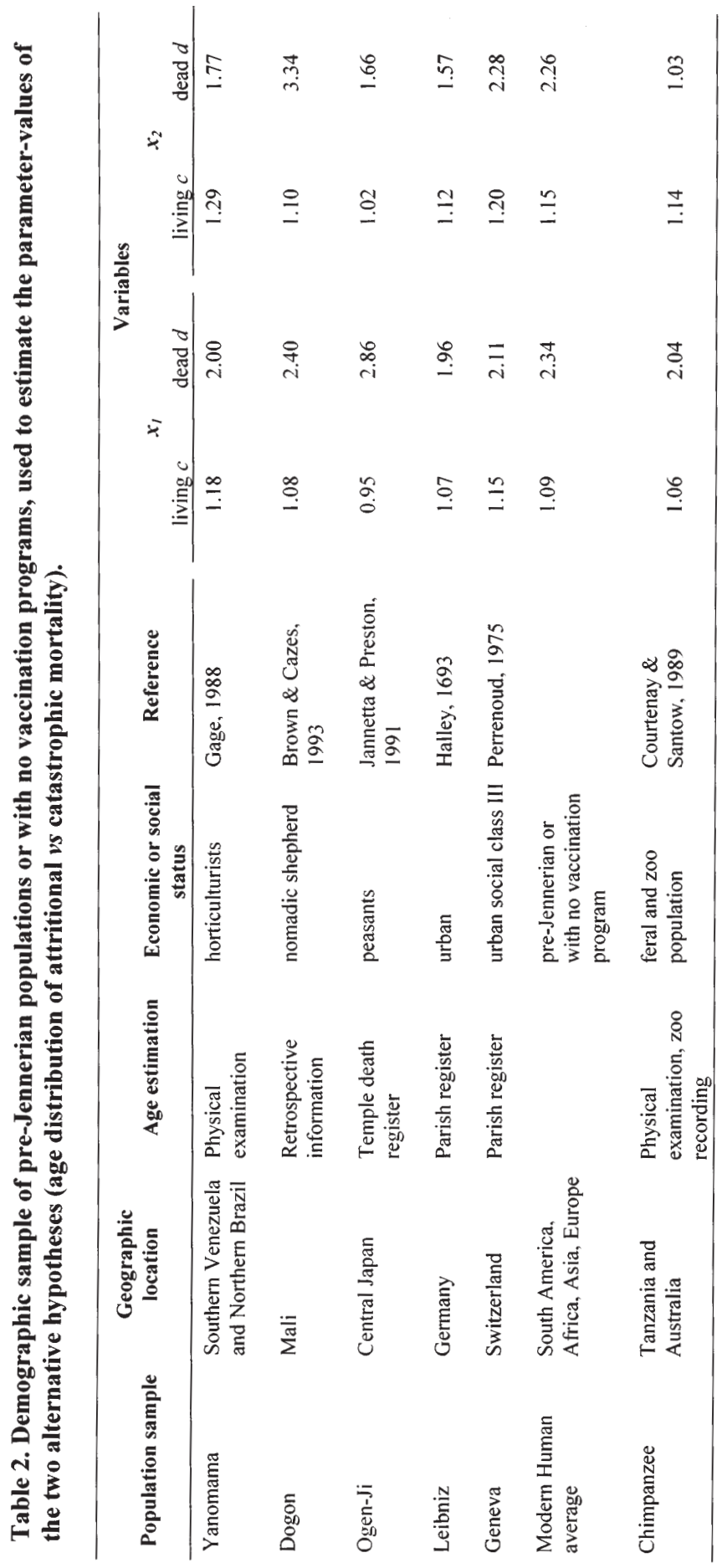




\section{Table 3. Demographic parameters ( $x_{1}$ and $\left.x_{2}\right)$ observed in Atapuerca, Krapina and the pooled Neanderthal sample along with their corresponding sample size (n).}

\begin{tabular}{lcccc}
\hline \multicolumn{1}{c}{ Sample } & $\boldsymbol{x}_{\boldsymbol{l}}$ & $\mathrm{n}$ & $\boldsymbol{x}_{2}$ & $\mathrm{n}$ \\
\hline Atapuerca & 0.333 & 8.0 & 0.533 & 23.0 \\
Krapina & 1.0 & 7.0 & 0.609 & 18.5 \\
Atapuerca and Krapina & 0.579 & 15.0 & 0.566 & 41.5 \\
Pooled Neanderthal & 1.930 & 39.5 & - & - \\
\hline
\end{tabular}

\section{Results}

Table 3 shows the $x$-values for the three hominid samples. Table 4 shows the test results. In both SH and Krapina, $x_{1}$ is in the acceptance region for $\mathrm{H}_{0}(\mathrm{Q}<1-\alpha=0.95)$ but not in the rejection region for $\mathrm{H}_{1}(\mathrm{P}<\beta=0.05)$.

Because of the small sample size for children aged 5-14 years, no decision can be reached using $x_{1}$. For $x_{2}$, it is within the acceptance region for $\mathrm{H}_{0}$ and at the limit of the traditional rejection region (0.05) for $\mathrm{H}_{1}$ in each of the two hominid samples and fully in the rejection region for $\mathrm{H}_{1}$ if both samples are regrouped.

The grouping of SH and Krapina is based on the implicit hypothesis that the two series are random samples of the same underlying demographic pattern, and that only the small size of each sample prevents conclusive results. For the three groups, it seems reasonable to accept $\mathrm{H}_{0}$, the catastrophic mortality hypothesis, because all the results point in the same direction. For the pooled Neanderthal sample, at first sight, no decision can be reached. The value of $x_{1}$ is in the acceptance region for $\mathrm{H}_{0}$ if the limit is set to the traditional value of 0.95 (but not far from this limit, with $\mathrm{Q}=0.899$ ), and in the acceptance region of $\mathrm{H}_{1}$. Nevertheless, a value so close to a limit which is regarded as an empirical marker for archaic mortality in modern humans (1.93 in pooled Neanderthal vs 2, the limit) is unexpected and must be emphasized.

Is it possible to go beyond the testing of simple hypotheses at SH and Krapina, i.e. to identify to what kind of catastrophe the samples might have suffered? This question is considered below.

\section{A brief insight into catastrophic mortality in modern human}

Catastrophic mortality is due to exceptional events which are generally beyond the control of the population and are of short duration (Heiling, 1992). For a foraging population, one cause of catastrophic mortality which immediately comes to mind is that of an environmental disaster which causes drastic local loss of biomass. But many other scenarios can also be imagined, ranging from a local climatic crisis (e.g. drought, flood, earthquake, storm, etc.) to an epizootic crisis, which might strike migrant prey (reindeers, horses, etc.) some distance away from the human settlements in question. Is there a demographic signature which might distinguish between the catastrophic scenario and other mortality scenarios? Here again, one must distinguish the pattern of a catastrophic mortality (the hierarchy between the age-class frequencies) from its level (the overall rate of mortality). The signature is the pattern.

Two broad patterns of catastrophe have been gathered from the literature - shortages and epidemics:

In the case of shortages, it is mainly at the two ends of the age pyramid (i.e. juveniles and the elderly) that death frequency increases. This is a general pattern observed in mortality crises for all mammals (for a review, see Levine, 1983). Shortages should produce a demographic signature closer to $\mathrm{H}_{1}$ than to $\mathrm{H}_{0}$.

For epidemics, Table 5 shows the observed death distribution for outbreaks of cholera (short life expectancy) and smallpox (relatively long life expectancy) in two samples from 18th-19th century Europe. Because of the very small number of individuals aged $<5$ years and $>30$ years in the SH and Krapina hominid samples, comparisons can be made only for the age-classes 5-9yrs, 10-19yrs and 
Table 4. Hypotheses testing for $H_{0}$ (catastrophic mortality) versus $H_{1}$ (attritional mortality) using the variables $x_{1}$ and $x_{2}$

\begin{tabular}{|c|c|c|c|c|c|c|c|c|c|c|c|c|}
\hline \multirow[t]{2}{*}{ Variable } & \multicolumn{3}{|c|}{ Krapina } & \multicolumn{3}{|c|}{ Atapuerca (SH) } & \multicolumn{3}{|c|}{ Both } & \multicolumn{3}{|c|}{ Pooled Neanderthal } \\
\hline & $Q$ & $\mathbf{P}$ & Decision & $Q$ & $\mathbf{P}$ & Decision & $\mathbf{Q}$ & $\mathbf{P}$ & Decision & $Q$ & $\mathbf{P}$ & Decision \\
\hline$x_{i}$ & 0.460 & 0.274 & none & 0.197 & 0.184 & none & 0.200 & 0.116 & none & 0.899 & 0.732 & none \\
\hline$x_{2}$ & 0.159 & 0.084 & $\mathrm{H}_{0}$ & 0.110 & 0.058 & $H_{0}$ & 0.057 & 0.016 & $\mathrm{H}_{0}$ & - & - & - \\
\hline
\end{tabular}

20-29yrs. The two epidemic patterns, although very different from each other, have a common high frequency of children aged from 5 to 9 years. This is quite different from the $\mathrm{SH}$ and Krapina distribution, where it is the frequency of adolescents and young adults which is highest. To summarize, as is clear from visual inspection, the death distribution observed in the two pooled hominid samples clearly does not fit the mortality profile of either a shortage or an epidemic.

\section{Discussion}

Three of six statistical tests point in the same direction: the SH and Krapina age distributions correspond to the age pyramid; a mortality profile of a sample reflects the age pyramid of a population only if all its members have the same probability of being sampled. But compared to a strongly catastrophic mortality pattern, the observed distribution of the SH and Krapina samples shows three anomalies:

i) Strong under-representation of infants and children.

Under the attritional model, under-representation of children under the age of 5 years is the general rule, even in historical cemeteries where the proportion of children aged 0-4 years may be as high as $40 \%$, as is attested by data obtained from the relevant parish registers. Differential preservation might explain the anomaly in the fossil sample. However, although the bones of children have less structural density than those of more mature individuals, and deciduous teeth are less resistant than permanent dentition, the general preservation of human and animal bones is so good in the SH sample (including very fragile and delicate elements like unfused epiphyses), that it seems improbable that a preservational bias alone can explain the lack of juveniles at this site.

ii) Too few children (5-14) or too many young adults (15-24).

The observed $x_{2}$-value obtained from the grouping of SH and Krapina is extreme in the context of a strongly catastrophic mortality hypothesis. In a one-sided test for the null hypothesis of no difference from $\mathrm{H}_{0}$ (the left side of the reference distribution for the catastrophe mortality hypothesis), the observed $x_{2}$-value is at the limit of the traditional rejection region $(\mathrm{Q}=0.057 \cong \alpha=0.05)$. This trend can be slightly observed in each sample individually. The $x_{2}$-value either has a numerator half its expected value or a denominator twice as high as its expected value.

iii) Strong under-representation of mature adults.

If one accepts a PML estimate for pre-Neanderthals and Neanderthals close to that for modern humans, then the small proportion of adults aged $\geq 25$ years at $\mathrm{SH}(2 / 32)$ and Krapina $(0.5 / 23.5)$ is quite abnormal. The suggestion made here is that the normal mortality pattern of the fossil hominids of SH and Krapina could not have differed drastically from that common to modern humans (before Jenner), chimpanzees (Bocquet-Appel \& Masset, 1982; Bocquet-Appel, 1985), Old World and New World monkeys (Gage \& Dyke, 1988, Dyke et al., 1993), and probably all primates. This pattern can be characterized by three major components (Dublin et al. 1927), where each component respectively represents immature individuals (declining), adults (steady) and senescents (Gompertz mortality function. This is comparable to the competing hazard function developed by Siler, 1979). In the universal mortality pattern (Anson, 1991), if the PML estimated by Cutler, given above, is true (thus setting an upper limit for the survival of pre-Neanderthals and Neanderthals), an approximate proportion 


\section{Table 5. Mortality patterns for individuals aged 5-29 years in two epidemics (cholera and smallpox) in modern humans compared with Atapuerca (SH) and Krapina hominid samples.}

\begin{tabular}{cccc}
\hline Age class & Cholera (\%) & Smallpox (\%) & Atapuerca (SH) and Krapina (\%) \\
\hline $5-9$ & 43.1 & 90.0 & 10.8 \\
$10-19$ & 20.2 & 5.0 & 55.9 \\
$20-29$ & 36.7 & 5.0 & 33.3 \\
\hline
\end{tabular}

of at least $25 \%$ of individuals should be aged above 40 years, in both the attritional and the catastrophic mortality models. Where are they? Miles' method ought to be retested (Kieser et al., 1983). One wonders if the functional relationship between the rate of dental wear and the chronological age would not be curvilinear, rather than linear, as implied by the technique. Thus, the individuals aged 40-60 years old would not have their teeth noticeably more worn than those aged 25-40 years old (see also Aiello \& Mollesson, 1993). Nevertheless, a re-calibration in this direction might not greatly increase the number of individuals aged $>40$ years (for discussions see also Trinkaus, 1995).

Because a few traces of a large carnivore were found within the SH assemblage, accumulation of the human bones by predation by lions (Panthera leo, Panthera $\mathrm{cf}$. gombaszoegensis) might be considered a possibility. However, prey of modern lions ranges in mass from $15 \mathrm{~kg}$ to $1000 \mathrm{~kg}$, with the mass of an average male lion at $190 \mathrm{~kg}$ (Tsukahara, 1993; Gowlishaw, 1994). Of the range of prey hunted annually by African lions (Kruuk \& Turner, 1967), 80\% weigh $169 \mathrm{~kg}$ or more, and only 5\% weigh $56 \mathrm{~kg}$ or less (i.e. a value close of the estimated average adult mass for archaic humans: Early and Late Middle Pleistocene, about $67 \mathrm{~kg}$; Ruff et al., 1997). Thus, modern lions seldom select prey as small as humans, clearly preferring larger animals. Moreover, the population density of pre-modern humans was always small in comparison with the abundant herbivores. At SH, the fossil assemblage is essentially $100 \%$ human (except for the carnivores mentioned earlier), and is completely lacking in herbivores. No African carnivore is known to prey on only a single species (Brain, 1981). The conclusion of the taphonomic analysis of Swartkrans and Sterkfontein is that humans had progressed to the top of the food chain, presumably as Homo erectus, at some time after the extinction of Australopithecus africanus (Brain, 1981). This conclusion would mean that the Atapuerca archaic humans were probably competing with large carnivores, and would only rarely have been taken as prey themselves. Therefore, assuming that extinct lions had similar preferences to modern lions, we can exclude the possibility that the $\mathrm{SH}$ accumulation was the result of predation.

No tools or other artefactual remains are found with the SH fossils, a fact which virtually precludes the possibility of SH having been an occupation site. Neither is the idea that SH was some sort of ritual cemetery plausible, because dispersion of burials, rather than grouping, is the usual practice of huntersgatherers (Masset, 1997). For a nomadic population; the probability of an individual death is roughly random in terms of geographic location, and the individual is likely to be buried at the place of death, i.e. geographically randomly. At both Krapina and SH the number of dead concentrated at the same location numbers in the tens, strongly indicating that they all died together at the same time.

The sample of individuals comes from a segment of the age pyramid whose members, at first sight, are physically resistant and mobile. Paradoxically, they are the very ones who would normally be regarded as best able to flee the impact area of a catastrophe.

One possible explanation for the observed departure from the catastrophic mortality pattern, i.e. the age-classes which are totally missing, is that these samples may represent the remains of small groups 
who were attempting to escape or counter the effects of a severe environmental upset, such as intense drought. In such a scenario, small bands of people may have set out to search for the resources needed for themselves and their communities to survive, leaving behind the two extremes of their community age-pyramids - the very young and the old. But in these cases they failed in their mission and became victims themselves. In terms of this suggestion, under conditions of severe privation, a group of youngsters (mainly aged 10-19 years) who were physically stronger than the two extreme parts of the age-pyramid, but not as resilient as the mature adults (20-39 years), stopped in the Sierra de Atapuerca, where many of them died. They may have been accumulated by the survivors in the Sima de los Huesos pit (as Arsuaga et al., 1997 suggest). A more or less similar scenario can be applied to Krapina.

Thus, the curious age distribution of the hominid samples from both $\mathrm{SH}$ and Krapina might be explained in terms of the dynamics of a catastrophe, a mortality crisis for a small population in a natural environment. In such a circumstance, one must expect a mortality pattern which is age-structured geographically in discrete units, perhaps along a gradient.

\section{References}

Aiello, L.C. \& Molleson, T. (1993). Are microscopic ageing techniques more accurate than macroscopic ageing techniques? Journal of Archaeological Science, 20, 689-704.

Allman, J., McLaughlin, T. \& Hakeem, A. (1993). Brain weight and life-span in primate species. Proceeding of National Academy Sciences, USA, 90, 118-22.

Anson, J. (1991). Model mortality patterns: a parametric evaluation. Population Studies, 45, 137-53.

Arsuaga, J.L., Martínez, I., Gracia, A., Carretero, J.M., Lorenzo, C., García, N. \& Ortega, A.I. (1997).Sima de los Huesos (Sierra de Atapuerca, Spain). The site. Journal of Human Evolution, 33, 109-27.

Bermúdez de Castro, J.M. (1995). The hominids from the Sima de los Huesos of the Sierra de Atapuerca karst: minimum number of individuals, age at death and sex. In: Human Evolution in Europe and the Atapuerca Evidence, ed. J.M. Bermúdez de Castro, J.L. Arsuaga \& E. Carbonell, pp. 263-81. Valladolid : Junta de Castilla y León.

Bermúdez de Castro, J.M. \& Díez, J.C. (1995). Middle Pleistocene mortality pattern and fertility: the case of the Atapuerca hominids (Sima de los Huesos site, Burgos, Spain). Revista Española de Paleontologia, 10(2), 259-72.

Bermúdez de Castro, J.M., Díez, J.C., Mosquera, M., Nicolás, E., Pérez, A., Rodríguez, J., Sánchez-Marco A. (1995). El nicho ecológico de los homínidos del Pleistoceno medio de Atapuerca. Complutum, 6, 9-56.

Bocquet-Appel, J.P. (1985). Small populations: demography and paleoanthropological inferences. Journal of Human Evolution, 14, 683-91.

Bocquet-Appel, J.P. \& Masset, C. (1982). Farewell to paleodemography. Journal of Human Evolution, 11, 321-33.

Bocquet-Appel, J.P. \& Arsuaga, J.L. (1999). Age distributions of hominid samples at Atapuerca (SH) and Krapina could indicate accumulation by catastrophe. Journal of Archaeological Sciences, 26, 327-38.

Brown, E. \& Cazes, M.H. (1993). Différences de la mortalité chez les Dogons de Boni. Sociétés et Sciences Médicales 36, 10, 1291-96.

Brain, C.K. (1981). The Hunter or the Hunted? An Introduction to African Cave Taphonomy. Chicago: University of Chicago Press.

Coale, A.J. \& Demeny, P. (1966). Regional Model Life Tables and Stable Populations. Princeton: Princeton University Press.

Courtenay, J. \& Santow, G. (1989). Mortality of wild and captive chimpanzees. Folia Primatologica, 52, 167-77.

Craig, G.Y. \& Oertal, G. (1966). Deterministic models of living and fossil populations of animals. Quarterly Journal of the Geological Society, London, 122, 315-55.

Cutler, R.G. (1975). Evolution of human longevity and the genetic complexity governing aging rate. Proceeding of the National Academy of Sciences, USA, 72, 4664-68.

Dublin, L.I., Kopf, E.W. \& Lotka, A.J. (1927). The components of death curves. American Journal of Hygiene, 7, 299-333.

Dyke, B., Gage, T.B., Ballou, J.D., Petto, A.J., Tardif, S.D.\& Williams, L.E. (1993). Model life tables for the smaller new world monkeys. American Journal of Primatology, 29, 269-85.

Gage, T.B. (1988). Mathematical hazard models of mortality: an alternative to model life tables. American Journal of Physical Anthropology, 76, 429-41. 
Gage, T.B. \& Dyke, B. (1988). Model life tables for the larger old world monkeys. American Journal of Primatology, $16,305-20$

Gowlishaw, G. (1994). Vulnerability to predation in baboon populations. Behaviour, 131, 293-304.

Hallam, A. (1972). Models involving population dynamics. In : Models in Paleobiology, ed. T.J.M. Schopf. San Francisco: Freeman.

Halley, E. (1693). An estimate of the degrees of the mortality of mankind drawn from curious tables of the births and funerals at the city of Breslau. Philosophical Transactions of the Royal Society, London, 17, 596-610.

Heiling G.K. (1992). Population-related crises : A typology. Working paper 92-58. International Institute for Applied Systems Analysis. Austria: Lasenburg.

Jannetta, A.B. \& Preston, S.H. (1991). Two centuries of mortality change in central Japan : The evidence from the temple death register. Population Studies, 45, 417-36.

Kieser, J.A., Preston, C.B. \& Evans, W.G. (1983). Skeletal age at death: an evaluation of the Miles method of ageing. Journal of Archaeological Sciences, 10(1), 9-12.

Kruuk, H. \& Turner, M. (1967). Comparative notes on predation by lions, leopard, cheetah and wild dog in the Serengeti area, East Africa. Mammalia, 31, 1-27.

Levine, M.A. (1983). Mortality models and the interpretation of horse population structure. In : Hunter-gatherer Economy in Prehistory, ed. G. Bailey, pp. 23-46. Cambridge: Cambridge University Press.

Lyman, R.L. (1994). Vertebrate Taphonomy. Cambridge: Cambridge University Press.

Mangel, M. \& Tier, C. (1993). Dynamics of metapopulations with demographic stochasticity and environmental catastrophes. Theoretical Population Biology, 44, 1-31.

Masset, C. (1997). Les Dolmens. Paris: Errance.

Miles, A.E.W. (1963). The dentition in the assessment of individuals age in skeletal material. In: Dental Anthropology, ed. D.R. Brothwell, pp. 191-209. Oxford: Pergamon Press.

Perrenoud, A. (1975). L'inégalité sociale devant la mort à Genève au XVIIè siècle. Population, 30, 221-43.

Royama, T. (1992). Analytical Population Dynamics. London: Chapman and Hall.

Ruff, C. B., Trinkaus, E. \& Holliday, T. W. (1997). Body mass and encephalization in Pleistocene Homo. Nature, 387, 173-76.

Siler, W. (1979). A competing-risk model for animal mortality. Ecology, 60, 750-57.

Trinkaus, E. (1995). Neanderthal mortality patterns. Journal of Archaeological Science, 22, 121-44.

Tsukahara, T. (1993). Lions eat chimpanzees: the first evidence of predation by lions on wild chimpanzees. American Journal of Primatology, 29, 1-11.

Wolpoff, M.H. (1979). The Krapina dental remains. American Journal of Physical Anthropology, 50, 67-114. 


\section{Jan Jelínek}

Moravske Museum, Zelný trh 6, 65937

Brno, Czech Republic

Keywords: "Non rational behaviour", sferoids, decorative activities, aesthetic approach

\section{Some Innovations and Continuity in the Behaviour of European Middle and Late Pleistocene Hominids}

\begin{abstract}
Human behaviour as reflected in some stone tool production in the European Middle and Late Pleistocene Hominids is considered, especially the capacity for the selection of material unusual in quality and colour and the shaping of the product in unusual shape and/or size. Also the use of some rare other features like fossils is mentioned and those activities which appear today to our contemporary European cultural traditions as non-rational are discussed. The continuity of such features from Middle to late Pleistocene is stressed.
\end{abstract}

\section{Introduction}

I consider Homo sapiens a polytypic species (sensu Wiley, 1978), with great intra- and interpopulation variability. This morphological variability can be observed whenever skeletal remains of several individuals are found (e.g. the intrapopulation variability seen in samples from Atapuerca - Sima de los Huesos, in Arago Cave, Bilzingsleben, Krapina, Ehringsdorf, Předmostí, Dolní Věstonice and other sites), or it can be compared when found in samples from a similar period or region (i.e interpopulation variability as seen in samples from Mauern, Vértesszöllös, Petralona or Krapina, Gánovce, Saccopastore or Kostjenki, Pavlov, Oberkassel, Chancelade).

During their existence individuals and populations are constantly exposed to a great variety of influences of various kinds - including biological, environmental, demographic, nutritional, social and cultural. These influences, manifested historically (in time) and regionally (in space), vary in their quality and quantity. In such situations, any innovations, whether biological or cultural, can appear only in a heterochronic mosaic pattern.

In order to better understand human behaviour, it is appropriate to consider Man as a single biocultural organism, composed inseparably of both domains, biological and cultural, which are interdependent and which constantly influence each other. A biological or cultural innovation may appear and be 'accepted' as information only if the 'hardware' exists as a precondition and if there is a complex need for such an innovation. If the anatomical, physiological, genetic and other biological preconditions exist together with the cultural, social, demographic and others (i.e. the 'hardware' in the sense used here), it does not mean that the potential innovation must necessarily appear, and, if it does appear, that it must necessarily be accepted. If it is accepted, it signals a change in human behaviour. The repeated types of special behaviour, and their survival, realised in different environmental conditions and documented in Man through similar archaeological finds and situations, signal a species-specific behaviour.

In considering the behaviour of mid- to late-Pleistocene hominids in Europe, I have selected as illustrative examples some stone tools because stone tools are the most common items among the archaeological finds of such early periods and because they constitute a kind of 'backbone' in most archaeological publications. Certainly, other cultural features such as bone tools, spears and the mode of hunting, the human relation to rarities or rarely found objects, the use of ochre pigment, etc., could also be assessed in a similar way as the results of human behaviour. 


\section{Handaxes.}

The most frequently encountered type of Lower Palaeolithic tools are handaxes, found over an enormous area and over a period of more than one million years. Let us investigate the psychological background to their production:

When producing a handaxe, the maker must have good knowledge of the quality of the raw material, and must be able to select a suitable piece. Such selection requires knowledge of the quality of the raw material, its visual characteristics (e.g. homogeneity, absence of cracks, etc.), and also a preconception of the intended artefact, its size and its shape. When starting to work, a suitable hammerstone of adequate size and weight must be found. The starting point for the first blow must be chosen and the blow must be directed at a particular angle, in an appropriate direction, and with suitable force. The result is not seen directly as the resulting flake is situated on the reverse side of the cobble from which it is struck; the raw piece must be turned to check the effect of the blow. The effect is then judged and, if found to be acceptable, the activity may continue with another blow in a similar direction, at a similar angle and with similar force, beside the first blow. In this way, a system of controlled actions is realised. The result is a preconceived shape, flat enough in its regular lens-like cross-section that is symmetrical in two longitudinal axes in three dimensional Euclidean space (Figure 1). This corresponds to the modern way of operative thinking, which differs from our way of thinking only quantitatively, not qualitatively.

Beginning in the Middle Acheulian, some effort toward better shaping can be recognised. The resulting edge-line of the handaxe is straighter, not undulating, and the surface is flaked in small flakes, reflecting a tendency to achieve a more elaborate product. In some cases the quality of finish is so advanced that it seems to go beyond what is required for practical use. It is evident that it reflects some kind of self-achievement linked with social appreciation by other members of the group; quality of

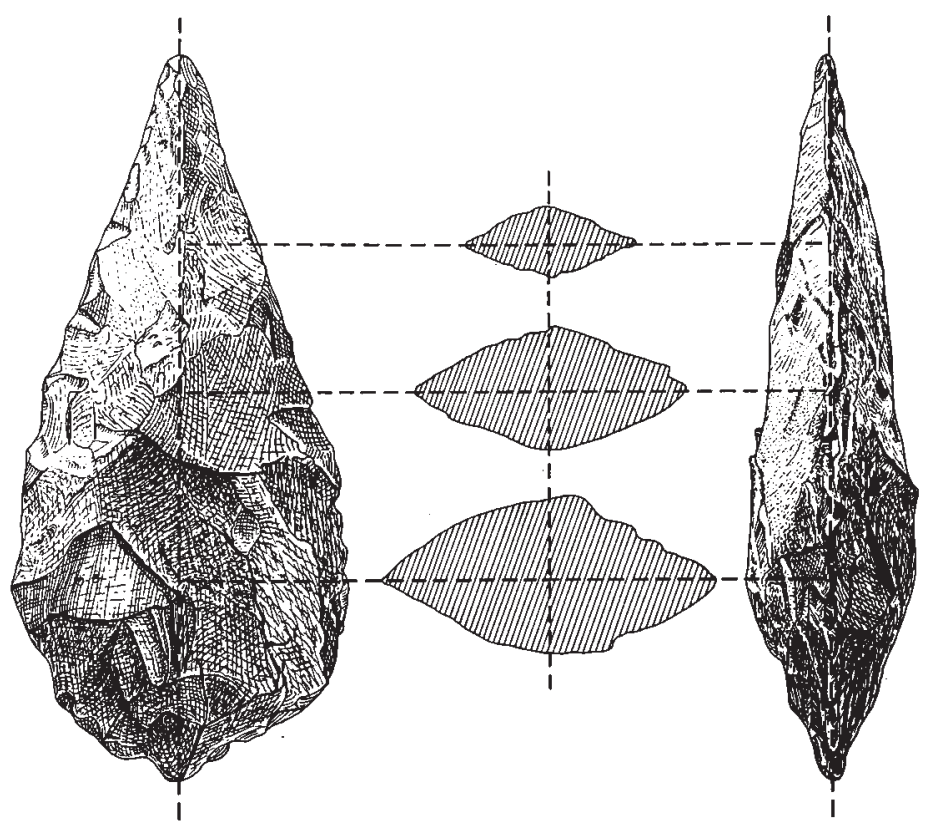

Figure 1. Two axes of longitudinal symmetry and symmetrical sections of a handaxe demonstrating the complex model of this artifact. 
craftsmanship plays a role and specialisation in a certain activity is obvious.

Selection of raw material can be demonstrated not only for size and shape, but also for colour. Some handaxes and other stone tools are obviously the result of specially selected colourful material (e.g. red striped jasper, Figure 2; Oliva, 1981); such a piece appears as a rare example among less colourful pieces and its just by chance occurrence can be excluded by comparison with other similar examples.

Other striking cases of intentional selection are seen in two handaxes from West Tofts and Hoxne in England, where in each case a fossil is preserved in the centre of the flaked surface, in one case a shell and in the other a sea urchin (Figure 3). The Acheulian Man evidently found a cobble on the surface of which was a fossilised object which had drawn his attention. The position of the fossil in the centre of the face of the handaxe was not incidental, as suggested by Noble \& Davidson (1997, p. 210). If the fossils were so common in the local flint cobbles that they might survive by chance until the period of handaxe production and appear in the centre of the new tool, as Noble \& Davidson suppose, then many other examples of partly preserved fossils, not all situated exactly in the centre of the tools, should be found - but they are not. The existence of such examples of the decorative use of rare features demonstrates unexpected mental qualities in these early hominids.

In Europe the early handaxe tradition survives into the Middle Palaeolithic, and bifacial flaking survives even later - in smaller or larger leaf-like shapes - up to Upper Palaeolithic times. Throughout Europe such elaborate pieces are known from Mousterian assemblages, but they are also found in the Upper Palaeolithic Szeletian or Gravettian; in the Gravettian of Moravia they are called 'mousterioliths' by Absolon (1945, figs. 207, 318, 320). The situation is similar in Předmostí, another important Moravian Gravettian site (Absolon \& Klíma, 1977, Tables. 16, 17, 18, 19, 35-41, 118-128, special chapter pp. 100-101). As for the well-known superb Solutrean bifacial Volgu points, nobody doubts that

Figure 2. Acheulian bifacial stone tool made of red jasper with white stripes. The raw material was selected for its colour.

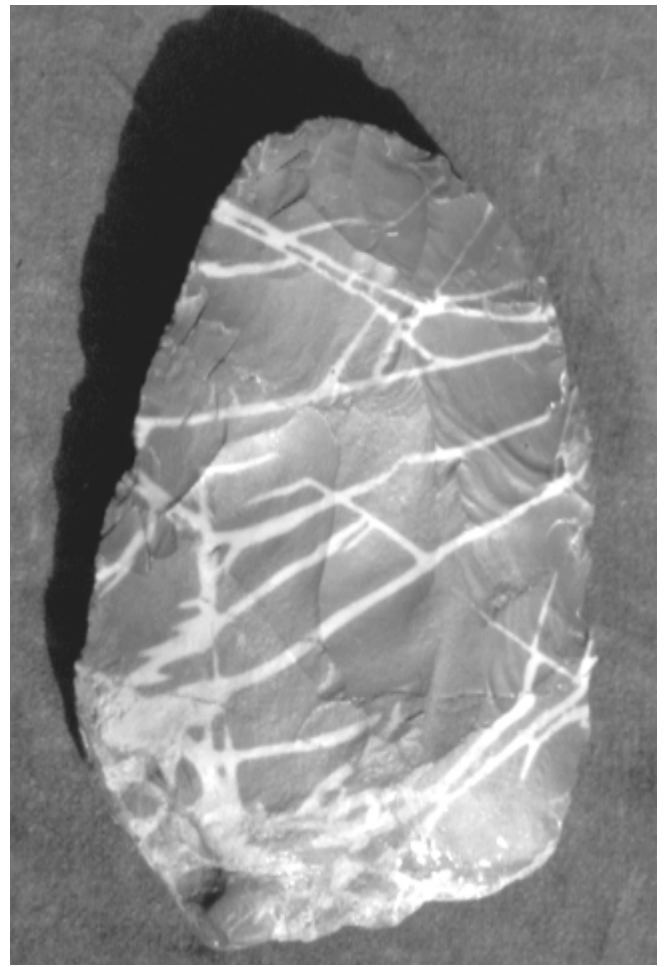


the limits between advanced craftsmanship and artistic creation are problematic, or indeed non-existent. Similar factors - technical, social and psychological - can be recognised in both. Bearing in mind the craftsmanship of Middle Palaeolithic bifacial tool makers, one may follow the continuity of this type of elaborate technology from the Lower Palaeolithic up to Upper Palaeolithic times, where it culminates in such masterpieces as the Solutrean Volgu points mentioned above.

In Moravia, where there was no handaxe tradition in Lower Palaeolithic times, another survival can be traced from the Lower Palaeolithic stone tool technology into the Upper Palaeolithic Gravettian. Several examples of archaic tools were found in the Gravettian layer at Dolní Věstonice and Předmostí sites (Absolon, 1945, Absolon \& Klíma, 1977, Tables 129-137). Their surprisingly rough shape and size might be considered a consequence of the use of other raw materials - quartz, quartzite, schist, limestone, rather than the usual ones - flint, chert or jasper. But this is not always the case. Even if the importance of the quality of raw material is taken into account (not permitting the production of finely elaborated micro-tools), this does not fully explain this feature. Some of the 'archaic' tool types are also made from flint or jasper, and some fairly advanced and elaborate Gravettian pieces are made of quartzite. Evidently the raw material itself does not fully explain the exceptional occurrence of archaic types of tools. Neither has their use been satisfactorily explained, although they are sometimes found among large mammoth bones. But they occur in other contexts as well, and therefore the idea of heavy duty tools does not provide a satisfactory explanation. Both the raw material and a specific use of the object are helpful in these surviving artefacts, but the behavioural chance convergence is not sufficient to explain such a continuity in the cultural tradition.
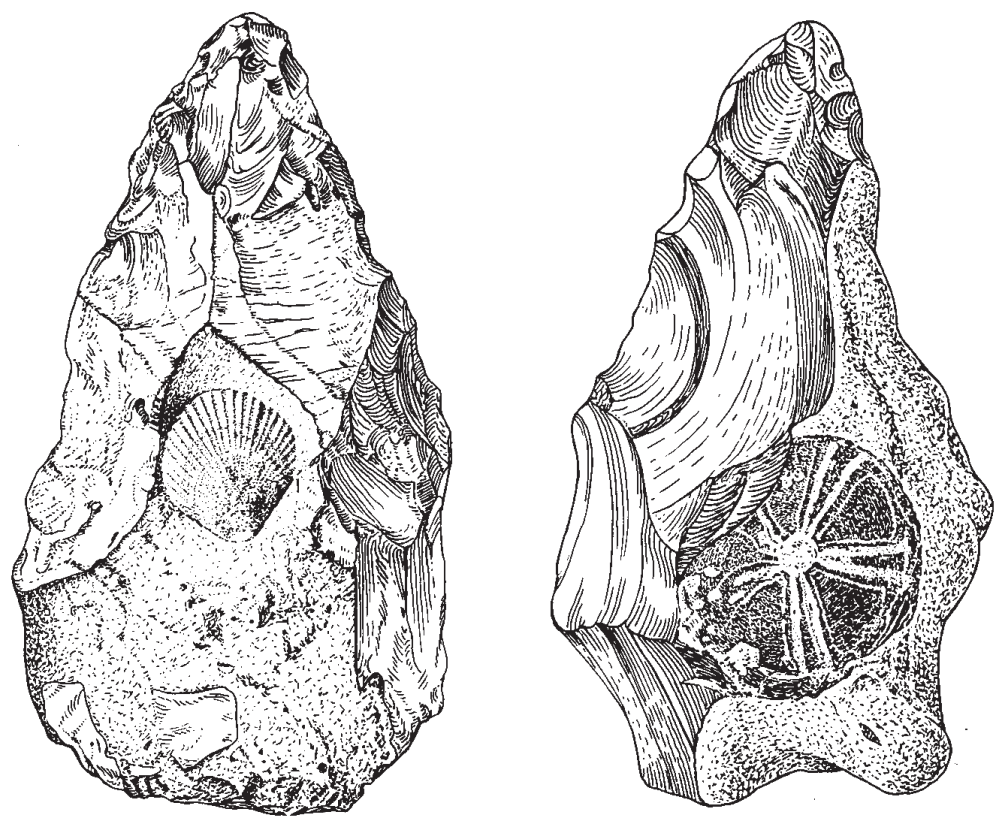

Figure 3. Two Acheulian handaxes with a fossil shell and sea urchin decorating the centre of the surface of both artifacts. This is not an incidental case but an intentional design. 


\section{Polyhedrals and spheroids}

Let us consider now other examples of special and remarkable tool types, the polyhedral and the spheroid. In Early Acheulian assemblages different types of polyhedrals are found, usually considered to be cores which remain after flake production. This is a possible explanation in cases where some kind of striking platform is evident. In such cases the polyhedral has a shape which is not quite symmetrically globular, and is slightly irregular. To achieve a more globular shape, the flaking must have been increasingly difficult as the angle became progressively more obtuse. Moreover, the required flakes could have been obtained in other and easier ways. The preconception of globular shaping should be considered as a purposefully followed leading idea.

Beginning in the Middle Acheulian, spheroids of fully globular shape appear. The literature on this subject is fairly rich (e.g., Absolon, 1945; Clark, 1955; Willoughby, 1985). They have generally been considered mostly as 'bola', throwing-stones or hammerstones. But the fact remains that spheroids of fully globular shape with finely and perfectly pecked surfaces were also produced. Such a shaping idea and process achieving a complete tridimensional symmetry is surprising at such early times and was certainly beyond what was needed for bola or throwing stones. In cases where the surface of these elaborate spheroids has been damaged in places, the hammerstone function is often considered as proven. But some spheroids are without any trace of damage by use, and they are moreover too large to be used as throwing-stones or hammerstones. They are also too rare in stone tool assemblages to be of frequent practical use, and a throwing-stone, if used as a hunting or defensive weapon, must have been used often. Whatever their practical use (if any), their production is the result of unusual preconception and craftsmanship. In this sense these pieces lie on the boundary between craft and art, as is true of some handaxes, which are unusual in their size, shape or colour.

Figure 4. A large rock crystal scraper made by Neandertal Man (Küna Cave, Moravia, Micoquian layer). The large size and transparent quality are intentional components of the design.

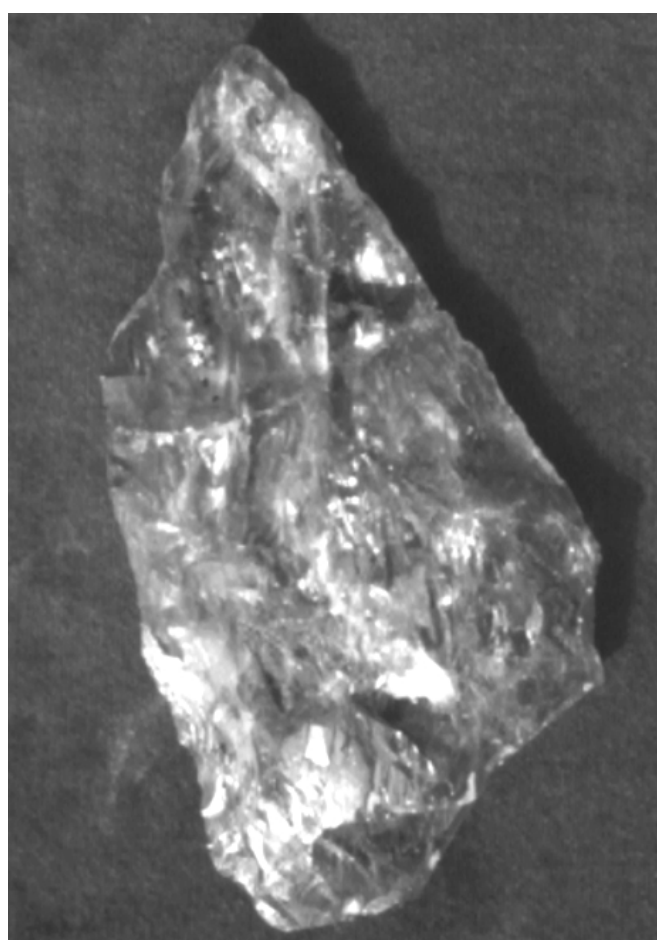


Not only the production and use of spheroids, but also their survival is of interest. Their existence in Middle Palaeolithic layers is well known. One illustrative example, not from Europe but from nearby Tunisia, comes from the El Guettar site near Gafsa (Gruet, 1950, 1952) where, in a Mousterian layer discovered in an artesian spring, Mousterian stone tools and bone fragments, as well as numerous more or less perfect spheroids were found in a heap $75 \mathrm{~cm}$ high and $150 \mathrm{~cm}$ in circumference. They were interpreted as the sacrifice of globular-shaped stones to the artesian spring. One of the best of them was situated on the apex of that artificial accumulation.

In that case, not only is the existence of globular shapes and their number striking, but also their accumulation in a spring, which signals the existence of some possibly religious ideas. This was certainly unexpected in a Middle Palaeolithic Mousterian tradition.

But the spheroids, evidently so attractive because of their shape, continue to exist, although exceptionally, in later periods. They certainly may have had different functions in different periods and regions, but their early existence in the Middle Acheulian calls for a reconsideration of the mental capacities of their Acheulian makers. Not only must rational intentions be re-analysed, as being responsible for their exceptional shape, but also their continuous existence from the Middle Acheulian up to the Upper Palaeolithic is significant.

\section{The search for special raw material}

In some Middle Palaeolithic sites special types of human behaviour can be followed in the study of stone tools, especially in terms of the raw material used and the morphology of the tools. One example comes from the important site of Külna Cave in Moravia, Central Europe, excavated over a period of 15 years (1961-1976) by Valoch (Valoch, 1988). In layer 7a, dated to $40000 \mathrm{yrs}$ BP, remains of Neandertal Man were found, associated with stone tools of Micoquian type. One large scraper found there was made from a piece of transparent quartz crystal (Figure 4) and another spectacular large handaxe-shaped core was made from smoky quartz. The nearest natural occurrence of this kind of exceptional raw material is some $55 \mathrm{~km}$ to the west as the crow flies, but on foot the terrain is arduous and the local creeks flow in diverse directions, therefore serving as no guides for a wanderer. Neandertal Man evidently roamed far, more than a one-day trip around his living site, and he must have had very good knowledge of the available resources in the area. It is also clear that the region was sparsely colonised, which accords with current knowledge of Mousterian sites in that region. The communication between inhabitants of local sites was much more limited than under the demographic situation that obtained later in the Upper Palaeolithic. The different demographic situation and the consequent limited possibility of exchange of information should be taken into consideration when investigating behaviour and its development in the Neandertals.

Making a large-size tool out of rock quartz was certainly possible, but was not easy. Evidently the exceptional transparent quality and colour of the raw materials were the reasons for using them to produce such unusual tools. But it is not only the physical qualities and colour of the raw material which demonstrate the emotional approach of Neandertal Man - the shape and size of the tool are other noteworthy factors. Early and Middle Palaeolithic tools are generally assessed only from a rational point of view. Perfect shape, sometimes more elaborate than was required practically, was a means of selfachievement of the maker and for emotional appreciation from other members of the group. These are important features also for later purely artistic activities. In the absence of products of Neandertal Man made from perishable materials, the stone tools represent a large field for an understanding of Middle Palaeolithic craftsmanship, and also for the artistic component in Neandertal behaviour. What was the worth and meaning of an exceptional bifacial point? Or of a perfectly shaped handaxe which was more elaborate than was needed in practice? Modern artistic European traditions, concentrating mainly on graphic art and sculpture, and less on dance, drama, singing or story-telling, may be misleading in a reflection of this kind. In prehistory there were different possibilities for artistic expression than those 
of today, and even the origins of sculpture need not only be figurative ones. The unusual shapes, sizes, and colours of some stone tools may be considered as the roots and bases of continuity towards later artistic activities which may be better recognised in the Upper Palaeolithic context because of a more evident similarity to the modern artistic tradition.

Although it is often argued that artistic activity is one of the principal differences in behaviour between Middle and Upper Palaeolithic European hominids, it should be kept in mind that the need for artistic behaviour can be satisfied by different means. Therefore, not all Homo sapiens sapiens populations in the Upper Palaeolithic were equally productive in artistic activities of the same type. And a similar situation obtains in later prehistory up to modern times; the appearance of artistic behavioural innovations and their distribution and continuity depend on many factors and of course on the possibilities and limits of communication - in reality on the conditions for regional cultural traditions.

These examples of species-specific behaviour, innovative thinking and continuity in behavioural and other cultural features have been presented here to demonstrate that, in order to explain them, there is no need to replace the subspecific populations of archaic Homo sapiens by any new species.

\section{References}

Absolon, K. (1945). Die Erforschung der Diluvialen Mammutjägerstation von Unter-Wisternitz an der Pollauer Bergen in Mähren. Brno: Polygrafia.

Absolon, K. \& Klíma, B. (1977). Předmostí, ein Mammutjägerplatz in Mähren. Praha: Academia.

Clark, J., D. (1955). The stone ball: its associations and use by prehistoric Man in Africa. In: Congrès Panafricaine de Préhistoire, II, Alger 1952, ed. L. Balout, pp. 403-17. Paris: Arts et Métiers Graphiques.

Gruet, M. (1950). Note préliminaire sur le gisement moustérien d'El Guettar. Bull. Soc. Préhist. Franco, 5, 232.

Gruet, M. (1952). Amoncellement pyramidal de sphéres calcaires dans une source fossile mousterienne à El Guettar (Sud Tunisien). Actes du Congrès Panafricaine de Préhistoire, Ve Session, Alger 1952, p. 449.

Gruet, M. (1958). Le Gisement d'El Guettar et sa flore. Libyca, 1959, vol.6-7, 79-126.

Noble, W. \& Davidson I. (1997). Human Evolution, Language and Mind. Cambridge: Cambridge University Press. Oliva, M. (1981). Acheulian finds from Karolín, district of Kromeríz (Czechoslovakia). Anthropologie, 19(1), 27-32.

Valoch, K. (1988). Die Erforschung der Kůlna Höhle 1961-1976. Anthropos (Anthropos Inst., Moravske Museum, Brno), 24, 1-318.

Wiley, E.O. (1978). The evolutionary species concept reconsidered. Systematic Zoology, 27, 17-26.

Willoughby, R.P. (1985). Spheroids and battered stones in the African Early Stone Age. World Archaeology, 17(1), 44-60. 


\section{Kenneth A.R. Kennedy}

Cornell University

Ithaca New York 14853 U.S.A.

Keywords: Palaeoanthropology, South Asia, Fossil Hominids, Out-of-Africa hypothesis

\section{Middle and Late Pleistocene Hominids of South Asia}

\begin{abstract}
Recent discoveries of hominid fossils and stone tools from India, Pakistan, Sri Lanka and Afghanistan indicate that parts of the Indian subcontinent were inhabited by the time of the PliocenePleistocene boundary. The association of the Acheulian lithic tradition and late Middle Pleistocene fauna with the Narmada Man skull from central India confirms that anatomically archaic Homo sapiens were present, although a phylogenetic association of these hominids with Asian populations of Homo erectus or the African Homo ergaster is not established. Anatomically modern $H$. sapiens date from 0.33 mya to Middle Holocene times in Sri Lanka. This South Asian palaeoanthropological record has significant implications for interpretations of the Out-of-Africa and the Multiregional hypotheses regarding the origins of modern humans.
\end{abstract}

\section{Introduction}

This paper discusses the relevance of the South Asian Pleistocene fossil hominid record and associated archaeological contexts to currently held hypotheses about human evolution as represented in the 'multiregional' and 'centre of origin' models.

In the 1993 edition of his popular book entitled Getting Here: The Story of Human Evolution, William Howells (1993:130) tells his readers that "The nearest thing to a link between early and late or between East and West, is the Narmada skull of central India, the only such find from that parsimonious subcontinent." Compared to the richness of the hominid palaeontological record in other parts of Asia, Europe and Africa, South Asia has been sparing and slow in yielding fossil bones and teeth of her Middle Pleistocene inhabitants. But Late Pleistocene and Early to Middle Holocene skeletal remains constitute a more impressive collection. Within the past two and a half decades, South Asia has gained a significant place in palaeoanthropological circles because of new discoveries in India, Pakistan and Sri Lanka. We need to appreciate the size and nature of this new body of data before addressing larger theoretical issues.

\section{Nature of the South Asian Fossil Hominid Record}

Three recent developments mark palaeoanthropological progress in the Indian subcontinent:

1. Recovery of a fossil hominid calvaria near Hathnora in the central Narmada valley by Aran Sonakia (1984) in 1982. Originally assigned to Homo erectus, re-examination of the specimen by the author, in collaboration with Sonakia and his colleagues of the Geological Survey of India, has revised its status to an archaic (or early) Homo sapiens (or Homo heidelbergensis, if you prefer that label) (Kennedy et al., 1991). This ascription is consistent with its late Middle Pleistocene antiquity as determined by stratigraphical, archaeological and faunal associations. In the Basal Gravel Conglomerate with the calvaria are remains of 
Bos namadicus, Hexaprotodon namadicus, Stegodon ganesa, Elephas hysudricus and Bubalus palaeindicus, as well as Palaeolithic quartzite choppers, flakes, cleavers and handaxes of a late Acheulian tradition. Thus a dating of.0.25 to.0.15 mya (million years ago) is probable (de Lumley \& Sonakia, 1985; Badam, 1989; Misra et al., 1990).

2. Series of hominid remains from three Late Pleistocene cave deposits in southern Sri Lanka: Fa Hien with occupation levels covering a time-frame from 33,000 to 4750 B.P. (Before Present); Batadomba Lena dating to 28,500 B.P.; Beli Lena Kitulgala within a time-frame of 16,000 to 12,000 B.P. Excavations of these sites from the 1970 s to the present day have been under the direction of S.U. Deraniyagala (1992), Director-General of Archaeology of the Government of Sri Lanka. The large number of hominid skeletal and dental remains from these three localities were shipped to the Human Biology Laboratory at Cornell University for preparation and morphometric and statistical analyses (Kennedy et al., 1987). The approximate number of individuals from these three cave sites, plus those from the open-air site of Bellanbandi Palassa and a recently excavated locality at Hambantota, is 76. Those from $\mathrm{Fa}$ Hien and Batadomba Lena are the earliest known anatomically modern Homo sapiens recovered thus far from South Asia. Microlithic tools occur in all of these Sri Lankan sites, non-geometrics preceding geometrics, hence the assignment of these Late Pleistocene to Middle Holocene industries to a Mesolithic (Bandarawelian or Balangodan) tradition.

3. Three sites on the Gangetic plain near Pratapgarh in Uttar Pradesh are Sarai Nahar Rai, Mahadaha and Damdama. Lekhahia is a fourth site in the adjacent Vindhya Hills in Uttar Pradesh. All were initially excavated by teams directed by G.R. Sharma of the University of Allahabad since the 1970s, but their skeletal remains in true burial deposits were not examined until a decade later (Kennedy et al., 1986, 1992; Lukacs, 1992; Lukacs \& Misra. 1997). A single thermoluminescent date of 10,050 B.P. from Sarai Nahar Rai led to the assumption that these specimens were of terminal Pleistocene antiquity, but subsequent radiocarbon assays indicate a more recent date of 2860 B.P. This is compatible with radiocarbon dates for Mahadaha of 4010 to 2828 B.P. (Possehl \& Rissman, 1992). However, the nearby Gangetic site of Damdama yields dates obtained by accelerator mass spectometry of 8370 to 8000 B.P., which are nearer to the Lekhahia dates of 8370 to 3560 B.P. for three occupation levels (Lukacs et al.,1997). The approximate number of individuals from these Gangetic and Vindhyan sites exceeds 114.

Langhnaj, a late Mesolithic site in northern Gujarat dating to 3875 B.P., has 14 skeletons (Ehrhardt \& Kennedy, 1965); the Bhimbetka caves in Madhya Pradesh contain Mesolithic deposits ranging from 7570 B.P. to the Historic Period with 20 individuals from six localities; Mesolithic sites with single human skeletons include Baghai Khor in the Vindhyas (Kennedy, 1990) and Bagor in Rajasthan (Lukacs et al., 1982). Elsewhere in India are individual or small skeletal samples from the Mesolithic sites of Pachmarhi, Mahara-Pahar, Tilwara and Valasna. Sri Lanka possesses additional Mesolithic sites at Alu Galge, Ravan Alle and Beli Lena Athula, skeletons from these localities having been collected during the first half of the twentieth century. In short, the South Asian prehistoric skeletal record from Pleistocene to Middle Holocene periods is not so parsimonious as our respected colleague William Howells suggests (Kennedy \& Caldwell, 1984, Kennedy \& Singh, 1997).

\section{What have we learned about this skeletal record?}

These osteological and dental samples have value not for their size alone, but for their capacity to allow palaeoanthropologists to reconstruct profiles of ancient biological diversity, adaptation, 
evolution and genetic affinities by methods unobtainable from their associated archaeological contexts. For example, the Narmada Man (actually a young adult female) exhibits some unique features of cranial anatomy not encountered in other anatomically archaic Homo sapiens. These include a prominent sagittal furrow, termination of the temporal line as a torus angularis, and an extremely elongated temporal bone with large external auditory meatus.

The Sri Lankan fossils from Fa Hien and Batadomba Lena were contemporary with Upper Palaeolithic peoples from Dolni Vestonice in Moravia (29,000 B. P.), Les Cottes in France (31,000 B.P.), Mumbwa in Zambia (22,000 B.P.), Nazlet Khater in Egypt (30,000 B.P.) and Lake Mungo in Australia (25,000 B.P.). The denizens of the Sri Lankan caves are associated with the earliest occurrence of geometric microliths in South Asia, predating those microlithic industries on the Indian mainland by some 10,000 years and within the time-frame of African microlithic assemblages from Matupi in the Congo (28,000 B.P.)

The series of Gangetic Mesolithic populations from Sarai Nahar Rai, Mahadaha and Damdama and from the Vindhya hill site of Lekhahia reveal phenotypic patterns of pronounced muscularskeletal robusticity, relatively tall stature, megadont teeth within the range of highest values for summed molar crown areas for South Asians, and skeletal markers of generally good health profiles indicative of attainment of full ontogenetic potential for growth and development in both males and females. These Gangetic hunter-foragers do not appear to have any living descendants in modern India, although some of the Middle Holocene skeletal series from Sri Lanka suggest biological affinities with the island's aboriginal population, the Veddas.

\section{That other critical link}

If this prehistoric skeletal record were the single piece of evidence of a link between 'early and late or between East and West', it would convince us that the Indian subcontinent had been settled by hominids since the Middle Pleistocene. But it is not the only high card in our hand, and it does not answer the question: "When did hominids first appear in this part of Asia?" To answer some of these questions we must look at the archaeological record.

South Asia entered world prehistory after 1863 when Robert Bruce Foote (1866) of the Geological Survey of India recovered and correctly identified Acheulian type handaxes and cleavers at Palavaram, Attarampakkam and other sites near Madras in southern India. Foote convinced fellow geologists and antiquarians in England and on the European continent that South Asian prehistory had an antiquity far greater than that represented by the mysterious megalithic monuments of the Indian Iron Age, the accounts of Vedic and other native chronicles, or the historic record of Alexander the Great's sojourn in the Indus valley in 326 B.C. Subsequent research demonstrated that an Acheulian tradition was present in South Asia by Middle Pleistocene times.

Recently, dates for the earliest lithic industries in South Asia are estimated from fission-track and palaeomagnetic methods at 2.2 mya. The reputed tools are flaked quartzite choppers recovered within Siwalik strata of the Soan valley at Riwat in Pakistan (Rendell \& Dennell, 1987; Dennell, 1991; Allchin, 1995). Announcement of this discovery was made in 1985, two years after the recovery of Acheulian handaxes from Dina, Jalalpur and neighboring localities on the Potwar plateau. The latter artifacts were dated by palaeomagnetic methods to.0.7 and.0.5 mya (Johnson et al., 1982). If confirmed, the dates from Riwat support the thesis that hominids were present in South Asia just before the Pliocene-Pleistocene boundary, but until the bones of the manufacturers of the flaked cobbles are found it is not possible to determine if they were members of a taxon already known from the hominid fossils of Africa, or if they were a hominid not yet encountered 
in the palaeontological record. The identification of these early tool users has overwhelming significance in the light of the present date of 1.8 mya for the evolution of Homo erectus in Africa.

What is certain is that these early dates were not welcomed by all palaeoanthropologists (Hemingway \& Stapert, 1989; Keates, 1992). One is reminded of the reactions by some of our older colleagues to the 40, 000 B.P. radiocarbon date for the Niah cave fossil from Borneo during a period in our history when it was assumed that anatomically modern Homo sapiens could not predate the period of Cro-Magnons in Europe. Today the antiquity of the Niah skull is no longer hotly debated as modern humans are presently ascribed an antiquity of some.0.2 mya (Kennedy, 1979).

A parallel shift in interpretations of chronometric data is taking place today with regard to the Pliocene-Pleistocene boundary dates for tool manufacturing in the Potwar area. Gradual acceptance of their antiquity is less the consequence of retrieval of new data than it is a recognition of recent forthcoming chronometric determinations from other Asian localities to the east and west of the Indian subcontinent. Thus, fission-track ages of stone tools and fossils of mammals and reptiles from the Indonesian island of Flores fall around.0.8 mya. These discoveries raise the question of Homo erectus having a capacity to reach islands by means of watercraft, if indeed this was the species leaving these lithic artifacts (Morwood et al., 1998; Gibbons, 1998). Volcanic rock samples from two hominid (Homo erectus?) localities in Java were dated in 1994 by Argon/Argon methods to 1.81 and 1.66 mya (Swisher et al., 1994). At Dmanisi in the Georgian Caucasus, a hominid mandible (Homo erectus?) was recovered in 1991 and has been dated by a variety of methods to 1.8 mya (Gabunia \& Vekua 1995).

Should all of these dates for hominid settlement in Asia, including those from the Potwar region, be considered spurious? Ian Tattersall of the American Museum of Natural History wrote in a recent issue of Scientific American: "Interestingly, a few years ago the archaeologist Robin W. Dennell caused quite a stir by reporting very crude stone tools from Riwat in Pakistan that are older than 1.6 Myr. Their great age is now looking decreasingly anomalous." (Tattersall, 1997:49). Accompanying his text is a map of Asian localities with other early dates, Riwat appearing with the Javan sites. So things are changing...

\section{In and Out of Africa}

My reading of these palaeoanthropological developments of the past decade is that the primary issue is the timing of a presumed migration of Homo erectus (or an ancestral form, Homo ergaster) out of Africa into Asia. A second, but also important question, is: "What kind of hominid, or hominids, first settled in the Caucasus, South Asia, Southeast Asia, China and Australasia?".

One scenario is that the manufacturing of crude stone tools of flakes struck from pebbles was initiated by the earliest African hominids, their lithic techniques continuing to be practised by Homo ergaster ca. 2.0 mya. Then, by 1.4 mya standardization of tool making developed on the African continent and resulted in the handaxe and cleaver tools we associate with an Acheulian tradition. An explanation for the absence of this tradition in Southeast Asia and the Far East may be that these regions were inhabited by hominids prior to the date of initiation of Acheulian tools in Africa. Acheulian tools did diffuse to western and southern Asia after 1.4 mya, but prior to that time the flaked pebble tools (chopper-chopping tools) continued to be made in the Potwar and other areas of the subcontinent. We must be careful to avoid the assumption that technological diffusions always imply demic migrations and displacements. The real issue here is why the Acheulian tradition formed an eastern boundary in South Asia along the trajectory called the 'Movius Line'.

How substantive is that venerable Movius Line concept? First, we need to understand that 
studies of the percentages of occurrences of tools of the handaxe-cleaver and pebble tool traditions in South Asia demonstrate that there are higher frequencies of Acheulian artifacts in north, central and peninsular India than in regions to the east of Movius' trajectory (Ghosh, 1985). Absence or infrequent occurrence of handaxes and cleavers in eastern Asia may not be due entirely to palaeoecological factors, such as availability of suitable raw materials for stone tool manufacture and replacement of stone with bamboo or other perishable materials (Pope, 1989), but to the timing of the introduction of Acheulian techniques into different parts of Asia. With or without an actual migration episode of Homo erectus from Africa, as Swisher and his associates favoured in their publication of 1994, South Asia was directly affected by these technological changes. The subcontinent has never been a biological or cultural cul-de-sac. It is probable that the Acheulian tradition did not become established in certain parts of central and peninsular India until ca.0.35 mya, as determined by Thorium/Lead dating methods from calcite materials at several sites, or by.0.67 mya, as determined by Argon/Argon dating methods from a tephra layer at Bori in Maharashtra (Mishra, 1992; Mishra et al., 1995). In these and other localities the Acheulian tradition succeeded the flaked pebble tool tradition, but in Sri Lanka the Acheulian tradition is absent. Here there was a replacement of a chopper-chopping tool and flake tradition (Ratnapuran culture) with microlithic Mesolithic technology (Bandarawelian or Balangodan culture). Bifacial stone tools from China (which are not Acheulian) appear at about the same time the handaxes and cleavers come into prominence in central and peninsular India ca.0.73 mya.

I do not think we are quite ready to erase the Movius Line, but it no longer implies the boundary between 'advanced' and 'retarded' prehistoric cultures as argued by its inventor (Movius, 1949), nor does it mark a barrier to movements of earlier hominids from western Asia across the Indian subcontinent and eastward to Indonesia and China. And if Homo erectus had evolved in Asia from a migrating African ancestor, then this Asian route may have been directed along a West-to-East course by the Middle Pleistocene.

At present we are unable to name the hominid manufacturers of the chopper tools found in the Potwar region, but we are able to associate the Acheulian tools of the central Narmada valley with an anatomically archaic Homo sapiens. Certainly the Narmada fossil bears close morphological resemblances to cranial specimens from Maba, Hexian and Zhoukoudian H3 (Wolpoff, 19961997). All of these are assigned to archaic forms of Homo sapiens rather than Homo erectus. But this specific case of a late Middle Pleistocene hominid does not eliminate the possibility of an earlier Homo erectus presence in South Asia. It has not as yet been established that this latter kind of hominid had extended into the Indian subcontinent, despite earlier claims to the contrary and the wishful thinking of some individuals who, for nationalistic purposes, rank a Homo erectus fossil above a very respectable representative of an archaic form of our own species!

Acheulian tools continued to be made until $c a$. 40,000 B.P. in various parts of Pakistan and India, when an increasing number of Levallois and non-bifacial tools heralded the Indian Middle Palaeolithic. At Darra-I-Kur in northeastern Afghanistan a Mousterian industry of this cultural period and dated to 30,000 B.P. was found in 1966 in association with a human temporal bone. The specimen had morphological features described by Angel (1972) as fitting "into a partly Neandertal population like Skhul as well as a modern one." I have examined this specimen and consider it to be a representative of anatomically modern Homo sapiens, as are its contemporaries from Fa Hien and Batadomba Lena in Sri Lanka. 


\section{South Asia and the Centre of Origin and Multiregional Hypotheses}

The relevance of the South Asian archaeological and palaeontological records to current controversies labelled the 'Out-of Africa' and 'Multiregional' hypotheses has been addressed elsewhere (Kennedy, 1994). The model of demic displacement of anatomically archaic Homo sapiens by anatomically modern representatives of our species migrating from Africa some 100,000 years ago does not find support from results of morphometric and statistical analyses of the skeletal and dental specimens recovered thus far from the Indian subcontinent. Nor does the archaeological record dating for this time-frame provide evidence of abrupt changes in stone tool technology, habitat preference, exploitation of new ecological settings or cultural changes associated with population (not to mention species!) displacement.

We have some understanding of African skeletal and dental morphology of $c a$. 100,000 years ago from a hominid fossil record at several localities on that continent. But even with the recognition of differences in cranial morphology between Late Pleistocene and Early Holocene Africans and their modern descendants, we do not encounter African morphological features, past or present, in the ancient and living peoples of Pakistan, India, Sri Lanka and their borderlands.

If we extend this time period of 100,000 years to one exceeding the 3300 generations it represents, we are no closer to an African-South Asian lineage. For example, the Narmada calvaria possesses unique morphological features, but these do not mean that some of its other traits are outside the range of variation encountered in other archaic Homo sapiens specimens of Middle and Late Pleistocene antiquity in different parts of Asia or, for that matter, among certain European specimens, e.g., Arago and Petralona. Aside from some parallels of biparietal breadth of Narmada with the fossil skull from Kabwe (Broken Hill) in Zambia, now dated to.0.13 mya and classified as an anatomically archaic Homo sapiens by most palaeoanthropologists, Narmada does not exhibit additional anatomical or mensural similarities to this or other African fossils. Nor are African features encountered in the Darra-I-Kur specimen from Afghanistan or from the skeletal series from Sri Lanka, localities at the opposite ends of the north-south geographical parameters of the Indian subcontinent and sharing an antiquity of $c a$. 30,000 B.P.

Within the time-frame of 100,000 years, the moment that some molecular biologists would have us believe that modern humans from Africa began their displacement of other hominids in Europe and Asia, South Asian prehistory is characterised by gradual, not abrupt, transitions in technological developments in stone tool manufacture. This would be difficult to explain if a new hominid species had entered this part of the world. More is involved here than stone tools, for the magnificent rock

paintings that are a major cultural feature of the South Asian Palaeolithic and Mesolithic periods also reveal continuity of artistic styles and representations of ritual activities, socio-economic strategies of hunting and foraging, scenes of family life, and the pleasures of dancing and feasting.

The two theoretical models of the origins, antiquity and dispersal of modern humans have undergone modifications since their emergence in the 1980s. Present evidence from South Asia, both archaeological and palaeontological, does not offer any parallels to the displacement model of European Neandertals by modern humans. Rather, a convincing case can be made for the establishment of both biological and cultural continuity of Late Pleistocene and Early Holocene populations in South Asia.

\section{Conclusions}

The continuous increase in the number of hominid fossil specimens now being recovered from South Asia for Middle Pleistocene to Middle Holocene periods allows palaeoanthropologists to 
compare this impressive record with fossil hominid remains from other parts of Asia, Africa, Europe and Australasia. Situated geographically at the crossroads of these continental landmasses and island chains, South Asia holds a critical place in palaeoanthropological research on the broader issues of hominid origins, phylogenetic affinities, adaptations to different and changing ecozones, and development of technological and socioeconomic strategies. Among the things we have learned over the past quarter century are that tools of the Acheulian tradition were manufactured by the kind of anatomically archaic Homo sapiens represented by the late Middle Pleistocene Narmada fossil, but that the archaeological evidence of pre-Acheulian flaked pebble tools from the Potwar plateau points to hominid settlement of the subcontinent prior to the time of the Pliocene-Pleistocene boundary and by a species not as yet found and identified. The earliest anatomically modern Homo sapiens fossils from South Asia come from cave sites in Sri Lanka dating to 33,000 and 28,500 BP, a time when microlithic tools were developing from non-geometric to geometric forms. No longer does South Asia appear to be a biological and cultural cul-de-sac receiving all of its changes from lands beyond the Himalaya in abrupt episodes suggestive of mass movements of foreign peoples and cultures. Rather gradual transitions and populational and cultural continuities characterise this part of the world situated at the intersection between Africa and Europe, Southeast Asia and the Far East. To maintain the momentum of research in this part of the world it is necessary for palaeoanthropologists, South Asian and foreign, to develop well organized teams for further investigations whereby systematic and long term explorations will be rewarded with new discoveries in this next frontier of our scientific disciplines of prehistoric archaeology and human palaeontology.

\section{References}

Allchin, B. (1995). Early human cultures and environments in the northern Punjab, Pakistan: An overview of the Potwar Project of the British Archaeological Mission to Pakistan (1981-1991). Memoir of the Geological Society of India, 32, 150-67.

Angel, J.L. (1972). A middle Palaeolithic temporal bone from Darra-I-Kur, Afghanistan. Transactions of the American Philosophical Society, 62, 54-56.

Badam, G.L (1989). Observations on the fossil hominid site at Hathnora, Madhya Pradesh, India. In: Perspectives in Human Evolution, ed. A. Sahni \& R. Gaur, pp.153-172. Delhi: Renaissance Publishing Company.

Dennell, R.W. (1991). Report of the British Archaeological Mission's Potwar Project for the year 1989-90. South Asian Studies, 7, 161-65.

Deraniyagala, S.U. (1992). The Prehistory of Sri Lanka: An Ecological Perspective. 2 vols. Colombo: Department of the Archaeological Survey, Government of Sri Lanka.

Ehrhardt, S. \& Kennedy, K.A.R. (1965). Excavations at Langhnaj: 1944-63. Part 3: The Human Remains. Deccan College Building Centenary and Silver Jubilee Series, 27.

Foote, R.B. (1866). On the occurrence of stone implements in lateritic formations in various parts of the Madras and North Arcot Districts. Madras Journal of Literature and Science, 2, 1-35.

Gabunia, L. \& Vekua, A. (1995). A Plio-Pleistocene hominid from Dmanisi, East Georgia, Caucasus. Nature, 373, 509-12.

Gibbons, A. (1998). Ancient island tools suggest Homo erectus was a seafarer. Science, 279, 1635-37.

Hemingway, M.F. \& Stapert, D. (1989). Early artefacts from Pakistan? Some questions for the excavators. Current Anthropology, 30, 317-22.

Howells, W.W. (1993) Getting Here: The Story of Human Evolution. Washington, D.C.: Compass Press.

Johnson, G.D., Zeitler, P.K., Naeser, C.W., Johnson, N.M., Summers, D.K., Frost, C.D., Opkyke, B.D. \& Tahirheli, R.A.K. (1982). Fission-track ages of Late Neogene and Quaternary volcanic elements, Siwalik group, northern Pakistan. Palaeogeography, Palaeoclimatology, Palaeoecology, 37, 63-93.

Keates, S.G. (1992). Review of H.M. Rendell, R.W. Dennell \& M.A. Halim (eds), 'Pleistocene and Palaeolithic Investigations in the Soan Valley, Northern Pakistan'. Asian Perspectives, 31(1), 109-11.

Kennedy, K.A.R. (1979). The deep skull of Niah: An assessment of twenty years of speculation concerning its evolutionary significance. Asian Perspectives, 20, 32-50. 
Kennedy, K.A.R. (1990). Porotic hyperostosis on human remains from Mesolithic Baghai Khor. In: Professor H.D. Sankalia Memorial Volume, ed. M.K. Dhavalikar, Bulletin of the Deccan College Post-Graduate and Research Institute, 49, 183-198.

Kennedy, K.A.R. (1994). Evolution of South Asian Pleistocene hominids: Demic displacement or regional continuity? In: South Asian Archaeology 1993, ed. A. Parpola \& P. Koskikalho, 1, 337-44. Helsinki: Suomalainen Tied Eakatemia.

Kennedy, K.A.R. \& Caldwell, P.C. (1984). South Asian prehistoric skeletal remains and burial practices. In: The People of South Asia: The Biological Anthropology of India, Pakistan and Nepal, ed. J.R. Lukacs, pp.159-97. New York: Plenum Press.

Kennedy, K.A.R. \& Singh, R. (1997). South Asia (India, Pakistan, Sri Lanka). In: History of Physical Anthropology, ed. F. Spencer, 2, 976-87. New York and London: Garland Publishing Company.

Kennedy, K.A.R., Disotell, T., Roertgen, W., Chiment, J. \& Sherry, J. (1986). Mesolithic human remains from the Gangetic plain: Sarai Nahar Rai. Occasional Papers and Theses of the South Asia Program, Cornell University, 10.

Kennedy, K.A.R., Deraniyagala, S.U., Roertgen, W., Chiment, J \& Disotell, T. (1987). Upper Pleistocene fossil hominids from Sri Lanka. American Journal of Physical Anthropology, 72, 441-61.

Kennedy, K.A.R., Sonakia, A., Chiment, J \& Varma, K.K. (1991). Is the Narmada hominid an Indian Homo erectus? American Journal of Physical Anthropology, 86, 475-96.

Kennedy, K.A.R., Lukacs, J.R., Pastor R.F., Johnston, T.L, Lovell, N.E., Pal, J.N., Hemphill, B.E. Ana Burrow, C.B. (1992). Human skeletal remains from Mahadaha: A Gangetic Mesolithic site. Occasional Papers and Theses of the South Asia Program, Cornell University, 11.

Lukacs, J.R. (1992). Mesolithic hunters and foragers of the Gangetic plain: A summary of current research in dental anthropology. Dental Anthropology Newsletter, 3, 3-8.

Lukacs, J.R. \& Misra, V.D. (1997). The people of Lekhahia: A biocultural portrait of Late Mesolithic foragers of North India. In: South Asian Archaeology 1995. ed. R. Allchin \& B. Allchin, pp. 873-89. New Delhi: Oxford-IBH.

Lukacs, J.R., Misra, V.N. \& Kennedy, K.A.R. (1982). Bagor and Tilwara: Late Mesolithic Cultures of Northwest India. Vol.1: The Human Skeletal Remains. Poona: Deccan College.

Lukacs, J.R., Pal, J.N. \& Misra, V.D. (1997). Chronology and diet in Mesolithic north India: A preliminary report on new AMS $\mathrm{C}$ dates, ${ }^{13} \mathrm{C}$ isotope values and their significance. In: Colloquium 1 of the International Congress of Prehistoric and Protohistoric Sciences 1996, 16, 301-11. Forli: ABACO Edizioni.

Lumley, H. de \& Sonakia, A. (1985). Contexte stratigraphique et archaeologique de l'homme de la Narmada, Hathnora, Madhya Pradesh, Inde. L'Anthropologie, 89, 3-12.

Mishra, S. (1992). The age of the Acheulian in India: New evidence. Current Anthropology, 33, 325-28.

Mishra, S., Ventakesan, T.R., Rajaguru, S.N. \& Somalajula, B.L.K. (1995). Earliest Acheulian industry from peninsular India. Current Anthropology, 36, 847-51.

Mishra, S., Rajaguru, S.N., Badam, G.L., Ranjoo, R.K. \& Korisettar, R. (1990). Further research in the prehistory and Quaternary geology of the Narmada valley. In: Adaptation and Other Essays, ed. N.C. Ghosh. \& S. Chakrabarti, pp. 53-59. Santiniketan: Research Publications, Visva-Bharati.

Morwood, M.J., O’Sullivan, P.B., Ariz, F. \& Raza, A. (1998). Fission-track ages of stone tools and fossils on the east Indonesian island of Flores. Nature, 392, 173-76.

Movius, H.L. (1949). The Lower Palaeolithic cultures of southern and eastern Asia. Transactions of the American Philosophical Society, 38, 3229-420.

Pope, G.G. (1989). Bamboo and human evolution. Natural History, 57, 49-57.

Possehl, G.L \& P.C. Rissman (1992). The chronology of prehistoric India from earliest times to the Iron Age. In: Chronologies in Old World Archaeology, ed. R.W. Ehrich, 1, 465-90. Chicago: University of Chicago Press.

Rendell, H. M. \& Dennell, R.W. (1987). Asian axe 2 million years old. The Geographical Magazine, 59, $270-72$.

Sonakia, A. (1984). The skull-cap of early man and associated mammalian fauna from Narmada valley alluvium, Hoshangabad area, Madhya Pradesh (India). Records of the Geological Survey of India, 113,159-72.

Swisher, C.C., Curtis, G.H., Jacob, T., Getty, A.G., Suprijo, A. \& Widiasmoro, M. (1994). Age of the earliest known hominids in Java, Indonesia. Science, 263, 1118-21.

Tattersall, I. (1997). Out of Africa again...and again. Scientific American, 276, 46-53.

Wolpoff, M.H. (1996-1997). Human Evolution. New York: McGraw-Hill. 


\section{Carlo Peretto}

\author{
Dipartimento di Scienze Geologiche e \\ Paleontologiche \\ Università degli Studi di Ferrara \\ Corso Ercole $I^{\circ}$ d'Este, $32^{2}$ \\ 44100 FERRARA
}

\section{The Oldest Human Population in Europe: 'Long' or 'Short' Chronologies}

Keywords: Origin of the population, Prehistory, Europe

\begin{abstract}
The oldest human population of Europe is certainly more ancient than has been supposed thus far. Several finds confirm this idea, thus allowing the hypothesis that the first population can be attributed to a more ancient human form than those retrieved so far on the continent.

The oldest European industries are characterised by a multitude of flakes and cores obtained by rapid and opportunistic knapping techniques. The presence of use-wear traces (Scanning Electron Microscopy) only on the cutting edges of flakes, enables us to consider as cores those groups of artifacts which are traditionally ascribed to choppers or chopping-tools.

Flake tools, that is blanks transformed by the use of retouch, spread widely and with a notable typological variability, only during the following Acheulean phase.
\end{abstract}

There is as yet no common viewpoint on the first human population in Europe, as is amply demonstrated by the number of publications on this theme, and by the different interpretations which have emerged at numerous round tables, colloquia and seminars held in many places, especially in Europe.

This state of turmoil has been provoked by new discoveries which give no peace to this sector of research, a sector which is highly visible since it is concerned with our own origins, our oldest roots, a topic which attracts the collective imagination more than most others.

I believe we are witnessing a period of great discovery of new information and the construction of new hypotheses which confront existing paradigms with new approaches and investigations, and with new research groups working systematically often with innovative criteria. The emergence of new models is therefore inevitable.

The confusion acquires even greater valency since it touches not only on the cultural aspects of our most ancient history, but also on human and general palaeontology, palynology, etc. Proof of the greatest antiquity of man in Europe involves other research areas, including the natural sciences, which find it difficult to accept the new data and to reconsider their chronological schemes in the light of the new data. These chronologies, bolstered by a long bibliography, often incorporate unresolved problems and are sometimes only of historical value.

From this point of view one could say that the technical and typological characteristics of material cultures (such as the lithic industries) are less constraining in determining the ages of the assemblages than naturalistic or morphological data, such as stratigraphic, palaeontological and palynological information.

Some might claim that the chronological definition of these cultural aspects is a subjective process. Behaviour, subsistence strategies and interactions with the environment might be the same or different, regardless of their chronological setting, or they might continue for periods longer than those defined by other disciplines, especially in their oldest phases.

For many, the new proposals on the antiquity of the human population of Europe seem still to reside in the realm of hypothesis rather than certainty, and therefore for some the problems raised in palaeontological terms should be rejected rather than discussed as part of a chronological revision of the naturalistic phenomena. This attitude derives from absolute sectionalism, where one's own discipline is 
regarded as being more indicative of the true facts than others.

Although on the one hand it is true that some cultural phenomena may last for a long time and crosscut certain environmental and chronological boundaries, on the other hand they often have a capacity for evolutionary change with well characterised, often multiple, phases within a single environmental event.

To the careful observer, this phenomenon is clear even in the oldest phases of the Lower Paleolithic during which the changes in the archaeological data are greater than has been hypothesised thus far. It is no longer possible to claim that cultural phenomena remained either static or primitive during this very long period. On the contrary, they seem to be increasingly elaborate, requiring a revision of the ancient sequences from several points of view, particularly as regards defining the date of their first appearance in Europe, which is certainly greater than one million years ago.

It is, however, clear that the data which have emerged during the last decades must not be passively accepted; a whole series of aspects which have been highlighted as a result of new excavations and research must be critically assessed.

For an idea of the amount of information which has emerged in recent years on the antiquity of the first human population of Europe, without going into specific detail, it is sufficient to refer to the summary chronological tables published by Bosinski (1996), the Transactions of the 13th International Congress of Prehistoric and Protohistoric Sciences, with particular reference to workshops 13 and 21 published in volume 6, tomes (a) and (b) (Antoniazzi et al., 1998; Arsuaga et al., 1998), and numerous recent articles such as those published in Antiquity (Gibert et al., 1998). This represents a mass of information, the quality and quantity of which bears on the by now sterile debate of the presumed 'short chronology' - a concept proposed on the basis of chronological alchemies and particularisms and which has been supported in particular by certain researchers from northern Europe (Roebroeks \& von Kolfschoten, 1994; Dennell \& Roebroeks, 1996).

There is no longer any doubt that the oldest flake industries, from about 1.5 million years ago, preceded the handaxe industries in Europe. The latter were the result of a renewal which, in the current state of our knowledge, dates to 600-700 kyr in this continent (Peretto \& Piperno, 1992; Peretto, 1994).

It must also be pointed out that this first phase was not sporadic or occasional, but on the contrary represents a widespread phenomenon which has been documented in the literature since the 1970s and 1980s. In fact sites such as Atapuerca (Arsuaga et al., 1988; Bermudez de Castro et al., 1997; Carbonell et al., 1995), Barranco Cinco and Fontenueva (Gibert et al., 1998), Vallonnet (Gagnepain et al., 1996), Ca' Belvedere di Monte Poggiolo (Peretto, 1992; Antoniazzi et al., 1998), Isernia La Pineta (Peretto 1994, 1996, 1998) and Dmanisi (Bosinski, 1996), constitute a wide range of sites of the same period.

Even if we restrict ourselves to research in Italy, there are many sites which, as a result of interdisciplinary studies, have been attributed to this group. These include Bibbona in Tuscany (Galiberti, 1984) and Anagni-Colle Marino, Arce, Fontana Liri and Castro dei Volsci in Lazio (Segre et al., 1982). In Emilia-Romagna, following the discovery of Ca' Belvedere di Monte Poggiolo, systematic research has led to the discovery of a virtually continuous distribution of sites along the Apennine foothills, such as Del Poggio (Fontana \& Peretto, 1996), Romanina Bianca (Farabegoli et al., 1996), Serra and Covignano (Antoniazzi et al., 1998).

If we briefly analyse the technical and typological characteristics of the pre-Acheulean industries in Europe, we see that they are represented by the simple and opportunistic knapping of pebbles or blanks for the production of flakes with cutting edges. That these were used as tools, without further modification or retouch, has been demonstrated by use wear analyses (Longo et al., 1997; Peretto et al., 1998). As the knapped pebbles lack traces of use wear, they should be considered as cores even though in some cases they are ascribable, on an exclusively morphological level, to choppers and chopping tools.

In this first phase retouch is completely absent: the flakes were used without any further transformation after having been detached. Therefore there is no typological variability among the flake 
tools; our attempts to recognise scrapers, points or denticulates seem to derive more from our way of conceiving typology rather than from real objectives in the approach to the lithic assemblages.

It is only with the following Acheulean phase that there was a substantial technological and typological renewal, with the appearance of a multitude of tools (retouched flakes), which present a notable and real morphological variability, including handaxes.

I should also emphasise that at the current stage of research, there is nothing which might suggest a European evolution of flake industries into handaxe industries. In the absence of any concrete confirmation of this, I believe that the first diffusion of humans with industries characterised by cores and flakes was followed in a more recent phase, about 600-700 kyr ago, by the diffusion of new human groups with Acheulean industries.

The presence of flake industries in Europe in a very ancient period constitutes certain evidence of the antiquity of the human population of this continent, and requires a general reorganisation of some aspects in relation to the greater number of sites discovered and studied:

\section{Aspects connected with the correlation of information.}

It is necessary to verify the sequence of naturalistic events, including landscape evolution particularly from geomorphological, pedological, faunal and floristic points of view. The chronology of the sites mentioned above, which has been confirmed by systematic radiometric and palaeomagnetic analyses (Gagnepain et al., 1998), is often in disagreement with the older chronological schemes elaborated for Europe on the basis of palaeontology or palynology.

\section{Anthropological aspects.}

A clearer definition of the characteristics of the first Europeans is necessary, as well as their specific attribution, and the investigation of the possible presence, in chronological terms, of more than one human type during the Lower Palaeolithic. If the diffusion from Africa took place in a very archaic period, one could hypothesise that human forms more ancient than Homo erectus spread onto our continent. This aspect has recently been highlighted by the discoveries made at Atapuerca (Arsuaga et al., 1998) and Ceprano (Ascenzi et al., 1996).

\section{Cultural and behavioural aspects.}

It is necessary to investigate the modes and rates of diffusion of the first human groups and in particular the dates, relationships and sequence of flake industries and handaxe industries. There is no clear evidence for in situ evolution of the sequence of flake and handaxe industries, from the oldest to the most recent, and therefore it is likely that the first diffusion was followed by a second one, about 700-600 kyr ago.

\section{Chronological aspects.}

There is still no precise chronological correlation between the African and European sequences. Although it is possible to find clear points of contact and derivation between the two series on the basis of the characteristics of the industries, it is not possible to justify the fact that there is a difference in age of about 1 million years, which is documented not only by the more recent age of the European sites with flake industries compared with the African sites, but also by the respective dates of the handaxe industries. Since we cannot suggest complex migratory theories, for which there is no analogy in the palaeo-ethnological or ethnographic field, if not for very short phases (such as hypothesising that the more evolved human groups forced less evolved human groups towards peripheral areas for hundreds of thousands of years), in this specific case it is only possible to advance hypotheses:

- a) The spread into Europe took place earlier than has been proposed hitherto; only the most recent evidence of this first phase has been found, dating to at least 1 million years ago. 
- b) The Acheulean arrived late in Europe. However, this hypothesis seems to conflict with the site of Ubeidiya in Israel (Bar-Yosef \& Goren-Inbar, 1993), which is characterized by a handaxe industry and is assigned an age of about 1.4 million years. This seems to demonstrate that human groups with this culture had already crossed the geographical limits of Africa.

- c) The European sequence is older than has been claimed so far. I am aware that this is a provocative claim, especially for those who, although ever less convinced and with more limited arguments, continue to support a short chronology for Europe. There is, however, no doubt that continued research is tending to narrow the chronological gap between the two continental series.

On this basis, it is not possible to reach a complete resolution of the various problems. The only certainty is that, as a result of recent European discoveries, the old schemes are breaking down.

Perhaps a new way of thinking about our most ancient history should be developed. In fact, on a strictly cultural level, the valency of the man-environment relationship remains to be discussed, which goes beyond the limit of the palaeo-ethnological knowledge available to us. In this regard, I believe that the production of artifacts like flakes in the earliest phase, though simple and opportunistic, represents evidence of a new mode of behaviour at the level of social structure. Freed from the constraints of the original ecological niche, this facilitated greater exploitation of the environment and made possible rapid diffusion into new territories.

The human capacity for diffusion from the original African territories manifested itself very early, much earlier than one might think. This statement is supported not only by archaeological evidence, but also by ways of thinking that might seem very speculative. In fact I believe that, from the very beginning, stone knapping allowed a consistent autonomy of behavioural choices regarding human responses to the limits imposed by nature. This in turn would have caused an important shift in the axis of the man-environment relationship in man's favour.

In conclusion, I believe that systematic stone working not only was a starting point for further acquisitions, as we all believe, but also represents the result of a long behavioural process which cannot be reduced to only identifying it, as we are used to doing, with long type lists created on the basis of discoveries made. The production of stone tools totally changed the strategies of the human group, putting it in the right condition to be able to adapt to new situations and new environments, not only in Africa but also out of Africa.

I therefore expect new and more ancient discoveries to be made in Europe which will go well beyond our current knowledge and highlight a closer chronological analogy with what is documented in Africa.

\section{References}

Antoniazzi, A., Antoniazzi, A., Cavallini, F., Fontana, F., Milliken, S. \& Peretto, C. (1998). Ca' Belvedere di Monte Poggiolo: the first inhabitants in Emilia-Romagna. Atti XIII International Congresso UISPP, Workshop 13, v.6, 1, Forli, A.B.A.C.O. Editore.

Antoniazzi, A., Ferrari, M. \& Peretto, C. (1993): Il giacimento di Ca' Belvedere di Monte Poggiolo del Pleistocene inferiore con industria litica (Forli). Bollettino di Paletnologia Italiana, 84, 1-56.

Arsuaga, J.L., Bermudez De Castro, J.M. \& Carbonell, E. (1998): The archaeo-palaeontological sites of the Sierra de Atapuerca (Spain); Actes XIII International Congress UISPP, Workshop 21, v.6,11, 1237-1323, Forli; A.B.A.C.O. Editore.

Ascenzi, A., Biddittu, I., Cassoli, P.F., Segre, A.G. \& Segre-Naldini, B. (1996): A calvarium of late Homo erectus from Ceprano, Italy. Journal of Human Evolution, 31, 409-23.

Bar-Yosef, O. \& Goren-Imbar, N. (1993): The lithic assemblages of Ubeidiya. A Lower Palaeolithic Site in the Jordan Valley. Qedem, 34.

Bermudez de Castro, J.M., Arsuaga, J.L., Carbonell, F., Rosas, A.., Martinez, I. \& Mosquera, M., (1997): A hominid from the Lower Pleistocene of Atapuerca, Spain: possible ancestor to Neanderthals and modern humans, Science, 276, 1392-95.

Bosinski G. (1996): Les origines de l'homme en Europe et en Asie: atlas des sites du paléolithique inférieur. Editions 
errance, Paris, 1-175.

Carbonell, E., Bermudez De Castro, J.M., Arsuaga, J.L., Diez, A., Rosas, U., Cuenca-Bescos, U., Sala, R., Mosquera, M. \& Rodriguez, X.P. (1995): Lower Pleistocene hominids and artifacts from Atapuerca-TD6 (Spain). Science, 269, 826-29.

Coltorti, M., Cremaschi, M., Delitala, M.C., Esu, D., Fornaseri, M., McPherron, A., Nicoletti, M., Van Otterloo, R., Peretto, C., Sala, B., Schmidt V. \& Sevink J. (1982): Reversed magnetic polarity at Isernia La Pineta, a new lower Paleolithic site in Central Italy. Nature, 300, 173-76.

Cremaschi, M. \& Peretto, C. (1988): Le Paléolithique inférieur de la Plaine orientale du Po. L'Anthropologie, 92(2), 643-82.

Crovetto, C., Ferrari, M., Longo, L., Peretto, C. \& Vianello, F. (1994): The carinated denticulates from the Paleolithic site of Isernia La Pineta (Molise, Central Italy): tools or flaking waste? The results of the 1993 lithic experiments. Human Evolution, 9, 175-207.

Dennell, R. \& Roebroeks, W. (1996): The earliest colonisation of Europe: the short chronology revisited. Antiquity, $70,535-42$.

Farabegoli, E. (1996): The Paleolithic sites between Bologna and Imola related to the geomorphological and paleogeographical evolution of the environment. In: Lenzi \& Nenzioni (eds), Editrice Compositori, Bologna, pp. 19-36.

Farabegoli, E., Nenzioni, G. \& Peretto, C. (1996): Romanina Bianca: In: Lenzi \& Nenzioni (eds), Editrice Compositori, Bologna, pp. 56-61

Fontana, F. \& Peretto, C. (1996): Bel Poggio. In: Lenzi \& Nenzioni (eds), Editrice Compositori, Bologna, pp. 25-42.

Gagnepain, J., Hedley, I., Bahain, J.J. \& Wagner, J.J. (1992): Etude magnétostratigraphique du site de Ca' Belvedere di Monte Poggiolo (Forli, Italie) et de son contexte stratigraphique. Premiers résultats. In: I Primi Abitanti della Valle Padana, Monte Poggiolo nel Quadro delle Conoscenze Europee, ed. C. Peretto, pp. 319-336. Jaca Books.

Gagnepain, J., I. Medley, J-J. Bahain, Peretto, C. \& Wagner, J.J. (1995): L'apport du paleomagnétisme pour la connaissance du cadre chronostratigraphique des sites d'Isernia La Pineta (Molise), Ca' Belvedere di Monte Poggiolo (Emilia Romagna) e la Grotte du Vallonet (Alpes-Maritime, France). XI Congresso degli Antropologi Italiani, Isernia, 1995.

Gagnepain, J., Medley, I., Bahain, J.J., De Lumley, H., Peretto, C. \& Wagner, J.J. (1996): Elaboration d'un cadre magnétostratigraphique dans le Pleistocène inférieur et moyen en Italie et en France meridionale d'après l'étude paléomagnetique des sites du Vallonnet (Alpes-Maritimes, France), Ca' Belvedere di Monte Poggiolo (Romagna, Italie) et Isernia La Pineta (Molise, Italie). XIII Congresso delle Scienze Preistoriche e Protostoriche, Workshop 13, Forli 1996, Abstracts, 2, Abaco Editore, p. 128.

Gagnepain, J., Medley, I., Bahain, J.J., Falgueres, C., Laurent, M., Peretto, C., Wagner, J.J. \& Yokoyama, Y. (1996): Synthèse des donées radiochronologiques et paléomagnetiques du site de $\mathrm{Ca}$ ' Belvedere di Monte Poggiolo (Romagna, Italie) et de son environnement géologique. XIII Congresso delle Scienze Preistoriche e Protostoriche, Workshop 13, Forli 1996, Abstracts, 2, Abaco Editore, p.129-130.

Galiberti, A. (1984): Bibbona. In: I Primi Abitanti d'Europa, Catalogo della mostra, ed. De Luca, pp. 121-123.

Gibert, J., Gibert, L., Inglesias, A. \& Maestro, B. (1998): Two "Oldowan" assemblages in the Plio-Pleistocene deposits of the Orce region, Southeast Spain. Antiquity, 72, pp.17-25.

Lenzi, F. \& Nenzioni, G. (1996): Lettere di pietra: i depositi pleistocenici - sedimenti, industrie e faune del margine appenninico bolognese. In: Editrice Compositori, Istituto per i Beni Culturali della Regione Emilia-Romagna, Museo Archeologico Luigi Donnini, Bologna, pp.1- 867.

Longo, L., Peretto, C., Sozzi, M. \& Vannucci, S. (1997): Artefacts, outils ou support épuisés? Une nouvelle approche pour l'étude des industries du paléolithique ancien: le cas d'Isernia La Pineta (Molise, Italie Centrale), L'Anthropologie, 101(4), 579-96.

Peretto, C. (ed.) (1992): I primi abitanti della Valle Padana: Monte Poggiolo nel quadro delle conoscenze europee. In: Origini, Atti Convegno Internazionale, Monte Poggiolo, ed. Collana, pp.368. Forli, Jaca Book.

Peretto, C. (ed.) (1994): Le industrie litiche del giacimento paleolitico di Isernia La Pineta: la tipologia, le tracce di utilizzazione, la sperimentazione. Iannone, C. (ed.). Isernia, pp. 1-493.

Peretto, C. (1995): Considerations on the Lower Palaeolithic in Italy. In: Human evolution in Europe and the Atapuerca evidence, v.11, ed. J.M. Bermudez, J.L Arsuaga \& F. Carbonell, pp. 357-65. Junta de Castilla y Leon. Peretto, C. (1996): The paleolithic in the Bologna area: considerations about the typology and chronology of lithic 
industries. In: Lenzi \& Nenzioni (eds), Editrice Compositori, Bologna, pp. 7-18.

Peretto, C. (ed.) (1996): I reperti paleontologici del giacimento paleolitico di Isernia La Pineta. Iannone, C. (ed.): Isernia, pp. 1-625.

Peretto, C. (ed.) (in press 1998): I suoli d'abitato di Isernia La Pieta: natura dei reperti e loro distribuzione planimetrica. Iannone, C. (ed.): Isernia, pp.

Peretto, C. \& Piperno, M. (1992): Il problema dei primi abitanti d'Itali. In: I primi abitanti della Valle Padana, Monte Poggiolo nel quadro delle conoscenze europee, ed. C. Peretto, pp. 95-103. Jaca Books.

Peretto C., Amore F.O., Antoniazzi Alberto, Bahain, J-J., Cattani, L., Esposito, P., Falgueres, C., Gagnepain, J., Hedley, I., Laurent, M., Lebreton, V., Longo, L., Milliken, S., Monegatti, P., Ollé, A., Pugliese, N., Renault Miskovsky, J., Sozzi, M., Ungaro, S., Vannucci, S., Vergès, J-M., Wagner, J-J. \& Yokoyama Y. (1999):

L'industrie lithique de Ca' Belvedere de Monte Poggiolo: stratigraphie, matiere première, typologie, remontages et traces d'utilisation. L'Anthropologie, tome 102, 4, pp 1-120.

Piperno, M. (1992): Il Paleolitico inferiore. In: Italia Preistorica, ed. Laterza, pp. 139-169.

Piperno, M. (ed.) (1996): Notarchirico, 500.000 anni fa (Venosa). Edizioni Osanna Venosa.

Roebroeks, W. \& van Kolfschoten, T. (1994): The earliest occupation of Europe: a short chronology. Antiquity, 68, 489-503.

Segre, A.G., Biddittu, I. \& Piperno, M. (1982): Il Paleolitico inferiore nel Lazio, nella Basilicata e in Sicilia. Atti della XXIII Riunione Scientifica I.I.P.P., Firenze, pp.177-206. 


\section{Günter Bräuer}

Institute of Human Biology

University of Hamburg

Allende-Platz 2

20146 Hamburg, Germany

Keyword: Out-of-Africa, archaic Homo sapiens, modern humans, gene flow, replacement.

\section{The 'Out-of-Africa' Model and the Question of Regional Continuity}

First indications of an early existence of modern humans in Africa were available by the early 1970 s, but there was much uncertainty about this evidence. Subsequent research brought more clarity to the evolutionary process in Africa and led to the formulation of an 'out-of-Africa' hypothesis termed the 'Afro-European' model in 1982. This hypothesis suggested a replacement of Neanderthals and other archaic populations by modern humans, ultimately coming from Africa. The replacement was thought as a complex biological process involving gene flow between archaic and modern groups to varying degrees in different regions.

Since 1987, data concerning the 'Mitochondrial Eve' have strongly influenced the discussion on modern human origins, focusing on one possible extreme interpretation, the complete replacement view. This had led to an artificial polarisation in the debate over a number of years. Opponents of the Out-of-Africa model assumed that any evidence for continuity outside Africa would disprove the model. However, this view is not valid, because some gene flow during the replacement period would not be in contradiction to the model and could even have mimicked the effects of evolutionary continuity. The present paper reviews the current evidence on regional continuity in the different parts of the world.

\section{Introduction}

This short review begins with a somewhat personal look at the history of the 'Out-of-Africa' model of modern human evolution. By the early 1970s, there were already indications of an early presence of anatomically modern humans in Africa, for example from Omo Kibish and Border Cave (Day, 1969; De Villiers, 1973; Protsch, 1975). But at the same time there also seemed to be evidence for a later presence of big-browed archaics in sub-Saharan Africa, like the Eyasi cranium from Tanzania (Protsch, 1976; but see Klein, 1973). Thus, the situation was rather unclear - did archaic humans survive long after anatomically modern humans had already appeared?

In the late 1970s, when there were more dates and specimens available, we started a new analysis of the Middle and Late Pleistocene hominid material from Africa. This research led to a new reconstruction of Homo sapiens evolution, suggesting a rather gradual process from early to late archaic Homo sapiens and to an early emergence of anatomically modern humans. Based on the new framework and a review of the fossil evidence from Europe and the Far East, I suggested at the " 1 er Congrès International de Paléontologie Humaine" in Nice in 1982 an Out-of-Africa scenario named the 'Afro-European sapiens' model (Bräuer, 1982). I chose this term because the best evidence for replacement of archaics appeared to come from Europe. In retrospect, perhaps this term was not ideal because it did not clearly imply that the model was a global one. The next year, in 1983, at the G.H.R. von Koenigswald Memorial Symposium in Frankfurt, I proposed that replacement was the most likely process for the Far East as 
well (Bräuer, 1984a). An essential element of this Out-of-Africa model was the assumption that the replacement process was a complex population biological process involving gene flow between spreading modern populations and resident archaic groups to varying degrees in different parts of the world (e.g. Bräuer 1984a,b).

In 1987, the pioneering work on human mitochondrial DNA (mtDNA) appeared (Cann et al., 1987), which strongly influenced the discussion and led to an artificial polarization focusing on one extreme interpretation, the complete replacement view - or 'Eve Theory'. However, this is only one possible interpretation of the mtDNA data. Neither geneticists like Cann or Cavalli-Sforza, nor Stringer or I excluded the possibility of gene flow between archaic and modern humans (see Cavalli-Sforza, 1989; Bräuer, 1992a; Stringer \& Bräuer, 1994). There were those, mainly multiregionalists, who thought that any evidence of continuity outside of Africa could disprove the Out-of-Africa model (e.g. Frayer et al., 1993), but this model as supported by Chris Stringer or myself cannot be disproved by showing some evidence of continuity. Instead, some degree of gene flow might even mimic a certain degree of continuity. This has been discussed in detail in a number of papers (e.g. Stringer \& Bräuer, 1994; Bräuer \& Stringer, 1997). Although over the last few years there has been overwhelming evidence from molecular biology and DNA studies in support of a common origin of modern humans in Africa (e.g. Deka et al., 1998; Nei, 1995, 1998; Tishkoff et al., 1996; Rogers \& Jorde, 1995), there is still the exciting question as to whether the degree of gene flow between archaics and moderns in the different parts of the world was negligible, minimal or of a somewhat greater extent. In this paper the current evidence on this much-debated aspect will be evaluated.

\section{Africa}

Before coming back to this question, especially with regard to the evidence from Europe, I would like to briefly comment on Africa and the increasing evidence in support of an early origin of modern humans on this continent (see also Bräuer, this volume). Recent dating results have demonstrated that a near-modern or late archaic anatomy as shown by specimens like Florisbad from South Africa, Laetoli Hominid 18 from Tanzania, and KNM-ER 3884 from Kenya, already occurred in Africa as early as about 250000 to 300000 years ago (Grün et al., 1996; Manega, 1995; Bräuer et al., 1997). These specimens and a number of other late archaic and early modern hominids from Africa clearly document the early origin of modern anatomy. There is no evidence from any other continent for such an evolution which provides a central basis for Africa being the probable source area for the modern humans in the other parts of the world as well. This might also hold for the adjoining Near East, where early modern humans were already present around 100000 years ago (e.g. Klein, 1995/1996).

\section{Europe}

The European continent provides the best fossil record to explore the question on the amount of gene flow or continuitiy at the archaic/modern transition. We now know that Neanderthals were still present in Croatia as late as 28000 years ago, and in Spain up to about the same time (Smith et al., 1999; Hublin et al., 1995, 1996). If there was considerable gene flow between Neanderthals and early modern populations, we should be able to see it in the anatomy of early modern skeletal remains.

I carried out a study of this topic in search of a fresh approach to the question. The Mladeč material from the Czech Republic was chosen to look for evidence of regional continuity or gene flow with Neanderthals. This material was also of special interest because multiregionalists like Frayer (1986), after re-analysing the Mladeč cranial sample, came to the conclusion that it is good evidence in support of a gradual evolution from Neanderthals. In addition to the Mladeč material, other early Czech remains from Zlatý Kůn, Svatý Prokop and Svitávka were included, all of them dating between 30000 and 32000 years B.P. (Jelinek, 1976; Svoboda, 1994; Vlček, 1995). In his thesis, Broeg used 15 non-metrical 
features of the cranium and mandible which are generally regarded as Neanderthal autapomorphies or regional continuity traits. Some of the results of this research have recently been published (Bräuer \& Broeg, 1998). It has been most surprising to us that among the whole early anatomically modern cranial remains from the Czech Republic, not a single feature could be found which can be unequivocally derived from Neanderthals.

The Mladeč I cranium is fully anatomically modern in its supraorbitals and the face. In lateral view there is a slight hemi-bun, but such conditions are widely found in material from other parts of the world as well (Trinkaus \& Le May, 1982). From my own observations, it occurs, for example, in specimens from North Africa, central Sahara and Nigeria. In occipital view, there are also no Neanderthal affinities in Mladeč 1 . A tiny resorptive area above the external occipital protuberance has little in common with the clearly defined suprainiac fossa in Neanderthals (see Nara, 1994). Such resorptive areas as seen in this and other Mladeč specimens are found in Africa and in the Far East as well. Hambly (1940) showed crania from New Guinea having a much more strongly developed resorptive area above the external occipital protuberance.

The Mladeč 5 calvaria has frequently been regarded by multiregionalists as a central piece showing clear evidence for regional evolution (e.g. Wolpoff, 1992). However, our fresh look at this robust male specimen revealed that there is no hard evidence for such an assumption. The supraorbital morphology of this specimen is indeed robust, but anatomically modern in pattern, showing a marked superciliary arch mostly projecting in the mid-orbital region, as well as a flattened supraorbital trigone. This morphology is also evident in basal view. The mid sagittal curvatures of Mladeč 5 and La Chapelle-auxSaints show clear differences not only in the frontal but also in the occipital. Mladeč 5 does not exhibit the strong lambdoidal flattening and strong bunning of Neanderthals. Instead, its hemi-bun is much more similar to the conditions seen in both Jebel Irhoud 1 and 2 (see Bräuer \& Broeg, 1998). The occipital view of Mladeč 5 does not show any affinities to Neanderthal conditions: There is no oval shape of the cranial vault, there is no Neanderthal horizontal torus, and there is no suprainiac fossa. In summary, we were not able to see any clear Neanderthal feature in this specimen.

Assuming that gene flow between Neanderthals and early modern humans was not only possible, but probably did occur, we were indeed ready to accept any good evidence for continuity or for Neanderthal features among these early modern humans, but we were not able to find any clear indication of gene flow among the whole material studied. Most surprising to us, however, was the fact that this very material has been claimed by multiregionalists to provide evidence for gradual evolution from Neanderthals to modern humans. Thus, if this material shows so little or in fact no evidence for continuity, it appears more likely that the amount of gene flow during the replacement period was probably only small. Nevertheless, I would not exclude the possibility of finding other early modern Europeans providing more support for gene flow and mixing between these populations.

\section{East Asia}

In China, there is clear evidence for a prolonged existence of Homo erectus. More recent Homo erectus discoveries, like those from Yunxian have, however, revealed that the cranial morphology of Chinese Homo erectus is more variable than has been thought before (Etler \& $\mathrm{Li}, 1994)$. The Yunxian specimens (EV 9001 and EV 9002) exhibit large and massive faces similar to those of Bodo or Petralona. Yinyun (1998) would even classify the crania as archaic Homo sapiens in spite of the fact that they are older than the Zhoukoudian Homo erectus; and Etler (1996: 286) stated: "Given their unexpected mix of features, the Yunxian crania also raise questions vis-a-vis the longstanding practice of using the Zhoukoudian remains as the sole yardstick for defining the morphology of Homo erectus." The obviously rather variable species Homo erectus is followed by a number of fossils generally classified as archaic Homo sapiens (Wu \& Poirier, 1995; Wu \& Bräuer, 1993). One of these specimens comes from Jinniushan 
in northern China and dates to around 200000 years B.P. (Chen et al., 1994). The cranium of this partial skeleton is clearly more derived than Homo erectus but is still very archaic with its projecting supraorbital torus and its angulated occipital bone. In total shape, it is difficult to see any evidence for a direct connection between Jinniushan and early modern or recent populations from China. Although quite a number of suggested regional continuity features for East Asia turned out to be problematic (e.g. Habgood, 1992; Lahr, 1992; Bräuer \& Stringer, 1997), the Jinniushan cranium does not even have these traits, as for example a flat face or $\mathrm{M}_{3}$ agenesis. Instead, the alveolar part and the nasal region project forward and the third molars are in place (see also Groves \& Lahr, 1994). It is also difficult to see any clear similarities between another famous Chinese specimen, the Dali cranium, and recent populations. This specimen, which might date to between 150000 and 200000 years ago, exhibits a heavily developed supraorbital torus, a broad and massively built face, and a number of other archaic features.

About ten years ago, a rather enigmatic specimen was found in Laishui County, Hebei Province. The specimen consists of a well preserved skeleton including a large part of the cranium. Several dates have been reported, ranging between 28000 years and 40000 years B.P. (Etler, 1995; Lü, pers.comm.). When I looked at the original, the most striking features to me were the archaic torus-like supraorbitals accompanied by a rather receding frontal bone as well as the robust protruding face. If the young age is further supported, the Laishui hominid could represent the first evidence that around 30000 or 40000 years ago archaic humans were still possibly co-existing with early anatomically moderns. Such early moderns are known from Liujiang, Southern China, and the Upper Cave at Zhoukoudian, dating probably around 30000 years (Etler, 1996; Wu \& Poirier, 1995). A number of independent studies of this early modern material has revealed that both Liujiang and Upper Cave are rather different from recent Chinese populations and are much closer to latest Pleistocene Africans and Europeans (e.g. Howells, 1995; Kamminga, 1992; Neves \& Pucciarelli, 1998; Bräuer, unpubl.).

Although this review cannot cover the whole fossil record, the archaic/modern transitional period in China is much more poorly known than that in Europe. Nevertheless, the recent evidence makes a late persistence of archaic humans and their replacement by anatomically modern populations possible.

The question concerning the amount of gene flow or continuity in this part of the world is currently difficult to assess. Much will depend on further analyses of the reliability of the suggested East Asian regional features.

\section{Australasia}

Turning to Southeast Asia and Australia, recent ESR and U-series dating results have pointed to a very late age of 40000 or even 30000 years for the Homo erectus-like Ngandong populations (Swisher et al., 1996). If these still debated dates can be further supported, there is little possibility for an evolutionary continuity from such archaic populations to early anatomically modern humans of that region because the latter already existed by at least 50000 or 60000 years ago as recent dating evidence has shown for the Lake Mungo 3 skeleton from Australia (Thorne et al 1999). Further fully modern gracile remains are known from Borneo (Niah Cave) as early as about 40000 years ago. On the other hand, there can be little doubt that the morphological variation within the more recent Australian material (e.g. Kow Swamp; WLH 50) is especially extensive, which requires explanation. Although the possibility cannot be excluded that parts of this wide range of variation are due to some mixing between archaic and modern populations (Bräuer, 1992), it is also possible that most of this variation was caused by genetic drift effects and adaptation of modern humans in Australia.

Suggestions for an archaic-modern evolutionary continuity in Australasia are mainly based on the occurrence of assumed regional clade features, as for example a number of facial traits (Frayer et al., 1993). However, only one Indonesian Homo erectus cranium, Sangiran 17, has its face preserved. According to the recent re-dating of the Sangiran deposits by Swisher et al. (this volume), this specimen 
could be even older than 1 million years. Thus, there is no fossil evidence documenting a regional transformation from this huge and massive Homo erectus face to the modern facial shape as seen in the terminal Pleistocene and Holocene material from Australia. Moreover, it appears highly unlikely that the suggested regional features like prognathism, everted malars and zygomaxillary tuberosities, could have been maintained during the whole process of morphological transformation and assumed gene flow among different populations over a million years (Nei, 1998). Finally, a new reconstruction of the Sangiran 17 hominid by Aziz et al. (1996) has shown that the major claimed regional features are no longer present on the hominid. The new reconstruction exhibits a much lesser degree of prognathism, no eversion of the lower malar border, and there is also no zygomaxillary tuberosity. Aziz et al. (1996) concluded from their re-examination of the new reconstruction that the observations on the morphological characters considered as evidence of regional continuity in Australasia by Thorne \& Wolpoff (1981) were not appropriate to a considerable degree.

\section{Conclusion}

In view of the many problems with regard to the assumed regional continuity features for both East Asia and Australasia, much of the suggested evidence for continuity is rather dubious or no longer tenable. Nevertheless, it appears necessary to further explore the variability and occurrence of the suggested continuity features (Bräuer \& Stringer, 1997). Such an analysis will enable us to better understand the amount of gene flow between modern and archaic populations during the replacement period and the dispersal process of modern humans around the globe. However, in view of all the current evidence there can be little doubt about our common origin in Africa; or as Stringer \& McKie (1996: 234) put it: "Our African Exodus, once a heresy, is today's orthodoxy".

\section{Acknowledgements}

I would like to thank Fred Smith and Phillip Tobias for inviting me to take part in this Colloquium. I am also grateful to the many colleagues who generously supported my research over more than two decades and cooperated with me in searching for the roots of modern humans.

\section{References}

Aziz, F., Baba, H. \& Watanabe, N. (1996). Morphological study on the Javanese Homo erectus Sangiran 17 skull based upon the new reconstruction. GRDC, Paleontology Series, 8, 11-25.

Bräuer, G. (1982). Early anatomically modern man in Africa and the replacement of the Mediterranean and European Neandertals. $1^{\mathrm{er}}$ Congr. Intern. Paléont. Hum., Nice, Resumés, p.112.

Bräuer, G. (1984a). The "Afro-European sapiens hypothesis" and hominid evolution in East Asia during the late Middle and Upper Pleistocene. Courier Forschungs-Institut, Senckenberg, 69, 145-65.

Bräuer, G. (1984b). A craniological approach to the origin of anatomically modern Homo sapiens in Africa and implications for the appearance of modern Europeans In: The Origins of Modern Humans: A World Survey of the Fossil Evidence, ed. F.H. Smith \& F. Spencer, pp.327-409. New York: Alan R. Liss.

Bräuer, G. (1992a). Africa's place in the evolution of Homo sapiens. In: Continuity or Replacement - Controversies in Homo sapiens Evolution, ed. G. Bräuer \& F.H. Smith, pp. 83-98. Rotterdam: Balkema.

Bräuer, G. (1992b). The origins of modern Asians: By regional evolution or by replacement? In: The Evolution and Dispersal of Modern Humans in Asia, ed. T. Akazawa, K. Aoki \& T. Kimura, pp. 401-13. Tokyo: Hokusen-Sha.

Bräuer, G. \& Broeg, H. (1998). On the degree of Neandertal-Modern continuity in the earliest Upper Palaeolithic crania from the Czech Republic: Evidence from non-metrical features. In: The Origins and Past of Modern Humans - Towards Reconciliation, ed. K. Omoto \& P.V. Tobias, pp. 106-25. Singapore: World Scientific.

Bräuer, G. \& Stringer, C.B. (1997). Models, polarization, and perspectives on modern human origins. In: Conceptual Issues in Modern Human Origins Research, ed. G.A. Clark \& C.M. Willermet, pp.191-201. New York: Aldine 
de Gruyter.

Bräuer, G., Yokoyama, Y., Falguères, C. \& Mbua, E. (1997). Modern human origins backdated. Nature, 386, 337-38. Cann, R.L., Stoneking, M. \& Wilson, A.C. (1987). Mitochondrial DNA and human evolution. Nature, 325, 31-36.

Cavalli-Sforza, L.L. (1989). The last 100,000 years of human evolution: the vantage points of genetics and archaeology. In: Hominidae, ed. G. Giacobini, pp.401-13. Milano: Jaca Book.

Chen, T., Yang, Q. \& Wu, E. (1994). Antiquity of Homo sapiens in China. Nature, 368, 55-56.

Day, M.H. (1969). Early Homo sapiens remains from the Omo River Region in South-west Ethiopia. Nature, 222, 1135-38.

Deka, R., Shriver, M.D., Jin, L., Yu, L.M., Ferrell, R.E. \& Chakraborty, R. (1998). Tracing the origin of modern humans using nuclear microsatellite polymorphisms. In: The Origins and Past of Modern Humans - Towards Reconciliation, ed. K. Omoto \& P.V. Tobias, pp.3-15. Singapore: World Scientific.

De Villiers, H. (1973). Human skeletal remains from Border Cave, Ingwavuma District, KwaZulu, South Africa. Annals of the Transvaal Museum, 28, 229-56.

Etler, D.A. (1996). The fossil evidence for human evolution in Asia. Annual Review of Anthropology, 25, 275-301.

Etler, D.A. \& Li, T.Y. (1994). New archaic human fossil discoveries in China and their bearing on hominid species definition during the middle Pleistocene. In: Integrative Paths to the Past: Paleoanthropological Advances in Honor of F. Clark Howell, ed. R. Corruccini \& R. Ciochon, pp.639-76. New York: Prentice Hall.

Frayer, D.W. (1986). Cranial variation at Mladeč and the relationship between Mousterian and Upper Paleolithic hominids. Anthropos (Brno), 23, 243-56.

Frayer, D.W., Wolpoff M.H., Thorne, A.G., Smith, F.H. \& Pope, G. (1993). Theories of modern human origins: the paleontological test. American Anthropologist, 95, 14-50.

Groves, C.P. \& Lahr, M.M. (1994). A bush not a ladder: speciation and replacement in human evolution. In: Perspectives in Human Biology, ed. Freedman, L., Jablonski, N. \& Bruce, N.W., pp. 1-11. Canberra: Australasian Society for Human Biology.

Grün, R., Brink, J.S., Spooner, N.A., Taylor, L., Stringer, C.B., Franciscus, R.G. \& Murray, A.S. (1996). Direct dating of Florisbad hominid. Nature, 382, 500-01.

Habgood, P.J. (1992). The origin of anatomically modern humans in east Asia. In: Continuity or Replacement Controversies in Homo sapiens Evolution, ed. G. Bräuer \& F.H. Smith, pp. 273-88. Rotterdam: Balkema.

Hambly, W. (1940). Craniometry of New Guinea. Anthropological Series, Field Museum of Natural History, 25, 3. Howells, W.W. (1995). Who's who in skulls. Peabody Museum of Archaeology and Ethnology, Harvard University. Cambridge (Mass.).

Hublin, J.J., Ruiz, C.B., Lara, P.M., Fontugne, M. \& Reyss, J.L. (1995). The Mousterian site of Zaffarraya (Andalucia, Spain): dating and implications on the palaeolithic peopling processes of Western Europe. C. R. Acad. Sci. Paris, 321, ser. 2a, 931-37.

Hublin, J.J., Spoor, F., Braun, M., Zonneveld, F. \& Condemi, S. (1996). A late Neanderthal associated with Upper Palaeolithic artefacts. Nature, 381, 224-26.

Jelinek, J. (1976). The Homo sapiens neanderthalensis and Homo sapiens sapiens relationship in Central Europe. Anthropos (Brno), 14, 79-81.

Kamminga, J. (1992). New interpretation of the Upper Cave, Zhoukoudian. In: The Evolution and Dispersal of Modern Humans in Asia, ed. T. Akazawa, K. Aoki \& T. Kimura, pp.379-400. Tokyo: Hokusen-Sha.

Klein, R.G. (1973). Geological antiquity of Rhodesian Man. Nature, 244, 311-12.

Klein, R.G. (1995/96). Neanderthals and modern humans in West Asia: A conference summary. Evolutionary Anthropology, 4, 187-93.

Lahr, M.M. (1992). The origins of modern humans: A test of the Multiregional Hypothesis. Unpublished Ph.D. dissertation, Cambridge University.

Manega, P. (1995). New geochronological results from the Ndutu, Naisiusiu and Ngaloba Beds at Olduvai and Laetoli in Northern Tanzania: Their significance for evolution of modern humans. Bellagio, Italy. 
Nara, M.T. (1994). Etude de la variabilité de certains caractères métriques et morphologiques des Néandertaliens. Thèse de Docteur, Bordeaux.

Nei, M. (1995). Genetic support for the out-of-Africa theory of human evolution. Proc. National Academy Science, USA, 92, 6720-22.

Nei, M. (1998). Genetic studies on the origin of modern humans. In: The Origins and Past of Modern Humans Towards Reconciliation, ed. K. Omoto \& P.V. Tobias, pp.27-41. Singapore: World Scientific.

Neves, W. \& Pucciarelli, H. (1998). The Zhoukoudian Upper Cave skull 101 as seen from the Americas. Journal of Human Evolution, 34, 219-222.

Protsch, R. (1975). The absolute dating of Upper Pleistocene sub-Saharan fossil hominids and their place in human evolution. Journal of Human Evolution, 4, 297-322.

Protsch, R. (1976). The position of the Eyasi and Garusi hominids in East Africa. In: Les Plus Anciens Hominidés, ed. P.V. Tobias \& Y. Coppens, pp.207-38. Paris: CNRS.

Rogers, A.R. \& Jorde, L.B. (1995). Genetic evidence on modern human origins. Human Biology, 67, 1-36.

Smith, F.H., Trinkaus, E., Pettitt, P.B., Karavanič, I. \& paunovič (1999).

Direct radiocarbon dates from Vindija $G_{1}$ and Velika Pećina late Pleistocene hominid remains. Proc. National Academy of Sciences 96, 12281-12286.

Stringer, C.B. \& Bräuer, G. (1994). Methods, misreading, and bias. American Anthropologist, 96, 416-24.

Stringer, C.B. \& McKie, R. (1996). African Exodus. London: Jonathan Cape.

Swisher, C.C., Rink, W.J., Antón, S.C., Schwarcz, H.P., Curtis, G.H., Suprijo, A. \& Widiasmoro, A.S. (1996). Latest Homo erectus of Java: Potential contemporaneity with Homo sapiens in Southeast Asia. Science, 274, 1870-74.

Thorne, A. \& Wolpoff, M.H. (1981). Regional continuity in Australasian Pleistocene hominid evolution. American Journal of Physical Anthropology, 55, 337-49.

Thorne, A., Grün, R., Mortimer, G., Spooner, N.A., Simpson, J.J., McCulloh, M., Taylor, L. \& Curnoe, D. (1999). Australia's oldest human remains: age of the Lake Mungo 3 skeleton. Journal of Human Evolution 36, 591-612.

Tishkoff, S.A., Dietzsch, E., Speed. W., Pakstis, A.J., Kidd, J.R., Cheung, K., Bonne-Tamir, B., SantachiraBenerecetti, A.S., Moral, P., Krings, M., Pääbo, S., Watson, W., Risch, N., Jenkins, T. \& Kidd, K. (1996). Global patterns of linkage disequilibrium at the CD4 Locus and modern human origins. Science, 271, 1380-87.

Trinkaus, E. \& Le May, M. (1982). Occipital bunning among later Pleistocene hominids. American Journal of Physical Anthropology, 57, 27-35.

Vlček, E. (1995). Evolution of human populations in the European Pleistocene. In: Man and Environment in the Palaeolithic, ed. H. Ulrich, pp.167-179. Liège: ERAUL.

Wolpoff, M.H. (1992). Theories of modern human origins. In: Continuity or Replacement -Controversies in Homo sapiens Evolution, ed. G. Bräuer \& F.H. Smith, pp. 25-63, Rotterdam: Balkema.

Wu, X. \& Bräuer, G. (1993). Morphological comparison of archaic Homo sapiens crania from China and Africa. Zeitschrift für Morphologie und Anthropologie, 79, 241-59.

Wu, X. \& Poirier, F.E. (1995). Human Evolution in China: A morphometric description of fossils and review of sites. Oxford: Oxford University Press.

Yinyun, Z. (1998). Fossil human crania from Yunxian, China: Morphological comparison with Homo erectus crania from Zhoukoudian. Human Evolution, 13, 45-48. 


\section{Günter Bräuer}

Institute of Human Biology

University of Hamburg

Allende-Platz 2

20146 Hamburg, Germany

Keywords: archaic Homo sapiens, modern humans, Guomde, Ileret, KNM-ER 3884, KNM-ER 999

\section{The KNM-ER 3884 Hominid and the Emergence of Modern Anatomy in Africa}

\begin{abstract}
Although there can be little doubt that modern anatomy originated very early in Africa, new results indicate that the evolutionary process of modernization occured even earlier than generally thought. Most recent indications for such a backdating are yielded by Uranium-series dates for two fragment of the KNM-ER 3884 cranium and a part of the KNM-ER 999 femur from Ileret, Kenya, suggesting ages of around 270000 and 300000 years, respectively. These results were surprising because of the near-modern morphology of the specimens. However, recent dating of Laetoli Hominid 18 (Tanzania) and Florisbad (South Africa) also support such an early age for late archaic Homo sapiens in Africa. These results raise again the interesting question whether the evolution of modern anatomy followed a mosaic-like pattern in most of Africa or whether it took place predominantly in one part of the continent. Not only late archaic $H$. sapiens, but also early archaic $H$. sapiens, appear to have existed earlier than has long been assumed. $\mathrm{Ar} / \mathrm{Ar}$ ages place the Bodo hominid from Ethiopia at around 600000 years BP, indicating that at this time a form existed which was more derived than H. erectus. While some workers classify Bodo and similar specimens as (early) archaic $H$. sapiens, others assign them to a species named $H$. heidelbergensis. The present paper discusses the current framework of Middle and early Late Pleistocene hominid evolution in Africa including questions of taxonomy.
\end{abstract}

\section{Introduction}

The evolution of modern anatomy in Africa has been a much debated topic for many years. I have been personally involved in this question for more than 20 years, and looking over this time period I can say that there has been increasing evidence from both fossils and dating that support a very early origin of modern anatomy in Africa. The most recent evidence comes from the Ileret specimen, KNM-ER 3884, also known as the Guomde cranium (Fig. 1). The date of the specimen has long been unknown because it was not possible to determine whether the cranium derived from undifferentiated later deposits of the Upper Chari Member of the Koobi Fora Formation or from the subsequent Holocene Galana Boi Formation (Bräuer, Leakey \& Mbua, 1992). It has therefore been unclear whether the cranium dates from more than 100000 , up to several hundred thousand years, or whether it could even be less than 10000 years old (Feibel et al., 1989).

In the 1980s, we carried out a preliminary analysis and comparison of the cranium (Bräuer, Leakey \& Mbua, 1992), and we found that the posterior cranial vault was basically anatomically modern, whereas the supraorbital fragment seemed to tell a different story. It clearly exhibits a continuous supraorbital torus running over both orbits. We compared the torus morphology with that seen in the Galana Boi material and other East African Holocene and final Pleistocene specimens. We could find no similarities. We also included in our comparison robust modern remains like the cranial fragment from 

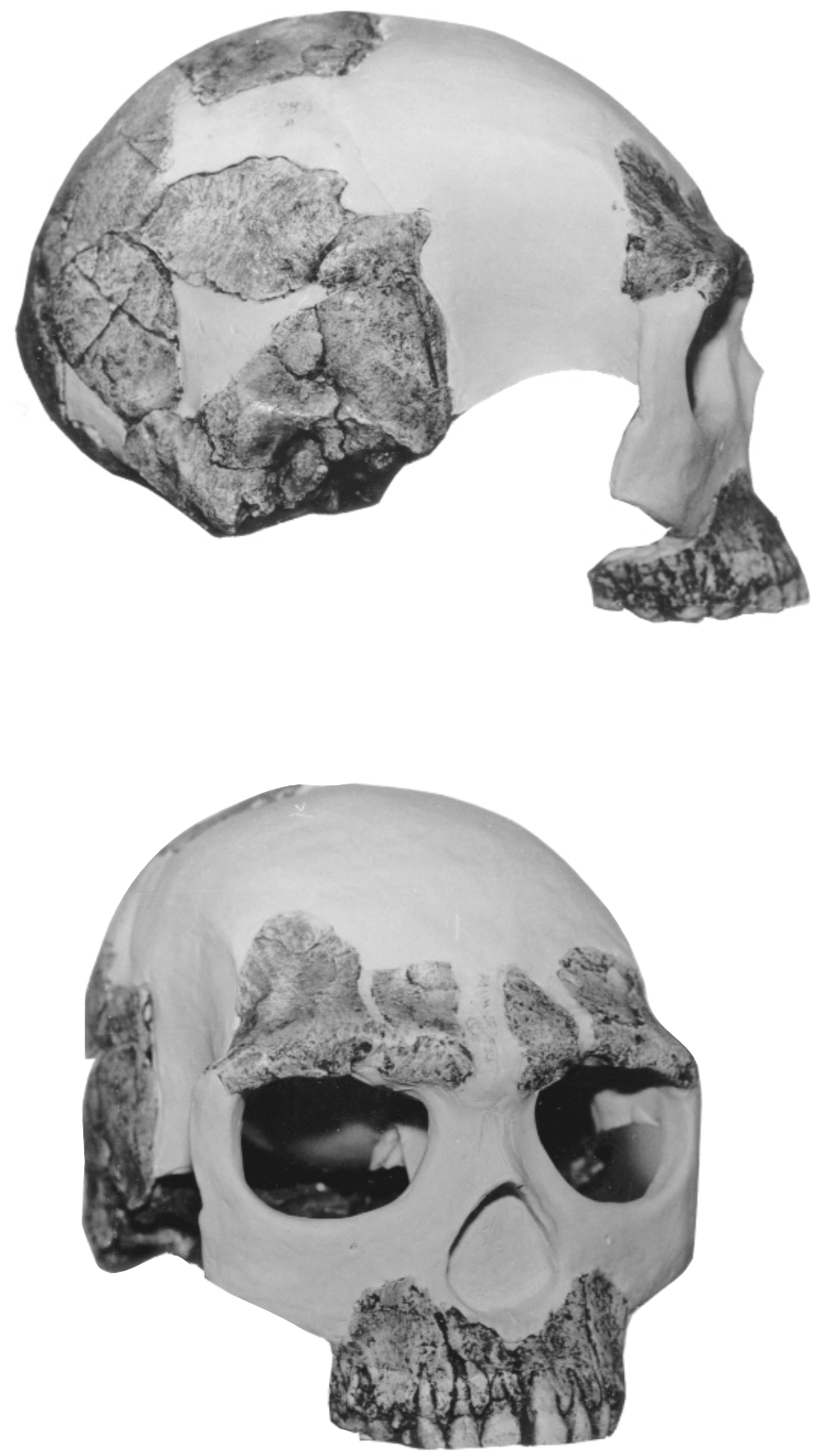

Figure 1. Reconstruction of the KNM-ER 3884 cranium from Ileret 
Lukenya Hill, which dates to roughly 17000 years. This specimen clearly deviates from the morphology of KNM-ER 3884 in having a modern supraorbital pattern with a pronounced but well defined superciliary arch and a flattened supraorbital trigone. The supraorbital morphology of KNM-ER 3884 instead showed closer affinities to archaic Homo sapiens.

\section{Recent dating evidence}

Over the years dating possibilities for the KNM-ER 3884 cranium have been sought, but only recently was a direct dating of the hominid possible using the non-destructive method of gamma-ray spectrometry. Yuji Yokoyama and Christophe Falguères of the Muséum National d'Histoire Naturelle in Paris were able to date two cranial fragments separately to 272000 and 279000 years respectively (Bräuer et al., 1997). To be on the safe side we also included in this dating project the so-called Guomde femur, KNM-ER 999, which derived from the same deposits as the KNM-ER 3884 cranium. The result of the gamma-ray spectrometry dating for the femur was about 300000 years, which also supported the great age of the cranium. The morphology of the KNM-ER 999 femur was analysed by Trinkaus (1993), who found close similarities to early modern specimens from the Near East. Although the femur is thick-walled, it exhibits a number of derived features such as a pilaster development and a very low neck-shaft angle.

The great age of the Ileret specimen was indeed surprising, but other recent evidence has supported such an early presence of near-modern humans in Africa. A few months after the Ileret cranium was dated to around 270000 years, Grün et al. (1996) published a new date for the Florisbad hominid of $259000( \pm 35000)$ years, based on ESR analysis of the single hominid tooth. The early presence of such near-modern humans in Africa has further been supported by new dating evidence for the Upper Ngaloba Beds in Tanzania, from which the Laetoli Hominid 18 cranium derived. Recent amino acid dates on ostrich eggshell material point to an age of more than 200000 years for this specimen (Manega, 1995). Thus there are three different hominids, dated by different methods and different laboratories, all pointing to the presence of a near-modern or late archaic anatomy in Africa between 250000 and 300000 years ago. The partial cranium from Florisbad exhibits a quite derived, near-modern anatomy which is especially evident from its canine fossa and the moderately developed supraorbital torus. The Laetoli Hominid 18 also shows a modern face and a slightly projecting supraorbital torus. A close look at the torus indicates that there is a division between the superciliary arch and the supraorbital trigone, as Magori (1980) pointed out in his dissertation.

Two further late archaic Homo sapiens crania from Jebel Irhoud, Morocco, might date to somewhat less than 200000 years (Grün \& Stringer, 1991). They also exhibit a derived supraorbital morphology and the face, only preserved in one specimen, appears quite modern. In view of these recent dates for late archaic Homo sapiens, a new comparative study of the Ileret cranium KNM-ER 3884 is currently underway (G. Bräuer and E. Mbua, in preparation).

\section{The modernization process}

The late archaic hominid specimens from Africa are followed by early anatomically modern humans (Fig. 2). The Singa cranium from Sudan, dating to about 150000 years (McDermott et al., 1996), can be regarded as being just on the threshold to modern humans. It has been classified both as late archaic and as anatomically fully modern.

Another important early anatomically modern specimen comes from the Omo Kibish Formation in Ethiopia. Uranium-series dates for the hominid level have yielded an age of around 130000 years. This date has been questioned because it is based on mollusc material. However, mollusc shells tend to accumulate Uranium after deposition, which would normally lead to an under-estimation of age. The cranium and post-cranial remains of the Omo Kibish I hominid are fully anatomically modern, and I would not be surprised to find a similar skull among early modern Europeans.

Another important site which yielded early modern cranial and post-cranial remains lies on the south 
coast of Africa, at the Klasies River Mouth. The oldest human remains came from the LBS Member, which dates to the last interglacial period around 120000 years ago. An analysis of the maxillary fragments found there has shown that the specimens fall into the range of a Holocene sample from Africa (Bräuer, Deacon \& Zipfel, 1992). One of the best preserved specimens from Klasies River is a 100 000-year-old mandible (no. 41815) from the lower SAS Member, showing a well developed chin and a fully modern anatomy.

The famous frontal fragment from this site is about 80000 years old and it also does not exhibit any archaic reminiscences. Its supraorbital margin is thin and it is quite unlikely that a supraorbital torus morphology could have developed, even if the specimen belonged to a sub-adult of around 15 or 16 years of age.

Nevertheless, the Klasies River human remains dated to between 60000 and 80000 years ago exhibit a rather great variability (Bräuer \& Singer, 1996a,b). The mandibular specimens range from extremely gracile (no.16424) to robust ones with weak chin development (no.13400). Although much of this variation might be due to sexual dimorphism, the question arises whether some features should be regarded as archaic retentions.

As there is much subjectivity in the assessment of chin development, Lam et al. (1996) carried out a metrical analysis of the depth of the anterior incurvature and the protrusion of the chin, and found that some Klasies specimens are marginal to, but still within, the $95 \%$ range of recent samples. There are also less pronounced chins in the early modern remains from Qafzeh, Israel (Tillier, 1989). A similar situation is found in the postcranial specimens from Klasies River and Border Cave. Here, too, the morphology of some specimens seems to show archaic reminiscences, as for example the Klasies River ulna with regard to the relative height of its coronoid and olecranon processes. Nevertheless, Churchill et al. (1996) stated that the morphology of the Klasies River ulna could be matched in samples from recent San and other sub-recent Africans (see also Pearson \& Grine, 1996). From Groves' (1998) Principal Components Analysis, the position of the Klasies River ulna is somewhere between archaic humans (Neanderthal, Baringo) and recent moderns and could also be interpreted as being ancestral to more modern humans. Whether special conditions of certain features seen in an early modern sample like that from Klasies River should be regarded as archaic retentions or as common early anatomically modern conditions is difficult to decide, but also not of much relevance. I think the morphological range of variation seen in the Klasies River material is exactly what one would expect in such an early modern population: fully anatomically modern specimens, like some mandibles, the frontal fragment and others, as well as pieces showing more archaic-looking conditions marginal to the recent variation.

We cannot expect that the recent morphological variation will cover the total range of early anatomically modern variation (Trinkaus, 1993; Bräuer \& Singer, 1996b). The range of variation will most likely be wider to the archaic and more robust side. Interestingly, Pfeiffer \& Zehr (1996: 57) found in their analysis of the robust humerus from Border Cave not only similarities to Early Upper Palaeolithic and Later Stone Age specimens, but also "that the oldest males of the dated sample of LSA humeri show high values for bone mass and strength relative to their overall size, similar to Border Cave". Therefore, I do not see any problem in classifying the Klasies River and Border Cave materials as anatomically modern humans.

In summary, the fossil hominids and the most recent dating evidence clearly indicate that the evolution of modern anatomy occurred relatively early in Africa (Fig. 2). Near-modern or late archaic humans already existed in eastern and southern Africa at least 250000 years ago. This process of modernization and sapiens evolution can be traced back up to around 600000 years to the earliest known specimen of early archaic Homo sapiens, the Bodo cranium from Ethiopia. This specimen deviates significantly from Homo erectus morphology in a number of features, as for example in its larger cranial capacity of around $1300 \mathrm{cc}$, the broader frontal and also in some derived features of its supraorbital morphology (Rightmire, 1996). Thus, it is quite probable that a speciation process occurred 


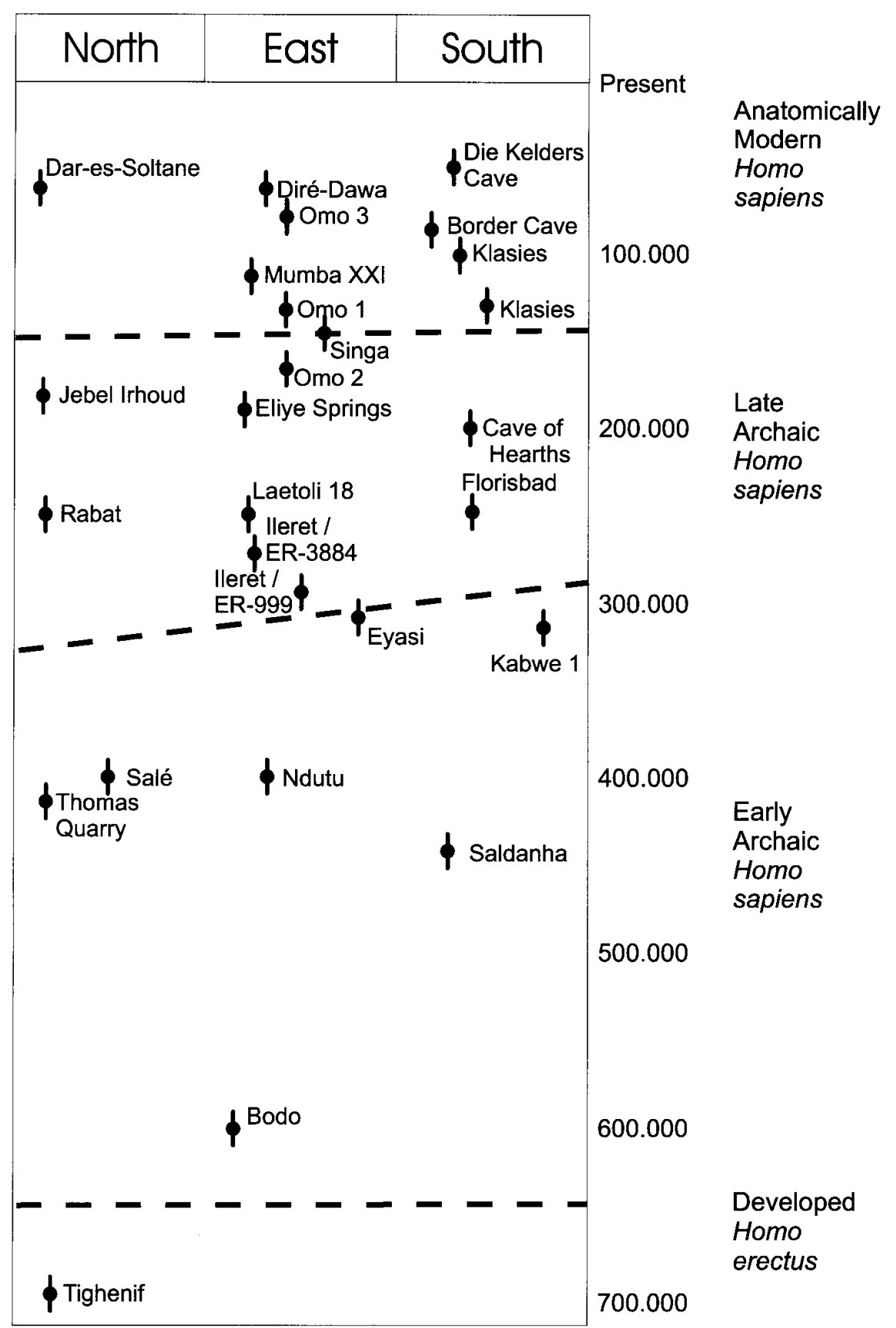


around 700000 years ago. Unfortunately, the hominid material from this time period is very sparse.

Another interesting question is whether the modernization process in Africa took place all over the continent in a mosaic-like pattern, or whether it occurred predominantly in one of the major areas of Africa and then spread to other regions. About 15 years ago it was widely believed that late archaic and modern humans appeared first in sub-Saharan Africa. At the end of the 1980s, new dates for the Jebel Irhoud hominids pointing to an age of up to 190000 years have drawn attention to North Africa as a possible cradle of modern anatomy. However, as outlined above, the last three years have again yielded more important new evidence for an earlier presence of near-modern humans in sub-Saharan Africa. Further analysis of the African cranial material with regard to derived and primitive conditions might yield more clarity on the process.

\section{Phylogenetic perspectives}

Finally, how do we put the African sequence into a larger phylogenetic scheme? I think that the speciation process in Africa around 700000 or 800000 years ago took place between Homo erectus and archaic Homo sapiens followed by more or less gradual evolution from early to late archaic Homo sapiens and finally to anatomically modern humans, whereas in Europe the evolution led from AnteNeanderthals to Neanderthals (for the Far East, see Bräuer, this volume). Rightmire $(1996,1998)$ has recently suggested a speciation from Homo erectus to Homo heidelbergensis, from which in Europe Homo neanderthalensis, and in Africa Homo sapiens, might be descended. However, the situation for Africa appears to be more difficult because the late archaic Homo sapiens group is already quite close to anatomically modern humans. In such a scenario, Homo sapiens could not be regarded as including only anatomically modern humans, as has been proposed by a number of authors, but it should also include the late archaic Homo sapiens group. On the other hand, it appears rather difficult clearly to distinguish early from late archaic Homo sapiens in Africa on a species or paleospecies level. Thus, to me it appears more plausible to consider the African sequence over the last 600000 years as a rather gradual evolution of our own species, Homo sapiens.

\section{Acknowledgements}

I would like to thank Giacomo Giacobini and Phillip Tobias for inviting me to take part in this Colloquium. I am also grateful to the organizers of the magnificent Dual Congress as well as to the German Research Foundation (DFG) for supporting my participation.

\section{References}

Bräuer, G., Deacon, H.J. \& Zipfel, F. (1992). Comment on the new maxillary finds from Klasies River, South Africa. Journal of Human Evolution, 23, 419-22.

Bräuer, G., Leakey, RE. \& Mbua, E. (1992). A first report on the ER 3884 cranial remains from Ileret/East Turkana, Kenya. In: Continuity or Replacement - Controversies in Homo sapiens Evolution, ed. G. Bräuer \& F.H. Smith, pp.111-19. Rotterdam: Balkema.

Bräuer, G. \& Singer, R. (1996a). The Klasies zygomatic bone: archaic or modern? Journal of Human Evolution, 30, $161-65$.

Bräuer, G. \& Singer, R (1996b). Not outside the modern range? Journal of Human Evolution, 30, 173-74.

Bräuer, G., Yokoyama, Y., Falguères, C. \& Mbua, E. (1997). Modern human origins backdated. Nature, 386, 337-38.

Churchill, S.E., Pearson, O.M., Grine, F.E., Trinkaus, E. \& Holliday, T.W. (1996). Morphological affinities of the proximal ulna from Klasies River Mouth Main Site: archaic or modern? Journal of Human Evolution, 31, 213-37.

Feibel, C.S., Brown, F.H. \& McDougall, I. (1989). Stratigraphic context of fossil hominids from the Omo Group deposits, northern Turkana Basin, Kenya and Ethiopia. American Journal of Physical Anthropology, 78, 595-622.

Groves, C.P. (1998). The proximal ulna from Klasies River. Journal of Human Evolution, 34, 119-21.

Grün, R. \& Stringer, C.B. (1991). Electron Spin Resonance dating and the evolution of modern humans. Archaeometry, 33, 153-99.

Grün, R., Brink, J.S., Spooner, N.A., Taylor, L., Stringer, C.B., Franciscus, R.G. \& Murray, A.S. (1996). Direct 
dating of Florisbad hominid. Nature, 382, 500-01.

Lam, Y.M., Pearson, O.M. \& Smith, C.M. (1996). Chin morphology and sexual dimorphism in the fossil hominid mandible sample from Klasies River Mouth. American Journal of Physical Anthropology, 100, 545-57.

Manega, P. (1995). New geochronological results from the Ndutu, Naisiusiu and Ngaloba Beds at Olduvai and Laetoli in Northern Tanzania: Their significance for evolution of modern humans. Paper presented at the Conference "Preservation and use of Olduvai Gorge, Laetoli, Rock art and other paleoanthropological resources in Tanzania". Bellagio, Italy.

Magori, C.C. (1980). Laetoli Hominid 18: Studies on a Pleistocene fossil human skull from Northern Tanzania. Unpublished Ph.D. Thesis, University College, London.

McDermott, F., Stringer, C., Grün, R., Williams, C.T., Din, V.K. \& Hawkesworth, C.J. (1996). New Late-Pleistocene uranium-thorium and ESR dates for the Singa hominid (Sudan). Journal of Human Evolution, 31, 507-16.

Pearson, O.M. \& Grine, F.E. (1996). Morphology of the Border Cave hominid ulna and humerus. South African Journal of Science, 92, 231-36.

Pfeiffer, S. \& Zehr, M.K. (1996). A morphological and histological study of the human humerus from Border Cave. Journal of Human Evolution, 31, 49-59.

Rightmire, G.P. (1996). The human cranium from Bodo, Ethiopia: evidence for speciation in the Middle Pleistocene? Journal of Human Evolution, 31, 21-39.

Rightmire, G.P. (1998). Human evolution in the Middle Pleistocene: The role of Homo heidelbergensis. Evolutionary Anthropology, 6, 218-27.

Tillier, A.-M. (1989). The evolution of modern humans: Evidence from young Mousterien individuals. In: The Human Revolution, ed. P.Mellars \& C.B. Stringer, pp 286-297. Edinburgh: Edinburgh University Press.

Trinkaus, E. (1993). A note on the KNM-ER 999 hominid femur. Journal of Human Evolution, 24, 493-504. 


\section{Philip G. Chase}

University of Pennsylvania

Museum of Archaeology and Anthropology

33 rd and Spruce Streets

Philadelphia, PA 19104-6324, U.S.A.

Keywords: Symbolism, Language, Culture, Archaeology, Human Paleontology

\section{'Symbolism' Is Two Different Phenomena: Implications for Archaeology and Paleontology}

\begin{abstract}
What usually goes under the rubric of "symbolism" is actually two phenomena that are logically separable- referntial symbolism, the purely referential use of symbols in communication, and symbolic culture, the creation of complex systems of symbolic concepts, beliefs and values that play a major role in determining how we think and in how we behave. I will argue that the paleontological record provides evidence concerning the evolution of the former, while the archaeological record provides evidence of the latter. Chronological discrepancies between the paleoanthropological and archaeological evidence for symbolism may simply indicate that the two phenomena did not evolve simultaneously and in tandem.
\end{abstract}

\section{Introduction}

Because symbolism is a crucial part of human adaptation, tracing its origins is essential for understanding the evolution of our species. Evidence from the historical sciences is indispensable to this process. Although disciplines such as neuroanatomy and comparative psychology can make contributions through actualistic research, historical data are available from only two fields, archaeology and human paleontology.

These two disciplines use different sets of evidence to infer the presence of symbolism in prehistory. Human paleontologists deal with skeletal morphology, while archaeologists deal with material culture. Nevertheless, it seems to be a generally held assumption that evidence from both disciplines reflects the same underlying phenomenon. In other words, the symbolism that is manifested anatomically and the symbolism manifested in material culture are essentially one and the same thing. Although I have never seen this assumption made explicit, it appears to underlie most discussions, and I am aware of no study in the literature that investigates its validity.

I will argue here that in fact the skeletal and archaeological evidence point to two different phenomena, which I will refer to as 'referential symbolism' and 'symbolic culture' respectively. The two are closely related, in that the latter depends for its existence on the former. It does not follow, however, that symbolic culture evolved in tandem with referential symbolism, and because these two phenomena have different implications for adaptation, we should look closely at what the evidence can tell us about the evolution of each.

What I would like to do here is, first, to define these two phenomena, explaining the distinction between them. Second, I will explain why I think that paleontological evidence points to the former, while most archaeological evidence points to the latter. Finally, I will discuss very briefly the implications of this difference for how we should be conducting research. I should make it clear that my purpose is not to provide any definitive answers or even hypotheses concerning the evolution of symbolism. Rather, I hope to point out what I see to be an unjustified assumption, one that I believe tends to obscure our understanding of the subject. 


\section{Referential symbolism and symbolic culture}

Human language as it exists today differs from the communications systems of other species in that it is based on referential symbolism. By this I mean 'symbolism' as Peirce (1932-1960) defined it. Although others have used the term differently, there should be no misunderstanding as long as my own usage is clear. To Peirce, a symbol is one kind of sign - a sign being something that stands for, points to, or refers to something else. Peirce recognized three kinds of signs. Icons point to their referents by resemblance a picture of a bison depicts the real animal. An index points to its referent by association - smoke indicates fire. Thus these signs point to their referents naturally, but symbols do so by arbitrary convention. The link between the word 'fire' and the phenomenon of fire is purely arbitrary. Other sets of sounds ('feu', 'fuego' etc.) can be used just as well, and there are no natural grounds for inferring that fire is the referent of the word 'fire'. Rather, speakers of a language 'agree' upon specific symbolic links by convention.

Thus, in Peirce's definition, symbolism is by nature referential. However, even in language, reference is not confined to the link between a noun and its referent. Any part of speech refers to some concept by convention and therefore symbolically. For example the pronoun 'into' refers to a specific category of movements (either concrete or abstract). Moreover, even syntax is referential in nature in that it consists of a set of rules for manipulating the relationships among symbols in order to communicate relationships among their referents - relationships that exist in the mind of the speaker and that the speaker wishes to convey to the hearer. For example, an English speaker who wants to convey the information that a dog bites a man, rather than the reverse, would use word order: "The dog bites the man", rather than "The man bites the dog." A Latin speaker, however, would use suffixes: "Canis mordet hominem", rather than "Canem mordet homo". Thus the arbitrary rules that make up syntax serve an essentially similar purpose to semantics; they permit us to communicate with others by referring to things, concepts, etc., and to perceived or imagined relationships among them.

When I use the term 'referential symbolism,' I am referring to this kind of arbitrary, conventional link between signs and referents. Referential symbolism is important because it lies at the heart of language. In terms of hominid adaptation, it is important because language is an extremely important part of how modern humans communicate. It may also be important as a tool for thinking and planning (Holloway, 1981; Noble \& Davidson, 1996; Parker \& Milbrath, 1993).

It should be noted that referential symbolism is used to refer to things that would exist anyhow, even in the absence of symbolism. These referents may be objects, phenomena, sensations, or emotions. They may also be concepts or ideas, but in this case they are the kinds of concepts or ideas that would exist without symbolism. For example, referential symbols might permit a Paleolithic adult to explain to a child that there will be no workable stone where they are going and that they must therefore take raw material with them. However, this is merely a matter of communicating something that the adult knows without symbolism.

We humans, however, construct a vast repertoire of 'things' that have no existence outside a symbolic context, things that depend on symbolism for their very existence. The game of chess, for example, is a set of definitions and rules that have no basis in the natural world. Chess has its origin in the context of symbolism and does not and cannot exist outside that context. Moreover, it is not itself essentially a referential symbol. It may be used as one, but only after the fact. It was not invented in order to refer to something else. Such symbolic inventions come in an almost infinite variety: beings (gods, demons), social roles (judges, godparents), objects (badges, altars), concepts (modesty, human rights), acts (oaths, initiation), values (virtuous, chic), and so forth.

Such symbolic phenomena do not exist in isolation from one another, but are integrated into overarching systems of symbolic entities. Different entities are related to one another in ways defined within the symbolic realm. Again, chess is a good example. Definitions of the board, of the pieces and their moves, and of the concepts of capture, mate and checkmate are all linked into one coherent whole. In fact, in the absence of the whole (the game of chess), the definitions of its parts and the rules it 
contains make little or no sense. In a broader context, food taboos may be related to totemic concepts linked to culturally defined social institutions, and all may be backed up by mythical explanations and reinforced by rituals.

In modern life, these symbolic webs have become all-encompassing. We live out our lives in an environment pervaded by symbolic entities. In fact, such symbolic systems play a large part in governing our behavior. As Byers (1994) has pointed out, almost nothing we do can be separated from its place in the symbol system, because that system now provides rules for defining what is or is not appropriate, or for what symbolic meaning any act or artifact has beyond its purely practical purpose. A garment may be made to keep one warm, but it also provides symbolic (i.e. arbitrarily coded) information about the wearer. The difference between a narrow and wide lapel may be negligible in terms of comfort, but it may be great in terms of what it tells other members of society about who you are, who you wish you were, or what your attitudes are. Thus any action, large or small, is now judged not only in terms of its practical consequences, but also in terms of its meaning within the larger symbol system.

This situation, where not only are symbols in common use, but where symbolism goes beyond reference, and where all actions and all things are caught up in a web of symbolic meanings, is what I refer to when I use the term 'symbolic culture'. In some ways, the appearance of symbolic culture may be of even greater significance in human evolution than is the appearance of language and referential symbolism. Unfortunately, an examination of its full significance lies beyond the scope of this paper and will be addressed elsewhere.

In the current context, the real importance of distinguishing between referential symbolism and symbolic culture is that the paleontological and archaeological correlates of each are very different, so that paleontological evidence for symbolism is actually evidence for referential symbolism and archaeological evidence is usually evidence for symbolic culture. Thus a discrepancy between paleontological and archaeological evidence may potentially reflect a temporal difference in the evolution of these two phenomena.

\section{Paleontological correlates of symbolism}

Modern human language depends on a set of genetically evolved neural and vocal structures, and it is these that are reflected in fossil skeletal anatomy. Thus human paleontologists have inferred the existence of language on the basis of endocranial evidence for such structures as Broca's area, for lateral asymmetries, or for general reorganization of the brain believed to be associated with language capacity (e.g. Holloway, 1976, 1985; Tobias, 1987, 1995). Others have inferred language on the basis of anatomic traits believed to have evolved to permit efficient communication through the use of formant frequencies in phonology (e.g. Arensburg et. al., 1988; Laitman, 1983; Laitman, Heimbuch \& Crelin 1979; Lieberman, 1984; Lieberman \& Crelin, 1971; Lieberman, Crelin \& Klatt, 1972).

Whenever a paleontologist uses an anatomic trait to infer the presence or absence of language, there will almost inevitably be another who disagrees, either with the trait's validity as evidence for language or with its identification in a given specimen (e.g. Burr, 1976; Falk, 1975; LeMay, 1975; Schepartz, 1993). Here, however, I am more concerned with the next step in the argument. Assuming that paleontologists can accurately recognize the anatomic evidence for language, they can then infer the existence of symbolism from the existence of language. However, given that I have argued that symbolism is really two phenomena rather than one, this inference deserves a closer look.

Language is, put quite simply, a system of referential symbolism, so that if language existed at any given point in the fossil record, then it does indeed follow that we can infer the existence of referential symbolism. The case for inferring symbolic culture is less clear. Language today is inextricably tied up with symbolic culture, but it does not follow that this was always the case. Whether or not the two evolved in tandem or one after the other is a question that must be tested against the evidence, without assuming the answer a priori. While referential symbolism is ipso facto a part of referential language, 
a linking argument must be found before one can infer symbolic culture from the existence of anatomic evidence alone. In the absence of such a linking argument, paleontological evidence for language constitutes evidence for referential symbolism but not necessarily evidence for symbolic culture.

\section{Archaeological correlates of symbolism}

Using archaeological rather than paleontological data to infer the existence of symbolism involves somewhat different arguments. In fact, there are really two separate chains of inference that may be used. The first is not a major concern in the present context, but it merits a brief discussion. As noted above, there are those who see symbolism as a tool for thought, particularly for planning (Noble \& Davidson, 1996; Parker \& Milbrath, 1993). For Parker \& Milbrath, symbols are essential to the mental construction and testing of scenarios characteristic of the 'declarative' planning typical of adult humans. Noble \& Davidson's argument is a bit more complicated. They define 'mindedness' as "being aware of [one's] experience and knowledge, able to make plans and form judgements on that basis, and thus be in a position of control and foresight relative to their circumstances" (Noble \& Davidson, 1966:105). They argue that mindedness is a socially constructed activity that occurs in linguistic interaction. In other words, mindedness and language are inseparable.

In these views, certain technological operations require planning that can only be performed with the use of symbols. Therefore, when one finds evidence of such operations in the archaeological record, the existence of symbolism can be inferred. For example, Noble \& Davidson (1996:134) cite the peopling of Australia as the earliest evidence of symbolism, on the grounds that it would have required boats and that building a boat "requires planning, the selection of actions that are not intrinsic in the use of a boat...".

Of course, one will accept such archaeological data as evidence for symbolism only if one also accepts this particular psychological perspective. However, the important point to recognize in the present context is that the symbolism in question is actually referential symbolism. Symbols are used referentially as mental tokens for solving problems or playing out scenarios, just as in language symbols are used as tokens for the purpose of communication. Thus, whether or not one accepts this particular theoretical stance, what is at issue is the existence of referential symbolism. As with evidence for language, the inference of symbolic culture would require a further linking argument.

Most of the archaeological evidence for symbolism that is cited in the literature is of a somewhat different nature, in that it is thought to reflect symbolism directly, rather than indirectly through planning abilities. Evidence of this sort usually involves phenomena such as art, ritual, or style. What constitutes the earliest archaeological evidence of this nature has been a matter of rather intense debate (e.g. Bednarik, 1992, 1995; Chase, 1991; Chase \& Dibble, 1987, 1992; Davidson \& Noble, 1989; Dibble, 1989; Duff, Clark \& Chadderdon, 1992; Gowlett, 1984; Holloway, 1969; Marshack, 1976, 1988).

I will discuss that debate below, but the first order of business is to determine exactly what is at issue. In order to do this, I will ask the reader to imagine three hypothetical hominid populations. (Whether I am justified in doing so is an issue to which I will also return below, but for the moment it will clarify the point I am trying to make.)

(1) The first population makes and uses tools on a regular basis, as a major part of its adaptation, but does not use language or referential symbolism.

(2) The second population is highly intelligent and uses language that is fully modern in its referential complexity and syntax. The use of language for communication (or for problemsolving and planning) is an integral part of their adaptation. However, these hominids do not possess symbolic culture.

(3) The third population is just like any Holocene population, and presumably like terminal Pleistocene populations. They use language for communication and they also live their lives in the context of fully developed symbolic culture.

The question then becomes, what would be the expected archaeological correlates of each 
population? As will be seen, the answers for the first and third hypothetical population are fairly obvious, but the answer for the second may be less so.

As habitual tool makers, our first population would leave behind an archaeological record. The nature of this record would depend on the nature of their technology and their problem-solving abilities. It might include rather complex stone tool technology, shelters, fire, and evidence for foresight and anticipation. In the absence of any symbolic basis for their behavior, however, it would obviously include no evidence of symbolism.

The third population, that of a people like ourselves, should in fact leave behind evidence of symbolic culture. Why this is so, however, is worth analyzing.

\section{Archaeological correlates of symbolic culture}

The crux of the matter is that, as Byers (1994) points out, symbolic culture governs behavior. It does this in a number of ways. It creates categories and concepts that are neither natural nor the product of purely practical considerations. For example, hats can exist without symbolic culture, but crowns are a category of head covering that can exist only in the context of symbolic culture. Telling a lie is natural behavior, in that it does not require symbolic culture, but perjury is a category of lying that is defined by symbolic culture. The behavior associated with proof of perjury differs from that provoked by a simple lie, and a crown is not treated like an ordinary hat.

Symbolic culture also creates values that influence behavior. These vary greatly in importance (both religious tolerance and fingernail polish may be positively valued, for example). Symbolic culture also provides rules for behavior. In the United States it would be considered a bit strange to shake hands with someone you see every day; in France, it is required by the rules of etiquette.

The control exerted by symbolic culture is obviously imperfect. For one thing, cultural demands may conflict. When he steals a pair of shoes his parents cannot afford, a teenage boy violates a cultural rule against theft. However, he does so because culture places a high positive value on wearing this particular brand of shoe. Moreover, the demands of symbolic culture are often in direct conflict with the evolutionary interests of the individual, while our natural tendencies, like those of every other species, have evolved to make us behave in ways that enhance our fitness (Chase,1999). For example, our species possesses a strong desire to survive long enough to reproduce and care for our young, yet culture may demand that we die in battle, not for a close relative with whom we share genes but for an abstract ideal or for a ruler we may never have met. We all have an urge to reproduce, but culture may enjoin celibacy. This being the case, it is hardly surprising that cultural norms are often violated. However, this does not alter the fact that culture influences behavior. In fact, it will be seen that this very conflict between the demands imposed by culture and the natural tendencies instilled by biological evolution probably serves to increase the visibility of symbolic culture in the archaeological record.

There are several ways in which symbolic culture influences material culture. The most direct influence comes when symbolic culture defines certain forms of artifact as appropriate and desirable and others as inappropriate and undesirable. For example, a chimpanzee who prepares a tool for fishing termites (Goodall, 1986: 536-539) need worry about only one issue - whether or not the tool will do its job efficiently. However, a modern human who makes a tool is likely to be concerned with a second issue, whether or not the form of the tool is culturally appropriate. Is it fashionable or unfashionable? Is it suitably 'masculine' or 'feminine'? Does it violate a taboo? In short, symbolic culture sets criteria for determining what is and is not appropriate - beyond the considerations of practical efficacy (Byers, 1994). The result is that the production of material culture is now influenced by cultural as well as practical considerations, and this fact is bound to be reflected in the material culture.

The result is what has generally been called 'style' by archaeologists. When only practical considerations govern artifact production, artifact form is free to vary within the limits set by function, raw material, and technological constraints. When cultural considerations are involved, artifacts are 
likely to be more uniform within artifact classes and more clearly differentiated between artifact classes. Byers (1994:380) uses the example of a hunting spear and a war spear. Although their functions demand similar design features, these are likely to be quite clearly differentiated for symbolic reasons - the "latter would warrant the user's killing but not eating other humans (ibid.)". By the same token, neighboring societies are likely, for cultural reasons, to produce artifacts that, while functionally equivalent, are stylistically different. Moreover, stylistic changes in material culture will occur through time, even in the absence of functional or technological change. The result is a pattern of greater uniformity of artifact form within restricted areas and restricted time periods than one would expect from practical considerations alone, along with greater variation across time and across space.

Because the demands of symbolic culture often run contrary to behavioral tendencies deeply ingrained by natural selection, it must provide motivation for complying with those demands. Cultures generally do this in three ways: by providing justification and rationalization, in the form of worldviews and mythology; by providing strong emotional reinforcement through ritual; and by providing culturally defined social roles with the symbolic reinforcement of their right to act in culturally defined ways. All three of these have archaeological correlates.

Culture rarely requires a particular behavior without any justification, at least not if it is a burdensome one. Rather, every norm or rule for behavior is embedded in a web of symbolic meanings and logic that provides a rationale. For example, the Hindu injunction against eating meat exists in the context of a moral system shaped by the concepts of karma, transmigration, and dharma, and this symbolic framework spells out both the logic of the prohibition and the spiritual consequences for the person who violates it. Rationales of this nature are usually embedded in mythology, in a web of mythic beings and symbols that often find expression in material culture in the form of representational or symbolic art and decoration.

However, cultures also go beyond appeals to reason and provide strong emotional motivation, both positive and negative, through the medium of ritual. It is difficult to conceive of symbolic culture without ritual, and the underlying theme of ritual seems to be an emotional one. Thus, if a population's behavior is governed by symbolic culture, then we would expect that behavior to include ritual, and we would expect to find evidence of ritual in the archaeological record.

Symbolic culture also permits societies to define social categories or roles. In other species, social statuses are determined by age and sex, by an individuals' actions or abilities, and by social alliances or rivalries (e.g. Gouzoules \& Gouzoules, 1987; de Waal, 1989). These statuses might be considered selfevident, in the sense that they are known to other members of the group by observation (Cheney \& Seyfarth, 1990). Among humans, social statuses are also in part defined in this way, but we also define statuses culturally, for example those of bridesmaid, policeman, archduke, or priest. I use the word 'status' here not in the sense of a level in a hierarchy but in the sense of a social or cultural category. However, these are not natural, self-evident statuses, and the result is that they tend to be marked symbolically by body ornamentation, clothing, tattoos, and similar material signs. This tendency is reinforced by the fact that culturally defined statuses are associated with culturally defined privileges, duties, etc., that often conflict with the interests of other members of society - for example, a sheriff's deputy has both the right and the duty to seize a house in lieu of unpaid taxes. In the absence of culture, an individual's actions are determined by what he or she can get away with. A subordinate chimpanzee may yield a food item to a dominant chimpanzee out of physical fear. Culture, however, reinforces its agents, even physically weak ones, by the use of symbols. Sometimes symbols (e.g. a general's stars) are used to indicate the bearer's authority; sometimes, as Byers (1994) points out, the authority to act is actually conferred by symbolic objects (e.g. search warrants). The symbolic items in question may be pieces of paper but they may also be items of personal marking such as badges, specific styles of clothing, or objects such as scepters. Thus, we would expect the archaeological record left behind by our hypothetical archaeological population with symbolic culture to include marking of personal status. 
There are, then, a number of reasons why symbolic culture comes to be reflected in the material culture. This is, of course, no surprise. The material culture of all societies today includes abundant evidence of the existence of symbolic culture. I have dwelt on the topic here only because these reasons are all associated with symbolic culture. In the absence of symbolic culture, even a society like our hypothetical hominids with referential language but not symbolic culture will lack any of these reasons or motivations for using material culture for symbolic expression.

Before I move on to that topic, however, I must again mention the point made above, that much debate surrounds the actual recognition in the archaeological record of such phenomena as symbolic style, ritual, warrants, mythological symbols, or marking of social status. Although this problem falls outside the scope of the current paper, we cannot lose sight of the fact that in practice recognizing such phenomena in the archaeological record is often very difficult. It is worth mentioning a few sources of this difficulty. In effect, all have to do with equifinality, with the possibility that causes other than symbolism may produce patterns in the archaeological record that resemble evidence of symbolism (see Chase \& Dibble, 1992).

Much of the debate about the origins of symbolism revolves around alternative interpretations of specific objects. For example, are holes in bones or teeth from Lower and Middle Paleolithic sites evidence of symbolic beadwork, carnivore chewing, or purely functional artifacts (e.g. Bednarik, 1992; Chase \& Dibble 1992; Marshack 1976)? Is a bone with perforations a flute or simply the product of carnivore chewing (Albrecht et al., 1998; Chase \& Nowell, 1998; d'Errico, Villa et al., 1998; Turk, Dirjec \& Kavur, 1997a,b)? Such questions arise constantly and are of crucial importance, but will not be treated here.

The problem is if anything more difficult in the case of ritual. The same problems of equifinality exist, but there are other complications as well. First of all, 'ritual' like 'culture' is a word that is open to many definitions, and is often applied to stereotyped behavior of any kind. It is perfectly valid to use 'ritual' for the mating dances of birds or the greeting behavior of dogs, but it does not follow that, because they have 'ritual' (in this sense), dogs and birds have symbolic culture. What is needed to infer symbolic culture from the archaeological record is evidence that a 'ritual' involved the web of symbolic meanings that characterizes the kind of ritual proper to symbolic culture. Second, there may be other motives for apparently ritual behavior. A burial, for example, may have been motivated by emotion, and reflect nothing more than a desire to protect the body of a loved one from carnivores or even from visible decay (Dibble \& Chase, 993). Thus while ritual is an inherent part of symbolic culture, recognizing in the archaeological record the kind of ritual that points to a web of symbolic meaning behind it is, like so much else discussed in this paper, not a simple matter.

The same is true of the recognition of style. Like 'ritual' the word 'style' is used in many ways, and what archaeologists consider to be style may or may not have anything to do with symbolism. Style will usually be inferred when artifact morphology is standardized and varies through time or space (e.g. Deacon, 1989; Gowlett, 1984; Holloway, 1966, 1969; White 1982), but the relationship between standardization and symbolic culture is not as simple a matter as it might seem (Chase, 1991). First, it is quite difficult to define exactly how to measure or even how to define standardization, for example in stone tool morphology. Second, the practical (non-symbolic) functions of stone tools may demand standardization in some cases. Third, the underlying technology may also impose standardization. For example, blade technology, by producing long narrow blanks, essentially dictates that all tools will be long and narrow, and this need have nothing to do with symbolism. Thus what we as archaeologists think of as style in the archaeological record need not necessarily indicate the kind of standardization and differentiation of artifact categories that follows from symbolic culture.

The other side of this coin is that although symbolic culture will inevitably shape material culture, this effect need not be visible to archaeologists in all aspects of the material culture. For example, Gould, Koster \& Sontz (1971) noted that, from a morphological perspective, the Australians of the Western 
Desert treat lithics very cavalierly, paying attention primarily to edge angle and using only two categories to classify most tools. ${ }^{2}$ Thus, although their material culture as a whole is affected by the symbolic culture, this is archaeologically all but invisible on the basis of lithics alone. Since only a small portion of the material culture of Paleolithic peoples survives to the present day, this lack of visibility may become a problem (Bednarik, 1995: 611-612). At a fine temporal and geographic scale, this problem is serious, although on a large scale it is less significant (Chase \& Dibble, 1992: 45).

Although they form the basis of most of the archaeological debate about the origins of symbolism, such practical considerations fall beyond the scope of what I am trying to do here, which is simply to examine some of the theoretical links between symbolism, behavior, and the archaeological record. However, they do pose serious problems that will not be solved without a great deal of hard work on the part of archaeologists.

\section{Archaeological correlates of referential symbolism}

The archaeological correlates of our second hypothetical population, who have fully developed referential language but not symbolic culture, are perhaps less self-evident than are those of the other two. In the absence of symbolic culture, the only grounds for evaluating their artifacts would be their functional or economic efficacy, so we would not expect to see evidence of symbolic style in their material culture. Since mythology, ritual, and the symbolic marking of social status cannot exist in the absence of symbolic culture, there would be no evidence of any of these in the material culture. In fact, beyond the enhanced communication, problem-solving, and planning capabilities provided by referential symbolism, the social and intellectual lives of this population would be very closely akin to that of non-human primates, in that they would not live their lives in a web of culturally defined symbolic entities, meanings, and norms. This fact would be reflected in the material culture, which would show no more evidence of symbolism than that of our first hypothetical population, who lacked both symbolic culture and referential symbolism.

There are two possible exceptions to this last statement. First, as was noted above, to the extent that referential symbolism permits people to perform certain mental tasks that are reflected in their technology, the presence of such technology (e.g. the construction of boats) will indicate the presence of referential symbolism. Second, there is no way to exclude, a priori, the possibility that artifacts (or some kind of marking or decoration on artifacts) may be created that have a purely referential symbolic function. In fact, it is to be expected that such artifacts would on occasion have been created. However, it is also true that in the absence of writing, artifacts with purely referential function make up at most a very small proportion of a material culture. Even those artifacts that can be said to have referential properties usually exist for reasons beyond just reference. The Christian cross is a good example. While a cross or image of a cross refers explicitly to the cross on which Jesus was executed, it does much more. It refers to the whole battery of concepts that lie behind the cross in Christian theology: sacrifice, death and resurrection, sin and redemption, sacred and profane, etc. It may in addition serve as a badge of ethnic affiliation or political attitudes. In fact, the cross is probably almost never displayed purely as a referential sign. Put another way, in the absence of symbolic culture, the Christian cross would not even exist as a symbol, much less appear in the material culture.

\section{Implications for future research}

In general then, the archaeological evidence usually points to the existence of symbolic culture, while the skeletal evidence for language points only to referential symbolism. This raises a number of issues, none of which has been systematically investigated. For the most part, these questions do not seem to have been posed at all; in most cases, the answers have probably been assumed implicitly. However, if my analysis of the nature of symbolism is correct, they are questions that will require serious research. 
(1) Is it in fact possible that referential symbolism could have evolved before symbolic culture, or is there some reason inherent in the neurological or psychological bases of these two phenomena that means that they must have evolved in tandem? Neither archaeology nor paleontology can provide the answer to this question. It will have to come from disciplines such as psychology and the neurosciences that deal with the actual mental and neurological bases of symbolism, rather than with the skeletal correlates of language or the material evidence for symbolic behavior.

(2) By the same token, it would be interesting to know if, according to the paleontological and archaeological evidence, the evolution of referential symbolism and symbolic culture are chronologically correlated. This is clearly a question for the historic sciences - archaeology, paleontology, and geochronology. To a considerable extent, the answer to this question might serve as an empirical test to hypothetical answers to the first question.

(3) If indeed symbolic culture appeared late in the course of hominid evolution, after referential language and symbolism, then did its evolution require further genetic evolution, or was the genetic basis for symbolic reference all that was needed for symbolic culture? Could symbolic culture have been an 'invention' analogous to agriculture, that changed our ancestors' way of life in fundamental ways but that owed nothing to a concomitant genetic change? Did it emerge at different times in different parts of the world in response to local conditions, much as agriculture did?

A positive answer of course implies a high level of behavioral plasticity for our species, but this is something already attested to by the Holocene record. For example, the 'invention' of food production was in many respects a more profound change than a shift from frugivory to omnivory or carnivory. Instead of exploiting the environment, we forced the environment to produce what we needed; instead of exploiting available niches, we created our own niches. While other species have made equivalent changes in their adaptation, they did so via genetic evolution. To cite another example, we have changed our way of processing information in fundamental ways without changing the genetic codes governing our neurological structures. Technological and occupational specialization in complex societies has meant that even if individual humans cannot master more information than was possible in the terminal Pleistocene, society can master, manipulate, and use much larger quantities of knowledge and information. Technologies for storing and transferring information, notably writing systems, have added to the scope of knowledge sharing, but more importantly they have permitted us to conserve and build upon the knowledge of previous generations, so that even mediocre twentieth century scientists understand much more about the world than did geniuses such as Galileo and Newton. Finally, the invention of technologies for analyzing information - everything from abacuses to mathematical notation to computers - have opened up whole new fields of knowledge and whole new ways of processing information. The result is that the way we process information today differs profoundly from terminal Pleistocene information processing, yet these changes owe nothing to genetic evolution. In short, thanks to our behavioral plasticity, modern-day human adaptation is very different from that of the late Pleistocene. We must therefore investigate whether the symbolic culture could have evolved without concomitant genetic evolution, rather than assume an answer to the question.

(4) What is the chronological relationship between the appearance of symbolic culture and speciation events in the hominid line? It would be possible to make an a priori case for a genetic change if the appearance of symbolic culture could be linked to a speciation event. The answer to this depends on one's reading of the skeletal and DNA evidence for a divergence between modern and archaic Homo sapiens ${ }^{3}$ in Africa (e.g. Aiello, 1993; Bräuer, 1992; Cann, 1988; Cann, Rickards \& Lum, 1994; Cann, Stoneking \& Wilson, 1987; Krings et al., 1997; Merriwether et al., 1991; Ruvolo et al., 1993; Smith, 1994; Stringer, 1989, 1992; Stringer \& 
Andrews, 1988; Templeton, 1993; Vigilant et al., 1991; Wolpoff, 1989; Wolpoff et al., 1994). It also depends on one's reading of the archaeological evidence for symbolic culture, and on being able to date both the speciation and the origins of symbolic culture with sufficient precision. If the origins of symbolic culture post-date the appearance of modern humans, then it would leave open the possibility that its appearance had nothing to do with genetic evolution. It would not, of course, eliminate the possibility of a genetic change, because such a change might well have occurred without altering the brain in a way that would be reflected in the skeletal anatomy.

(5) Did more than one species of hominid possess symbolic culture? If in fact Neandertals were a separate species from Homo sapiens, and if we take at face value the associations in the French Upper Paleolithic of Neandertals with the Châtelperronian industry at Saint Césaire (Lévêque \& Vandermeersch, 1980; Vandermeersch, 1993) and Arcy-sur-Cure (Hublin et al., 1996) and the discovery of probable objects of personal adornment in the Châtelperronian of Arcy-sur-Cure (Leroi-Gourhan, 1961; Leroi-Gourhan \& Leroi-Gourhan, 1965; Taborin, 1990), then two species of hominids evidently had the capacity for symbolic culture. ${ }^{4}$ This is true even if the Neandertals were influenced by immigrant populations of Homo sapiens, since they could not have adopted symbolic culture without the capacity for symbolic culture (see also d'Errico et al., 1998: 21).

(6) In the course of the above discussion, I have in some places made an implicit assumption that has important implications for the archaeological visibility of symbolic culture, but that is perhaps not tenable. I have assumed that symbolic culture is an all-or-nothing phenomenon, that it could not have evolved gradually. I have made this assumption because while I can find adaptive explanations for symbolic culture as a way of life (Chase, 1999), I find it hard to find any adaptive value to having just a little bit of symbolic culture. Thus I am strongly inclined to agree that "arranging behaviour according to symbolic codes is an all or nothing situation. The onset of symbolic behaviour can be compared to the flick of a switch..." (Stringer \& Gamble, 1993: 203). However, I will be the first to acknowledge that this is a subject where serious investigation rather than assumption is called for.

As I stated at the beginning, It has not been my intention here to provide answers, even in the form of hypotheses, to any of these questions. Rather, it has been my primary purpose to argue that what usually goes under the rubric of 'symbolism' is actually two phenomena that are logically separable the purely referential use of symbols in communication and the creation of complex systems of symbolic concepts that influence everything we think and do. Whether or not further investigation demonstrates that they actually evolved separately, it seems that the archaeological and paleontological evidence points to different kinds of symbolism.

My second purpose has been to show that if I am right in making a distinction between referential symbolism and symbolic culture, then it follows that there are many issues that will have to be investigated. If one does not distinguish between the two kinds of symbolism, then many of these issues do not even arise. However, the result is that researchers are making implicit assumptions about questions that should be investigated scientifically. The majority of the issues I listed have not been investigated at all systematically. Hopefully, a conceptual distinction between referential symbolism and symbolic culture can serve as a tool that will help to clarify exactly what it is that we are studying when we investigate the evolution of 'symbolism,' and that will help us to determine where our research efforts should be directed.

\section{Acknowledgments}

I would like to thank Harold Dibble for reading a draft of this paper. I would also like to thank Hilary Deacon and the organizers and sponsors of the Dual Congress for the opportunity to participate in the Congress. 


\section{Notes}

${ }^{1}$ I am aware that language today is inextricably bound up with symbolic culture and that many language acts are in fact cultural rather than purely referential acts. In a sense, one might divide language in two, much as I have done with symbolism. For this reason, I will attempt to use 'referential language' to refer to language when it is a purely referential phenomenon.

${ }^{2}$ There are two sacred tool types that are used for essentially ritual purposes and that receive special treatment (Gould, Koster \& Sontz, 1971: 155-156). However, one of these, the small knives used for circumcisions, would probably not be recognizable archaeologically as a type, since they are distinguished only by size, and size variability is continuous.

${ }^{3}$ Of course, if 'modern' and 'archaic' forms do not belong to the same species, then the latter cannot logically be referred to as 'archaic' Homo sapiens.

${ }^{4}$ This issue was also raised by Marshack (1989), albeit from a very different perspective.

\section{References}

Aiello, L.C. (1993). The fossil evidence for modern human origins in Africa: A revised view. American Anthropologist, 95, 73-96.

Albrecht, G., Holdermarin, C-S., Kerig, T., Lechterbeck, J. \& Serangeli, J. (1998). "Flöten” aus Bärenknochen - Die frühesten Musikinstrumente? Archäologisches Korrespondenzblatt, 28, 1-19.

Arensburg, B., Tillier, A.-M., Vandermeersch, B., Duday, H., Schepartz, L.A. \& Rak, Y. (1988). A Middle Paleolithic human hyoid bone. Nature, 338, 758-60.

Bednarik, R.G. (1992). Palaeoart and archaeological myths. Cambridge Archaeological Journal, 2, 27-57.

Bednarik, R.G. (1995). Concept-mediated marking in the Lower Palaeolithic. Current Anthropology, 36, 605-34.

Bräuer, G. (1992). Africa's place in the evolution of Homo sapiens. In: Continuity or Replacement: Controversies in Homo sapiens evolution, ed. G. Bräuer \& F.H. Smith, pp.83-98. Rotterdam: A.A.Balkema.

Burr, D.B. (1976). Neandertal vocal tract reconstructions: a critical appraisal. Journal of Human Evolution, 5, 285-90.

Byers, A.M. (1994). Symboling and the Middle-Upper Paleolithic transition: A theoretical and methodological critique. Current Anthropology, 35, 369-400.

Cann, R.L. (1988). DNA and human origins. Annual Review of Anthropology, 17, 127-43.

Cann, R.L., Rickards, O. \& Lum, J.K. (1994). Mitochondrial DNA and human evolution: Our one lucky Mother. In: Origins of Anatomically Modern Humans, ed. M.H. Nitecki \& D.V. Nitecki, pp.135-48. New York: Plenum Press.

Cann, R.L., Stoneking, M. \& Wilson, A.C. (1987). Mitochondrial DNA and human evolution. Nature, 325, 31-36.

Chase, P.G. (1991). Symbols and Paleolithic artifacts: style, standardization, and the imposition of arbitrary form. Journal of Anthropological Archaeology, 10, 193-214.

Chase, P.G. (1999). Symbolism as reference and symbolism as culture. In: The Evolution of Culture: An Interdisciplinary View, ed. R. Dunbar, C. knight \& C. Power, pp.34-49. Edinburgh: Edinburgh University Press.

Chase, P.G. \& Dibble, H.L. (1987). Middle Paleolithic Symbolism: a review of current evidence and interpretations. Journal of Anthropological Archaeology, 6, 263-96.

Chase, P.G. \& Dibble, H.L. (1992). Scientific archaeology and the origins of symbolism: a reply to Bednarik. Cambridge Archaeological Journal, 2, 43-51.

Chase, P.G. \& Nowell, A. (1998). Taphonomy of a suggested Middle Paleolithic bone flute from Slovenia. Current Anthropology, 39(4), 549-53.

Cheney, D.L. \& Seyfarth, R.M. (1990). How Monkeys see the World. Chicago: University of Chicago Press.

Davidson, I. \& Noble, W. (1989). The archaeology of perception - traces of depiction and language. Current Anthropology, 30, 125-55.

Deacon, H.J. (1989). Late Pleistocene palaeoecology and archaeology in the Southern Cape, South Africa. In: The Human Revolution, ed. P. Mellars \& C. Stringer, pp.547-64. Edinburgh: Edinburgh University Press.

d'Errico, F., Villa, P., Pinto Llona, A.C. \& Ruiz Idarraga, R. (1998). A Middle Palaeolithic origin of music? Using cave- 
bear accumulations to assess the Divje Babe I bone 'flute'. Antiquity, 72, 65-79.

d'Errico, F., Zilhão, J., Julien, M., Baffier, D. \& Pelegrin, J. (1998). Neanderthal acculturation in Western Europe? A critical review of the evidence and its interpretation. Current Anthropology, 39, 1-44.

Dibble, H.L. (1989). The implications of stone tool types for the presence of language during the Middle Paleolithic. In: In The Human Revolution: Behavioural and Biological Perspectives on the Origins of Modern Humans, ed. P. Mellars \& C. Stringer, pp.415-32. Edinburgh: Edinburgh University Press.

Dibble, H.L. \& Chase, P.G. (1993). On Mousterian and Natufian burials in the Levant. Current Anthropology, 34, 170-72.

Duff, A.I., Clark, G.A. \& Chadderdon, T.J. (1992). Symbolism in the Early Paleolithic: a conceptual odyssey. Cambridge Archaeological Journal, 2, 211-29.

Falk, D. (1975). Comparative anatomy of the larynx in man and the chimpanzee: Implications for language in Neanderthal. American Journal of Physical Anthropology, 43, 123-32.

Goodall, J. (1986). The Chimpanzees of Gombe: Patterns of Behavior. Cambridge: The Belknap Press of Harvard University Press.

Gould, R., Koster, D. \& Sontz, A. (1971). The lithic assemblage of the Western Desert Aborigines of Australia. American Antiquity, 36, 149-69.

Gouzoules, S. \& Gouzoules, H. (1987). Kinship. In: Primate Societies, ed. B.B. Smuts, D.L. Cheney, R.M. Seyfarth, R.W. Wrangham \& T.T. Struhsaker, pp.299-305. Chicago: University of Chicago Press.

Gowlett, J.A.J. (1984). Mental abilities of early Man: A look at some hard evidence. In: Hominid Evolution and Community Ecology: Prehistoric Human Adaptation in Biological Perspective, ed. R.A. Foley, pp.167-92. New York: Academic Press.

Holloway, R.L. (1966). Cranial capacity, neural reorganization, and hominid evolution: A search for more suitable parameters. American Anthropologist, 68, 103-21.

Holloway, R.L. (1969). Culture: A human domain. Current Anthropology, 10, 395-412.

Holloway, R.L. (1976). Paleoneurological evidence for language origins. Annals of the New York Academy of Sciences, 280, 330-48.

Holloway, R.L. (1981). Culture, symbols, and human brain evolution. Dialectical Anthropology, 5, 287-303.

Holloway, R.L. (1985). The poor brain of Homo sapiens neanderthalensis: see what you please... In: Ancestors: The Hard Evidence, ed. E. Delson, pp.319-24. New York: Alan R. Liss.

Hublin, J.-J., Spoor, F., Braun, M., Zonneveld, F. \& Condemi, S. (1996). A late Neanderthal associated with Upper Palaeolithic artefacts. Nature, 381, 224-26.

Krings, M., Stone, A., Schmitz, R.W., Krainitzki, H., Stoneking, M. \& Pääbo, S. (1997). Neandertal DNA sequences and the origin of modern humans. Cell, 90, 19-30.

Laitman, J.T. (1983). The evolution of the hominid upper respiratory system and implications for the origin of speech. In: Glossogenetics: The Origin and Evolution of Language, ed. B. de Grolier, pp.63-90. Paris: Harwood Academic Press.

Laitman, J.T., Heimbuch, R.C. \& Crelin, E.S. (1979). The basicranium of fossil hominids as an indicator of their upper respiratory systems. American Journal of Physical Anthropology, 51, 15-34.

LeMay, M. (1975). The language capability of Neanderthal man. American Journal of Physical Anthropology, 42, 9-14. Leroi-Gourhan, A. (1961). Les fouilles d'Arcy-sur-Cure (Yonne). Gallia Préhistoire, 4, 3-16.

Leroi-Gourhan, A. \& Leroi-Gourhan, A. (1965). Chronologie des grottes d'Arcy-sur-Cure (Yonne). Gallia Préhistoire, 7, 1-64.

Lévêque, F. \& Vandermeersch, B. (1980). Découverte de restes humains dans un niveau castelperronien à Saint-Césaire (Charente-Maritime). Comptes Rendus de l'Academie des Sciences de Paris, 291, 187-89.

Lieberman, P.1984. The Biology and Evolution of Language. Cambridge (Mass.): Harvard University Press.

Lieberman, P. \& Crelin, E.S. (1971). On the speech of Neanderthal Man. Linguistic Inquiry, 2, 203-22.

Lieberman, P., Crelin, E.S. \& Klatt, D.H. (1972). Phonetic ability and related anatomy of the newborn and adult Human, Neanderthal Man, and the Chimpanzee. American Anthropologist, 74, 287-307. 
Marshack, A.A. (1976). Some implications of the Paleolithic symbolic evidence for the origin of language. Annals of the New York Academy of Sciences, 280, 289-311.

Marshack, A.A. (1988). The neanderthals and the human capacity for symbolic thought: cognitive and problem-solving aspects of Mousterian symbol. In: L'Homme de Neandertal, ed. M. Otte. Actes du Colloque International de Liège (4-7 décembre 1986). Vol.5: La Pensée, 57-91. Liege: ERAUL.

Marshack, A.A. (1989). Evolution of the Human Capacity: The symbolic evidence. Yearbook of Physical Anthropology, 32, 1-34.

Merriwether, D.A., Clark, A.G., Ballinger, S.W., Schurr, T.G., Soodyall, H., Jenkins, T., Sherry, S.T. \& Wallace, D.C. (1991). The structure of human mitochondrial DNA. Journal of Molecular Evolution, 33, 543-55.

Noble, W. \& Davidson, I. (1996). Human Evolution, Language and Mind: A Psychological and Archaeological Inquiry. Cambridge: Cambridge University Press.

Parker, S.T. \& Milbrath, C. (1993). Higher intelligence, propositional language, and culture as adaptations for planning. In: Tools, Language and Cognition in Human Evolution, ed. K.R. Gibson \& T. Ingold pp.314-34. Cambridge: Cambridge University Press.

Peirce, C.S. (1932/1960). The icon, index, and symbol. In: Collected Papers of Charles Sanders Pierce, vol. II, ed. C. Hartshorne \& P. Weiss, pp.156-73. Cambridge (Mass.): Harvard University Press.

Ruvolo, M., Zehr, S., Domum, M.v., Pan, D., Chang, B. \& Lin, J. (1993). Mitochondrial COII sequences and modern human origins. Molecular Biology and Evolution, 10, 1115-35.

Schepartz, L.A. (1993). Language and modern human origins. Yearbook of Physical Anthropology, 36, 91-126.

Smith, F.H. (1994). Samples, species, and speculations in the study of modern human origins. In: Origins of Anatomically Modern Humans, ed. M.H. Nitecki \& D.V. Nitecki, pp. 227-52. New York: Plenum Press.

Stringer, C. (1989). The origin of early modern humans: a comparison of the European and non-European evidence. In: The Human Revolution, ed. P. Mellars \& C. Stringer, pp.232-44. Edinburgh: Edinburgh University Press.

Stringer, C. (1992). Replacement, continuity and the origin of Homo sapiens. In: Continuity or Replacement: Controversies in Homo sapiens evolution, ed. G. Bräuer \& F.M. Smith, pp. 9-24. Rotterdam: A.A. Balkema.

Stringer, C. \& Andrews, P. (1988). Genetic and fossil evidence for the origin of modern humans. Science, 239, 126368.

Stringer, C. \& Gamble, C. (1993). In Search of the Neanderthals: Solving the Puzzle of Human Origins. London: Thames and Hudson.

Taborin, Y. (1990). Les prémices de la parure. In: Paléolithique moyen récent et Paléolithique supérieur ancien en Europe: Colloque international de Nemours, 9-11 mai 1988. ed. C. Farizy, Mémoires du Musée de Préhistoire de l'Isle-de-France 3, pp.335-44. Paris.

Templeton, A.R. (1993). The "Eve" hypothesis: A genetic critique and reanalysis. American Anthropologist, 95, 51-72.

Tobias, P.V. (1987). The brain of Homo habilis: A new level of organization in cerebral evolution. Journal of Human Evolution, 16, 741-61.

Tobias, P.V. (1995). The Communication of the Dead: Earliest Vestiges of the Origin of Articulate Language. Zeventiende Kroon-Voordracht. Amsterdam: Nederlands Museum voor Anthropologie en Praehistorie.

Turk, I., Dirjec, J. \& Kavur, B. (1997). Description and explanation of the origin of the suspected bone flute (Opis in razlaga nastanka domnevne koščene piščale). In: Mousterian "Bone Flute" and Other Finds from Divje Babe I Cave Site in Slovenia (Moustérienska "koščene pǐ̌čale" in Druge Najdbe iz Divjih Bab I v Sloveniji). ed. I. Turk, Opera Instituti Archaeologici Sloveniae, 2, pp.157-75. Ljubljana: Znanstvenoraziskovalni Center SAZU.

Turk, I., Dirjec, J. \& Kavur, B. (1997). A-t-on trouvé en Slovénie le plus vieil instrument de musique de l’Europe? L'Anthropologie, 101, 531-40.

Vandermeersch, B. (1993). Was the Saint-Césaire discovery a burial? In: Context of a Late Neandertal. Implications of Multidisciplinary Research for the Transition to Upper Paleolithic Adaptations at Saint Césaire, CharenteMaritime, France, ed. F. Lévêque, A. Backer \& M. Guilbaud, pp.129-31. Madison: Prehistory Press.

Vigilant, L., Stoneking, M., Harpending, H., Hawkes, K. \& Wilson, A.C. (1991). African populations and the evolution 
of human mitochondrial DNA. Science, 253, 1503-07.

Waal, F. de (1989). Chimpanzee Politics: Power and Sex Among Apes. Baltimore: Johns Hopkins Univ. Press

White, R. (1982). Rethinking the Middle-Upper Paleolithic Transition. Current Anthropology, 23, 169-92.

Wolpoff, M.H. (1989). Multiregional Evolution: The Fossil Alternative to Eden. In: The Human Revolution, ed. P. Mellars \& C. Stringer, pp.62-108. Edinburgh: Edinburgh University Press.

Wolpoff, M.H., Thorne, A.G., Smith, F.H., Frayer, D.W. \& Pope, G. (1994). Multiregional evolution: a world-wide source for modern human populations. In: Origins of Anatomically Modern Humans, ed. M.H. Nitecki \& D.V. Nitecki, pp.175-200. New York: Plenum Press. 


\section{Hilary J. Deacon}

University of Stellenbosch, $P B X 1$, Matieland 7602, South Africa.

KeyWords: Late Pleistocene, climate change, Upper Palaeolithic, Middle Stone Age, modern behaviour, Klasies River

\section{Modern Human Emergence: an African Archaeological Perspective}

\begin{abstract}
The study of modern human origins is multidisciplinary in scope and global in compass. Archaeology contributes primary information on the dispersal and densities of past populations and on their behaviour. This information is used to show that the continent-wide expansion of early modern populations was achieved in the earliest Late Pleistocene in Africa. The origins of modern humans would have been in the Middle Pleistocene. The African population expansion between 130000 and 60000 years ago can be linked to environmental changes in the middle to low latitudes due to orbital forcing. It is only after 60000 years ago that populations in the higher latitudes of Eurasia expanded, an expansion in part associated with the spread of the modern humans of the Upper Palaeolithic. Differences in the population histories in different continental regions are reflected in the archaeological records from these regions. The Upper Palaeolithic has no counterpart in Africa and was not a 'package' assembled in sub-Saharan Africa for export Out-of-Africa. It is argued that the Upper Palaeolithic is not the earliest evidence for modern symbolic behaviour because such behaviour is evident at the beginning of the Late Pleistocene in the Middle Stone Age of Africa.
\end{abstract}

\section{Introduction}

The archaeology of modern human origins is a challenging topic, but not a new one. For more than a century, following the discovery of the spectacular archaeological riches and human remains of the Middle and Upper Palaeolithic caves and open stations, it has been a central theme of research in Europe (Mellars, 1992; Straus, 1995). The focus of the research has been in understanding the apparent coincidence in the replacement of archaic Neanderthals by modern Cro-Magnons with the advent of the Upper Palaeolithic (Chase \& Dibble, 1990). However, the geographical relevance of this theme is limited because the Neanderthals of the Middle Palaeolithic were restricted to Europe and western Asia and the Upper Palaeolithic was not a universal cultural stage. A fair question to ask is what was going on elsewhere in the world while Neanderthals and Cro-Magnons were occupying Europe? The shift to seeing the emergence and dispersal of modern humans in global and not exclusively eurocentric terms is new and this has made the archaeology of even far-flung regions like southernmost Africa and Australasia relevant to the discussions. The globalisation of the problem has given Palaeolithic archaeology new purpose and direction.

This paper is concerned with the archaeology of modern humans in Africa. Currently the most plausible hypothesis is that there was a centre of origin for the evolution of modern humans and that centre was located in sub-Saharan Africa (Foley \& Lahr, 1997). This proposition rests on palaeontological and genetic rather than archaeological evidence. Artefacts, the primary archaeological evidence, do not come stamped with labels like 'made by Homo neanderthalensis' or 'made by $H$. sapiens'. What archaeology does provide is detailed information on the context and dating of fossil finds and the archaeological record provides essential information on population history and behaviour. 
Following the emergence of modern humans there was a very significant increase in world populations, one of the most important events in human history and a process set in train long before food production. Indications are that this population expansion was initiated earlier in Africa than in other continental regions. This would be consistent with their longer history in the continent, but it raises two questions. Firstly, what triggered the expansion and secondly, was there a selective advantage possessed by early modern humans that was causally related to the expansion? The answer to the first question may lie in environmental change and the answer to the second, in behaviour. While not bearing makers' labels, artefacts do carry information on what people were doing, and the archaeological record suggests that modern humans had the capacity for sophisticated behaviour in advance of that of their archaic ancestors. The apparent quantum jump in complexity of behaviour, the 'symbolic revolution' (Mellars, 1991), associated with the Upper Palaeolithic is widely accepted to have been the product of modern minds (Chase, 1994). Behaviour is context-specific and even density dependent and in other continental regions like Africa, the markers for the emergence of behaviours equally attributable to modern minds would be different from those evidenced in the European Upper Palaeolithic. However, the attribute that modern people everywhere would have shared was a capacity to use symbols to structure the fabric of their societies. The African record can be searched for the emergence of this attribute.

\section{Environments and Population Archaeology}

The archaeological record is a register of the distribution and density of people in time and space, a history of populations, because stone artefacts indicate where people were living. With advances in dating methods providing more adequate chronological controls, it is becoming possible to identify apparent gaps in the record, periods of low archaeological visibility, and conversely periods of time when, on a regional scale, sites were well represented. There is a dynamic to the archaeological record, which is more than a listing of successive cultures or stages. The well-dated Holocene record shows climatic forcing to have explanatory primacy in population history through changing the productivity of environments. One example is the significant increase in occupation sites in the last 5000 years in southern Africa (Deacon, 1995) with initiation of the El Niño-Southern Oscillation circulation (Sandweiss et al., 1996) in its present mode. A second example is the wide distribution of sites on lacustrine margins in the early Holocene (10 000-5000 years) in northern and eastern Africa (Sutton, 1974) in response to stronger monsoon circulation and pluvial conditions. The Holocene data are dated with a precision not possible for the Pleistocene, but climatic forcing played the same role in earlier times (Deacon \& Lancaster, 1988).

Aridity has been the limiting factor for population distributions and densities in Africa. The latitudinal position, the elevation of the landmass and the narrow, cool Atlantic Ocean bordering the western margin, all contribute to this being a drought-prone continent. Aridity has been relieved by pluvial events. In the middle and lower latitudes pluvials can be associated with enhanced meridional or monsoon circulation and aridity with stronger trade winds and zonal circulation. The general rule (Deacon \& Thackeray, 1984; Szabo et al., 1995) is that pluvials corresponded to the global interglacial periods and aridity to glacial periods. It follows that population expansion in Africa was in the interglacials and contraction in the glacials.

The environmental evidence available for the Late Pleistocene in northern Africa is illustrated by a core drilled off the coast of Senegal (Lezine, 1991). This provides a record of humid phases when pollens of tropical and equatorial vegetation types transported by competent rivers were well-represented and arid phases when the pollens of arid vegetation transported by trade winds increased. This record of the effective strengths of trade wind and monsoon circulation over North Africa has the advantage of being well dated and can be correlated with a similar record from the Arabian Sea. Trade wind circulation and therefore aridity increased after 60000 years, with an apparent departure from this trend centred on 47000 years ago, possibly representing a brief pluvial event. The maximum aridity was at the Last 
Glacial Maximum (18 000 years ago). The beginning of the Late Pleistocene in the Last Interglacial (140 000-118 000 years) was a period of maximum humidity only paralleled in the Holocene. The warmer stadia in MIS 5, about 103000 and 84000 years ago, were periods indicated as less pronounced humid peaks. The test that pluvial periods were periods of population expansion is in the archaeological data.

The study of lacustrine deposits associated with Middle Palaeolithic occupation at Bir Tarfawi in the Western Desert (Wendorf et al., 1993; Szazo et al., 1995) shows a number of pluvial events were associated with the Last Interglacial and earlier interglacials. The main Middle Palaeolithic/Middle Stone Age occupation at Bir Tarfawi, that would be relevant to the distribution of early modern humans, occurred in the period between 140000 and 65000 years ago and there was no further record of human habitation until the end of the Pleistocene. This is one of the driest places on earth and it is habitable only at times of expansion. By contrast, the lower Nile (Vermeersch et al., 1990, Van Peer, 1998) has a longer record of habitation in the Late Pleistocene, but the valley appears to have been occupied by insular communities with a specialised riverine adaptation and thus less vulnerable to environmental forcing. The stability of this local population is of interest because the eastward spread of the Saharawide Aterian, possibly achieved in a Late Pleistocene humid episode at the end of MIS 5 (AllsworthJones, 1987), was blocked at the Nile Valley. The Aterian is best known from long Middle Palaeolithic cave sequences in the Maghreb, like Taforalt and Rhafas, where it is stratified above the Mousterian layers. The ESR dating of the Mousterian levels in Jebel Irhoud cave in Morocco (Hublin, 1993) is to MIS 5-6 (90 000-190 000 years), the Last Interglacial and possibly earlier. This is an indication that the age of the Maghreb sequences and industries, and notably the Aterian (Wengler, 1997), have been underestimated through placing too much reliance on finite radiocarbon age determinations made on materials susceptible to contamination (Clark, 1992). From the thick Middle Palaeolithic layers in cave sequences associated with human remains there was an expansion of a regional population of early modern humans (Hublin, 1993) in the Maghreb initiated in the Last Interglacial.

South of the Sahara, there are large areas where research is still at a reconnaissance level. Southern Africa is one of the better-studied regions and the Late Pleistocene record (Deacon \& Lancaster, 1988) is comparable to that in North Africa. Most of the Middle Stone Age sequences represent occupation in the Last Interglacial or the first half of the Late Pleistocene. The typologically distinctive Howiesons Poort dated to 70000 years ago (Deacon, 1992,1995) serves as a horizon marker in correlating sequences from Zimbabwe to the Cape. Thick Middle Stone Age deposits pre-date the Howiesons Poort in caves and deposits that are younger than the Howiesons Poort are more ephemeral or absent. The archaeology of the latter half of the Late Pleistocene is difficult to study because of low archaeological visibility. Typically, sequences show that end-Pleistocene and Holocene occupation was again on a more substantial scale. There is limited information on the time ranges prior to the Last Interglacial. The earlier phases of the Middle Stone Age that have been suggested typologically (Volman, 1984) remain to be adequately dated and defined.

Archaeological visibility is low in the forest zone and its margins in West and Central Africa (Allsworth-Jones, 1987). Acheulian, Sangoan and Middle Stone Age sites have been recorded, but they are not adequately dated. The transition from the Acheulian to the Middle Stone Age is equated with the poorly defined Sangoan throughout Central and East Africa. The best dated evidence for the beginning of the Middle Stone Age is from the Kapthurin Formation in northern Kenya (McBearty et al., 1996) that is dated to 250000 years ago. In Central Tanzania, Mehlman $(1989,1991)$ has recorded a Njarasa industry (Sangoan) in the Eyasi Beds that are mid-Middle Pleistocene on the basis of the fauna. The Eyasi Beds are stratigraphically older than the long Middle Stone Age sequence in the nearby Mumba cave. The Middle Stone Age horizon at the base of the 7,8 m cave sequence is dated to the beginning of the Late Pleistocene (130 000 years). These lowest deposits of gravels and sands, $20 \mathrm{~m}$ above the present lake level, indicate a fuller lake and humid conditions. A shingle beach $2 \mathrm{~m}$ from the top of the sequence represents a younger high lake stand that is bracketed between dates of 65000 and 35000 years ago. As 
the area is under the influence of the East African monsoon, the $2 \mathrm{~m}$ beach is possibly correlated with a pronounced peak at 47000 years ago in the Monsoon Upwelling Index in core MD76-135 in the Arabian Sea (Prell \& van Campo, 1986). The Mumba industry, a Howiesons Poort-like culture stratigraphic horizon, is dated to 65000 years and occurs in aeolian deposits below the $2 \mathrm{~m}$ beach. In the deposits overlying the beach a Nasera industry has been recognised which may date in the range $40000-20000$ years and is better represented in the rock shelter of that name $70 \mathrm{~km}$ distant. At these two sites there is evidence for a substantial build up in the deposits in the first half of the Late Pleistocene, but also for more persistent occupation in the latter part of the Late Pleistocene than, for example, in sequences in southern Africa. Mumba is another of the sites that has produced early modern human remains dating to the early Late Pleistocene. Age determinations for other Middle Stone Age occurrences in East Africa give a spread of results; 181000 years at Gaddamotte, Ethiopia (Wendorf et al., 1975); 129000 years for the Ngaloba Beds, Tanzania (Hay, 1987), 90000 years at Katanda, Congo (Brooks et al., 1995) and 46000 and more years at Enkapune Ya Muto, Kenya (Ambrose, 1998a). The data from East Africa are consistent with an early modern population expansion in the beginning of the Late Pleistocene. However, they are too few to answer the question, posed by Ambrose (1998b) in his argument on the effects of the Toba eruption, whether these tropical central and eastern areas were a main reservoir of African populations in the Late Pleistocene.

\section{Out of Africa}

The two regions of direct interest in terms of the various 'out of Africa' scenarios (Allsworth-Jones, 1993; Foley \& Lahr, 1997) are Europe and the Near East. Populations in Europe expanded after 60000 years ago as populations contracted in northern Africa. Many of the classic Mousterian sequences date to between 60000 and 40000 years, suggesting that expansion involved Neanderthals and not only the later Cro-Magnons. The timing of the expansion was a response to the same control that caused the aridification of the Sahara in a different latitude, a higher pole-to-equator temperature gradient, and increased zonal circulation with the onset of a glacial mode of global climates. McIntyre \& Molfino (1996) have pointed out that the eccentricity of the earth's orbit declined rapidly from 60000 years ago to a nadir at 42000 years making the climates of the latter half of the Late Pleistocene unusual in earth history. They suggest that low eccentricity in combination with another Milankovitch factor, precession, was the cause of long period (7500 radiocarbon years) El Niño-type cycles affecting the North Atlantic to explain the Heinrich events. Such cycles would have affected terrestrial productivity and go someway to explain the complex population history of Europe in the Late Pleistocene (Mellars, 1993; Straus, 1995). The high level of social signalling that characterises phases of the Upper Palaeolithic indicates crowding or density dependent behaviour (Clark, 1994) and the molecular data (Harpending \& Relethford, 1997) point to a population expansion of two orders of magnitude.

To explain the diversity in the human fossil finds made in the Near East (Bar-Yosef, 1983), it has been proposed that the region functioned as a refugium for fragmented populations in the latter Pleistocene. This presupposes that a number of habitat factors combined to buffer the full impact of Pleistocene climatic changes. The evidence of small mammals (Tchernov, 1992) indicates periods, one of which was the Last Interglacial, when elements of the African fauna have been able to disperse via North Africa to the Levant. The fossil finds of early modern humans like those from Qafzeh, associated with the Mousterian $\mathrm{C}$ and dated to the Last Interglacial, would have been part of the same pattern of dispersal. However, dispersal beyond the Levant at any stage meant breaching the Zagros-TaurusLebanon mountain chain. The archaeological evidence from the Late Pleistocene indicates this did not take place until the appearance of the beginning of the Upper Palaeolithic, some 45000 years ago.

It is useful to borrow the term 'spread' from historical-comparative linguistics (Nichols, 1997), because the spread of the Upper Palaeolithic has many of the characteristics of a language spread. The source area appears to have been in the Negev (Marks, 1990) and probably the north-eastern corner of 
Africa, the lower Nile Valley and Cyrenaica (McBurney, 1967). A source area located on the periphery of the spread zone and a direction or pathway of the spread would be consistent with the linguistic model. In this case the direction of spread followed the same path as the later spread of agriculture in the Neolithic (Bar-Yosef, 1993). While a language spread must involve the movement of some individuals or groups, it does not necessarily imply large-scale migration and/or population replacement. If Neanderthals were specifically different from modern humans then replacement or, less probably, hybridisation was a factor in this archaeological example. A spread model predicts the occurrence of isolates near the limits of the spread and this is perhaps what the late surviving Neanderthals in western Europe represent. The interest in this paper is not in the spread of the Upper Palaeolithic per se. It is in promoting the argument that while the source may have included the north-eastern corner of Africa, the spread occurred in isolation from the rest of the continent. As the source did not lie in sub-Saharan Africa, the Upper Palaeolithic 'package' was not assembled here for export by a migrating horde. Out of Africa models that have been proposed have been too mechanistic and simplistic. However, there is another dimension to which the archaeology of modern humans can contribute and that has to do with behaviour.

\section{The Emergence of Modern Behaviour}

The overwhelming view in the discipline is that the emergence of modern behaviour was a punctuated event, signalled by the Upper Palaeolithic. "A flick of a switch" is how Gamble (1993) has described this symbolic revolution in Europe. The punctuated nature of the event, as argued above, is best explained as a spread and not as a direct export from sub-Saharan Africa. For this reason the archaeological markers for the Upper Palaeolithic event, specialised stone tools, bone artefacts, personal ornaments and art, artefacts that distinguish this stage from the preceding Mousterian in Eurasia, cannot be taken as universal markers for the recognition of the emergence of symbolic behaviour elsewhere.

In spite of this, a pioneer generation of South African archaeologists searched for burins and other Upper Palaeolithic types amongst the collections of stone tools from their sites. They anticipated being able to demonstrate that Upper Palaeolithic or Neoanthropic (Goodwin \& van Riet Lowe, 1929) influences had diffused down the length of the African continent. A current generation of archaeologists, working on the assumption that Neoanthropic Man originated in Africa rather than Europe, is repeating this exercise. Their anticipation is that the same markers for modern behaviour should be evident earlier in Africa. It is now a search for the roots of the Upper Palaeolithic in Africa.

Among the evidence that has been cited for sophisticated behaviours in African contexts that predate the Upper Palaeolithic are:

- blade production at 250000 years ago in the Kapthurin Formation (Gutin, 1995);

- the association of bone harpoons, ochre, evidence for catching spawning fish and patches of occupation debris indicating a nuclear family pattern (Gibbons, 1995; Brooks et al., 1995; Yellen et al., 1995; Yellen 1996) at 90000 years ago at the Katanda site;

- formal bone tools, ochre and evidence for catching fish at the coast site of Blombos (Henshilwood \& Sealy, 1997), sometime prior to 40000 years;

- the transition from the Middle to the Later Stone Age taking place before 50000 years ago in tropical Africa, signifying the origin of modern behaviour on this continent (Ambrose, 1998a), based primarily on the evidence from the Kenyan site of Enkapune Ya Muto that has produced finds of microlithic formal stone tools, ochre and beads.

The significance of the evidence cited needs to be argued in each case, but weight is given to features that are important in the Upper Palaeolithic: blades, bone tools and ornaments.

There is little merit in searching for specific parallels in artefacts and by extension behaviour between Upper Palaeolithic and early modern people in African because the contexts are so different. Rather it has been suggested (Deacon, 1995) the Late Pleistocene record should be searched for 
attributes that distinguish modern behaviour from behaviour that is non-modern. This approach makes it possible to develop a chain of inference from the ethnographic present to the Holocene and Pleistocene archaeology. It also shifts the focus from artefact markers to general levels of behaviour. Thus attributes that indicate modern behaviour in the southern African context have been stated to include:

- family basis to foraging groups with social mechanisms for aggregation and dispersal;

- individual hearths (carrying the implication they were owned by reproductive women) and formal organisation of living space;

- active hunting of all sizes of bovids and management of plant food resources;

- colour symbolism and the reciprocal exchange of artefacts.

These stress the commonalties between behaviours in the Middle Stone Age, associated with early modern humans, and with those recorded in later times in southern Africa. The contrast is with the prior period associated with archaic humans. Some of the evidence available is discussed in more detail below.

There are no other living species of the genus Homo for comparative studies in behaviour. The living apes are too remote in our ancestry to be relevant other than to the behaviour of the australopithecines and earliest hominines. Thus comparisons have focused on the differences in behaviour between the Neanderthals, as archaic kinds of people, and Cro-Magnons, as representing early modern humans. Neanderthals and Cro-Magnons were at least different populations or closely related species living in Europe and western Asia in the Late Pleistocene. The fundamental difference that emerges from such comparative studies is that early modern humans had a larger repertoire of symbolic behaviour than the Neanderthals. This is an attribute that may be recognised in different contexts where early modern humans occurred.

In Africa, outside the range of the Neanderthals, it is the comparisons drawn between the behaviour of Middle Stone Age early modern humans and the behaviour of Later Stone Age people whose lifeways continue into the ethnographic present that is relevant. In particular, through very detailed faunal studies, Klein (1995) has pointed to significant differences in the ways marine and terrestrial resources were used in the Middle and Later Stone Ages. On economic grounds he has cogently argued that Middle Stone Age people, 60000 or more years ago, did not utilise the potentials of their environment as fully as Later Stone Age peoples in the recent past. The question is whether an increase in the intensity of resource usage can be taken as a measure of the neurological differences between populations, living in the same area but about 50000 years apart. The danger here is in assuming that early modern humans in the Middle Stone Age in Africa were behaviourally like their contemporaries, the Neanderthals, with whom they shared prepared core (Levallois) technology, and that Later Stone Age and Upper Palaeolithic people were a grade more advanced in their behaviours. Differences in economies between time successive populations may be due to changes in densities, adoption of new technologies and other factors. They do not necessarily imply neurological differences. However, earlier in time as discussed below in relation to Acheulian populations, there is evidence to suggest behaviour that is different from modern people at a higher order and this would imply significant neurological differences.

Central to discussions of the behaviour of Middle Stone Age people has been the evidence from the Klasies River main site (Deacon, 1995). This is a $20 \mathrm{~m}$ sequence of Middle Stone Age deposits dated between 120000 and 60000 years. The succession includes multiple short-term occupations marked by hearths with carbonised surrounds, stone artefacts, shell middens and faunal remains. What is noteworthy in study of this and Later Stone Age deposits in the same area is that the site formation processes are the same. The deposits have built up through episodic occupation by family units with the disposal of food waste in middens. The artefact finds are also significant. For example, red ochre occurs throughout and pieces show ground facets. It was a commodity. Ochre is still used in traditional communities locally and more widely and has value as a colour coded symbol as in rites of passage. Other than its symbolic value there is no other persuasive reason to have accumulated ochre in these sites. The horizon marker, the Howiesons Poort with its typologically distinctive backed tools, is stratified near the top of the sequence and the dating centred on 70000 years as noted above. The main 
site sequence shows Howiesons Poort to be only a phase in the sequence and the making of the typologically distinctive backed tools was discontinued in the top of the sequence. That these design types became redundant later in time is some of the clearest evidence that they had symbolic meaning in addition to a functional use (Wurz, 1997). Such evidence for symbolism is more germane to discussions of behaviour in the Middle Stone Age than an argument grounded on economics. Like Upper Palaeolithic people, early anatomically modern people in the Late Pleistocene in Africa were able to think in symbols. They were symboling humans. This may be part of the answer to the second question of the selective advantage possessed by modern humans posed in the introduction. Early modern humans may also have possessed the biological advantage of longer life expectancy (Pfeiffer \& Zehr, 1996), which in turn would have behavioural implications.

Two further points can be made. Firstly, the Howiesons Poort is of interest in a wider context. It occurs not only at Klasies River but also at sites throughout southern Africa. The geographic distribution can be compared to that of the Later Stone Age San naturalistic rock art province and to that of click language speakers (Deacon, 1992). The concordance even extends to a possible outlier in the Mumba industry of Central Tanzania where naturalistic art is also recorded and San click language speakers are still resident. Overlapping spreads of peoples, industries and language may be a fortuitous product of geography, but that must be considered a remote possibility. A more probable explanation is that there has been a high level of continuity, genetically and culturally, between early modern peoples in Late Pleistocene and recent populations in this part of Africa. This degree of continuity reflects the relative isolation of southern Africa, a remote cul-de-sac in the inhabited world in the Late Pleistocene. It is a unique situation where continuities can be traced over an extended time. The similarities in the style of artefact production in the Howiesons Poort (Wurz, 1997) is evidence for a communication network and by extension the spread of a common language. A language in the modern sense would be necessary to explain the meaning of symbols held in common. Click languages are unique to this part of Africa and probably had their origins here (Nichols, 1997). It is entirely possible they were spoken in an ancestral form in the Late Pleistocene. Language would have been an attribute of early modern humans.

Secondly, Middle Stone Age foragers like those in the Later Stone Age were eurytopic and able to occupy all positions in the landscape. In this they were significantly different from Acheulian groups of archaic humans. The distribution of Acheulian sites in riverine and wetland habitats suggests they were stenotopic and occupied a narrow ecological niche. It is conjectured (Deacon, 1998) that they were organised socially and economically in ways different from later peoples and, unlike Middle and Later Stone Age foragers, their lifeways cannot be understood by analogy to ethnographically known huntergatherers. The Acheulian sites potentially provide evidence of archaic people whose lives were not structured by symbolic behaviour.

\section{Conclusions}

The archaeological study of modern human origins is global in its compass. The perspective offered in this paper is from the African evidence. Two themes are discussed, population history and behaviour. Aridity has been the most important control on population distributions and densities in the Late Pleistocene and the results are reflected in changes in archaeological visibility. In the sub-tropical and extra-tropical regions of northern and southern Africa, the expansion of early anatomically modern human African populations took place under pluvial conditions in the Last and Present Interglacials. These populations contracted in the aridity of the Last Glacial. The archaeology of tropical and equatorial Africa is less well known and it is still to be established whether Late Pleistocene populations in these latitudes were less subject to flux. The expansion of populations in the latitudes of Europe in the Last Glacial was after 60000 years and was out of phase with the African expansion. It appears to have involved Neanderthals as well as later Cro-Magnons. In as far as the latter can be associated with the spread of the Upper Palaeolithic, source area on the periphery of this spread included north-eastern Africa but not sub- 
Saharan Africa. The Upper Palaeolithic 'package' was not assembled in sub-Saharan Africa and exported.

The Upper Palaeolithic Cro-Magnons who shared in the 'symbolic revolution' are accepted as having been behaviourally modern, but the Middle Palaeolithic Neanderthals are not. However, the artefact markers that distinguish the Upper Palaeolithic from the Middle Palaeolithic in Eurasia cannot be used to chart the emergence of modern behaviour elsewhere. The Upper Palaeolithic was not a universal cultural stage. In the different context of Africa, there is continuity in behaviour in the Middle and Later Stone Ages seen in the similarities in site formation processes, in the distribution of sites in all landscape positions denoting eurytopia, and in the investment of artefacts with symbolic meaning. The Middle Stone Age/Middle Palaeolithic to Later Stone Age/Epipalaeolithic transition, unlike the Middle to Upper Palaeolithic transition, did not signal population replacement or a quantum change in behaviour. Early modern humans of the Middle Stone Age, like the peoples of the Later Stone Age, were modern in their behaviour. Arguments to the contrary based on the relative intensity of the use of food resources cite data that are more reasonably explained in terms of differences in population densities than neurological differences. In this paper a contrast is drawn between behavioural evidence from the Acheulian sites and the sites of later peoples. There is the indication that Acheulian groups were markedly different in their behaviour from ethnographically known foragers. They were the non-modern outgroup.

\section{Acknowledgements}

I would like to thank Phillip Tobias and his committee for inviting me to organise Colloquium 17 on the archaeology of modern human origins, those who took part in the colloquium, Philip Chase, Paul Mellars, Virendra Misra, Alan Thorne and Pierre Vermeersch, and those who for reasons beyond their control were prevented from attending, Rhys Jones, Bert Roberts and Mike Smith. Sarah Wurz is thanked for her comments on the paper.

\section{References}

Allsworth-Jones, P. (1987). The earliest human settlement in West Africa and the Sahara. In: Foundations of Civilization in Tropical Africa, ed. B.W. Andah \& A.I. Okpoko, pp. 87-128. Special book issue of West African Journal of Archaeology, Volume 17.

Allsworth-Jones, P. (1993). The archaeology of archaic and early modern Homo sapiens: an African perspective. Cambridge Archaeological Journal, 3, 21-39.

Ambrose, S.H. (1998a). Chronology of the Later Stone Age and food production in East Africa. Journal of Archaeological Science, 25, 377-92.

Ambrose, S.H. (1998b). Late Pleistocene human population bottlenecks, volcanic winter, and differentiation of modern humans. Journal of Human Evolution, 34, 623-51.

Bar-Yosef, O. (1993). The role of western Asia in modern human origins. In: The Origin of Modern Humans and the Impact of Chronometric Dating, ed. M.J. Aitken, C.B. Stringer \& P.A. Mellars, pp. 132-47. Princeton: Princeton University Press.

Brooks, A.S., Helgren, D.M., Cramer, J.S., Franklin, A. Hornyak, W., Keating, J.M., Klein, R.G., Rink, W.J., Schwarcz, H.P., Smith, J.N.L., Stewart, K., Todd, N.E., Verniers, J \& Yellen, J.E. (1995). Dating and context of three Middle Stone Age sites with bone points in the Upper Semliki Valley, Zaire. Science, 268, 548-53.

Chase, P.G. (1994). Palaeolithic archaeology and the human mind. Review of: Stringer, C. \& Gamble, C. (1993). In Search of the Neanderthals: solving the puzzle of human origins. London : Thames \& Hudson. Cambridge Archaeological Journal, 4, 110-12.

Chase, P.G. \& Dibble, H.L. (1990). On the emergence of modern humans. Current Anthropology, 31, 58-9.

Clark, G.A. (1994). Migration as an explanatory concept in Paleolithic archaeology. Journal of Archaeological Method and Theory, 1(4), 305-43.

Clark, J.D. (1992). African and Asian perspectives on the origins of modern humans. Philosophical Transactions of the Royal Society, London, B 337, 201-15.

Deacon, H.J. (1992). Southern Africa and modern human origins. Philosophical Transactions of the Royal Society, London, B 337, 177-83. 
Deacon, H.J. (1995). Two Late Pleistocene-Holocene archaeological depositories from the southern Cape, South Africa. South African Archaeological Bulletin, 50, 121-31.

Deacon, H.J. (1998). Elandsfontein and Klasies River revisited. In: A Master of his Craft: Papers in Stone Age Archaeology Presented to John Wymer, ed. N.M. Ashton, F. Healy \& P.B. Pettitt, pp. 23-8. Oxford: Oxbow Books.

Deacon, H.J. \& Thackeray, J.F. (1984). Late Pleistocene environmental changes and implications for the archaeological record in southern Africa. In: Late Cainozoic Palaeoclimates of the Southern Hemisphere, ed. J.C. Vogel, pp. 375-90. Rotterdam: A.A. Balkema.

Deacon, J. \& Lancaster, N. (1988). Late Quaternary Palaeoenvironments of Southern Africa. Oxford: Clarendon Press.

Foley, R. \& Lahr, M. (1997). Mode 3 technologies and the evolution of modern humans. Cambridge Archaeological Journal, 7(1), 3-36.

Gamble, C. (1993). Timewalkers: the Prehistory of Global Colonization. Cambridge (Mass.): Havard University Press.

Gibbons, A. (1995). Old dates for modern behaviour. Science, 268, 495-96.

Goodwin, A.J.H. \& Van Riet Lowe, C. (1929). The Stone Age cultures of South Africa. Annals of the South African Museum, 27.

Gutin, J-A. (1995). Do Kenya tools root birth of modern thought in Africa. Science, 271, 1118-19.

Harpending, H. \& Relethford, J. (1997) Population perspectives on human origins research. In: Conceptual Issues in Modern Human Origins Research. ed. G.A. Clark \& C.M. Willermet, pp. 361-68. New York: Aldine de Gruyter.

Hay, R. (1987). Geology of the Laetoli area. In: Laetoli: a Pliocene Site in Northern Tanzania, ed. M.D. Leakey \& J.M. Harris, pp. 23-47. Oxford: Clarendon Press.

Henshilwood, C.S. \& Sealy, J.C. (1997). Bone artefacts from the Middle Stone Age at Blombos Cave, southern Cape, South Africa. Current Anthropology, 38, 890-95.

Hublin, J-J. (1993). Recent human evolution in North-western Africa. In: The Origin of Modern Humans and the Impact of Chronometric Dating, ed. M.J. Aitken, C.B. Stringer \& P.A. Mellars, pp. 118-31. Princeton: Princeton University Press.

Klein R.G. (1995). Anatomy, behaviour and modern human origins. Journal of World Prehistory, 9, 167-98.

Lezine, A-M. (1991). West African paleoclimates during the last climatic cycle inferred from an Atlantic deep-sea pollen record. Quaternary Research, 35, 456-63.

Marks, A.E. (1990). The Middle and Upper Palaeolithic of the Near East and the Nile Valley: the problem of cultural transformations. In: The Emergence of Modern Humans, ed. P.A. Mellars, pp. 56-80. Edinburgh: Edinburgh University Press.

McBrearty, S., Bishop, L. \& Kingston, J. (1996). Variability in traces of Middle Pleistocene hominid behavior in the Kapthurin Formation, Baringo, Kenya. Journal of Human Evolution, 30, 563-80.

McBurney, C.B.M. (1967). The Haua Fteah (Cyrenaica) and the Stone Age of the south-east Mediterranean. Cambridge: Cambridge University Press.

McIntyre, A. \& Molfino, B. (1996). Forcing of Atlantic equatorial and subpolar millennial cycles by precession. Science, 274, 1867-70.

Mehlman, M.J. (1989). Later Quaternary archaeological sequences in northern Tanzania. Unpublished PhD thesis, University of Illinois at Urbana-Champaign. Ann Arbor: University Microfilms International.

Mehlman, M.J. (1991). Context for the emergence of modern man in eastern Africa: some new Tanzanian evidence. In: Cultural Beginnings: Approaches to Understanding Early Hominid Lifeways in the African Savanna, ed. J.D. Clark, pp. 177-96. Mainz: Römisch-Germanisches Zentralmuseum.

Mellars, P.A. (1991). Cognitive changes and the emergence of modern humans. Cambridge Archaeological Journal, 1, 63-76.

Mellars, P.A. (1992). Outlining the problem. Philosophical Transactions of the Royal Society, London, B 337, 225-34.

Mellars, P.A. (1993). Archaeology and the population-dispersal hypothesis of modern human origins in Europe. In: The Origin of Modern Humans and the Impact of Chronometric Dating, ed. M.J. Aitken, C.B. Stringer \& P.A. Mellars, pp. 196-216. Princeton: Princeton University Press.

Nichols, J. (1997). Modelling ancient population structures and movement in linguistics. Annual Review of Anthropology, 26, 359-84.

Pfeiffer, S. \& Zehr, M.K. (1996). A morphological and histological study of the human humerus from Border Cave. Journal of Human Evolution, 31, 49-59.

Prell, W.L. \& Van Campo, E. (1986). Coherent response of Arabian Sea upwelling and pollen transport to late Quaternary monsoon winds. Nature, 323, 526-28. 
Sandweiss, D.H., Richardson, J.B., Reitz, E.J., Rollins, H.B. \& Maasch, K.A. (1996). Geoarchaeological evidence from Peru for a 5000 years B.P. onset of El Niño. Science, 273, 1531-33.

Straus, L.G. (1995). The Upper Palaeolithic of Europe: an overview. Evolutionary Anthropology, 4, 4-16.

Sutton, J.E.G. (1974). The aquatic civilization of middle Africa. Journal of African History, 15, 527-46.

Szabo, B.J., Haynes, C.V. \& Maxwell, T.A. (1995). Ages of Quaternary pluvial episodes determined by uraniumseries and radiocarbon dating of lacustrine deposits of Eastern Sahara. Palaeogeography, Palaeoclimatology, Palaeoecology, 131, 227-42.

Tchernov, E. (1992). Biochronology, paleoecology, and dispersal events in the southern Levant. In: The Evolution and Dispersal of Modern Humans in Asia, ed. Takeru Kazawa, Kenichi Aoki \& Tasuku Kimura, pp. 149-88. Tokyo: Hokusen-Sha.

Van Peer, P. (1998). The Nile corridor and the Out-of-Africa model: an examination of the archaeological record. Current Anthropology, 39, S115-40.

Vermeersch, P.M., Paulissen, E., \& Van Peer, P. (1990). Le Paleolithique del la Vallee du Nil egyptien. L'Anthropologie, 94, 435-58.

Volman, T.P. (1984). Early prehistory of southern Africa. In: Southern African Prehistory and Palaeoenvironments, ed. R.G. Klein, pp. 169-220. Rotterdam : Balkema.

Wendorf, F., Laury, R.L., Albritton, C.C., Schild, R., Haynes, C.V., Damon, P.E., Shafiqullah, M. \& Scarborough, R. (1975). Dates for the Middle Stone Age of East Africa. Science, 187, 740-42.

Wendorf, F., Schild, R., Close, A.E. \& Associates. (1993). Egypt during the Last Interglacial: the Middle Palaeolithic of Bir Tarfawi and Bir Sahara east. New York: Plenum Press.

Wengler, L. (1997). La transition du Mousterien a l'Aterien. L'Anthropolgie, 101, 448-81.

Wurz, S. (1997). The Howiesons Poort at Klasies River: from artefacts to cognition. Unpublished MA thesis, University of Stellenbosch.

Yellen, J.E. (1996). Behavioural and taphonomic patterning at Katanda 9: a Middle Stone Age site, Kivu Province, Zaire. Journal of Archaeological Science, 23, 915-32.

Yellen, J.E., Brooks, A.S, Cornelissen, E., Mehlman, M.J. \& Stewart, K. (1995). A Middle Stone Age worked bone industry from Katanda, Upper Semliki Valley, Zaire. Science, 268, 553-6. 


\section{Virendra N. Misra}

Deccan College Post-Graduate \& Research Institute

Pune, India

Keywords: Palaeolithic Archaeology, Indian sub-continent, human settlement

\section{Archaeological Evidence of Early Modern Human Occupation in South Asia}

\begin{abstract}
Significant archaeological evidence for colonization of South Asia begins to appear from the Acheulian stage of the Lower Palaeolithic. Evidence for Acheulian occupation is the richest. Two phases of the Acheulian can be recognized: an earlier phase characterized by high proportions of core tools (e.g. choppers, polyhedrons, spheroids, handaxes), a low proportion of crudely made cleavers and flake tools, with predominant use of stone hammer techniques and absence of Levallois technique; and a later phase marked by a low proportion of bifaces, use of large flakes for making them and high ratio of cleavers to handaxes, very high proportion of flake tools like scapers, extensive use of the soft hammer technique and use of Levallois and discoid core techniques. Several $\mathrm{Th} / \mathrm{U}$ and $\mathrm{TL}$ dates from sites in the Thar desert and peninsular India and palaeomagnetic stratigraphy of sites in Pakistan suggest that the Acheulian in India goes back at least to 0.6 Myr- or early Middle Pleistocene age. Archaeological data and the radiometric dates show that, the Acheulian survived well into the Upper Pleistocene. The Hatnora site in the Narmada valley has yielded a hominid calvaria, associated with Late Acheulian tools, which belongs to archaic Homo sapiens. Middle Palaeolithic sites are fewer and poorer than those of the Lower Palaeolithic. Core tools disappear almost completely and bifaces are replaced by flake and blade tools like scrapers, points, borers, notches and denticulates. The artefacts become smaller and thinner. Levallois and discoid core techniques become dominant. Relatively coarse-grained rocks like quartzite, quartz and basalt, which were commonly used during the Lower Palaeolithic, are replaced by fine-grained siliceous materials like chert, jasper and chalcedony. TL dates from Rajasthan and ${ }^{14} \mathrm{C}$ dates from central and western India shows that the Middle Palaeolithic spans from the last interglacial to the last glacial. The Upper Palaeolithic in India has even fewer and poorer sites than the Middle Palaeolithic. The paucity of archaeological sites of this period is a consequence of this aridity. Technologically the Upper Palaeolithic represents a clear break from the Middle Palaeolithic even though blades were produced both by the Acheulian and Middle Palaeolithic peoples, it is during the Upper Palaeolithic period that the blade and burin technology came into full form.
\end{abstract}

\section{Introduction}

The Indian sub-continent is the gateway to the East and has occupied an important position in the context of the dispersal of human populations, languages and ideologies through time. Stone Age research in the region began in the early 1860 s, and a reasonable assessment of the kind and distribution of relevant sites has accumulated since then. However, this is a vast area and given the number of 
institutions and individuals engaged in such research and the multidisciplinary expertise required for it, much remains to be done. There is a plenitude of stone artifacts in the landscape and several thousand Palaeolithic sites have been located, but only some 40 have been excavated. The archaeology of the subcontinent is best known for later periods, with good exposures and better preservation available for study. Much of the older evidence lies deeply buried in the alluvium of rivers like the Ganga (Ganges) and the Narmada.

\section{Lower Palaeolithic}

The earliest human occupation of the Indian sub-continent is known from the Lower Palaeolithic. Combined magnetic dates from the Riwat section in the Sohan syncline, south-east of Rawalpindi, and fission track dates from elsewhere in the Siwalik Hills in Pakistan, indicate an age possibly as early as 2,01 million years for the earliest man-made tools reported from the sub-continent (Rendell et al., 1987; Dennell et al., 1988). This early age requires confirmation through the discovery of more in situ artefact occurrences with good stratigraphic provenance that can be dated with chronological precision. However, even conservative estimates would put the earliest occupation in the Lower Pleistocene, at least one million years ago. The dating of the initial dispersal of people to the Far East, presumably from Africa, remains a contentious issue that will only be resolved through further research not only in the sub-continent but also in Java and China.

The Lower Palaeolithic is represented by two cultures or technological traditions, the Sohanian characterised by pebble tools (choppers and chopping tools), flakes and cores and the Acheulian characterised by bifaces, pebble tools, and a variety of scrapers, flakes, blades, and cores. These are considered separate but temporally overlapping artefact traditions much in the same way that the Developed Oldowan tradition in Africa is considered to continue after the appearance of Acheulian toolmakers. Mohapatra (1976), who has studied both Sohanian and Acheulian sites in the HoshiarpurChandigarh sector of the Siwaliks, has argued that the Acheulian and Sohanian populations inhabited two distinct types of environment, the former occupying the flat surfaces of the Siwalik Frontal Range and the latter the duns or valleys of the Himalayan flank.

The Sohanian is known only from the Siwalik Hills in north India and Pakistan (de Terra \& Paterson, 1939). The name derives from Sohan River and the terrace gravel and associated loess deposits of the Indus-Sohan in the Potwar region of Pakistan and the valleys of the Sutlej, Beas, Banganga and other rivers in the Punjab-Himachal Pradesh region in India (Lal, 1956; Karir, 1985) have yielded artefacts of earlier and later phases of the Sohanian. Acheulian tools are found in the same deposits, though at discrete localities. The faunal remains from the older stratigraphic units on the Potwar Plateau included horse, buffalo, straight-tusked elephant and hippopotamus, suggesting an environment characterised by perennial water, tree vegetation and grass steppes. The Late Sohan B in loess and associated with Levallois flakes and blades and a fauna that includes horse, bovids, camel and wolf (Wadia, 1928) may be Late Pleistocene in age. It needs to be stressed that the archaeological material in the Siwaliks has so far been found almost entirely on the surface and this compounds problems of associations and dating.

The first effective colonisation of South Asia was achieved by people associated with the Acheulian culture. The remains of this culture, almost entirely in the form of stone tools, have been found extensively and in vast quantities from the Siwalik Hills in the north to near Chennai, formerly Madras, in peninsular India (Paddayya, 1984; Misra, 1989). Sites are particularly densely concentrated and richer in central India and the southern part of the Eastern Ghats. The only areas devoid of Acheulian occupation are the Western Ghats and the coastal region running parallel to them (Guzder, 1980), northeastern India, and the Ganga plains. Heavy rainfall and dense vegetation in the Western Ghats and Northeast India and the total absence of stone in the alluvial Ganga plains probably inhibited colonisation of these regions. Acheulian occupation occurred in a wide range of ecological zones from desert to humid tropics and in a variety of microhabitats, around lakes and pools, along river courses and 
on gravel beds. There was even rare occupation of rock shelters (Joshi, 1978; Misra, 1980), the most substantial example of which is the $2.5 \mathrm{~m}$ thick Acheulian occupation of the Bhimbetka shelter IIIF-23 in central India.

It can be assumed that the Acheulian tradition covers a long time interval. Research by the British Archaeological Mission to Pakistan has dated some in situ Acheulian occurrences in the Pakistan Siwaliks to between 700000 and 400000 years (Rendell \& Dennell, 1985). Across the border in the Indian Siwaliks, the Acheulian tradition is thought to be no older than 200000 years and the Sohanian only slightly older at about 300000 years (Mohapatra, 1976). More secure dating is provided by a tephra underlying a colluvial gravel containing unabraded Early Acheulian artefacts like choppers, picks, handaxes, cores and flakes at Bori in District Pune, Maharashtra. The tephra has been dated by the potassium-argon method to $0,67 \pm 0.03$ million years ago (Mishra et al., 1995). On geomorphological and stratigraphic grounds, the authors believe that the deposition of the gravel was induced by the fluvial response to the ash fall, and that there was no significant time lag between the two events. Thermoluminescence and thorium/uranium decay series dating have been used to date the sites of Umrethi in Saurashtra (Marathe, 1981) and 16R at Didwana in Rajasthan (Misra \& Rajaguru, 1986). The results point to ages older than 200000 years. The upper age limit of the Acheulian is uncertain. It is possible that the Acheulian tradition persisted, at least in some areas, well into the Late Pleistocene. The discovery of handaxes in a Upper Palaeolithic context at the 16R locality near Didwana in Rajasthan is an example.

Faunal remains have been preserved in Acheulian-bearing gravels in some of the peninsular rivers. The Lower Group of the Narmada stratigraphy, which has yielded Acheulian tools, contains fossils of Sus namadicus, Bos namadicus. Elephas hysudricus. Equus namadicus, Hexaprotodon namadicus, Stegodon insignis and Stegodon ganesa which are all believed to be of Middle Pleistocene age (de Terra \& Paterson, 1939; Badam, 1979, 1984). The coarse gravel unit of the Pravara river, a tributary of the Godavari has yielded fossils of Bos namadicus, Equus namadicus and Elephas namadicus as well as pieces of fossilized tree trunks and branches in association with Acheulian assemblages (Corvinus, 1984). While these animals indicate the existence of both forest and open grassland environments and were a possible source of food, no fauna have been found in association with undisturbed occupation sites.

A calvaria belonging to Homo erectus or archaic Homo sapiens has been discovered in the basal gravels of the Narmada River at Hathnora near Hoshangabad in Madhya Pradesh. From the same deposit Acheulian tools, some of them typologically and technologically similar to those of Bhimbetka rock shelters, have also been found (Sonakia, 1984; de Lumley, H. \& Sonakia, 1985; de Lumley, M-A. \& Sonakia, 1985). Although both the hominid fossil and the tools come from a secondary archaeological context, their association appears quite plausible considering that elsewhere in the Old World, the Acheulian is associated with Homo erectus and archaic Homo sapiens fossils.

Acheulian artefact assemblages comprise choppers, chopping tools, polyhedrons, spheroids, discoids, handaxes. cleavers, scrapers, denticulates, notches, flakes and blades. These artefacts are believed to have served a variety of functions like hunting, butchering and skinning of animals, shattering and breaking open bones for the extraction of marrow, digging of roots and tubers, processing of plant foods and making of wooden tools and weapons. On the basis of stratigraphy, typology and technology, two developmental stages - Early and Late - can be recognised in Acheulian industries. The Early Acheulian is characterised by the predominance of core tools like choppers, chopping tools, polyhedrons, spheroids and handaxes, a very low proportion of crudely made cleavers and flake tools, predominant use of the stone-hammer technique, and the absence of the Levallois technique. The handaxes are massive and thick and have uneven surfaces and irregular edges. This stage is best represented at sites like Singi Talav in Rajasthan (Misra et al. 1982), Chirki-Nevasa in Maharashtra (Corvinus, 1984), Hunsgi (Paddayya, 1982) and Anagwadi (Pappu, 1974) in Karnataka.

The Late Acheulian is marked by a low proportion of bifaces; high ratio of cleavers to handaxes, very high ratio of flake tools like scrapers to bifaces, extensive use of soft hammer technique and use of 
the Levallois and discoid core techniques. Handaxes and cleavers are almost entirely made on flakes and have even surfaces and symmetrical profiles. There is extensive secondary trimming along the sides to make them perfectly symmetrical. In some specimens the ventral flake surface has minimal trimming making the distinction between a flake and handaxe difficult. The cleavers display the entire range of classical forms - V and U-shaped butts and straight, oblique and convex cutting edges. Some of the handaxes and cleavers are so symmetrical, thin and delicate as to appear a work of art and raise doubt about their functional utility. There is little doubt that a sense of aesthetics had appeared among the Late Acheulian people. Scrapers and other flake tools are hardly different from Middle Palaeolithic tools. The technological shift from the Early to Late Acheulian seems more marked than that from the Late Acheulian to the Middle Palaeolithic. This shift may well have coincided with the biological transition from Homo erectus to archaic Homo sapiens.

\section{Middle Palaeolithic}

In Europe, the Near East and Central Asia the Middle Palaeolithic sites are associated with the remains of Neanderthals. No Neanderthals have been found in the Indian sub-continent but the stone tools are very comparable to those found within the known geographic distribution of Neanderthals. However, it is still possible that populations of early modern humans, as represented in the Late Pleistocene in the Near East, were able to disperse to the subcontinent.

The Middle Palaeolithic culture developed during the Late Pleistocene which was in part a period of intense cold and glaciation in the Himalayas and of intense aridity in the areas bordering glaciated regions. This is perhaps the reason why Middle Palaeolithic sites are few in western Rajasthan, the Mewar plateau and the Gujarat plain. In general, however, the Middle Palaeolithic populations occupied the same regions and habitats as were occupied by the Acheulian populations. Middle Palaeolithic stone tool assemblages have been found in the Sanghao cave near Peshawar and the Sohan valley in the Potwar region in Pakistan, Luni valley, in the now defunct river flood plains around Didwana and around Budha Pushkar in western Rajasthan, at numerous sites in the valleys of the Chambal, Son and Narmada and their tributaries and in rock shelters in central India, in the Chota Nagpur plateau, on the Deccan plateau and in the Eastern Ghats (Paddayya, 1984; Misra, 1989).

Significant changes in technology took place during this period. The use of handaxes and cleavers and also of heavy core tools like choppers, polyhedrons and spheroids gave way to flakes and blades. Side scrapers of various types, end scrapers, denticulates, notches, points and borers are the most common tool types of this period. Many of the scraper forms are believed to have been used for manufacturing wooden tools and weapons as also for processing animal hides. Some of the points are thought to have been hafted in wooden shafts for use as spears. Tools became smaller, thinner and lighter. Improved and economical techniques of removing flakes from cores like the Levallois and discoid core were used extensively. There was also a significant change in the choice of rocks for making tools. While quartz, quartzite and basalt continued to be used, in many areas they were replaced by fine grained siliceous rocks like chert and jasper. The smaller size of the tools is probably due to the choice of the raw material. Chert and jasper are usually available in the form of small nodules and therefore impose a natural restriction on the size of the tools.

Our knowledge of the environment of this period is limited. In the northern part of western Rajasthan the discovery of Middle Palaeolithic assemblages in fine-grained deposits shows that the drainage system continued to function though perhaps considerably differently. The presence of several phases of dune accumulation and stabilisation in the 16R profile at Didwana is indicative of multiple fluctuations in rainfall. The faunal remains from the Upper Group of the Narmada alluvium comprising Equus namadicus, Bos namadicus, Hexaprotodon palaeindicus, Elephas hysudricus, Stegodon inignis, Stegodon ganesa and Cervus sp. are similar to those from the Lower Group of Middle Pleistocene age suggesting a savannah grassland environment interspersed with swamps and forests (de Terra \& 
Paterson, 1939; Badam, 1984)

Several TL dates available from the 16R dune profile in western Rajasthan range between 150000 and 100000 years ago. Nearly twenty radiocarbon dates obtained mostly on shell and bone are available from sites in the Deccan and central India. These range in age from 40000 to 10000 years ago. However, the identification of Middle Palaeolithic associations is not always certain, and shell and bone are susceptible to secondary contamination. The dates are therefore considered minimum age estimates. The Middle Palaeolithic was probably restricted to the terminal Middle Pleistocene and the earlier part of the Late Pleistocene.

\section{Upper Palaeolithic}

The Upper Palaeolithic is well dated. Over 30 radiocarbon dates from Upper Palaeolithic sites in central and western India and the Eastern Ghats range from about 40000 to 10000 years ago. Human colonisation and adaptations in this period were shaped by the semi-arid and arid climate of the Last Glacial over much of the subcontinent. The south-westerly monsoons were weak and the sea level was lower by scores of metres. Dune sands were mobilised in desert areas and decreased rainfall and reduction in vegetation cover on the valley slopes in other areas resulted in the formation of colluvial sheets. Under these conditions settlement was restricted in distribution and a reduction in population is suggested. In Pakistan (Allchin, 1976) and western India (Rajasthan and Gujarat) only isolated Upper Palaeolithic sites have been found. In central India and the northern Deccan a limited number of sites are known from the Son Valley (Kenoyer \& Pal, 1983), Bhimbetka rock shelters (Misra, 1985) and Tapti Valley (Sali, 1985). It is in the relatively humid region of the Eastern Ghats that the Upper Palaeolithic sites are plentiful, suggesting a concentration of population there (Murty, 1981; Raju, 1988). For example, at Vodikalu and other sites in the Gunjana valley in the Cuddapah District of Andhra Pradesh there are extensive and extremely rich occurrences of artefacts, sometimes running for several hundred metres either on the surface or buried in fine-grained sediments, often near perennial deep pools in the river.

The Upper Palaeolithic tool assemblages are essentially characterised by blade tools and show a marked regional diversity in respect of refinement of techniques and standardisation and numerical proportion of finished tool forms. Wherever these assemblages occur in a stratified context, they succeed the Middle Palaeolithic and precede the Mesolithic. The principal artefact forms in these assemblages are scrapers, backed blades, burins and unifacial, bifacial and tanged points. Scrapers suggest continuity of Middle Palaeolithic tradition. Broad and thick blades (flake-blades) struck from crude prismatic cores are the important feature of sites in the Subarnarekha valley of Bihar (Ghosh, 1970) and Garo Hills in Meghalaya. Parallel-sided blades struck from standardised prismatic cores are common on sites in the Thar desert (Misra \& Rajaguru, 1986), Belan and Son valleys (Sharma \& Clark, 1983), Damin (Dhamni) area of Rajmahal Hills, Bhimbetka shelters (Misra, 1985), Maharashtra plateau (Sali, 1985), Telangana plateau, Mysore plateau (Paddayya, 1970) and Eastern Ghats (Raju, 1988). Though backed blades, retouched blade tools and burins occur at most of the sites, a predominant component of amorphous elements is a striking feature of all south and south-eastern Asian assemblages.

The fauna associated with the Upper Palaeolithic occupations comprises species like cattle, buffalo, horse, hippopotamus, rhinoceros and elephant as well as smaller game (Badam, 1980; Sharma \& Clark 1983). In the hinterland riverine ecosystems of the Eastern Ghats the lithic assemblages with predominant backed blade and burin elements have another important tool - a large crescentic backed piece with blunted arc and straight cord, recalling the Australian Elouera. Most of these tools have damaged cords, indicating that they were certainly used for wood work. Another striking feature of sites in this region is the presence of a considerable number of bored stones and grinding slabs. Similar bored stones today are used by the Yanadis as net sinkers in riverine fishing, and the heavier ones are used by Voda Balije and other groups for marine fishing. Further, these occupations in the Eastern Ghats are 
invariably associated with permanent water sources, which are still exploited by the Yanadis, lending support to the inference that aquatic foods (fish, prawn, crabs, tortoise, resident and migratory water birds) must have been used during the terminal Pleistocene times as much as they are used today. The grinding stones are likely to have been used in the processing of wild rice (Oryza nivara) found widespread in the Eastern Ghats, and other plant foods. The small microlithic backed blade element of the Upper Palaeolithic assemblages is suggestive of its use in sickles for harvesting.

The technological shift from the Middle Palaeolithic to the Upper Palaeolithic is even more marked than that from the Early Acheulian to Late Acheulian. As in western Europe and Africa this shift probably coincided with the emergence of the true modern humans.

\section{Conclusion}

The Indian subcontinent was a gateway for human dispersal to the east. The record of human habitation may be from as early as 2 million years ago but such early dates need substantiation from this and other parts of Asia. The conventional wisdom is that the primary dispersal event, 'out of Africa 1', dated closer to one million years ago. Two Lower Palaeolithic traditions have been recognised, the Sohanian that was restricted to the Siwalik Hills region and the more widespread Acheulian. The Acheulian marked the first effective peopling of the subcontinent and may date from 700000 years ago. This was the most easterly distribution of the Acheulian (the so-called Movius line) and is a link with the Near East, Europe and Africa rather than the Far East. The Narmada calvarium of Middle Pleistocene age and variously categorised as Homo erectus or archaic $H$. sapiens, can be associated with this period.

The archaeological evidence suggests a more significant shift in technology and typology between the earlier and later Acheulian assemblages than between the latter and the Middle Palaeolithic. The later Acheulian assemblages include cleavers as a prominent biface form and they are more a link with the African than European Acheulian. This may hint at the possible importance of connections to Africa via the Red Sea and the Yemen. This is the low latitude route (Foley \& Lahr, 1997) that has been suggested for the later dispersal of modern humans to Australia in the Late Pleistocene, some 60000 years ago. It is possible that the Middle Palaeolithic in India, like that in the Near East, holds unexpected complexities which future research must resolve. The Upper Palaeolithic on the subcontinent appears to have a similar antiquity to that in Europe and the Near East and is possibly part of the same phenomenon. What is striking is the apparent continuity between the Upper Palaeolithic, the Holocene Mesolithic and the ethnographic present. There are extant communities still functioning as huntergatherers, following an age-old tradition.

\section{References}

Allchin, B. (1976). Palaeolithic sites in the Plains of Sind and their geographical implications. The Geographical Journal, 142, 471-89.

Badam, G.L. (1984). Pleistocene faunal succession in India. In: The Evolution of the East Asian Environment, ed. R.O. Whyte. pp. 746-75.

Corvinus, G. (1984). The Pravara River System Vol 2: The excavations of the Acheulian site of Chirki-on-Pravara, India. Tübingen: Verlag Archaeologica.

De Lumley, H. \& Sonakia, A. (1985). Contexte, stratigraphique et archeologique de l'Homme de la Narmada, Hathnora, Madhya Pradesh, Inde. L'Anthropologie, 89, 3-12.

De Lumley, M-A. \& Sonakia, A. (1985). Premiere decouverte d'un Homo erectus sur le Continent Indien a Hathnora. dans la Moyenne Vallee de la Narmada. L'Anthropologie, 89, 13-61.

Dennell, R.W., Rendell, H.M. \& Hailwood, E. (1988). Early tool-making in Asia: two-million-year-old artefacts in Pakistan. Antiquity, 62, 98-106.

De Terra, H. \& Paterson, T.T. (1939). Studies on the Ice Age in India and associated human cultures. Washington. D.C.: Carnegie Institution.

Foley, R. \& Lahr, M. (1997). Mode 3 technologies and the evolution of modern humans. Cambridge Archaeological 
Journal 7(1):3-36.

Ghosh, A.K. (1970). The Palaeolithic cultures of Singhbhum. Transactions of the American Philosophical Society, $60,1-68$.

Guzder, S. (1980). Quaternary Environment and Stone Age cultures of the Konkan Coastal Maharashtra, India. Pune: Deccan College.

Joshi, R.V. (1978). Stone Age cultures of central India: report on the excavations of rock-shelters at Adamgrh. Madhya Pradesh. Poona: Deccan College.

Karir, B.S. (1985). Geomorphology and Stone Age culture of North-Western India. Delhi: Sadeep Prakashan.

Kenoyer, J.M. \& Pal, J.N. (1983). Report on the excavation and analysis of an Upper Acheulian assemblage from Sihawal II. In: Palaeoenvironments and Prehistory in the Middle Son Valley (Madhya Pradesh. North central India), ed. G.R. Sharma \& J.D. Clark, pp. 23-8. Allahabad: Abinash Prakashan.

Lal, B.B. (1956). Palaeoliths from the Beas and Banganga valleys. Punjab. Ancient India, 12, 58-92.

Marathe, A.R. (1981). Geoarchaeology of the Hiran Valley, Saurashtra, India. Poona: Deccan College.

Mishra, S., Venkatesan, T.R., Rajaguru, S.N. \& Somayajulu, L.K. (1995). Earliest Acheulian industry from Peninsular India. Current Anthropology, 36, 847-51.

Misra, V.N. (1980). The Acheulian Industry of rock-shelter IIIF-23 at Bhimbetka. Central India. Australian Archaeology, 8, 68-106.

Misra, V.N. (1985). Microlithic industries in India. In: Recent Advances in Indo-Pacific prehistory, ed. V.N. Misra \& P. Bellwood, pp. 111-23. New Delhi: Oxford-IBH.

Misra, V.N. (1989). Stone Age India: an ecological perspective. Man and Environment, 14:17-64.

Misra, V.N., Rajaguru, S.N., Raju, D.R., Raghavan, H. \& Gaillard, C. (1982). Acheulian occupation and evolving landscape around Didwana in the Thar Desert, India. Man and the Environment, 6, 72-86.

Misra, V.N. \& Rajaguru, S.N. (1986). Environment et culture de l'Homme Prehistorique dans le Desert du Thar, Rajasthan, Inde. L'Antropologie, 90(3), 407-37.

Mohapatra, G.C. (1976). Geotectonic developments, sub-Himalayan lithic complex and post-Siwalik sediments. In: Perspectives in Palaeoanthropology, ed. A.K. Ghosh, pp. 31-59. Calcutta: Firma K.L. Mukhopadhyay.

Murty, M.L.K. (1981). Hunter-gatherer ecosystems and archaeological patterns of subsistence behaviour on the Southeast coast of India: an ethnographic model. World Archaeology, 13, 47-58.

Paddayya, K. (1970). The blade tool industry of Shorapur Doab. Indian Antiquary (Third series), 4, 165-90.

Paddayya, K. (1982). The Acheulian culture of Hunsgi Valley (Peninsular India): a settlement system perspective. Pune: Deccan College.

Paddayya, K. (1984). Old Stone Age in India. In: Neue forschungen zur Alysteiniet, ed, H. Mueller-Karpe, pp. 345403. Munich: C.H. Beck Verlag.

Pappu, R.S. (1974). Pleistocene studies in the Upper Krishna Basin. Poona: Deccan College.

Raju, D.R. (1988). Stone Age hunter-gatherers: an ethno-archaeology of Cuddapah Region, South-east India. Pune: Ravish Publishers.

Rendell, H. \& Dennell, R.W. (1985). Dated Lower Palaeolithic artefacts from northern Pakistan. Current Anthropology, 16, 393.

Rendell, H.M., Hailwood, E.A. \& Dennell, R.W. (1987). Magnetic polarity stratigraphy of Upper Siwalik SubGroup, Soan Valley, Pakistan: implications for Early Human Occupance of Asia. Earth and Planetary Science Letters, 85, 488-96.

Sali, S.A. (1985). The Upper Palaeolithic culture at Patne, District Jalgaon, Maharashtra. In: Recent Advances in Indo-Pacific prehistory. eds, V.N. Misra \& P. Bellwood, pp.137-45. New Delhi: Oxford-IBH.

Sharma, G.R. \& Clark, J.D. (eds). (1983). Palaeoenvironment and Prehistory in the Middle Son Valley. Allahabad: Abinash Prakashan.

Sonakia, A. 1984. The skull-cap of early man and associated mammalian fauna from the Narmada Valley alluvium, Hoshangabad area, Madhya Pradesh, India. Geological Survey of India Records, 113(6), 159-72.

Wadia, D.N. (1928). Geology of Poonah State (Kashmir). Memoirs of the Geological Survey of India, 51,185-370. 


\section{G. Philip Rightmire}

Department of Anthropology

State University of New York at

Binghamton, Binghamton NY 13902, U.S.A.

Keywords: Klasies River Mouth, Late

Pleistocene, origins of modern humans

\section{Diversity in the Earliest 'Modern' Populations From South Africa, Northern Africa and Southwest Asia}

\begin{abstract}
Trees based on blood allele frequencies, DNA microsatellite data, dental traits and cranial measurements generally agree in showing an early branching of Africans from non-African populations, suggesting that Africa may be the homeland from which humans have dispersed during the later Pleistocene. More direct support for this replacement view comes from the prehistoric record. Localities such as Die Kelders and Klasies River Mouth in South Africa offer important clues. The main site at Klasies contains a variety of stone flakes, hearths, shell and other food waste, and human bones. Cranial parts, mandibles, and teeth demonstrate that the Middle Stone Age people are anatomically modern in a number of key features. The bones are also ancient, as the caves were first inhabited during the last Interglaciation, more than 100,000 years ago. Additional sites outside of southern Africa also demand close attention. The cave at Dar es Soltan in Morocco has yielded adult and juvenile remains that share derived characters with living populations. Skeletons from Qafzeh and Skhul in the Near East differ appreciably from the Neanderthal condition. Perhaps these people are best regarded as part of a single close-tomodern stock resident in North Africa and the Levant as well as the sub-Saharan region. Links to specific later populations are tenuous, although some genetic contribution from the Klasies group to recnt San is certainly possible.
\end{abstract}

\section{Introduction}

Hominids with large faces, low braincases and robust postcranial skeletons are known from Middle Pleistocene localities across the Old World. Described either as 'archaic' Homo sapiens or as representatives of one or more distinct species, these people have given way to populations that are modern anatomically. This shift did not take place everywhere at the same time. Modern humans seem to be present in Africa and the Near East at an especially early date, while in Europe and other regions, Neanderthals or even Homo erectus persist until relatively recently. Interpreting this complex history is a challenge, and of course there has been no lack of controversy. I want to side-step some of this debate, by moving directly to the view that most groups of archaic Homo became extinct. More modern humans evolved just once, in a restricted geographic area.

\section{Phylogenetic trees for living populations}

Some of the more convincing evidence in this regard comes from comparisons of living people. Such surveys can be based on genetic information or on aspects of the phenotype, including blood or bones and teeth. Distances calculated from gene frequencies or measurements are often used to construct trees. In fact, anthropological theorists like trees a lot, and there are many of them in the literature. I have selected just a few, to illustrate current interpretations (Figure 1). 
1. Classical markers (Cavalli-Sforza et al., 1994)

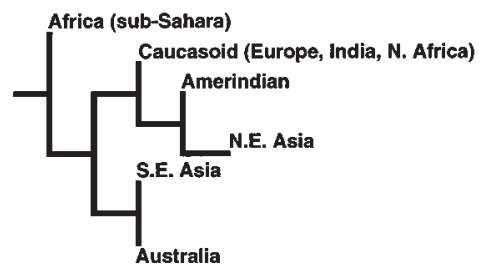

3. Dental traits (Stringer et al., 1997) (Data from Turner, 1992)

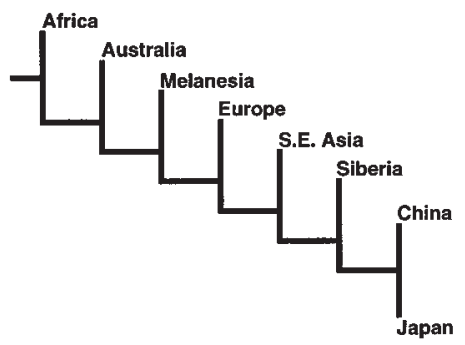

2. DNA microsatellite loci (Nei and Takezaki, 1996)

(Data from Bowcock et al., 1994)

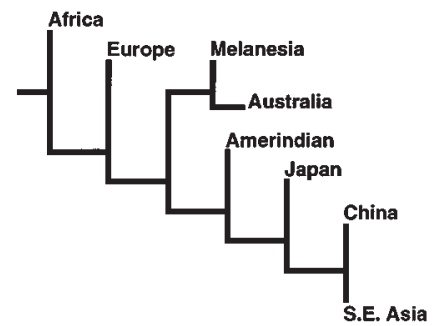

4. Cranial measurements (Relethford and Harpending, 1994) (Data from Howells, 1973, 1989)

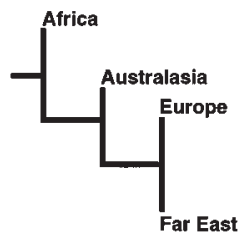

Figure 1. Four phylogenetic trees for human populations based on blood allele frequencies, microsatellite DNA data, dental traits and cranial measurements. Details concerning the populations sampled and methods of analysis are given in the references. All of the trees agree in showing a first separation of Africans from non-African groups.

The first diagram is from the work of Cavalli-Sforza et al. (1994). Here 42 populations are compared for 120 alleles, all of them 'classical' markers. In this (simplified) version of the full tree, the first fission separates sub-Saharan Africans from Berbers and non-Africans. The second fission distinguishes Australia from all other non-Africans, either uniquely or jointly with Southeast Asians. Branching leads next to Europeans and North Asians.

Tree number two is computed for 14 populations and 25 DNA microsatellite loci (Nei \& Takezaki, 1996). The root is located between Africans and non-Africans. The order of branching is then Europe followed by Australia, America and Asia (although the significance of this sequence is not well established).

Trees three and four are constructed for teeth and cranial measurements. Nine dental characters analyzed by Stringer et al. (1997) show an early divergence of Africa. Australia and Melanesia are intermediate, followed by Eurasian populations. It should be pointed out that this result differs from that of Turner (1992), who uses another method to find that Southeast Asians are closest to the ancestral condition.

Finally, cranial measurements studied by Relethford \& Harpending (1994) give much the same picture as do the dental traits and classical genetic markers.

So, information from genetics and morphology suggests an early branching of Africa from nonAfrican people, and a later split between Europe and the Far East. Of course there is room for other opinions here, and not everyone agrees on how the trees should be computed. Also, population distances 


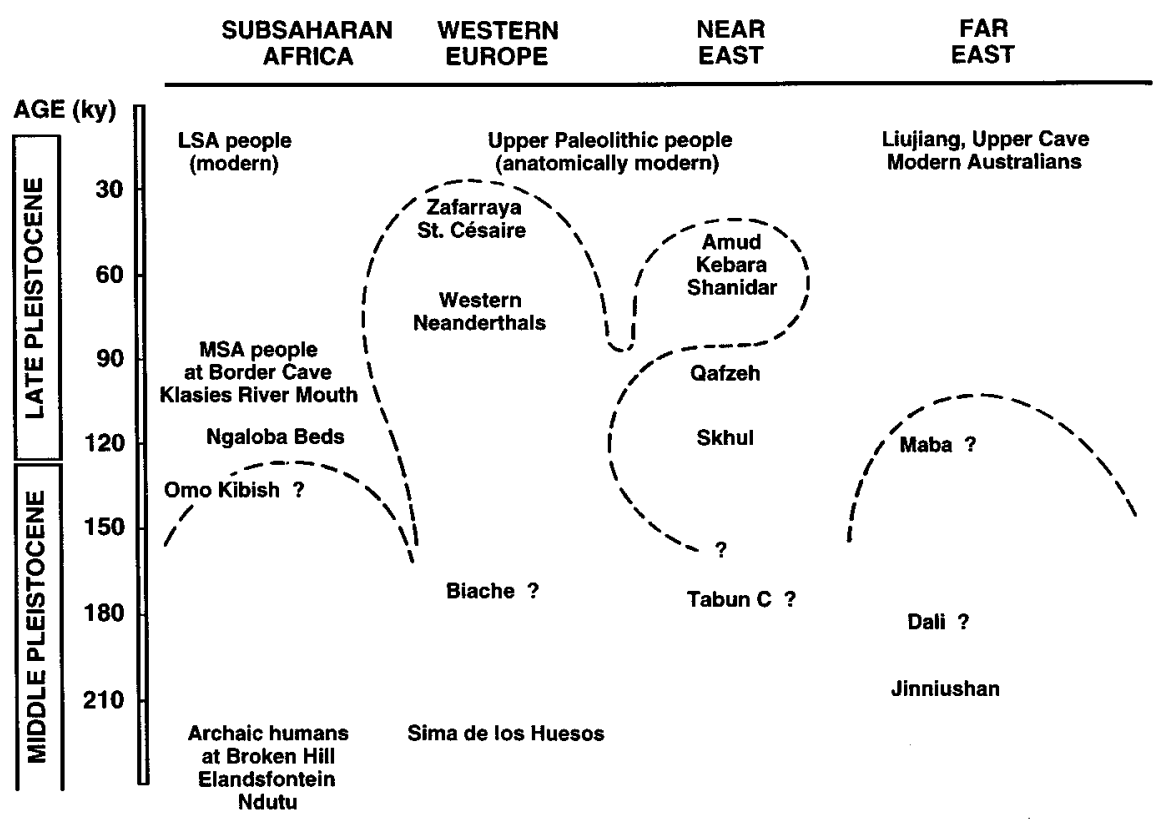

Figure 2. Dating for archaic populations and anatomically modern humans in different regions of the Old World. In Europe, Neanderthals persist at sites such as Zafarraya until perhaps 30.000 years ago. Neanderthals are present also in southwestern Asia, and apparently the fossils at Kebara and Shanidar are younger than anatomically advanced hominids at Qafzeh and Skhul. The latter are approximately contemporary with other 'modern' people documented at Klasies River Mouth in South Africa.

may not always reflect a branching process, and there are questions about population size (Relethford, 1995). Nevertheless, there is an impressive weight of evidence pointing to Africa as the homeland, or the area from which humans have dispersed in relatively recent times.

\section{Fossil evidence for African origins}

More direct support for the replacement view comes from the prehistoric record (Figure 2). A key question, of course, is whether an hypothesis of evolutionary continuity is reasonable, for one or more of the regions listed. As space is limited, I can address only the situation for Africa. Here the record is frustrating. There is nothing approaching the density of material (complete fossils associated with long archaeological sequences) present in Europe. However, there is a useful collection of hominids from sites including Florisbad in South Africa, Laetoli in Tanzania, the Omo in Ethiopia and Jebel Irhoud in Morocco. The cranium from Laetoli is less archaic than earlier Middle Pleistocene specimens, and it exhibits several features that foreshadow the modern condition. The brow is only moderately projecting, and the parietal bones are large and strongly curved. The back of the vault is rounded rather than flexed. Still, differences from recent people are apparent, and the evidence for continuity is not as convincing as it might be.

I will hasten to add that there are more discoveries, which prove quite interesting. Localities in South Africa offer some of the clearest clues. One site is Die Kelders, not far from Cape Town. This cave has recently been studied, and there is no doubt about the provenience of the remains found in Middle Stone 
Age context. Unfortunately, the Die Kelders humans are known so far only from their teeth (Grine et al., 1991; Avery et al., 1997). Klasies River Mouth is also situated on the Cape coast. The main site at Klasies consists of several caves and shelters, which lie in a spectacular setting. These caves were excavated in 1967-1968, and many artifacts were collected, along with shell, animal bones, and human remains (Singer \& Wymer, 1982). More recently, the main site has been worked by Hilary Deacon and a crew from the University of Stellenbosch. These 1984-to-present excavations have been aimed at clarifying stratigraphy and dating (Deacon \& Geleijnse, 1988; Deacon, 1995). The oldest deposits in the cave are grouped in the LBS member, which can be dated by oxygen isotope analysis (shell) and uranium disequilibrium determinations (stalagmite) to $>110.000$ years. The overlying SAS member is composed of sand, ash, pebbles and some very thick shell lenses. The lower part of this member seems to approach 100.000 years in age. Many of the human remains have been recovered from the SAS deposits, but a few teeth are known from the Upper member. In the top of the Upper member, occupation horizons are infrequent.

It is well established that the inhabitants of the Klasies caves were skilled tool-makers, and they produced a variety of stone flakes, flake-blades and scrapers. These tools resemble the Mousterian artifacts of Europe and the Near East. The people probably hunted (and scavenged?), but they avoided the more dangerous game, such as buffalo and pigs. Instead, there are a lot of eland bones, representing animals of all ages (Klein \& Cruz-Uribe, 1996). Also, there is much evidence for the use of marine resources. Some of the earliest middens reflecting regular consumption of intertidal shellfish are found here and in other sites along the coastlines of the southern and western Cape. The importance of such foods as a source of fatty acids enhancing brain development is discussed by Parkington (this volume). A final point is that there is at least the possibility of cannibalism, although the evidence is inconclusive. Part of a human frontal bone shows cutmarks, probably made with a stone edge. This may document intentional defleshing of the head (White, 1987).

Unfortunately, the human remains are rather scarce, and many of the fossils are damaged. They seem to have been treated as food waste (like the bones of other animals), and there was no deliberate burial. One intriguing specimen is the partial frontal bone bearing cutmarks. Whether or not the person was eaten, it is clear that the brow is smooth and not heavily projecting. This individual seems to be an adult (on the basis of overall size, growth of the sinus cavity, and condition of the sutures). Of course, it may be female. Whatever the sex, there is an emphatic contrast to the anatomy of more archaic people, even those at Laetoli or Florisbad (Rightmire \& Deacon, 1991). Another item added recently to the Klasies inventory is part of a small temporal bone, including some of the squama along with the glenoid fossa and the zygomatic root. The fossa is relatively broad and short, but the temporal is decidedly modern, both morphologically and metrically (Grine et al., 1998). Lower jaws suggest the same conclusion. Some, like KRM 21776, are robust, with only moderate expression of a chin. Others, such as KRM 41815 , recovered from the base of the SAS member, are virtually indistinguishable from mandibles of recent Khoisan. Dimensions of the teeth that are preserved also fall within the range of variation for living southern Africans.

So, it is apparent that the Klasies people are anatomically modern in a number of key features, even if there are some differences relative to present populations. The bones are also ancient. Klasies was first inhabited during the Last Interglaciation, more than 100.000 years ago. This I think constitutes about the strongest direct evidence we have that points to an African origin for recent humans.

At the same time, there are additional sites outside of southern Africa that demand close attention. These include Dar es Soltan in Morocco and Skhul and Qafzeh in Israel. The cave at Dar es Soltan has yielded a partial adult cranium and mandible, along with juvenile remains. The cranium exhibits substantial supraorbital relief, and the mandible is quite robust, with large teeth. Nevertheless, the hominids share numerous derived characters with living populations (Hublin, 1993). Two of the Qafzeh adult skulls are well preserved, and both have rather large, heavily constructed faces. A bony chin is 
prominent. The braincases are modern in their proportions (Vandermeersch, 1981). At Skhul, there is a good deal of variation. Skull number 5 is big-browed but modern, while some of the other specimens display more archaic features. All of the skeletons do seem to differ from the Neanderthal condition.

\section{Discussion}

One problem of course is how the northwest African and Levantine humans relate to those at Klasies River Mouth. This is important, if all of the skeletons are about the same age. There are indications that the South African cranial pieces, which tend to be lightly built, and perhaps even the more robust mandibles, differ from the other fossils. One possibility is that these differences are tied to geography, and that (separate) local lineages can be identified in the several regions. One could then ask whether the Klasies people might be the direct ancestors of later San, or whether the Qafzeh population can be linked with recent southwest Asians. In fact, there is not much evidence for these connections. At this early date, there may be no clear differentiation of populations along boundaries that we would recognize today.

Much the same point is made by Howells $(1973,1989)$, who has measured recent human crania representing 28 far-flung populations. There is some variation, especially in the upper face, but the impression is one of overall homogeneity of shape. This pattern can be recognized in some older specimens, but none of any real antiquity. In general, fossils fall beyond the range established for any living groups. This seems to be the case for the Klasies, Dar es Soltan and Skhul-Qafzeh hominids as well. In my view, these people are best regarded as part of a single 'close-to-modern' stock, resident in North Africa and the Levant as well as the sub-Saharan region. Differences between the asemblages may reflect some early variation within this stock, which probably dispersed from a more restricted source in Africa. Links to specific later populations are tenuous, although some genetic contribution from the Klasies group to recent San is certainly possible. The point to be emphasized is that the Klasies River Mouth and other people are the most ancient of 'modern' aspect to be found anywhere. They may well be broadly ancestral to much of later humanity, including populations of Europe, southern Asia or even the Far East.

\section{Acknowledgements}

For the invitation to attend the Dual Congress 1998 and participate in Colloquium 16, I am most grateful to Fred Smith and Phillip V. Tobias. The L.S.B. Leakey Foundation funded my research.

\section{References}

Avery, G., Cruz-Uribe, K., Goldberg, P., Grine, F.E., Klein, R.G., Lenardi, M.J., Marean, C.W., Rink, W.J., Schwarcz, H.P., Thackeray, A.I., \& Wilson, M.L. (1997). The 1992-1993 excavations at the Die Kelders Middle and Late Stone Age cave site, South Africa. Journal of Field Archaeology, 24, 263-91.

Bowcock, A.M., Ruiz-Linares, A., Tomfohrde, J., Minch, E., Kidd, J.R. \& Cavalli-Sforza, L.L. (1994). High resolution of human evolutionary trees with polymorphic microsatellites. Nature, 368, 455-57.

Cavalli-Sforza, L.L., Menozzi, P. \& Piazza, A. (1994). The History and Geography of Human Genes. Princeton: Princeton University Press.

Deacon, H.J. (1995). Two Late Pleistocene-Holocene archaeological depositories from the southern Cape, South Africa. South African Archaeological Bulletin, 50, 121-31.

Deacon, H.J. \& Geleijnse, V.B. (1988). The stratigraphy and sedimentology of the main site sequence, Klasies River, South Africa. South African Archaeological Bulletin, 43, 5-14.

Grine, F.E., Klein, R.G. \& Volman, T.P. (1991). Dating, archaeology, and human fossils from the Middle Stone Age levels of Die Kelders, South Africa. Journal of Human Evolution, 21, 363-95.

Grine, F.E., Pearson, O.M., Klein, R.G. \& Rightmire, G.P. (1998). Additional human fossils from Klasies River Mouth, South Africa. Journal of Human Evolution, 35, 95-107.

Howells, W.W. (1973). Cranial variation in man. A study by multivariate analysis of patterns of difference among recent human populations. Papers of the Peabody Museum, 67, 1-259. 
Howells, W.W. (1989). Skull shapes and the map. Craniometric analyses in the dispersion of modern Homo. Papers of the Peabody Museum, 79, 1-189.

Hublin, J.J. (1993). Recent human evolution in northwestern Africa. In: The Origin of Modern Humans and the Impact of Chronometric Dating, ed. M.J. Aitken, C.B. Stringer, \& P.A. Mellars, pp. 118-31. Princeton: Princeton University Press.

Klein, R.G. \& Cruz-Uribe, K. (1996). Exploitation of large bovids and seals at Middle and Later Stone Age sites in South Africa. Journal of Human Evolution, 31, 315-34.

Nei, M. \& Takezaki, N. (1996). The root of the phylogenetic tree of human populations. Molecular Biology and Evolution, 13, 170-77.

Relethford, J.H. (1995). Genetics and modern human origins. Evolutionary Anthropology, 4, 53-63.

Relethford, J.H. \& Harpending, H.C. (1994). Craniometric variation, genetic theory, and modern human origins. American Journal of Physical Anthropology, 95, 249-70.

Rightmire, G.P. \& Deacon, H.J. (1991). Comparative studies of Late Pleistocene human remains from Klasies River Mouth, South Africa. Journal of Human Evolution, 20, 131-56.

Singer, R. \& Wymer, J. (1982). The Middle Stone Age at Klasies River Mouth in South Africa. Chicago: University of Chicago Press.

Stringer, C.B., Humphrey, L.T. \& Compton, T. (1997). Cladistic analysis of dental traits in recent humans using a fossil outgroup. Journal of Human Evolution, 32, 389-402.

Turner, C.G. (1992). The dental bridge between Australia and Asia: following Macintosh into the East Asian hearth of humanity. Archaeology of Oceania, 27, 143-52.

Vandermeersch, B. (1981). Les Hommes Fossiles de Qafzeh (Israel). Paris: CNRS.

White, T.D. (1987). Cannibals at Klasies? Saggitarius, 2, 7-9. 


\section{Richard G. Roberts ${ }^{1}$ \& Rhys Jones ${ }^{2}$}

\author{
${ }^{1}$ Department of Earth Sciences \\ La Trobe University \\ Melbourne, VIC 3083, Australia
}

${ }^{2}$ Department of Archaeology \& Natural History

Research School of Pacific \& Asian Studies

The Australian National University,

Canberra, ACT 0200, Australia

Keywords: Australia, human occupation, rock shelters, radiocarbon dating, charcoal, elemental carbon, thermoluminescence dating, optical dating, optically stimulated luminescence, quartz sediments, single grains

\section{Chronologies of Carbon and of Silica: Evidence Concerning the Dating of the Earliest Human Presence in Northern Australia}

\begin{abstract}
Establishing the time of arrival of modern humans in Australia is an important issue in word archaeology. A Pleistocene antiquity for initial colonisation was first demonstrated using radiocarbon dating methods, but the last decade has seen luminescence (thermoluminescence and optical) dating extand the time depth of occupation to almost 60000 years at two rock shelters (Malakunanja II and Nauwalabila I) in northern Australia. Recent claims, based on thermoluminescence measurments, have been made for a human presence extending back to more than 100000 years at Jinmium rock shelter, whereas adherents of a radiocarbon-based chronology place initial occupation at no more than 40000 years. Here we review the latest developments in radiocarbon and optical dating and their application to the archeological deposits at these key sites to resolve questions of age and stratigraphic integrity. We also discuss the problems of long-term charcoal preservation in such deposits and of radiocarbon dating close to the practical limits of the method, and conclude that humans first arrived in Australia shortly after 60000 years ago.
\end{abstract}

\section{Introduction}

The question of the dating of the human occupation of the Australia-New Guinea continent has assumed a critical importance within the broader debate concerning the geographical spread of modern Homo sapiens (Klein, 1995; O'Connell \& Allen, 1998; Jones, 1998). The archaeological record from the earliest sites in Australia documents nothing less than fully modern sapient behaviour; sites mentioned below are shown in Figure 1. Despite the archaic morphology of some fossil skulls, in particular the Willandra Lakes hominid WLH 50 and the Kow Swamp series (Frayer et al., 1994), there is no hint of any evidence for a pre-sapient colonist in Australia. This is despite the fact that the adjacent Sunda region of southeast Asia has been seen as one of the potential origins of the earliest humans since the discovery by Eugene Dubois of Pithecanthropus erectus in Java more than a century ago (Dubois, 1894).

Recent fission-track dating of the site of Mata Menge on the east Indonesian island of Flores (Morwood et al., 1998) seems to confirm previous assessment of this site that there is genuine stratigraphic association of flaked stone tools with extinct Stegodon fossils in a water-lain tuffaceous sandstone dated to between $880000 \pm 70000$ and $800000 \pm 70000$ years ago. Further work needs to be done to establish beyond all reasonable doubt that these stratigraphic associations are primary. This evidence may indicate a greater water-crossing ability by early humans than had previously been considered, but there is no suggestion that the Sahul shore witnessed the footprint of people other than modern sapiens.

The past 35 years has seen the establishment of a human presence on the Australia-New Guinea landmass from at least 35000 years ago in most of the varied ecological zones across the continent 


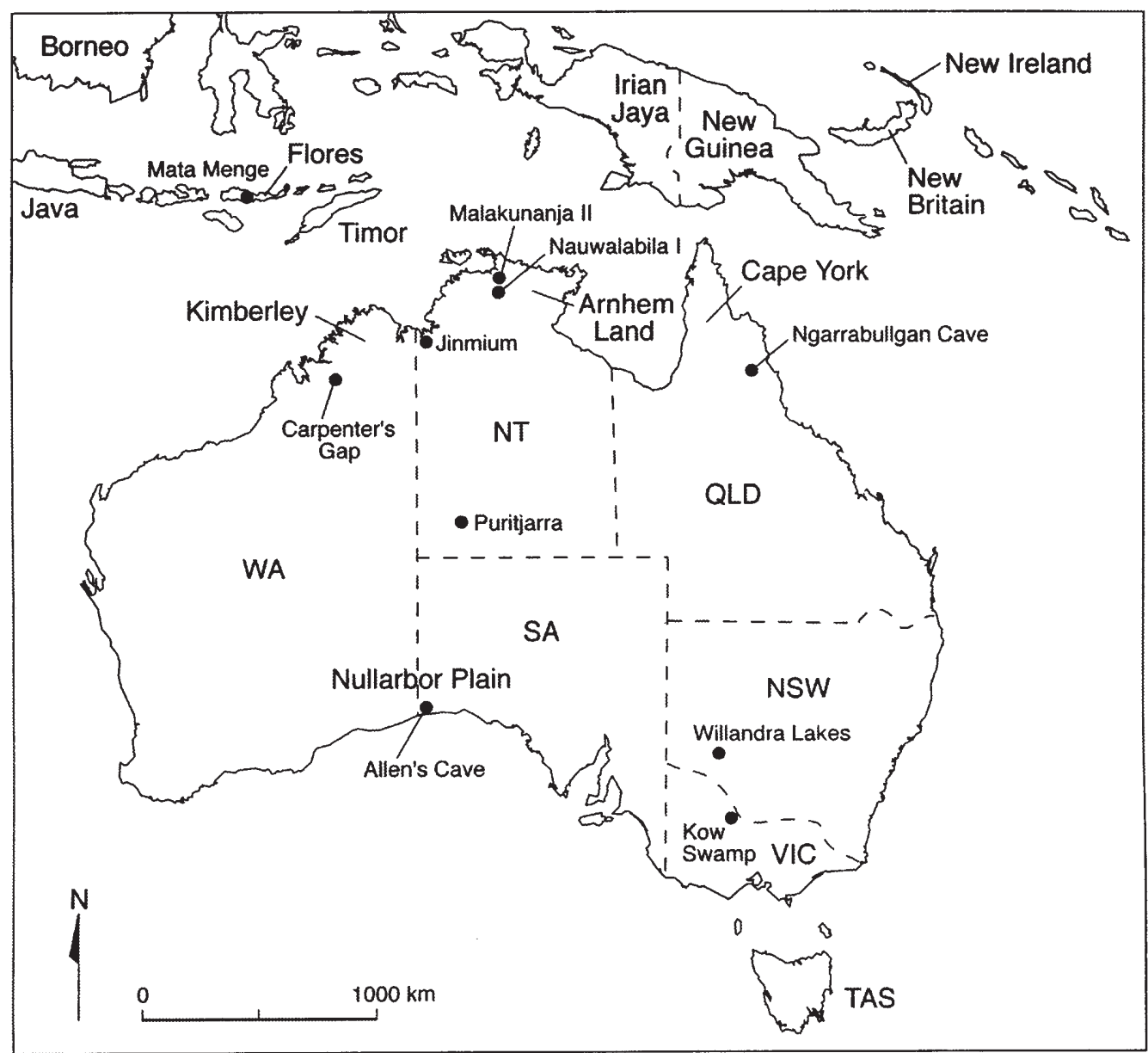

Figure 1. Location map of sites discussed in the text.

(Smith \& Sharp, 1993). Detailed sequences of this antiquity now exist in regions as far flung as the tropical north, the southwest of Western Australia, and Tasmania in the extreme southeast. Puritjarra rock shelter in the core desert region of the continent (Smith et al., 1997) and the truly oceanic islands of inner Melanesia, such as New Britain and New Ireland (Leavesley \& Allen, 1998), seem also to have been occupied by this time.

But there remains the question of the oldest dates for initial colonisation. Thus far, the oldest apparently reliable radiocarbon $\left({ }^{14} \mathrm{C}\right)$ ages come from the excavation at Carpenter's Gap, where a large rock shelter has formed in the Devonian limestone reef that skirts the southern edge of the Kimberley region in northwestern Australia (O'Connor, 1995). Several ${ }^{14} \mathrm{C}$ ages for the site have been published, the oldest pair being $39220 \pm 870$ and $39700 \pm 1000$ years BP (O’Connor, 1995), and work in press confirms these ages. Underneath this dated unit was a fine powdery silt that contained flaked stone artefacts (S. O'Connor, personal communication), and efforts are continuing to obtain numerical-age 
estimates for this unit.

To the east of Carpenter's Gap lies the Jinmium rock shelter, where human habitation stretching back more than 100000 years was proposed by Fullagar et al. (1996) on the basis of artefact-bearing sediments which were dated by thermoluminescence (TL). TL dating had previously been used to derive ages for archaeological sediments at Malakunanja II (Roberts et al., 1990), a rock shelter located in western Arnhem Land in the far north of the Northern Territory, a likely entry point for the first human arrivals into Australia. First occupation of Malakunanja II was placed at between 50000 and 60000 years, and a similar age envelope was obtained subsequently by optically stimulated luminescence (OSL, or optical) dating of sediments in the nearby rock shelter of Nauwalabila I (Roberts et al., 1994a).

These luminescence-based ages remain contentious (e.g. O'Connell \& Allen, 1998), especially the high ages claimed for Jinmium. Our views on the ${ }^{14} \mathrm{C}$ and luminescence chronologies for the timing of human colonisation of Australia have been expressed recently at length elsewhere (Roberts, 1997: 848867; Jones, 1998), so in this paper we restrict our discussion to the most recent turn of events.

\section{Silica Chronologies}

The last few years have seen some significant advances in our efforts to reliably date the first time of entry of humans into Australia. The use of luminescence methods has been at the vanguard of these efforts, with the development of single-grain optical dating techniques foremost among them. This trend toward extreme reductionism - dating each grain individually - parallels similar trends by other numerical-age methods, such as fission-track and argon-argon. For these methods, as for luminescence, the objective is to identify and discard any 'contaminant' grains in a sample before calculating its age (see Wintle, 1996). For readers wishing to learn more about the latest developments in luminescence dating, An Introduction to Optical Dating by Aitken (1998) is an up-to-date account written with the non-specialist in mind.

Single-grain optical dating was first applied to quartz sediments from the archaeological site of Allen's Cave on the Nullarbor Plain in South Australia (Murray \& Roberts, 1997). A subsequent application to the dating of rock paintings in the northern Kimberley region of Western Australia (Roberts et al., 1997) foreshadowed the deployment of single-grain methods at the habitation and rock art site of Jinmium. The wall of this shelter is covered in pecked cupules, and the original excavators (Fullagar et al., 1996) reported that a fallen fragment of engraved sandstone was buried in sediments dated to between $50000 \pm 6100$ and $75300 \pm 7000$ years using TL. Fullagar et al. (1996) also recovered stone artefacts from levels dated by TL to between $116000 \pm 12000$ and $176000 \pm 16000$ years, which would have made it the oldest known human occupation site on the continent, two to three times as ancient as Malakunanja II (Roberts et al., 1990) or Nauwalabila I (Roberts et al., 1994a).

In 1994, we had warned about the possibility of contamination of rock shelter deposits with grains of weathered rubble or bedrock, and for the need to check for such contamination to avoid distortion of luminescence ages (Roberts \& Jones, 1994). Luminescence dating methods give the time elapsed since the sediment grains in a sample were last exposed to sunlight (a process known as 'bleaching'). A grain derived from rubble will not have had its luminescence 'clock' reset by sunlight, so the incorporation of such grains into a sedimentary deposit, and the analysis of sub-samples composed of many grains, may give rise to luminescence ages that are much too old. The dating of single grains circumvents this problem.

Some researchers considered that contamination of the Jinmium occupation deposit by rubble grains was a likely cause of its high ages (e.g. David et al., 1997; Roberts, 1997). As a direct test of that proposition, we applied single-grain optical dating methods to a set of six sediment samples from the Jinmium deposit. The results were dramatic and unequivocal: the occupation deposit was much younger than had been suggested using TL, and the reason was that most of the grains in the deposit had not been sufficiently bleached by sunlight to reset their luminescence clocks (Roberts et al., 1998a, 1999). Some of the grains had very high ages, consistent with their being derived from rubble. A large proportion of 
grains were therefore buried with an appreciable 'inherited age' which gave rise to age overestimates using any multiple-grain method.

Nonetheless, the multiple-grain optical ages indicated that the deposit began to accumulate no more than 20000 years ago, ten times less than the TL age estimate for the basal deposit. The reason for this difference can be explained by the observation (Wintle, 1997; Aitken, 1998) that it takes only a few seconds or minutes to reset the OSL signal, whereas it takes many hours to reset the TL signal used by Fullagar et al. (1996). Hence, while the TL signal had been reduced only slightly, the OSL signal of many grains (but not those derived from rubble) had been mostly erased before burial.

A few quartz grains at Jinmium had been bleached sufficiently to reset completely the OSL signal before burial. These grains yield the most reliable optical ages, and they indicate that the entire deposit is less than 10000 years old (Roberts et al., 1998a, 1999). A Holocene antiquity fits also with geomorphological indications of a relatively young age, and with the ${ }^{14} \mathrm{C}$ chronology obtained using elemental carbon extracted from large $(>125 \mu \mathrm{m})$ pieces of charcoal (see below). It is also consistent with two reinterpretations of the published TL data for Jinmium (Roberts, 1997; Spooner, 1998), both of which concluded that the reported TL ages (Fullagar et al., 1996) were much too old.

With the redating of the Jinmium artefacts to the Holocene, the oldest dated human occupation sites in northern Australia remain those of Malakunanja II (Roberts et al., 1990) and Nauwalabila I (Roberts et al., 1994a). Both of the sites were first occupied around 50 000-60 000 years ago, the ages being derived from TL dating (Malakunanja II) and optical dating (Nauwalabila I) of multiple-grain subsamples. Since completing the Jinmium study, we have redated two key samples from the Malakunanja II deposit using the same single-grain optical dating methods. These optical ages confirm the previous TL ages for initial human occupation of Malakunanja II. Sediments from the level of the lowest artefact gave a TL age of $61000 \pm 10000$ years (Roberts et al., 1990; Roberts \& Jones, 1994), and multiplegrain and single-grain optical ages of $60700 \pm 7500$ and $55500 \pm 8200$ years, respectively (Roberts et al., 1998b). Importantly, the single-grain study at Malakunanja II indicated that neither sample was contaminated with rubble grains and that neither sample had experienced significant post-depositional disturbance (Roberts et al., 1998b).

Correspondence between the TL and optical ages at Malakunanja II was not unexpected. First, the bedrock in western Arnhem Land is much less friable than that at Jinmium, so the rate of release of rubble grains is much slower. Second, the lowest occupation horizon at Malakunanja II is separated $2 \mathrm{~m}$ vertically from the nearest rubble, so there is much less chance of incorporation of contaminant grains than at Jinmium, where the deposit was flanked by heavily weathered rubble. And third, the TL samples from Malakunanja II passed the 'plateau test' for adequacy of bleaching (Roberts et al., 1990), whereas those from Jinmium did not (Roberts, 1997; Spooner, 1998).

Single-grain optical dating at Nauwalabila I has been thwarted by the very low levels of OSL emitted by individual quartz grains. Until technical improvements allow such 'dim' grains to be examined, the multiple-grain optical ages of 53 000-60 000 years (Roberts et al., 1994a) provide the best 'age bracket' for initial occupation of this site. We consider these ages to be reliable because, as at Malakunanja II, the bedrock does not weather rapidly and both of the TL samples from the upper occupation levels passed the 'plateau test'. Another indication that rubble contamination is not a significant problem at Nauwalabila I is the close match obtained between the age of $60300 \pm 6700$ years for the basal sample in the rock shelter and the age of $58300 \pm 5800$ years for the homogeneous sand sample collected from the base of the neighbouring, rubble-free, sand apron (Roberts et al., 1994a: 582). The TL, optical and ${ }^{14} \mathrm{C}$ ages for the upper strata are in good agreement, and this concordance is reaffirmed by a new ${ }^{14} \mathrm{C}$ age determination of $19880 \pm 360$ years BP (ANU-10928) on charcoal collected from a depth of $1.5 \mathrm{~m}$ below the ground surface (excavation unit L29-46). This corresponds to a calibrated ${ }^{14} \mathrm{C}$ age of about 23800 years (Bard et al., 1993; Kitagawa \& van der Plicht, 1998) which is comfortably bracketed by optical ages of $13500 \pm 900$ years at $1.1 \mathrm{~m}$ depth and $30000 \pm 2400$ years at $1.7 \mathrm{~m}$ depth; it also fits with the 
expected age-depth correlation established previously for this part of the site (Roberts et al., 1994a).

At the present stage, therefore, we view the human colonisation of Australia as having taken place shortly after 60000 years ago, a result derived using a range of luminescence dating methods, including the latest single-grain techniques.

\section{Carbon Chronologies}

The comparison of luminescence and ${ }^{14} \mathrm{C}$ chronologies has been an integral part of our investigations since their inception in 1988 (Jones, 1989, 1998; Roberts, 1997). The basis of our work has always been to make dating cross-checks whenever feasible, but often this is not possible in northern Australia because of the lack of preservation of organic material in Pleistocene sandy deposits influenced by seasonal soil water movement. Such deposits include those at Malakunanja II and Nauwalabila I. The paucity of carbon in Pleistocene sediments is even more acute in geomorphological deposits in western Arnhem Land (e.g. Roberts, 1991; Murray et al., 1992; Nanson et al., 1993) - archaeological sites are, by comparison, rich in carbon. It was this phenomenon that prompted R.G.R. to contact R.J. in 1988 to undertake a comparison of TL and ${ }^{14} \mathrm{C}$ ages in western Arnhem Land, focusing on archaeological sites where ${ }^{14} \mathrm{C}$ ages extended back the farthest in time.

One of the drawbacks of ${ }^{14} \mathrm{C}$ dating, however, is the 'glass ceiling' at 30 000-40 000 years BP (Roberts et al., 1994b; Chappell et al., 1996). This 'event horizon' can extend further back under favourable conditions and is a function of a number of interacting variables, such as sample medium (e.g. wood, charcoal, shell, coral), preservation environment (e.g. acidic or alkaline, permanently/seasonally wet or dry), and pretreatment in the laboratory (e.g. acid-alkali-acid, oxidative degradation). In exposed sandy deposits across northern Australia, the glass ceiling is possibly at its lowest. Organic remains are subject to annual leaching by acidic monsoonal rainfall, to oxidative processes, and to the activities of tropical soil fauna, resulting in poor preservation of organic matter and charcoal. Hence, as we have argued for several years (Jones, 1982, 1989, 1998; Roberts et al., 1994b), ${ }^{14} \mathrm{C}$ ages of $30000-40000$ years BP should conservatively be viewed as being that age or older.

Others (principally Allen \& Holdaway, 1995, and O'Connell \& Allen, 1998) instead prefer to view all ${ }^{14} \mathrm{C}$ ages as being the quoted age, and, as no ${ }^{14} \mathrm{C}$ ages significantly greater than 40000 years BP have thus far been reported from archaeological sites in Australia, they see the initial human colonisation of the continent as having taken place within the last 40000 years. To bolster their claim, they point out that ${ }^{14} \mathrm{C}$ ages in excess of 40000 years BP have been obtained at some geomorphological (i.e. nonoccupation) sites, and that samples of this age should also be found at archaeological sites if any are older than 40000 years BP.

There are a number of misconceptions in this approach that we should discuss briefly. First, ${ }^{14} \mathrm{C}$ ages require calibration for changes in the production rate of radiocarbon in the upper atmosphere that have occurred during the Quaternary. The addition of a few millennia is required to calibrate ${ }^{14} \mathrm{C}$ ages in the range 30 000-40 000 years BP (e.g. Guyodo \& Valet, 1996; Laj et al., 1996; Vogel \& Kronfeld, 1997; Frank et al., 1997; Kitagawa \& van der Plicht, 1998), so an uncalibrated age of 40000 years BP probably corresponds to a calendar-year age in the range $42000-47000$ years - not the '40 000 years' commonly quoted, as in, for example, "A 35000 to 40000 year date for initial occupation of Greater Australia ..." (O’Connell \& Allen, 1998: 132).

Second, the use of simple ${ }^{14} \mathrm{C}$ age-frequency distributions to infer general patterns of human occupation is hazardous. This point has been well made by Chappell et al. (1996) who dissect the data and conclusions of Allen \& Holdaway (1995) and find them wanting because they do not adequately account for the many possible causes of ${ }^{14} \mathrm{C}$ age-frequency distributions. Unfortunately, O'Connell \& Allen (1998) largely ignore the critique of Chappell et al. (1996). Age-frequency distributions, as employed by Allen and colleagues, are prone to distortion because of the inclusion of ${ }^{14} \mathrm{C}$ ages of different qualities. For example, ${ }^{14} \mathrm{C}$ ages of more than 40000 years BP from geomorphological sites 
often grossly underestimate the true age of the deposit (see Chappell et al., 1996).

Third, the approach taken by Allen \& Holdaway (1995) makes no distinction between different environments of sample preservation. A pertinent question, but one not asked by Allen and colleagues, is: Have any geomorphological sites in western Arnhem Land been discovered that have yielded ${ }^{14} \mathrm{C}$ ages in excess of 40000 years BP? The answer, to the best of our knowledge, is No. Wetlands may preserve charcoal for long periods of time (and, indeed, are responsible for most of the ages of $>40000$ years BP reported by Allen \& Holdaway, 1995, for geomorphological sites), but we doubt that any sand apron in the region will yield charcoal of this age because they are unfavourable biogeochemical environments for the long-term preservation of charcoal. Hence, we do not expect charcoal to be retained in the 50 000-60 000 year-old levels of the sand apron deposits at Malakunanja II or Nauwalabila I.

But as a direct test of our hypothesis, we have been collaborating with Michael Bird at The Australian National University, who has developed a method to extract the elemental carbon from sediments (Bird \& Gröcke, 1997; Bird \& Cali, 1998). With this technique, organic carbon and incompletely carbonised material is removed, leaving only the oxidation-resistant elemental carbon, produced by combustion, for ${ }^{14} \mathrm{C}$ dating. By comparison, standard acid-alkali-acid sample pretreatment may result in the incomplete removal of contaminants such as humic and fulvic acids. Pretreatment of samples from a number of archaeological sites is underway, including key samples from Malakunanja II and Nauwalabila I. We note in passing that Gillespie (1997) has independently developed a similar oxidative degradation pretreatment to distinguish between burnt and unburnt carbon. He has applied it to charcoal and burnt bone from the important Willandra Lakes region in southeastern Australia and has obtained significantly younger ${ }^{14} \mathrm{C}$ ages than previous determinations based on less rigorous sample pretreatments.

There are possible problems associated with post-depositional disturbance of sediments and any charcoal fragments contained therein. One of the important findings of the single-grain OSL studies at Jinmium (Roberts et al., 1998a, 1999) and Malakunanja II (Roberts et al., 1998b) is our ability to detect grains that have been displaced into older deposits from younger (overlying) strata. In both studies we used quartz grains of 90-125 $\mu \mathrm{m}$ diameter for optical dating and, at both sites, a small number of grains were found to have intruded into older deposits. This observation has serious implications for ${ }^{14} \mathrm{C}$ dating of composite samples because if individual fragments of charcoal are also mobile then a composite sample may contain contaminant fragments that could distort the ${ }^{14} \mathrm{C}$ age. The isolation of elemental carbon removes one source of uncertainty in ${ }^{14} \mathrm{C}$ dating - chemical contamination of samples - but it does not diminish the potential for physical displacement of charcoal fragments.

To avoid this problem, it is necessary to sample charcoal from intact hearths. For example, large lumps of charcoal are found in well preserved hearths at Ngarrabullgan Cave in north Queensland, so that physical displacement is not at issue. Elemental carbon from one of these hearths yielded a ${ }^{14} \mathrm{C}$ age of $35500 \pm 600$ years BP, in good accord with 20 other ${ }^{14} \mathrm{C}$ age determinations and with optical ages for the adjacent unheated sediments (David et al., 1997; Roberts et al., 1998a). But when charcoal fragments are finely dispersed through sediments, as at Jinmium, we have concentrated on extracting fragments of $>125 \mu \mathrm{m}$ for ${ }^{14} \mathrm{C}$ dating. These should be affected less than smaller fragments by the movement of soil water and they may also be less prone to disturbance by the activities of soil invertebrates, although even large particles are subject to bioturbation and transport through soil voids (e.g. Paton et al., 1995).

At Jinmium, we obtained ${ }^{14} \mathrm{C}$ ages from elemental carbon extracted from $>125 \mu \mathrm{m},<125 \mu \mathrm{m}$, and mixed-size charcoal fragments (Roberts et al., 1998a). The $>125 \mu \mathrm{m}$ fraction gave the most reliable ${ }^{14} \mathrm{C}$ chronology, and indicated that the top half (upper metre) of the occupation deposit had accumulated since about 3000 years BP, in close agreement with the single-grain optical ages for these strata. By contrast, the elemental carbon extracted from the $<125 \mu \mathrm{m}$ and mixed-size fragments sometimes produced anomalous ${ }^{14} \mathrm{C}$ ages. As chemical contamination can be discounted as a cause, then physical displacement of the fine fraction seems the most probable explanation. 


\section{Conclusions}

The combination of single-grain optical dating and ${ }^{14} \mathrm{C}$ dating of elemental carbon from large charcoal fragments offers a powerful new tool to explore the integrity of archaeological deposits, and to obtain a more robust chronology than has hitherto been possible.

Applications so far attempted include the redating of the rock shelter deposits at Jinmium, Malakunanja II and Allen's Cave. The Jinmium sediments were dated to less than 10000 years, compared with the TL ages of more than 100000 years (Roberts et al., 1998a, 1999), whereas the TL ages of 50 000-60 000 years for initial occupation of Malakunanja II have been confirmed by singlegrain optical dating (Roberts et al., 1998b). Optical dating of individual grains from Allen's Cave also gave ages in accord with the existing TL and OSL chronology, and with ${ }^{14} \mathrm{C}$ ages on charcoal from a 10000 year-old hearth (Murray \& Roberts, 1997). Construction of elemental carbon ${ }^{14} \mathrm{C}$ records for Allen's Cave, Malakunanja II and other archaeological sites is in progress, as the natural extension to the cross-dating approach that we have advocated and applied over the past decade.

\section{Addendum}

Since this paper was written, the results of two studies have been published that are relevant to the timing of the human colonisation of Australia.

In the first study, a combination of electron-spin resonance and uranium-series determinations was used to infer an age of $62000 \pm 6000$ years for the Mungo III human skeleton from the Willandra Lakes region (Simpson \& Grün, 1998; Thorne et al., 1999). This skeleton, however, is dug into sediments that were deposited no earlier than $61000 \pm 2000$ years ago, based on optical dating of multiple-grain subsamples (Thorne et al., 1999). The latter estimate provides a maximum age for the skeleton. Even this limit, however, is much older than the TL ages of 42 000-45 000 years obtained previously for the sediments into which the body was inserted (Oyston, 1996; Bowler \& Price, 1998). It is possible that the optical ages are too old because the sediments dated by Thorne et al. (1999) had been insufficiently bleached before burial (Olley \& Spooner, 1999).

A number of concerns have been raised that the dating methods used by Thorne et al. (1999), and the stratigraphic correlations made by them, are subject to uncertainties that could give rise to a much younger age for the Mungo III human remains (Gillespie \& Roberts, 2000; Bowler \& Magee, 2000). Further work is therefore needed to test the validity of these claims, and to determine the age of the numerous stone artefacts found in situ in the underlying Lower Mungo sediments (Bowler, 1998).

In the second study, amino acid racemization ratios were measured for eggshells of emu and Genyornis newtoni (a giant flightless bird) collected from deposits in the arid and semi-arid parts of southeastern Australia (Miller et al., 1999). The rate of racemization was calibrated by direct $\left({ }^{14} \mathrm{C}\right.$ and uranium-series) dating of the eggshell and by multiple-grain optical dating of the associated sediments. These analyses indicated that G. newtoni disappeared suddenly from this region $50000 \pm 5000$ years ago. As climate change during this period was modest, Miller et al. (1999) interpreted this extinction event as being due to the ecological impact of the first humans to colonise this region.

There seems now, therefore, to be a convergence of evidence from a variety of sites in Australia that points to human arrival shortly after 60000 years ago.

\section{Acknowledgements}

We thank an anonymous referee for comments, and R.G.R. acknowledges the receipt of a Queen Elizabeth II Fellowship from the Australian Research Council.

\section{References}

Aitken, M.J. (1998). An Introduction to Optical Dating. Oxford: Oxford University Press.

Allen, J. \& Holdaway, S. (1995). The contamination of Pleistocene radiocarbon determinations in Australia. 
Antiquity, 69, 101-12.

Bard, E., Arnold, M., Fairbanks, R.G. \& Hamelin, B. (1993). ${ }^{230} \mathrm{Th}-{ }^{234} \mathrm{U}$ and ${ }^{14} \mathrm{C}$ ages obtained by mass spectrometry on corals. Radiocarbon, 35, 191-99.

Bird, M.I. \& Cali, J.A. (1998). A million-year record of fire in sub-Saharan Africa. Nature, 394, 767-69.

Bird, M.I. \& Gröcke, D.R. (1997). Determination of the abundance and carbon isotope composition of elemental carbon in sediments. Geochimica et Cosmochimica Acta, 61, 3413-23.

Bowler, J.M. (1998). Willandra Lakes revisited: environmental framework for human occupation. Archaeology in Oceania, 33, 120-55.

Bowler, J.M. \& Magee, J.W. (2000). Redating Australia's oldest human remains: a sceptic's view. Journal of Human Evolution, 38, 719-26.

Bowler, J.M. \& Price, D.M. (1998). Luminescence dates and stratigraphic analyses at Lake Mungo: review and new perspectives. Archaeology in Oceania, 33, 156-68.

Chappell, J., Head, J. \& Magee, J. (1996). Beyond the radiocarbon limit in Australian archaeology and Quaternary research. Antiquity, 70, 543-52.

David, B., Roberts, R., Tuniz, C., Jones, R. \& Head, J. (1997). New optical and radiocarbon dates from Ngarrabullgan Cave, a Pleistocene archaeological site in Australia: implications for the comparability of time clocks and for the human colonization of Australia. Antiquity, 71, 183-88.

Dubois, E. (1894). Pithecanthropus erectus: eine Menschenaehnliche Uebergangsform aus Java. Batavia: Landesdruckerei.

Frank, M., Schwarz, B., Baumann, S., Kubik, P.W., Suter, M. \& Mangini, A. (1997). A 200 kyr record of cosmogenic radionuclide production rate and geomagnetic field intensity from ${ }^{10} \mathrm{Be}$ in globally stacked deep-sea sediments. Earth and Planetary Science Letters, 149, 121-29.

Frayer, D.W., Wolpoff, M.H., Thorne, A.G., Smith, F.H. \& Pope, G.G. (1994). Getting it straight. American Anthropologist, 96, 424-38.

Fullagar, R.L.K., Price, D.M. \& Head, L.M. (1996). Early human occupation of northern Australia: archaeology and thermoluminescence dating of Jinmium rock-shelter, Northern Territory. Antiquity, 70, 751-73.

Gillespie, R. (1997). Burnt and unburnt carbon: dating charcoal and burnt bone from the Willandra Lakes, Australia. Radiocarbon, 39, 225-36.

Gillespie, R. \& Roberts, R.G. (2000). On the reliability of age estimates for human remains at Lake Mungo. Journal of Human Evolution, 38, 727-32.

Guyodo, Y. \& Valet, J-P. (1996). Relative variations in geomagnetic intensity from sedimentary records: the past 200,000 years. Earth and Planetary Science Letters, 143, 23-36.

Jones, R. (1982). Ions and eons: some thoughts on archaeological science and scientific archaeology. In: Archaeometry: An Australasian Perspective, ed. W. Ambrose \& P. Duerden, Occasional Papers in Prehistory 12, pp. 22-35. Canberra: Department of Prehistory, Research School of Pacific Studies, The Australian National University.

Jones, R. (1989). East of Wallace's line: issues and problems in the colonisation of the Australian continent. In: The Human Revolution: Behavioural and Biological Perspectives on the Origins of Modern Humans, ed. P. Mellars \& C. Stringer, pp. 743-82. Edinburgh: Edinburgh University Press.

Jones, R. (1998). Dating the human colonization of Australia: radiocarbon and luminescence revolutions. Proceedings of the British Academy, 99, 37-65.

Kitagawa, H. \& van der Plicht, J. (1998). Atmospheric radiocarbon calibration to 45,000 yr BP: late glacial fluctuations and cosmogenic isotope production. Science, 279, 1187-90.

Klein, R.G. (1995). Anatomy, behavior, and modern human origins. Journal of World Prehistory, 9, 167-98.

Laj, C., Mazaud, A. \& Duplessy, J-C. (1996). Geomagnetic intensity and ${ }^{14} \mathrm{C}$ abundance in the atmosphere and ocean during the past 50 kyr. Geophysical Research Letters, 23, 2045-48.

Leavesley, M. \& Allen, J. (1998). Dates, disturbance and artefact distributions: another analysis of Buang Merabak, a Pleistocene site on New Ireland, Papua New Guinea. Archaeology in Oceania, 33, 63-82.

Miller, G.H., Magee, J.W., Johnson, B.J., Fogel, M.L., Spooner, N.A., McCulloch, M.T. \& Ayliffe, L.K. (1999). Pleistocene extinction of Genyornis newtoni: human impact on Australian megafauna. Science, 283, $205-08$.

Morwood, M.J., O’Sullivan, P.B., Aziz, F. \& Raza, A. (1998). Fission-track ages of stone tools and fossils on the east Indonesian island of Flores. Nature, 392, 173-76.

Murray, A.S. \& Roberts, R.G. (1997). Determining the burial time of single grains of quartz using optically stimulated luminescence. Earth and Planetary Science Letters, 152, 163-80.

Murray, A., Wohl, E. \& East, J. (1992). Thermoluminescence and excess ${ }^{226}$ Ra decay dating of late Quaternary fluvial 
sands, East Alligator River, Australia. Quaternary Research, 37, 29-41.

Nanson, G.C., East, T.J. \& Roberts, R.G. (1993). Quaternary stratigraphy, geochronology and evolution of the Magela Creek catchment in the monsoon tropics of northern Australia. Sedimentary Geology, 83, 277-302.

O'Connell, J.F. \& Allen, J. (1998). When did humans first arrive in Greater Australia and why is it important to know? Evolutionary Anthropology, 6, 132-46.

O'Connor, S. (1995). Carpenter's Gap Rockshelter 1: 40,000 years of Aboriginal occupation in the Napier Ranges, Kimberley, WA. Australian Archaeology, 40, 58-59.

Olley, J.M. \& Spooner, N.A. (1999). A short note on optically stimulated luminescence determinations on $1 \mathrm{~mm}$ single aliquots of samples from Lake Mungo. Canberra: CSIRO Land \& Water, Technical Report 6/98.

Oyston, B. (1996). Thermoluminescence age determinations for the Mungo III human burial, Lake Mungo, southeastern Australia. Quaternary Science Reviews (Quaternary Geochronology), 15, 739-49.

Paton, T.R., Humphreys, G.S. \& Mitchell, P.B. (1995). Soils: A New Global View. London: University College London Press.

Roberts, R.G. (1991). Sediment budgets and Quaternary history of the Magela Creek catchment, tropical northern Australia. Unpublished Ph.D thesis, University of Wollongong [and Open File Record 80. Sydney: Supervising Scientist for the Alligator Rivers Region].

Roberts, R.G. (1997). Luminescence dating in archaeology: from origins to optical. Radiation Measurements, 27, $819-92$.

Roberts, R.G. \& Jones, R. (1994). Luminescence dating of sediments: new light on the human colonisation of Australia. Australian Aboriginal Studies, 1994/2, 2-17.

Roberts, R.G., Jones, R. \& Smith, M.A. (1990). Thermoluminescence dating of a 50,000 year-old human occupation site in northern Australia. Nature, 345, 153-56.

Roberts, R.G., Jones, R., Spooner, N.A., Head, M.J., Murray, A.S. \& Smith, M.A. (1994a). The human colonisation of Australia: optical dates of 53,000 and 60,000 years bracket human arrival at Deaf Adder Gorge, Northern Territory. Quaternary Science Reviews (Quaternary Geochronology), 13, 575-83.

Roberts, R.G., Jones, R. \& Smith, M.A. (1994b). Beyond the radiocarbon barrier in Australian prehistory. Antiquity, 68, 611-16.

Roberts, R., Walsh, G., Murray, A., Olley, J., Jones, R., Morwood, M., Tuniz, C., Lawson, E., Macphail, M., Bowdery, D. \& Naumann, I. (1997). Luminescence dating of rock art and past environments using mud-wasp nests in northern Australia. Nature, 387, 696-99.

Roberts, R., Bird, M., Olley, J., Galbraith, R., Lawson, E., Laslett, G., Yoshida, H., Jones, R., Fullagar, R., Jacobsen, G. \& Hua, Q. (1998a). Optical and radiocarbon dating at Jinmium rock shelter in northern Australia. Nature, 393, 358-62.

Roberts, R., Yoshida, H., Galbraith, R., Laslett, G., Jones, R. \& Smith, M. (1998b). Single-aliquot and single-grain optical dating confirm thermoluminescence age estimates at Malakunanja II rock shelter in northern Australia. Ancient TL, 16, 19-24.

Roberts, R.G., Galbraith, R.F., Olley, J.M., Yoshida, H. \& Laslett, G.M. (1999). Optical dating of single and multiple grains of quartz from Jinmium rock shelter, northern Australia: Part II, results and implications. Archaeometry, 41, 365-95.

Simpson, J.J. \& Grün, R. (1998). Non-destructive gamma spectrometric U-series dating. Quaternary Science Reviews (Quaternary Geochronology), 17, 1009-22.

Smith, M.A. \& Sharp, N.D. (1993). Pleistocene sites in Australia, New Guinea and Island Melanesia: geographic and temporal structure of the archaeological record. In: Sahul in Review: Pleistocene Archaeology in Australia, New Guinea and Island Melanesia, ed. M.A. Smith, M. Spriggs \& B. Fankhauser, Occasional Papers in Prehistory 24, pp. 37-59. Canberra: Department of Prehistory, Research School of Pacific Studies, The Australian National University.

Smith, M.A., Prescott, J.R. \& Head, M.J. (1997). Comparison of ${ }^{14} \mathrm{C}$ and luminescence chronologies at Puritjarra rock shelter, central Australia. Quaternary Science Reviews (Quaternary Geochronology), 16, 299-320.

Spooner, N.A. (1998). Human occupation at Jinmium, northern Australia: 116,000 years ago or much less? Antiquity, 72, 173-78, 251-52.

Thorne, A., Grün, R., Mortimer, G., Spooner, N.A., Simpson, J.J., McCulloch, M., Taylor, L. \& Curnoe, D. (1999). Australia's oldest human remains: age of the Lake Mungo 3 skeleton. Journal of Human Evolution, 36, 591-612.

Vogel, J.C. \& Kronfeld, J. (1997). Calibration of radiocarbon dates for the Late Pleistocene using U/Th dates on stalagmites. Radiocarbon, 39, 27-32. 
Wintle, A.G. (1996). Archaeologically-relevant dating techniques for the next century. Journal of Archaeological Science, 23, 123-38.

Wintle, A.G. (1997). Luminescence dating: laboratory procedures and protocols. Radiation Measurements, 27, 769-817. 


\section{Henry P. Schwarcz}

School of Geography and Geology, McMaster University, Hamilton, Ontario, L8S $4 M 1$ Canada

Keywords: U-series, uranium, thorium, isotopes, electron spin resonance, radiocarbon, speleothems, enamel, cementum, dentine, gamma rays, Qafzeh, Mungo

\section{Dating Bones and Teeth: The Beautiful and the Dangerous}

\begin{abstract}
Mammalian faunal bones and teeth are a common component of most archaeological sites. They apear to provide a suitable subject for determination of chronological age by a variety of different methods including radiocarbon, uranium-series dating and electron spin resonance. We find, however, that application of these methods is fraught with difficulty, espescially due to the unstable nature of bones, and their tendency to be altred diagenetically during their burial history. Limitations and prospects for the application of chronometric dating methods to bones are discussed.
\end{abstract}

\section{Introduction}

In our efforts to determine the age of prehistoric sites, we are constantly seeking materials at sites whose chronology could provide us with evidence as to the time of occupation of the site. Amongst the various materials which are revealed during the excavation of such sites, the skeletal remains of animals and humans would seem to offer an ideal target for dating. Many of these skeletal remains can be clearly demonstrated to be coeval with the occupation of the site. Indeed, their presence at the site or in particular stratigraphic layers of a site is often the critical evidence needed to demonstrate that the site was occupied, especially when bones appear to have been 'processed' by hominids, often with the aid of spatially associated lithic artifacts.

Skeletal remains would seem to be ideal for dating for further reasons. First, they are materials which came into existence shortly before the occupation of the site, and therefore we can be assured that an accurate date obtained on such a material would be a good age estimate for a layer in the site; this is clearly not the case for other materials brought into the site by humans, such as lithic raw materials or artefacts. Secondly, bones and teeth are composed of combinations of chemical systems which offer a variety of potential chronologic indicators. We can think of a piece of bone as being a set of 'clocks' each of which was set to read zero time at the time the bone was deposited at the site. We can therefore obtain a number of different readings on the age of the bone by taking a reading on each independent clock at the time that the bone is brought back to the laboratory.

But, as the title of this article implies, there are some risks involved in analysing these fascinating, and sometimes beautiful, relics of past human activity (amongst which we may count the skeletal remains of some hominids themselves). The essence of the problem lies in the well known characteristic that distinguishes a modern bone from one recovered from a site: the latter is typically described as having been 'fossilized'. This is a rough-and-ready term that sums up a large number of transformations that have affected the bone since it was buried. These include processes of biological decay that alter the organic constituents present in living bone, as well as inorganic transformations that reorganize the crystalline ('mineral') part of bone. These processes are progressive, that is, have taken place over some time span which may be quite long and comparable to the time elapsed since the bone was buried. On 
the other hand, we may be fortunate in that the fossilization process essentially terminated soon after the time of burial, in which case we can think of the readout of the 'clocks' in that bone as being not significantly different from the age of the site. However, we are often not so fortunate: dates obtained on bones can be seriously in error. We must appreciate that bones and teeth are formed in a specialized biological environment. Once they are removed from that environment at the death of the organism, they are thrust into chemically, physically and biologically different conditions. The constituents of the bone immediately begin to change as they equilibrate with the external environment, and this process will disrupt the 'ticking' of the clocks which we wish to use.

\section{'Clocks' in teeth and bones}

As I have indicated, teeth and bones have the potential for providing a wide variety of chronometric data which arise from processes acting on many different constituents of these tissues. I will describe each one, and briefly summarize their utility and their limitations.

\section{Radiocarbon}

The best known, and in some respects most reliable, timepiece present in bones (and to a lesser extent in teeth) is the decay of atoms of radiocarbon, ${ }^{14} \mathrm{C}$, that were incorporated into the collagen of the bone from the diet of the animal. Although carbonate molecules are also present as constituents of bone mineral (apatite) they are generally not considered to be reliable for radiocarbon dating because of the tendency of bone mineral to re-equilibrate with dissolved carbonate in groundwater. Collagen is a complex biochemical molecule, a protein that can only be synthesized by animals. Therefore, if it can be cleanly extracted from the bone, it provides an excellent substrate for ${ }^{14} \mathrm{C}$ dating. The techniques for extraction and purification of bone collagen have been laid out by various authors (e.g., Longin, 1971; Collins \& Galley, 1998). Stafford et al. (1991) have shown that different modes of extraction of collagen can result in significantly different dates, and there is no absolutely reliable technique to guarantee that the carbon recovered is just that of the original animal and not contaminated by modern carbon. In relation to the study of human evolution, we note that the maximum age that can be accurately determined by the ${ }^{14} \mathrm{C}$ method is about $45000 \mathrm{y} \mathrm{(45} \mathrm{ka).} \mathrm{This} \mathrm{is} \mathrm{due} \mathrm{to} \mathrm{the} \mathrm{relatively} \mathrm{short} \mathrm{half-life} \mathrm{of}$ ${ }^{14} \mathrm{C}(5740 \mathrm{y})$ as a result of which $99 \%$ of the original dose of radiocarbon in a bone has decayed by 45 ka after the death of the animal. Most of human evolution was complete by this date: anatomically modern humans flourished in Europe and Asia, and Neanderthals were close to extinction.

Unfortunately there is a temptation to push the radiocarbon method beyond its experimental limits when dating earlier hominid sites. Many sites which are now known to date to $>100$ ka once also yielded finite radiocarbon ages; for example Schwarcz \& Skoflek (1978) showed that the Hungarian travertine site of Tata dated to $100 \mathrm{ka}$, while earlier studies had obtained finite ${ }^{14} \mathrm{C}$ dates on bones from the site. Less than $1 \%$ of modern carbon mixed into an infinite-age sample will cause it to give a finite (c. $45 \mathrm{ka}$ ) age.

A further limitation on the applicability of radiocarbon to bones is the disappearance of collagen from bones due to decay. Bacteria and fungi catabolize collagen; the 'half-life' of collagen in some regions is a few thousand years, and bones whose age is well within the time-range of radiocarbon dating are found to have no collagen remaining in them. This statement appears to be widely applicable to bones from the Levant (Weiner \& Bar-Yosef, 1992).

\section{Amino acid racemization (AAR)}

Collagen is a protein composed of amino acids (AA), all but one of which are optically active. That is, they can occur in a D- and L-form, which are mirror images of one another. Only L-amino acids are present 
in living tissues, but D-forms can be spontaneously generated by racemization after the animal's death. Therefore the $\mathrm{D} / \mathrm{L}$ ratio is a measure of the time elapsed since death. The half-life of the racemization process depends on temperature, on the specific AA, and to some extent on its position in the protein molecule. Attempts to date bones using AAR have not been very successful, possibly because the racemization rate is too dependent on the specific conformation of the collagen molecule and therefore must be calibrated for each bone type separately. Blackwell et al. (1990) found generally poor agreement between AAR dates on bones and U-series dates on speleothems from the same site. Currently, AAR is not considered to be a viable technique for bones although it has considerable potential as a method of assigning relative ages to mollusc shells and ratite egg shells (Brooks et al., 1990). Hare et al. (1997) give a well-balanced outlook on the prospects for AAR dating of bones, and conclude that it is not very reliable by itself, although it may provide additional insights when combined with other dating methods.

\section{Uranium series dating}

One of the earliest attempts to date older animal and human bones was that devised by Oakley (1975), which he described as the 'FUN method': the letters stand for fluorine, uranium and nitrogen. Two of these elements (fluorine, uranium) were found to increase in bone with time since burial, while nitrogen (in the form of collagen) decreased. The increase in $U$ was presumed to be due to the gradual uptake of $U$ by the bone as it lay buried in the ground. Much of the apparent increase in $U$ content of bones which Oakley observed turns out to have been an accident of the method of analysis, namely, the counting of the beta-particle activity of the bones. This principally reflects the growth of the daughter isotope thorium-230 $\left({ }^{230} \mathrm{Th}\right)$ from its parent ${ }^{234} \mathrm{U}$, since the former emitted only feeble beta activity, whereas the latter, together with its daughter isotopes, is a strong beta emitter. Bones absorb uranium from the soil or sediment in which they are buried, but the daughter isotope ${ }^{230} \mathrm{Th}$ is relatively insoluble and is not absorbed. As $U$ is adsorbed onto bone decays, it produces a new crop of ${ }^{230} \mathrm{Th}$ whose radioactivity level gradually rises to equal that of the parent $U$. This process reaches a steady-state after about 500000 years, after which ${ }^{230} \mathrm{Th}$ is decaying as fast as it is being produced. Up to that date, the age of the bone can, in principle, be determined from the ${ }^{230} \mathrm{Th} /{ }^{234} \mathrm{U}$ ratio of the bone. However, that ratio depends not only on the age but also on when $U$ was absorbed by the bone. If the $U$ present in the bone today was taken up soon after burial, then the apparent age will agree well with the true age of the bone. This is described as the 'early uptake' (EU) scenario. Szabo (1980) for example showed that for many sites on the Great Plains of the United States, the ${ }^{14} \mathrm{C}$ and ${ }^{230} \mathrm{Th} /{ }^{234} \mathrm{U}$ ages of bones agreed, indicating that EU had occurred. On the other hand, we have many examples of sites where comparison between Useries analyses of bones and other more reliable criteria indicate that longer-term U-uptake must have occurred, leading to errors in ${ }^{230} \mathrm{Th} /{ }^{234} \mathrm{U}$ dates on bone (e.g., Ayliffe \& Veeh, 1988).

We refer to ${ }^{230} \mathrm{Th} /{ }^{234} \mathrm{U}$ ages as uranium series ages because ${ }^{234} \mathrm{U}$ and ${ }^{230} \mathrm{Th}$ are the second and fifth in a series of radio-isotopes that form as a result of the decay of the parent isotope ${ }^{238} \mathrm{U}$. These two daughter isotopes have sufficiently long half-lives (248 and $75 \mathrm{ka}$ respectively) that they are useful for dating prehistoric deposits. Another isotope, protactinium-231 $\left.{ }^{231} \mathrm{~Pa}\right)$, the 31 ka-half-life daughter of ${ }^{235} \mathrm{U}$, is also useful although of much lower abundance and therefore harder to detect with accuracy.

The growth of these daughter isotopes is measured by a number of different analytical methods: 1) alpha-particle spectrometry; 2) thermal ionization mass spectrometry (TIMS); or 3) gamma-ray counting.

The first two methods are destructive, and require that we first dissolve the sample of bone and extract the thorium and uranium from it (Schwarcz \& Blackwell, 1991). Gamma ray analysis is non-destructive and therefore has the advantage that it can be used to analyse museum specimens of hominid remains (Simpson \& Grün, 1998). The range of these methods is up to c. $500 \mathrm{ka}$, which is determined by the point 
at which the activity of the daughter reaches that of its parent (e.g., $\left.{ }^{230} \mathrm{Th} /{ }^{234} \mathrm{U}=1.00\right)$. On the other hand, the accuracy of the dates is highly dependent on knowledge of the uranium uptake history of the sample. Two samples exhibiting the same ratio of parent to daughter (e.g., $\left.{ }^{230} \mathrm{Th} /{ }^{234} \mathrm{U}\right)$ may have ages which differ by a factor of two or more depending on their U-uptake histories. In general, the EU age is the youngest age that can be inferred from a given ${ }^{230} \mathrm{Th} /{ }^{234} \mathrm{U}$ ratio. Where the ${ }^{231} \mathrm{~Pa} /{ }^{235} \mathrm{U}$ ratio has also been determined in a bone sample, it is often found that this ratio has reached its maximum value (1.0) while the ${ }^{230} \mathrm{Th} /{ }^{234} \mathrm{U}$ ratio is still significantly less than 1.0. This suggests (but does not prove) that the sample absorbed most of its $U$ early in its history since, if $U$ uptake had gone on continuously after burial, neither ratio would attain its limiting ratio (J. J. Simpson, pers. comm., 1999). For a series of coeval samples whose initial ${ }^{234} \mathrm{U} /{ }^{238} \mathrm{U}$ ratio was the same, we can use the relation between ${ }^{230} \mathrm{Th} /{ }^{234} \mathrm{U}$ and ${ }^{234} \mathrm{U} /{ }^{238} \mathrm{U}$ to determine the Uuptake history in a continuum from EU to linear uptake, that is, where the bone has absorbed the same amount of $U$ every year from the time of burial.

\section{ESR dating}

The last method we shall describe is the use of electron spin resonance (ESR) spectrometry to determine the age of a bone or, more commonly, a mammalian tooth from an archaeological site. Teeth and bones buried in sites are exposed to radioactivity from the surrounding sediment and cosmic rays, as well as radiation from $U$ atoms absorbed in the tooth. This radiation knocks electrons off atoms of the tooth, and some of the electrons are then trapped at certain locations in the crystals which make up the tooth. Although these trapped electrons are unstable and will eventually recombine with atoms, they persist in these traps for long times (hundreds of millions of years). Thus we can use the slow buildup of electrons as a clock. The presence of the trapped electrons is visualized by placing them in an electron spin resonance spectrometer, where a characteristic peak is seen, whose height is proportional to the number of trapped electrons. For a description of the methods of ESR dating of tooth enamel, see Rink (1998). The age is determined from the ratio of the number of trapped electrons to the rate at which they are being trapped, which is basically determined by the radioactivity of the sample and its enviroment. This rate depends to a large extent on the $\mathrm{U}$ content of the tooth, and therefore also on the U uptake history, as already discussed in the case of U-series dating. For any given set of data, the earliest (youngest) possible age is that assuming EU, while a linear uptake model would result in age about twice that of EU.

Although ESR dating suffers from some of the same problems of U-series dating, namely uncertainty about U-uptake history, this problem can be partly alleviated by simultaneously determining the U-series and ESR ages of a tooth. Since both measurements depend on the U uptake history, the two data sets can be used to determine the uptake history of the sample (Grün et al., 1988). For example, if the EU U-series age and the EU ESR age agree, then we know that the tooth must have experienced early uptake of U. In general, the U-series (EU) age may be younger than the EU ESR age, in which case some mode of continuous $U$ uptake must have occurred; for example, the tooth may have taken up $\mathrm{U}$ at a constant rate, a condition which is described as linear uptake (LU). A complete model calculation using U-series and ESR data has been devised, called 'Rosy' (Brennan et al., 1997), and is available on request from the author.

\section{Examples and Problems}

As I indicated at the outset, bones are common constituents of archaeological sites. They are attractive features that tempt the archaeologist or prehistorian to submit them for some sort of dating analysis. Therefore, we find many examples in the literature where the various methods of dating of bones described above have been tested at archaeological sites with variable degrees of success. I shall 
give a few selected examples, to show the potential of these methods.

\section{ESR dating of hominids from South Africa:}

ESR dating has been applied to a number of South African sites, principally those at which anatomically modern humans or related hominids had been found. These include the site of Border Cave (Grün et al., 1990a) and Klasies River Mouth Cave (Grün et al., 1990b), where ages in the range from 120 to $60 \mathrm{ka}$ were obtained, demonstrating the antiquity of modern humans in South Africa. At the other extreme in the study of hominid chronology, Schwarcz et al. (1994) analysed tooth enamel from Sterkfontein and showed that ESR signals in the teeth were far from saturation, and gave apparent ages of the order of 2.3 million years (assuming linear uptake of uranium).

The site of Florisbad, near Bloemfontein, was studied by Grün et al. (1996). Using a new method devised by Grün, they were able to obtain a date on one of the hominid teeth from the site: $259 \pm 35 \mathrm{ka}$. This age appeared to the authors to be consistent with the mixture of modern and archaic characteristics displayed by the hominid. This study demonstrates the remarkable versatility of the ESR dating method which allows us to do non-destructive dates on single human teeth.

Research at the site of Die Kelders in the southern Cape has also yielded some evidence of the former presence of humans (Avery et al., 1997). ESR dating of teeth from this site has shown that the entire thickness of the sedimentary fill at this site, containing MSA artefacts and some skeletal remains believed to be of anatomically modern humans, was deposited over a period of less than $10000 \mathrm{y}$, probably centered around $72.1 \pm 1.5 \mathrm{ka}$ (Schwarcz \& Rink, 1999).

\section{ESR dating in other regions}

This dating method has now been recognized as a major tool in the study of human evolution over the time scale up to at least 2 Ma. ESR dating laboratories now exist in many countries, including China, Australia, Britain, France, Canada and the U.S. A recent survey of the application of ESR in archaeology and palaeo-anthropology (Rink, 1998) lists over 60 published studies presenting dates for sites. Because tooth enamel is an almost ubiquitous component of archaeological sites of all ages, ESR dating provides the widest access of any dating method to prehistoric chronology. However an overview of these published studies reveal certain consistent hazards that must be considered when turning to ESR dating.

As has already been emphasized, the interpretation of a given set of data (equivalent doses based on ESR intensities; external dose rates; internal $U$ content of enamel and dentine) can be read as a range of possible dates, depending on the U-uptake history of the tooth. This is a problem whenever the internal U-derived dose is a significant fraction $(>50 \%)$ of the total dose rate to the tooth. Typically it is the dentine, and not the enamel itself, which is the source of this dose: dentine, because of its more porous and organic-rich character, has a much greater tendency to absorb U; cementum (external to the enamel) may also be a contributor. The best way to 'solve' this problem of U uptake is to make simultaneous Useries measurements of the dentine, to determine a combined U-series/ESR uptake model.

Alternatively, if the sample happens to be one in which the internal dose (i.e., the U content) is uniformly low, then uptake ceases to be a problem. In that case, however, an accurate determination of the external dose rate is crucial to the accuracy of the date. This requirement presents three separate problems. First, the moisture content of the sediment may have changed through the past, causing a change in the attenuation of the gamma and beta rays that bombarded the tooth. Second, the site may be inhomogeneous ('lumpy' - Schwarcz, 1994; or stratified into layers with different radioactivity levels). Therefore the precise dose rate at the spot where the sample was extracted must be determined. Third, the local dose environment where the tooth was collected, and especially the sediment surrounding the 
tooth that contributed a beta dose to the tooth, must be saved by the excavators; the range of beta rays is only 2 millimetres, so the sediment adjacent to the tooth is a key contributor to the dose rate.

\section{U-series dating by alpha spectrometry and TIMS}

Bones were some of the first materials to be subjected to U-series dating (Cherdyntsev, 1971). They were found, however, to give inconsistent results for the reasons listed earlier. In spite of these early cautions, many attempts to use U-series to date bones at important archaeological sites continue to be published; some of these are summarized in Schwarcz \& Blackwell (1991) and in Blackwell \& Schwarcz (1995). Two examples demonstrate the current state of use of these methods. Chen \& Yuan (1988) made an extensive study of bones from three paleo-anthropological sites in China at which no other U-seriesdatable materials were available. At some sites, especially those in limestone caves, they obtained very consistent isotope ratios by alpha spectrometric analysis of bones from the same stratigraphic levels, strongly suggesting that these bones had experienced early uptake. This is because any other continuous uptake model would not be likely to have led to identical isotopic ratios in all samples from a given site. Relatively small differences in uptake parameters (defining the fraction of $U$ taken up per year) would be expected to produce different values of ${ }^{230} \mathrm{Th} /{ }^{234} \mathrm{U}$ and ${ }^{234} \mathrm{U} /{ }^{238} \mathrm{U}$ in the different bones from the same site. Therefore, it is likely that these dates are accurate estimates of the age of the site. However, at some sites, especially open air deposits on stream-terraces, bones had apparently experienced open-system behavior, and some model of continuous $U$ uptake had to be invoked.

Bischoff et al. (1997) studied both animal and human bones from the Sima de los Huesos site at Atapuerca, Spain. They carried out both TIMS and alpha spectrometric U-series dating, and also ESR dating of some of the bear bones. For one suite of bear bones, they found that EU U-series and ESR dates agreed at a date of close to $200 \mathrm{ka}$. Other samples, however, gave U-series ages ranging from 320 to about $200 \mathrm{ka}$. U-series dates on hominid skeletal remains also scattered rather widely, over a range from 220 to $80 \mathrm{ka}$, but suggested a minimum EU age of around $200 \mathrm{ka}$. Stratigraphic evidence suggests that humans preceded bears into the cave. One would conclude therefore that the EU age for the bones is a significant underestimate; a continuous uptake model would be more appropriate, but the data themselves do not rigorously define what this should be.

\section{$U$-series dating by gamma-ray spectrometry}

The gamma-spectrometric analysis of bones has the singular advantage that it is a non-destructive technique and can therefore be carried out directly on hominid skeletal remains. It does not, however, have any particular advantage from the standpoint of the multiplicity of possible U-uptake 'solutions' for a given set of isotopic data. Some workers in this field have simply assumed an early uptake model in interpretation of their data. For example, Yokoyama et al. (1997) analysed one of the modern human crania from the Israeli site of Qafzeh and obtained a U-series age of $92 \mathrm{ka}$, in good agreement with the previously determined thermoluminescence age for the site. On the other hand, Barton \& Stringer (1997) recognized that the uncertainty in U-uptake models, together with the imprecision of their gamma-ray measurement of the ${ }^{234} \mathrm{U} /{ }^{238} \mathrm{U}$ ratio, made it impossible to assign a definite age to the Swanscombe cranium.

Well-shielded gamma-counters exist in some physics laboratories where they were formerly employed for measurements in nuclear physics, but lately have been under less demand. Such a facility was available at the University of Guelph under the supervision of Dr. J.J. Simpson. Working with the author and with C. Stringer, Simpson has helped to develop a better scheme for gamma-ray analysis, and we have used this system to date some hominid skeletal materials from sites in Israel and Africa. For example, we were able to borrow the mandible and part of one femur of the female Neanderthal 
believed to be derived from layer C at the site of Tabun (Schwarcz et al., 1998). We showed that the apparent U-series ages of these two skeletal elements were quite different, but could be reconciled if the mandible was assumed to have experienced early uptake, while the femur experienced approximately linear uptake. The combined age of the two is about $35 \mathrm{ka}$, which would clearly imply that the skeleton was buried in layer B (independently dated by ESR by Grün et al., 1991).

In addition to the opportunistic use of existing gamma counting apparatuses, new systems are being constructed. One such now in operation in the Australian National University (Simpson \& Grün, 1998) is being used to date Australian fossil humans. (Thorne et al., 1999).

\section{Conclusions}

We have seen that bones and teeth of mammals, widely encountered in archaeological sites of all ages, have considerable potential as datable materials. We must, however, be keenly aware of the limitations of these materials when studied by all the existing methods. Both U-series and ESR dating of bones and teeth suffer from the same fundamental concern: when did the uranium in the bone/teeth arrive? There is good reason to believe that, at least for relatively young samples, most of the $U$ in a bone or in dentine of teeth arrived early, while the tissue still contained significant amounts of organic matter. The latter acted as a chemical trap to enhance the buildup of $U$ in the bone. This process would begin soon after burial, and for bones less than $100000 \mathrm{y}$ old, this probably represents the majority of $\mathrm{U}$ found in them today. As the bones lie buried for longer times, it is possible that $U$ may be gradually picked up from pore-water in the surrounding sediment. This will eventually constitute an additional component of the total $U$ content of the bone. Without knowing this $U$ uptake history, the interpretation of isotope data obtained by any method (TIMS, alpha, gamma) is fraught with danger.

\section{References}

Avery, G., Cruz-Uribe, K., Goldberg, P., Grine, F.E., Klein, R., Lenardi, M. J., Rink, W.J., Schwarcz, H.P., Thackeray, A.I. \& Wilson, M.L. (1997). The 1992-93 excavations at the Die Kelders Middle and Later Stone Age cave site, South Africa. Jour. Field Archaeol., 24, 263-91.

Ayliffe, L. K. \& Veeh, H. H. (1988). Uranium-series dating of speleothems and bones from Victoria Cave, Naracoorte, South Australia. Chem. Geol., 72, 211-34.

Barton, J.C. \& Stringer, C.B. (1997). An attempt at dating the Swanscombe skull bones using non-destructive gamma-ray counting. Archaeometry, 39, 205-16.

Bischoff, J. L., Fitzpatrick, J.A., León, L., Arsuaga, J.L., Falgueres, C., Bahain, J.J. \& Bullen, T. (1997). Geology and preliminary dating of the hominid-bearing sedimentary fill of the Sima de los Huesos Chamber, Cueva Mayor of the Sierra de Atapuerca, Burgos, Spain. Jour. Hum. Evol., 33, 129-54.

Blackwell, B., Rutter, N.W. \& Debenath, A. (1990). Amino acid racemization analysis of mammalian bones and teeth from La Chaise-de-Vouthon (Charente), France. Geoarchaeology, 5, 121-47.

Blackwell, B. \& Schwarcz, H. P. and (1995). Uranium series disequilibrium dating. In: Dating Methods for Pleistocene Deposits, ed. N. Rutter \& N.R. Catto. Geological Assoc. Canada, Geotext 2.

Brennan, B. J., Rink, W.J., McGuirl, E.L., Schwarcz, H.P. \& Prestwich, W. V. (1997). Beta doses in tooth enamel by "one-group" theory and the ROSY ESR dating software. Radiation Meas., 27, 307-14.

Brooks, A. S. Hare, P.E., Kokis, J. and Miller, G. H., Ernst, R.D. \& Wendorf, F. (1990). Dating Pleistocene archaeological sites by protein diagenesis in ostrich egg shells. Science, 248, 60-64.

Chen Tiemei \& Yuan Sixun (1988). Uranium series dating of bones and teeth from Chinese Paleolithic sites. Archaeometry, 30, 59-76.

Cherdyntsev, V.V. (1971). Uranium-234. Jerusalem, Israel Program for Scientific Translation. 234 pp.

Collins, M.J. \& Galley, P. (1998). Towards an optimal method of archaeological collagen extraction: The influence of $\mathrm{pH}$ and grinding. Ancient Biomolecules, 2, 209-22.

Grün, R., Beaumont, P. B. \& Stringer, C.B. (1990a). ESR evidence for early modern humans at Border Cave in South Africa. Nature, 344, 537-39.

Grün, R., Shackleton, N. \& Deacon, H. (1990b). Electron spin resonance dating of tooth enamel from Klasies River 
Mouth Cave. Current Anthropology, 31, 427-32.

Grün, R., Brink, J. S., Spooner, N., Stringer, C.B. Franciscus, R.G. \& Murray, A.S. (1996). Direct dating of Florisbad hominid. Nature, 382, 500-01.

Grün, R., Schwarcz, H.P. \& Chadam, J. (1988). ESR dating of tooth enamel: Coupled correction for U-uptake and U-series disequilibrium. Nuclear Tracks and Radiation Measurement, 14, 237-41.

Grün, R., Stringer, C.B. \& Schwarcz, H.P. (1991). ESR dating of teeth from Garrod's Tabun Cave collection. Jour. Human Evolution, 20, 231-48.

Hare, P.E., Von Endt, D.E. \& Kokis, J.(1997). Protein and amino acid diagenesis dating. In: Chronometric Dating in Archaeology, ed. R.E. Taylor. \& M.J. Aitken, 261-96. New York, Plenum.

Longin, R. (1971). New method of collagen extraction for radiocarbon dating. Nature, 230, 241-42.

Oakley, K.P.(1975). A re-consideration of the date of the Kanam jaw. Jour. Archaeol. Sci., 2, 151-55.

Rink, J.W. (1998). Electron spin resonance (ESR) dating and ESR applications in Quaternary science and archaeometry. Radiation Measurements, 27, 975-1025.

Schwarcz, H.P. (1994). Current challenges to ESR dating. Quaternary Geochronology (Quat. Sci. Reviews), 13, 601-05.

Schwarcz, H.P. \& Blackwell, B. (1991). Archaeometry. In: Uranium Series Disequilibrium: Application to Environment Problems in the Earth Sciences (2nd ed.), ed. M. Ivanovich \& R.S. Harmon, 513-52. Oxford: Oxford University Press.

Schwarcz, H.P., Grün, R. G. \& Tobias, P.V. (1994). ESR dating of the australopithecine site of Sterkfontein, Transvaal, South Africa. Jour. Human Evol., 26, 175-81.

Schwarcz, H. P. \& Rink, W.J. (1999). ESR dates for tooth enamel from Die Kelders. submitted to Jour. Archaeol. Sci. (in press).

Schwarcz, H.P., Simpson, J. \& Stringer, C. (1998). Neanderthal skeleton from Tabun: U-series dating by gamma ray spectrometry. Journal of Human Evolution, 35, 635-645.

Schwarcz, H. P. \& Skoflek, I. (1982). New dates for the Tata, Hungary Paleolithic site. Nature, 295, 590-91.

Simpson, J.J. \& Grün, R. (1998). Non-destructive gamma spectrometric U-series dating. Quat. Sci. Rev., 17, 10091022.

Stafford, T., Hare, P.E., Currie, L., Jull, A.J.T. \& Donahue, D.J. (1991). Accelerator radiocarbon dating at the molecular level. Jour. Archaeol. Sci., 18, 35-72.

Szabo, B.J. (1980). Results and assessments of uranium series dating of vertebrate fossils from Quaternary alluviums in Colorado. Arctic and Alpine Research, 12, 95-100.

Thorne A., Simpson J.J., McCulloch M., Taylor L., Curnoe D. Grün, R., Mortimer G., Spooner N.A. (1999) Australia's oldest human remains: Age of the Lake Mungo 3 skeleton. Journal of Human Evolution, 36, 591-612.

Yokoyama, Y., Falguères, and de Lumley. M.A. (1997) Datation direct d'un crăne Proto-Cro-Magnon de Qafzeh par la spectrométrie gamma non destructive. Comptes Rendus Acad. Sci. Francaise, Paris, 324, 773-779. 


\section{Guanjun Shen}

Institute for Coastal and Quaternary Studies Nanjing Normal University

Nanjing 210097, P. R. China

Keywords: Numerical dating, Mid-Late

Pleistocene, Hominid Sites, China

\section{Current Status and Prospects for Dating Fossil Hominid Sites in China}

\begin{abstract}
This paper discusses the reliability of U-series dating of speleothem calcites. The application of this chronometer demonstrates that the previously accepted chronological sequence of Chinese Middle-Late Pleistocene sites may have been distorted and compressed. Taking into account the fact that important Chinese hominid/paleolithic sites are located in limestone caves where speleothem formations may often be found in stratigraphic context, this chronometer should be promising in addressing issues of human evolution. Important evidence relating to the origin of modern Homo sapiens may be expected to be found particularly in the numerous cave sites in Southern China.
\end{abstract}

\section{U-series dating of speleothem and fossil materials}

Almost all the dating methods applicable to Quaternary geology, including ${ }^{14} \mathrm{C}$, U-series disequilibrium, thermoluminescence (TL), electron spin resonance (ESR) and amino acid racemization (AAR) etc., have been established in China. Among them, U-series disequilibrium is the one most commonly used for hominid fossil and/or Paleolithic sites between tens and hundreds of millennia in age. From the late 1970 s to the 1980 s, fossil bones and teeth constituted the principle category of samples for dating. Using two U-series methods $\left({ }^{230} \mathrm{Th} /{ }^{234} \mathrm{U}\right.$ and $\left.{ }^{231} \mathrm{~Pa} /{ }^{235} \mathrm{U}\right)$ in parallel, Chen \& Yuan (1988) analyzed more than 200 fossil samples from some 20 key Paleolithic sites, providing the first numerical sequence for Chinese hominid sites.

Beginning in the mid-1980s, speleothem calcites taken from stratigraphic sequences have become more and more important as temporal markers. Our experiments have demonstrated that with carefully selected, compact, well crystallized speleothem deposits, valid U-series dates can be obtained. Evidence in support of this conclusion has been provided in the consistency between numerous speleothem dates and their stratigraphy, in the concordance between ${ }^{230} \mathrm{Th} /{ }^{234} \mathrm{U}$ and ${ }^{227} \mathrm{Th} /{ }^{230} \mathrm{Th}$ (equivalent to ${ }^{231} \mathrm{~Pa} /{ }^{235} \mathrm{U}$ ) ages, and in the radiometric secular equilibrium between ${ }^{230} \mathrm{Th}$ and ${ }^{234} \mathrm{U}$ for samples of $>350 \mathrm{ka}$ (Schwarcz, 1992; Shen, 1996a). Even more unequivocal evidence comes from the concordance between high precision thermal ionization mass spectrometric (TIMS) ${ }^{230} \mathrm{Th} /{ }^{234} \mathrm{U}$ and ${ }^{231} \mathrm{~Pa} /{ }^{235} \mathrm{U}$ dates (Edwards et al., 1996). These points lead us to suggest that the U-series dating of speleothem formations, especially using the TIMS technique, may meet all the criteria to be regarded as a well established 'absolute' or 'numerical' dating method. The reliability of this chronometer should be comparable to that of the well documented potassium-argon ( $\mathrm{Ar} / \mathrm{K}$ or $\left.{ }^{40} \mathrm{Ar} /{ }^{39} \mathrm{Ar}\right)$ dating of volcanic ash and of the ${ }^{14} \mathrm{C}$ dating of charcoal grains.

In order to draw comparisons with previous dating results, we have also analyzed 20 fossil bones and teeth, 19 of them with two U-series methods (Shen, 1996b). Among the 19 age sets, 8 display significant discrepancy between the results of two U-series methods. If we accept the accuracy of independent age controls provided by the U-series dating of speleothem deposits, ${ }^{14} \mathrm{C}$ dating and biostratigraphic evidence with wide margins, 8 out of the 11 concordant age sets are not acceptable. Moreover, by analyzing the U-series isotopic ratios, evidence has been found that uranium may cycle into or out of fossil bones. Apparently no simple model may depict such complex geochemical processes and no known conditions of preservation may securely protect fossil bones from being affected. So on the whole we agree with 
other researchers working in the field that the U-series dating of fossil materials is of limited reliability (Bischoff et al.; 1988; Rae et al., 1989; Schwarcz, 1992).

\section{Challenging the existing chronological sequence}

Over approximately the past 10 years of U-series dating of speleothem deposits, we have studied the chronology of several key Paleolithic sites in China, such as Locality 1 of Zhoukoudian (the site of 'Peking Man') in Beijing (Shen \& Jin, 1991; Shen et al., 1996), Guanyindong, Yanhuidong ('Tongzi Man'), Xiaohuidong ('Shuicheng Man') and Dadong in Guizhou Province (Shen, 1994; Shen et al., 1997) and Yinshan ('Chaoxian Man') in Anhui Province (Shen et al., 1994). Recently we have further studied the site of Peking Man with TIMS U-series dating (Shen et al., in prep.), as well as a New Cave at Zhoukoudian (Shen et al., submitted). The chronology of several Late Pleistocene hominid sites in Southern China, including the site of the world renowned Liujiang Man, is currently under study in our laboratory.

Of these studies, probably the most noteworthy work is the dating of the site of Peking Man, generally accepted as typically representative of Homo erectus in East Asia. Earlier efforts assigned an age of $\sim 230 \mathrm{ka}$ to the uppermost layers 1-3 (including the Skull No. V, one of the latest $H$. erectus in China), and an age of 450-500 ka to the rest of the hominid fossils from the site (Zhao et al., 1985). Our results show that the much discussed Skull No. V must be older than $410 \mathrm{ka}$ (Shen et al., 1996) and the hominid fossils from the lower strata should be of an age of at least $600 \mathrm{ka}$, possibly $800 \mathrm{ka}$ or even older (Shen et al., in prep.). A much older age assignment to Peking Man has important implications for current theories of human evolution.

From the dating results of these sites, a general tendency is evident: dates from speleothem deposits are markedly older than former age assignments. The existing chronological sequence for Chinese hominid sites has been mainly based on the tuning of biostratigraphic relative age estimation and Useries dating of fossil materials. As both of the two chronometers can only provide loose age controls, we tend to consider that this sequence may have been deformed and compressed. The phenomenon that many of the Chinese late $H$. erectus and early $H$. sapiens sites were clustered around 200 ka may be an artifact of systematic uncertainties of the dating methods used, perhaps similar to the once condensed chronology of European Late Pleistocene sites (Grün \& Stringer, 1991).

Thus the U-series dating of speleothem deposits has begun to make an impact on shaping the chronology of Middle-Late Pleistocene sites in a general sense. However, it should be noted that Chinese anthropologists and archaeologists have greeted these new results with caution. The previous temporal frame remains the one most frequently cited in developing theories in relevant sciences. This situation is probably understandable, as in China other chronometers mostly give results concordant with each other. Moreover, their results are in general agreement with relative age estimations based on biostratigraphic studies. But the U-series dating of speleothem deposits often provides somewhat 'abnormal' dates, thus confusing the situation of quasi-unanimity. In view of this, further studies on the reliability of the dating techniques are warranted. Systematic inter-comparisons of U-series and other dating methods should be carried out. As far as the reliability of the U-series dating of speleothem deposits is concerned, the cross-check between two U-series methods with TIMS technique provides the most stringent check on the closed-system behavior for a given sample. We look forward to international collaboration in this respect.

\section{Future prospects}

As we look into the future development in dating Chinese hominid sites, exploiting the full potential of the U-series dating of speleothem deposits remains the first choice. The reasons are:

First, it is justified by the excellent reliability of the chronometer. With the availability of a suite of dating techniques, age results are no longer 'rare commodities' for prehistoric sciences. But several of the frequently applied chronometers are still in early developing stages, the reliability of results thereof has 
not yet been well proved. On the other hand current issues in anthropology urgently need dates from well established chronometers. As an example we cite here the apparent lack in China of hominid fossil records between 50 and $100 \mathrm{ka}$. We have yet to verify whether this gap is a reality or an artifact. To address such an issue only age results with well verified precision and accuracy are meaningful. So the U-series dating of speleothem deposits is probably the most suitable one among all available dating techniques.

Second, the usefulness of this chronometer resides in its ability to cover two periods critical for human evolution. At the upper end, the TIMS technique expands the range of U-series dating to 500-600 ka, therefore reaching the interface between late $H$. erectus and early $H$. sapiens. For long the relationship between these two hominid species has remained unresolved. An extensive application of this chronometer may therefore shed light on this subject of controversy. At the lower end, this chronometer may provide reliable temporal scales to the evolution patterns of human species since $\sim 200 \mathrm{ka}$. The temporal position of the Middle East and African sites closely relevant to the origin of modern humans has been mainly established on the TL dating of burnt flint and on the ESR dating of tooth enamel (Grün \& Stringer, 1991) - chronometers generally regarded as having factors of uncertainty. The U-series dating of speleothem formations should be able to play a part in addressing these hotly debated issues.

Third, such a strategy well suits the context of Chinese sites, as a significant number of Chinese hominid/Paleolithic sites are located in limestone caves. In these situations, speleothem formations may often be found intercalated in a stratigraphic context, offering rare opportunities to rigorously constrain the time of human occupation.

With the U-series dating of speleothem deposits, we are actually establishing a new chronological sequence for Chinese Middle-Late Pleistocene sites. The chronology of Chinese sites is generally regarded as poorly established, and this is often blamed on the absence of volcanic activity during the periods in question. However, this situation is changing. The frequent presence of speleothem formations makes Chinese cave sites suitable locales to address a number of issues in human evolution. A number of Late Pleistocene hominid cave sites have been reported in southern China, and they can be expected to provide important evidence on the emergence, evolution and dispersal of modern $H$. sapiens.

\section{Acknowledgements}

The author thanks the Organizing Committee of the Dual Congress for generous assistance to attend the Congress.

\section{References}

Bischoff, J., Rosenbauer, R., Tavoso, A. \& Lumley H. de. (1988). A test of uranium-series dating of fossil tooth enamel: results from Tournal Cave, France. Appl. Geochem., 3, 145-51.

Edwards, L. et al. (1997). Protactinium-231 dating of carbonates by thermal ionization mass spectrometry: implications for Quaternary climate change. Science, 276, 782-86.

Grün, R. \& Stringer, C.B. (1991). Electron spin resonance dating and the evolution of modern humans. Archaeometry, 33(2): 153-99.

Ludwig, K.R., Simmons, K.R., Szabo, B.J., Winograd, I.J., Landwehr, J.M., Riggs, A.C. \& Hoffman, R.J. (1992). Mass-spectrometric ${ }^{230} \mathrm{Th}-{ }^{234} \mathrm{U}-238 \mathrm{U}$ dating of the Devils Hole calcite vein. Science, 258, 284-87.

Rae, A., Hedges, R. \& Ivanovich, M. (1989). Further studies for uranium-series dating of fossil bones. Appl. Geochem., 4, 331-37.

Schwarcz, H.P. (1992). Uranium-series dating and the origin of modern man. Phil. Trans. R. Soc. Lond. B, 337, 131-37.

Shen, G.J. (1994). Position chronologique de quatre sites paléolithique en Chine. L'Anthropologie (Paris), 98(4): $554-61$.

Shen, G.J. (1996a). ${ }^{227} \mathrm{Th} /{ }^{230} \mathrm{Th}$ dating method, methodology and application to Chinese speleothem samples. Quaternary Science Reviews (Quaternary Geochronology), 15, 699-707. 
Shen, G.J. (1996b). U-series dating of fossil bones: results from Chinese sites and discussion on its reliability. Chinese Journal of Geochronology, 15(4), 303-13.

Shen, G.J. \& Jin, L.H. (1993). Re-study of the upper age limit of Peking Man site. International Journal of Anthropology, 8(2), 95-8.

Shen, G.J., Fang, Y.S. \& Jin, L.H. (1994). Re-examination of the chronological position of Chaoxian Man. Acta Anthropologica Sinica, 13(3), 249-56 (in Chinese with English abstract).

Shen, G.J., Ku, T.L., Gahleb, B. \& Yuan, Z.X. (1996). Preliminary results on U-series dating of Peking Man site with high precision TIMS. Acta Anthropologica Sinica, 15(3), 210-17 (in Chinese with English summary).

Shen, G.J., Jiu, J. \& Jin, L.H. (1997). Preliminary results on U-series dating of Panxian Dadong in Guizhou Province, S-W China. Acta Anthropologica Sinica, 16(3), 221-30 (in Chinese with English summary).

Zhao, S.S., Xia, M., Zhang, C.H., Liu, M.L., Wang, S.X., Wu, Q.F. \& Ma, Z.B. (1985). Uranium-series dating of the Peking Man site. In: Multi-disciplinary Study of the Peking Man Site at Zhoukoudian, ed. R.K. Wu et al. (eds). pp. 246-50. Beijing: Science Press (in Chinese). 
John C. Vogel

QUADRU, clo Environmentek, CSIR, P O Box 395, Pretoria 0001, South Africa

Keywords: Middle Stone Age, human origins, uranium series dating, speleotheres

\section{Radiometric Dates for the Middle Stone Age in South Africa}

\begin{abstract}
Uranium series analysis of dripstone material imbedded in occupation levels of three long sequence caves have provided some significant dates for the Middle Stone Age in South Africa. Two small satalagmites from Wonderwork Cave place the beginning of the MSA at least at $160 \mathrm{ka}$ ago while samples from Boomplaas Cave and Klasies River Mouth provide an age of 60$70 \mathrm{ka}$ from the distinctive Howieson's Poort Industry. Radiocarbon dates suggest that MSA technology was practised until c.22 ka in the southern Cape.
\end{abstract}

\section{Introduction}

Over the years we have produced several uranium series dates relating to the Middle Stone Age period in South Africa. The data are presented here in detail and placed in their context so that they can be compared with other more recently obtained age determinations based on the Luminescence (TL and OSL), Electron Spin Resonance (ESR) and Amino Acid Racemization (AAR) techniques.

The Middle Stone Age (MSA) in sub-Saharan Africa is of special interest because it is associated with the remains of anatomically modern Homo sapiens. We have known for a long time that much of this stage of human technological development lies beyond the range of radiocarbon dating (Vogel \& Beaumont, 1972) and it has, therefore, been necessary to turn to other dating methods. A chronological framework for this important period in human development has, however, been slow in coming, the reason being, on the one hand, uncertainties intrinsic in the new dating methods, and on the other, a lack of a detailed characterization of the relative sequence of stone tool assemblages during the MSA. The latter is partly due to the paucity of long stratified depositories covering the MSA in the region.

In the terrestrial environment, cavestone has been found to provide reliable uranium series dates (c.f. Vogel, 1983; Vogel \& Kronfeld, 1996), and the occasional occurrence of stalagmites and flowstone that developed on the surface of the slowly accumulating deposit in a cave with human occupation makes it possible to date the level on which they occur. From three caves in South Africa with important MSA deposits we have been able to obtain such material for analysis, namely Boomplaas, Klasies River Mouth and Wonderwerk Caves. The results obtained at these three sites will be discussed in that order.

The uranium and thorium isotopes were analysed by alpha-spectrometry. The procedure used was to dissolve the samples in concentrated hydrochloric acid and to co-precipitate the uranium and thorium with iron hydroxide from the solution. These two elements were then separated from each other and from contaminating cations on an ion exchange column and electroplated onto steel disks for measurement.

\section{Boomplaas Cave}

This cave is situated in the foothills of the Swartberg range on the farm Boomplaas $\left(33^{\circ} 23^{\prime} \mathrm{S}\right.$, $22^{\circ} 11^{\prime} \mathrm{E}$ ) just west of the Cango Caves near Oudtshoorn in the southern Cape. Excavations in the 1970s by H.J. Deacon revealed some $5 \mathrm{~m}$ of deposit containing a long sequence of Stone Age occupation levels (Deacon, 1979). The culture-stratigraphic sequence as briefly mentioned by Deacon $(1979,1995)$ ranges from a historic and herder level at the top through Later Stone Age (LSA) levels down to c. $2.2 \mathrm{~m}$ depth, 
Table 1. Radiocarbon dates for Boomplaas Cave.

\begin{tabular}{|c|c|c|c|c|}
\hline Analysis No. & Unit & $\delta^{13} \mathrm{C}(\%)$ & $\mathrm{pmC}^{*}$ & Age (yrs BP) \\
\hline & Charcoal Samples & & & \\
\hline Pta-1828 & CL 1 & -24.8 & 22.3 & $12060 \pm 110$ \\
\hline Pta-3899 & CL 3 & -25.2 & 19.3 & $13220 \pm 250$ \\
\hline Pta-3283 & GWA & -25.3 & 10.9 & $17830 \pm 180$ \\
\hline Pta- 1810 & LPC & -24.8 & 7.1 & $21220 \pm 190$ \\
\hline Pta-2274 & BP base & -22.4 & 1.7 & $32670 \pm 240$ \\
\hline Pta-2219 & BP base (alkali extr.) & -24.7 & 1.5 & $33920 \pm 770$ \\
\hline Pta-2220 & (alkali res.) & -24.7 & 1.3 & $34740 \pm 360$ \\
\hline \multirow[t]{2}{*}{ Pta-1811 } & OLP1 & -25.1 & 1.0 & $37400 \pm 1370$ \\
\hline & Dripstone Samples & & & \\
\hline Pta-2262 & CBM & -4.6 & 72.7 & $2890 \pm 50$ \\
\hline Pta-2259 & CL base & -5.9 & 20.1 & $13210 \pm 120$ \\
\hline Pta-2298 & LPC & -3.9 & 7.6 & $21070 \pm 180$ \\
\hline Pta-2268 & BP top & -3.3 & 3.8 & $26670 \pm 280$ \\
\hline Pta-2302 & OLP1 & -3.9 & 2.0 & $31680 \pm 550$ \\
\hline Pta-2464 & $\mathrm{OCH} 2$ & -6.8 & 0 & $>49000$ \\
\hline
\end{tabular}

*pmC: percent modern Carbon viz. the relative $14 \mathrm{C}$ level in the carbon sample with respect to the modern day refernce standard

followed by two late Middle Stone Age (MSA) occupation levels and at the base layers containing an artefact assemblage assigned to the distinctive Howieson's Poort (HP) Industry of the MSA.

A set of radiocarbon dates for the site was initially produced by Fairhall et al. (1976) and later supplemented by us with six charcoal dates given in Table 1. The age-depth relationship, using the approximate depths given by Deacon (1979) and Deacon et al. (1984), is shown in Fig. 1. On the left hand side of the graph the different stratigraphic units defined by the excavator are also shown. The uppermost MSA occupation is in level BP, the base of which is dated to 34 thousand years Before Present (34 ka BP). The overlying occupation layer, LPC, contains an early LSA assemblage and has a date of $21 \mathrm{ka} \mathrm{BP.}$ LSA technology thus replaced the MSA in this region at some date between these two figures.

In the southern foothills of the Drakensberg, some $660 \mathrm{~km}$ ENE of Boomplaas, Opperman has excavated an MSA stone tool assemblage from a shallow deposit in a cave on the farm Strathalan (Opperman \& Heydenrych, 1990; Opperman, 1992, 1996). We have obtained 11 radiocarbon dates ranging between $21 \mathrm{ka}$ and $29 \mathrm{ka} \mathrm{BP}$ for this deposit, which fills the gap in the dates at Boomplaas and represents the youngest MSA in South Africa. Unfortunately the artefact collection from the MSA levels at Boomplaas have not yet been published so that no comparison with the Strathalan material can be made.

The layers below OLP, with a date of $37.4 \mathrm{ka}$ BP, lie beyond the range of radiocarbon dating and since the main objective of our dating programme for the site was to obtain a date for the Howieson's Poort Industry in the $\mathrm{OCH}$ level, we turned to uranium series dating. Fortunately the cave does contain some stalagmite growth: on the side of the deep sounding a stalagmite developed between the OCH and CL levels. It grew at about the same rate as that at which the surrounding deposit was accumulating, so 


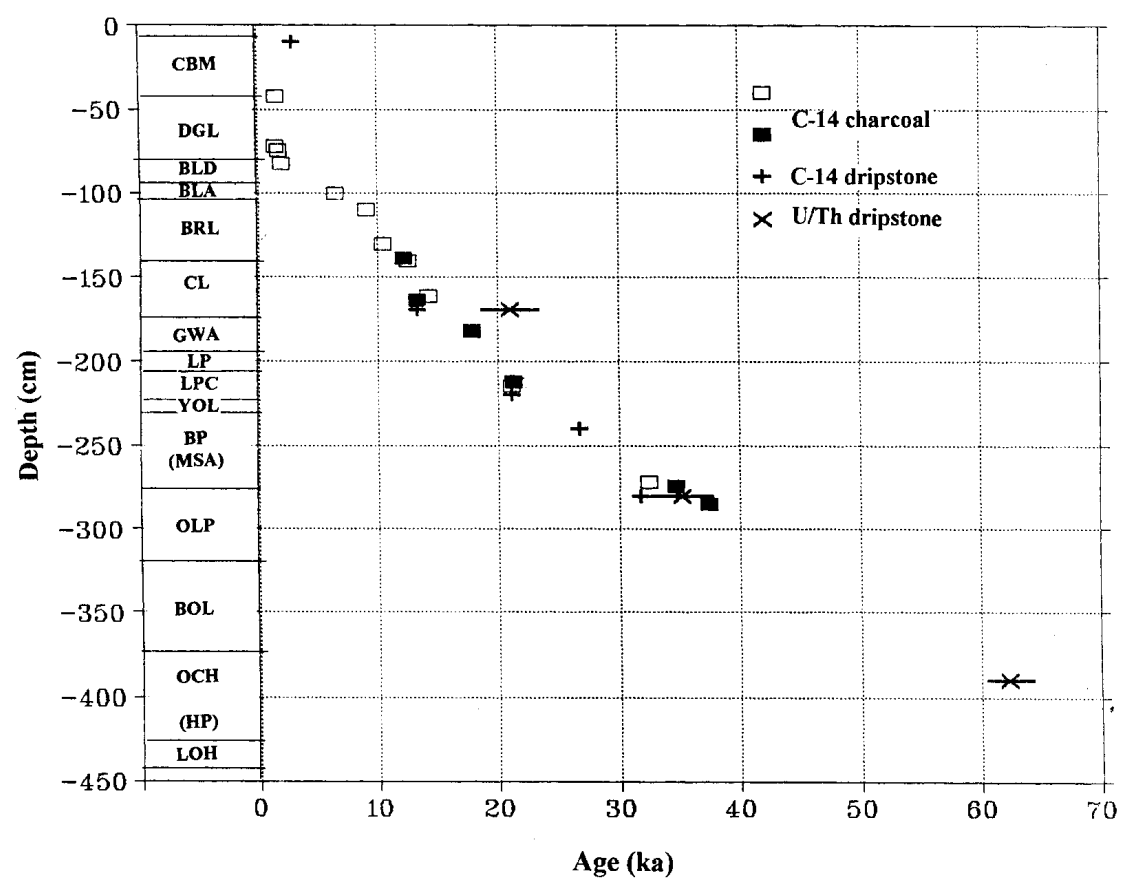

Figure 1. The age/depth relationship for the deposit in Boomplaas Cave. On the left side are the designations of the units identified by the excavator.

Open squares: ${ }^{14} \mathrm{C}$ dates on charcoal by Fairhall et al. (1976)

Filled squares: ${ }^{14} \mathrm{C}$ dates on charcoal from Table 1

Pluses: ${ }^{14} \mathrm{C}$ dates on dripstone from Table 1

Crosses: Uranium-series dates on dripstone from Table 2

that the calcium carbonate either precipitated slightly above the surface at the time or it cemented the already deposited surface layers just below. The age can thus correspond to a date somewhere between that of the underlying and overlying levels. In addition to this feature, some small stalagmites had developed in the historic level at the top, and significantly, a small stalagmite, only a few $\mathrm{cm}$ high, was uncovered in the middle unit of the $\mathrm{OCH}$ level $(\mathrm{OCH} 2)$. This latter sample provided the material for dating the Howieson's Poort assemblage.

In order to establish to what extent the speleothems acted as a closed system, the radiocarbon ages of six samples of dripstone were measured. The results are listed in Table 1 and also included in Fig. 1. Except for the small surface stalagmite, the ${ }^{14} \mathrm{C}$ ages appear slightly younger than the charcoal dates in the adjacent levels, especially when one recalls that the cavestone in this area can be expected to show an apparent initial age of some 1500 years (see Vogel, 1983). It thus appears that some slight recrystallization of the carbonate took place while the overlying deposit was being laid down. Fortunately, this would not affect the uranium series dating markedly.

The uranium and thorium isotope content of three of the carbonate samples was measured. The results are given in Table 2. The uranium contents are very low and all three samples contained significant amounts of natural thorium, ${ }^{232} \mathrm{Th}$. This detrital thorium is derived from the impurities in the 
dripstone and indicates that the sample also would initially have incorporated some radiogenic ${ }^{230} \mathrm{Th}$. Calculation of the age since formation from the ${ }^{230} \mathrm{Th} /{ }^{234} \mathrm{U}$ ratio thus gives a maximum age. The problem can be overcome by analysing several sub-samples with varying amounts of detritus and extrapolating to zero contamination (Kaufman, 1971). This was done in the case of the OCH2 stalagmite. The results of three sub-samples are given in Table 2 and plotted in Figure 2. The extrapolated isotope activity ratios give an age of $62.4 \pm 2.0 \mathrm{ka}$ for the $\mathrm{OCH} 2$ level. This result confidently places the Howieson's Poort Industry at Boomplaas in the range of 60 to $70 \mathrm{ka}$.

Experience has shown that the initial ${ }^{230} \mathrm{Th} /{ }^{232} \mathrm{Th}$ activity ratio, usually lies between 0.5 and 1.5 . The value that best matches the three $\mathrm{OCH} 2$ results is 0.8 . If this figure is also applied to the other two samples, the ages in the last column of Table 2 are obtained. The ages for the CL and BP units are markedly higher than the corresponding radiocarbon dates. This is to be expected, since we now know that radiocarbon dates in this time range are several thousand years too young (Vogel, 1983; Vogel \& Kronfeld 1997).
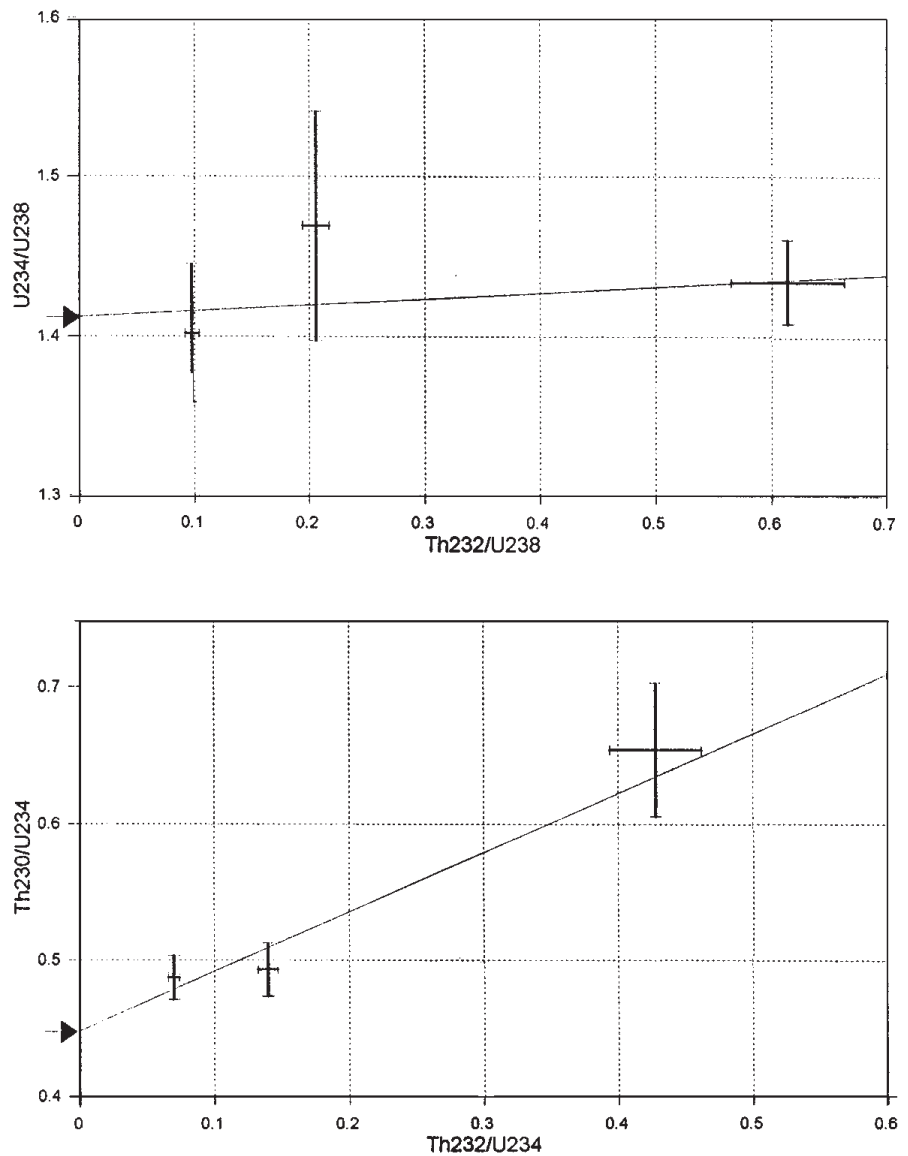

Figure 2. Activity ratios of the Uranium and Thorium of three sub-samples of a small stalagmite from the OCH 2 Howieson's Poort level in Boomplaas Cave. Extrapolation to $\mathrm{Th}=0$ gives the ratios of uncontaminated calcium carbonate. These ratios correspond to an age of $62.4 \mathrm{ka}$. 
Table 2. Uranium series results for Boomplaas Cave.

\begin{tabular}{|c|c|c|c|c|c|c|c|c|}
\hline \multirow{2}{*}{$\begin{array}{c}\text { Analysis } \\
\text { no. }\end{array}$} & \multirow[t]{2}{*}{ Level } & \multirow[t]{2}{*}{ Association } & \multirow{2}{*}{$\begin{array}{l}\text { U-conc. } \\
\text { (ppm) }\end{array}$} & \multicolumn{3}{|c|}{ Activity Ratios } & \multicolumn{2}{|c|}{ Age (ka) } \\
\hline & & & & U-234/U-238 & Th-230/U-234 & Th-230/Th-232 & $f=0$ & $f=0.8$ \\
\hline U-368 & CL base & LSA Robberg & 0.080 & $1.276 \pm .087$ & $0.249 \pm .017$ & 2.30 & $30.7 \pm 2.5$ & $21.0 \pm 2.4$ \\
\hline U-366 & OLP 1 & MSA & 0.086 & $1.497 \pm .068$ & $0.356 \pm .017$ & 2.78 & $46.5 \pm 2.7$ & $35.2 \pm 2.6$ \\
\hline $\mathrm{U}-417$ & $\mathrm{OCH} 2$ & HP & 0.063 & $1.402 \pm .043$ & $0.487 \pm .016$ & 6.96 & $69.9 \pm 3.2$ & $64.0 \pm 3.2$ \\
\hline U-365 & $\mathrm{OCH} 2$ & HP & 0.075 & $1.469 \pm .072$ & $0.493 \pm .020$ & 3.52 & $70.6 \pm 3.9$ & $58.6 \pm 3.7$ \\
\hline $\mathrm{U}-414$ & OCH 2 & HP & 0.087 & $1.434 \pm .026$ & $0.665 \pm .049$ & 1.53 & $107.4 \pm 12.3$ & $66.1 \pm 13$ \\
\hline Composite & OCH 2 & HP & - & $1.412 \pm .047$ & $0.449 \pm .021$ & - & - & $62.4 \pm 2.0$ \\
\hline
\end{tabular}

\section{Klasies River Mouth Caves}

These caves are situated directly on the Cape south coast at the mouth of the Klasies or Kaapsedrif river $\left(34^{\circ} 06^{\prime} \mathrm{S}, 24^{\circ} 24^{\prime} \mathrm{E}\right)$, some $35 \mathrm{~km}$ west of Humansdorp. The mainly Middle Stone Age deposits were excavated in 1966-68 by J. Wymer (Singer \& Wymer, 1982) and were re-examined by H.J. Deacon in the 1980s (Deacon \& Geleijnse, 1988; Deacon, 1995).

The basal deposits started at about $7 \mathrm{~m}$ above present sea level at the mouth of Cave 1 (KRM1) and, after the cave mouth became blocked by accumulating dune sand against the cliff, the build-up continued against the slightly overhanging cliff face (KRM1A) for a further $16 \mathrm{~m}$ and more. The culturestratigraphic sequence as described by Singer \& Wymer (1982) consists of MSA I in and at the front of Cave 1 layers 40-37, followed by MSA II levels in Cave 1 layers 17-14. These layers continue for 10m up against the cliff face (KRM 1A, layers 36 to 23) and underlie $1.5 \mathrm{~m}$ of intensive occupation debris with a Howieson's Poort assemblage (La 21-10) and 1.5m of MSA III. Not in stratigraphic order is an aeolian sand layer in KRM 1 which apparently accumulated after most of the deposit in front of the cave had eroded away again and which contains a sparse MSA IV artefact assemblage. Finally an LSA shell midden accumulated on the top of the deposit in KRM 1.

Initially 27 rather unsatisfactory ${ }^{14} \mathrm{C}$ dates were obtained for the MSA levels from a commercial laboratory (Singer \& Wymer, 1982). Subsequently we re-analysed three of the same samples after careful pre-treatment, with the following results:

$\begin{array}{lll}\text { Pta-1856 } & \text { KRM 1A la. 6 (MSA III) } & >45200 \mathrm{yrs} \mathrm{BP} \\ \text { Pta-1767 } & \text { KRM 1A la. 17 (HP) } & >50000 \mathrm{yrs} \mathrm{BP} \\ \text { Pta-1765 } & \text { KRM 1A la. 18 (HP) } & >40000 \mathrm{yrs} \text { BP }\end{array}$

These dates clearly show that the whole sequence from the MSA III down, lie beyond the range of radiocarbon dating.

Toward the back of Cave 1 some stalagmites were formed during the accumulation of the deposit, providing suitable material for the uranium series dating of the levels on which they developed. At the top of the sequence thin flowstone patches also occur. In the Shelter 1A numerous levels are solidly cemented with lime up against the shelter wall (c.f. Singer \& Wymer, 1982: pp 21,22). This more impure carbonate is less ideal for dating, but is potentially also usable.

The results of the various samples that have been analysed are given in Table 3 . The natural ${ }^{232} \mathrm{Th}$ 
in the samples was relatively low, so that the correction for initial ${ }^{230} \mathrm{Th}$ is small and does not affect the derived ages markedly (compare the last two columns in the table). The first sample listed, U-615, is a calcium carbonate crust in Layer 14 of Shelter 1A, towards the top of the Howieson Poort levels (La 10 to 21). The adjusted age of $65.6 \mathrm{ka}$ corresponds closely with the age of $62.4 \mathrm{ka}$ found for the HP at Boomplaas (see above, Table 2). The second sample, U-367, is a similar carbonate crust in the MSA II Layer 30 some $2.7 \mathrm{~m}$ below the HP levels. The next two samples, U-075 and U-061, are from the tip and base of a small $30 \mathrm{~cm}$ stalagmite that developed in the back of Cave 1 on the base of Layer 14, which contained numerous beach cobbles and was interpreted by Butzer (1982) to represent Oxygen Isotope Stage 5c. Sample U-142 is from the base of a larger stalagmite in the same stratigraphic position in the back of Cave 1, but on the other side of the witness section. The results for these last four samples reliably date the MSA II levels of Singer \& Wymer (1982) to between c. $100 \mathrm{ka}$ and somewhat after 77 $\mathrm{ka}$. The final stalagmite sample, U-369, is again from the base of a rather substantial stalagmite that developed on the basal beach sand level ( $\mathrm{La} \mathrm{40}$ ) on the west side of Cave 1. The age obtained for this sample of $108.6 \mathrm{ka}$ places the MSA I levels into the Oxygen Isotope Stage 5d after the Last Interglacial high sea level.

Also included in the table are two samples of shell. Shells are, however, known to produce unreliable uranium series dates due to their tendency to absorb uranium from percolating moisture long after deposition, thus producing an apparent age which is much younger than the shell itself: They do, however, show that post-depositional uranium has been accumulated in the deposit - a matter which affects the reliability of ESR and Luminescence dates. Finally, four thin flowstone layers which overlie the terminal MSA IV in layer 13 at the back of Cave 1 are all of late Holocene age and do not supply a useful terminus post quem for the MSA at the site.

\section{Wonderwerk Cave}

The site, $45 \mathrm{~km}$ south of the town of Kuruman in the Northern Cape $\left(27^{\circ} 51^{\prime} \mathrm{S}, 23^{\circ} 33^{\prime} \mathrm{E}\right)$, is a north facing cavity that extends some $150 \mathrm{~m}$ into an eastern foothill of the Kuruman Hills. Investigations by B. D. Malan and associates in the 1940s revealed evidence of Middle and Later Stone Age occupation

Table 3. Uranium series results for Klasies River Mouth Caves.

\begin{tabular}{|c|c|c|c|c|c|c|c|c|}
\hline \multirow{2}{*}{$\begin{array}{l}\text { Analysis } \\
\text { No. }\end{array}$} & \multirow[t]{2}{*}{ Position \& material } & \multirow[t]{2}{*}{ Association } & \multirow{2}{*}{$\begin{array}{l}\text { U-conc. } \\
\text { (ppm) }\end{array}$} & \multicolumn{3}{|c|}{ Activity Ratios } & \multicolumn{2}{|c|}{ Age (ka) } \\
\hline & & & & $\mathrm{U}-234 / \mathrm{U}-2,38$ & Th-230/U-234 & Th-230/Th-232 & $\mathbf{f}=\mathbf{0}$ & $f=1$ \\
\hline & Cavestone samples & & & & & & & \\
\hline $\mathrm{U}-615$ & $\begin{array}{c}\text { Shelter IA, La } 14 \\
\text { crust }\end{array}$ & $\mathrm{HP}$ & $2.14 \pm .07$ & $1.259 \pm .022$ & $0.489 \pm .026$ & 9.8 & $70.9 \pm 5.3$ & $65.6 \pm 5.3$ \\
\hline$U-367$ & $\begin{array}{c}\text { Shelter } 1 \mathrm{~A}, \text { La } 30 \\
\text { crust }\end{array}$ & MSA II & $1.51 \pm .04$ & $1.248 \pm .024$ & $0.545 \pm .032$ & 10.9 & $82.7 \pm 7.0$ & $77.4 \pm 7.0$ \\
\hline $\mathrm{U}-075$ & $\begin{array}{l}\text { Ca 1, Sec D, La } 14 \text { base } \\
\text { stalagmite top }\end{array}$ & MSA II & $1.28 \pm .02$ & $1.380 \pm .018$ & $0.561 \pm .009$ & 307 & $85.2 \pm 2.1$ & $85.2 \pm 2.1$ \\
\hline$U-061$ & $\begin{array}{c}\text { Ca I, Sec D, La I } 4 \text { base } \\
\text { stalagmite base }\end{array}$ & MSA !I & $0.98 \pm .02$ & $1.367 \pm .019$ & $0.601 \pm .013$ & 410 & $94.6 \pm 3.2$ & $94.6 \pm 3.2$ \\
\hline $\mathrm{U}-142$ & $\begin{array}{l}\text { Ca 1, Sec M, La } 14 \text { base } \\
\text { stalagmite base }\end{array}$ & MSA II & $0.63 \pm .03$ & $1.409 \pm .056$ & $0.631 \pm .029$ & 73 & $101.7 \pm 7.5$ & $100.8 \pm 7.5$ \\
\hline \multirow[t]{2}{*}{$\mathrm{U}-369$} & $\begin{array}{c}\text { Ca } 1 \text {, Sec K, La } 40 \text { top } \\
\text { stalagmite base }\end{array}$ & MSA I & $0.54 \pm .01$ & $1.360 \pm .014$ & $0.672 \pm .012$ & 15.6 & $113.0 \pm 3.4$ & $108.6 \pm 3.4$ \\
\hline & Marine shell samples & & & & & & & \\
\hline$U-139$ & $\begin{array}{l}\text { Shelter } 1 \mathrm{~A}, \text { La } 22 \\
\text { shell }\end{array}$ & MSA II & $0.89 \pm .006$ & $1.292 \pm .091$ & $0.233 \pm .016$ & 54.5 & $28.5 \pm 2.2$ & $28.1 \pm 2.2$ \\
\hline$U-140$ & $\begin{array}{l}\text { Ca I, Sec A, La } 15 \\
\text { fine shell }\end{array}$ & MSA II & $0.06 \pm .003$ & $1.346 \pm .091$ & $0.295 \pm .021$ & 29.9 & $37.4 \pm 3.2$ & $36.6 \pm 3.2$ \\
\hline
\end{tabular}


Table 4. Uranium series results for Wonderwerk Cave.

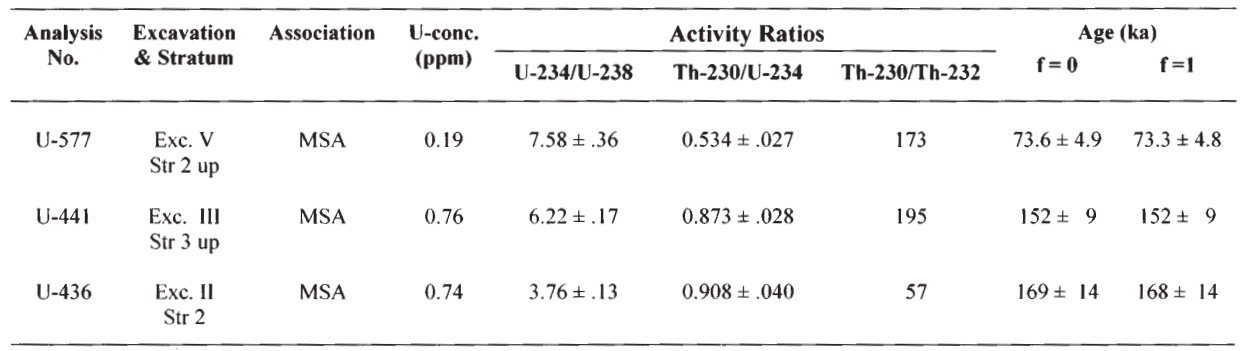

(Malan \& Wells, 1943). In the same period an individual was allowed to remove 'guano' from the interior of the cave for sale. In 1978 P. Beaumont, and in 1979 A. and F. Thackeray together with Beaumont, excavated the LSA levels towards the front of the cave (Thackeray et al., 1981).

Subsequently Beaumont removed the extensive amount of disturbed deposit from the interior and conducted a number of controlled excavations at points along the main axis of the cave. Evidence of human occupation during the Middle to Early Stone Age was found in all the test pits. Dripstone was also recovered from various levels. These embryonic stalagmites had developed on the exposed surface and provide excellent material for Uranium/Thorium dating of the levels on which they formed.

Three of the dripstone samples pertain to the MSA. The results obtained for these are given in Table 4. Here again the thorium contamination is minimal and does not affect the calculated ages noticeably. Although the artefacts from the different levels have not yet been analysed in detail, they all pertain to the MSA. Typical Howieson's Poort material was recovered from disturbed deposit in Excavation V, but its relationship with Stratum 2 is unclear (P. Beaumont, pers. comm.). When the date for this level of 73 $\mathrm{ka}$ is compared with those for the Howieson's Poort assemblages from Boomplaas and Klasies River Mouth given above, it may be suspected that it immediately underlies an HP level.

The two results for the small stalagmites from Excavations III and II of $152 \mathrm{ka}$ and $168 \mathrm{ka}$ are the oldest dates thus far obtained for the MSA in the country. They are significant in that they clearly show the MSA to extend back well beyond the Last Interglacial period.

\section{Conclusions}

The uranium series dates on dripstone samples from Wonderwerk Cave place the beginning of the Middle Stone Age beyond $160 \mathrm{ka}$ ago. On the other end of the time scale the radiocarbon dates for Boomplaas Cave and Strathalan Cave suggest that the MSA survived until c. $22 \mathrm{ka} \mathrm{BP}$ in the southern Cape. Within this long time span results of our analyses on material from Klasies River Mouth and Boomplaas show that the age of the Howieson's Poort industry lies between 60 and $70 \mathrm{ka}$. The other dates from Klasies River Mouth show that the MSA I of Singer \& Wymer (1982) dates to Oxygen Isotope Stages 5d, while their MSA II starts before Stage 5b and continues into Stage 4.

These results can be compared with those produced by other dating methods. The ESR dates on tooth enamel that Grün produced for Klasies River Mouth and Border Cave consistently are some 20 to 30\% younger than both our radiocarbon and uranium-series dates (Grün et al., 1990a, b). On the other hand the AAR results on ostrich eggshell obtained by Miller for Border Cave and elsewhere (unpubl.) are slightly older (Miller et al., 1992; Beaumont et al., 1992).

These techniques at this stage still suffer from some major uncertainties, the main one being the changes in the environmental conditions over time: both Luminescence and ESR dates depend directly on the radioactive dose the sample has received, and the potential mobility of uranium and potassium in cave deposits can influence the calculation of the average dose rate and age significantly. Amino acid 
racemization, on the other hand, is highly sensitive to temperature changes and dates produced by the AAR method carry this uncertainty.

Now that more dates are becoming available for the MSA, we feel that there is an urgent need for the re-assessment and closer definition of the changes that took place in the stone tools over this long period of time. Only then will it be possible to make meaningful advances in the interpretation of the development of early human behaviour in sub-saharan Africa.

\section{Acknowledgements}

H.J. Deacon and P.B. Beaumont are thanked for providing me with sample material from their excavations at Boomplaas and Wonderwerk caves, respectively. Deacon also assisted me with the collection of the first samples at Klasies River Mouth. The help of those who participated in the laboratory analyses, J. Kronfeld, D. Schulte, D. Oschadleus and F. Morris, is gratefully acknowledged.

\section{References}

Beaumont, P.B., Miller, G.H. \& Vogel, J.C. (1972). Contemplating old clues to the impact of future greenhouse climates in South Africa. S. Afr. J. Sci., 88, 490-98.

Butzer, K.W. (1982). Geomorphology and sediment stratigraphy. In: The Middle Stone Age at Klasies River Mouth in South Africa, pp. 33-42. Chicago: Univ. of Chicago Press.

Deacon, H.J. (1979). Excavations at Boomplaas cave - a sequence through the Upper Pleistocene and Holocene in South Africa. World Archaeol., 10, 241-57.

Deacon, H.J. (1995). Two Late Pleistocene-Holocene archaeological depositories from the southern Cape, South Africa. S. Afr. Archaeol. Bull., 50, 121-31.

Deacon, H.J., Deacon, J., Scholtz, A., Thackeray, J.F., Brink, J.S. \& Vogel, J.C. (1984). Correlation of palaeoenvironmental data from the Late Pleistocene and Holocene deposits at Boomplaas cave, southern Cape. In: Late Cainozoic Palaeoclimates of the Southern Hemisphere, ed. J.C. Vogel, pp. 339-51. Rotterdam: Balkema.

Deacon, H.J. \& Geleijnse, V.B. (1988). The stratigraphy and sedimentology of the main site sequence, Klasies River, South Africa. S. Afr. Archaeol. Bull., 42, 5-14.

Fairhall, A.W., Young, A.W. \& Erickson, J.L. (1976). University of Washington dates IV. Radiocarbon, 18, 221-39.

Grün, R., Beaumont, P.B. \& Stringer, C.B. (1990). ESR dating evidence for early modern humans at Border Cave in South Africa. Nature, 344, 537-39.

Grün, R., Shackleton, N.J. \& Deacon, H.J. (1990). Electron-spin resonance dating of tooth enamel from Klasies River Mouth Cave. Current Anthropology, 31, 427-32.

Kaufman, A. (1971). U-series dating of Dead Sea basin carbonates. Geochim. et Cosmochim. Acta., 35, 1269-81.

Malan, D.B. \& Wells, L.H. (1943). A further report on the Wonderwerk Cave, Kuruman. S. Afr. J. Sci., 40, 258-70.

Miller, G.H., Beaumont, P.B., Jull, A.J.T. \& Johnson, B. (1992). Pleistocene geochronology and palaeothermometry from protein diagenesis in ostrich eggshells: implications for the evolution of modern humans. Philosophical Trans. Royal Soc. London, B, 337, 149-58.

Opperman, H. (1992). A report on the results of a test pit in Strathalan Cave B, Maclear District, North-eastern Cape. Southern African Field Archaeol., 1, 98-102.

Opperman, H. (1996). Strathalan Cave B, North-eastern Cape Province, South Africa: Evidence for human behaviour 29,000 - 26,000 years ago. Quat. Intern., 33, 45-53.

Opperman, H. \& Heydenrych, B. (1990). A 22,000 year-old Middle Stone Age campsite with plant food remains from the north-eastern Cape. S. Afr. Archaeol. Bull., 45, 93-99.

Singer, R. \& Wymer, J. (1982). The Middle Stone Age at Klasies River Mouth in South Africa, pp. 234. Chicago: University of Chicago Press.

Thackeray, A.I., Thackeray, J.F., Beaumont, P.B. \& Vogel, J.C. (1981). Dating rock engravings from Wonderwerk Cave, South Africa. Science, 214, 64-67.

Vogel, J.C. (1983). ${ }^{14} \mathrm{C}$ variations during the Upper Pleistocene. Radiocarbon 25, 2, 213-18.

Vogel, J.C. \& Kronfeld, J. (1997). Calibration of radiocarbon dates for the Late Pleistocene using U/Th dates on stalagmites. Radiocarbon, 39, 1, 27-32.

Vogel, J.C. \& Beaumont, P. (1972). Revised radiocarbon chronology for the stone age in South Africa. Nature, 237, 50-51. 


\section{Camilo J. Cela-Conde}

Department of Philosophy

Universidad de las Islas Baleares

07071 Palma de Mallorca, Spain.

Keywords: Hominoidea, Systematics, Cladistics, genus Homo

\section{Hominid Taxon and Systematics of the Hominoidea}

\begin{abstract}
Since Simpson's times, Systematics of the superfamily Hominoidea has included separate families of Pongidae and Hominidae, proposing a classification of human and extant apes that collides head on with the results of molecular studies. Therefore, Professor Morris Goodman defined a family Hominidae consisting of the genera Gorilla, Pan and Homo, thus starting a tendency to consider human beings and African apes as closely related. Lately, Professor Goodman and collaborators have placed chimpanzees and human being into the genus Homo. This scheme obliges us to re-arrange the systematics of what were formerly called the 'hominids' - australopithecines included - and makes it very difficult to match molecular phylogenies, cladistic episodes and Linnaean taxonomy. Some theoretical possibilities in order to try to solve this problem are examined.
\end{abstract}

\section{Introduction}

From its inception, cladistic systematics has forced us to construct taxonomies using only monophyletic groups as taxa. This is not a matter of caprice, but the result of a widely accepted statement that taxonomies must reflect evolutionary facts. As Smith \& Patterson (1988) say, cladistics brought rigour and consistency into systematics, considering that any taxon must be seen as a monophyletic lineage, starting and ending at a precise node. This cannot always be taken for granted. Crisp \& Chandler (1996), for instance, gave evidence, mainly from plants, that many recognised species are paraphyletic, and that any species lacking an evident autapomorphy is, potentially at least, paraphyletic. Nevertheless, Crisp \& Chandler (1996) hold that higher taxa should always be monophyletic, and can be made so.

Almost forty years ago, that demand of monophyly led Goodman (1963) to disregard Simpson's proposal of a family Pongidae consisting of, among others, Asian and African apes. Instead, Goodman proposed a family Hominidae which included Gorilla, Pan, and Homo. Since then, Goodman's proposal has had a vast influence. However, the content of the hominid taxon, as well as the category given to the human clade, has changed in the course of time. Schwartz and collaborators (1978), Groves (1989), and McKenna \& Bell (1997) gave the category of tribe (Hominini) to humans and their direct ancestors. Bailey et al. (1992), and Goodman and collaborators (1994), placed the human clade in the category of genus, sharing the taxon of Hominina (subtribe) with chimpanzees. Taking the matter even further, in a later paper just published, Goodman and collaborators (Czelusniak and Groves amongst them) give the category of only a subgenus (Homo homo) to the human clade, sharing the genus Homo with chimpanzees (Homo pan) (Goodman et al., 1998). If I have understood correctly, Watson and collaborators propose in this colloquium to include gorillas in the genus Homo, too. This is at the moment the most radical proposal, and the least that can be said about it is that few anthropologists will feel comfortable with this solution. However, discomfort is not a strong scientific argument against any classification. Let me argue in favour of a reduced, stronger concept of 'hominid', taking into account some more objective reasons.

The disagreement about where to place the human clade refers to the rank of the taxon, not to the 
content of that taxon. Nevertheless, confusion still lingers on. Using a sentence of Ereshefsky, we are giving different names to what we agree is the same taxon, and giving the same name to what we agree are different taxa (Ereshefsky, 1997, in reference to Simpson's and Wiley's discussion about the taxon rank of Homo). It is worth trying to arrive at some solution capable of putting an end to this ambiguous situation. How can this be done? Even if we take for granted that classifications must be grounded on monophyly, this principle does not give us any help in settling what category best fits the human clade taxon. In fact, to be in agreement with the phylogenetic sequence proposed by Goodman, and to follow the taxonomy proposed by him, are different aspects that we should consider independently. To express this in Martin's words, "although cladistic principles may dictate the divisions expressed in a classification, they do not dictate the taxonomic rank at which those divisions are made" (Martin, 1990, p. 96).

\section{The Criterion of Last Common Ancestor (LCA)}

It is often held that categories in which taxa are placed are matters of arbitrary choice. However, the existence of different taxonomies of Hominoidea that collide head on is not a good solution; this, incidentally, is the current situation. Human beings and their ancestors are seen variously as a family, subfamily, tribe, genus, or subgenus, depending on each scholar's point of view. A different scheme appears if taxa are considered individuals rather than classes (Ghiselin, 1966, 1981, 1984; Eldredge \& Salthe, 1984). If we think about it in this way, categories should not be arbitrary, but should be a reflection of some adaptive and evolutionary episodes that led to the appearance of each and every new clade. What kind of episodes would they have been? The appearance of only a new trait is enough to identify a new species under the Phylogenetic Species Concept (PSC) (1). However, it seems clear that if just one trait, no matter how trivial it may be, is enough for the recognition of a species, many extant subspecies, proved to be so under the Biological Species Concept (BSC), should be promoted to the rank of species (the danger of multiplying species in this way is pointed out by Avise \& Ball, 1990). As any Phylogenetic species was, in its day, a Biological species, we should accept that a trait is not enough to characterise any species, unless this character may reflect a strong tendency to follow an isolated interbreeding journey.

What kind of character would be strong enough to result in the appearance of not only a new species, but a new genus, or even a new family? This is a question that can be answered only retrospectively. As Härlin \& Sundberg (1998) say: "Clades can never be observed empirically since they are historical individuals inferred from present knowledge, and we can never be sure of having found the true phylogenetic chronology". However, once the node gave way to some amount of diversification, higher taxa could be considered to classify the new clade. Nevertheless, what happens when two branches that appeared at the same node end up having different amounts of diversification? This is the case if one branch consists of just one species, with no further cladistic episodes, while the other branch includes one or several new nodes (see Figure 1). In what category must taxon 1, and taxon $2+3+4+5+6$, be placed?

The latest proposal by Goodman and collaborators (Goodman et al., 1998) uses the relationship between cladistic branching and geological dating, that is to say, the age of the estimated LCA (Last Common Ancestor), as a tool to decide in which category a taxon should be placed. As Goodman et al. (1998) say: "Pan and Homo are sister-groups with an estimated LCA age of 6 Myr. Thus by the principle of rank equivalence with other primate clades of the same age, Pan and Homo should be treated as subgenera of Homo".

\section{Diversity Criterion}

LCA age is a criterion that may be used to place taxa into categories, but it is not the only possible criterion; it is doubtful if it might even be considered a good one. In his study on the origin of higher taxa, Holman (1996) concluded that this origin is actually a function, not of time, but of cumulative diversity, which depends upon the number of branches that have previously diverged within a larger 
group. Furthermore, the category to be given to any taxon depends on the rate of divergence of lower taxa deriving from it. This rate may very well vary within sister clades. As Vrba (1980) says: “... one of the most interesting aspects of evolution concerns the very different histories, in terms of morphological diversification, which such sister taxa often have". Chimpanzees, for instance, have no ancestral species known to us thus far (unless Ardipithecus eventually proves to be ancestral to Pan). On the other hand, humans may have as many as four ancestral genera and fourteen ancestral species as suggested by Groves (1989) (see Table 1). As is well known, other species belonging to the genus Homo have been proposed after the publication of Groves' list, such as Australopithecus anamensis (Leakey et al., 1995), Australopithecus bahrelghazali (Brunet et al., 1995) and Homo antecessor (Bermúdez de Castro et al., 1997).

It seems difficult to match this diversity of species with existing taxonomic tools, under the category of subgenus, but the lack of flexibility of Linnaean categories should not be an obstacle to scientific classifications. In their study on Phylogenetic taxonomy, De Queiroz \& Gauthier (1992) hold that it may be best served by abandoning the Linnaean categories, and this is something that could be achieved, in part at least, by using the annotated hierarchy proposed by Wiley (1979) (Wiley follows an idea discussed by Hull, 1966, which was also used by Hennig in his cladistic taxonomies; see Figure 2). Thus, the real problem is not the lack of intermediate categories, but the categorical range that, in order to reach a useful taxonomy of Hominoidea, must be given to every taxon.

Diversification is a criterion that suggests the need of a higher category in which to place the human taxon. On its own, a subgenus will not sit comfortably with anthropologists dealing with such a quantity of species. In fact, Simpson (1963) used the divergence of Homo as one of his main arguments to give the category of family to the human branch. Even if we do not agree with Simpson's proposal of the Pongidae as a polyphyletic group, the human clade still deserves the rank of family because of its wide diversity. The use of 'plesions' may be a good solution to avoid complications in the Linnaean hierarchy, but it cannot diminish the phylogenetic meaning of that great diversity. Vrba's (1979) study of evolutionary rates in

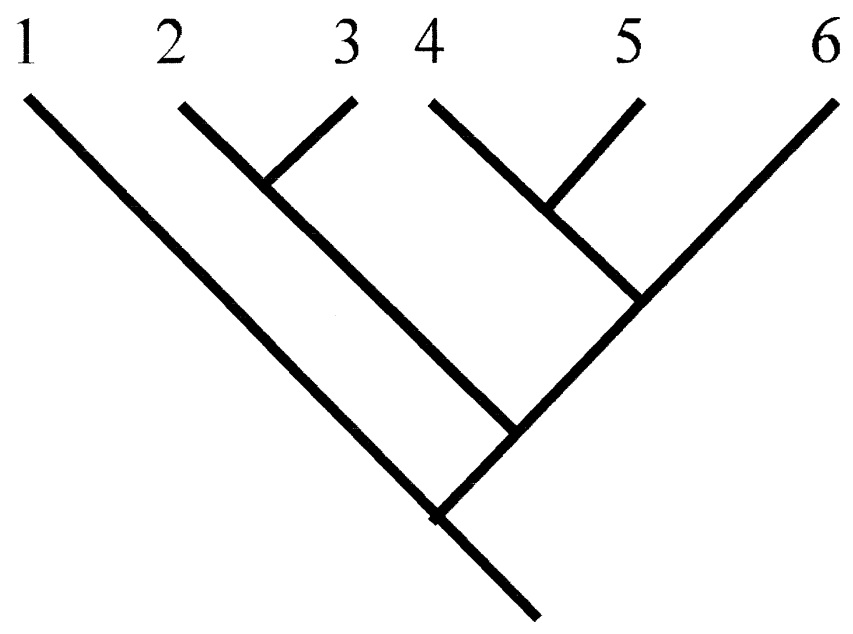

Figure 1. 
Table 1. Genera and Species of Hominini, (From Groves, 1989).

genus unnamed (plesiomorphic sister taxon to all other Hominini)
genus Paranthropus
P. robustus
P. crassidens
P. boisei
P. cf. boisei
P. walkeri
genus Australopithecus
A. africanus
A. afarensis
genus Homo
H. sp. (unnamed) (Hadar)
H. aethiopicus
H. rudolfensis
H. habilis
H. ergaster
H. sp. (unnamed) (Koobi Fora)
H. erectus
H. sapiens

African bovids, for instance, concluded that two basal sister groups differed in rate of branching: Aepycerotini (with two species) and Alcelaphini (with at least 27 species). Both Aepycerotini and Alcelaphini have an estimated LCA age of $6 \mathrm{Myr}$, like the chimpanzee/Homo example, but each one of these bovids achieved the rank of tribe. Nevertheless, let me mention another criterion in favour of the strong concept of a family Hominidae: that of the evolutionary vector in the context of macroevolution (Eldredge \& Cracraft, 1980). Michener (1957) was very precise when pointing out the connection that exists between group size and higher categories, but he did not ignore the fact that the success of any group is a result of some kind of adaptive solution (Michener gives the example of bees and pollen collecting).

\section{Functional Criteria}

Morphological differences between chimpanzees and humans have often been suggested as proof of strong divergence. On the other hand, genetic data support a closer relationship (Ruvolo, 1997) (2). I would like to point out that neither morphological nor genetic distance are, by themselves, clear-cut enough to place taxa in a particular category. Once again, the problem of conspicuous traits surfaces. Therefore, we are compelled to find a character, or a set of characters, that prove to be of great adaptive and evolutionary importance. This principle has had the support of different concepts, such as the 'magic trait' or the 'initial kick', i.e., a particular character of great evolutionary importance, giving way to new functional possibilities with strong adaptive meaning - an evolutionary vector.

However, an obstacle appears. Cracraft (1981) strongly criticised the place of functional arguments in evolutionary studies. As Cracraft reminds us, statements about natural selection should be restricted to the intrapopulation level of analysis. Extending natural selection to supraspecific levels confuses the issue of process analysis and leads to axiomatic reasoning in its treatment of causal processes. Nevertheless, functional traits have often been used as an important tool in cladistics, either to get rid of the multiple consideration of functionally related characters (Strait et al., 1997) (functionally related 


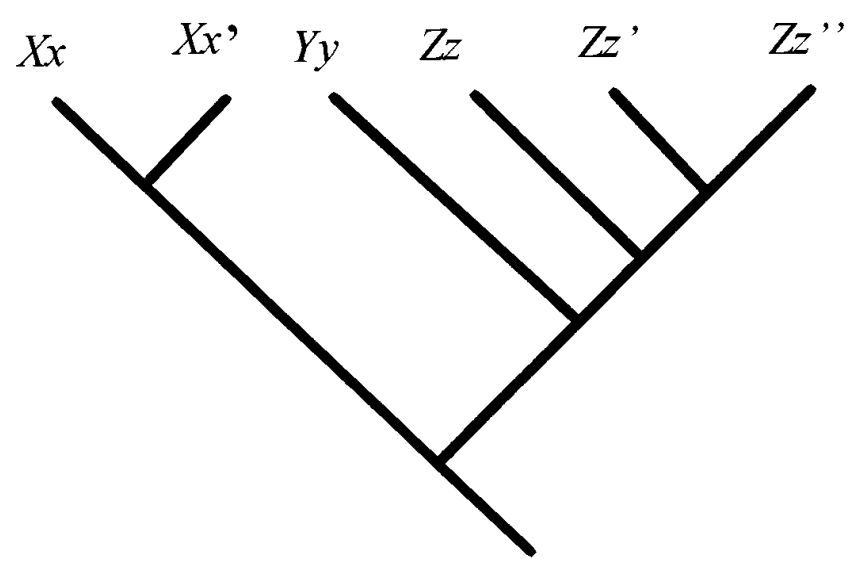

Family XYZ

Genus $X$

Species $X x$

Species $X x$,

Genus $Y$

Species $Y y$

Genus $Z$

Species $Z z$

Species $Z z$ '

Species $Z z$ ',

Figure 2. Annotated Linnaen Hierarchy, (From Wiley, 1979).

characters violate the assumption of character independence that is implicit in cladistic analysis), or to decide the polarity of morphoclines (Gutmann, 1977; Skelton et al. 1986).

The adaptive advantage of the character 'bipedalism' means that a clade owning this trait gave way to distinct systems of profiting from bipedal opportunities, thus leading to several functional solutions. The fitness of each of these functional solutions must be tested within each of the several populations. Some of the ancestral humans were probably not fully bipedal, some of them specialized in hard-vegetal diet, some made stone tools, but internally, in each and every different branch of ancestral humans, the functional trait of bipedalism was of great importance. Taking this importance into account, we may hold that 'bipedalism' is a characteristic shared between different species and different genera, that gave a strong evolutionary vector to the human clade. Many authors sympathetic to phylogenetic criteria of classification group Australopithecus and Homo together because of their shared characters related to erect posture and bipedal locomotion.

Bipedalism gave way to a huge amount of diversification after the appearance of the Pan-Homo cladogeny. This is not an arbitrary coincidence. Jablonski \& Bottjer (1991) gave evidence on how environmental variables are important factors in the origin of higher taxa. Anyway, we do not know whether the Pan clade diverged, but we are sure that the Homo clade did. However, neither this process of divergence, nor the evolutionary vector, are recognised from my point of view by placing the polytaxic human branch into a subgenus. Humans and their direct or collateral ancestors must be placed in a category higher than that given to their several Pliocene branches (Australopithecus, early Homo and, perhaps, Ardipithecus), which are widely considered to have the rank of genera. Amongst the different possibilities that exist for us to place them, i.e., tribe, supertribe, subfamily or family, it seems that the enormous weight of the strong, traditional, meaning of 'hominid' is a good reason to keep the family grade when classifying the human clade. This is also the conclusion reached by Martin (1990) and Schwartz (1986), after detailed examination of the order Primates. To give some recent examples, 
Stringer (1987), Kennedy (1991) and Bräuer \& Mbua (1992) still use the traditional meaning of 'hominid' in their cladistically-oriented studies.

\section{Taxonomy of the Great Apes}

Another different question is how we may classify the African Great Apes. Two different solutions spring to mind. On the one hand, we may accept monophyly, according to Goodman (1963), as the main criterion to reach Hominoidea taxonomy. In this case, the chimpanzee and gorilla clades must each be placed in a category of the same rank as the human clade, i.e., that of family. This is my own suggestion (Cela-Conde, 1998, 1999). Therefore, we are faced with a problem of a phylogenetic tree with 'three crown taxa' (de Queiroz \& Gauthier, 1994). This is almost impossible to avoid in a Linnaean hierarchy (see Ereshefsky, 1997).

On the other hand, monoplyhly may be rejected in favour of the strong adaptive resemblance of African Great Apes. Schwartz (1986) is of this opinion when he suggests using the family Panidae to subsume Pan and Gorilla, even if this violate the confines of monophyly. The ecological approach to systematics (Van Valen, 1985) would "view paraphyletic groups as real, identifiable elements of the biosphere that can be objectively discovered and have a history and death that reflect evolutionary processes" (Smith \& Patterson, 1988, p. 131). It is not held here that we either disagree with Goodman's phylogeny of Hominoidea, or support a Hominidae taxonomy that rejects the principles of cladistics.

Therefore, when trying to reach an accurate taxonomy of humans and great apes we are faced with some predicaments:

1) If we accept the results of molecular studies, then there is no room to place human ancestors. We might even be forced to group all Ardipithecus, Australopithecus and Homo into a single species, Homo sapiens.

2) If we classify on the grounds of functional characters, and at the same time retain monophyly, then we must separate gorillas from chimpanzees, that have similar adaptive solutions, and place them in different families.

3) If we group by means of adaptive characteristics, then we are forced to reject monohpyly, keeping gorillas and chimpanzees together in the same family, as Simpson did.

None of these solutions is satisfactory. However, it is worth trying to reach an agreement, avoiding the current ambiguity of what a hominid is.

\section{Notes}

${ }^{1}$ If we follow the concept of PSC proposed by Nixon \& Wheeler (1990), the "unique combination of character states" ends up being the main criterion to identify a phylogenetic species. Nixon \& Wheeler (1990) distinguish between 'characters' (attributes that are found in all comparable individuals in a terminal lineage) and 'traits' (attributes that are not so). Polymorphisms refer, in this case, to traits, not to characters. In spite of Nixon \& Wheleer's distinction, I use the words 'trait' and 'character' here as equivalents.

${ }^{2}$ When taxonomies based on morphology and on genetic distances disagree, it is not always clear that the genetic distance method will be more plausible. Considering each locus as a discrete character, Altaba (1997) infers a phylogeny that better matches with the taxonomic treatment of the genus Alytes based on morphology.

\section{References}

Altaba, C.R. (1997). Phylogeny and biogeography of midwife toads (Alytes, Discoglossidae): a reappraisal. Contributions to Zoology, 66, 257-62.

Avise, J.C. \& Ball, R.M. (1990). Principles of genealogical concordance in species concepts and biological taxonomy. Oxford Surveys in Evolutionary Biology, 7, 45-67.

Bailey, W.J., Hayasaka, K., Skinner, C.G., Kehoe, S., Sieu, L.C., Slightom, J. \& Goodman, M. (1992). Reexamination of the African Hominoid Trichotomy with additional sequences from the Primate b-Globin Gene Cluster. Molecular Phylogenetics and Evolution, 1, 97-135. 
Bermúdez de Castro, J.M., Arsuaga, J.L., Carbonell, E., Rosas, A., Martínez, I. \& Mosquera, M. (1997). A hominid from the Lower Pleistocene of Atapuerca, Spain: possible ancestor to Neandertals and modern humans. Science, 276, 1392-95.

Bräuer, G. \& Mbua, E. (1992). Homo erectus features used in cladistics and their variability in Asian and African hominids. Journal of Human Evolution, 22, 79-108.

Brunet, M., Beauvilain, A., Coppens, Y., Heintz, E., Moutaye, A.H.E. \& Pilbeam, D. (1995). The first australopithecine 2,500 kilometres west of the Rift Valley (Chad). Nature, 378, 273-75.

Cela-Conde, C.J. (1998). The problem of hominoid systematics, and some suggestions on the possibilities of solving it. South African Journal of Science, 94, 255-62.

Cela-Conde, C.J. (1999). The meaning of Hominidae. Human Evolution, 14(1/2), (in press).

Cracraft, J. (1981). The use of functional and adaptive criteria in phylogenetic systematics. American Zoologist, 21, 21-36.

Crisp, M.D. \& Chandler, G.T. (1996). Paraphyletic species. Telopea, 6, 813-44.

De Queiroz, K. \& Gauthier, J. (1992). Phylogenetic taxonomy. Annual Review in Ecology and Systematics, 23, 449-80.

De Queiroz, K. \& Gauthier, J. (1994). Toward a phylogenetic system of biological nomenclature. Trends in Ecology and Evolution, 9, 27-31.

Eldredge, N. \& Cracraft (1980). Phylogenetic Patterns and Evolutionary Process. New York: Columbia University Press.

Eldredge, N. \& Salthe, S.N. (1984). Hierarchy and evolution. Oxford Surveys in Evolutionary Biology, 1, 184-208.

Ereshefsky, M. (1997). The evolution of Linnean hierarchy. Biology and Philosophy, 12, 493-519.

Ghiselin, M.T. (1966). On psychologism in the logic of taxonomic controversies. Systematic Zoology, 15, $207-215$.

Ghiselin, M.T. (1981). Categories, life, and thinking. Behavioral and Brain Sciences, 4, 269-313.

Ghiselin, M.T. (1984). 'Definition', 'character', and other equivocal terms. Systematic Zoology, 33, $104-10$.

Goodman, M. (1963). Man's place in the phylogeny of the primates as reflected in serum proteins. In: Classification and Human Evolution, ed. S.L. Washburn, pp. 204-34, Chicago, Ill.: Aldine.

Goodman, M., Bailey, W.J., Hayasaka, K., Stanhope, M.J., Slightom, J. \& Czelusniak, J. (1994). Molecular evidence on primate phylogeny from DNA sequences. American Journal of Physical Anthropology, 94, 3-24.

Goodman, M., Porter, C.A., Czelusniak, J., Page, S.L., Schneider, H., Shoshani, J., Gunnell, G. \& Groves, C.P. (1998). Toward a phylogenetic classification of primates based on DNA evidence complemented by fossil evidence. Molecular Phylogenetics and Evolution, 9, 585-98.

Groves, C.P. (1989). A Theory of Human and Primate Evolution. Oxford: Clarendon Press.

Gutmann, W.F. (1977). Phylogenetic reconstruction: theory, methodology, and application to chordate evolution. In: Major Patterns in Vertebrate Evolution, ed. M.K. Hecht, P.C. Goody \& B.M. Hecht, pp. 645-69, New York, N.Y.: Plenum.

Härlin, M. \& Sundberg, P. (1998). Taxonomy and philosophy of names. Biology and Philosophy, 13, $233-44$.

Holman, E.W. (1996). The independent variable in the early origin of higher taxa. Journal of Theoretical Biology, 181, 85-94.

Hull, D. (1966). Phylogenetic numericlature. Systematic Zoology, 15, 14-17.

Jablonski, D. \& Bottjer, D.J. (1991). Environmental patterns in the origins of higher taxa, the post-Paleozoic fossil record. Science, 252, 1831-33.

Kennedy, G.E. (1991). On the autapomorphic traits of Homo erectus. Journal of Human Evolution, 20, $375-412$.

Leakey, M.G., Feibel, C.S., McDougall, I. \& Walker, A. (1995). New four-million-year-old hominid species from Kanapoi and Allia Bay, Kenya. Nature, 376, 565-72.

Martin, R.D. (1990). Primate Origins and Evolution. A Phylogenetic Reconstruction. London: Chapman and Hall.

McKenna, M.C. \& Bell, S.K. (1997). Classification of Mammals Above the Species Level. New York: Columbia University Press.

Michener, C.D. (1957). Some bases for higher categories in classification. Systematic Zoology, 6, $160-73$.

Nixon, K.C. \& Wheeler, Q.D. (1990). An amplification of the phylogenetic species concept. Cladistics, 6, $211-23$.

Ruvolo, M. (1997). Molecular phylogeny of the hominoids: inferences from multiple independent DNA sequence data sets. Mol. Biol. Evol., 14, 248-65.

Schwartz, J.H. (1986). Primate systematics and a classification of the Order. Comparative Primate Biology, 1: Systematics, Evolution and Anatomy, 1-41.

Schwartz, J.H., Tattersall, I. \& Eldredge, N. (1978). Phylogeny and classification of the primates revisited. Yearbook of Physical Anthropology, 21, 95-133. 
Simpson, G.G. (1963). The meaning of taxonomic statements. In: Classification and Human Evolution, ed. S.L. Washburn, pp. 1-31, Chicago, Ill.: Aldine.

Skelton, R.R., McHenry, H.M. \& Drawhorn, G.M. (1986). Phylogenetic analysis of early hominids. Current Anthropology, 27, 21-35.

Smith, A.B. \& Patterson, C. (1988). The influence of taxonomic method on the perception of patterns of evolution. Evolutionary Biology, 23, 127-216.

Strait, D.S., Grine, F.E. \& Moniz, M.A. (1997). A reappraisal of early hominid phylogeny. Journal of Human Evolution, 32, 17-82.

Stringer, C.B. (1987). A numerical cladistic analysis for the genus Homo. Journal of Human Evolution, 16, 135-46. Van Valen, L.M. (1985). A theory of origination and extinction. Evolutionary Theory, 7, 133-42.

Vrba, E.S. (1979). Phylogenetical analysis and classification of fossil and recent Alcelaphini Mammalia: Bovidae. Biological Journal of the Linnaean Society, 11, 207-28.

Vrba, E.S. (1980). Evolution, species and fossils: how does life evolve? South African Journal of Science, 76, 61-84. Wiley, E.O. (1979). An annotated Linnaean hierarchy, with comments on natural taxa and competing systems. Systematic Zoology, 28, 308-37. 


\section{Morris Goodman, John Czelusniak, Scott Page \& Carla M. Meireles}

Wayne State University School of Medicine, Department of Anatomy and Cell Biology, 540 E. Canfield Avenue, Detroit, Michigan 48201, USA

Keywords: DNA, phylogeny, primates

\section{Where DNA Sequences Place Homo sapiens in a Phylogenetic Classification of Primates}

Cladistic evidence from extensive DNA data, especially from orthologous nuclear genomic sequences, is providing a clear picture of the phylogenetic relationships of humans and other primates. This DNA evidence and the time scale provided by the model of local molecular clocks coupled to fossil evidence yields a phylogenetic classification that has all of its taxa represent clades and assigns the same hierarchical rank to taxa of roughly equivalent age. In this classification, when each clade is traced back to its last common ancestor with a sister clade (each taxon treated as a total group, i.e. crown group plus stem group), the haplorhine suborders Tarsiiformes and Anthropoidea along with the strepsirhine suborders Lemuriformes and Lorisiformes represent clades that originated at estimated ages of 58-50 Ma (Millions of years ago); the lemuriform infraorders Chiromyiformes and Eulemurides along with the anthropoid infraorders Platyrrhini and Catarrhini originated at 45-40 Ma, and families within these infraorders at 28-25 Ma, subfamilies at 23-22 $\mathrm{Ma}$, tribes at 20-14 Ma, subtribes at 14-10 Ma, genera at 11-7 Ma, and subgenera at 6-4 Ma. in contrast to the traditional family Hominidae, which has Homo sapiens as its only living species, the age-equals-rank system places all living apes and humans in the subfamily. In turn Homininae divides into Hylobatini (common and siamang gibbons) and Hominini, the latter into Pongina for Pongo (orangutans) and Hominina for Gorilla and Homo. Homo itself divides into the subgenera $H$. (Homo) for humans and $H$. (Pan) for chimpanzees and bonobos. Even on disbanding Australopithecus and Ardipithecus by placing their species into Homo (Homo), the presumed phylogenetic relationships of these extinct species to each other and to living humans can be depicted by how the species are listed and indented under the subgenus rank.

\section{Introduction}

Sizeable amounts of DNA sequence data represent not only members of almost all primate taxa above the generic level but also 41 of the 60 currently recognized extant genera. Phylogenetic reconstructions carried out on these data have elucidated the genealogical relationships that exist among primate clades. In doing so the genealogical findings call for revisions in the formal taxonomic classification of primates, including positioning the human species Homo sapiens in a radically new way. Not only do all the apes group with humans within a single family, but also the common and pygmy chimpanzees as a subgenus are the sister of a subgenus for humans, the two subgenera grouping together in the genus Homo.

The phylogenetic classification (Table 1) that has this radically different position for Homo sapiens was constructed according to three principles proposed by Hennig (1966), the founder of cladistic taxonomy. The first principle is that each taxon should represent a monophyletic group or clade, i.e. represent all the species descended from a common ancestor. The second principle is that the 
hierarchical groupings of lower ranked taxa into higher ranked taxa should reflect the sister-group relationships of the clades. The third principle is that ideally taxa at the same hierarchical level or rank should represent clades that are equally old, i.e. at an equivalent evolutionary age.

The phylogenetic classification (Table 1) that we have constructed according to these three principles portrays a series of phylogenetic branchings during the course of primate evolution from Paleocene ancestors of the modern primates to representative present-day species. We obtained this phylogenetic information from studies conducted on aligned orthologous noncoding DNA sequences from the nuclear genomes of extant primates (Goodman et al., 1998; Meireles et al., 1999; Page et al., 1999). Maximum parsimony and maximum likelihood analyses of these aligned noncoding DNA sequences produced highly resolved phylogenetic trees with most nodes receiving strong support by the parsimony and likelihood criteria. Thus our classification focuses on the sister-group relationships of the primate taxa that contain extant members.

\section{Ages of Primate Clades}

For each phylogenetic branching (i.e., division of a higher ranked taxon into lower ranked taxa), the time of the branching estimated in units of millions of years ago (Ma) is shown in parenthesis after the time of the higher ranked taxon. Calculations by the model of local molecular clocks (Goodman, 1986), i.e. calculations constrained by the fossil evidence on primate phylogeny, yielded these estimated ages of primate clades from the percentages of sequence change on the branches of phylogenetic trees constructed from the DNA data (Bailey et al., 1992; Porter et al., 1997a,b; Goodman et al., 1998; Meireles et al., 1999; Page et al., 1999; Porter et al., 1999; Chaves et al., 1999).

The age in Ma units placed after the name of a taxon is the estimated age of that taxon treated as a crown group-but also of that taxon's closest (at a step below in rank) subordinate taxa treated as total groups. A crown group includes the last common ancestor (LCA) of the extant species in a clade and all descendant species (extinct and extant) of the LCA, but does not include the stem of the LCA (Jeffries, 1979). The total group includes, in addition to all members of the crown group, the stem of the LCA and all extinct offshoots of the stem. Thus the age of $63 \mathrm{Ma}$ for the LCA of all living primates, i.e. the age for Primates as a crown group, is the age for Strepsirhini as a total group, also for Haplorhini as a total group. In turn the ages of $50 \mathrm{Ma}$ and $58 \mathrm{Ma}$ listed alongside Strepsirhini and Haplorhini, respectively, are the ages for these two taxa treated as crown groups.

After this first major branching of the early Paleocene ancestors of modern primates into semiordinal clades, subordinal clades emerged. The late Paleocene haplorhines divided into Tarsiiformes and Anthropoidea; in turn, the early Eocene strepsirhines divided into Lemuriformes and Loriformes. The middle Eocene lemuriforms (at about $45 \mathrm{Ma}$ ) divided into infraorders Chiromyiformes and Eulemurides, the former represented today by the enigmatic aye-aye (the single species Daubentonia madagascariensis) and the latter by all other Malagasy strepsirhines. The middle Eocene anthropoideans (at about $40 \mathrm{Ma}$ ) divided into infraorders Platyrrhini and Catarrhini. In the late Oligocene, superfamilies as crown groups divided (at about 28 and $25 \mathrm{Ma}$ ) into families as total groups.

Table 2 summarizes the data from our study on the estimated ages of primate taxa on proceeding from the Paleocene origin of the order (as a crown group) and its semiorders (as total groups) to the Pliocene and Pleistocene origins of subgenera and species. In developing this scheme in which the taxa represent clades and the ages of the clades determine the ranks of the taxa, we found that many of the taxonomic arrangements in other primate classifications (e.g. Martin, 1990; Groves, 1993) could be utilized. Even in traditional primate classifications, the monophyletic taxa far outnumber paraphyletic and polyphyletic taxa. However, the sister-group relationships among taxa, generally, are not well depicted in traditional primate classifications. Also, taxa at the same rank are not necessarily of an equivalent age. Nevertheless a crude correlation does exist between the age of origin of a taxon and its rank. In this regard, Romer (1962) in his assessment of the fossil record observed that among mammals 
Table 1

Order Primates (63 Ma)

Phylogenetic Classification of Primates Examined in this Study

Semiorder Strepsirhini (50 Ma)

Suborder Lemuriformes (45 Ma)

Infraorder Chiromyiformes

Family Daubentoniidae

Daubentoni madagascariensis: aye-aye

Infraorder Eulemurides

Superfamily Lemuroidea (28 Ma)

Family Cheirogaleidae (22 Ma)

Subfamily Microcebinae

Microcebus murinus: gray mouse lemur

Subfamily Cheirogaleinae

Cheirogaleus medius: fat-tailed dwarf lemur

Family Indridae

Propithecus verreauxi: verreaux's sifaka

Family Lemuridae

Suborder Loriformes

Eulemur fulvus: brown lemur

Family Loridae (23 Ma)

Subfamily Galagoninae

Otolemur crassicaudatus: thick-tailed greater bush baby

Subfamily Perodicticinae

Perodicticus potto: potto

Subfamily Lorinae

Nycticebus coucang: slow loris

Semiorder Haplorhini (58 Ma)

Suborder Tarsiiformes

Family Tarsiidae

$$
\begin{aligned}
& \text { Tarsius }(6 \mathrm{Ma}) \\
& \text { T. syrichta: Philippine tarsier } \\
& \text { T. bancanus: western tarsier }
\end{aligned}
$$

Suborder Anthropoidea (40 Ma)

Infraorder Platyrrhini

Superfamily Ceboidea (26 Ma)

Family Cebidae (22 Ma)

Subfamily Cebinae (20 Ma)

Tribe Cebini

Cebus (5 Ma)

C. albifrons: white-fronted capuchin

C. olivaceus: weeper capuchin

C. kaapori: capuchin

Tribe Saimiriini

Saimiri (2 Ma)

S. sciureus: common squirrel monkey

S. boliviensis: Bolivian squirrel monkey 
Subfamily Aotinae

Aotus (3 Ma)

A. azarae: red-necked night monkey

A. nancymai: red-necked night monkey

Subfamily Callitrichinae

Tribe Callitrichini (14 Ma)

Subtribe Saguinina

Saguinus (6 Ma)

S. fusicollis: saddleback tamarin

S. bicolor: bare-faced tamarin

$S$. midas: golden-handed tamarin

Subtribe Leontopithecina

Leontopithecus rosalia: golden lion tamarin

Subtribe Callimiconina

Callimico goeldii: goeldi's monkey

Subtribe Callitrichina

Callithrix (5 Ma)

C. (Callithrix) (1 Ma)

C. (C.) jacchus: common marmoset

C. (C.) geoffroyi: geoffroy's tufted-eared marmoset

C. (Cebuella) pygmaea: pygmy marmoset

C. (Mico) (3 Ma)

C. (M.) argentata: bare-ear marmoset

$C$. (M.) humeralifer: tassel-eared marmoset

$C$. (M.) mauesi: maues marmoset

Family Pitheciidae

Subfamily Pitheciinae (19 Ma)

Tribe Callicebini

Callicebus ( $7 \mathrm{Ma}$ )

C. moloch: dusky titi monkey

C. torquatus: collared titi monkey

Tribe Pitheciini (11 Ma)

Pithecia irrorata: bald-faced saki

Chiropotes (6 Ma)

C. (Cacajao) calvus: bald uacari

C. (Chiropotes) satanas: bearded saki

Family Atelidae

Subfamily Atelinae (17 Ma)

Tribe Alouattini

Alouatta (3 Ma)

A. caraya: black-and-gold howler

A. belzebul: red-handed howler

A. seniculus: red howler

Tribe Atelini (12 Ma)

Subtribe Atelina

Ateles (4 Ma)

A. paniscus: black spider monkey 
A. geoffroyi: black-handed spider monkey

Subtribe Brachytelina (10 Ma)

Lagothrix lagotricha: woolly monkey

Brachyteles arachnoides: woolly spider monkey

Infraorder Catarrhini

Superfamily Cercopithecoidea (25 Ma)

Family Cercopithecidae

Subfamily Cercopithecinae (15 Ma)

Tribe Colobini (10 Ma)

Subtribe Colobina

Colobus guereza: Abyssinian colobus

Subtribe Presbytina (7 Ma)

Trachypithecus obscuris: spectacled leaf monkey or langur

Nasalis larvatus: proboscis monkey

Tribe Cercopithecini (10 Ma)

Subtribe Cercopithecina ( $9 \mathrm{Ma}$ )

Cercopithecus

C. cephus: mustached guenon

Erythrocebus

E. patas: patas monkey

Chlorocebus

C. aethiops: green monkey

Subtribe Papionina ( $9 \mathrm{Ma}$ )

Macaca (4 Ma)

M. mulatta: rhesus macaque

M. nigra: Celebes macaque

Cercocebus (5 Ma)

C. (Mandrillus) (4 Ma)

$C$. (M.) sphinx: mandrill

C. (M.) leucophaeus: drill

C. (Cercocebus) galeritus: Tana river mangabey

Papio (4 Ma)

P. (Papio) hamadryas cynocephalus: yellow baboon

$P$. (Theropithecus) gelada: gelada baboon

Family Hominidae

$P$. (Lophocebus) aterrimus: black mangabey

Subfamily Homininae (18 Ma)

Tribe Hylobatini

Subtribe Hylobatina ( $8 \mathrm{Ma}$ )

Symphalangus syndactylus: siamang

Hylobates lar: white-handed gibbon

Tribe Hominini (14 Ma)

Subtribe Pongina

Pongo pygmaeus: Borneo orangutan

Subtribe Hominina (7 Ma)

Gorilla gorilla: gorilla

Homo (6 Ma) 


\author{
H. (Pan) (3 Ma) \\ H. (P.) troglodytes: chimpanzee \\ $H$. (P.) paniscus: pygmy chimpanzee or bonobo \\ H. (Homo) sapiens: humankind
}

\begin{abstract}
a An age placed in parenthesis after the name of a higher taxon in this hierarchical classification represents the estimated age of that higher taxon, treated as a crown goup, but also of the next lower ranking taxa, treated as total groups. Common names for extant species are from Rowe (1996). Estimated ages are either the same or very close to previous estimates (Goodman et al., 1998, 1999). Additional information from the molecular phylogenetic trees produced in recent studies were used in recalculating the estimated ages for taxa within Platyrrhini (Meireles et al., 1999; Porter et al., 1999; Chaves et al., 1999) and within Cercopithecidae (Page et al., 1999). Subgeneric names are used here for any collection of species with an estimated LCA age of $6 \mathrm{Ma}$ or less and with at least some species in the collection having different full generic names in Groves (1993), also in Rowe (1996) who follows Groves in his use of generic names. In fact to have a rough equivalance for taxa at the same rank, subgeneric names should also have been used for the subdivisions within Tarsius, Cebus, Saguinus, Callicebus, Ateles, and Macaca as the estimated crown group ages of these genera are 6,5,6,7,4, and $4 \mathrm{Ma}$, respectively.
\end{abstract}

the rise of modern orders and suborders occurred in the Eocene, the rise of modern families in the Oligocene, and modern subfamilies in the Miocene. In correlation, our classification with its rankequals-age system places the primate suborders, families, and subfamilies, when treated as total groups, in the Eocene, Oligocene, and Miocene geological epochs, respectively.

\title{
Later Descent of Strepsirhines and Tarsiers
}

In the early Miocene both the lemuriform cheirogaleids (at about $22 \mathrm{Ma}$ ) and loriform lorids (at about $23 \mathrm{Ma}$ ) branched into subfamilial clades. Much later at the end of the Miocene (at about $6 \mathrm{Ma}$ ) subgeneric clades emerged from a phylogenetic branching in the crown group Tarsius. Out of 47 currently recognized extant strepsirhine species, only eight are represented in our DNA studies. Because of this gross under-representation of strepsirhines, the strepsirhine portion of our classification is not yet able to depict sister taxa at tribal, subtribal, and subgeneric levels.

\section{Anthropoidean Descent: Platyrrhines}

Platyrrhines and catarrhines are much better represented in our DNA studies; thus our classification depicts for them sister taxa at all ranks between the family and species. In the late Oligocene the platyrrhine superfamily Ceboidea began dividing (at about $26 \mathrm{Ma}$ ) into families. The DNA evidence depicts three ceboid families, Cebidae, Pitheciidae, and Atelidae, but does not yet reveal which two of the three are most closely related. Cebidae consists of subfamilies Cebinae, Aotinae, and Callitrichinae; these three subfamilial cebid clades branched apart (starting at about $22 \mathrm{Ma}$ ) in the early Miocene. Soon thereafter, the early Miocene cebines (at about $20 \mathrm{Ma}$ ), divided into tribes Cebini and Saimiriini, each with only a single extant genus. Except for the lineages to Cebus and Saimiri, all other lineages in the two cebine tribes became extinct. Similarly, extinctions in the cebid subfamily Aotinae left Aotus as the only extant aotine genus. All extant members of the cebid subfamily Callitrichinae group together in the tribe Callitrichini. In the middle to late Miocene (starting at about $14 \mathrm{Ma}$ ) the basal callitrichins branched into the monogeneric subtribes Saguinina (Saguinus), Leontopithecina (Leontopithecus), Callimiconina (Callimico), and Callitrichina (Callithrix). Within Cebidae in the early Pliocene, genera as crown groups branched into subgenera as illustrated by Cebus (at about $5 \mathrm{Ma}$ ), Saguinus (at about $6 \mathrm{Ma}$ ), and Callithrix (starting at about $5 \mathrm{Ma}$ ). In turn later in the Pliocene and early Pleistocene (at about 3 to $<1 \mathrm{Ma}$ ), the subgenera as 
Table 2. Ages of Origins of Euprimate Taxa. Taxa treated as:

\begin{tabular}{llll}
\hline Crown Groups & Total Groups & $\boldsymbol{M a}^{\boldsymbol{a}}$ & Geological Epoch \\
\hline Order & Semiorders & 63 & Paleocene \\
Semiorders & Suborders & $58-50$ & late Paleocene to early Eocene \\
Suborders & Infraorders & $45-40$ & middle Eocene \\
Infraorders & Superfamilies & $39-29^{b}$ & middle Eocene to middle Oligocene \\
Superfamilies & Families & $28-25$ & middle to late Oligocene \\
Families & Subfamilies & $23-22$ & early Miocene \\
Subfamilies & Tribes & $20-16$ & early to middle Miocene \\
Tribes & Subtribes & $14-11$ & middle to late Miocene \\
Subtribes & Genera & $10-7$ & late Miocene \\
Genera & Subgenera & $6-4$ & late Miocene to early Pliocene \\
Subgenera & Species & $3-<1$ & middle Pliocene to Pleistocene \\
\hline
\end{tabular}

a Ages are taken from those listed in Table 1; each pair of ages brackets the range of ages for crown groups at that rank. Because the ordinal crown group Primates has only one LCA for its descendant clades (the semiorders treated as total groups), only one age (the reference date of $63 \mathrm{Ma}$, see text) is listed for the crown group rank of order.

$\mathrm{b}$ The Classification (Table 1) shows no examples of more than one superfamily per infraorder. However the origins of the superfamilies in an age related system would be placed between the origins of infraorders and the origins of families, when the taxa at these three ranks are treated as total groups.

crown groups branched into species. In the genus Callithrix, with its three subgenera, C. (Cebuella) and $C$. (Mico) are sister-groups. Thus in the listing of Callithrix subgenera, C. (Cebuella) and C. (Mico) follow C. (Callithrix) and have a more indented position.

Within the platyrrhine family Pitheciidae, the early-to-middle Miocene pitheciines (at about $19 \mathrm{Ma}$ ) divided into tribes Callicebini and Pitheciini. Callicebini has Callicebus as its only extant genus, and Pitheciini has Pitheciina as its only extant subtribe. In the late Miocene (at about $10 \mathrm{Ma}$ ), Pitheciina divided into the generic clades Pithecia and Chiropotes. At the end of the Miocene (at about to $6 \mathrm{Ma}$ ), Callicebus branched into subgenera and so did Chiropotes, the latter into C. (Cacajao) and C. (Chiropotes).

Within the third extant platyrrhine family, Atelidae, the early to middle Miocene atelines (at about $17 \mathrm{Ma}$ ) divided into tribes Alouattini and Atelini. Alouattini has Alouatta as its only extant genus, but Atelini in the middle to late Miocene (at about $12 \mathrm{Ma}$ ) divided into subtribes Atelina and Brachytelina. Atelina has Ateles as its only extant genus, but in the late Miocene (at about $10 \mathrm{Ma}$ ) Brachytelina divided into the generic clades Lagothrix and Brachyteles. In the early Pliocene (at about $4 \mathrm{Ma}$ ) Ateles divided into subgenera. Within Alouatta, the yardstick of age places the three species examined all in the same subgenus. Within this clade, A. belzebul and A. seniculus share the closest kinship, thus they are listed after $A$. caraya and at a more indented position.

\section{Catarrhine Descent}

The infraorder Cararrhini like its sister-group, Platyrrhini, has only one extant superfamily. The members of the two catarrhine superfamilies of traditional classifications, Cercopithecoidea and Hominoidea, all become members of Cercopithecoidea by the yardstick of age. In the late Oligocene (at 
about $25 \mathrm{Ma}$ ), cercopithecoids branched into the familial cercopithecid (Old World monkeys) and hominid (ape and human) clades. Within the cercopithecid clade, the middle Miocene cercopithecines (at about $15 \mathrm{Ma}$ ) branched into Colobini (the leaf-eating monkeys) and Cercopithecini (the cheek-pouch monkeys) each in turn in the middle-to-late Miocene (at about $10 \mathrm{Ma}$ ) branched into subtribes: the colobins into the Colobina and Presbytina, the cercopithecins into Cercopithecina and Papionina.

Within Presbytina (at about $7 \mathrm{Ma}$ ) the clades with lineages to Trachypithecus and Nasalis separated from each other. Within Cercopithecina (at about $9 \mathrm{Ma}$ ) a clade with the lineage to Cercopithecus separated from the clade with lineages to Erythrocebus and Chlorocebus. Subsequently (at about $7 \mathrm{Ma}$ ) Erythrocebus separated from Chlorocebus. Within Papionina, a phylogenetic branching (at about $9 \mathrm{Ma}$ ) separated a clade with the lineage to Macaca from the clade with lineages to Cercocebus and Papio. A subsequent branching (at about $8 \mathrm{Ma}$ ) separated Cercocebus from Papio. Papio consists of the subgenera P. (Papio), P. (Theropithecus), and P. (Lophocebus), and Cercocebus consists of the subgenera $C$. (Mandrillus) and C. (Cercocebus). The phylogenetic branchings that produced these subgenera occurred in the late Miocene and early Pliocene (starting at about $4 \mathrm{Ma}$ in the case of Papio and at $5 \mathrm{Ma}$ in the case of Cercocebus). The early Pliocene macaques (at about $4 \mathrm{Ma}$ ) branched into subgenera of Macaca.

Within Hominidae the first branching occurred in the early-to-middle Miocene (at about $18 \mathrm{Ma}$ ). This places all extant members of Hominidae into subfamily Homininae. This first branching divided the subfamily into tribes Hylobatini and Hominini. Within Hylobatini, a phylogenetic branching (at about $8 \mathrm{Ma}$ ) in the subtribal hylobatan clade separated Symphalangus from Hylobates. Within Hominini, a phylogenetic branching (at about $14 \mathrm{Ma}$ ) separated the monogeneric subtribe Pongina (for Pongo) from subtribe Hominina. Within Hominina, a phylogenetic branching (at about $7 \mathrm{Ma}$ ) separated Gorilla from Homo, and within Homo a phylogenetic branching (at about $6 \mathrm{Ma}$ ) separated the subgenus for common chimpanzees and pygmy chimpanzees or bonobos, i.e. $H$. (Pan), from the subgenus for humans, i.e. H. (Homo). It is the principle of rank equivalence with other primate clades of the same age that requires this grouping of the chimpanzee clade with the human clade in the same genus.

Humans and chimpanzees are more than $98.3 \%$ identical in their typical nuclear noncoding DNA and more than $99.5 \%$ identical in the active coding nucleotide sequences of their functional nuclear genes (Goodman et al., 1989, 1990). In mammals such high genetic correspondence is commonly found between sibling species below the generic level but not between species in different genera. The genetic and cladistic evidence that groups humans and chimpanzees together as sister subgenera of the same genus justifies the belief that the two chimpanzee species can provide insights into distinctive features of humankind's own evolutionary origins. Indeed chimpanzees use tools and have material cultures (McGrew, 1992), are highly social animals and ecological generalists (DeWaal, 1995; Goldberg, 1998), and may even have the mental capacity for conscious thought and rudimentary language (SavageRambaugh \& Lewin, 1994; Fouts, 1997).

\section{Descent of Bipedal Hominids}

Anthropologists and science writers invariably use the term 'hominids' for the members of the clade that contains humans and the fossils that are cladistically closer to Homo sapiens than to any other living species. Clearly this usage is an impediment to accepting our classification that has the family Hominidae include all apes as well as humans and has the genus Homo include as extant members the two chimpanzee species as well as Homo sapiens. To overcome this impediment, the term 'bipedal hominids', as used by Kohler \& Moya-Sola (1997), could substitute for 'hominids' and still serve the purpose of ready communication among professionals and with the lay public. Nevertheless, if the genus Homo includes both fossil bipedal hominids and living humans as well as chimpanzees and bonobos, how can the sister-group relationships among the extinct and extant bipedal hominid species be displayed in the genealogical classification? After all, paleoanthropologists currently place the extinct species in at least three different genera: Ardipithecus, Australopithecus, and Homo. The following 


\section{Table 3. A genealogical classification of extant and extinct species within the genus} Homo.

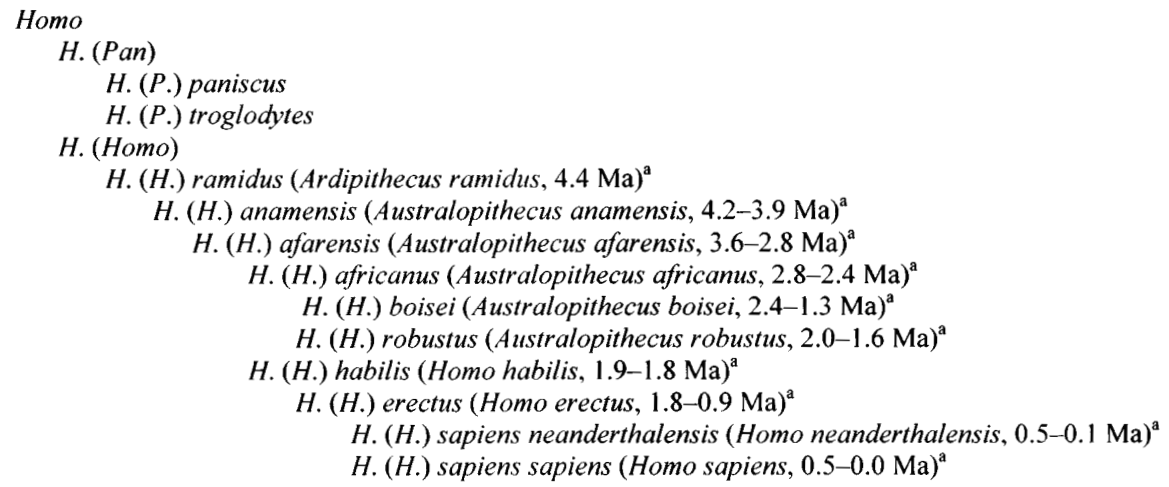

\footnotetext{
a Shown in parenthesis is the species' name and age from Yoon (1995) for each species that we treat as a member of subgenus Homo (Homo).
}

exercise shows how a genealogical classification can place the extinct species as well as Homo sapiens in subgenus Homo (Homo) and still display the sister-group relationships of these species.

In this exercise we focus on the presumed genealogical relationships of nine extinct species to one another and to modern humans as portrayed by Yoon (1995). The fossil species are Ardipithecus ramidus, five Australopithecus species (A. anamensis, A. afarensis, A. africanus, A. robustus, and $A$. boisei), and three Homo species (H. habilis, H. erectus, and H. neanderthalensis). In our classification (Table 3) all nine extinct species are members of subgenus Homo (Homo). As the oldest extinct species thought to be cladistically closer to humans than to chimpanzees, ramidus is listed before the other extinct species in the Homo (Homo) clade. At age 4.4 Ma, ramidus could be viewed either as the LCA of the members of this clade or as a close relative of the LCA. The next listed species anamensis (at age 4.2 - 3.9 Ma and at a more indented position than ramidus) may be viewed as a lineal descendant of the LCA represented by ramidus; thus anamensis represents a clade that originated closer to the present than the clade represented by ramidus. Again, the next listed species, afarensis (at age $3.6-2.8 \mathrm{Ma}$ and at a more indented position than anamensis) represents a clade closer to the present than the clade represented by anamensis. From a basal population within the afarensis clade two diverging descendant clades emerged, one represented by africanus (at age $2.8-2.4 \mathrm{Ma}$ ) and the other by habilis (at age 1.9 - 1.8 Ma). The extinct species boisei (at age $2.4-1.3 \mathrm{Ma}$ ) and robustus (at age $2.0-1.6 \mathrm{Ma}$ ) are members of the africanus clade, while erectus (at age $1.8-0.9 \mathrm{Ma}$ ) is a member of the habilis clade. The two sapiens subspecies, i.e. extinct s. neanderthalensis (at age $0.5-0.1 \mathrm{Ma}$ ) and extant s. sapiens (at age 0.5 - $0.0 \mathrm{Ma}$ ) are members of the erectus clade.

If afarensis and the africanus and habilis members of the afarensis clade all share a more recent common ancestor or LCA with one another than with anamensis, then the paleoanthropological genus Australopithecus (which includes anamensis, afarensis, and the members of the africanus clade but not the members of the habilis clade) is a paraphyletic taxon. In contrast our subgenus Homo (Homo) (which includes all members of the paleoanthropological Ardipithecus, Australopithecus, and Homo genera) is a monophyletic taxon. Moreover our classification displays the presumed genealogical relationships of 
the extinct species to one another as well as to living humans.

\section{Acknowledgements}

This study received support from the following granting agencies: NSF-USA, NIH-USA, and CNPqBrazil.

\section{References}

Bailey, W.J., Hayasaka, K., Skinner, C.G., Kehoe, S., Sieu, L.C., Slightom, J.L., \& Goodman, M. (1992). Reexamination of the African hominoid trichotomy with additional sequences from the primate $\beta$-globin gene cluster. Mol. Phylogenet. Evol., 1, 97-135.

Chaves, R., Sampaio, I, Schneider, M.P., Schneider, H., Page, S.L., \& Sevdman, M. (1999). The place of Callimico goeldü in the callitrichine phylogenetic tree: evidence from von Willebrand factor gene (OWF) intron II sequences. Mol. Phylogenet. Evol., 13, 392-404.

DeWaal, F.B.M. (1995). Bonobo sex and society. Sci. Am., 272, 82-88.

Fouts, R. (1997). Next of Kin. New York: William Morrow and Company.

Goldberg, T.L. (1998). Biogeographic predictors of genetic diversity in populations of eastern African chimpanzees (Pan troglodytes schweinfurthi). Int. J. Primatol., 19, 237-254.

Goodman, M. (1986). Molecular evidence on the ape subfamily Homininae. In: Evolutionary Perspectives and the New Genetics, ed. H. Gershowitz, D.R. Rugknagel, \& R.E. Tashian, pp. 121-132. New York: Alan R. Liss.

Goodman, M., Koop, B.F., Czelusniak, J., Fitch, D.H.A., Tagle, D.A., \& Slightom, J.L. (1989). Molecular phylogeny of the family of apes and humans. Genome, 31, 316-35.

Goodman, M., Tagle, D.A., Fitch, D.H.A., Bailey, W., Czelusniak, J., Koop, B.F., Benson, P., \& Slightom, J.L. (1990). Primate evolution at the DNA level and a classification of hominoids. J. Mol. Evol., 30, 260-66.

Goodman, M., Porter, C.A., Czelusniak, J., Page, S.L., Schneider, H., Shoshani, J., Gunnell, G., \& Groves, C.P. (1998). Toward a phylogenetic classification of primates based on DNA evidence complemented by fossil evidence. Mol. Phylogenet. Evol., 9, 585-98.

Goodman, M., Page, S.L., Meireles, C.M., \& Czelusniak, J. (1999). Primate phylogeny and classification elucidated at the molecular level. In: Evolutionary Theory and Processes: Modern Perspectives, ed. S.P. Wasser, pp. 193212. Dordrecht: Kluwer academic Publishers.

Groves, C.P. (1993). Order Primates. In: Mammal Species of the World, ed. D.E. Wilson \& D.M. Reader, pp. 24377. Washington, D.C.: Smithsonian Institution Press.

Hennig, W. (1966). Phylogenetic Systematics. Urbana: University of Illinois Press. (Reissued 1979).

Jeffries, R.S.P. (1979). The origin of the chordates - a methodological essay. In: The Origin of Major Invertebrate Groups, ed. M.R. House, pp. 443-477. London: Academic Press.

Kohler, M. \& Moya-Sola. (1997). Fossil muzzles and other puzzles. Nature, 388, 327-328.

Martin, R.D. (1990). Primate Origins and Evolution: A Phylogenetic Reconstruction. London: Chapman and Hall.

McGrew, W.C. (1992). Chimpanzee Material Culture Implications for Human Evolution. Cambridge: Cambridge University Press.

Meireles, C.M., Czelusniak, J., Schneider, M.P.C., Muniz, J.A.P.C., Brigido, M.C., Ferreira, H.S., \& Goodman, M. (1999). Molecular phylogeny of ateline New World monkeys (Platyrrhini, Atelinae) based on $\gamma$-globin gene sequences: Evidence that Brachyteles is the sister group of Lagothrix. Mol. Phylogenet. Evol., 12, 10-30.

Page, S.L., Chiu, C-H., \& Goodman, M. (1999). Molecular phylogeny of Old World monkeys (Cercopithecidae) as inferred from $\gamma$-globin DNA sequences. Mol. Phylogenet. Evol., 13, 348-359.

Patterson, C. \& Rosen, D.E. (1977). Review of ichthyodectiform and other Mesozoic teleost fishes and the theory and practice of classifying fossils. Bull. Am. Mus. Nat. Hist., 158, 81-172.

Porter, C.A., Page, S.L., Czelusniak, J., Schneider, H., Schneider, M.P.C., Sampaio, I., \& Goodman, M. (1997a). Phylogeny and evolution of selected primates as determined by sequences of the $\varepsilon$-globin locus and 5 ' flanking regions. Int. J. Primatol., 18, 261-295.

Porter, C.A., Czelusniak, J., Schneider, H., Schneider, M.P.C., Sampaio, I., \& Goodman, M. (1997b). Sequences of 
the primate $\varepsilon$-globin gene: implications for systematics of the marmosets and other New World primates. Gene, 205, 59-71.

Porter, C.A., Czelusniak, J., Schneider H., Schneider, M.P.C., Sampaio, I. \& Goodman, M. (1999). Sequences from the 5' flanking region of the $\varepsilon$-globin gene support the relationship of Callicebus with Pithecines, Am. J. Primatol. $48,69-75$.

Romer, A.S. (1962). The Vertebrate Body. Philadelphia: W. B. Saunders.

Rowe, N. (1996). The Pictorial Guide to the Living Primates. East Hampton, New York: Pogonios Press.

Savage-Rambaugh, S. \& Lewin, R. (1994). Kanzi - The Ape at the Brink of the Human Mind. New York: Wiley.

Yoon, C.K. (1995). New hominid species was bipedal 3.9 - 4.2 million years ago. The Journal of NIH Research, 7, 30-32. 


\section{Colin P. Groves}

Department of Archaeology \& Anthropology Australian National University

Canberra, ACT 0200, Australia
Keywords: Taxonomy, Cladistics, Homo, Pan, Gorilla, Pongo

\section{Towards a Taxonomy of the Hominidae}

Cladistic taxonomy classifies organisms according to their lineage affiliations, so that sister-groups have equal rank; evolutionary taxonomy, according to overall degrees of resemblance.

The argument for organising taxonomy according to cladistic principles is that taxonomy is meant to depict relationships, 'relatedness' means 'sharing a common ancestor', therefore taxa are more closely related the more recent is their common ancestor. The arguments for evolutionary taxonomy are that there may be unequal amounts of divergence between sister-groups; an evolutionary classification remains stable despite changing views on phylogenetic relationships; and fossil taxa from early stages of a lineage may not show its derived character states, for example because of incompleteness, and may more closely resemble their contemporaries from different lineages. In both schemes, a classification is an information retrieval system, but a cladistic classification is a scientific hypothesis, subject to modification as new evidence accumulates, while an evolutionary classification is a device for facilitating reference to organisms, and is relatively stable over time.

Under a cladistic scheme, the Hominidae includes (at the very least) humans and 'great apes'; moreover, since the sister-groups are the lineages leading to Pongo and to Homo/Pan/Gorilla, the prime divisions should be (1) a group containing Pongo and its fossil relatives and (2) a group containing Homo, Pan, Gorilla and their fossil relatives. These would be subfamilies, tribes, or whatever rank an author decides to give them. This was originally because molecular data indicated an 'orangutan first' split, but now there is plenty of morphological information which, when analysed cladistically, leads to the same conclusion. There is also evidence for a special sister-group relationship between Homo and Pan. Under an evolutionary scheme, the family Hominidae (and its vernacular derivative, hominid) includes only Homo and its extinct relatives, while the 'great apes' are placed in a separate family, Pongidae. This is because humans, since separating from their closest relatives, have undergone unusual amounts of morphological divergence. I will detail the relevant morphological evidence, and assess how it should be used in taxonomy.

\section{Introduction}

Taxonomy was defined by Simpson in 1961 as "the theoretical study of classification, including the bases, principles, procedures, and rules"; and classification as "the ordering of [organisms] into groups (or sets) on the basis of their relationships". Since that time there has been a growing tendency to extend the term taxonomy to cover classification in practice, such that 'a taxonomy' means much the same as a classification, with the added proviso that it incorporates something of the rationale for it, which a 
classification need not.

A related term is Systematics. Simpson (1961) defined Systematics as "the scientific study of the kinds and diversity of organisms and of any and all relationships among them". For Simpson, the implications of the term were much wider than for taxonomy, more or less equivalent, in fact, to the modern buzzword 'biodiversity'. Today, Systematics has become a virtual synonym for Taxonomy, and I make no apology for using the two words synonymously here, but we must realise that there has been a kind of musical chairs in terminology over the past 30 or 40 years, so that we are in some respects no longer speaking the same language as Simpson.

The basis of taxonomy is the taxon. A taxon (plural, taxa) is "a group of real organisms recognised as a formal unit at any level of a hierarchic classification" (Simpson, 1961:19). Thus the species Cercopithecus mitis is a taxon, so is the genus Ateles, so is the family Lemuridae, so is the order Primates... and so on.

\section{'Relatedness': at the heart of taxonomic statements}

The value - one might insist, indispensability - of a taxonomy lies in its role as an information retrieval system (Mayr \& Ashlock, 1991). It orders otherwise unwieldy masses of information, like the Dewey system in libraries. What sort of information? Why, information about relatedness - as Simpson said so long ago.

What is it, then, this relatedness? Simpson's (1961) definition of 'classification' was quoted above, but left incomplete; it concludes by explaining that 'relationships' means 'associations by contiguity, similarity, or both'. The mention of 'contiguity' is puzzling, as earlier on the same page he had implied that he meant synecology, which is indeed a part of what Simpson called systematics, and what we today call biodiversity, but to my mind has nothing to do with classification as such.

What does it mean when we say that two people are related? Brothers and sisters are more closely related than cousins; first cousins are more closely related than second cousins. Being more closely related means sharing a more recent common ancestor. When we move across generations the questions become more difficult: are parents and children more closely related than brothers and sisters? Here we appeal to genetics - what proportion of their genome do they share?

We can readily transfer these criteria to the natural world. That species A and B share a more recent common ancestor than with species $\mathrm{C}$ should mean that $\mathrm{A}$ and $\mathrm{B}$ are more closely related to each other than to $\mathrm{C}$; they share a bunch of DNA sequences, inherited from their common ancestor, which are missing from C. If we think 'relatedness' in this sense (recency of common ancestry) is worth celebrating, we can place $\mathrm{A}$ and $\mathrm{B}$ in a taxonomic group which excludes $\mathrm{C}$. A taxonomic schema in which a group $\mathrm{AB}$ is contrasted with a group $\mathrm{C}$ immediately predicts that members of group $\mathrm{AB}$ will have more in common genetically than they do with group $\mathrm{C}$ or any other.

Is this sufficient? The proposition has been put (Ashlock, 1971) that lineage A may have changed so rapidly since its separation from its sister lineage B as to leave B sharing more of its genome with C. A good example would be the position of Homo among the Hominoidea. While admitting that Homo (human) and Pan (chimpanzee) share a common ancestor subsequent to the separation of the ancestry of Pongo (orangutan), it is obvious that far more morphological change occurred during human evolution, so that chimpanzees and orangutans seem to resemble each other more than chimpanzees resemble humans. It was on this basis that chimpanzees and orangutans (and gorillas, and sometimes gibbons) used to be placed together in a family Pongidae, leaving humans and their fossil relatives alone in the family Hominidae. - Well, why not?

It is because, when we measure total genomic resemblance, chimpanzees and humans really do share more - significantly more - of their genetic equipment than they do with orangutans. The explanation is as follows: First, the proportion of the genome that consists of actual genes (that code for phenotypic characters) is very small, under $10 \%$, so that rapid change in genes coding for gross morphological 


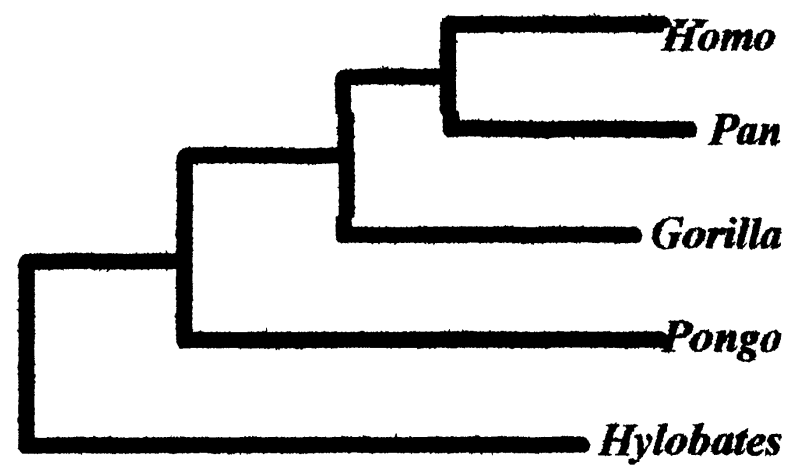

Figure 1. The most parsimonious phylogeny of the Hominoidea, using 170 characters from the dataset of Shoshani et al. (1996). Length 347, Consistency Index 0.65.

features gets swamped by the stochastic change occurring in the noncoding $90+\%$. Secondly, gross morphological features themselves account for only a small fraction of the phenotype, which also concerns immunology, biochemistry, and other less obvious morphological features (patterns of blood vessels, musculature, details of skin and hair structure). Finally, there is the likelihood that, the 'grosser' are these morphological features, the more probable it is that they are not separately coded characters as much as functional epiphenomena of a few general trends. Any way we look at it, the 'rapid change argument' falls away, and we are returned to the equation between relatedness and common ancestry.

As an aside - why bother with morphology at all? Why not go straight to the DNA, which after all can these days be extracted from preserved skin, bone, even faeces? There are many reasons why not. DNA extraction and sequencing is still quite an expensive business, and is a skill which is not within everyone's competence. DNA sequences may not survive in fossils beyond a few tens of thousands of years (though this is the subject of a ferocious controversy at the moment!), but we still need to be able to compare fossils with extant taxa. Taxonomy has come to be highly valued in conservation, and when a monkey is glimpsed in the tree-tops we generally want to identify it on the spot, not only after collecting its faeces and taking them back to the lab. Finally, I for one would not want to miss the excitement of finding out something of the why and how of evolutionary change, its functional correlates, geography, ecology, demography, and perhaps contributing to the current ferment in evolutionary theory. The importance of getting back to the genome cannot be overestimated, but when we have done this a vast amount is still left unsaid.

There is another argument, put by such authors as Martin (1990), that taxonomic stability is important, and as such may sometimes require us to override its phylogenetic content. As an overall philosophy, this cannot be accepted: a classification that has been stable for twenty years was preceded by a different one that was stable for twenty years before that - and so on. The Hominidae vs. Pongidae classification, which some authors might like to preserve (on the grounds of stability), represented in its time an advance in knowledge over one which separated humans as a distinct suborder, Bimana, opposed to all other primates (Quadrumana). Each taxonomic scheme represents an advance in understanding on what went before; stability as such is not a virtue. Yet before we dismiss the plea for stability out of hand, let us admit that some taxonomists have hastened to revise 'accepted' classifications on the evidence of little more than this week's cladogram or - perish the thought! - of comparisons of DNA sequences of 


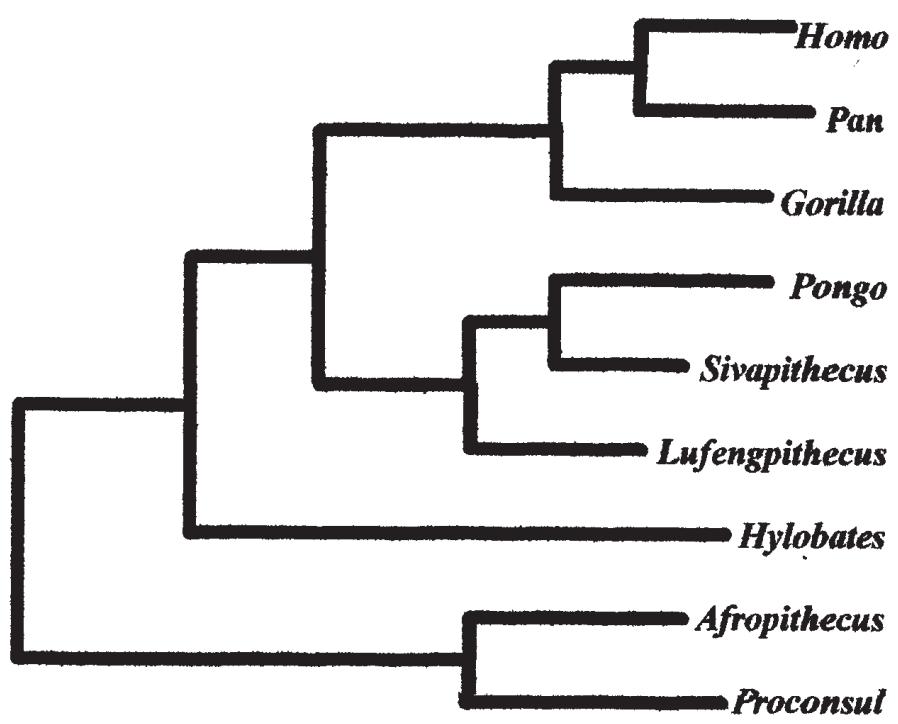

Figure 2. Aless parsimonious phylogeny of the Hominidea, using the same 170 characters, and incorporating four fossil genera, Length 385, Consistency Index 0.59.

just a few hundred base-pairs. Taxonomists do owe their colleagues the courtesy of a thought-out, careful analysis; a slenderly based revision is as misleading as a spurious orthodoxy.

\section{Relatedness among the Hominoidea}

Prior to what we may refer to as the 'Hennigian revolution', it was usual to divide the Hominoidea into two families: Pongidae (for Gorilla, Pan, Pongo and Hylobates) and Hominidae for Homo alone. Among fossil taxa, Australopithecus was sometimes allocated to the Pongidae (Simpson, 1945), sometimes to the Hominidae (Le Gros Clark, 1959). The 1960s saw an increasing trend towards awarding the gibbons their own family, Hylobatidae (Napier \& Napier, 1967).

As long ago as 1963, Goodman's immunological study of serum proteins divided the Hominoidea into three branches: the gibbons, the orangutan, and an irreducible cluster of human, gorilla and chimpanzee. In a step that was years ahead of its time, he proposed that this ought to be recognised in taxonomy, with the families Hylobatidae; Pongidae, restricted to the orangutan; and Hominidae for Homo, Pan and Gorilla. Molecular evolutionary techniques have progressed from immunology through amino-acid sequencing, DNA-DNA hybridisation, RFLP to DNA sequencing itself, but all have confirmed the same basic groupings, merely refining the trifurcations, so it is now evident that the gibbon line did diverge before that of the orangutan, and most studies have concluded that the gorilla diverged before the human and chimpanzee lines separated.

How could molecular and morphological data give such different results - or did they? I collected numerous morphological characters to test the commonly held assumption that they did: and found that, when analysed cladistically, the morphological analysis produced exactly the same phylogeny as the molecular ones (Groves, 1986). My proposed taxonomy was two families, Hylobatidae and Hominidae, the latter being divided into Ponginae (for Pongo alone) and Homininae (for Homo, Pan and Gorilla). 


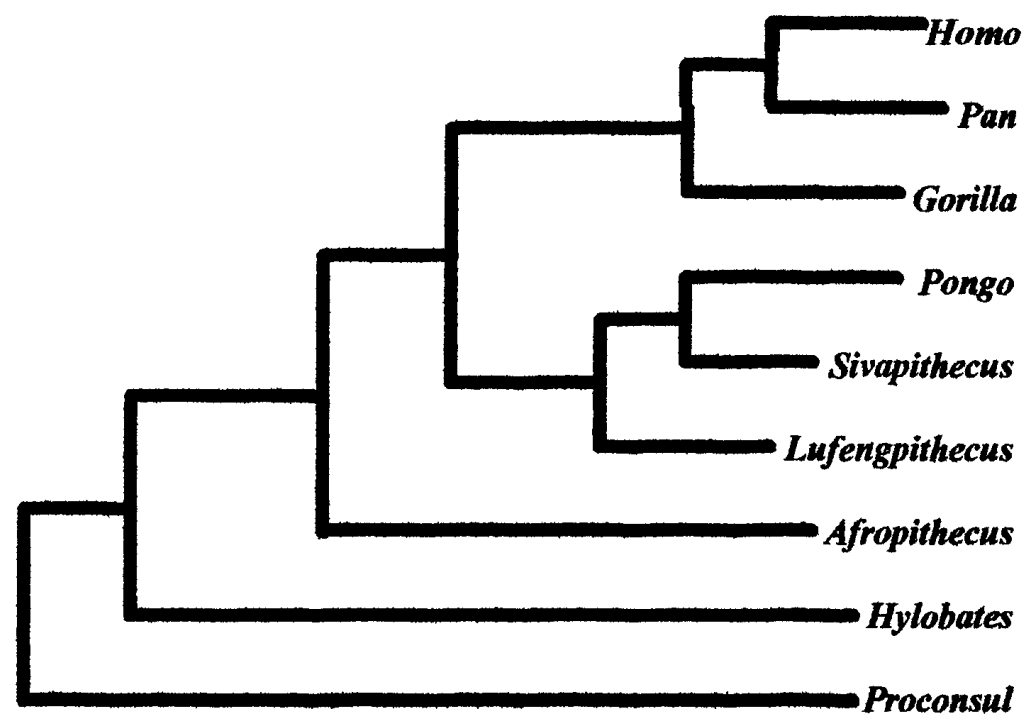

Figure 3. A less parsimonious phylogeny of the Hominidea, using the same 170 characters, and incorporating the same four fossil genera, Length 386, Consistency Index 0.59.

This analysis was done by hand; there were a few errors, and no significance tests were performed. Groves \& Patterson (1991) reworked the analysis using a computer program in several different ways. Recently, I revised the dataset again and used it as part of the dataset for a full cladistic analysis of Primates (Shoshani et al., 1996). Here I report the results of the hominoid-specific analysis.

I used 170 characters in all: 38 concerned the skull; 31 , the postcranial skeleton; 23 , the dentition; 10, the muscular anatomy; 33, other visceral anatomy; 19, reproductive anatomy and physiology; and 16, external characters. The outgroup was Old World Monkeys. Multistate characters were ordered.

The shortest tree (Fig.1) has 347 steps, with a consistency index of 0.65. Pan and Homo form a clade, sister-group to Gorilla. Placing Pan instead on a clade with Gorilla increased the length by 5, and decreased the C.I. by 1 . The 'traditional' tree, Hominidae vs Pongidae, was much longer, and so was a tree in which, as proposed by Schwartz (1984), it is Pongo that is sister to Homo.

Dr John Trueman kindly ran a PTP test on the entire dataset, and a t-PTP test on the Homo/Pan clade. The PTP (Permutation Tail Probability) test randomises the data many times (here, 100 times), and tests whether any tree resulting from a randomised dataset is as short as the tree obtained by the actual dataset. The t-PTP (topology-dependant PTP) test randomises the data that support a particular clade (in this case the Homo/Pan clade) and tests whether any randomised data produce a tree as short as the one in which that clade appears. In the present case, the shortest tree derived from randomised data was 385 steps, that is 38 steps longer than the actual tree; hence the dataset really does offer abundant cladistic information. On the other hand, only 85 of the 100 randomised Homo/Pan clades were shorter than that based on the real data; hence the sister-group relationship between human and chimpanzee, though the most favoured hypothesis, is not mandated by the data.

At Dr David Pilbeam's suggestion, I ran separate analyses on the different character sets (skulls, postcranial and so on). The overall tree (Hylobates(Pongo(Gorilla(Pan,Homo $)))$ ) is much the shortest 
tree for the skull, 'other visceral' and reproductive sets. The Schwartz tree (Pongo sister to Homo) is favoured by the dental set, with a C.I. of 0.74. A Gorilla/Homo clade is favoured by the postcranial and external sets. Finally, the shortest tree for the muscular anatomy data is a peculiar one: (Pongo(Hylobates,Homo)(Gorilla,Pan)).

Although the t-PTP test does not exclude other solutions, the phylogeny in which human and chimpanzee form a clade is still much the shortest. A diagnosis of a human/chimpanzee clade would look like this:

Encephalisation increased; frontal pole of cerebrum broadened; occlusal edge of upper lateral incisor straight (not sloped); no basal keel on lower canine; ankle epiphyses fused early relative to elbow and hip; digastric insertion on inferior transverse torus; female's receptivity period widened; puberty delayed; penis elongate; labia minora developed; relatively reduced sexual dimorphism in size.

I coded the available data on some well-represented fossil genera, and placed them on the shortest tree of living taxa. The shortest tree (Fig.2) has a Proconsul/Afropithecus clade diverging even before the Hylobates clade, and Sivapithecus and Lufengpithecus part of the Pongo branch, but one in which Afropithecus (but not Proconsul) diverges above the Hylobates branch is one step longer (Fig.3). Other possible solutions are all increasingly less parsimonious.

\section{Taxonomic levels}

Recently Goodman et al. (1998) proposed to set taxonomic level, among living primates at any rate, according to how long a group has been separate. They propose, for discussion, that superfamilies have a time depth of 28-25 million years, families of 23-22 million, subfamilies of 20-14, and genera of 6-4 million. Thus the gibbons are included in the Hominidae, as they and the great apes separated (according to molecular clock calculations) only 18 million years ago; and as chimpanzees and humans separated only 6 million years ago, they are both placed in the genus Homo.

As this last is the most controversial claim of all, I investigated from the literature the fossil evidence for the time depth of some non-primate mammalian genera. I found the following first-occurrence dates:

- 18 ma (Rusinga, Songhor): Rhynchocyon, Geogale, Zenkerella

- 8-9 ma (Ngorora, Samos): Mellivora, Orycteropus

- 7 ma (Mpesida): Hippopotamus

- 6 ma (Langebaanweg): Genetta, Viverra, Herpestes, Hyaena, Lynx, Ceratotherium, Giraffa, Kobus, Raphicerus, Tragelaphus

- 4.5-5 ma (Nkondo): Aepyceros

- 4-4.5 ma (Kanapoi, Ekora, Lothagam I): Civettictis, Loxodonta, Elephas, Equus, Hexaprotodon, Alcelaphus, Damaliscus

There are, therefore, genera which appear to be much older than the 6 million years put as maximum by Goodman et al. (1998); but, wherever a group's fossil record is at all well known, 4 million does seem to be rather young for the first-occurrence datum of any genus. We are in need of good data for the higher categories, if we are to be in any way consistent across the mammals.

\section{Conclusion}

Morphologists should not be afraid of molecular studies, nor especially in awe of them: when treated cladistically, with a large enough dataset, morphological information gives the same results as molecular. This makes it for the first time possible to try to objectivise the higher taxonomic ranks in primates, perhaps in mammals as a whole, but more work needs to be done before we can link rank with time depth with consistency. For a while, competing classifications are bound to be current; but, whether we spread out the apes (including humans) within the superfamily Hominoidea, or squeeze them all into a single subfamily Homininae, it is very evident that both consistency and objectivity demand a 
phylogenetic scheme in which the great apes and gibbons are contrasted at one level, orangutans and African apes at another, and (probably) gorillas and the human/chimpanzee clade at another.

\section{References}

Ashlock, P.D. (1971). Monophyly and associated terms. Systematic Zoology, 20, 63-69.

Goodman, M., Porter, C.A., Czelusniak, J., Page, S.L., Schneider, H., Shoshani, J., Gunnell, G. \& Groves, C.P. (1998). Toward a phylogenetic classification of Primates based on DNA evidence complemented by fossil evidence. Molecular Phylogenetics and Evolution, 9, 585-98.

Groves, C.P. (1986). Systematics of the Great Apes. In: Comparative Primate Biology, ed. D.R. Swindler \& J.Erwin, 1, 187-217. New York: Alan R. Liss

Groves, C.P. \& Patterson, J.D. (1991). Testing hominoid phylogeny with the PHYLIP programs. Journal of Human Evolution, 20, 167-83.

Le Gros Clark, W.E. (1959). The Antecedents of Man. Edinburgh: Edinburgh University Press.

Martin, R.D. (1990). Primate Origins and Evolution: a Phylogenetic Reconstruction. Princeton: Princeton University Press.

Mayr, E. \& Ashlock, P.D. (1991). Principles of Systematic Zoology, $2^{\text {nd }}$ edition. New York: McGraw-Hill.

Napier, J.R. \& Napier, P.H. (1967). A Handbook of Living Primates. London \& New York: Academic Press.

Schwartz, J.H. (1984). The evolutionary relationships of man and orang-utans. Nature, 308, 501-5.

Shoshani, J., Groves, C.P., Simons, E.L. \& Gunnell, G.F. (1996). Primate phylogeny: morphological vs. molecular results. Molecular Phylogenetics and Evolution, 5,102-54.

Simpson, G.G. (1945). The principles of classification and a classification of mammals. Bulletin of the American Museum of Natural History, 85, 1-350.

Simpson, G.G. (1961). Principles of Animal Taxonomy. London: Oxford University Press. 


\section{Naoyuki Takahata}

\author{
Department of Biosystems Science \\ Graduate University for Advanced Studies \\ Hayama, Kanagawa 240-0193, Japan
}

Keywords: Primate phylogeny, Ancestral population size, DNA sequences, Population genetics, Maximum likelihood model, Primate demography

\section{Molecular Phylogeny and Demographic History of Humans}

\begin{abstract}
The silent or synonymous nucleotide differences within and/or between species can provide useful information about the phylogenetic and demographic history of organisms. A population genetic method is applied to DNA sequences of orthologous gene pairs in order to estimate the divergence time of the human lineage from seven taxonomic groups of primates, as well as the extent of silent diversity in these common ancestral species. The method demonstrates (1) a rather ancient divergence between Strepsirrhini and Haplorrhini, between Platyrrhini and Catarrhini, and between cercopithecoids and hominoids and (2) greater ancestral polymorphism than in the extant human population. The accurate dating of primate divergences is, however, hampered by the lack of appropriate calibration points for silent substitution rates and the possible acceleration during early primate evolution. The rather high silent diversity in the ancestral human lineage suggests a large effective size, which is consistent with the unusually high silent diversity at functional major histocompatibility complex (MHC) loci. It is argued that a significant reduction in effective population size began when Homo erectus emerged and migrated out of Africa and that the likely cause was frequent extinction of local populations. It is also argued that because of the reduction during the Pleistocene, a great majority of modern people are too closely related genetically to support the multiregional hypothesis for the origin of modern humans.
\end{abstract}

\section{Introduction}

Molecular (immunological) phylogenetic work was initiated for primates (Nuttal, 1904; Sarich \& Wilson, 1967) and now the available DNA sequence data for them are the most extensive among a variety of organisms (e.g. Goodman et al., 1998; Czelusniak \& Goodman, 1998). Nevertheless, the present status of molecular primatology or anthropology seems still far from complete and many important issues remain unsettled. For example, little consensus has been reached about the closest relative to the Order Primates (Pettigrew et al., 1989; Bailey et al., 1992; Novacek, 1992) and about datings of major diversifications in primate evolution (Martin, 1993). In our previous study (Takahata \& Satta, 1997), we suggested that rapid accumulation of DNA sequence data would improve this status, together with a population genetic method which permits us to study the phylogeny as well as the demography of organisms. The method is based on a simple probability model of DNA sequence divergences. Applying this method to the then available DNA sequences of orthologous gene pairs between humans and non-human primates, we estimated the divergence time of the human lineage from the chimpanzee, the gorilla, Old World Monkeys (OWM), and New World Monkeys (NWM) as 4.5, 8.0, 31 , and 57.5 million years ago (Ma), respectively. We also inferred that the nucleotide diversity (or the effective population size $\mathrm{N}_{\mathrm{e}}$ ) in the ancestral species might have been much greater than in the extant human population. However, during the past two years, many more relevant DNA sequence data have 
become available. This prompted us to up-date our estimates and at the same time to examine carefully the validity of the underlying assumptions. The most important assumption is the rate homogeneity of silent substitutions across loci. If this assumption is violated, the silent diversity or the effective size of the ancestral species is overestimated, whereas the species divergence time is proportionally underestimated. In fact, several loci show that silent substitutions might have accumulated more rapidly or more slowly than expected. The molecular cause for the rate heterogeneity of silent substitutions is not well understood, but there are some suggestions.

Recently, Kumar \& Hedges (1998) used protein sequences to set a time scale in vertebrate evolution. In addition, they dated the human-lineage divergence from the chimpanzee, the gorilla, the orangutan, the gibbon, OWMs and NWMs as 5.5, 7.7, 8.2, 14.6, 23.3 and 47.6 Ma, respectively. However, the number of loci used in these comparisons except in OWMs is no greater than 7 , so these datings may suffer from large sampling errors. In this paper, after testing the rate heterogeneity of silent substitutions across various loci, we report our latest results about the phylogenetic and demographic history of the human lineage. In relation to these, we also discuss the implication of a significant reduction in genetic variability since Homo erectus first migrated out of Africa 1-2 Ma ago.

\section{Methods and Results}

Before applying our population genetic method, we tested the rate heterogeneity of nucleotide substitutions across loci. We used only silent substitutions that do not alter encoded amino-acids and that occur mostly at the third codon positions of two- and four-fold degenerated codon families. We applied both chi-square or G test, and extended Fisher's exact test for the rate heterogeneity. For relatively closely related species such as the chimpanzee and gorilla, there are only a few loci at which silent substitutions have accumulated significantly faster or slower than at other loci. However, for distantly related species, there are several such loci; 8 out of 66 loci in the comparison with OWMs, and 9 out of 38 loci in the comparison with NWMs. For conservative estimates of the nucleotide diversity in the ancestral species, we excluded them from the present analysis (Table 1).

We also carried out the relative rate test to examine if different lineages have different silent substitution rates. There are some loci at which the rate is significantly higher (e.g. P450) or slower (e.g.

\section{Table 1. Silent nucleotide divergences (d) between the human and seven non-human primates.}

\begin{tabular}{lcccc}
\hline $\begin{array}{l}\text { Human } \\
\text { vs. }\end{array}$ & $\begin{array}{c}\text { No. of loci } \\
\text { used }\end{array}$ & No. of sites used & No. of substitutions & $\begin{array}{c}\text { Sequence divergence } \\
\text { d (\%) }\end{array}$ \\
\hline Chimpanzee & 37 & 6497 & 114 & 1.75 \\
Gorilla & 24 & 4944 & 101 & 2.04 \\
Orangutan & 25 & 4118 & 166 & 4.03 \\
Gibbon & 11 & 1702 & 83 & 4.88 \\
OWMs & $58(8)$ & 11568 & 893 & 7.72 \\
NWMs & $29(9)$ & 4840 & 635 & 13.1 \\
Lemurs & $2(2)$ & 814 & 217 & 27.7 \\
\hline
\end{tabular}

The numbers of loci excluded by rate heterogeneity tests are indicated in parentheses. The number of silent sites at the third position of a two-fold degenerated codon is counted as 0.5 , and the number of silent substitutions per locus is computed by multiple-hit correction formulas (e.g. Kimura, 1983). 
cystatin C) in NWMs than in the human lineage, but overall there is no strong indication for the lineagespecific rate of silent substitutions (data not shown). However, this test cannot show the time dependent change of the substitution rate if it occurred in a similar manner in both lineages. Although relevant data are still meager, there is an indication that the rate might be higher in the early evolution of primates, irrespective of lineages. This may be exemplified by the relatively large $d$ value in the comparison with lemurs (Table 1). The phylogenetic analysis of some other genes (e.g. BRCAl exon 11) also indicates a rather long internodal branch leading to both haplorrhines and strepsirrhines. It was indeed shown that the silent molecular clock hypothesis is valid only within limited taxonomic groups, but it is violated between distantly related taxa (Britten, 1986).

There are seven comparisons of the human lineage with non-human primates in the present data set. We wish to calibrate the rate $(r)$ of silent substitutions in primates. A difficulty arises from the fact that none of the seven species pairs, or any other species pairs in primates, can be used, without dissent, as the calibration point. The phylogenetic relationships among human, chimpanzee and gorilla have been the subject of a great deal of controversy (e.g. Sarich \& Wilson, 1967) and the fossil dating of the most recent common ancestor of OWMs, NWMs or primates of modern aspect has been questioned (Martin, 1993). DNA-DNA hybridization (Sibley \& Ahlquist, 1987) suggested that gibbons and orangutans might have split away about 20 and 15 Ma ago, respectively. However, these molecular datings too depend on assumed fossil-based calibration points and may differ from those from other molecules (e.g. 15 and 8 Ma, respectively, in Kumar \& Hedges, 1998). Because of the lack of obvious calibration points within primates and possible acceleration of silent substitution rates during early primate evolution, a reliable estimate of $r$ has not yet been fully established even with enough DNA sequence data now available. The following examples underscore this situation. If $\mathrm{r}=2.0-2.25 \times 10^{-9}$ per site per year, the divergence time ( $\mathrm{t}$ ) between human and chimpanzee estimated from $\mathrm{d} /(2 \mathrm{r})$ becomes about $4 \mathrm{Ma}$ (e.g. Easteal \& Herbert, 1997). This estimated divergence postdates the occurrence of Ardipithecus ramidus, suggesting that the common ancestors of humans and chimpanzees were bipedal and that the trait has been lost in chimpanzees rather than gained in humans. However, this estimated divergence also places into their common ancestor some Australopithecus fossils dated at 3.9-4.2 Ma (Leakey et al., 1995). Furthermore, if we use Table 1 and assume the global clock, all other primate divergence times become correspondingly recent; 4.7 Ma for the gorilla, 9.2 Ma for the orangutan, 11.2 Ma for gibbons, 17.6 Ma for OWMs, 29.9 Ma for NWMs, and 63.3 Ma for lemurs. In addition, the effective size of the extant human population becomes as small as $5000[=0.00081 /(4 \mathrm{gr})]$ during the past 200000 years, where $\mathrm{g}$ is the generation time and is set as 20 years (for the formula used, see below). We believe that the rate used in Easteal \& Herbert (1997) is too high and their suggestions are not really supported by molecular data. On the other hand, Li et al. (1996) used intron sequences and estimated $\mathrm{r}$ as $1.4 \times 10^{-9}$ from $\mathrm{d}=2 \mathrm{rt}=7.1 \%$ and $\mathrm{t}=25 \mathrm{Ma}$ between humans and OWMs, whereas $\mathrm{r}$ becomes $2.1 \times 10^{-9}$ from $\mathrm{d}=14.1 \%$ and $\mathrm{t}=35$ Ma between humans and NWMs. These d values are very similar to those in Table 1, but they include the nucleotide diversity in the ancestral population, and the assumed t values (e.g. Pilbeam, 1984) may not be entirely correct (Martin, 1993). For these reasons alone, it is possible that $r$ is still somewhat overestimated.

Takahata \& Satta (1997) emphasized that the sequence divergence (d) between two species must be the sum of two different categories of nucleotide substitutions. One category of substitutions (x) results from polymorphism that had already existed in the ancestral species and was transmitted to descendant species. Like that in an extant population, the nucleotide diversity in the ancestral species reflects the effective population size $\left(\mathrm{N}_{\mathrm{e}}\right)$ and per-generation substitution rate. The other category of substitutions (y) results from those that have accumulated independently in the two descendant species. These two categories of nucleotide substitutions follow different probability laws and it is this difference that allows us to partition $\mathrm{d}$ (Table 1) into $\mathrm{x}$ and $\mathrm{y}$ (via maximum likelihood or some other methods) when DNA sequence data are available at independently evolving orthologous loci. For convenience, the $\mathrm{x}$ and $y$ values are measured at individual silent sites and are expected to equal $4 \mathrm{~N}_{\mathrm{e}}$ gr and $2 \mathrm{rt}$, respectively. 
It may be instructive to note that $\mathrm{d}=\mathrm{x}+\mathrm{y}$ does not necessarily hold true when the number of silent sites differs from locus to locus. If we use $\mathrm{x}$ and $\mathrm{y}$ thus estimated (Table 2), we can compute $\mathrm{N}_{\mathrm{e}}$ and $\mathrm{t}$ from:

$$
\mathrm{N}_{\mathrm{e}}=\mathrm{x} / 4 \mathrm{gr} \text { and } \mathrm{t}=\mathrm{y} / 2 \mathrm{r}
$$

A point here is that $\mathrm{y}$ in Table 2, rather than $\mathrm{d}$ in Table 1, must be used to date the divergence of two species.

The best calibration of substitution rate $r$ may be obtained from the comparison between humans and chimpanzees. It is rather ironical to state this, if we recall that their divergence time per se was once the subject of heated debate. However, it now seems that most, if not all, molecular as well as palaeontological work has come to the conclusion that they diverged 5-7 Ma ago. If we use this estimate together with the y of $1.32 \%$ (Table 2), $\mathrm{r}$ becomes $1.0-1.3 \times 10^{-9}$ per site per year. Alternatively, one may prefer to use only relative values of $\mathrm{x}$ and $\mathrm{y}$. The last two columns in Table 2 stand for the $\mathrm{x}$ values relative to $0.081 \%$ in the extant human population and the y values relative to $\mathrm{y} 1.32 \%$ between the human and chimpanzee. These suggest that the nucleotide diversity in all seven ancestral species is much greater than that in the extant human population, and that major diversifications of primates took place in the rather early stage of evolution. However, it appears that the inferred divergence between haplorrhines and strepsirrhines is too ancient (see below).

\section{Demography in the Pleistocene}

The silent diversity, $\mathrm{x}$, estimated for the ancestral population is 5 to 10 times greater than $0.081 \%$ in the extant human population. When we convert $\mathrm{x}$ into $\mathrm{N}_{\mathrm{e}}$ based on formula (1), the short generation time $(\mathrm{g})$ in the ancestral species requires even greater $\mathrm{N}_{\mathrm{e}}$. The shorter the generation time, the more frequent the operation of random genetic drift per unit of time and the greater $\mathrm{N}_{\mathrm{e}}$ is required to maintain the same level of x. Various molecular data concerning polymorphism currently maintained in the human population have consistently estimated that $\mathrm{N}_{\mathrm{e}}$ is of the order of $10^{4}$ (Takahata, 1993). Conversely, if $\mathrm{N}_{\mathrm{e}}$

Table 2. The maximum likelihood estimates of $x$ and $y$ based on the DNA sequence data in Table 1.

\begin{tabular}{llllcc}
\hline $\begin{array}{l}\text { Human } \\
\text { vs. }\end{array}$ & g (years) & $\mathbf{x ~ ( \% )}$ & $\mathbf{y ~ ( \% )}$ & x relative to 0.081\% & $\begin{array}{c}\text { y relative to } \\
\text { chimpanzee }\end{array}$ \\
\hline Chimpanzee & 10 & 0.45 & 1.32 & 5.6 & 1 \\
Gorilla & 10 & 0.50 & 1.60 & 6.2 & 1.2 \\
Orangutan & 10.5 & 0.92 & 3.16 & 11.4 & 2.4 \\
Gibbon & 8.5 & 0.91 & 4.01 & 11.2 & 3.0 \\
OWMs & 7.5 & 0.4 & 7.35 & 4.9 & 5.6 \\
NWMs & 5 & 1.05 & 12.1 & 13.0 & 9.2 \\
Lemurs & 2.5 & 0.4 & 26.0 & 4.9 & 19.7 \\
\hline
\end{tabular}

The linkage relationships among silent sites at individual loci are important and so are the numbers of sites and substitutions per locus (data not shown). The $95 \%$ confidence limits of $\mathrm{x}$ and $\mathrm{y}$ are reasonably small when more than 20 loci are used (data not shown). The maximum likelihood estimate of $\mathrm{x}$ in extant humans is $0.081 \%$ (cf. Li \& Sadler, 1991). 
$=10^{4}$ and $\mathrm{g}=16-20$, the silent nucleotide substitution rate $(\mathrm{r})$ must be $1.0-1.3 \times 10^{-9}$ per site per year, precisely in the same range as that of the phylogenetic estimate above. In any case, the estimated value of $\mathrm{r}$ must account for both $\mathrm{x}$ and $\mathrm{y}$ in a coherent way (Kimura, 1983).

Since the silent diversity (x) in the ancestral species common to the human and chimpanzee or other non-human primates indicate that $\mathrm{N}_{\mathrm{e}}$ had been at least about $10^{5}$, there must have been a 10 -fold reduction in the effective population size somewhere in the past. Our interest is to relate such a reduction to human palaeo-demography. To do so, we first note the persistence time (T) of silent or selectively neutral polymorphism in a population of effective size $\mathrm{N}_{\mathrm{e}}$. The coalescence theory for describing the family relationships of neutral genes at a locus shows that $\mathrm{T}$ is $4 \mathrm{~N}_{\mathrm{e}}$ generations on average, although the variance is almost as large as the average (e.g. Tavaré, 1984). If $\mathrm{N}_{\mathrm{e}}=10^{4}$ and $\mathrm{g}=20$ for the extant human population, then $\mathrm{T}$ would be $4 \times 10^{4}$ generations, or 0.8 million years, and if $\mathrm{N}_{\mathrm{e}}=10^{5}$ and $\mathrm{g}=$ 10 for the common ancestral species between human and chimpanzee, then $\mathrm{T}$ would be 4 million years. For only two genes sampled at a locus, these T-values become halved, but they too point out that polymorphism we observe today is a reflection of a fairly long history of organisms. In other words, the silent diversity in the extant human population began to accumulate well before $H$. sapiens but probably after the $\mathrm{H}$. habilis stage emerged. Nonetheless, the silent diversity indicates that a great majority of people today are too closely related to each other to validate the multiregional origin of modern humans (e.g. Thorne \& Wolpoff, 1992, but see Klein, Takahata \& Ayala, 1993).

Not all kinds of polymorphism have a history similar to that described above because of the differences in the mode of inheritance and exposure to natural selection. Genes encoded for by $\mathrm{Y}$ chromosome or mitochondnal DNA are essentially of haploid nature and are inherited by only one sex, so that the effective size becomes one quarter of that for an autosomal locus. The persistence time (T) for those genes is therefore 0.2 million years rather than 0.8 million years. The actual DNA sequence data for both genetic systems indeed indicate that this is the case (e.g. Dorit et al., 1995; Horai et al., 1993). In this regard, the mitochondrial (mt) DNA of the Neandertal-type specimen (Krings et al., 1997) is of particular interest. If Neandertals had evolved in Europe by 230000 years ago (Stringer \& Gamble, 1993) and lived for some 100000 years in isolation before they coexisted and possibly exchanged genes with $H$. sapiens, the last common ancestor of human mtDNA genes can be older than 200000 years. The absence of such remotely related mtDNAs, despite extensive searches, may therefore rule out the possibility of gene exchanges between $H$. sapiens and $H$. neanderthalensis, although a preliminary study by E. A. Stahl suggests that the possibility of finding Neandertal mtDNA in our gene pool, even if massively transmitted, is not high enough: this low possibility results from the fact that genetic loci encoded by either $\mathrm{Y}$ chromosome or mtDNA undergo strong random drift and share the same evolutionary history by linkage. In any case, the genealogy of human Y chromosomes and mtDNAs is rather shallow and does not support the multiregional hypothesis.

However, there is another genetic system in which polymorphism well predated 5-6 Ma. The system encodes for major histocompatibility complex (MHC) genes and the expressed molecules exhibit an extraordinarily high level of polymorphism. It has resulted from the operation of natural selection. However, since natural selection is ineffective in small populations, the MHC polymorphism also suggests that the long-term $\mathrm{N}_{\mathrm{e}}$ in the human lineage is $10^{5}$ rather than $10^{4}$ (Takahata, 1993; Klein et al., 1993). We can use these kinds of information to infer, even though roughly, when the population reduction began. Intuitively, if the reduction occurred a long time ago, the level of MHC polymorphism even under natural selection must be reduced; if, on the other hand, it occurred recently, the silent diversity in the extant human population must be elevated. Population genetic analysis suggests that the reduction began concomitantly with the appearance of the Homo erectus-phase on the evolutionary scene. Reduction in the effective size of the whole population, if subdivided, may occur as gene flow among local populations becomes high. However, it would be difficult to keep gene flow high among local populations if they were dispersed worldwide. It is therefore rather unlikely that increased amounts 
of gene exchanges between populations were responsible for the reduction. More likely, the reduced effective size is an indication of frequent extinction of local populations over the past 1 or 2 million years. Although the reason for extinction of populations at the Homo erectus-phase is only speculative, it would be interesting to examine the possibility in more detail from various viewpoints. Obviously, this kind of issue must concern various fields such as human biology, geology, archaeology, climatology and ecology. At present it is left for future study (but see Stewart \& Disotell, 1998, for an integration of molecular, fossil and biogeographical data).

\section{Primate Phylogeny}

The evolutionary relationships among humans, chimpanzees and gorillas have attracted much attention since the classical work by Sarich \& Wilson (1967). It seems that the relationships are by and large resolved. A majority of DNA sequence data support their view that chimpanzees are closest to humans (Czelusniak \& Goodman, 1998). However, the internode between the chimpanzee and gorilla divergences is only $1.60-1.32=0.28 \%$ in terms of silent divergences (Table 2 ). This silent divergence is smaller than the silent diversity $\mathrm{x}=0.45 \%$ in the ancestral population of humans and chimpanzees. The time period of 1-2 million years is also shorter than the persistence time of polymorphism in the ancestral population of effective size $10^{5}$. These results suggest that molecular data do not always support the same evolutionary relationships among the trio. Retrospectively, the trichotomy problem appears to have been inevitable where the trio are so closely related compared to the effective size of the ancestral population.

Our results generally support the view of Martin (1993) who wrote: "Although the origin of the simian primates is obscure, new fossil evidence could push it further back by at least 10 million years. Such uncertainties reflect the low sampling level of the primate fossil record, which can potentially also lead to underestimation of times of origin within the primate tree." Martin (1993) suggested an age of 80 Ma for the origin of primates of modern aspect. However, Gingerich \& Uhen (1994) rejected the notion of such an old age and Gingerich (1986) reported that the divergence between Lemuriformes and Tarsiiformes took place at the beginning of the Eocene (53 Ma). Goodman recognizes the possible underestimation of fossil-based datings, but he does not fully agree with Martin. Goodman adds 14\% to the fossil dates (Goodman et al., 1998) rather than 40\% as suggested by Martin (1993), so that the age of primates is estimated to be $63 \mathrm{Ma}$ rather than $80 \mathrm{Ma}$. If we use the relative y value for lemurs in Table 2 and assume that the chimpanzee divergence time is 5-7 Ma, the age of primates becomes nearly or more than $100 \mathrm{Ma}$. Therefore, in addition to the small number of loci used, we note the possible fast rate of silent substitutions during early primate evolution and a somewhat slowed down rate subsequently. Under the assumption of a 6 Ma divergence between humans and chimpanzees, and therefore $r=1.1 \times 10^{-9}$, Table 2 shows that the age of catarrhines-plus-platyrrhines (or Simiiformes) becomes $55 \mathrm{Ma}$. This age is as old as the age of the oldest primate fossils. The dating of the hominoid-cercopithecoid divergence also becomes rather old: $33 \mathrm{Ma}$. This is older than the earliest primitive hominoid fossil (Kamoyapithecus hamiltoni, 24.2-27.5 Ma) and the earliest primitive cercopithecoid fossil (Victoriapithecus, 14.7-16 Ma), but it is almost the same age as the earliest known OWM skulls (e.g. Aegyptopithecus and Catopithecus). This may support the possibility that these catarrhine skulls are actually placed on the stem-lineage leading to hominoids and cercopithecoids. Finally, the gorilla, orangutan and gibbon branched off $7.3 \mathrm{Ma}$, $14 \mathrm{Ma}$, and $18 \mathrm{Ma}$, respectively (Stewart \& Disotell, 1998). To establish primate phylogeny, however, it is clear that we need accurate calibration points. In particular, comparative study with Lemuriformes or Tarsiiformes is eagerly awaited, although it seems that DNA sequence data are generally in good agreement with the revised view of primate evolution by Martin (1993). 


\section{Acknowledgements}

I thank Drs. Phillip V. Tobias and Colin P. Groves for their interest and comments as well as Drs. Yoko Satta, Yi-Ju Li and Eli A. Stahl for their comments and help.

\section{References}

Bailey, W. J., Slightom, J. L. \& Goodman, M. (1992). Rejection of the "flying primate" hypothesis by phylogenetic evidence from the $\beta$-globin gene. Science, 256, 86-89.

Britten, R. J. (1986). Rates of DNA sequence evolution differ between taxonomic groups. Science, 231, 1393-98.

Czelusniak, J. \& Goodman, M. (1999). Where DNA sequences place Homo sapiens in a phylogenetic classification of primates. (This volume).

Dorit, R. L., Akashi, H. \& Gilbert, W. (1995). Absence of polymorphism at the ZFY locus on the human Y chromosome. Science, 268, 1183-85.

Easteal, S. \& Herbert, G. (1997). Molecular evidence from the nuclear genome for the time frame of human evolution. J. Mol. Evol., 44(Suppl 1), S121-32.

Gingerich, P. D. (1986). Early Eocene Cantius torresi - oldest primate of modern aspect from North America. Nature, 319, 319-21.

Gingerich, P. D. \& Uhen, M.D. (1994). Time of origin of primates. J. Hum. Evol., 27, 443-45.

Goodman, M., Poeter, C.A., Czelusniak, J., Page, S.L., Schneider, H., Shoshani, J., Gunnell, G. \& Groves, C.P. (1998). Toward a phylogenetic classification of primates based on DNA evidence complemented by fossil evidence. Mol. Phylogenet. Evol., 9, 585-98.

Horai, S., Kondo, R., N-Hottori, Y., Hayashi, S., Sonoda, S. \& Tajima, K. (1993). Peopling of the Americas, founded by four major lineages of mitochondrial DNA. Mol. Biol. Evol., 10, 23-47.

Kimura, M. (1983). The Neutral Theory of Molecular Evolution. Cambridge: Cambridge University Press.

Klein, J., Takahata, N. \& Ayala, F. J. (1993). Mhc polymorphism and human origins. Sci. Am., 269, 46-51.

Krings, M., Stone, A., Schmitz, RW., Krainitzki, H., Stoneking, M. \& Pääbo, S. (1997). Neanderthal DNA sequences and the origin of modern humans. Cell, 90, 19-30.

Kumar, S. \& Hedges, S.B. (1998). A molecular timescale for vertebrate evolution. Nature, 392, 917-19.

Leakey, M.G., Feibel, C.S., McDougall, I. \& Walker, A. (1995). New four-million-year-old hominoid species from Kanapoi and Allia Bay, Kenya. Nature, 376, 565-71.

Li, W.-H., Ellsworth, D.L., Krushkal, J., Chang, B.H.J., \& Hewett-Emmett, H. (1996). Rates of nucleotide substitution in primates and rodents and the generation-time effect hypothesis. Mol. Phylo. Evol., 5, 182-87.

Li, W.-H. \& Sadler, L.A. (1991). Low nucleotide diversity in man. Genetics, 129, 513-23.

Martin, R.D. (1993). Primate origins, plugging the gaps. Nature, 363, 223-34.

Novacek, M.J. (1992). Mammalian phylogeny: shaking the tree. Nature, 356, 121-25.

Nuttal, G.H.F. (1904). Blood Immunity and Blood Relationships. Cambridge: Cambridge University Press.

Pettigrew, J.D., Jamieson, B.G.M., Robson, S.K., Hall, L.S., McAnally, K.I. \& Cooper, H.M. (1989). Phylogenetie relations between microbats, megabats and primates (Mammalia, Chiroptera and Primates). Phil. Trans. R. Soc., Lond., B, 325, 489-559.

Pilbeam, D. (1984). The descent of hominoids and hominids. Sci. Am,. 252, 84-96.

Sarich, V.M. \& Wilson, A.C. (1967). Immunological time scale for hominid evolution. Science, 158, 1200-03.

Sibley, C.G. \& Ahlquist, J.E. (1987). DNA hybridization evidence of hominoid phylogeny, Results from an expanded data set. J. Mol. Evol., 26, 99-121.

Stewart, C.-B. \& Disotell, T.R. (1998). Primate evolution - in and out of Africa. Current Biology, 8, R582-88.

Stringer, C. \& Gamble, C. (1993). In Search of the Neanderthals: Solving the Puzzle of Human Origins. London: Thames and Hudson.

Takahata, N. (1993). Allelic genealogy and human evolution. Mol. Biol. Evol., 10, 2-22.

Takahata, N. \& Satta, Y. (1997). Evolution of the primate lineage leading to modern humans, Phylogenetic and demographic inferences from DNA sequences. Proc. Natl Acad. Sci., USA, 94, 4811-15.

Tavaré, S. (1984). Line-of-descent and genealogical processes, and their applications in population genetics models. Theor. Popul. Biol., 26, 119-64.

Thorne, A.G. \& Wolpoff, M.H. (1992). The multiregional evolution of humans. Sci. Am., 266, 76-83. 


\section{Elizabeth E. Watson ${ }^{1}$, Simon Easteal ${ }^{2} \&$ David Penny ${ }^{1}$}

\author{
${ }^{1}$ Institute of Molecular BioSciences, \\ Massey University, Palmerston North, \\ New Zealand \\ ${ }^{2}$ Human Genetics Group, John Curtin \\ School of Medical Research, The Australian \\ National University, Canberra, ACT 0200, \\ Australia
}

Keywords: classification, humans, great apes, history, molecular genetics, Homo

\section{Homo Genus: A Review of the Classification of Humans and the Great Apes}

\begin{abstract}
From the time the first great apes arrived in Europe in the early seventeenth century, the position of humans in nature has been under scrutiny. The fact that the apes shared many physical characters with humans, led to a preoccupation with defining what was uniquely human, apparently in an attempt to preserve the apical place of humans in nature (that is the highest link on the 'great chain of being'). Darwin's theory of evolution provided strong evidence that the physical similarities between humans and apes are a result of common origin. With the advent of molecular techniques the proximity of humans to apes has been confirmed and has revealed the chimpanzee as our closest living relative, in fact as close as sister species. Recent accumulation of data provides compelling evidence for revising the taxonomic status of hominoids from its eighteenth century stasis. We propose that the gorilla, chimpanzee, and orang-utan be included in the family Hominidae together with the human; and that the chimpanzee and gorilla be included in the genus Homo, thereby assuming the names Homo niger and Homo gorilla, respectively.
\end{abstract}

\section{Introduction}

The French naturalist Buffon (1707-1788) said,

'at what distance from man shall we place the great apes, which resemble him so perfectly in bodily conformation?'

This has remained a question since the great apes were discovered by the Western world in the sixteenth century. Most scientists have acknowledged physical similarities between humans and the great apes, but it is difficult to translate these similarities into a taxonomic scheme. Groves (1986) says:

'If taxonomy (above the species level) is ever to become more than mere stamp collecting, it must define its spheres of usefulness and examine its philosophical basis. It will be an objective science if it can reflect some part of the real world and if it can be made testable against some other standard;...'

Molecular genetics, although not infallible, may be able to provide the most objective measure of distance between species.

The current taxonomic scheme places humans in a separate family from the other great apes (see Table 1). In this paper, we review the history of the classification of humans and the great apes, and examine the molecular genetic data for these species. We conclude that a taxonomic revision is necessary that includes chimpanzee and gorilla within the genus Homo. It is not within the scope of this paper to address issues of subspecies of the great ape species, and for the purposes of this paper we have included the bonobo (pygmy chimpanzee) with the chimpanzee. The following section is a review of the history of classification, which has led to the current taxonomy. We will focus on Western history of classification and will not discuss the classification and belief systems of other groups of peoples. Often, however, the groups living close to apes acknowledged them as being close to, and sharing the same taxonomic category as humans. 
Table 1. The Classification of the Great Apes and Humans (Eisenberg, 1981).

\begin{tabular}{c} 
Superfamily Hominoidea \\
Family Hominidae \\
Genus Homo \\
Family Pongidae \\
Genus Pongo \\
Genus Gorilla \\
Genus Pan \\
\hline
\end{tabular}

\section{History}

The explorers of the sixteenth and seventeenth centuries returned home with descriptions of various beasts, amongst the most remarkable of which were the first descriptions of the apes. The first recorded description in Europe of the chimpanzee was given by the Portuguese sailor Eduardo de Lopez (Pigafetta, 1598; cited Huxley, 1863; p.1), and the first accounts of the gorilla were mentioned together with the chimpanzee by the Englishman, Andrew Battell (Purchas, 1613; cited Huxley, 1863: p.4). Europe at this time had just faced a paradigm shift. In 1543, Copernicus published his theory that the earth's position was not central in the universe, but instead that it orbited around the sun together with the other planets. With earth's central position denounced, it seemed that the time was right for challenging human's place in nature, but this was not to be the case.

It was not until the seventeenth century that the first great ape specimen arrived in Europe. In 1641, Tulpius (Nikolaas Tulp, 1593-1674), a Dutch physician, described a young chimpanzee (probably a bonobo - Reynolds, 1967). Because Tulp thought it was the same species as the Indonesia ape, he named it after the Malay term 'Orang outang', meaning 'people of the forest', and translated this to Homo sylvestris. Bontius (Jakob de Bondt, 1592-1631) studied a young orang-utan and followed Tulpius by naming it Homo sylvestris; this was published posthumously in 1658. Edward Tyson (1650-1708), an English anatomist, meticulously dissected a young chimpanzee specimen, providing accurate sketches (see Figure 2). Tyson noted that the chimpanzee (whom he named Pygmie) shared 48 characters with humans as opposed to 34 with monkeys, and despite this he concluded it was an animal (Tyson, 1699). Tyson thought his specimen was different from Tulpius's and claimed it was 'a pygmie that hitherto had only been a creature in ancient tales'. Following Tulpius and Bontius, Tyson also named his specimen Homo sylvestris. Naming the apes as Homo acknowledged their similarities to humans; however it did not imply that they shared the same genus as humans, as this was prior to Linnaeus' time.

Tyson predicted the chimpanzee knuckle-walked but anthropomorphised it by illustrating it in an erect position aided with a stick (see Figure 1). This was a common motif (see Figures 2,3) in illustrations of monkeys and apes, which persisted through the seventeenth and eighteenth centuries (Spencer, 1995; p.25).

The discovery of the great apes added intermediate steps between humans and animals on the 'great chain of being'. This 'great chain of being', also known as Scala Natura, was an Aristotelian concept of nature being ordered in a fine gradation from the primitive to advanced, humans occupying the highest rung (Lovejoy, 1936). Most scientists of this time (including Cuvier, Descartes and Tyson) were clear to point out that, although apes bridged the gap between humans and animal, they were certainly animals. There were a few exceptions, such as Lord Monboddo (James Burnett), a Scottish judge, who claimed apes should be given human status. Monboddo gave examples of human-like qualities, citing their ability to build rudimentary huts, and to use sticks for attacking and defending, as well as claiming 


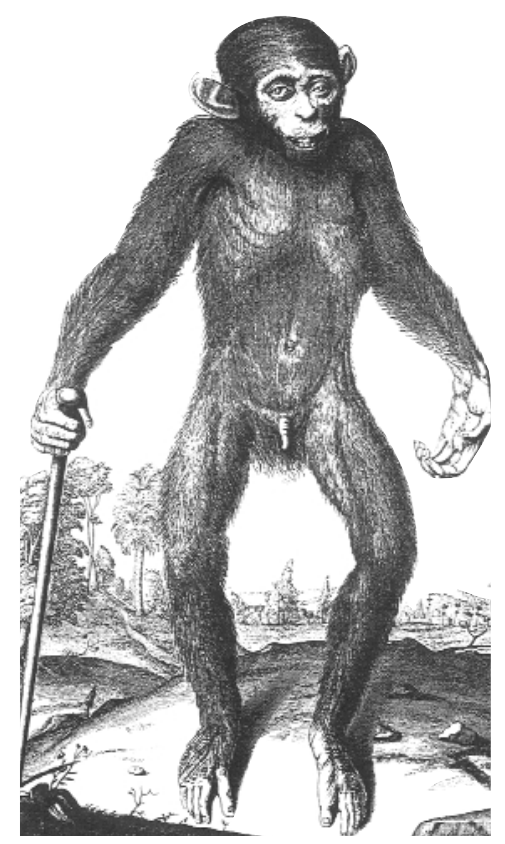

Figure 1. Reproduction of figures from Tyson's Anatomy of Homo sylvestris (1699).

This figure shows the high level of detailed knowledge used by Tyson, and contrasts with the inaccurate illustrations used later in 1763 (see Figure 2).

that they were able to use fire, bury their dead and interbreed with humans (Monboddo, 1779: pp. 7577).

Linnaeus (Carl Linné, 1707-1778), the father of modern classification, proposed a taxonomic system which established the current system of binomial nomenclature. He not only devised a naming scheme but provided a higher structure of kingdoms, classes and orders (Linnaeus, 1735). In his first edition of Systema Naturae he named humans Homo sapiens and placed them in the order Anthropomorpha, which he later changed to Primates to reflect their higher position on the 'great chain'. Linnaeus renamed the young orang-utan from Bontius as Homo nocturnus and later in the $10^{\text {th }}$ edition as Homo troglodytes (Stiles \& Orleman, 1927: p. 9). Linnaeus renamed the chimpanzee from Scotin (which he mistakenly thought was from Tulpius) as Satyrus indicus and later in the $10^{\text {th }}$ edition as Simia satyrus (Stiles \& Orleman, 1927: p.10). In his scheme he included a tailed animal (probably a baboon, see legend for Figure 2) from Aldrovandus (1645) and named it Homo caudatus. This information is represented in his student Hoppius's class Anthropomorpha published in Amoenitates Academicae (1763). This was probably Linnaeus's own work as at this time in Sweden, the professor wrote the thesis and the student's duty was to learn it (Colin Groves, pers. comm.). In addition to Scotin's chimpanzee and Edwards' orang-utan, he included poor renditions of Aldrovandus's baboon and Bontius's orang-utan. The confusion within Anthropomorpha was due in part to poor descriptions and illustrations (see Figure 2). The illustrations were copied from copies, each time losing resolution and in some cases becoming more anthropomorphised. An example of this is Hoppius's (1763) second figure from Aldrovandus which was probably copied from Breydenbach's (1483-4: cited Spencer, 1995) and Gesner's (1602) figures (see Figure 6). Through time the face of this creature became more human-like. Classification based on such information is obviously incorrect. In addition, Linnaeus' classification unfortunately lacked the knowledge of the contemporary literature such as the detailed work of Tulpius and Tyson.

Later, Linnaeus did question why humans and apes should be classed in different genera: 


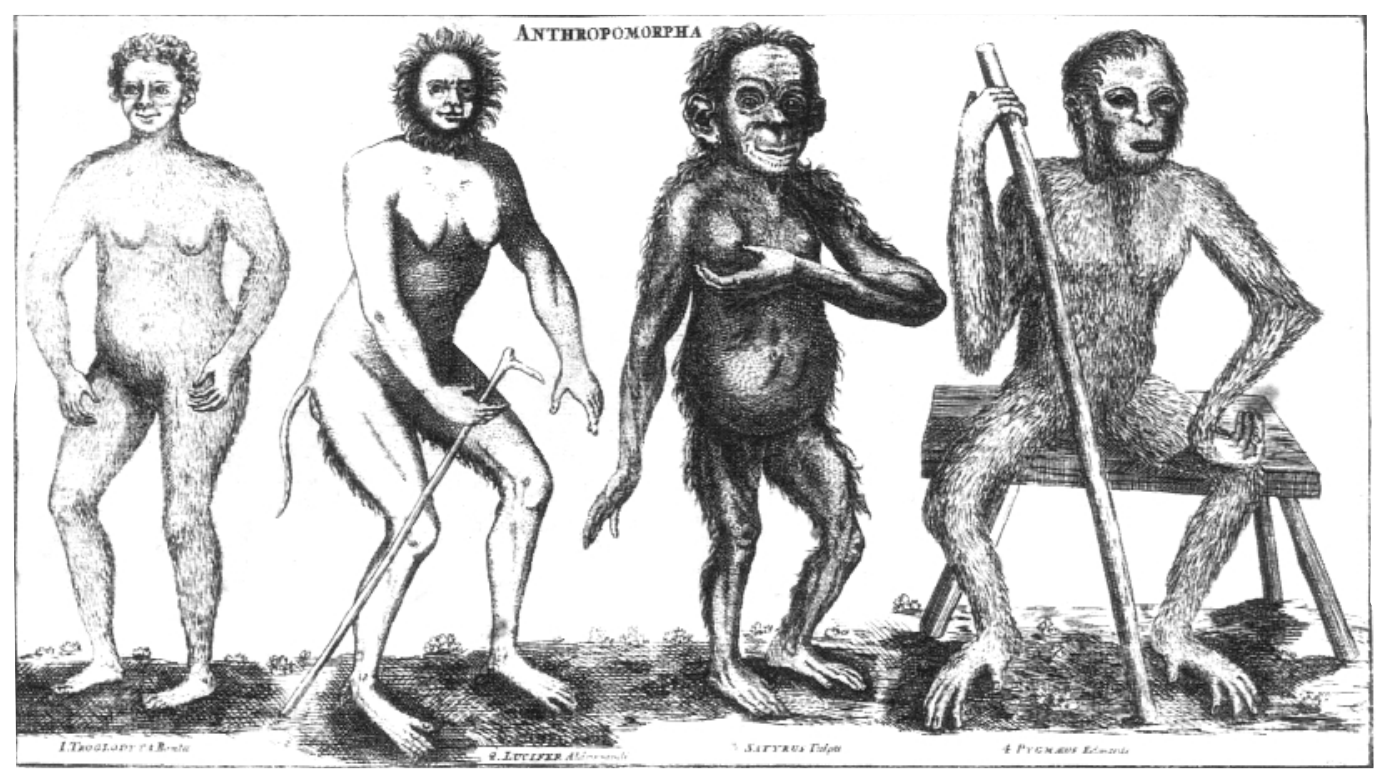

Figure 2. Reproduction of figures of Anthropomorpha (from Hoppius, 1763). The first species is from Bontius and is in fact supposed to represent a young orang-utan. Linnaeus classifies this as Homo nocturnus and later in the $10^{\text {th }}$ edition as Homo troglodytes (Stiles \& Orleman, 1927; p.9). The second species is from Aldrovandus (1645). This looks similar to Gesner's (1602) and von Breydenbach's illustrations supposedly representing a baboon (Spencer, 1995: p.25). Linnaeus classifies this as Homo caudatus. The third species is a chimpanzee claimed to be from Tulpius but in fact it is from Scotin (1739; cited by Stiles \& Orleman,1927;p.12). Linnaeus classifies this as Satyrus indicus and later in the $10^{\text {th }}$ edition as Simia satyrus (Stiles and Orleman, 1927;p.10). The fourth species is an orangutan from Edwards (1758) which was published after Linnaeus' $10^{\text {th }}$ edition. In 1766 Linnaeus named it Simia satyrus (Stiles \& Orleman, 1927). All illustrations represent the different species as bipedal.

'I demand of you, and of the whole world that you show me a generic characteristic ... by which to distinguish between man and ape. I myself most assuredly know of none. I wish somebody would indicate one to me' (Linnaeus, 1778).

However, there were no attempts to rectify this in later editions of his Systema Naturae, and two hundred years later humans and the great apes still remain in different genera.

Confusion regarding the number and location of great ape species lasted well into the nineteenth century. A plethora of names and classifications was proposed, as recorded in the nomenclature revision of Stiles \& Orleman (1927). Juveniles and adults were often classed as separate species. Initially no distinction was made between African and Asian apes and later no distinction between chimpanzees and gorillas. This accounts for the anomaly that an African name for gorilla 'mpunga' is applied to the orangutan as Pongo (Rijksen, 1995: p.291) and the Malay name Orang outang, was for a while, a name applied to the chimpanzee. It was as late as 1847 before the gorilla was accurately described by Savage and Wyman, who named it Troglodytes gorilla; and it was not until 1929 that the bonobo was recognised by Schwarz (1934), who regarded it as a chimpanzee subspecies, and named it Pan satyrus paniscus.

Despite the suggestion of Linnaeus that the great apes and humans were very similar, there was a phase when they became even more separated taxonomically. This probably coincided with the decline 

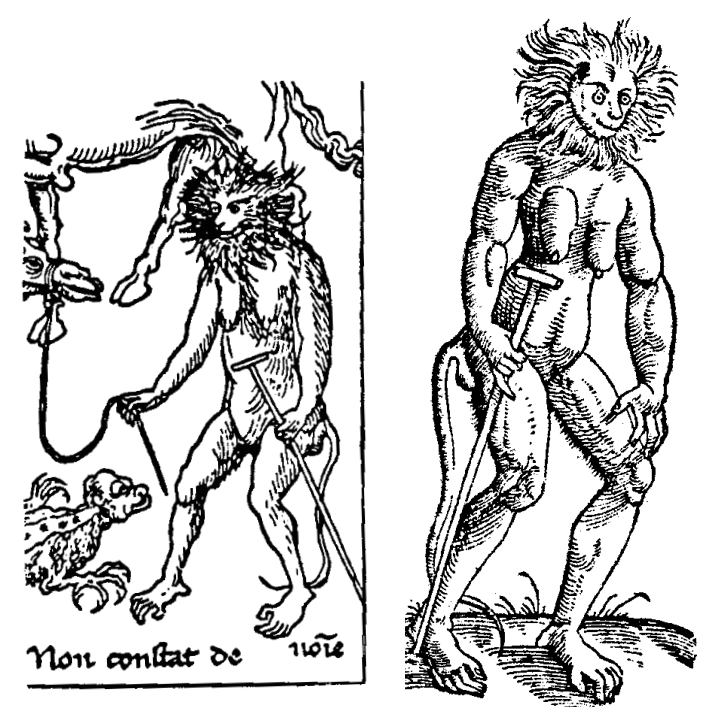

Figure 3. Reproduction of figures from von Breydenbach (1483-4) and Gesner (1602). These figures are believed to represent a baboon. The first figure is from von Breydenbach's Journey to the Holy Land (1483-4: cited by Spencer, 1995) and the second from Gesner's Historiae animalium (1602: cited by Spencer, 1995).

of the concept of the 'great chain', when it was no longer expected that a series of closely related species would exist. In the eighteenth century the position of humans as a separate family was challenged by the German anatomist Blumenbach (1752-1840) (1779: p.67), who assigned them to a separate Order Bimanus. Later, Illiger (1811) assigned humans a separate order Erecta (Schultz, 1962) and Julian Huxley went as far as to place humans in a separate kingdom Psychozoa (Lewin, 1988).

Linnaeus thought nature's system was God's plan underlying creation. Based on the similar body plans between primates and humans, he placed humans within a biological scheme. Linnaeus, however, did not think his hierarchical scheme represented common origin; to him each species was a separate creation on the great chain. Linnaeus believed on the other hand, that humans had wisdom, hence the name Homo sapiens - 'wise man'. He labelled humans Nosce te ipsum, 'know yourself', believing humans to be alone in possessing self-awareness.

Labelling the unique characteristics of humans continued as a pastime for many philosophers and scientists. Although by definition a species must have unique characteristics, recent research has shown that most characteristics considered uniquely human are seen in some degree in the great apes, for example self-awareness (Gallup, 1979), language ability (Gardner \& Gardner, 1969; Fouts \& Fouts, 1993; Patterson \& Cohn, 1990; Savage-Rumbaugh \& Lewin, 1994), tool use (Goodall, 1971: p.234), problem solving (Goodall, 1990: p.18-19), war (Goodall, 1990: p. 208-9), and complex society (Goodall, 1990).

The 'great chain' notion persisted until Charles Darwin's theory of evolution was published in 1859. One of the more unsettling implications of Darwin's theory was that humans had originated from, as Darwin put it, 'a hairy quadruped' (Darwin, 1871; cited McCown \& Kennedy, 1972: p.154). These conclusions met with fierce resistance from both scientists and the public. Alfred Russel Wallace claimed that an independent origin for humans was not supported by fact and was very improbable (Wallace, 1889; cited McCown \& Kennedy, 1972, p.183). Linnaeus's hierarchical classification scheme could, with hindsight, easily be represented as a tree reflecting the speciation events proposed by Darwin. Linnaeus's classification not only represented shared features but reflected evolutionary processes.

Nuttall, as early as 1904, thought that testing reactivity of sera between different animals was an 


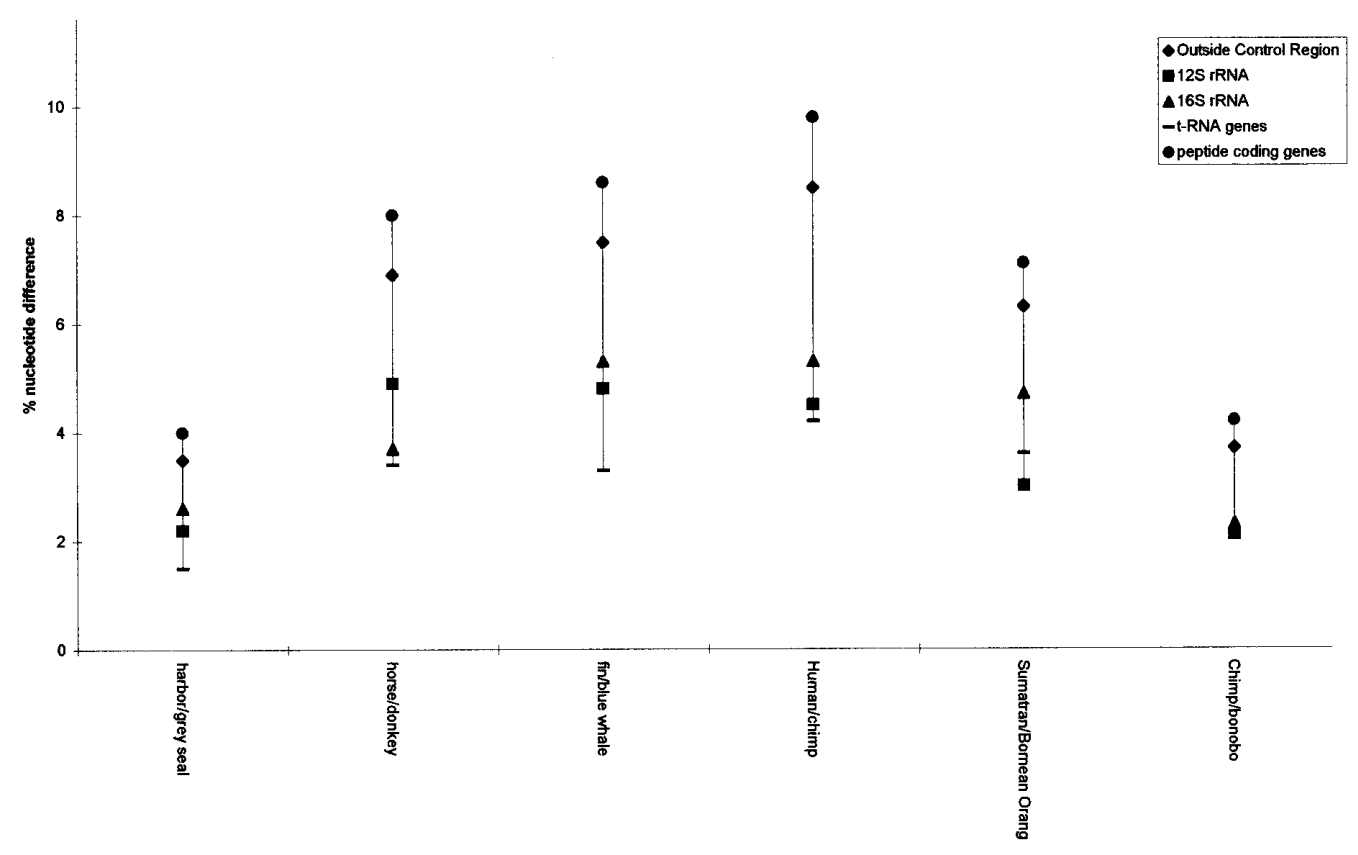

Figure 4. Distances of species pairs within genera from mitochondrial DNA sequences.

Graph of percentage nucleotide difference for pairs of mammals from the mtDNA (from Xu \& Arnason, 1996). Note that the relative percent differences between the mtDNA regions are not consistent. The distance of the human/chimpanzee pairs is close to that of sister taxa from the same genera (with the exception of the seals, which are in two genera - see text).

objective way to measure relatedness and evolutionary history. He found the orang-utan and especially the chimpanzee were strikingly similar to humans (Nuttall, 1904, p.137). With the advent of molecular techniques, scientists began to investigate the relationships of humans to the great apes. Pioneering work was done by Morris Goodman (1963) using immunological methods which grouped the humans in the same clade as the African apes. This was confirmed by other studies using different loci and different analytical methods (Sarich \& Wilson, 1967; Ferris et al., 1981; Brown et al., 1982; Goodman et al., 1983; Hasegawa et al., 1987: Kishino \& Hasegawa, 1989; Koop et al., 1989). Goodman (1963) was the first to suggest taxonomic revision, when he proposed that the great apes be classified in the same family as humans.

\section{Data}

We present two different genetic systems to illustrate that the genetic distances between human, chimpanzee and gorilla are equivalent to the distance between mammalian species within the same genus. The first example measured distances from mitochondrial sequence data (Xu \& Arnason, 1996). Xu \& Arnason (1996) have chosen very close pairs of species. All the species pairs are within the same genus except the seal species. De Muizon (1982) acknowledges the proximity of the two seal species and Arnason et al. (1993) argue they should be in the same genus. Most of these species pairs are known 


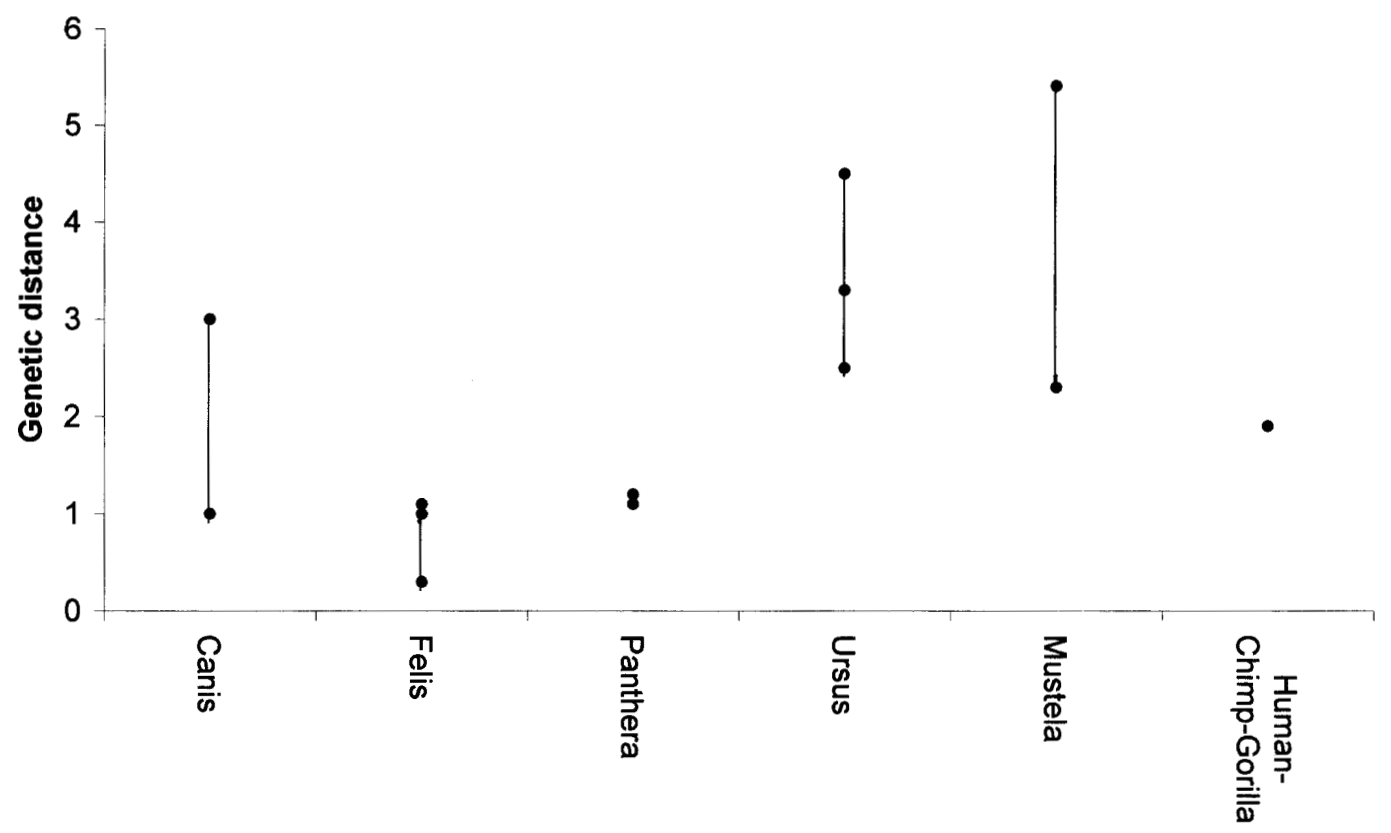

Figure 5. Distance of species pairs within genera from DNA hybridisation values. The Tm values from DNADNA hybridisation for taxa within a genus (from Wayne et al., 1991). The values for the species pairs are represented by circles.

to hybridise and produce viable offspring with varying degrees of fertility. The human-chimpanzee pair is only slightly more distant than these examples of very closely related sister species (see Figure 4). The second genetic system measured the DNA-DNA hybridisation $\Delta \mathrm{Tm}$ distances from Wayne et al. (1991). The distances between the human, chimpanzee and gorilla fall within the range of distances observed in several mammalian genera (see Figure 5).

Early on, genetic studies identified that the orang-utan branched early from the African apes and humans. But it was more difficult to resolve confidently the order in which the human, chimpanzee and gorilla diverged; this became known as 'The Trichotomy' (Smouse \& Li, 1987; Holmquist et al., 1988; Kishino \& Hasegawa, 1989; Horai et al., 1992). With the accumulation of much longer sequences, the trichotomy can now be considered resolved (Ruvolo, 1997). The gorilla diverged first, followed by the chimpanzee and human divergence. This is also the favoured relationship when morphological characters are considered (Groves, 1989). When considering the genetic information, the usual taxonomic scheme for the humans and great apes is paraphyletic (Figure 6). A paraphyletic group is one that has a common ancestor but does not include all descendants of that ancestor.

\section{Discussion}

The former taxonomic system (which separated humans and great apes at the family level) has persisted despite the accumulated evidence of decades of morphological, immunological, protein and DNA sequence data, and numerous reasonable theoretical models. There now is definitive agreement on 


\section{Pongidae Chimpanzee}

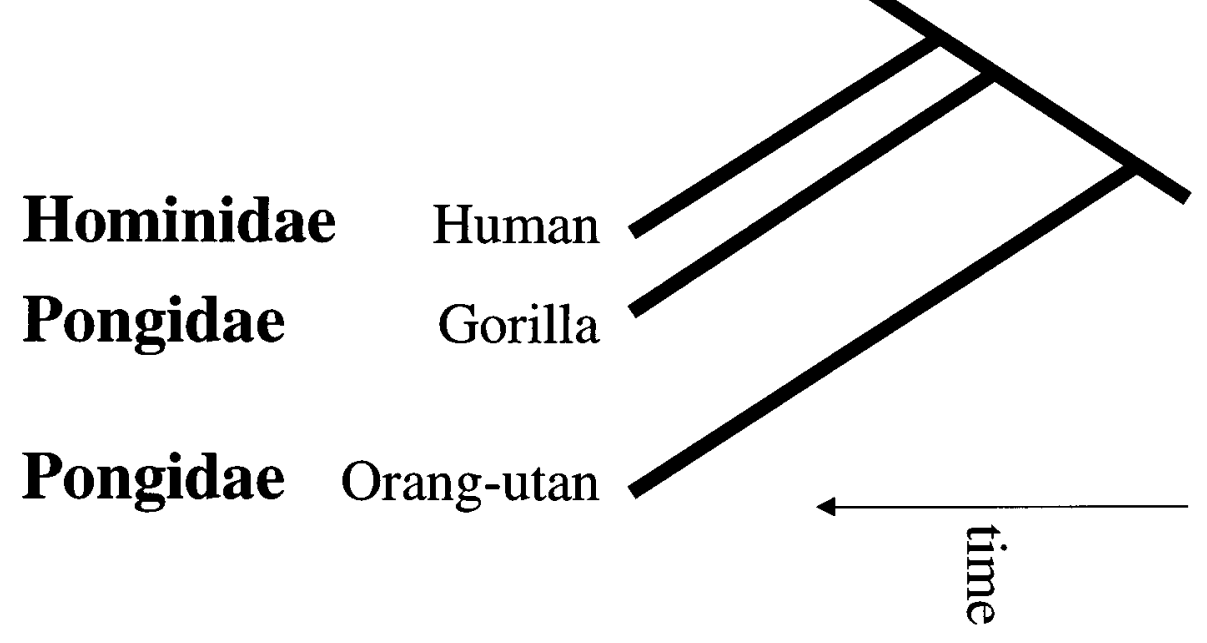

Figure 6. Schematic diagram of the phylogenetic relationship between the human, chimpanzee, gorilla, orang-utan. The bold type indicates which family the species belong to in the usual taxonomic scheme, which is in conflict with the phylogenetic tree.

the branching order of the human, chimpanzee and gorilla (Ruvolo, 1997). The present knowledge base demonstrates that there is a major inconsistency within higher primate taxonomy that requires rectification.

Objective evidence for a taxonomic reorganisation has existed for thirty years, and although several authors have promoted it, the scheme has remained unchanged. One possible reason is that people are still uneasy about accepting themselves as an animal species. Rene Descartes' (1596-1650) philosophy proposed two states of matter: physical and thinking substance (Descartes, 1637), which separated humans from animals. In fact Descartes (1637: p.46) said:

'...there is none that is more powerful in leading feeble minds astray from the straight path of virtue than the supposition that the soul of the brutes is the same nature with our own; and consequently that after this life we have nothing to hope for or fear, more than flies or ants; ...'

Mayr (1982) suggests that scientists have clung to Descartes' doctrine for too long and describes him as having 'created a millstone around the neck of biology' (Mayr, 1982: p.97).

The taxonomic scheme for humans and the great apes arose from the milieu of the seventeenth, eighteenth and nineteenth centuries. The ideas of the seventeenth century influenced the nomenclature of the apes and in the nineteenth century when the taxonomic level of Family was introduced, humans were given their own Family Hominidae. It is relevant to review the classification in light of the twentieth century advancements, most notably in molecular genetics.

Genetically humans are nested within the great apes and are closest to the chimpanzee. The genetic 


\title{
Table 2. The Classification of the Great Apes and Humans (proposed revision)
}

\author{
Family Hominidae \\ Subfamily Homininae \\ Genus Pongo \\ Pongo pygmaeus \\ Genus Homo \\ Homo sapiens (human) \\ Homo gorilla (gorilla) \\ Homo niger* (chimpanzee)
}

\begin{abstract}
* Homo troglodytes is a preoccupied name (a secondary homonym), as it was used to denote a composite of Bontius' orang-utan and the Kakurlacko, which were apparently unusual-looking African people, thus making Homo troglodytes unavailable for the chimpanzee. In Linnaeus (1758), satyrus was a specific name based on Tulpius's (1739) chimpanzee, but this is also unavailable because satyrus was also applied to another species. The next available name for the chimpanzee would appear to be Homo niger (E. Geoffroy St. Hilaire, 1812), proposed as Troglodytes niger.
\end{abstract}

distances show humans are genetically very similar to the great apes, in fact close enough to warrant sister species status. Sister species status of human and chimpanzee was first suggested by King \& Wilson (1975), after they compared distances within genera of Drosophila, amphibians, reptiles and mammals. Consistency of genetic distance and taxonomic distance would be difficult to achieve across the biological world, but we can aim for some consistency within Mammalia.

Goodman and colleagues have challenged the existing scheme, first in 1963 at the family level, proposing that the human, chimpanzee and gorilla should be in the same family (Goodman, 1963). They later modified this to the same subfamily (Miyamoto et al., 1988), then same tribe (Goodman et al., 1990; Bailey et al., 1992), then eventually in 1998 the same subtribe, with the chimpanzee and humans in the same genus (Goodman et al., 1998). We propose taking this one step further by including the gorilla in the genus Homo.

We propose a new taxonomic scheme (Table 2) which reflects both the branching topology and the genetic distances. This includes the gorilla in the genus Homo along with the human and chimpanzee. We base this on the short distance (or time) between the gorilla divergence and the chimpanzee-human divergence as implied by the difficulty in resolving the trichotomy. Diamond (1991: p. 21) has previously suggested that humans, chimpanzee and gorilla share the same genus. We propose that the orang-utan Pongo pygmaeus share the same subfamily as the genus Homo (see Table 2).

Goodman et al. (1998) based their classification on dates of divergence and aimed to rank clades of similar age throughout the Primate Order. In our examples we focus on genetic distances, but as substitution rate is reasonably consistent within mammals (Easteal, 1990), genetic distances equate closely with time. Goodman et al. (1990) were initially hesitant to include humans and chimpanzees in the same genus on two grounds. Their first consideration was that the two chimpanzee species are closer than the human and the chimpanzee. This problem is removed if the bonobo is classified as a subspecies of chimpanzee. There has been debate as to whether the bonobo is a species or subspecies ever since they were first described by Schwarz in 1934. In terms of cranial characters (Shea et al., 1993) and behaviour (de Waal, 1989: p.180) the bonobo are distinct from the other chimpanzee subspecies, but the distinctions may not be sufficient to warrant species status. The bonobo and chimpanzee produce viable 
offspring (Vervaecke \& van Elsacker, 1992) and genetically the chimpanzee and bonobo are equivalent to the distance between the subspecies of gorilla and of orang-utan, supporting the proposition that they are a subspecies of chimpanzee. The second problem for Goodman et al. (1990) was the confusion which might ensue regarding the nomenclature of early hominid fossils. We believe the knowledge of extinct species should not affect the classification of extant species - after all, not all species have the rich fossil record of humans, the chimpanzee and gorilla being good examples.

When the living great apes were discovered by the western world, they were recognised to be close to humans and the implications of this threatened existing conceptions about the unique position of humans in the natural world. The similarities and differences between humans and the great apes have been difficult to look at objectively, but molecular technology provides the most objective measure of determining relationships between species. The molecular genetic information which has accumulated over the last thirty years supports the very recent divergence of humans, chimpanzees and gorillas; we believe the classification system should reflect this.

\section{Acknowledgements}

We are very grateful to Colin Groves for comments on the manuscript and information regarding nomenclature. We thank Raymond Corbey for sending us the very useful volume he co-edited.

\section{References}

Arnason, U., Gullberg, A., Johnsson, E. \& Ledje, C. (1993). The nucleotide sequence of the mitochondrial DNA molecule of the Grey Seal, Halichoerus grypus, and a comparison with mitochondrial sequences of other true seals. Journal of Molecular Evolution, 37, 323-30.

Bailey, W.J., Hayasaka, K., Skinner, C.G., Kehoe, S., Sieu, L.C., Slightom, J.L. \& Goodman, M. (1992). Reexamination of the African hominoid trichotomy with additional sequences from the primate $\Psi$-globin gene cluster. Molecular Phylogenetics and Evolution, 1, 97-135.

Blumenbach, J.F. (1779). Order I: Bimanus Order II: Quadrumana. (reprinted 1972). In: Climbing Man's Family Tree: A Collection of Major Writings on Human Phylogeny, 1699 to 1971. (1972), ed. T.D. McCown \& K.A.R. Kennedy; pp 67-73. New Jersey: Prentice Hall.

Brown, W.M., Prager, E.M., Wang, A. \& Wilson, A.C. (1982). Mitochondrial DNA sequence of primates: Tempo and mode of evolution. Journal of Molecular Evolution, 18, 225-39.

Darwin, C.R. (1871). On the affinities and genealogy of man: General summary and conclusion. In: Climbing Man's Family Tree: A Collection of Major Writings on Human Phylogeny, 1699 to 1971. (1972), ed. T.D. McCown \& K.A.R. Kennedy; pp 149-58. New Jersey: Prentice Hall.

Descartes, R. (1637). A Discourse on Method and Other Writings (reprinted1962). London: Penguin.

De Waal, F.B.M. (1989). Peacemaking Among Primates. Cambridge: Harvard University Press.

Diamond, J. (1991). The Rise and Fall of the Third Chimpanzee. Raduis: London.

Easteal, S. (1990). The pattern of mammalian evolution and the relative rate of molecular evolution. Genetics, 124, $165-73$.

Eisenberg, J.F. (1981). The Mammalian Radiations: An Analysis of Trends in Evolution, Adaption, and Behavior. Chicago: University of Chicago Press.

Ferris, S.D., Wilson, A.C. \& Brown, W.M. (1981). Evolutionary tree for apes and humans based on cleavage maps of mitochondrial DNA. Proceedings of the National Academy of Science USA, 78, 2432-36.

Fouts, R. \& Fouts, D.H. (1993). Chimpanzees' use of sign language. In: The Great Ape Project, ed. P. Cavalieri \& P. Singer, pp. 28-41. New York: Fourth Estate.

Gallup, G.G. (1979). Self-awareness in primates. American Scientist, 67, 417-21.

Gardner, R.A. \& Gardner, B.T. (1969). Teaching sign language to a chimpanzee. Science, 165, 664-72.

Geoffroy St. Hilaire, È. (1812). Tableau des Quadrumanes. etc. Ann. Mus. Hist. Nat. Paris, 19, 86-122.

Goodall, J. (1971). In the Shadow of Man. London: Collins.

Goodall, J. (1990). Through a Window: My Thirty Years With the Chimpanzees of Gombe. Boston: Houghton Mifflin. Goodman, M. (1963). Serological analysis of the systematics of recent hominoids. Human Biology, 35, 377-436.

Goodman, M., Braunitzer, G., Stangl, A. \& Schrank, B. (1983). Evidence on human origins from haemoglobins of 
African apes. Nature, 303, 546-48.

Goodman, M., Koop, B.F., Czelusniak, J., Fitch, D.H.A., Tagle, D.A. \& Slightom, J.L. (1989). Molecular phylogeny of the family of apes and humans. Genome, 31, 316-35.

Goodman, M., Porter, C.A., Czelusniak, J., Page, S.L., Schneider, H., Shoshani, J., Gunnell, G. \& Groves, C.P. (1998). Toward a phylogenetic classification of primates based on DNA evidence complemented by fossil evidence. Molecular Phylogenetics and Evolution, 9, 585-98.

Goodman, M., Tagle, D.A, Fitch, D.H.A., Bailey, W., Czelusniak, J., Koop, B.F., Benson, P. \& Slightom, J.L. (1990). Primate evolution at the DNA level and classification of hominoids. Journal of Molecular Evolution, 30, 260-66.

Groves, C.P. (1986). Systematics of the great apes. In: Comparative Primate Biology. Vol 1. ed. D.R. Swindler \& J. Erwin, pp. 187-217. New York, Alan R. Liss.

Groves, C.P. (1989). The Theory of Human and Primate Evolution. Oxford: Clarendon Press.

Hasegawa, M., Kishino, H., \& Yano, T. (1987). Man's place in Hominoidea as inferred from molecular clocks of DNA. Journal of Molecular Evolution, 26, 132-47.

Holmquist, R., Miyamoto, M.M. \& Goodman, M. (1988). Higher primate phylogeny - Why can't we decide? Molecular Biology and Evolution, 5, 201-16.

Hoppius, E. (1763). Amoenitates Academicae VI. Stockholm.

Horai, S., Satta, Y., Hayasaka, K., Kondo, R., Inoue, T., Ishida, T., Hayashi, S. \& Takahata, H. (1992). Man's place in Hominoidea revealed by mitochondrial DNA genealogy. Journal of Molecular Evolution, 35, 32-43.

Huxley, T.H. (1906). Man's Place in Nature and Other Essays. Dent \& Co, London.

King, M-C. \& Wilson, A.C. (1975). Evolution at two levels in humans and chimpanzees. Science, 188, 107-16.

Kishino, H. \& Hasegawa, M. (1989). Evaluation of the maximum likelihood estimate of the evolutionary tree topologies from DNA sequence data, and the branching order in Hominoidea. Journal of Molecular Evolution, 29,170-79.

Koop, B.F., Tagle, D.A., Goodman, M. \& Slightom, J.L. (1989). A molecular view of primate phylogeny and important systematic and evolutionary questions. Molecular Biology and Evolution, 6, 580-612.

Lewin, R. (1988). Family relationships are a biological conundrum. Science, 242, 671.

Linnaeus, C. (1735). Systema Naturae. (facsimile of the first edition 1964). ed. M.S.J. Engel-Ledeboer \& H. Engel. de Graaf: Nieukoop.

Linnaeus, C. (1778). Systema Naturae. $10^{\text {th }}$ edition. Stockholm.

Lovejoy, A.O. (1936). The Great Chain of Being. Cambridge (Mass.): Harvard University Press.

Lyons, S. (1998). Taxonomy recapitulates society. Science, 279, 38.

Mayr, E. (1982). The Growth of Biological Thought: Diversity, Evolution and Inheritance. Cambridge ( Mass.): Harvard University Press.

Miyamoto, M.M. (1988). Molecular systematics of higher primates: genealogical relations and classification. Proceeding of the National Academy of Sciences, USA, 85, 7627-31.

McCown T.D. \& Kennedy K.A.R. (Eds) (1972). Climbing Man's Family Tree: A Collection of Major Writings on Human Phylogeny, 1699 to 1971. New Jersey: Prentice Hall.

Monboddo, J. (1779). Of the several steps of the human progression from the brute to man. In: Climbing Man's Family Tree: A Collection of Major Writings on Human Phylogeny, 1699 to 1971. (1972), ed. T.D. McCown \& K.A.R. Kennedy; pp 75-77. New Jersey: Prentice Hall.

Muizon de, C. (1982). Phocid phylogeny and dispersal. Annals of the South African Museum, 89(2), 175-213.

Nuttall, H.F. (1904). Blood Immunity and Blood Relationships: A demonstration of certain blood-relationships amongst animals by means of precipitin test for blood. Cambridge: Cambridge University Press.

Patterson, F.G. \& Cohn, R.H. (1990). Language acquisition by a lowland gorilla: Koko's first ten years vocabulary development. Word, 41, 97-143.

Reynolds, V. (1967). On the identity of the ape described by Tulp in 1641. Folia Primatologica, 5, 80-87.

Rijksen, H.D. (1995). Forest, men and man: The Evolution of civilised assertiveness. In: Ape, Man, Apeman: Changing View since 1600, ed. R. Corbey \& B. Theunissen, pp.289-96. Leiden: Leiden University.

Ruvolo, M. (1997). Molecular phylogeny of the hominoids: inferences from multiple independent DNA sequence data sets. Molecular Biology and Evolution, 14, 248-65.

Sarich, V.M. \& Wilson, A.C. (1967). Immunological time scale for hominid evolution. Science, 158, 1200-03.

Savage, T.S. \& Wyman, J. (1847). Notice of the external characters and habits of Troglodytes gorilla, a new species of orang from the Gaboon River; Osteology of the same. Journal of Natural History, V, 417-43. 
Savage-Rumbaugh, S. \& Lewin, R. (1994). Kanzi: The Ape at the Brink of the Human Mind. London: Doubleday. Schultz, A.H. (1950). The physical distinctions of man. In: Ideas on Human Evolution: Selected Essays, 1949-1961, ed. W. Howells, pp.36-68. (1962). Cambridge (Mass.): Harvard University Press.

Schwarz, E. (1934). On the local races of the chimpanzee. Annals and Magazine of Natural History, 1, 576-83.

Shea, B.T., Leigh, S.R. \& Groves, C.P. (1993). Multivariate craniometric variation in chimpanzees: implications for species identification. In: Species, Species Concepts, and Primate Evolution. ed. W.H. Kimbel \& L.B. Martin. pp.265-96. New York: Plenum Press.

Smouse, P.E \& Li, W-H. (1987). Likelihood analysis of mitochondrial restriction-cleavage patterns for the humanchimpanzee-gorilla trichotomy. Evolution, 41(6), 1162-76.

Spencer, F. (1995). Pithekos to Pithecanthropus: An abbreviated review of changing scientific views on the relationship of the anthropoid apes to Homo. In: Ape, Man, Apeman: Changing View Since 1600, ed. R. Corbey \& B. Theunissen, pp.13-28. Leiden: Leiden University.

Tyson, E. (1699). Orang-outang, sive Homo sylvestris or, the Anatomy of a Pygmie Compared with that of a Monkey, Ape and Man. (Facsimile edition, 1966), London: Dawsons.

Vervaecke, H. \& van Elsacker, L. (1992). Hybrids between common chimpanzees (Pan troglodytes) and pygmy chimpanzees (Pan paniscus) in captivity. Mammalia, 56, 667-69.

Wallace, A. R. (1889). Darwinism applied to man. In: Climbing Man's Family Tree: A Collection of Major Writings on Human Phylogeny, 1699 to 1971. (1972), ed. T.D. McCown \& K.A.R. Kennedy; pp 181-88. New Jersey: Prentice Hall.

Wayne, R.K., van Valkenburgh, B. \& O'Brien, S.J. (1991). Molecular distance and divergence time in carnivores and primates. Molecular Biology and Evolution, 8, 297-319.

Xu, X. \& Arnason, U. (1996). The mitochondrial DNA molecule of Sumatran orangutan and a molecular proposal for two (Bornean and Sumatran) species of orangutan. Journal of Molecular Evolution, 43, 431-37. 


\section{Julia Lee-Thorp}

$\&$

\section{Andrew Sillen}

\author{
Archaeometry Research Unit \\ Department of Archaeology \\ University of Cape Town \\ Private Bag, Rondebosch 770 \\ South Africa
}

Keywords: Hominids, dietary niche,

Swartkrans, chemical indicators, carbon

isotopes, trace elements strontium isotopes

\section{Chemical Signals in Fossils Offer New Opportunities for Assessing and Comparing Dietary Niches of South African Hominids}

\begin{abstract}
Information about the dietary niches of Plio-Pleistocene hominid taxa is important for understanding their biology and evolutionary pathways, but it is not easily acquired. Morphological clues may be ambiguous, as are the few traces of activities which survive to discovery and excavation. These problems are exacerbated in the South African karstic infill fossil sites where conventional stratigraphy and context is lacking, and moreover, where more than one species frequently co-occur. New tools based on chemical tracers in the fossils themselves can provide fresh perspectives on diet and habitat niche. We outline briefly the principles and potential of these tools, and summarise the main results of carbon $\left({ }^{13} \mathrm{C} /{ }^{12} \mathrm{C}\right)$ and strontium $\left({ }^{87} \mathrm{Sr} /{ }^{86} \mathrm{Sr}\right)$ isotope ratio, and trace element (strontium/calcium), studies of tooth enamel or bone of hominids and a suite of associated fauna from the site of Swartkrans. Enamel-based ${ }^{13} \mathrm{C} /{ }^{12} \mathrm{C}$ ratios for Australopithecus robustus indicate incorporation of small but significant contributions of carbon derived originally from ${ }^{13} \mathrm{C}$-rich $\mathrm{C}_{4}$ grasses or sedges. ${ }^{87} \mathrm{Sr} /{ }^{86} \mathrm{Sr}$ suggests that the hominids foraged in the open veld, and riverine sedges can be excluded as a source of ${ }^{13} \mathrm{C}$-rich carbon, however, while $\mathrm{Sr} / \mathrm{Ca}$ for $A$. robustus fall between those for herbivores and for carnivores, as do results for two individuals attributed to Homo. Overall, the results are most consistent with omnivory for $A$. robustus, raising questions about the extent of niche separation between the two hominid genera present at Swartkrans.
\end{abstract}

\section{Introduction}

The dietary niche of an animal provides vital insights into many important aspects of its biology. This is no less the case for hominids. Today, humans subsist fairly successfully on diets which span a huge range of possibilities, from those exceedingly rich in animal foods to those which seem to be dangerously protein-poor. Notwithstanding the overwhelming success of humankind, dietary factors are widely believed to play a leading role in many diseases today. Consequently, there is a deep interest in a so-called 'natural' human diet, i.e. the kind acquired during the course of human evolution (Eaton et al., 1997). For palaeoanthropologists, information about hominid diets and dietary comparisons between different species provides broader clues about biology and ecological niche, and further, helps to throw light on evolutionary trajectories.

Yet the nature of hominid diets has proved somewhat elusive because hominids were, and still are, generalists. Early hominids, furthermore, did not use stone tools and left few traces of their activities. Such traces as do exist are difficult to interpret. This is particularly true for the South African early 
hominid sites, which are karstic cavities lacking conventional stratigraphy and contextual information. Frequently more than one hominid species occurs in the same deposit.

Partly because of these difficulties, perhaps, the South African early hominid sites have seen the pioneering of several new, direct tools for investigating hominid diets. They represent departures from conventional approaches which have relied largely on comparative morphology of fossils and other primates. The first of these was the use of occlusal molar microwear studies to reveal differences in consistency and texture of diets between various taxa (Grine, 1981; Grine \& Kay, 1988; Teaford \& Ungar, this volume). A more recent development, on which we focus here, is a series of studies based on chemical tracers in the bones and teeth of the fossils themselves, and of the fauna with which they are associated. The advantages of chemical techniques include a direct reflection of what was actually eaten, without the taphonomic biases associated with contextual information from classes of material such as animal bones (Brain, 1981). Data is acquired at the level of individuals, hence inter-individual variability and inter-species differences can be assessed.

The approaches discussed here are stable carbon isotope ratios $\left({ }^{13} \mathrm{C} /{ }^{12} \mathrm{C}\right)$, trace element ratios $(\mathrm{Sr} / \mathrm{Ca})$, and strontium isotope ratios $\left({ }^{87} \mathrm{Sr}{ }^{86} \mathrm{Sr}\right)$ in fossil tooth enamel and bone. We have concentrated on the site of Swartkrans, where all three techniques have been applied. These techniques are founded on independent principles, as outlined below, but all require a sound understanding of fossil calcified tissue chemistry. No approach is without drawbacks. Finer points about the interpretation of isotopic and trace element composition are still subject to debate, and one of the most important concerns when dealing with all chemical signals remains diagenesis, which we discuss first.

\section{Diagenesis}

Chemical changes occurring during the long period of burial and fossilisation are inevitable (Sillen, 1989). If they did not occur, bones and teeth would not be preserved at all. The extent and nature of change must be carefully assessed to determine whether biogenic patterns of the extracted isotopic or trace element signals are maintained. A number of procedures for eliminating altered or intrusive mineral phases, and assessing the reliability of isotopic or trace element signals, have been developed.

In the case of carbon isotopes, the problem has been overcome through use of acid pretreatment procedures to eliminate more soluble mineral phases, use of animal controls (animals with known browsing and grazing diets and hence predictable isotopic values), and finally, a focus on tooth enamel as sample material. Enamel is denser and more crystalline, and has been shown to be structurally and isotopically stable for very long periods (Lee-Thorp et al., 1994; Cerling et al., 1997; Sponheimer \& LeeThorp, 1999). This raises a further problem because damage to fossil enamel surfaces must be avoided. However, damage is minimised as a result of recent developments in mass spectrometry which require tiny amounts of powdered sample so that the sampling site is barely visible (Lee-Thorp et al., 1997).

Bone mineral remains the traditional sample material for $\mathrm{Sr} / \mathrm{Ca}$ analyses. A 'solubility profile' technique has been developed which targets and extracts $\mathrm{Sr}$ and $\mathrm{Ca}$ only from that component of the mineral with the characteristics of biological mineral (Sillen, 1986). Highly soluble phases of any mineral not meeting these criteria are not used. $\mathrm{Sr} / \mathrm{Ca}$ patterns in associated fauna are used as controls. Strontium for the purpose of ${ }^{87} \mathrm{Sr} /{ }^{86} \mathrm{Sr}$ analysis may be extracted in the same manner (Sillen et al., 1995). The solubility profile technique requires such tiny samples of bone that it can be considered to be virtually non-destructive.

As long as strict precautionary measures are taken, many studies have shown that reliable, robust stable isotope and trace element signals can be obtained by these means.

\section{Carbon isotopes}

Stable carbon isotope ratios indicate the proportions of foods derived ultimately from plants following $\mathrm{C}_{3}$ or $\mathrm{C}_{4}$ photosynthetic pathways. The distinction is made possible because $\mathrm{C}_{3}$ plants 
discriminate more strongly against ${ }^{13} \mathrm{C}$ during carbon conversion, resulting in their being depleted (including less of the heavier ${ }^{13} \mathrm{C}$ isotope) compared to plants following the $\mathrm{C}_{4}$ pathway (Smith $\&$ Epstein, 1971). Stable carbon isotope ratios are by convention expressed in the $\delta$ notation in parts per thousand $(\%$ oo $)$ relative to the Peedee Belemnite standard:

$$
\delta^{13} \mathrm{C}=\left({ }^{13} \mathrm{C} /{ }^{12} \mathrm{C}_{\text {sample }} /{ }^{13} \mathrm{C} /{ }^{12} \mathrm{C}_{\text {reference }}-1\right) \times 1000 .
$$

In savanna environments the grasses are $\mathrm{C}_{4}$, and have average values of $-12.5 \%$ oo while $\mathrm{C}_{3}$ plants include trees, shrubs, forbs and their edible parts (seeds, fruits, nuts, leaves, and corms) and have average values of about $-26.5 \%$. These distinctive isotopic signatures are reflected in the bones and teeth of consumers (Vogel, 1978; Lee-Thorp \& van der Merwe, 1987). Thus carbon isotopes provide a way of establishing where an individual fitted into this spectrum in an ancient foodweb, as well as providing information about the ancient environment (Lee-Thorp et al., 1994; Koch, 1998; Cerling et al., 1997; Sponheimer \& Lee-Thorp, 1999).

Using results of a large suite of fauna as a framework, $\delta^{13} \mathrm{C}$ for Australopithecus robustus from Members 1-3 at Swartkrans demonstrated a $\sim 25 \%$ contribution of $\mathrm{C}_{4}$-based foods to their diets, on average (Lee-Thorp et al., 1994). This is a previously unsuspected component. It could derive either from direct consumption of grass itself (as blades, rhizomes or seeds), or indirectly, via consumption of animals which ate grass. Since both tooth morphology and microwear do not support eating of phytolithrich grass blades (Grine, 1981), and $\mathrm{C}_{4}$ grass seeds are tiny, seasonally restricted and hard to collect without specialised tools, on balance it seems more plausible that animal foods were eaten. In savanna biomes a high proportion of the animal biomass is isotopically enriched. The finding implies omnivory and runs counter to assessments that robust australopithecines were vegetarians specialising in one or other class of plant foods. More recent studies of contemporaneous Homo individuals from Swartkrans (Lee-Thorp et al., unpubl. data), and earlier hominids from Makapansgat (Sponheimer \& Lee-Thorp, 1999) and Sterkfontein (van der Merwe et al., in prep) hint that something of a similar pattern, incorporating variable but always significant proportions of $\mathrm{C}_{4}$-based foods, prevailed throughout.

\section{Strontium/calcium ratios}

Mammals discriminate against strontium $(\mathrm{Sr})$ compared to calcium $(\mathrm{Ca})$, a phenomenon known as 'biopurification of calcium'; the result is lower $\mathrm{Sr} / \mathrm{Ca}$ in bone compared to that in food. Hence $\mathrm{Sr} / \mathrm{Ca}$ is reduced stepwise at higher trophic levels, and this was recognised early on as providing a potential tool for detecting the amount of animal food in the diet (Toots \& Voorhies, 1965). It is now recognised, however, that considerable variability in $\mathrm{Sr} / \mathrm{Ca}$ occurs within each trophic level, including variability within and between individual plants (Runia, 1987; Sealy \& Sillen, 1988; Sillen et al., 1995).

Roots, rhizomes and stems have elevated $\mathrm{Sr} / \mathrm{Ca}$ compared to leaves, likely due to transport phenomena of $\mathrm{Ca}$ and $\mathrm{Sr}$ in plants (Runia, 1987). Hence leaf-eating herbivores have lower $\mathrm{Sr} / \mathrm{Ca}$ in bone compared to herbivores which eat more stem material, and animals which eat underground parts have significantly higher $\mathrm{Sr} / \mathrm{Ca}$ (Sillen, 1988). This complicates inferences about trophic levels, because a carnivore (not all carnivores) has reduced $\mathrm{Sr} / \mathrm{Ca}$ compared to its particular prey species. Identified predator-prey pairs follow the pattern of trophic reduction of $\mathrm{Sr} / \mathrm{Ca}$.

Measurements of $\mathrm{Sr} / \mathrm{Ca}$ in fossil fauna and hominids from Swartkrans Member 1 show that patterns similar to those observed in a modern foodweb can be observed (Sillen, 1992): highest $\mathrm{Sr} / \mathrm{Ca}$ occurs in Procavia (hyrax) and Hystrix (porcupine), as is the case for a modern African foodweb. The two carnivores measured, Panthera pardus and Hyena, show reduced $\mathrm{Sr} / \mathrm{Ca}$ compared to most of the other animals including the primates, but not the browsing Tragelaphus cf. strepsiceros (kudu). $\mathrm{Sr} / \mathrm{Ca}$ for $A$. robustus is fairly low, between the carnivores and most of the herbivores. This pattern is most consistent with omnivory (Sillen, 1992). Sr/Ca in two Homo sp. individuals is slightly higher: SK 27 falls at the 
upper end of the A. robustus range, and SK 847 is elevated beyond the range (Sillen et al., 1995). Although admittedly a very small sample size, this result is best explained by consumption of relatively high $\mathrm{Sr} / \mathrm{Ca}$ foods, possibly underground storage organs.

\section{Strontium isotopes}

Isotopic composition of the strontium extracted from fossils may also be measured. Unlike carbon isotopes, the mass difference between ${ }^{87} \mathrm{Sr}$ and ${ }^{86} \mathrm{Sr}$ is too small to cause fractionation during physical and chemical reactions, hence ${ }^{87} \mathrm{Sr} /{ }^{86} \mathrm{Sr}$ in calcified tissues is directly related to their abundances in the biome, deriving ultimately from available strontium in the local geology (Sillen et al., 1995).

Consequently, ${ }^{87} \mathrm{Sr}{ }^{86} \mathrm{Sr}$ in fossils may be used to indicate where in the landscape hominids preferred to forage (Sillen et al., 1998). At Swartkrans, ${ }^{87} \mathrm{Sr} /{ }^{86} \mathrm{Sr}$ in the Member 1 breccia closely resembles that in the present Blaauwbank stream, and it is significantly lower than abundances in soils, plants and animals in the surrounding veld. Low values are likely due to differential leaching of a soluble, depleted, carbonate phase in the dolomitic substrate. Low ${ }^{87} \mathrm{Sr} /{ }^{86} \mathrm{Sr}$ delimits a zone of influence for the stream on plants and animals in the riverine greenbelt. With the notable exception of the riverine rodent Mystromys, all the Member 1 fauna analysed have relatively high ${ }^{87} \mathrm{Sr}{ }^{86} \mathrm{Sr}$ values, suggesting that they ranged and fed in the veld away from the immediate river environs. All A. robustus and Homo sp. individuals fall into the 'open veld' range (Sillen et al., 1998). The results suggest that they were not reliant on riverine resources, but rather exploited open country resources.

\section{Summary information}

Results for ${ }^{13} \mathrm{C} /{ }^{12} \mathrm{C}$ in $A$. robustus demonstrate a significant contribution of $\mathrm{C}_{4}$-based foods which may be derived directly from grasses or from animal foods. The $\mathrm{Sr} / \mathrm{Ca}$ data for $A$. robustus are most consistent with omnivory, while the slightly elevated data for Homo hint at the inclusion of more elevated $\mathrm{Sr} / \mathrm{Ca}$ foods such as underground storage organs, when compared to the former species. The lack of riverine foraging suggested by the ${ }^{87} \mathrm{Sr} /{ }^{86} \mathrm{Sr}$ data mitigates against one class of more edible and less phytolith-rich $\mathrm{C}_{4}$ grasses, namely sedges, which grow in wet environments. Taken together, the data suggest that $A$. robustus subsisted on open veld food that included some animal foods, such as small vertebrates and insects. Data for Homo are less complete and await the publication of $\delta^{13} \mathrm{C}$ studies. It should also be pointed out that a combination of $\delta^{13} \mathrm{C}$ and $\mathrm{Sr} / \mathrm{Ca}$ analyses greatly clarifies predator-prey relationships in a fossil assemblage, since both predator and prey are similar for $\delta^{13} \mathrm{C}$ but predators are reduced compared to prey for $\mathrm{Sr} / \mathrm{Ca}$. At Swartkrans Papio baboons, hominids and Hyrax were likely prey of leopard, but Theropithecus oswaldi were not (Sillen \& Lee-Thorp, 1994).

These three techniques represent useful tools for elucidating different aspects of the diets and preferred foraging ranges for hominids, and permit comparisons of their dietary niches. Combinations of these tools are more powerful still. Some of the more subtle problems now within our reach include, for instance, questions about intra-individual seasonal dietary shifts amongst australopithecines and early Homo.

\section{Acknowledgments}

We thank Bob Brain, Judith Sealy, J. Francis Thackeray, Phillip Tobias and Nikolaas van der Merwe, for their contributions to the development of this avenue of research. The FRD, University of Cape Town Research Committee and Harry Oppenheimer Institute for African Studies supported this work. 


\section{References}

Brain, C.K. (1981). The Hunters or the Hunted? An Introduction to African Cave Taphonomy. Chicago, University of Chicago Press.

Cerling, T.E., Harris, J.M., MacFadden, B.J., Leakey, M.G., Quade, J., Eisenmann, V. \& Ehleringer, J. (1997). Global vegetation change through the Miocene/Pliocene boundary. Nature, 389, 153-58.

Eaton, S.B., Eaton, S.B. \& Konner, M.J. (1997) Paleolithic nutrition revisited: a twelve year retrospective on its nature and implications. European Journal of Clinical Nutrition, 51, 207-16.

Grine, F.E. (1981). Trophic differences between "Gracile" and "Robust" australopithecines: a scanning electron microscope analysis of occlusal events. South African Journal of Science, 77, 204-29.

Grine, F.E. \& Kay, R.F. (1988). Early hominid diets from quantitative image analysis of dental microwear. Nature, $333,765-68$.

Koch, P. (1998). Isotopic reconstruction of past continental environments. Annual Review of Earth \& Planetary Sciences, 26, 573-613.

Lee-Thorp, J.A. \& van der Merwe, N.J. (1987). Carbon isotope analysis of bone apatite. South African Journal of Science, 83, 71-74.

Lee-Thorp, J.A., van der Merwe, N.J. \& Brain, C.K. (1994). Diet of Australopithecus robustus at Swartkrans from stable carbon isotope analysis. Journal of Human Evolution, 27, 361-72.

Lee-Thorp, J.A., Manning, L. \& Sponheimer, M. (1997). Problems and potential for very small samples of fossil tooth enamel. Bulletin de la Société Géologique de France, 168, 767-73.

Runia, L.J. (1987). Strontium and calcium distribution in plants: effect on paleodietary studies. Journal of Archaeological Science, 14, 599-608.

Sealy, J.C. \& Sillen, A. (1988). Sr and Sr/Ca in marine and terrestrial foodwebs in the southwestern Cape, South Africa. Journal of Archaeological Science, 15, 425-38.

Sillen, A. (1986). Biogenic and diagenetic $\mathrm{Sr} / \mathrm{Ca}$ in Plio-Pleistocene fossils of the Omo Shungura Formation. Paleobiology, 12, 311-23.

Sillen, A. (1986). Elemental and isotopic analyses of mammalian fauna from Southern Africa and the implications for paleodietary research. American Journal of Physical Anthropology, 76, 49-60.

Sillen, A. (1989). Diagenesis of the inorganic phase of cortical bone. In: The Chemistry of Prehistoric Human Bone, ed. T.D. Price, pp. 211-29. Cambridge: Cambridge Univ. Press.

Sillen, A. (1992). Strontium-calcium ratios $(\mathrm{Sr} / \mathrm{Ca})$ of Australopithecus robustus and associated fauna from Swartkrans. Journal of Human Evolution, 23: 495-516.

Sillen, A. \& Lee-Thorp, J.A. (1994). Trace element and isotopic aspects of predator-prey relationships in terrestrial foodwebs. Palaeogeography, Palaeoclimatology, Palaeoecology, 107, 243-55.

Sillen, A., Hall, G., \& Armstrong, R. (1995). Strontium calcium ratios $(\mathrm{Sr} / \mathrm{Ca})$ and strontium isotopic ratios $\left({ }^{87} \mathrm{Sr}{ }^{86} \mathrm{Sr}\right)$ of Australopithecus robustus and Homo sp. from Swartkrans. Journal of Human Evolution, 28, 277-85.

Sillen, A., Hall, G., Richardson, S. \& Armstrong, R. (1998). ${ }^{87} \mathrm{Sr} /{ }^{86} \mathrm{Sr}$ in modern and fossil foodwebs of the Sterkfontein Valley: implications for early hominid habitat preference. Geochimica et Cosmochimica Acta, 62, 2463-73.

Smith, B.N. \& Epstein, S. (1971). Two categories of ${ }^{13} \mathrm{C} /{ }^{12} \mathrm{C}$ ratios for higher plants. Plant Physiology, 47, 380-84.

Sponheimer, M. \& Lee-Thorp, J.A. (1999). Isotopic evidence for the diet of an early hominid, Australopithecus africanus. Science, 283, 368-70.

Teaford, M. \& Ungar, P.S. (this volume). The dietary split between apes and the earliest human ancestors.

Toots, H. \& Voorhies, M.R. (1965). Strontium in fossil bones and the reconstruction of food chains. Science, 149, $854-55$.

Vogel, J.C. (1978). Isotopic assessment of the dietary habits of ungulates. South African Journal of Science, 74, 298-301. 


\section{John Parkington}

Department of Archaeology,

University of CapeTown,

Private Bag Rondebosch 7701

South Africa

Keywords: marine food, fatty acids, Pleistocene, South Africa

\section{Milestones: the Impact of the Systematic Exploitation of Marine Foods on Human Evolution}

The earliest shell middens arguably represent the beginning of systematic and regular exploitation of marine foods, including intertidal shellfish. At this point there is excellent evidence for many last interglacial shell middens along the southern and western coasts of the Cape in South Africa and less convincing evidence of shellfish gathering around the shores of the Mediterranean Sea. The juxtaposition of unproductive terrestrial and rich offshore ecosystems may help explain these early occurrences. Because marine foods are rich in omega-3 long chain polyunsaturated fatty acids (LC PUFA) they would provide the nutritional substrate that would have allowed the selection of larger brains. More specifically, women would have been able to access high quality foods during pregnancy and lactation, the critical times when most LC PUFA need to be eaten to maximise brain growth. The evidence is consistent with the scenario of a shift toward greater and more systematic exploitation of marine foods by the beginning of the late Pleistocene in the Cape, leading to the expansion of brain size and appearance of behavioural traits recognisable as the emergence of anatomically and behaviourally modern people.

\section{Earliest evidence for regular marine food exploitation}

In reviewing the milestone events of human evolution, and specifically the role of nutrition, it is important to examine the impact that the shift to the systematic exploitation of marine foods might have had on human biological and cultural development. This presupposes that there was one or more such an event and that we can locate it or them in time and space. Archaeological evidence for marine food use exists in the form of coastal shell middens, which, although often dominated by molluscs gathered from the intertidal zone, usually include variable quantities of marine mammal, bird and fish bone either of animals actively caught or of carcasses scavenged as wash-ups. Although people may have snacked on marine foods as they walked the beaches prior to the formation of localised midden debris, it seems reasonable to associate the appearance of substantial accumulations in favoured locations with a move to more regular, scheduled and systematic use.

The questions are, thus, where are the oldest middens and how old are they? I am not confident that we can currently distinguish the 'evidence of absence' from the 'absence of evidence' well enough to provide neat answers to these questions. Some points, though, are clear, and help to establish a tentative time-space framework for investigation. During the last 12000 years or so of the Holocene, in oxygen isotope stage 1, people have systematically exploited marine foods in all of the occupied parts of the global coastal landscape (Bailey \& Parkington, 1988). The shift we are looking for must have happened before that. Evidence for earlier marine food consumption is severely impacted by the lowering and subsequent rise in sea level during oxygen isotope stages 4,3 and 2 . The absence of well dated marine 
foods in archaeological sites from these stages almost anywhere in the world is largely preservational, and simply reflects the massive loss of land, and with it the sites from which coastal resources were exploited, since about 15000 years ago. The important issue is, thus, the evidence for shell middens associated with higher sea level episodes before the Holocene, and particularly during oxygen isotope stage 5 .

The southern and western coasts of the Cape of South Africa stand out in the archaeological record as having abundant, well preserved and increasingly reliably dated shell middens from oxygen isotope stage 5, associated with Middle Stone Age (MSA) stone tool assemblages. For comparison with sites elsewhere, it is useful to note that MSA stone tool assemblages are technologically similar to Middle Palaeolithic assemblages of Europe, the near East and north Africa. The best known Cape sites are those from near the mouth of the Klasies River about 600 km east of Cape Town (Singer \& Wymer, 1982; Deacon, 1992; Deacon \& Geleijnse, 1988), but many others are known west of this and north of Cape Town as far as the mouth of the Orange River (Figure 1). This pattern has been summarised by Klein (1989) and specific sites such as Blombos Cave (Henshilwood \& Sealy, 1997), Die Kelders (Avery et al. , 1997), Sea Harvest (Volman, 1978; Grine \& Klein, 1993), Hoedjiespunt (Berger \& Parkington, 1995) and Boegoeberg (Klein \& Cruz-Uribe, 1996) have also been mentioned in the literature. Our own surveys along the Cape west coast have brought to light several more shell middens associated with MSA stone tools that are certainly older than 30000 years and probably at least as old as oxygen isotope stage 5. Because these sites are found in eroded or commercially mined areas, we are confident that the total number of localities is very much higher, many remaining deeply buried. The dates on these Cape sites have come from U series, ESR and luminescence methods (Woodborne and Vogel, pers. comm.) and leave no room for doubt that people along this shoreline were regularly exploiting shellfish from as early as the early part of oxygen isotope stage 5, the last or Eemian interglacial. There is still some discussion (Klein, 1989; Klein \& Cruz-Uribe, 1995; Deacon, 1992) about the extent and manner of the exploitation of other marine foods, but the bones of marine mammals, marine fish and marine birds are common in these sites.

A survey of the literature on Middle Palaeolithic sites from Europe and the Mediterranean coasts does not reveal quite the same abundance of evidence, although shellfish are recorded at many cave sites, including Haua Fteah (McBurney, 1960), High Cave near Tangiers (Howe, 1967) and the caves of Italy (Stiner, 1994) and Gibraltar (Stringer, pers. comm.). These appear to be occasional or casual collections of molluscs by comparison with, say, Klasies River Mouth, but it is nevertheless interesting to note that the mediterranean climates of north and south Africa have so far provided the best evidence for early marine food use. Large numbers of open sites with MSA or Middle Palaeolithic associations seem as yet to be limited to the Cape. Some thoughts on why this might have been the case are given later. The absence of such early evidence from other mediterranean type ecosystems elsewhere in the world, areas such as south western Australia, Chile and the California coast, is presumably explained by the absence of evidence for occupation of these coasts during oxygen isotope stage 5. This is arguably the evidence of absence of people not the evidence of absence of marine food use. Nowhere else in the world, as far as I am aware, have archaeologists found regular or substantial remains of shell middens prior to the Holocene. It seems reasonable to conclude that such systematic exploitation of marine foods from coastal bases began either in the Cape, or in the Mediterranean, or both, at least as early as the beginning of the last interglacial period.

What this means is that we should look for the impact of such a shift in resource use from at least as early as the beginning of the Late Pleistocene and in the kinds of hominid fossil remains and associated archaeology of this time period. In the western Cape sites, with which I am most familiar, the MSA shell middens are marked by very high frequencies of tortoise bones, ostrich eggshell fragments and ochre. The ochre is abundant and often bevelled from use to derive pigment. Ochre is similarly abundant at the site of Blombos Cave, where a well developed bone tool assemblage is recorded along with MSA stone tools which include exceptionally finely made bifacial leaf-shaped points (Henshilwood \& Sealy, 1997). At Klasies River Mouth, Sea Harvest and Die Kelders these MSA 

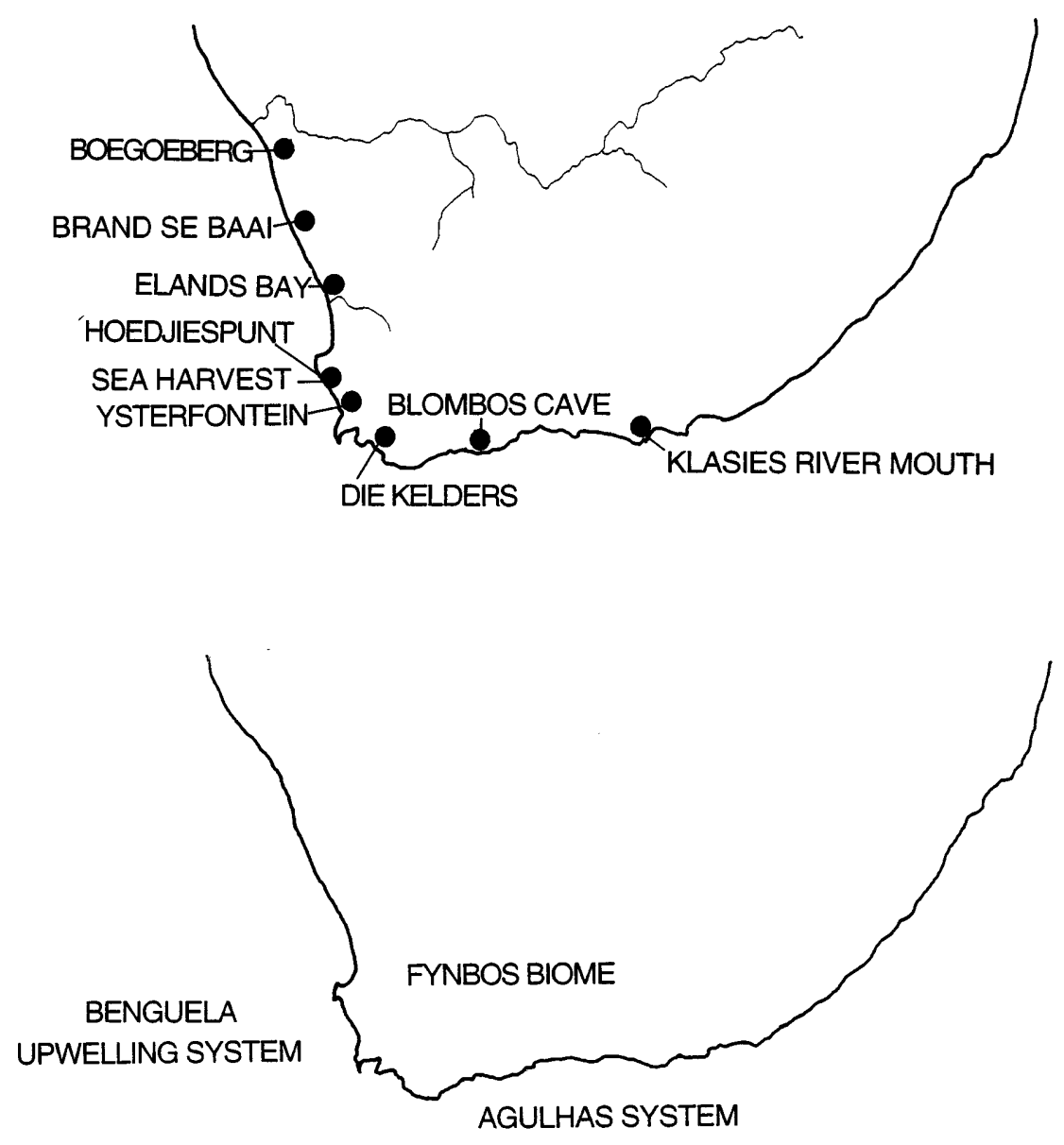

Figure 1. MSA shell middens along the southern and western coasts of South Africa

middens are the sites from which some of the earliest human remains of apparently modern form are claimed (Rightmire \& Deacon, 1991; Grine \& Klein, 1993); Avery et al,. 1997). It seems that some of the earliest moderns are in some of the earliest middens. Whereas this connection has previously been circumstantial, empirical but unexplained, we can now offer some thoughts on the causal connections between marine food consumption, modern people and modern behaviour.

\section{Ecological context in the southern and western Cape}

What, we may ask, is so special about the western and southern Cape that may have promoted an early, and apparently successful, shift toward the regular exploitation of marine foods? From the distribution of MSA shell middens (Figure 1), it appears that they lie along the coastal interface between extremely rich marine ecosystems and arguably rather poor terrestrial ones. Inland of the Cape, people would have been foraging in the Fynbos Biome, a mediterranean-type ecosystem of low productivity and 
low animal carrying capacity. Animal populations would never have been comparable in numbers with those of the Karoo, grassland or bushveld biomes further north. Archaeological remains from Later Stone Age sites in the Cape reveal a long dependance upon underground corms of the family Iridaceae as staples. These are carbohydrate-rich and seasonally available. Corms would provide a useful waterbased source of energy but little in the way of structural lipids or fats, though they may represent the best collectable items available (Figure 2, derived from Arnold et al., 1989). Oil-rich nuts and seeds are not a feature of this landscape, as they are of the more productive subtropical ecosystems to the north.

Along the Cape west coast the offshore ecosystem is the southern part of the highly productive Benguela system, an upwelling regime that brings vast quantities of nutrients into the upper waters and promotes a rich network of fish, marine birds and marine mammals. In the intertidal zone there are large populations of sessile mussels, limpets, whelks and crustaceans such as the local 'rock lobsters'. The southern Benguela is seasonal, driven by the predominantly southerly summer winds that are replaced in winter by onshore westerlies and northwesterlies. Along the Cape south coast the Agulhas system is different, less seasonal, less driven by upwelling, but nevertheless productive in terms of the variety and biomass of marine resources, including the intertidal. Arguably it was the incentive provided by the poor and seasonal resources of the near coastal landscape juxtaposed to very productive intertidal ecosystems that persuaded people to experiment with and then emphasise the collection of marine foods. The Mediterranean juxtaposition is not so strongly contrasting, in that the Mediterranean Sea itself is not as productive as the Benguela and the adjacent terrestrial ecosystem is not as unproductive as the Fynbos. Nevertheless, these may be more seductive juxtapositions than others presented to people in the other occupied parts of the last interglacial world, a proposition testable by the unfolding archaeological record.

Perhaps it is more than coincidence that the best documented example of baboon exploitation of intertidal resources comes from the Cape Peninsula. Hall (1962; Hall \& deVore, 1965) has reported the consumption of mussels and limpets by baboon troops on the Cape Peninsula, although admittedly following a snacking model rather than one of midden creation at chosen sites. It is surely significant, though, that these primates also make extensive use of the underground corms of the Fynbos landscape and resort to intertidal molluscs mostly in the winter months when corms are least available. It is this kind of integration, though on a more systematic and regularly scheduled basis, that is suggested for end Middle Pleistocene hominids.

If this is a tentative answer to the 'where' question, the 'when' question remains much more difficult to answer, largely because the chronology of the earliest systematic marine food use is so poor. It would be dangerous to suggest any kind of linkage as yet between changing environments and shifts in exploitation strategies, because we cannot date any behavioural shifts to specific parts of the climate change cycle. Klein \& Cruz-Uribe (1991) have, however, suggested that some parts of the Middle Pleistocene may have been less obviously seasonal than later periods from their analysis of the Elandsfontein faunal assemblages. It is possible that changes in the seasonality of resource availability contributed to the shift from casual snacking to more localised and systematic shellfish gathering during the late Middle Pleistocene.

\section{Encephalisation, 'expensive tissue' and the cost of larger brains}

What is the likely impact of a move toward increased shellfish gathering and marine food use at the end of the Middle Pleistocene? After the earlier development of bipedal locomotion, the dramatic expansion in brain size undoubtedly characterises the hominid evolutionary trajectory in the Pleistocene. More specifically, many authors have noted that modern humans have a far larger brain than any other mammal of equivalent body weight (Tobias, 1971; Jerison, 1973; Martin, 1981, 1983; Foley \& Lee, 1991; McHenry, 1994; Milton, 1993; Aiello \& Wheeler, 1995; Dunbar 1998). Jerison's (1973) concept of an encephalisation quotient, or EQ, is widely used as a measure of the extent to which a species has a higher (or lower) cranial capacity than would have been predicted by body size, and shows modern 


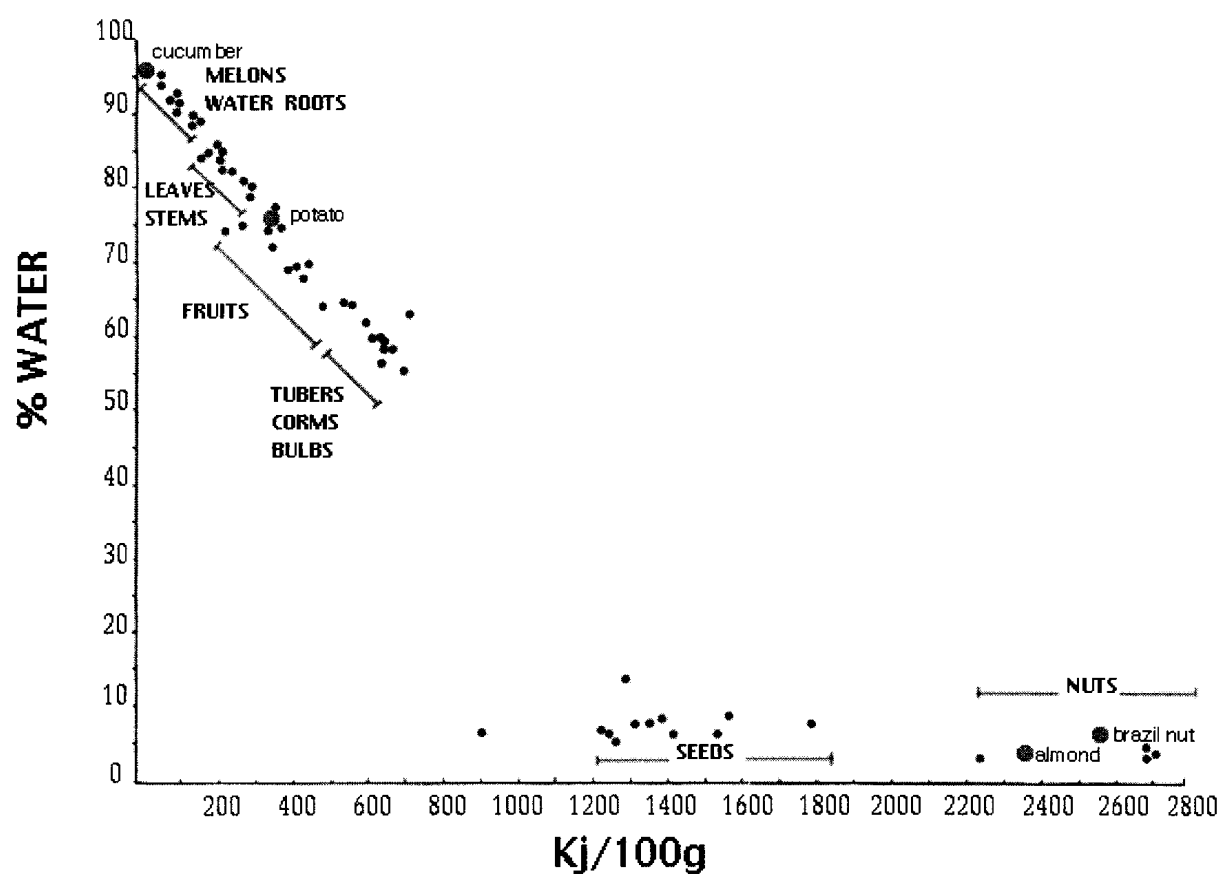

Figure 2. Food Values of Foods from Southern Africa

people to be uniquely large brained. Whilst there are many problems associated with this concept, not least those of calculating it for fragmentary, isolated specimens, all researchers agree that EQ has risen consistently through the late Pliocene and Pleistocene. Although brain size may be a crude, proxy measure of the changes in intelligence and abilities, these changes in EQ demand an explanation.

One representation is that of Aiello \& Wheeler (1995), reproduced here as Figure 3, but whatever equation is used, it is clear that australopithecine species were already significantly encephalised compared with modern primates. As Martin (1983) has noted, this probably means that they were even more substantially encephalised than the last common ancestors of modern primates and people, though this is a comparison that is still difficult to make. Another feature of all EQ trajectories is the very dramatic rise in EQ somewhere and sometime in the late Middle Pleistocene, reflected in the steep rise noted between Homo erectus and Homo sapiens in Figure 3. More detailed and more resolved figures (Ruff et al., 1997; Aiello \& Dunbar, 1993) make it clear that such a rise in EQ had happened by the last interglacial and is visible in early modern populations such as represented by Skhul and Qafzeh and, to a lesser extent, in neandertalers. Here I avoid the issue of what constituted the selective framework for bigger brains (Dunbar, 1998) and focus on the necessary substrate or nutrient base that allowed bigger brains to be built.

A point agreed by all commentators is the fact that building a large brain is an expensive undertaking. The human brain, whilst only $2 \%$ of body weight, consumes more than $18 \%$ of available energy, a figure that is as high as $60 \%$ in the foetus. The investment in a larger brain is, thus, particularly high in utero and in the first year or so of life. As has been noted (Martin 1983), this implies an enormous maternal investment in the increased encephalisation of modern humans. Across a range of mammals relative brain size decreases with increasing body size, and is interestingly scaled allometrically to body size almost exactly as is basal metabolic rate (Martin, 1983). Both brain weight to body weight and basal 
metabolic rate to body weight have exponents of about 0.75 . People have managed to deviate significantly from both of these regression lines. The question arises: how have modern humans managed to afford such a large brain without having developed a much larger body size or altered their metabolic rate considerably? Crawford \& Marsh (1995) suggest that this is better phrased: how have humans kept their brain size whilst all around them were losing theirs?

All who have commented on this issue agree that the key to a larger EQ lies in the ecological and nutritional contexts of human evolution. The consensus is that humans, and hominids before them, were able to build bigger brains by increasing their intake of high quality foods, often supposed to imply meat, though this will be qualified later. Aiello \& Wheeler (1995) have developed the 'expensive tissue hypothesis' to explain the association of large brains with small guts, arguing for an energetic trade off between the two. Whatever the success of this argument, it is clear that to allow evolutionary processes to select for increasingly large brains through the Pleistocene, people would have been obliged to obtain reliable access to high quality foods. Whereas some of the Pliocene or early Pleistocene advances may have been facilitated by increased access to scavenged carcasses, my argument here is that end Middle Pleistocene advances in EQ were underwritten by regular harvesting of marine foods, including intertidal shellfish, which as brain food are very high quality.

\section{Nutrients, marine foods and fatty acids}

Several authors have emphasised that there can be no selection for larger brains without the provision of an adequate nutritional substrate (Broadhurst et al., 1998; Crawford \& Marsh, 1995; Cunnane et al., 1993). Human brains are compositionally very similar to those of other mammals in that they are $60 \%$ structural fats or lipids by dry weight; they are simply much bigger. More specifically, there is a strong selection for the use of long chain polyunsaturated fatty acids (LC PUFA) for the central nervous system and the brain. The shorter chain precursors of these LC PUFAs (Figure 4), such as linoleic acid and alpha-linolenic acid, are essential, must be taken in in the diet and cannot be made in the body. These are used for muscle mass development, whilst the longer chain fatty acids that are consumed are shuttled into use at the synaptic junctions of the brain and at the retinal receptors, where

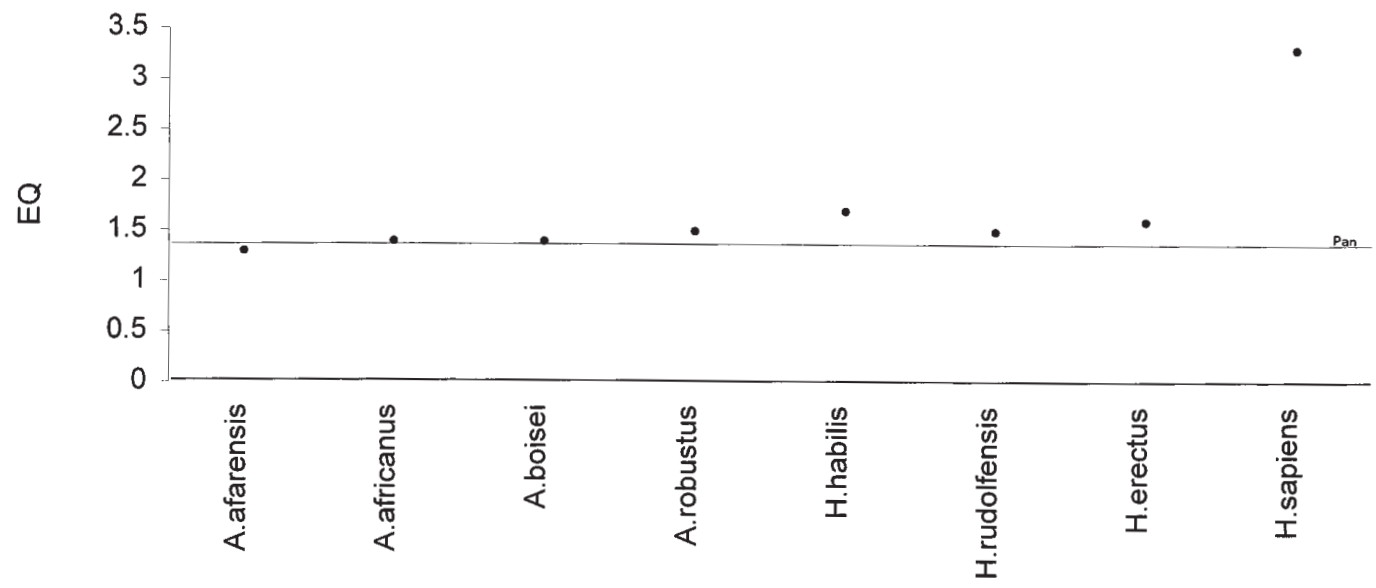

Figure 3. Encephalisation Quotients for hominids compared to the Pan Baseline (Aiello \& Wheeler 1995) 
they facilitate rapid information transfers. Moreover, the elongation of shorter chains into longer chains is very slow and imperfect in humans, which effectively means that the LC PUFAs are essential too. The brain requires a balance of the two families of LC PUFAs, known as the n-3 and n-6, or omega- 3 and omega-6 series. Docosahexaenoic acid (DHA) is the main derivative of the omega-3 series and is extremely rare in terrestrial ecosystems, but common in marine oils and fats. It is the quintessential component of brain food.

This allows a refined definition of the brain as expensive tissue, one that defines the expense in terms of specific required nutrients. Crawford and his colleagues (Broadhurst et al., 1998; Crawford \& Marsh, 1995; Cunnane et al., 1993) have shown that about $50 \%$ of DHA requirements need to be met in utero and most of the rest in the first year of life, essentially the time when all nutrients are passed through the mother. This is not surprising as human infant brains are almost the size of adult brains by the age of one year (Martin, 1983). Neonates cannot synthesise DHA in sufficient quantity. Studies of modern children have demonstrated the irreversible effects of deprivation of dietary DHA on visual acuity and intelligence. Controlled comparisons between children that were breast fed, children fed formula and children fed formula supplemented by marine oils showed that by seven or eight years old there were detectable differences in visual and intellectual performance. Thereafter the chemical differences could be altered but the behavioural effects not corrected.

Fish, then, really are 'brain food', but so are all other marine foods based on the marine algae that

$\begin{array}{ll}\text { W3 } & \text { W6 } \\ \text { C16:3 } & \text { C16:2 } \\ \text { CE } & \text { CE } \\ \text { C18:3 LNA } \alpha \text {-LINOLENIC ACID } & \text { C18:2 LA LINOLEIC ACID } \\ \text { D } & \text { D } \\ \text { C18:4 } & \text { C18:3 } \\ \text { CE } & \text { CE } \\ \text { C20:4 } & \text { C20:3 } \\ \text { D } & \text { D } \\ \text { C20:5 EPA EICOSAPENTAENOIC ACID } & \text { C20:4 AA ARACHIDONIC ACID } \\ \text { CE } & \text { CE } \\ \text { C22:5 } & \text { C22:5 } \\ \text { D } & \\ \text { C22:6 DHA DOCOSAHEXAENOIC ACID } & \\ \text { D DESATURATION } & \\ \text { CE CHAIN ELONGATION } & \\ & \\ & \\ & \end{array}$

Figure 4. Long Chain fatty Acid Chains for the Omega 3 and Omega 6 Groups (Broadhurst et al. 1998) 


\section{BRAIN GROWTH}

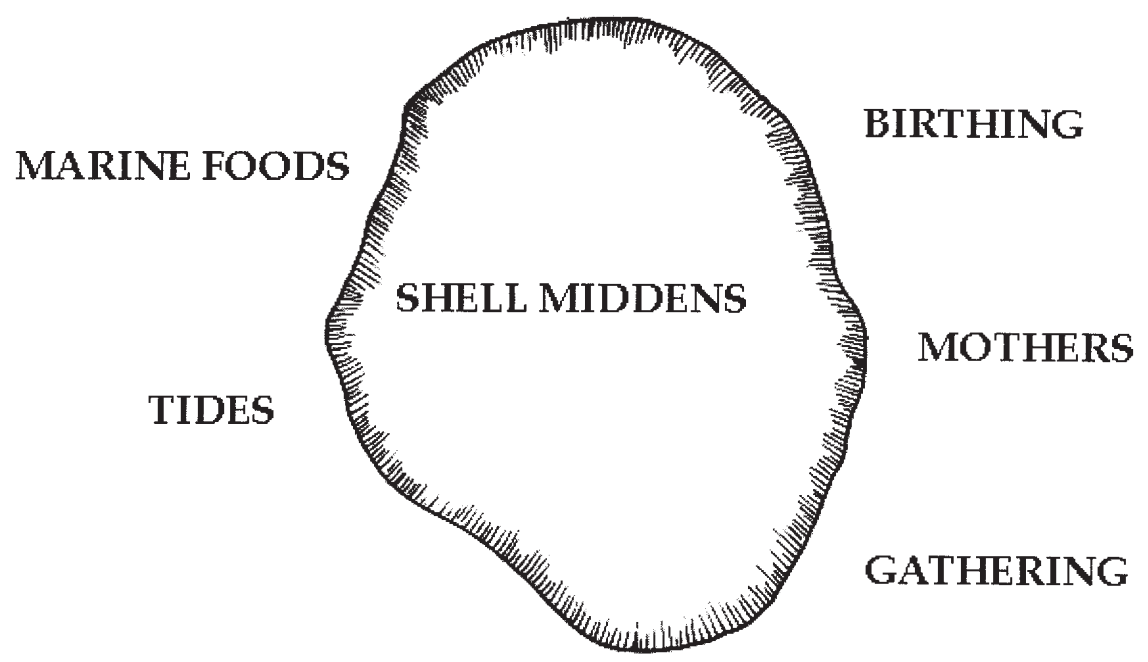

OCHRE

Figure 5. The Connectedness of Brain Growth, Shellfish Gathering and Women's Work

are the source of the omega-3 fatty acid series (Leaf, 1993). Studies of large numbers of terrestrial animal species show negligible quantities of the long chain derivatives of this series such as DHA or its precursor, eicosapentaenoic acid or EPA (Cunnane et al., 1993). Carnivores obtain these by consuming the lifetime accumulations of their prey, and humans would have been obliged to access even more in order to generate EQs far in excess of any terrestrial carnivore. The need for increased intake of LC PUFAs sheds new light on the supposed interest of early hominids in the marrow and brains of scavenged or hunted carcasses, but these sources of fatty acids go rancid quickly and may not have been available or accessible to the appropriate people. Any shift toward greater and more regular intake of marine foods, including the intertidal shellfish, would have provided the nutritional substrate required to allow larger brains to have been selectively favoured, by whatever means (Dunbar, 1998). But such intake would have been especially critical for pregnant and nursing women.

\section{Women, shellfish, gathering and evolution}

It is remarkable how many of these separately derived arguments lead back to the role of women, and particularly to the relationship between women and the neonate (Figure 5). It is women who bear the cost of a larger brain in the difficulties of birthing and the responsibilities of a precocial infant. It is also they who must provide the regular supply of essential LC PUFAs that support the in utero and early post partum growth in brain size. The previously empirical but unexplained relationship between shell midden accumulation and modern behavior is perhaps clarified in this responsibility. Ethnographically women collect shellfish, at least in part because molluscs are sessile and easily gathered on a daily basis. Access to the brains of hunted prey or scavenged carcasses can never have been as reliable as access to limpets and mussels in the intertidal zone, especially for pregnant and lactating women.

The relationship between shell midden accumulation and the fossil remains of the first anatomically, 
and arguably intellectually, modern humans is also explained in these empirical relationships. Systematic collecting of intertidal shellfish, unlike the scavenging of wash-ups, requires an understanding of the complex cycles of tides and seasons, which in turn impacts the question of settlement mobility and resource scheduling. Although the 'embededness' (Foley \& Lee, 1991) of shellfish may be no greater than that of underground corms, the daily and monthly cycles of tides provides a unique intellectual challenge to those who would base their settlement decisions on shellfish gathering. The nutritional prize is both the cause and the effect of the shift toward more complex, more planned integrations of resources, in which intelligence and nutrition are strongly linked.

More speculatively, we could try to distinguish the roles of men and women in these supposed developments. In an evolutionary sense it makes very little difference whether or not men consume the brains of hunted kills and accumulate impressive amounts of DHA in adult life. There may have been health advantages, but these could not have been converted into encephalisation gains in future generations. It does, however, make an enormous difference what women choose to do. Women, familiar with menstrual cycles, may have been instrumental in recognising the monthly cycles of tides, leading the move toward more regular gathering of shellfish and, thus, sparking the trajectory of increased LC PUFA intake, selection for larger brains and increasing visual and intellectual capacity.

My suggestion then is that the Pleistocene was a period when the selection for larger brains would have generated a continuous need for the provision of better nutritional substrates. The notable advances of Pliocene and early Pleistocene australopithecine and Homo species over modern primates in encephalisation may have been based on increased access to meat, but especially to fatty acids in the marrow and brains of terrestrial animals. Alternatively, as Broadhurst et al., (1998) suggest, these advances may have been derived from increased intake of freshwater fish and shellfish from Rift Valley lakes. The later, more dramatic rise in encephalisation levels, coincident with the appearance of early modern Homo sapiens, must have required a shift toward an even more suitable nutritional substrate, arguably marine foods such as easily gathered intertidal shellfish. The rather poorly resolved chronology of global shell midden distributions supports this notion.

\section{Acknowledgements}

I am very grateful to Dick Riley, Adrian de Koning and George Lindsey for helpful advice in Cape Town. Leslie Aiello, Michael Crawford, Leigh Broadhurst, Stephen Cunnane and Robert Martin responded to my email calls for help and were extremely supportive of my presentation in Sun City. Many years ago John Speth tried hard to tell me what I now know to be the case: fatty acids make a difference. These colleagues are not, however, to blame for what I have done with their advice.

\section{References}

Aiello, L.C. \& Dunbar, R.I.M. (1993). Neocortex size, group size, and the evolution of language. Current Anthropology, 34(2), 184-93.

Aiello, L.C. \& Wheeler, P. (1995). The Expensive-Tissue Hypothesis. Current Anthropology, 36(2), 199-221.

Arnold, T.H., Wells, M.J., \& Wehmeyer, A.S. (1989). Khoisan food plants: taxa with potential for future economic exploitation. CSIR Report, Pretoria: Council for Scientific and Industrial Research.

Avery, G., Cruz-Uribe, K., Goldberg, P., Grine, F., Klein, R., Lenardi, M., Marean, C., Rink, J., Thackeray, A. \& Wilson, M. (1997). The 1992-1993 Excavations at the Die Kelders Middle and Later Stone Age Cave Site, South Africa. Journal of Field Archaeology, 24, 263-91.

Bailey, G. \& Parkington, J. (1988). The archaeology of prehistoric coastlines: an introduction. In: The Archaeology of Prehistoric Coastlines, eds. G. Bailey \& J.Parkington, pp. 1-10. Cambridge: Cambridge University Press.

Berger, L.R. \& Parkington, J.E. (1995). Brief communication: a new Pleistocene hominid-bearing locality at Hoedjiespunt, South Africa. American Journal of Physical Anthropology, 98, 601-09.

Broadhurst, C.L., Cunnane, S.C. \& Crawford, M.A. (1998). Rift Valley lake fish and shellfish provided brainspecific nutrition for early Homo. British Journal of Nutrition, 79, 3-21. 
Cunnane, S.C., Harbige, L.S. \& Crawford, M.A. (1993). The importance of energy and nutrient supply in human brain evolution. Nutrition and Health, 9, 219-35.

Crawford, M.A. \& Marsh, D. (1995). Nutrition and Evolution. New Canaan, CT: Keats Publishing.

Deacon, H.J. (1992). Southern Africa and modern human origins. Philosophical Transactions of the Royal Society, London, B 337, 177-83.

Deacon, H.J. \& Geleijnse, V.B. (1988). The stratigraphy and sedimentology of the main site sequence, Klasies River, South Africa. South African Archaeological Bulletin, 43, 5-14.

Dunbar, R.I.M. (1998). The Social Brain Hypothesis. Evolutionary Anthropology, 7, 178-90.

Foley, R.A. \& Lee, P.C. (1991). Ecology and energetics of encephalization in hominid evolution. Philosophical Transactions of the Royal Society, London, B 334:223-32.

Grine,F.E. \& Klein, R.G. (1993). Late Pleistocene human remains from the Sea Harvest site, Saldanha Bay, South Africa. South African Journal of Science, 89, 145-51.

Hall, K.R.L. (1962). Numerical data, maintenance activities and locomotion of the wild Chacma baboon, Papio ursinus. Proceedings of the Zoological Society of London, 139(2), 181-220.

Hall, K.R.L. \& De Vore, I. (1965). Baboon social behaviour. In: Primate Behaviour - Field Studies of Monkeys and Apes, ed. I. De Vore, pp. 53-110. New York: Holt, Rinehart and Winston.

Henshilwood, C. \& Sealy, J. (1997). Bone artifacts from the Middle Stone Age at Blombos Cave, Southern Cape, South Africa. Current Anthropology, 38(5), 890-95.

Howe, B. (1967). The Palaeolithic of Tangier, Morocco: Excavations at Cape Ashakar, 1939-1947. American School of Prehistoric Research, Bulletin 22.

Jerison, H.J. (1973). Evolution of the Human Brain and Intelligence. London: Academic Press.

Klein, R.G. (1989). The Human Career. Chicago: University of Chicago Press.

Klein, R.G. \& Cruz-Uribe, K. (1991). The Bovids from Elandsfontein, South Africa, and their implications for the age, palaeoenvironment, and origins of the site. African Archaeological Review, 9, 21-79.

Klein, R.G. \& Cruz-Uribe, K. (1996). Exploitation of large bovids and seals at Middle and Later Stone Age sites in South Africa. Journal of Human Evolution, 31(4), 315-35.

Leaf, A. (1993). Omega-3 PUFA, an update: 1986-(1993). Omega-3 News, 8, 1-4.

Martin, R.D. (1981). Relative brain size and basal metabolic rate in terrestrial vertebrates. Nature, 293, 57-60.

Martin, R.D. (1983). Human Brain Evolution in an Ecological Context. Fifty-second James Arthur Lecture on the Evolution of the Human Brain. New York: American Museum of Natural History.

McBurney, C.B.M. (1960). The Haua Fteah (Cyrenaica) and the Stone Age of the South-East Mediterranean. Cambridge: Cambridge University Press.

McHenry, H.M. (1994). Behavioural ecological implications of early hominid body size. Journal of Human Evolution, 27, 77-87.

Milton, K. (1993). Diet and primate evolution. Scientific American, 269(2), 86-93.

Parkington, J.E. (1998, in press). Western Cape Landscapes. In: Grahame Clark \& World Prehistory, ed. P. Mellars, London: British Academy.

Rightmire, G.P. \& Deacon, H.J. (1991). Comparative studies of Late Pleistocene human remains from Klasies River Mouth, South Africa. Journal of Human Evolution, 20, 131-56.

Ruff, C.B., Trinkaus, E. \& Holliday, T.W. (1997). Body mass and encephalization in Pleistocene Homo. Nature, 387, 173-76.

Singer, R. \& Wymer, J. (1982). The Middle Stone Age at Klasies River Mouth in South Africa. Chicago: Chicago University Press.

Speth, J.D. (1989). Early hominid hunting and scavenging: the role of meat as an energy source. Journal of Human Evolution, 18, 329-49.

Speth, J.D. \& Spielmann, K.A. (1983). Energy source, protein metabolism, and hunter-gatherer subsistence strategies. Journal of Anthropological Archaeology, 2, 1-31.

Stiner, M.C. (1994). Honor Among Thieves: a Zoological Study of Neanderthal Ecology. Princeton: Princeton University Press.

Tobias, P.V. (1971). The Brain in Hominid Evolution. New York: Columbia University Press.

Volman, T. P. (1978) The early archaeological evidence for shellfish collecting. Science, 201, 911-13. 


\section{Peter S. Ungar ${ }^{1}$ and Mark Teaford ${ }^{2}$}

\author{
${ }^{1}$ Department of Anthropology, Old Main 330, \\ University of Arkansas, Fayetteville, AR \\ 72701 \\ ${ }^{2}$ Department of Cell Biology and Anatomy, \\ Johns Hopkins University School of \\ Medicine, 725 North Wolfe Street, Baltimore, \\ MD 21205
}

Keywords: Diet, australopithecines, dental allometry, morphology, microwear, mandibular biomechanics

\section{The Dietary Split Between Apes and the Earliest Human Ancestors}

\begin{abstract}
Diet is fundamental to understanding the biology and ecology of early hominids. In this paper we examine the gnathodental evidence for early hominid diets. Most austalopithecines show a unique suite of diet-related features including small incisors, large, flat molars, thick tooth enamel and thick mandibular corpora. These features along with the microwear evidence, suggest that these hominids would have been well-suited to consuming hard, brittle items that did not require extensive incisal preparation rather than tough foods, or larger ones with thick husks. Still, differences between australopithecine taxa suggest an increasing ability to process harder foods through the Pliocene, culminating in the Pleistocene with the specialized "rubust" australopithecines. Dietary changes associated with the origins and the early evolution of our family are more likely related to increasing microhabitat variability than to global cooling and drying.
\end{abstract}

\section{Introduction}

Since the discovery of Australopithecus afarensis, many researchers have emphasized the importance of bipedality in scenarios of human origins (e.g., Lovejoy, 1975; Susman et al., 1984). Less attention has been focused on the role played by diet in the ecology and evolution of the early hominids. This is surprising because diet is the most important parameter underlying behavioral and ecological differences among living primates. Thus it is critical to understanding hominid paleobiology. We need to focus not just on how the earliest hominids moved between food patches, but also on what they ate when they got there.

New and important fossil finds from the early Pliocene raise new questions concerning the role that dietary changes may have played in the origins and early evolution of the Hominidae. The discovery of thin molar enamel for Ardipithecus ramidus (White et al., 1994), and unique aspects of the mandible and dentitions of Australopithecus anamensis (Ward et al., 1999) lead us to new questions, and highlight the importance of this type of research.

This paper presents a review of the fossil evidence for the diets of the earliest hominids. We also trace what has been inferred concerning the diets of the 'gracile' australopithecines through time to put changes in Pliocene hominid diets into some temporal perspective. Such evidence has come in basically five categories: tooth size, tooth shape, enamel structure, dental microwear and jaw biomechanics. These lines of evidence suggest a dietary shift in the early australopithecines indicating an improved ability to consume hard, abrasive foods compared with their hominoid forebears. Changes in diet-related adaptations from Australopithecus anamensis to A. afarensis to A. africanus suggest that hard, abrasive foods became increasingly important through the Pliocene.

\section{Tooth Size}

Incisors

Jolly (1970) noted that australopithecines had relatively small incisors compared with molars, and 


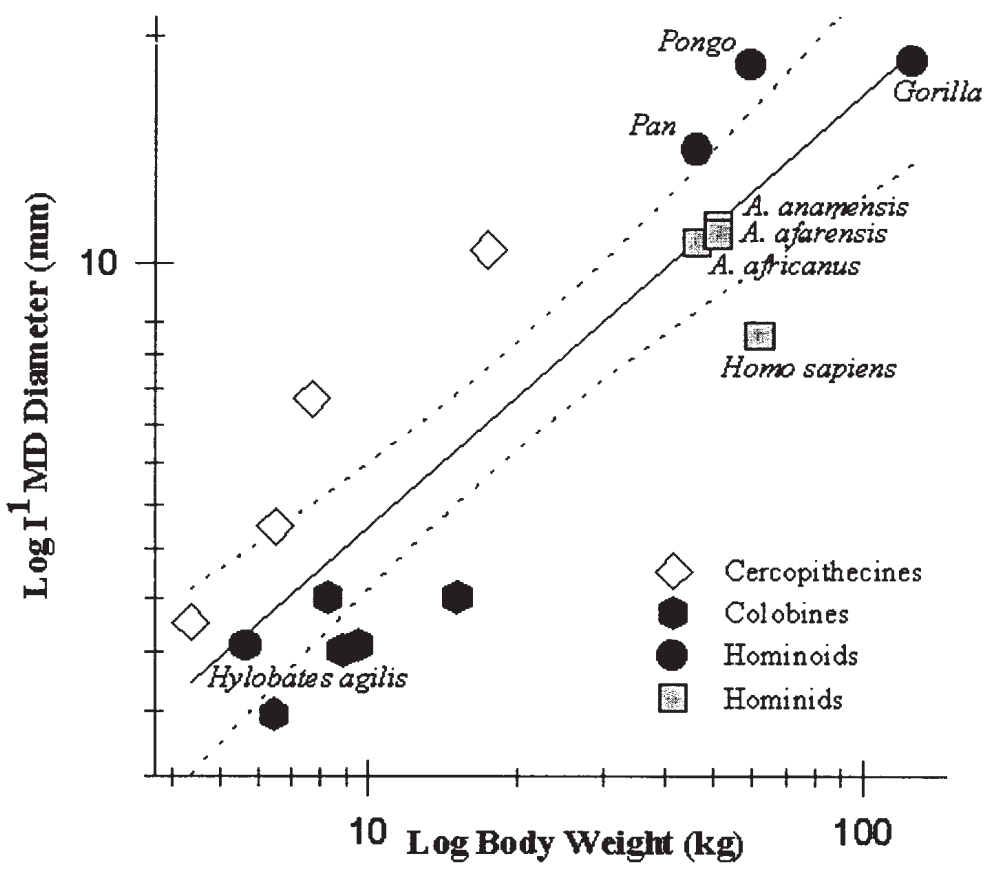

Figure 1. Relative incisor sizes in catarrhines. Dashed lines indicate $95 \%$ confidence limits of the least squares regression plot (data from Ungar \& Grine, 1991; Wood, 1991; Jungers, 1988; Coffing et al., 1994; and Leakey et al., 1995).

speculated that this might be associated with terrestrial seed-eating, as seen in Theropithecus today. While this idea has been the subject of some controversy (e.g., Dunbar, 1976), Jolly's efforts have stimulated considerable research on relative incisor size in a wide variety of living and fossil primates. Most notably, Hylander (1975) examined the relationship of incisor row length (relative to body size) in a range of living anthropoids, and found that those species with larger incisors tend to consume larger, tougher fruits, whereas those with smaller front teeth tend to feed on smaller foods, or those that require less extensive incisal preparation, such as leaves or berries. Since then, numerous workers have looked to incisor size in early hominids and other fossil primates for clues concerning diet.

What can front tooth size tell us of the diets of Miocene apes? Unfortunately, not as much as we would like. Ideally, to consider relative incisor sizes among taxa, we need estimates of species body-weight means based on attributes independent of the dentition. Such estimates are unavailable for most taxa. Further, Miocene apes as a whole evidently had small incisors compared with extant hominoids, in much the same way that platyrrhines as a whole have relatively smaller incisors than do catarrhines independent of diet (Kay \& Ungar, 1997). Such phylogenetic effects make it difficult to find an extant comparative baseline series with which to compare these basal taxa of uncertain phyletic affinities.

On the other hand, incisor size might give us some clues to diet and tooth use for the early australopithecines, and we have good, consistent weight estimates from independent studies (Junger, 1988; McHenry, 1992) for many of these taxa. If we look at a regression of maxillary central incisor breadth on body size for species representing a variety of catarrhine genera, we see a nice separation of 


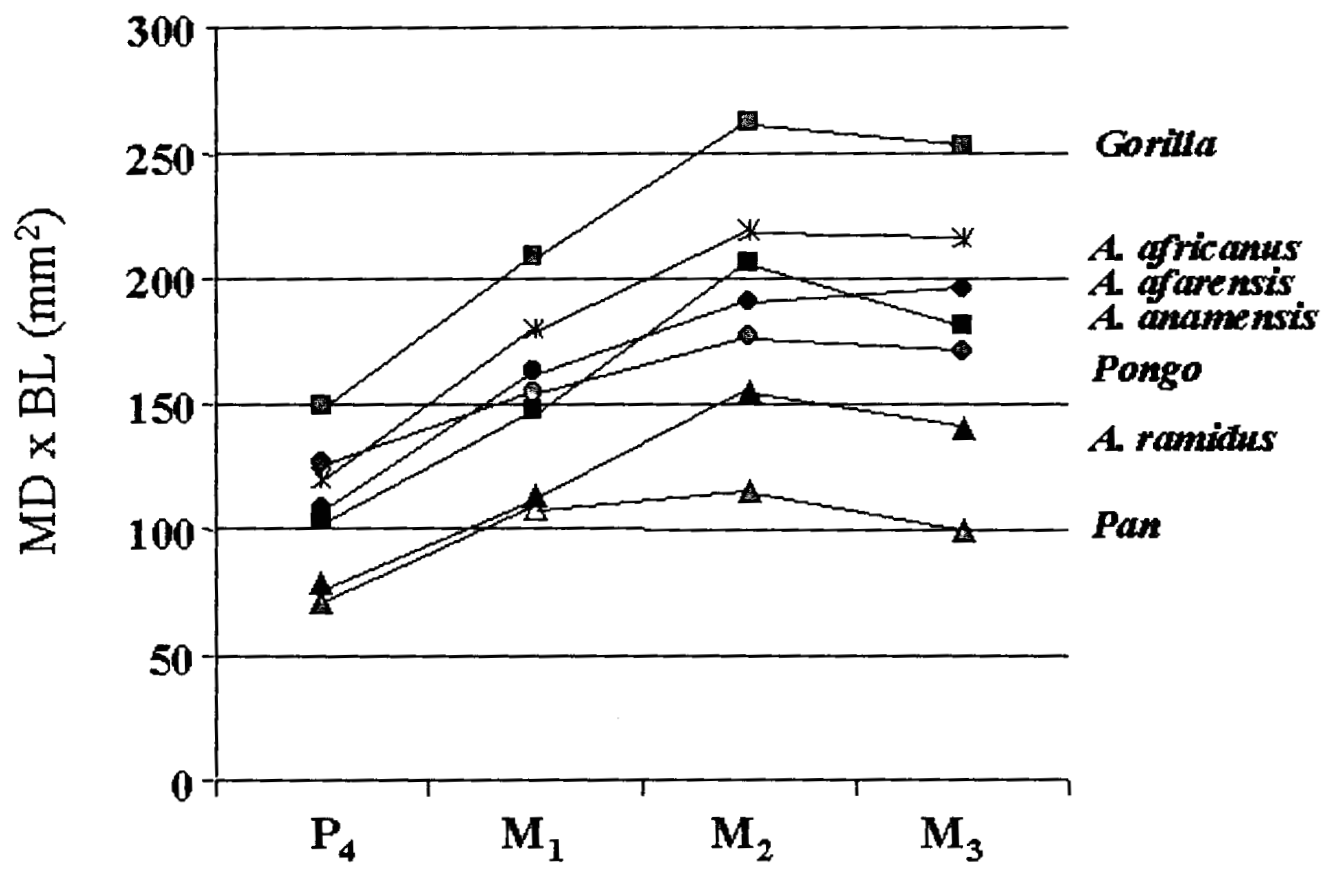

Figure 2. Mandibular postcanine tooth areas in extant apes and early hominids (data from Coffing et al., 1994; Leakey et al., 1995; Mahler, 1973; White et al.,1994 and Wood, 1991).

cercopithecines (with relatively larger incisors) above the line and colobines below (Fig.1). Further, more frugivorous chimpanzees and orangutans fall above the line, whereas gibbons and gorillas fall close to the line, with relatively smaller incisors. Indeed, values for the living frugivorous great apes fall above the $95 \%$ confidence limits of expected incisor size for modern catarrhines. The human values fall below the $95 \%$ confidence limits, indicating that we have very small incisors relative to body size.

Relative incisor sizes for the three 'gracile' australopithecines are remarkably similar, and fall very close to the regression line, much like the gorilla. These results are similar to those reported by Kay (1984) and Ungar \& Grine (1991), and suggest that these hominids used their incisors in ingestion to a similar degree, although they all probably used these teeth less than either the chimpanzee or orangutan. As an interesting side note, australopithecine relative incisor size is very similar to those of both gorillas and gibbons, so these data cannot distinguish folivorous from frugivorous adaptations. On the other hand, they can give us some idea of whether a taxon often eats foods that require incisal preparation. For instance, while lar gibbons have much smaller incisors than orangutans (and they spend more of their day eating fruits on average), they depend on smaller fruits requiring little incisal preparation (Ungar, 1994, 1996a). From this perspective, the australopithecines probably put less emphasis on foods that require substantial incisor use, such as those with thick husks or hard shells, and those with flesh adherent to large, hard seeds. Body weight estimates and incisor size data for Ardipithecus ramidus should provide more insights. 


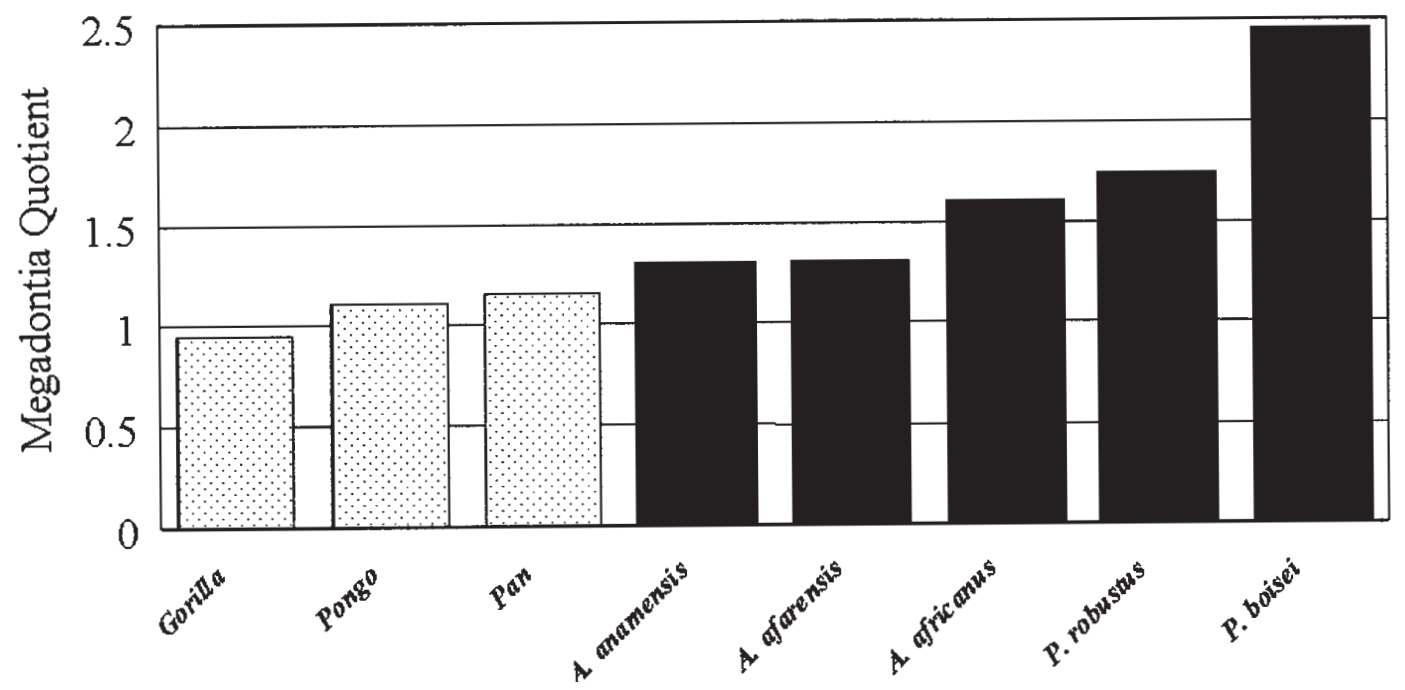

Figure 3. Megadontia quotients for early hominids and extant primates (data from Coffing et al., 1994; Leakey et al., 1995; Mahler, 1973; McHenry, 1984, 1988).

\section{Molars}

One of the hallmarks of the australopithecines has always been their large, relatively flat molars (Kay, 1985; McHenry, 1984; Robinson, 1956; Suwa et al., 1994; Wood \& Abbott, 1983; Wolpoff, 1973). There may well be differences in the amount of occlusal relief between gracile and robust australopithecines (Grine, 1981). However, by comparison with other primates, the australopithecines' molars are flat and huge. Even in the earliest hominids, this can be seen in a simple plot of mandibular postcanine tooth area (MD x BL), where most taxa have teeth larger than those of the modern orangutan (Fig. 2).

The only exception is Ardipithecus, which is more chimp-sized in the $\mathrm{P}_{4}-\mathrm{M}_{1}$ region, but intermediate between chimpanzees and orangutans in the $\mathrm{M}_{2}-\mathrm{M}_{3}$ region. Again, interpretations of such differences are hampered by the lack of body size estimates for Ardipithecus, but if a body size estimate of $51 \mathrm{~kg}$ is used for Australopithecus anamensis the average of the two different estimates based on the tibia, (Leakey et al., 1995), McHenry's 'megadontia quotient' (Fig. 3) for this taxon is essentially identical to that for $A$. afarensis. In other words, its molars are large for a hominoid, but smaller than those of $A$. africanus or the 'robust' australopithecines.

As one might expect, the Miocene hominoids show a tremendous range of mandibular molar sizes (Fig. 4). Many have postcanine tooth areas larger than that of Ardipithecus, and some (such as Ouranopithecus) even have larger postcanine tooth areas than that of $A$. anamensis, but as all body size estimates for them have been computed from dental remains, a megadontia quotient cannot be computed. The main message from a simple look at postcanine tooth size is that the earliest hominids make a nice progression leading into subsequent hominids, but they do not have larger postcanine teeth than all of the mid-late Miocene hominoids.

\section{So what does this mean?}

It might just mean that a variety of body sizes are sampled in these taxa. However, as shown by the work 


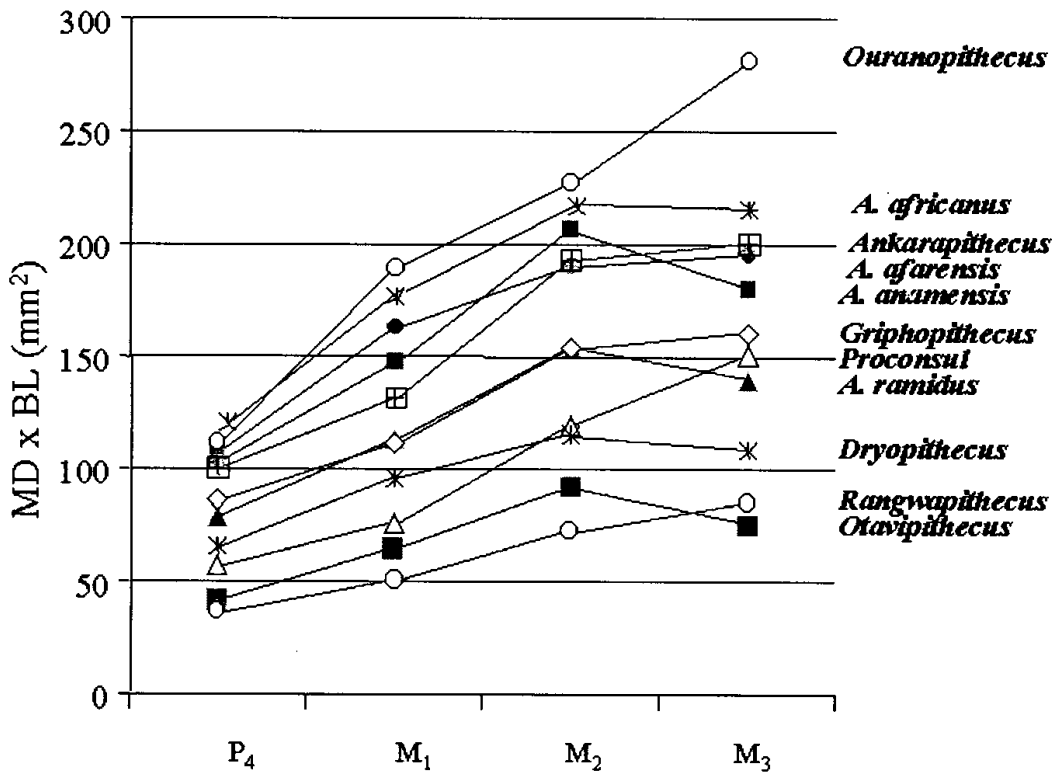

Figure 4. Mandibular postcanine tooth areas $\left(\mathrm{P}_{4}-\mathrm{M}_{3}\right)$ defined as the product of maximal mesiodistal and buccolingual diameters in Miocene apes and early hominids (data from Alpagut et al., 1990, 1996; Andrews, 1978; Begun \& Gulec, 1998; Coffing et al., 1994; de Bonis \& Melentis, 1984; Leakey et al., 1995, 1998, Mahler, 1973; White et al., 1994; and Wood, 1991).

of Lucas and colleagues (Lucas et al., 1986), variations in tooth size are a means of adapting to changes in the external characteristics of foods such as their size, shape, abrasiveness, and stickiness. Clearly, some of these food characteristics were changing during the evolution of the earliest hominids, as postcanine teeth got relatively larger and larger. However, evidence from the mid-to-late Miocene shows that tooth size by itself cannot pinpoint the initial change to a hominid diet, at least not with the samples at hand.

One other way of looking at postcanine tooth size is to look at the ratio of the areas of M1 and M3 (Fig. 5). Lucas et al. (1986) showed that this ratio was inversely related to the percentage of leaves, flowers, and shoots in the diet, that is, anthropoids with a high ratio of M1 to M3 area consumed more fruit than did those with a low M1 to M3 ratio. When this is computed for the earliest hominids, plus a sample of Miocene apes, a clear separation is evident, with the early hominids, including Ardipithecus, showing higher ratios than the Miocene apes. So, does this indicate more fruit in the diet of the earliest hominids? To begin to answer that question, we must look at analyses of tooth shape.

\section{Tooth Shape}

Natural selection dictates that primate tooth shape should reflect the mechanical properties of foods. As shown by numerous workers, variations in tooth shape are a means of adapting to changes in the internal characteristics of foods such as their strength, toughness, and deformability (Lucas \& Teaford, 1994; Spears \& Crompton, 1996; Strait, 1997; Yamashita, 1998). Clearly, foods are complex structures; thus it is impossible to describe all of the internal characteristics that might have confronted the earliest hominids' teeth. However, another approach is to describe the capabilities of those teeth. 


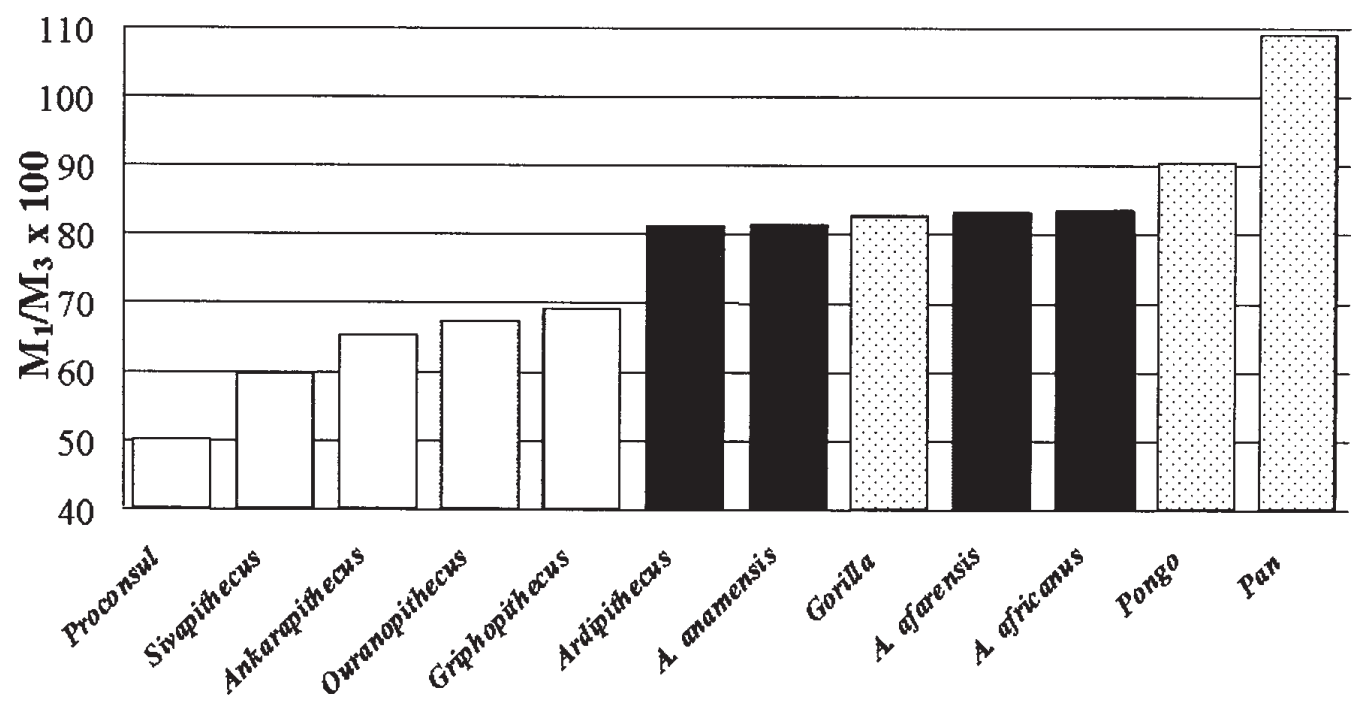

Figure 5. Ratios of $\mathrm{M}_{1}$ to $\mathrm{M}_{3}$ areas, defined as the products of maximal mesiodistal and buccolingual diameters (data from Alpagut et al., 1990, 1996; Andrews, 1978; Begun \& Gulec, 1998; Coffing et al., 1994; de Bonis \& Melentis, 1984; Leakey et al., 1995, 1998, Mahler, 1973; White et al., 1994; and Wood, 1991).

For example, tough foods are sheared between the leading edges of sharp crown crests whereas hard, brittle foods are crushed between planar surfaces. As such, reciprocally concave, highly crested teeth have the capability of efficiently processing tough items such as insect exoskeletons and leaves, whereas rounder and flatter cusped teeth are best suited for a more brittle frugivorous diet. Kay (1984) has devised a 'shearing quotient' (SQ) as a measure of relative shear potential of a molar tooth. He and colleagues have demonstrated that more folivorous species have the longest crests, followed by those that prefer brittle, soft fruits. Finally, hard-object feeders have the shortest crests and bluntest molars (Kay, 1984; Meldrum \& Kay, 1997).

Shearing crest studies have been conducted on early Miocene African apes and middle to late Miocene European apes (Fig. 6). Such studies show a considerable range of diets very consistent with microwear results for these same taxa. For example, Rangwapithecus and Oreopithecus have relatively long shearing crests suggesting folivory, Ouranopithecus has extremely short crests suggesting a hard-object specialization, whereas most other Miocene taxa studied, such as Proconsul and Dryopithecus, have the intermediate length crests of a frugivore (Kay \& Ungar, 1997; Ungar \& Kay, 1995). It may well turn out shearing crest studies suggest that Miocene apes, especially those from the later Miocene of Europe, show a substantial range of diets.

As for the early hominids, Grine (1981) has noted differences between Australopithecus africanus and Paranthropus robustus in molar form, such that the 'gracile' species had more occlusal relief than did the 'robust' form, suggesting a dietary difference. While no shearing crest length studies have been published for early hominids, all australopithecines have relatively flat, blunt molar teeth and lack the long shearing crests seen in some extant hominoids (e.g., Kay, 1985). By itself, this indicates that the earliest hominids would have had difficulty breaking down tough, pliant foods, such as soft seed coats and the veins and stems of leaves - although they probably were capable of processing buds, flowers, and shoots. 


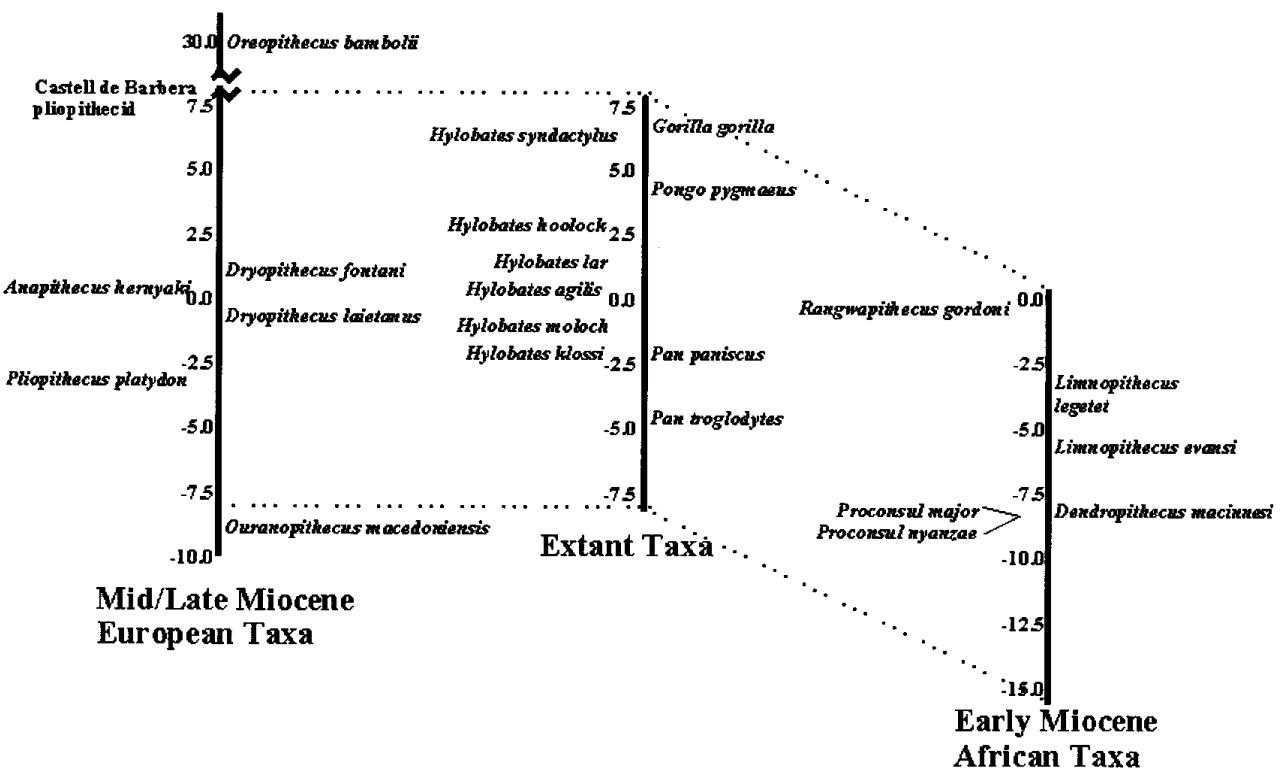

Figure 6. Shearing quotient data for extant and fossil apes (data from Ungar \& Kay, 1995; Kay \& Ungar, 1997).

Interestingly, as suggested by Lucas \& Peters (in press) another tough pliant food they would have had difficulty in processing is meat. In other words, the early hominids were not dentally pre-adapted to eat meat - they simply did not have the sharp, reciprocally-concave shearing blades necessary to retain and cut such foods. By contrast, given their flat, blunt teeth, they were admirably equipped to process hard brittle objects. What about soft fruits? It really depends on the toughness of those fruits. If they were tough, then they would also need to be precisely retained and sliced between the teeth. Again, early hominids would be very inefficient at it. If they were not tough, then the hominids could certainly process soft fruits.

In sum, Miocene ape molars show a range of adaptations including folivory, soft-fruit eating and hard-object feeding. This range exceeds that of living hominoids, and especially the early hominids. While comparable shearing crest length studies have not been conducted on early hominids, australopithecines certainly have relatively flat molar teeth compared with many living and fossil apes. These teeth were well suited to breaking down hard, brittle foods including some fruits and nuts, and soft, weak foods such as flowers and buds; but again, they were not well suited to breaking down tough pliant foods like stems, soft seed pods, and meat.

\section{Enamel Structure}

Another area of interest regarding dental functional anatomy is the study of enamel thickness. There are certainly methodological differences between studies (e.g., Beynon \& Wood, 1986; Beynon et al. 1991; Grine \& Martin, 1988; Macho \& Thackeray 1992; Martin 1985; Spoor et al. 1993), but the consensus still seems to be that the australopithecines had relatively thick enamel compared with living primates, and that many of the Miocene apes also had thick enamel (Andrews \& Martin, 1991; Beynon et al. 1997; Beynon \& Wood, 1986; Gantt, 1986; Grine \& Martin, 1988; Kay, 1985; Macho \& Thackeray 1992; Robinson, 1956). 


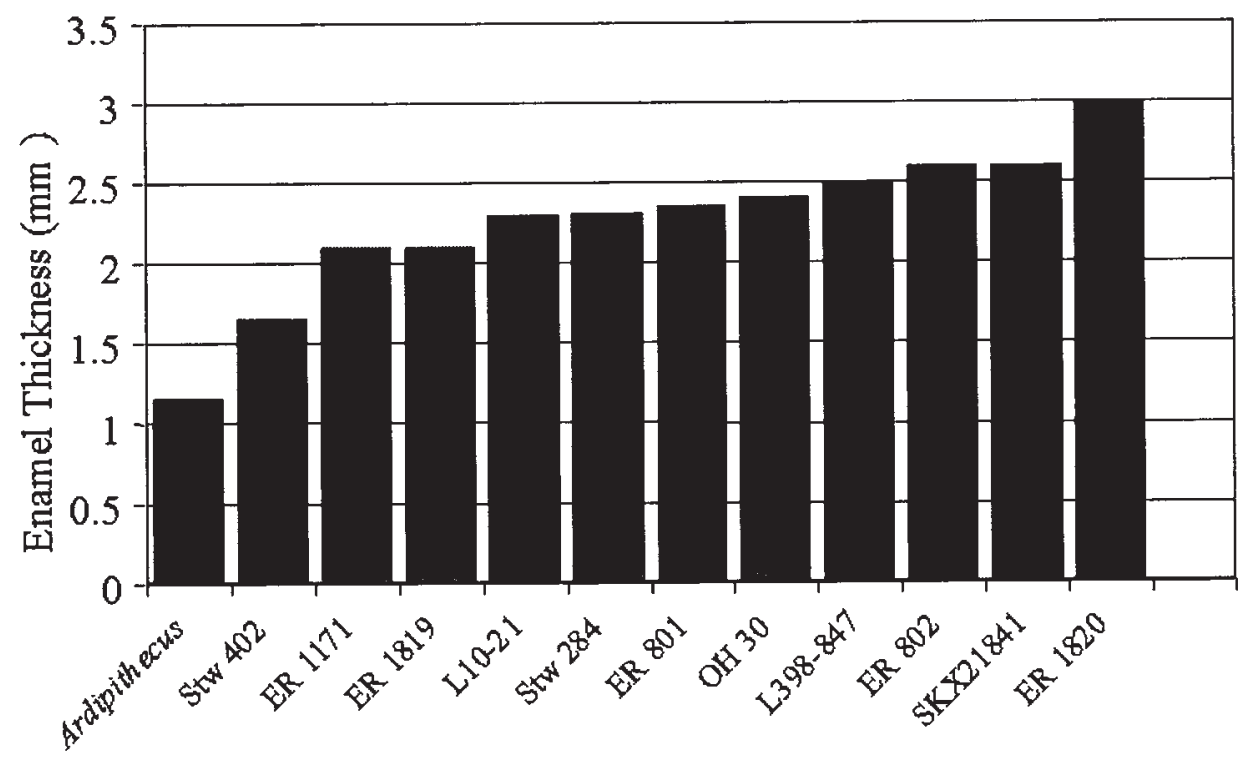

Figure 7. Molar enamel thickness in early hominids (data from Beynon \& Wood, 1986; Grine \& Martin, 1988; and White et al., 1994).

Interestingly, this perspective may be changing as we get glimpses of more and more new taxa. For instance, Conroy et al. (1995) have noted that Otavipithecus may have had thin enamel, and White et al. (1994) have made the same observation for Ardipithecus (Fig. 7). Granted, in neither case do we have a detailed series of measurements over the tooth crown, but still, the figures that have been quoted (less than $1 \mathrm{~mm}$ for Otavipithecus and 1.1-1.2 mm for Ardipithecus) are far less than those quoted for the australopithecines.

So what might be the functional significance of enamel thickness? A number of ideas have been put forth (see Andrews \& Martin, 1991, and Martin, 1983, for reviews), but the most frequently cited correlation is that between the consumption of hard food items and thick molar enamel (Kay, 1981; Dumont, 1995). There are many potential complicating factors (such as differences in enamel thickness within, and between, teeth) (Macho \& Thackeray 1992; Macho \& Berner, 1993; Dumont, 1995). Thus it is perhaps not surprising that the correlation between enamel thickness and hard-object feeding isn't a perfect one. Moreover, thick enamel by itself doesn't necessarily provide protection against hard objects - which commonly cause fracture of enamel. The best protection against that is prism or crystallite decussation. Workers are now beginning to study the functional implications of variations in enamel prism (and crystallite) arrangements throughout the dentition. Unfortunately, as that work generally requires the sectioning and etching of teeth, it has rarely been done on fossil apes and hominids. The work of Maas, Rensberger and others has shown that prism and crystallite orientations can give clues to intricate details of dental function, and that decussation (or inter-weaving) can be an effective crack-stopping mechanism in many animals (Maas, 1993; Rensberger, 1997). Only anecdotal references to this phenomenon in Miocene apes and early hominids have been made thus far. Still, after some discussion and debate (Beynon \& Wood, 1986; Gantt 1986; Grine \& Martin, 1988), a consensus now seems to be that they did have a significant degree of prism decussation. It may well turn out in the end that the thick enamel of the early hominids was both a means to resist breakage during the consumption of hard objects and an adaptation to prolong the life of the tooth given an abrasive diet. 


\section{Dental Microwear}

Numerous workers have recognized that microscopic patterns of wear on the incisors and molar teeth of primates reflect tooth use and diet. For example, those primates that often use their front teeth in ingestion have higher densities of microwear striations on their incisors than those that do not. Further, folivores have higher incidences of long narrow microwear scratches on their molar teeth whereas frugivores have more pits on those surfaces. Among frugivores, hard-object feeders have even higher pit incidences than soft-fruit eaters. These and other relationships between microwear and feeding behaviors in living primates have been used to infer diet in fossil forms.

Much of this work has focused on Miocene apes. To this point, microwear studies have been published for a diverse array of taxa from the early to middle Miocene of Africa, and the middle to late Miocene of Eurasia. While none of these may be the last common ancestor of humans and African apes, they can give us some clues as to the diversity of adaptations of apes that lived around the time of, if not just before the divergence, especially the late Miocene forms.

Miocene apes have a remarkable range of microwear patterning, greatly exceeding that of living hominoids. For example, relatively high scratch densities suggest that Micropithecus, Rangwapithecus and especially Oreopithecus (Ungar et al., 1996; Ungar, 1996b) included more leaves in their diets. In contrast, high pit percentages suggest that Griphopithecus, and Ouranopithecus (King, 1998; Ungar, 1996b) were hard-object specialists. Finally, intermediate microwear patterns suggest that most other species studied, such as Gigantopithecus, Dendropithecus, Proconsul, Dryopithecus and perhaps Sivapithecus (Daegling \& Grine, 1994, Teaford \& Walker, 1984; Ungar, 1996b; Ungar et al., 1996) had diets dominated by soft fruits. These microwear data give us a glimpse at the extraordinary variation that must have characterized the diets of Miocene apes. It is from this range of variation that the last common ancestor evidently came.

So, what is known of the microwear of early australopithecines? Precious little. No microwear research has yet been published for either $A$. ramidus or $A$. anamensis, though there has been some done on $A$. afarensis and $A$. africanus. The work on A. afarensis has been largely qualitative and focused on the anterior teeth. Much of this research has used a baboon analogy to argue that these hominids were beginning to exploit savanna resources. For example, Puech \& Albertini (1984) argued that upper canines from Laetoli and Hadar show wear crenulations comparable to those seen on baboons. They also argued that $A$. afarensis incisors show labiolingually oriented furrows related to stripping and clamping small, hard vegetable materials in open savanna habitats. Further, Ryan \& Johanson (1989) argued that Australopithecus afarensis had a mosaic of gorilla-like fine wear striae and baboon-like pits and microflakes indicating the use of incisors to strip gritty plant parts such as seeds, roots and rhizomes. These authors also suggested that wear striae and marked pitting on the flattened distal edges of the canine and occlusal surface of $\mathrm{P}^{3}$ suggest a functional shift in this complex from ape-like slicing and cutting to hominid puncture-crushing.

Work on $A$. africanus has been more quantitative, but focused on comparing this taxon to Paranthropus robustus rather than to an extant comparative baseline series. Grine (1986) found, for example, that $A$. africanus molars have lower incidences of pitting than seen for Paranthropus (Fig. 8). A. africanus scratches are also longer and narrower, and show more homogeneity in orientation. Grine argued that, compared with the 'robust' forms, $A$. africanus ate more soft fruits and leaves. Comparisons with work from Teaford (1988) places A. africanus between Cebus olivaceus on one hand, and Pan troglodytes on the other, though different techniques were used to collect the microwear data. Work on A. africanus incisors (Fig. 9) has shown that this taxon has higher microwear feature densities on all surfaces examined than does Paranthropus (Ungar \& Grine, 1991). This suggests that A. africanus processed a greater variety of foods with their front teeth, including larger, more abrasive ones, than were encountered by Paranthropus. Comparisons with an extant baseline series examined by Ungar (1998) puts Australopithecus between Pongo pygmaeus and the seed predator/folivore Presbytis 


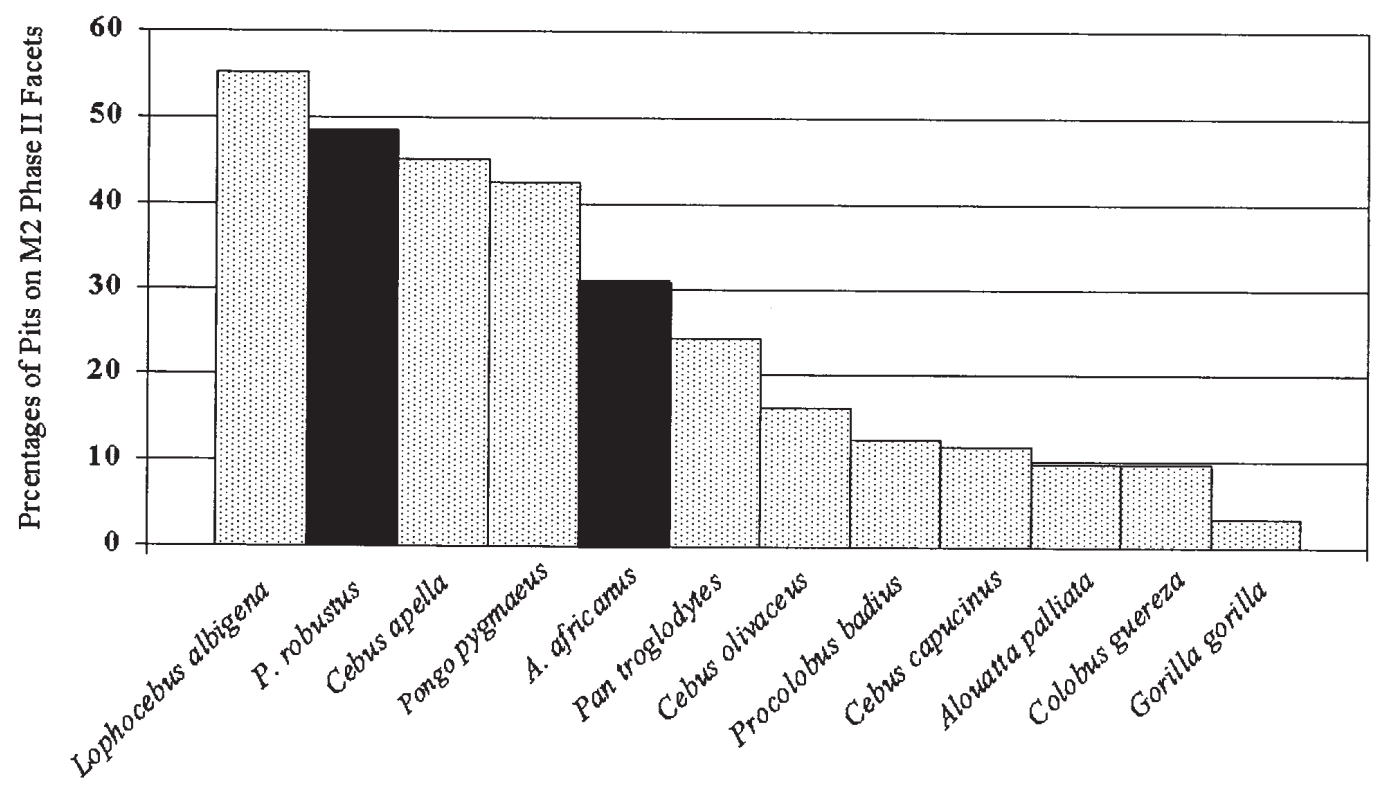

Figure 8. Molar microwear pit percentage data for second molar, Phase II facets (adapted from Ungar, 1998).

thomasi in degree of anterior tooth use in ingestion.

In sum then, what can be said of the microwear data? These data indicate that by the end of the Miocene, hominoids had a wide range of diets. Preliminary work on Australopithecus afarensis suggests that these hominids may already have begun to incorporate into their diets some abrasive, terrestrial resources that required incisal stripping. Quantitative work on Australopithecus africanus microwear suggests that this taxon may still have focused attention on soft fruit, particularly that which did not require considerable incisal preparation. Clearly however, considerably more work is needed on these and other early hominids to put together a reasonable picture of diet based on microwear evidence.

\section{Mandibular Biomechanics}

Finally, there are other lines of evidence beyond teeth that we can examine to look for evidence of diet. Mandibular fragments are among the most common bony remains found in assemblages of australopithecines and other fossil primates. It makes sense, then, that many researchers have focused attention on the functional anatomy of the lower jaw. The basic idea is that the architecture of this bone has been adapted to withstand stresses and strains associated with oral food processing and thus should reflect some aspects of diet. While studies of early primate jaws have focused on symphyseal fusion, analyses of australopithecine mandibular biomechanics have concentrated more on corpus size and shape.

Comparisons of australopithecine and extant hominoid jaws have shown some qualitative differences. Hylander (1988) and Daegling \& Grine (1991) independently found, for example, that $A$. afarensis and $A$. africanus respectively have relatively thick mandibular corpora compared with extant catarrhines. These authors also found this pattern for Paranthropus boisei and P. robustus. Figure 10 shows mandibular robusticity index values for extant great apes, some Miocene apes and early australopithecines. The values represent a ratio of corpus breadth to height at the level of the first molar. Thus, larger numbers indicate a relatively thicker corpus. The early hominids show relatively thicker mandibular corpora than both 


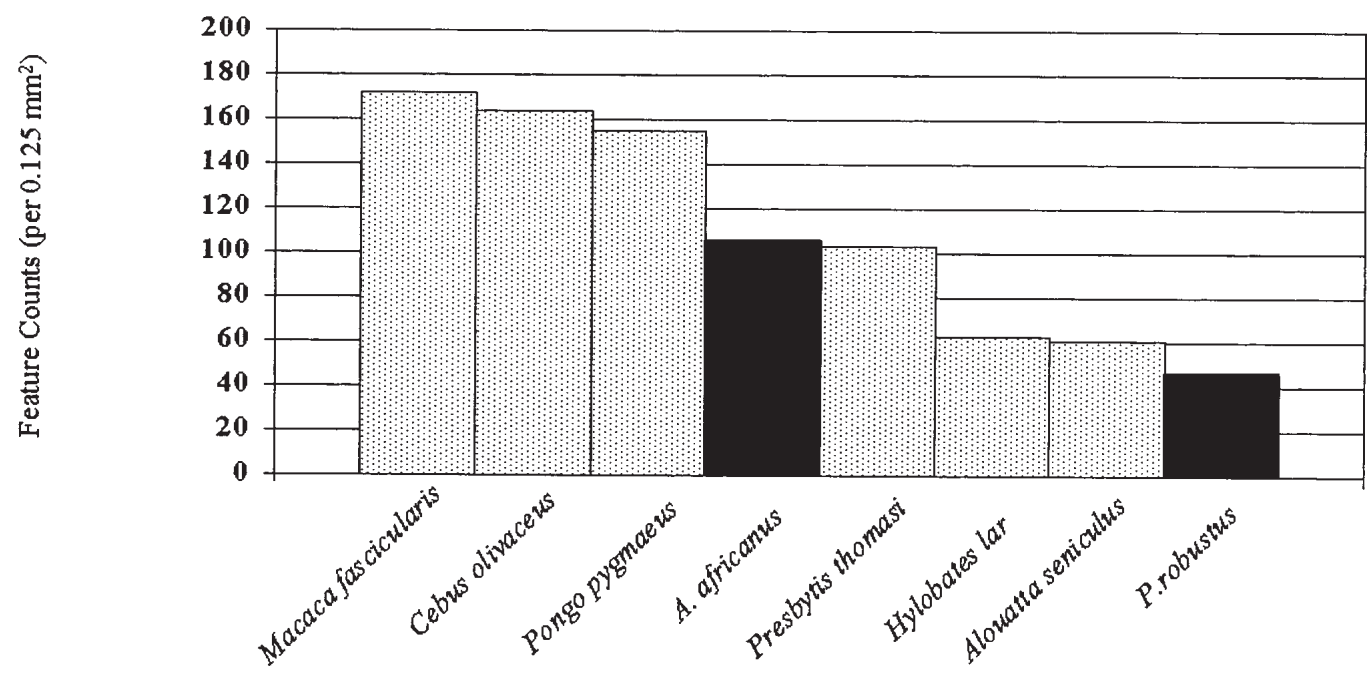

Figure 9. Incisor microwear feature density for maxillary central incisor labial surfaces (adapted from Ungar, 1998).

extant great apes and Miocene catarrhines, suggesting a morphological shift in the former.

Both functional and non-functional interpretations have been offered to explain this phenomenon. For example, it may be simply that a thick mandibular corpus is an effect of large cheek teeth, or a reduced canine. These are not likely explanations, however, as australopithecines still have relatively broad mandibles when considered relative to molar size, and there appears to be no relationship between mandibular robusticity and relative canine size among the australopithecines (Daegling \& Grine, 1991).

Even though functional interpretations of mandibular differences are difficult, it seems more likely that the unique shape of the australopithecine mandibular corpus relates to the functional demands of mastication. Thickened mandibles can act to resist extreme stresses associated with transverse bending (that is, 'wishboning') and torsion. Because wishboning stresses decline towards the back of the corpus, torsion is likely a more important explanation. Corpus torsion can result from bite force and muscle activity during mastication. Therefore, it may be that australopithecine mandibular morphology reflects elevated stresses associated with unusual mechanical demands. Daegling \& Grine (1991) suggest that australopithecines may have eaten fibrous, coarse foods that required repetitive loading. While this fails to explain why colobines do not have thick corpora, it does suggest a fundamental difference between australopithecines and living great apes that may reflect a shift in diet in the early hominids.

Studies of corpus shape in $A$. anamensis and $A$. ramidus will likely provide further clues regarding differences in mandibular architecture between great apes and later australopithecines. Corpus robusticity indices for $A$. anamensis below $\mathrm{M}_{1}$ are 63.7 and 53.5 for female and male mandibles respectively (Ward, Pers.Comm.). These values fall at the upper range for extant hominoids (Pan = 39.2-57.8; Gorilla $=43.5-59.7$; Pongo $=35.7-52.0)$ and at the lower end of the range for later fossil hominids (A. afarensis $=49.8-79.5$, A africanus $=54.8-79.0)$ (data from Daegling \& Grine, 1991).

Interestingly, $A$. anamensis is also intermediate between great apes and later australopithecines in that their maxillary postcanine tooth rows are set nearly parallel. This contrasts with the condition seen in extant hominoids, where the rows converge slightly posteriorly and those of later australopithecines, 


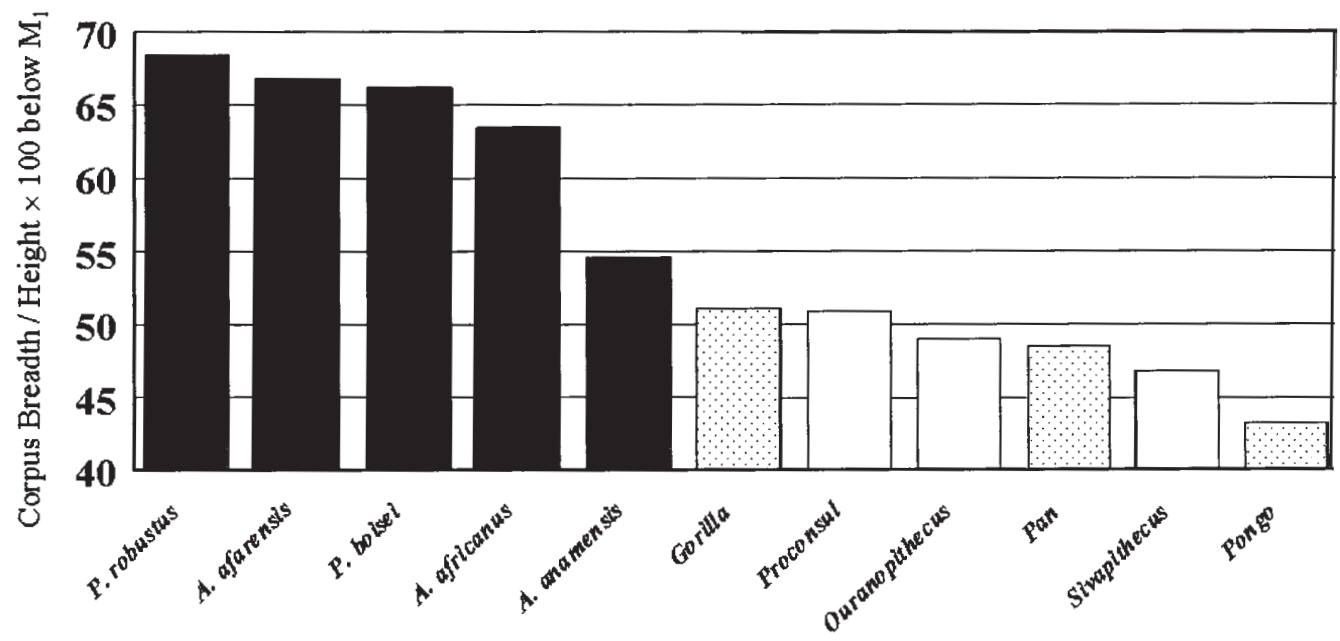

Figure 10. Mandibular corpus shape (data from Smith, 1980; Daegling \& Grine, 1991; and Walker, unpublished).

where the rows tend to diverge toward the back. The functional significance of this change in configuration is not yet clear, but according to Walker (pers. com.), it may also be related to the way in which masticatory stresses are dissipated.

In sum, the architecture of the mandibular corpus suggests that Australopithecus afarensis and A. africanus differed from living apes in their abilities to dissipate masticatory stresses. Taken with other lines of evidence, this certainly suggests a difference in diet between living apes and A. anamensis, and between A. anamensis and later hominids, with Australopithecus anamensis intermediate between the African ape and later australopithecine conditions.

\section{Discussion}

The australopithecines exhibited a complex of morphological features related to diet that are unique compared with living hominoids or Miocene apes. These early hominids all had small-to-moderate sized incisors; large, flat molars with little shear potential; a ratio of first to third molar area low compared with extant apes, but generally higher than those of Miocene apes; thick tooth enamel; and thick mandibular corpora. This suite of traits is distinctive of australopithecines, and suggests a dietary shift at or near the stem of hominid evolution. Their thick-enamelled, flattened molars would have had great difficulty propagating cracks through tough foods, suggesting that the australopithecines were not well-suited for eating tough fruits, leaves or meat. The dental microwear data agree with this, as the australopithecine patterns documented to date are most similar to those of modern-day seed predators and soft fruit eaters. Further, given their comparatively small incisors, these hominids probably did not specialize on large, husked fruits or those requiring extensive incisal preparation. Instead, the australopithecines would have been easily able to break down hard, brittle foods. Their large flat molars would have served well for crushing, and their thick enamel would have withstood abrasion and fracture. Their mandibular corpora would probably have conferred an advantage for resisting failure given high occlusal loads. In essence, for much of their history, the australopithecines had an adaptive package that allowed them ready access to hard objects, plus soft foods that were not particularly tough. These 
hominids could have eaten both abrasive and non-abrasive foods.

So, does this mean we can talk of a characteristic 'australopithecine' dietary pattern? Perhaps to some extent, but while the australopithecines shared many features in common, they also differed from one another, suggesting a change in diet through time. Such morphological changes occurred as a mosaic, much as that seen for locomotor anatomy.

Much of the evidence for Ardipithecus ramidus is not yet available, but despite its thin molar enamel and absolutely smaller teeth than those of later hominids, it shows molar size proportions that may hint at dietary changes to come. Australopithecus anamensis shows the first indications of thicker molar enamel in a hominid, and its molar teeth were equivalent in size to those of A. afarensis. Still, its mandibular corpus is intermediate in robusticity between those of living great apes and later australopithecines. This combination of features suggests that $A$. anamensis might have been the first hominid to be able to withstand effectively the functional demands of hard and perhaps abrasive objects in its diet, whether or not such items were frequently eaten or only an important occasional food source. Australopithecus afarensis was similar to A. anamensis in relative tooth sizes and probably enamel thickness, yet it did show a large increase in mandibular robusticity. This may be due to changes in peak force magnitude or degree of repetitive loading in mastication. Either way, hard and perhaps abrasive foods may have become even more important components of the diet of A. afarensis. Australopithecus africanus shows yet another increase in postcanine tooth size, which by itself would suggest an increase in the sizes and abrasiveness of foods. However, its molar microwear does not show the degree of pitting one might expect from a classic hard-object feeder. As the subsequent 'robust' australopithecines do show such patterns, the divergence of Paranthropus probably represents another substantial dietary change, with even greater specialization on hard, abrasive foods.

In sum, diet was probably an important factor in the origin and early evolution of our family. The earliest australopithecines show a unique suite of diet-related features unlike those of Miocene apes or living hominoids. Such features suggest that the earliest hominids may have begun to experiment with harder, more brittle foods at the expense of softer, tougher ones early on. This does not mean that all of the australopithecines were specialized hard-object feeders.

Still, such foods probably became increasingly important in hominid diets through the Pliocene, culminating in the specializations seen in Paranthropus. Another important aspect of early hominid trophic adaptations is evident from data presented here - the dietary shift from apes to early hominids did not involve an increase in the consumption of tough foods, and so the australopithecines were not pre-adapted for eating meat.

\section{Environmental Dynamics}

Investigators have tried to relate patterns of hominid evolution with patterns of climatic change for some time (see for example Vrba,1995; Potts, 1996). The focus of recent work has been on the origin of the genus Homo. Can the dietary shifts in the earliest hominids be tied to such changes? While there is some evidence of large-scale climatic changes around the Mediterranean (Bernor, 1983) and unusual faunal turnover in parts of western Asia (Barry, 1995), there are no large-scale changes evident in sub-Saharan Africa until after the earliest hominids have come and gone (1.5-2.5 Ma). There is the slow and inexorable cooling and drying of the Miocene, but perhaps the crucial resultant of that was the increase in microhabitat variability. In other words, after Ardipithecus, the early hominids are almost always found in lake and river margin habitats, often in the vicinity of a mixture of woodland and bushland and even grassland. In such a land of variable opportunities, the generalized craniodental tool kit of the very earliest hominids may have had a distinct advantage. 
Journal of Human Evolution, 19, 397-422.

Alpagut, B., Andrews, P., Fortelius, M., Kappelman, J., Temizsoy, I., Çelebi, H. \& Lindsay, W. (1996). A new specimen of Ankarapithecus meteai from the Sinap Formation of central Anatolia. Nature, 382, 349-51.

Andrews, P. (1978). A revision of the Miocene Hominoidea of East Africa. Bulletin of the British Museum (Natural History), 30, 85-224.

Andrews, P. \& Martin, L. (1991). Hominoid dietary evolution. Philosophical Transactions of the Royal Society, London, B, 334, 199-209.

Barry, J.C. (1995). Faunal turnover and diversity in the terrestrial Neogene of Pakistan. In: Paleoclimate and Evolution, with Emphasis on Human Origins, eds, E.S. Vrba, G.H. Denton, T.C. Partridge \& L.H. Burckle, pp.115-34. New Haven: Yale University Press.

Begun, D.R. \& Güleç, E. (1998). Restoration of the type and palate of Ankarapithecus meteai: Taxonomic and phylogenetic implications. American Journal of Physical Anthropology, 105, 279-314.

Beynon, A.D. \& Wood, B.A. (1986). Variations in enamel thickness and structure in East African hominids. American Journal of Physical Anthropology, 70, 177-93.

Beynon, A.D., Dean, M.C. \& Reid, D.J. (1991). On thick and thin enamel in hominoids. American Journal of Physical Anthropology, 86, 295-309.

Bonis, L. de \& Melentis, J. (1984). La position phylétique d'Ouranopithecus. Courier Forschungsinstitut Senckenberg, 69, 13-23.

Coffing, K., Feibel, C., Leakey, M. \& Walker, A. (1994). Four-million-year-old hominids from East Lake Turkana, Kenya. American Journal of Physical Anthropology, 93, 55-65.

Conroy, G.C., Pickford, M., Senut, B., Van Couvering, J. \& Mein, P. (1992) Otavipithecus namibiensis, first Miocene hominoid from southern Africa. Nature, 356, 144-48.

Daegling, D.J. \& Grine, F.E. (1991). Compact bone distribution and biomechanics of early hominid mandibles. American Journal of Physical Anthropology, 86, 321-39.

Daegling, D.J. \& Grine, F.E. (1994). Bamboo feeding, dental microwear, and diet of the Pleistocene ape Gigantopithecus blacki. South African Journal of Science, 90, 527-32.

Dumont, E.R. (1995). Enamel thickness and dietary adaptation among extant primates and chiropterans. Journal of Mammalogy, 76, 1127-36.

Dunbar, R.I.M. (1976). Australopithecine diet based on a baboon analogy. Journal of Human Evolution, 5, 161-67.

Gantt, D.G. (1986). Enamel thickness and ultrastructure in hominoids: with reference to form, function, and phylogeny. In: Comparative Primate Biology. Volume 1. Systematics, Evolution, and Anatomy, eds, D.R. Swindler \& J. Erwin, pp. 45375. New York: Alan R. Liss.

Grine, F.E. (1981). Trophic differences between "gracile" and "robust" australopithecines: a scanning electron microscope analysis of occlusal events. South African Journal of Science, 77, 203-30.

Grine, F.E. (1986). Dental evidence for dietary differences in Australopithecus and Paranthropus: a quantitative analysis of permanent molar microwear. Journal of Human Evolution, 15, 783-822.

Grine, F.E. \& Martin, L.B. (1988). Enamel thickness and development in Australopithecus and Paranthropus. In: Evolutionary History of the "Robust" Australopithecines, ed. F.E. Grine, pp. 3-42. New York: Aldine de Gruyter.

Hill, A. (1994). Late Miocene and early Pliocene hominoids from Africa. In: Integrative Paths to the Past: Paleoanthropological Advances, eds, R.S. Corruccini \& R.L. Ciochon, pp. 123-46. Englewood Cliffs, NJ: Prentice-Hall.

Hill, A. (1995). Faunal and environmental change in the Neogene of East Africa: Evidence from the Tugen Hills Sequence, Baringo District, Kenya. In: Paleoclimate and Evolution, with Emphasis on Human Origins, eds, E.S. Vrba, G.H. Denton, T.C. Partridge \& L.H. Burckle, pp. 178-93. New Haven: Yale University Press.

Hylander, W.L. (1975). Incisor size and diet in anthropoids with special reference to Cercopithecoidea. Science, 189, 1095-98.

Hylander, W. L. (1988). Implications of in vivo experiments for interpreting the functional significance of "robust" australopithecine jaws. In: Evolutionary History of the "Robust" Australopithecines, ed. F.E. Grine, pp.55-58. New York: Aldine de Gruyter.

Jolly, C.J. (1970). The seed-eaters: A new model of hominid differentiation based on a baboon analogy. Man, 5, 1-26.

Jungers, W. L. (1988). New estimates of body size in australopithecines. In: Evolutionary History of the "Robust" Australopithecines, ed. F.E. Grine, pp. 115-25. New York: Aldine de Gruyter.

Kay, R.F. (1981). The nut-crackers - a new theory of the adaptations of the Ramapithecinae. American Journal of Physical Anthropology, 55, 141-51.

Kay, R. F. (1984). On the use of anatomical features to infer foraging behavior in extinct primates. In: Adaptations for Foraging in Nonhuman Primates: Contributions to an Organismal Biology of Prosimians, Monkeys and Apes, eds, P.S. 
Rodman \& J.G.H.Cant, pp. 21-53. New York:Columbia University Press.

Kay, R.F. (1985). Dental evidence for diet of Australopithecus. Annual Review of Anthropology, 14, 315-41.

Kay, R.F. \& Ungar, P.S. (1997). Dental evidence for diet in some Miocene catarrhines with comments on the effects of phylogeny on the interpretation of adaptation. In: Function, Phylogeny and Fossils: Miocene Hominoids and Great Ape and Human Origins, eds, D.R. Begun, C. Ward \& M. Rose, pp. 131-151. New York: Plenum Press.

King, T.C. (1998). Dental microwear in Griphopithecus alpani. American Journal of Physical Anthropology, Supplement, 26, 139.

Leakey, M.G., Feibel, C.S., McDougall, I. \& Walker, A. (1995). New four-million-year-old hominid species from Kanapoi and Allia Bay, Kenya. Nature, 376, 565-71.

Leakey, M.G., Feibel, C.S., McDougall, I., Ward, C. \& Walker, A. (1998). New specimens and confirmation of an early age for Australopithecus anamensis. Nature, 393, 62-66.

Lovejoy, C.O. (1975). Biomechanical perspectives on the lower limb of early hominids. In: Primate Functional Morphology and Evolution, ed. R.L. Tuttle, pp. 291-326. The Hague: Mouton.

Lucas, P.W., Corlett, R.T. \& Luke, D.A. (1986). Postcanine tooth size and diet in anthropoid primates. Zeitschrift für Morphologie und Anthropologie, 76, 253-76.

Lucas, P.W. \& Peters, C.R. (2000). Function of postcanine crown shape in mammals. In: Development, Function and Evolution of Teeth, eds, M.F. Teaford, M.M. Smith, \& M.W.J. Ferguson, pp. 282-289. Cambridge: Cambridge University Press.

Lucas, P.W. \& Teaford, M.F. (1994). Functional morphology of colobine teeth. In: Colobine Monkeys: Their Ecology, Behaviour and Evolution, eds, A.G. Davies \& J.F. Oates, pp. 173-203. Cambridge: Cambridge University Press.

Maas, M.C. (1993). Enamel microstructure and molar wear in the greater galago, Otolemur crassicaudatus (Mammalia, Primates). American Journal of Physical Anthropology, 92, 217-33.

Macho, G.A. \& Berner, M.E. (1993). Enamel thickness of human maxillary molars reconsidered. American Journal of Physical Anthropology, 92, 189-200.

Macho, G.A. \& Thackeray, J.F. (1992). Computed tomography and enamel thickness of maxillary molars of Plio-Pleistocene hominids from Sterkfontein, Swartkrans, and Kromdraai (South Africa): An exploratory study. American Journal of Physical Anthropology, 89, 133-43.

Mahler, P.E. (1973). Metric Variation in the Pongid Dentition. Unpublished Ph.D. Thesis, University of Michigan, Ann Arbor.

Martin, L.B. (1983). The Relationships of the Later Miocene Hominoidea. Unpublished Ph.D. Thesis, University of London.

Martin, L.B. (1985). Significance of enamel thickness in hominoid evolution. Nature, 314, 260-63.

McHenry, H.M. (1984). Relative cheek-tooth size in Australopithecus. American Journal of Physical Anthropology, 64, 297-306.

McHenry, H.M. (1988). New estimates of body weight in early hominids and their significance to encephalization and megadontia in "robust" australopithecines. In: Evolutionary History of the "Robust" Australopithecines, ed. F.E. Grine, pp. 133-147. New York: Aldine de Gruyter.

McHenry, H.M. (1992). How big were the early hominids. Evolutionary Anthropology, 1, 15-20.

Meldrum, D.J. \& Kay, R.F. (1997). Nucicruptor rubicae, a new pithecin seed predator from the Miocene of Colombia. American Journal of Physical Anthropology, 102, 407-28.

Potts, R. (1996). Humanity's Descent. The Consequences of Ecological Instability. New York: William Morrow \& Co.

Puech, P.-F. \& Albertini, H. (1984). Dental microwear and mechanisms in early hominids from Laetoli and Hadar. American Journal of Physical Anthropology, 65, 87-91.

Rensberger, J.M. (1997). Mechanical adaptation in enamel. In: Tooth Enamel Microstructure, eds, W. von Koenigswald \& M. Sander, pp. 237-257. Rotterdam: A.A. Balkema.

Robinson, J.T. (1956). The Dentition of the Australopithecinae. Memoirs of the Transvaal Museum, 9, 1-179.

Ryan, A.S. \& Johanson, D.C. (1989). Anterior dental microwear in Australopithecus afarensis. Journal of Human Evolution, $18,235-68$.

Schwartz, G.T. \& Conroy, G.C. (1996). Cross-sectional geometric properties of the Otavipithecus mandible. American Journal of Physical Anthropology, 99, 613-23.

Spears, I.R. \& Crompton, R.H. (1996). The mechanical significance of the occlusal geometry of great ape molars in food breakdown. Journal of Human Evolution, 31, 517-35.

Spoor, C.F., Zonneveld, F.W. \& Macho, G.A. (1993). Linear measurements of cortical bone and dental enamel by computed tomography: Applications and problems. American Journal of Physical Anthropology, 91, 469-84.

Strait, S.G. (1997). Tooth use and the physical properties of foods. Evolutionary Anthropology, 5, 199-211.

Susman, R.L., Stern, J.T. \& Jungers, W.L. (1984). Arboreality and bipedality in the Hadar hominids. Folia Primatologica, 43, 
113-56.

Suwa, G., Wood, B.A. \& White, T.D. (1994). Further analysis of mandibular molar crown and cusp areas in Pliocene and early Pleistocene hominids. American Journal of Physical Anthropology, 93, 407-26.

Suwa, G., White, T.D. \& Howell, F.C. (1996). Mandibular postcanine dentition from the Shungura Formation, Ethiopia: Crown morphology, taxonomic allocations, and Plio-Pleistocene hominid evolution. American Journal of Physical Anthropology, 101, 247-82.

Teaford, M.F. (1988). A review of dental microwear and diet in modern mammals. Scanning Microscopy, 2, $1149-66$.

Teaford, M.F. \& Walker, A.C. (1984). Quantitative differences in dental microwear between primate species with different diets and a comment on the presumed diet of Sivapithecus. American Journal of Physical Anthropology, 64, $191-200$.

Ungar, P.S. (1994). Patterns of ingestive behavior and anterior tooth use differences in sympatric anthropoid primates. American Journal of Physical Anthropology, 95, 197-219.

Ungar, P.S. (1996). Relationship of incisor size to diet and anterior tooth use in sympatric Sumatran anthropoids. American Journal of Primatology, 38, 145-56.

Ungar, P.S. (1996). Dental microwear of European Miocene catarrhines: evidence for diets and tooth use. Journal of Human Evolution, 31, 335-66.

Ungar, P.S. (1998). Dental allometry, morphology and wear as evidence for diet in fossil primates. Evolutionary Anthropology, 6, 205-17.

Ungar, P.S. \& Grine, F.E. (1991). Incisor size and wear in Australopithecus africanus and Paranthropus robustus. Journal of Human Evolution, 20, 313-40.

Ungar, P.S. \& Kay, R.F. (1995). The dietary adaptations of European Miocene catarrhines. Proceedings of the National Academy of Sciences, USA, 92, 5479-81.

Ungar, P.S., Kay, R.F., Teaford, M.F. \& Walker, A. (1996). Dental evidence for diets of Miocene apes. American Journal of Physical Anthropology, Supplement, 22, 232-33.

Vrba, E.S., Denton G.H., Partridge, T.C. \& Burckle, L.H. (eds.) (1995). Paleoclimate and Evolution, with Emphasis on Human Origins. New Haven: Yale University Press.

Ward , C., Leakey, M. \& Walker, A. (1999). The new hominid speices Australopithecus anamensis. Evolutionary Anthropology, 7, 192-205.

White, T.D., Suwa, G. \& Asfaw, B. (1994). Australopithecus ramidus, a new species of early hominid from Aramis, Ethiopia. Nature, 371, 306-12.

Wolpoff, M.H. (1973). Posterior tooth size, body size, and diet in South African gracile australopithecines. American Journal of Physical Anthropology, 39, 375-94.

Wood, B.A. (1991). Koobi Fora Research Project. Volume 4: Hominid Cranial Remains. Oxford: Clarendon Press.

Wood, B.A. (1995). Evolution of the early hominin masticatory system: mechanisms, events and triggers. In: Paleoclimate and Evolution, with Emphasis on Human Origins, eds, E.S. Vrba, G.H. Denton, T.C. Partridge \& L.H. Burckle, pp. 439 448. New Haven: Yale University Press.

Wood, B.A. \& Abbott, S.A. (1983). Analysis of the dental morphology of Plio-Pleistocene hominids. I. Mandibular molars: crown area measurements and morphological traits. Journal of Anatomy, 136, 197-219.

Yamashita, N. (1998). Functional dental correlates of food properties in five Malagasy lemur species. American Journal of Physical Anthropology, 106, 169-88. 


\section{Francisco Aboitiz}

Programa de Morfología

Instituto de Ciencias Biomédicas

Facultad de Medicina

Universidad de Chile.

P.O. Box 70079

Santiago 07, Chile.

Keyword: Brain size, Broca's area, Frontal lobe, Language, Wernicke's area, Working memory

\section{Size and Complexity of the Brain in Human Evolution}

\begin{abstract}
There are two characteristics of the human brain that distinguish it from other primate brains: its large relative and absolute size, and the capacity for language that is localized in specialized regions of the brain and which results from the elaboration of specific neurocognitive networks in the cerebral cortex. Increase in the size of the human brain results mostly from a process called active growth, which is a consequence of selection for increased cognitive and behavioral capacity. Concomitant with this increase in size, the connectivity of the human brain may have developed from a large-scale network of cortico-cortical connections that also exists in the non-human primate and is essential for the organization of behavior. In the hominid lineage this system may have been co-opted for the development of language. In fact, the anatomical organization of language-related areas in the human brain closely fits the large-scale arrangement of the temporoparietal-prefrontal connections in the monkey. Although our brain is much larger than that of any other primate, and some connectional rearrangements must have taken place in the hominid lineage, it is important to consider that its overall organization is in several respects rather conservative in relation to the brains of other primates.
\end{abstract}

\section{Introduction}

Our species is characterized by its intellectual abilities and particularly by the capacity to learn language. The origin of these capacities has been a matter of controversy since the very beginnings of evolutionary theory. Here I will address some unanswered questions on this topic such as (i) is there or is there not a relation between brain size and cognitive/linguistic capacities?; and (ii) what is the difference between our brain and that of other primates besides the difference in size?

The first question concerns the size of the brain. Considering the high degree of encephalization (brain size in relation to body size) of hominids, the most frequent assumption is that the origins of human cognitive and linguistic abilities are somehow associated with the increase in brain size. However, it is not clear if increases in brain size automatically produce an increase in cognitive capacity. The second question relates to the possibility that there is some unique type of connectivity that distinguishes the human brain from the rest of the primates. The structuralist linguistic approach (Chomsky, 1978) suggests that there is a unique 'language organ' in the human brain, which cannot have been produced by natural selection and is responsible for most of our species-specific capacities. In my view, this position is inconsistent with current neuroanatomical evidence.

Although admittedly we may still have a long wait for direct answers to these questions, my intention in this paper is to propose a perspective based on recent neuroanatomical studies, which implies that our cognitive capacities and language can be seen as gradually emerging from the organization of an ancestral primate-like brain through a dual process in which there has been both an 
expansion of neural space (increase in brain size) and a rearrangement of the connectivity. However, such rearrangements are not considered to be so dramatic as to imply that the organization of the human brain has no forerunners in primates.

\section{Is brain size related to cognitive capacity?}

I have proposed before (Aboitiz, 1996) that there are two different modalities of increase in brain size in evolution: passive and active growth. The former is the most common, and occurs as a consequence of generalized increases in body mass. The brain is not exempt from the regulation of cell proliferation that occurs in the rest of the animal. So, if the animal becomes bigger, the brain also becomes bigger. One model (Riska \& Atchley, 1985) implies that most brain growth is determined in the prenatal period. In larger mammals, the period of postnatal growth becomes more important in determining final body size, while prenatal growth becomes relatively less important. This results in larger animals tending to have relatively smaller brains. This type of growth is not necessarily associated with increases in brain processing capacity because it is not related to the specification of neural circuits. The second modality, active growth, results from selection for processing capacity. In this type of growth, the most important aspect is the generation of neuronal rearrangements that will produce enhanced plasticity and more refined neuronal maps. Increase in brain size results in more brain space to perform such rearrangements and is therefore favoured by natural selection. In other words, the increase in processing capacity is not due so much to size per se, or to the higher number of processing units. Rather, the increase in neural space results in better opportunities to develop connective rearrangements, which are responsible for higher processing capacities.

There has been some recent controversy as to whether the different brain components may increase in size independently of each other, or if the distinct parts are correlated in their growth, resulting in a coordinated increase in size of the distinct brain regions (for example, see Finlay \& Darlington, 1995; Barton et al., 1995). I proposed (Aboitiz, 1996) that in passive growth, which is the most common type of evolutionary increase in brain size, the brain tends to grow as a whole since there is no particular pressure to increase the size of any component over the others. In the case of active growth (which is far less common), I initially suggested that specific brain components would be favoured, since usually the behavioral or perceptual tasks that are under selection are being programmed or processed in specific brain parts. These parts should therefore be the targets of more intense selective pressure than other brain parts. There are some examples of disproportionate growth of specific brain structures, which can be related to active growth (Pirlot, 1987; Stephan et al., 1991; Barton et al., 1995; Aboitiz, 1996; Rilling \& Insell, 1998: Barton, 1998). However, in many cases the observed species differences in relative size of the distinct brain parts are not too dramatic, and some methodological problems in statistics have been claimed (for details, see Finlay et al., 1998). Further studies are needed to determine more precisely to what extent and in which instances the distinct brain parts may grow independently of one another if they do.

\section{Increase in size of the human brain}

Humans have the largest brain of all known primates, in both absolute and relative terms. There is agreement that this increase in brain size has mostly resulted from selection for increased cognitive abilities (active growth). Evidence indicates that the relative size of the human cerebral cortex does not deviate dramatically from the proportions observed in other primates. That is, although we have a larger neocortex, and an even larger proportion of neocortical tissue than other primates, this increase is what is to be expected for a primate with a brain size similar to ours (B.L. Finlay and R.B. Darlington, pers. comm.). In other words, our cortical development follows the trend observed in all primates toward increasing the relative amount of neocortex.

The development of specific cortical areas may, however, differ in humans in relation to other primates. Deacon (1990) has reported that humans differ from other primates in having higher 
proportions than expected of association cortex in relation to sensory/motor cortices (and also in the increased volume of laminar - cerebral plus cerebellar cortices, as compared to non-laminar structures - the rest of the brain). More recently, Holloway et al. (1998) also indicate that the relative size of the primary visual cortex is quite diminished in humans relative to other primates, being less than expected for a primate with our brain size. This suggests that in the human lineage a significant reorganization of the posterior parietal and temporal lobes has taken place. This concept is consistent with comparative analyses of the visual cortices in primates, showing differential development of the color-sensitive area V4 in nocturnal and diurnal primates. This produces as a consequence diverse topographical arrangements of other visual areas like the motion-sensitive area MT (Kaas, 1993). Likewise, changes in the relative development of particular cortical areas may well have taken place in the hominid lineage.

The prefrontal cortex (located in the front of the brain and related to the control of complex behaviors and emotional impulses) is a controversial case. It has been claimed that the prefrontal cortex is particularly developed in the human brain (particularly the lateral prefrontal cortex that includes area 46; see Fig. 1; Preuss, 1995). However, Jerison (1997) has argued that in humans the prefrontal cortex follows typical primate trends. He claims that, although our prefrontal cortex is larger, even in relative terms, than that of other primates, its size corresponds to what is expected for a primate with our brain size. (However, Jerison plotted prefrontal cortex volume against total brain size; the latter includes as a significant component the size of prefrontal cortex itself, which may have artificially minimized the differences between humans and other primates.)

The evidence thus suggests that in our species, the increase in brain size has been associated with at least some reorganization in terms of the relative development of some cortical regions, although it still remains to be determined how significant this reorganization has been. However, perhaps more important than the relative development of distinct components, the increase in overall brain size may have been directly favouring the development of specific patterns of connectivity (as occurs in active brain growth; Aboitiz, 1996). Below, I will discuss some aspects of the connectivity of the primate brain and its possible relation with the human.

\section{Brain connectivity: the origin of language from a working memory network}

As mentioned earlier, the structuralist linguistic approach, championed by Noam Chomsky (1978), denies the origin of language through natural selection and proposes the existence of a 'language organ' in the human brain that has no parallel in other brain structures or in the brains of other primates. On the other hand, Aboitiz \& García (1997) proposed that the neuroanatomical substrate for language, consisting of a posterior Wernicke's area (related to cytoarchitectonic area Tpt; see Fig. 1), an anterior Broca's area (related to Brodmann's areas 44/45), and their corticocortical connections, has important similarities with widespread neural networks connecting temporoparietal and prefrontal regions that exist in other brain regions and in the brain of other primates. Such networks participate in what has been denominated 'working memory' (Baddeley, 1986), a kind of short-term memory that permits one to maintain 'on-line' cognitive and sensory information that is being used for immediate or for shortterm behavior (for example, the memory used by a waiter to remember the orders in a restaurant). Working memory can be of several kinds, one of which is linguistic (short-term memory for words). The neural systems that participate in this kind of working memory in large part correspond to the language areas and their connections. Of particular interest is the supramarginal gyrus that contains area 40 (Fig. 1), that has been claimed to transiently store a representation of the sound of words, which is to be posteriorly rehearsed in the anterior Broca's area (Fig. 1; see Aboitiz \& García, 1997).

The circuit involved in linguistic working memory therefore fits closely the anatomy of the language areas in the brain. Aboitiz \& García (1997) have postulated that the language areas originated as a specialized working memory device for transiently storing and retrieving complex phonological utterances, that were of behavioral significance in the complex social system of primitive hominids. 


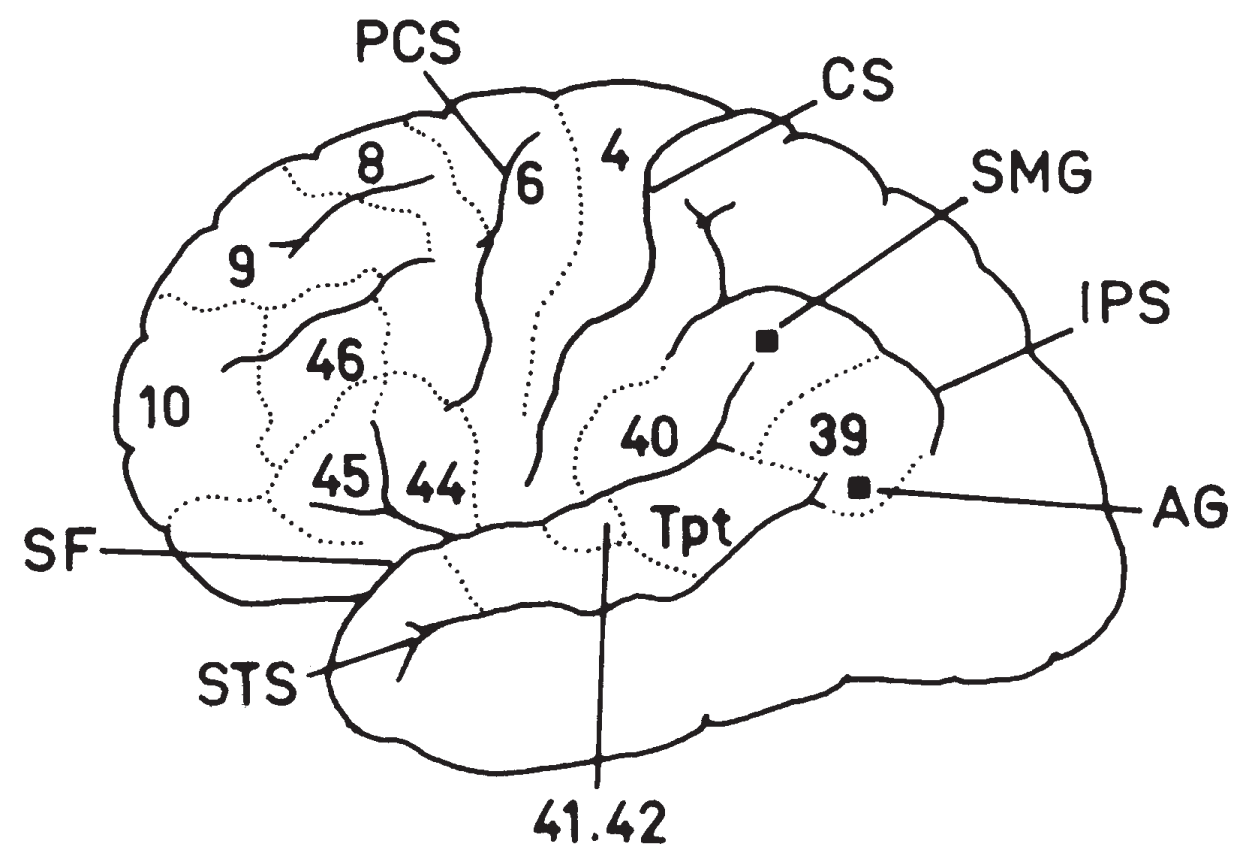

Figure 1. Diagram of a human brain (left hemisphere), showing the location of the language areas described in this article. Broca's area corresponds to Brodmann's areas 44/45; and Wernicke's area has been proposed to correspond to area Tpt. The arcuate fasciculus has been proposed to connect anterior and posterior language regions but the details of its connections have not yet been elucidated. Area 40 in the inferior parietal lobe has recently been found to be involved in short-term memory for language.

Abbreviations: AG, angular gyrus; CS, central sulcus; IPS, intraparietal sulcus; PCS, precentral sulcus; SF, sylvian fissure; SMG, supramarginal gyrus; STS, superior temporal sulcus.

Such complicated phonological sequences were probably learned by imitation in infancy and became increasingly complex as the social interactions became more elaborate. A sophisticated working memory system became necessary in order to produce a sensorimotor loop that internally rehearsed these utterances while they were learned. This sensorimotor loop eventually differentiated as an anatomically delimited system, defining a primordial language apparatus in the cerebral cortex. Progressive interaction between this incipient language device and other regions in the posterior, sensory and association cortices, and also with other prefrontal areas (particularly the dorsolateral prefrontal cortex) permitted the generation of a complex reference system to objects and actions, establishing a primitive lexicon and its associated syntactic rules. A somewhat similar scenario to this has been proposed also by Lieberman (1991), but he does not emphasize the role of working memory as do Aboitiz \& García (1997).

\section{Conclusion}

In this paper I have suggested that the origin of the human brain has consisted of the coordinated operation of two main processes: one (i) an increase in brain size, which by providing more neural space for connectional rearrangements, (ii) promoted the elaboration of pre-existing macroscopic neural 
networks into specific short-term memory devices that participated in the learning of increasingly complex phonological sequences. Finally, these sequences elaborated into a primordial linguistic communication system. Contrary to other perspectives, it is argued that language can be seen as gradually emerging as a consequence of natural selection in the human brain, and does not necessarily have to be considered an isolated system, or a system with no precursors in the brain. This view also claims that, although significant connective rearrangements have taken place in the human brain, these are kept within a general framework that characterizes the primate brain: the maintenance of a macroscopic system of neural projections that connect the sensory cortices and the frontal lobe, which participates in short-term memories and in the organization of behavior.

\section{Acknowledgements}

I am most grateful to Ricardo García, Daniver Morales and Guillermo Soto, who reviewed early drafts of this manuscript and contributed several suggestions. Supported by FONDECYT grant 1970294 and by a donation from EMEC S.A. and ENAEX S.A. to Francisco Aboitiz.

\section{References}

Aboitiz, F. (1996). Does bigger mean better? Evolutionary determinants of brain size and structure. Brain, Behavior and Evolution, 47, 225-45.

Aboitiz, F. \& García, R. (1997). The evolutionary origin of the language areas in the human brain. A neuroanatomical perspective. Brain Research Reviews, 25, 381-96.

Baddeley, A.D. (1986). Working Memory. Oxford: Clarendon Press.

Barton, R.A. (1998). Visual specialization and brain evolution in primates. Proceedings of the Royal Society of London (B), 265, 1933-37.

Barton,R.A., Purvis, A. \& Harvey, P.H. (1995). Evolutionary radiation of visual and olfactory brain systems in primates, bats and insectivores. Philosophical Transactions of the Royal Society, London, B 348, 381-92.

Chomsky, N. (1978). Rules and Representations. New York: Columbia University Press.

Deacon, T.W. (1990). Fallacies of progression in theories of brain size evolution. International Journal of Primatology, 11, 193-236.

Finlay, B.L. \& Darlington, R.B. (1995). Linked regularities in the development and evolution of mammalian brains. Science, 268, 1578-84.

Finlay, B.L., Jersman, M.N., \& Darlington, R.B. (1998). Patterns of vertebrate neurogenesis and the paths of vertebrate evolution. Brain, Behavior and Evolution, 52, 232-42.

Holloway, R.L., Gannon, P., Broadfield, D. \& Yuan, M. (1998). The parietal lobe in hominid evolution: newer evidence from chimpanzee brains. In: Dual Congress 1998 (International Association for the Study of Human Palaeontology and the International Association of Human Biologists). Abstracts of Contributions, ed. M.A. Raath, H. Soodyall, D. Barkhan, K.L. Kuykendall \& P.V. Tobias, p.28. Johannesburg: Dual Congress Organising Committee.

Jerison, H.J. (1997). Evolution of prefrontal cortex. In: Development of the Prefrontal Cortex. Evolution, Neurobiology and Behavior, ed. N.A. Krasnegor, G.R. Lyon, \& P.S. Goldman-Rakic, pp. 9-26. London: Paul H. Brookes.

Kaas, J.H. (1993). The organization of visual cortex in primates: problems, conclusions, and the use of comparative studies in understanding the human brain. In: Functional Organisation of the Visual Cortex, ed. B. Gulyás, D. Ottoson \& P.E. Roland, pp. 1-11. Oxford: Pergamon Press.

Lieberman, P. (1991). Uniquely Human. Chicago: University of Chicago Press.

Pirlot, P. (1987). Contemporary brain morphology in ecological and ethological perspectives. Journal für Hirnforschung, 28, 145-211.

Preuss, T. (1995). The argument from animals to humans in cognitive neuroscience. In: The Cognitive Neurosciences, ed. M.S. Gazzaniga, pp.1227-41. Cambridge (Mass.): MIT Press.

Rilling, J.K. \& Insel, T.R. (1998) Evolution of the cerebellum in primates: differences in relative volume among monkeys, apes and humans. Brain, Behavior and Evolution, 52, 308-14.

Riska, B. \& Atchley, W.R. (1985). Genetics of growth predict patterns of brain-size evolution. Science, 251, 56568.

Stephan, H., Baron, G. \& Frahm, H.D. (1991). Comparative Brain Research in Mammals. Vol. 1. Insectivora. New York: Springer-Verlag. 


\section{Sergio U. Dani}

\author{
Laboratory of Gerontogenetics and Gene \\ Therapy \\ Medical School \\ University of São Paulo Ribeirão Preto, \\ Brazil
}

Keywords: brain aging, brain size increase, longevity, human evolution

\section{Neural Aspects of Aging, Longevity and Expectation of Life}

\begin{abstract}
Nerve cell metabolic adaptations predict not only the size and complexity of brain substructures that determine the increased complexity of function and intelligence that characterize the brainbehavioral relationships in a given species, but also the longevity or resistance to failure of the species. During hominid evolution, there appears to be common metabolic basis to account for three distinguished hominid adaptations, namely: encephalization, neoteny, and increased longevity. Encephalization and longevity in the human species are largely determined by the creation of an excess of neural cells during embryonal development, followed by conservative growth of neurons after birth. Since nerve cells are highly active metabolically, marked encephalization, by increasing brain size relative to the rest of the body, effectively leads to diminution of bodily resources: the brain's demands are met during encephalization at the expense of the nutrients that would otherwise be available to the rest of the body. The brain being an effective nutrient sink, causes a steady nutrient restriction to the rest of the body. To our knowledge, nutrient restriction is the only method for significantly increasing longevity and expectation of life in a wide range of metazoa, including mammals. Thus, encephalization has the property to enhance longevity by promoting nutrient restriction to the body. This accounts for the retardation of growth and maturation - neoteny - and increased life span. Prolongation of life span would then elicit more directed selection for enhanced longevity. It is conceivable that nutrient surplus in modern societies can overwhelm some of these branmetabolic adaptations, precipitating the onset of age-related conditions such as diabetes mellitus and Alzheimer's diseases.
\end{abstract}

At the outset, I wish to thank Professor Phillip Tobias for inviting me to take part in the Dual Congress, and also because it was in a series of letters exchanged with Professor Tobias that I found the motivation for the main ideas of this contribution. At that time I was preparing our most recent book entitled Principles of Neural Aging. As editor of the book, author and neuropathologist, I was particularly interested in the problem of how evolution of the brain could be connected with the evolution of longevity in the hominid lineage. Professor Tobias's magnificent chapter entitled 'Evolution of Brain Size, Morphological Restructuring and Longevity in Early Hominids' (Tobias, 1997) gave me the necessary insight, which I could then accommodate with my own neuropathological data and present it here in brief.

There is a very common type of neurodegeneration called 'Alzheimer-type degeneration', which is caused by the age-related accumulation of abnormal proteins within nerve cells. The abnormal deposits are histologically recognized as neuritic plaques and neurofibrillary tangles. Our group has found that morphological and quantitative evidence collected in our laboratory (Dani et al., 1994, 1997) suggests 
that the larger a nerve cell, the higher its propensity to accumulate plaques and tangles. In that work we were able to show that geographically different human populations have distinct patterns of nerve cell size distribution in their brains. Moreover, in our post-mortem material from three geographically distinct series of normal aging people, Germans, Japanese and Brazilians, there was a positive correlation between higher proportions of larger nerve cells and more intense Alzheimer-type degeneration (Dani et al., 1994, 1997). In other words, the group presenting the highest incidence of plaques and tangles, in this case the German group, presented the highest proportions of large nerve cells in the hippocampus, and the lowest proportions of nerve cells of the small-size category. We then hypothesized that, with aging of the brain, there is a slowing of the metabolic capacity, which leads to slowing of protein turnover rates and deposition of abnormal, non-metabolized proteins such as neuritic plaques and neurofibrillary tangles. The severity of the metabolic disorder would correlate with nerve cell size.

When we looked at body mass of the autopsied patients, we observed that those patients presenting intense age-related neurodegeneration were also the patients with larger body mass. They had the larger brains as well, and the higher proportions of large nerve cells. These data pointed to a typical conservative change: the brain increasing its size by incrementing the size of its constituents - the nerve cells. A quite related instance of conservative change is the widely recognized secular acceleration of body size (Chamla, 1983; Haug, 1984; Sidhu et al., 1982). Through searches in the literature and direct evidence from our post-mortem material, it was not difficult to conclude that the Germans had already experienced a secular acceleration (Jolicoeur et al., 1988); the Japanese were in the middle of the process (Matsumoto, 1982; Ohyama et al., 1987), and the Brazilian group was at its beginning.

We had then the happy circumstance of having a large spectrum of body mass, nerve cell size, and neurodegeneration as a longevity parameter, when I started my letter exchange with Professor Tobias. From the palaeontological evidence addressed by Tobias (1997) I took the main support for the hypothesis that I am going to defend next. I take the liberty to quote the following which appears in Tobias' s (1997) chapter in our book Principles of Neural Aging: "The maximum life span has doubled from the earliest hominids to modern Homo sapiens, but the curve of change has not been a smooth and uninterrupted one. There seems to have been a decided drop in longevity with the emergence of Homo habilis and this was sustained through Homo erectus. The critical determinants of this drop were twofold: the dramatic and surprising increase in brain size with its enhanced metabolic demands; secondly, the untimeliness of this brain burst when the climate of Africa showed, after 2.5 Mya, a marked deterioration. Only after the stage of $H$. erectus, when encephalization had attained 70-80 percent of that of modern humans, does human longevity increase. In the late stage of hominid evolution, increases in brain size and longevity appear to go hand in hand, to reach their pinnacles in the last hundred thousand years." (Tobias, 1997, p. 171).

Here is my hypothesis of how a large, highly metabolically active brain may affect human longevity. First of all, nerve cell metabolic adaptations predict not only the size and complexity of brain substructures which determine the increased complexity of function and 'intelligence' that characterize the brain-behavioral relationships in a given species (Purves \& Lichtman, 1985; Ringo, 1991; Roth et al., 1994), but also the longevity or resistance to failure of the species. Secondly, during hominid evolution, there appears to be a common metabolic basis to account for three distinct hominid adaptations (Dani, 1997a), namely: encephalization, neoteny, and increased longevity. Encephalization and longevity in the human species are determined largely by the creation of excess neural cells during embryonic development, followed by a conservative growth of neurons after birth. Since nerve cells are highly metabolically active, marked encephalization, by increasing brain size relative to the rest of the body, effectively leads to diminution of bodily resources: the brain's demands are met during encephalization at the expense of the nutrients that would otherwise be available to the rest of the body. Finally, the brain, being an effective 'nutrient sink', causes a nutrient restriction to the rest of the body. To our knowledge, nutrient restriction is the only method for significantly increasing longevity and 
expectation of life in a wide range of Metazoa, including mammals. Thus, encephalization has the property to enhance longevity by promoting nutrient restriction to the body. This accounts for the retardation of growth and maturation - neoteny - and increased life span. Prolongation of life span would then elicit more directed selection for enhanced longevity, though always within 'accepted' limits of nutrient intake. To return to the neuropathological evidence presented above, it is conceivable that nutrient surplus in some modern societies can overwhelm some of the brain-metabolic adaptations attained during human evolution, such as saturation of the 'nutrient sink'. This would precipitate the onset of age-related conditions such as Alzheimer-type of neurodegeneration and its most dreadful consequence, Alzheimer disease (Dani, 1997b).

\section{Aknowledgement}

I wish to thank Professor Phillip Tobias for inviting me to take part in the Dual Congress, and also because it was in the series of letters exchanged with Professor Tobias in1995, mentioned in the introduction, that I found the motivation for the main ideas of this short communication.

\section{References}

Chamla, M.C. (1983). L'évolution récente de la stature en Europe occidentale (Période 1960-1980). Bull. Mém. Soc. d'Anthrop. Paris, 10, s.9, 13(2), 195-224.

Dani, S.U. (1997a). The metabolic basis of encephalization, prolonged life span and the evolution of longevity. In: Principles of Neural Aging, eds., S.U. Dani, A. Hori \& G.F. Walter, pp. 205-16. Amsterdam, Elsevier.

Dani, S.U. (1997b). Evolution, secular changes, and aging: How old is our brain? In: Principles of Neural Aging, eds., S.U. Dani, A. Hori \& G.F. Walter, pp. 217-25. Amsterdam, Elsevier.

Dani, S.U., Pittella, J.E.H., Hori, A., Bergmann, B., Stan, A. \& Walter, G.F. (1994). Different rates of neuronal degeneration: An exquisite variation of the cascade hypothesis. Dementia, 5(2),110-18.

Dani, S.U., Pittella, J.E.H., Boehme, A., Hori, A. \& Schneider, B. (1997). Progressive formation of neuritic plaques and neurofibrillary tangles is exponentially related to age and neuronal size: A morphometric study of three geographically different series of aging people. Dementia and Cognitive Geriatric Disorders, 8, 217-27.

Haug, H. (1984). Der Einfluss der sekularen Acceleration auf das Hirngewicht des Menschen und dessen änderung während der Älterung. Gegenbaurs Morphol. Jahrb., 130, 481-500.

Jolicoeur, P., Baron, G. \& Cabana, T. (1988). Cross-sectional growth and decline of human stature and brain weight in 19th-century Germany. Growth, Dev., Aging, 52, 201-06.

Matsumoto, K. (1982). Secular acceleration of growth in height in Japanese and its social background. Ann. Hum. Biol., 9, 399-410.

Ohyama, S., Hisanga, A., Inamasu, T., Yamamoto, A., Hirata, M. \& Ishinishi, N. (1987). Some secular changes in body height and proportion of Japanese medical students. American J. Phys. Anthrop., 73, 179-83.

Purves, D. \& Lichtman, J. W. (1985). Geometrical differences among homologous neurons in mammals. Science, 228, 298-302.

Ringo, J. L. (1991). Neuronal interconnection as a function of brain size. Brain Behav. Evol., 38, 1-6.

Roth, G., Blanke, J. \& Wake, D. B. (1994). Cell size predicts morphological complexity in the brains of frogs and salamanders. Proc. Natl. Acad. Sci. USA, 91, 4796-800.

Sidhu, L. S., Bhatnagar, D. P. \& Dubey, A. P. (1982). Secular trends in heights and weights of Punjabi boys. Anthrop. Anz., 40, 187-92.

Tobias, P.V. (1997). Evolution of brain size, morphological restructuring and longevity in early hominids. In: Principles of Neural Aging, eds., S.U. Dani, A. Hori \& G.F. Walter, pp. 153-74. Amsterdam, Elsevier. 


\section{R.L. Holloway ${ }^{1}$, D.C. Broadfield ${ }^{2}$, \& M.S. Yuan ${ }^{1}$}

\author{
${ }^{1}$ Dept. of Anthropology \\ Columbia University \\ NY, NY 10027 \\ ${ }^{2}$ Dept. of Anthropology \\ City University of New York, NY, NY 10036, \\ USA
}

Keywords: Brain evolution, paleoneurology, visual cortex, parietal association cortex, reorganization, Australopithecus, chimpanzees

\section{The Parietal Lobe in Early Hominid Evolution: Newer Evidence from Chimpanzee Brains}

\begin{abstract}
The evolution of the human brain has involved an intertwined process of reorganization and size increases during its 4- million year journey. While the fine details of these processes will most probably remain unknown, the broader outlines can be understood by using a judicious mixture of comparative neuroanatomy and the actual paleoneurological record from fossil hominids. One early aspect of reorganization in hominid brain evolution was the reduction of primary visual striate cortex (area 17 of Brodmann), PVC, which we can deduce from the comparative quantitative evidence in which the modern human brain has roughly $121 \%$ less PVC than expected for a primate of its brain weight. A major controversy surrounds the question: when did this reduction take place? We demonstrate here that the claims of various writers that the human brain first had to increase in size before such a reduction took place are wrong. We adduce evidence from chimpanzee brain morphology to show that reduction of PVC can occur in an animal with a smaller brain size than the earliest hominids, Australopithecus (afarensis and africanus). The neurogenetic bases for PVC are quite variable in chimpanzees and modern humans. We must assume they were also variable in our fossil ancestors. Both the Taung (A. africanus) and the Hadar 16228 (A. afarensis) specimens suggest a reduction in PVC and a concomitant increase in posterior parietal association cortex, which in turn suggests that our earliest hominid ancestors were undergoing selection for more complex cognitive behavioral repertoires than found in modern chimpanzees.
\end{abstract}

\section{Introduction}

The question of how the brain evolved during early hominid evolution will probably never be answered fully. Comparative evidence is found only among living extant primates, and the paleoneurological evidence is extremely limited, depending on interpretations of cerebral cortical surface features which invite differing and strongly held opinions (see Holloway, 1996, for reviews of these and other matters related to human brain evolution). While the situation may appear hopeless to many within human evolutionary disciplines, as judged by the lack of any consensus by various authors, this paper will argue that selective evidence from both the comparative and paleoneurological realms are of considerable importance to any understanding of how the human brain evolved in its earlier stages, and in particular how this evidence relates to issues of cortical reorganization that may have occurred prior to the 3-fold enlargement of the brain that so typifies the genus Homo ( for a synthesis between brain enlargement and reorganization, see Holloway, 1995). 


\section{The Issue}

When the volume of primary visual striate cortex (PVC, area 17 of Brodmann) is plotted against the volume of the brain minus the visual striate cortex (both in log base 10 units) for some 45 species of primates using the data of Stephan et al. (1981), it is apparent that the modern human point falls discernibly underneath the regression line for such a sample (see Fig. 1, Holloway 1992: p. 167). The correlation between these log variables is about 0.98 , and when one calculates the residual of the human value from a non-human primate regression line, the residual is about $121 \%$ less than expected; for the lateral geniculate body, the residual is $144 \%$ less than expected. No one appears to argue with the point that the comparative evidence clearly suggests a reduction in the relative amount of area 17 in the human brain relative to that of its closest relatives, the great apes, particularly the chimpanzee. Rather, the question is: when did this reduction occur in hominid evolution? The importance of this reduction is not simply that it is an example of a facet of cortical reorganization, but that a relative reduction in PVC means there would have been a relative increase in parietal cortical association area and/or possible enlargements of areas 18 and 19 of Brodmann, para- and peri-striate cortical areas of the occipital lobe of the brain, all of which have a considerably complex role in adaptive cognitive behavior (Holloway 1979, 1983b).

The issue is: did this happen prior to the enlargement of the brain in early Homo from an earlier australopithecine precursor, or did this reduction first require an enlargement in size of the overall brain? Holloway $(1983,1992)$ believes it happened by early australopithecine times (i.e., A. afarensis), and Armstrong et al. (1991), Falk (1985), and Jerison $(1984,1991)$ believe it happened after the enlargement.

\section{Evidence}

First, my colleagues and I ( Gannon et al., 1998a,b, Kheck et al., 1998) have found evidence that a human-like planum temporale (PT) asymmetry favoring the left side is strongly present in modern chimpanzee (Pan troglodytes). This is clear evidence of a shared character state in the organization of the brain that must extend back to some 5-7 Mya. While we know that the PT plays important roles in human language behavior, we are not certain what its role is in the chimpanzee. One possibility might be that gestural and other non-verbal forms of social communication between chimpanzees are more complex than we have heretofore thought. This finding, incidentally, is completely at odds with what has been the consensus view that the differences between ape and human brains are purely matters of differences in size and asymmetry (e.g., Geschwind \& Levitsky, 1968). More recently, Gannon et al. (1998b) and Kheck et al. (1998) have shown that the sylvian fissure morphometric picture is similar between Pan and Homo in this asymmetry.

Neither of these two findings directly demonstrate anything about PVC, but they do strongly suggest that certain patterns of temporal lobe cortical organization relating to cognition may have been established prior to the appearance of the genus Homo. It is possible that the PT asymmetry was independently evolved by Pan, but this is highly improbable. The most parsimonious explanation would be that these are shared characteristics, and if so, one must consider the possibility that early hominids such as australopithecines may have had these shared character states also.

More directly, however, it is well appreciated that the amount of PVC found in modern Homo is quite variable (Gilissen et al. 1995; Gilissen \& Zilles, 1995,1996), suggesting that the neurogenetic bases for ontogenetic development of PVC does vary within the species, and indeed there is some evidence that the volume of PVC is significantly larger in Australian Aborigines than in Caucasians (Klekamp et al., 1994).

If such variability existed in Pan, would it mean that the neurogenetic bases were similar? This is a difficult question, but the discovery of two modern chimpanzee brains, those of "Chuck" and "Frank" from the Yerkes regional Primate Center, strongly suggests this to be quite possible. As has been discussed elsewhere (Holloway, 1985) there is an almost invariable relationship between the morphological landmarks that help define the PVC in the great apes. The PVC is bounded anteriorly by the now infamous 
lunate sulcus (LS) and the position of the LS is usually in a significantly anterior position in pongids when compared to modern humans, in which there is seldom a clear-cut LS; when it does appear, it is far more posteriorly located in Homo. The interparietal sulcus (IP), which separates superior and inferior parietal lobules, normally abuts the lunate sulcus at the most anterior dorsal part of its curvature.

The lateral calcarine fissure usually runs diagonally from the occipital pole in a lateral and dorsal direction toward the lunate sulcus, but does not reach it. It is this pattern which appears almost invariably in pongid brains, and we are describing it once again here as this pattern is possibly present in the Hadar AL 162-28 brain endocast of $A$. afarensis. This brain endocast is of considerable interest as some of these features are apparent, although their interpretation is controversial. Figure 1a shows this basic pongid pattern.

Enter now, "Chuck" and "Frank" (see Figures 1b,c).

The brain of Frank shows that the LS is in a more posterior position than found in most adult chimpanzees. The arc distance from occipital pole (OP) to LS is usually about 30-35 $\mathrm{mm}$ in chimpanzees, but in Frank it is about $20 \mathrm{~mm}$. The IP is far more tortuous, suggesting a more complicated and folded parietal cortex. Both hemispheres show the same pattern.

Chuck is different in that the left hemisphere shows the typical anteriorly placed LS while the right hemisphere shows a posterior placement as in the case of Frank. There is no evidence of any pathology, nor any evidence of behavioral or visual problems. While this condition is surely rare (I have seen it only once in about 40 brains thus far), it does indicate that the neurogenetic basis for reduction in volume of PVC is also present in Pan. Furthermore, preliminary study of histological sections of these two chimpanzee brains indicates that the stripe of Gennari (layer 4c), which helps define the cytoarchictecture of PVC, is bounded by the LS in both chimpanzees.

If the same neurogenetic bases for variability in reduction of PVC are present in Pan and Homo, why would the australopithecines necessarily be without such variability?

Unfortunately, there are too few well-preserved australopithecine brain endocasts to speak with great confidence about lunate sulcal variability. On the other hand, two specimens in particular, the endocasts of Taung and Hadar AL 162-28, do tend to show morphological features suggesting that if a lunate sulcus did exist in this genus, it was in a non-pongid, more posteriorly located position than in the brains of today's pongids, particularly the chimpanzee. As these arguments have been presented elsewhere (e.g., Holloway 1983, 1985; Falk 1985, 1986, 1991), we will only briefly mention our major findings. Falk's (1980) placement of the 'dimple' she identified as the lunate sulcus on the Taung specimen is placed even anteriorly to where it would occur on a macaque brain, which Holloway demonstrated in 1981 using stereoplotting techniques showing the range of locations in Pan brain casts. Her location was some 2+ standard deviations anterior to the Pan average location. In addition, there is no crescentshaped dimple on the lateral surface of the Taung endocast in the zone where the average Pan lunate sulcus appears. If the Taung endocast is held in an oblique manner and one 'sights' down the lambdoid suture, one can see a depressed region all along the lambdoid sutural region. Is this depression possibly the lunate sulcus? Yes, it is possible, but we cannot prove it by any known techniques at present. This is, of course, where Dart (1925) thought the lunate sulcus was, and we still do not believe that he confused the lunate sulcus with the lambdoid suture, which Falk (1980) has claimed (this matter was reviewed in Holloway, 1984,1985). Neither Sts 60 nor Sts 5 (or other so-called 'gracile' australopiths) show a morphology that sheds any light on this controversy. Sts 5 shows no sulcal morphology in the posterior half of the brain endocast, and Sts 60 lacks the posterior part of the cerebral cortex.

In a rare moment of agreement between Falk and Holloway, the interparietal (IP) sulcus suggested by Holloway (1983) for the Hadar AL 162-28 A. afarensis specimen was accepted by Falk (1985). In all pongid brains we have examined, the posterior end of the IP generally abuts on the lunate sulcus. Holloway's 1983 article did not claim that there was a lunate sulcus on the endocast (although Falk 1985, 1986 did so claim), but that if there were one, it would be in a more human-like posterior position. 


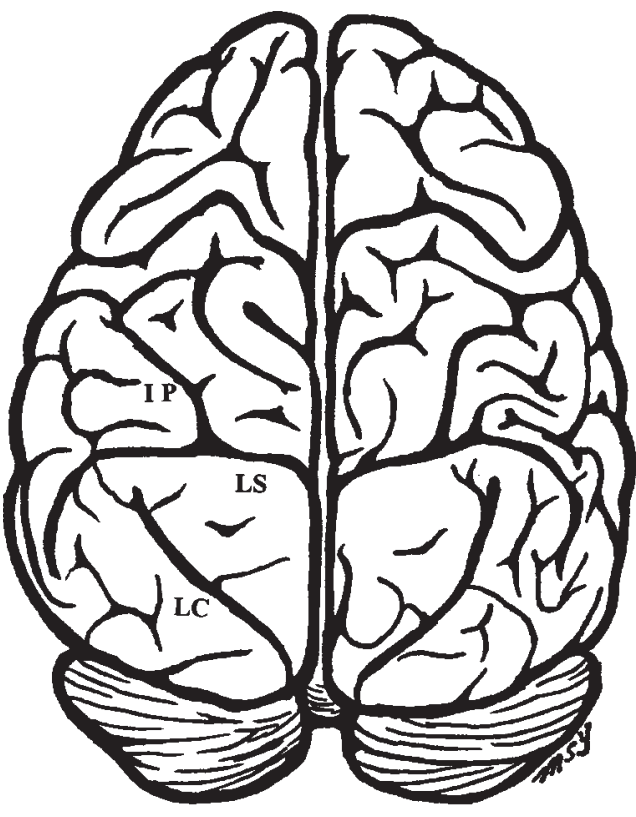

a.

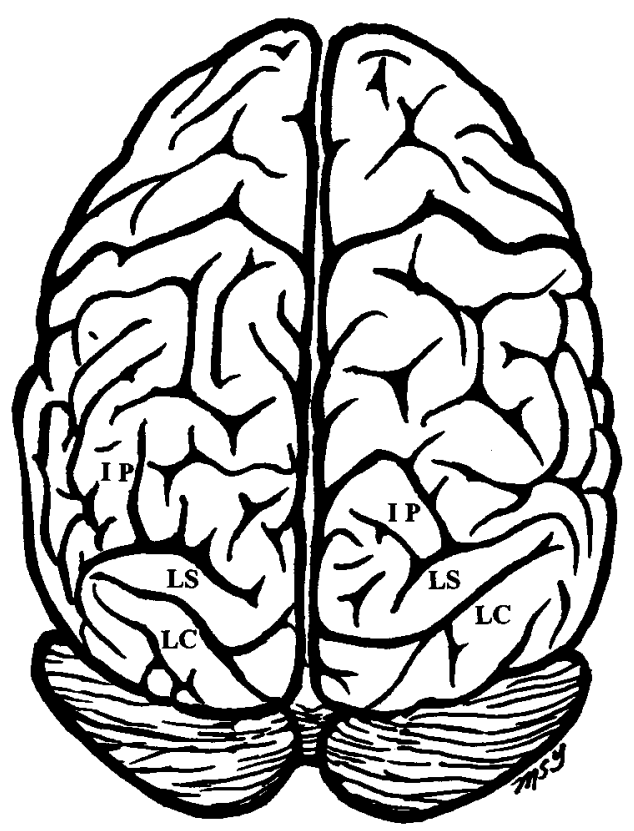

C.

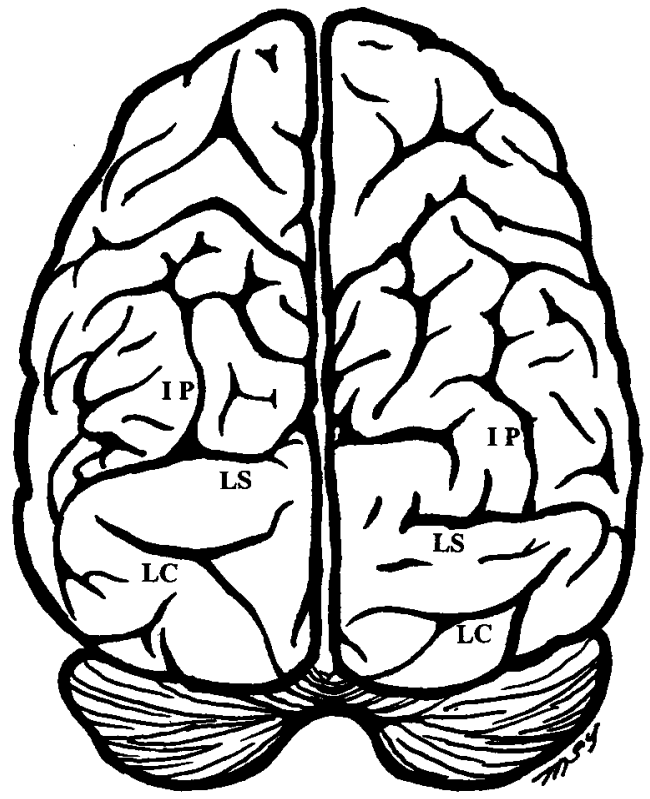

b.

Figure 1.

a; dorsal posterior view of a chimpanzee brain showing the most common morphological pattern and the relationships between the lunate sulcus (LS), the interparietal sulcus (IP), and the lateral calcarine fissure (LC).

b: same view of the chimpanzee "Chuck", showing the normal pattern on the left hemisphere (as in Figure 1a) but a significantly more posterior placement of the LS on the right side.

c: same view of the chimpanzee "Frank", showing the more posterior placement of the LS on both hemispheres. 
Holloway \& Kimbel (1986) and Holloway (1988) provided statistical arguments based on a large collection of chimpanzee brains that showed that, if the terminal end of the IP did abut on a LS, that position on the Hadar specimen would be more than 3+ SDs posterior to where it would be on chimpanzee brains, many of which were actually smaller than the Hadar 162-28 brain endocast. (See Figure 2, from Holloway 1983.)

The morphometric features on the two chimpanzee brains, Frank and Chuck, are very relevant here. The distance from the OP to the proposed posterior part of IP on the Hadar endocast is about $15.5 \mathrm{~mm}$. The mean distance for chimpanzees ( $\mathrm{N}=39$ hemispheres) is $31.5 \mathrm{~mm}$. The OP-LS distance in Frank is $22 \mathrm{~mm}$ (left) and 20mm (right). For Chuck, these distances are $35 \mathrm{~mm}$ (left) and $20 \mathrm{~mm}$ (right). Even when the two unusual chimpanzee brain measurements are included in the total chimpanzee sample, the Hadar 162-28 brain endocast shows a posterior IP position some 2.93 SDs posterior to the chimpanzee mean, and 3.49 SDs posterior if Frank and Chuck are not included. Due to shrinkage from formalin solution over the years, the chimpanzee hemispheric volumes are often less than the volume calculated for the Hadar specimen of $385 \mathrm{cc}$. We feel that this provides strong evidence that if the posterior part of

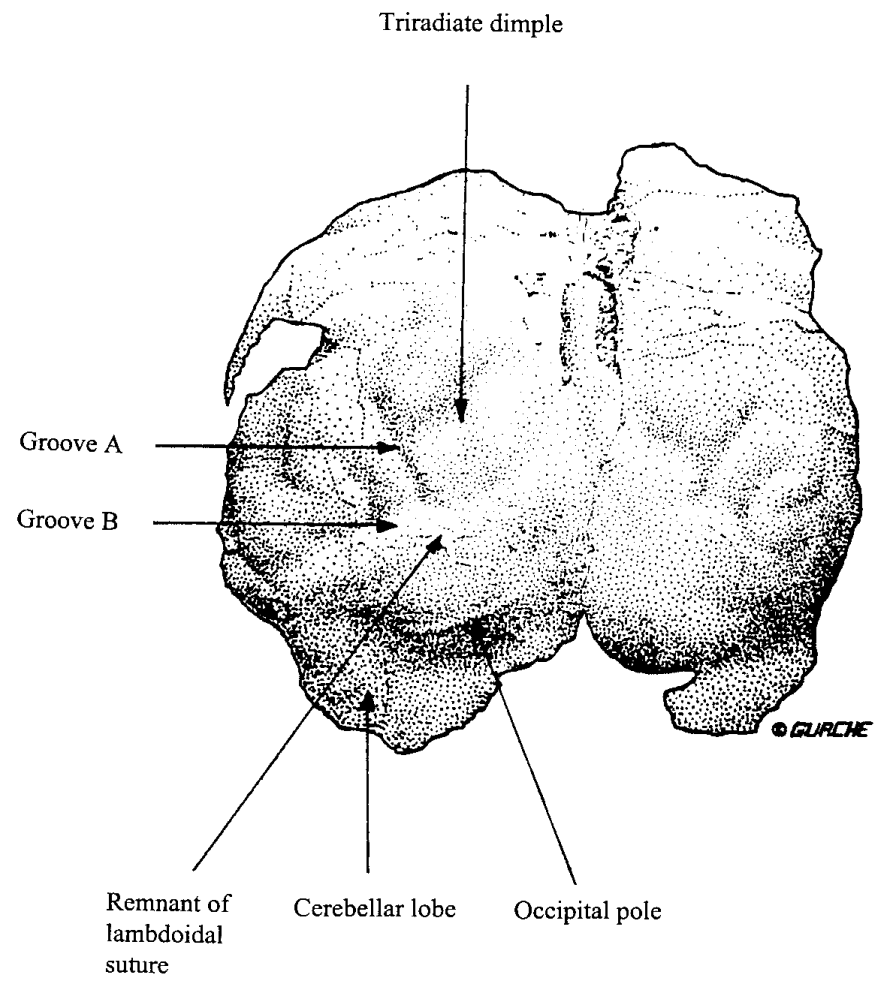

Figure 2. (From Holloway 1983: 420). Occipital view of the Hadar AL 162-28 brain endocast of A. afarensis showing the proposed gyri and sulcal patterns suggesting a more human-like posterior placement of a lunate sulcus (LS). Groove A is the interparietal sulcus (IP), and Groove B is a depression caused by the inferior lip of the posterior portion of the parietal bone. Falk has identified this groove as the lunate sulcus. The distance from the most posterior part of IP to occipital pole (OP) is $15.5 \mathrm{~mm}$, roughly half of the usual chimpanzee distance. 
IP is correctly identified on the Hadar specimen, and Falk's $(1985,1986)$ claim that the lunate is there underneath the remnant of the lambdoid suture, that 'lunate' is in a more human than pongid position.

Needless to say, the obverse part of our argument must also apply to australopithecines. That is, if there was some common form of neurogenetic basis for these morphological variations, then we must expect some of the australopithecines to have lunate sulci in a more anterior position, such as in most Pan brains. It is interesting that to date none have appeared.

Finally, one might ask why the issue and controversy are of such importance. If we are correct in our assertions that there had been some cortical reorganization well back some 3-4 Mya, such that there had been a relative increase in posterior cortical association areas, it would most likely mean that natural selection had operated on aspects of cortically-mediated adaptive behavior well before cortical brain tissue expanded to any Homo level. It means, in essence, that some critical aspects of human behavior, perhaps language, perhaps tool-making, indeed the prerequisites of a cultural adaptation, are far older than many paleoanthropologists wish to believe (Holloway 1967, 1969, 1970, 1981a). The roots of our unique adaptations are indeed far more ancient than we realize.

\section{Acknowledgments}

The authors would like to thank N.M. Kheck, P.J. Gannon, S. Marquez, and C. Sherwood for their help and comments with various phases of this research.

\section{References}

Armstrong, E, Zilles, K., Kurtis, M. \& Schleicher, A. (1991). Cortical folding, the lunate sulcus and the evolution of the human brain. J. Hum. Evol., 20, 341-48.

Dart, R.A. (1925). Australopithecus africanus: the man-ape of South Africa. Nature, 115, 195-99.

Falk, D. (1980). A re-analysis of the South African australopithecine natural endocasts. Am. J. Phys. Anthrop., 53, 525-39.

Falk, D. (1985). Hadar AL162-28 endocast as evidence that brain enlargement preceded cortical reorganization in hominid evolution. Nature, 313, 45-47.

Falk, D. (1986). Endocast morphology of Hadar hominid AL 162-28. Nature, 321, 536-37.

Falk, D. (1991). Reply to Dr. Holloway. Shifting positions on the lunate sulcus. A. J. Phys. Anthrop., 84, 89-92.

Gannon, P.J., Holloway, R.L., Broadfield, D.C. \& Braun, A.R. (1998a). Asymmetry of chimpanzee planum temporale: humanlike pattern of Wernicke's brain language area homologue. Science, 279, 220-22.

Gannon, P.J., Broadfield, D.C., Kheck, N.M., Hof, P.R., Braun, A.R., Erwin, J.M. \& Holloway, R.L. (1998b). Anatomic expression of Heschel's gyrus and planum temporale asymmetry in great apes, lesser apes and Old World monkeys. Soc. For Neuroscience, 24 (I):64.15, p. 160 (Abstract).

Geschwind, N. \& Levitsky, W.(1968). Human brain: left-right asymmetries in temporal speech regions. Science, $161,186-87$.

Gilissen, E. \& Zilles, K. (1995). The relative volume of primary visual cortex and its intersubject variability among humans: a new morphometric study. C.R. Acad. Sci., Paris, t.320, serie II, 897-902.

Gilissen, E. \& Zilles, K. (1996). The calcarine sulcus as an estimate of the total volume of the human striate cortex: a morphometric study of reliability and intersubject variability. J. of Brain Res., 37, 57-66.

Gilissen, E., Iba-Zizen, T, Stievenart, J-L, Lopez, A., Trad, M., Cabanis, E.A. \& Zilles, K. (1995). Is the length of the calcarine sulcus associated with brain size of the human visual cortex? A morphometric study with magnetic resonance tomography. J. Brain Res., 36, 451-59.

Holloway, R.L. (1967). The evolution of the human brain: some notes toward a synthesis between neural structure and the evolution of complex behavior. General Systems, 12, 3-19.

Holloway, R.L. (1969). Culture: a human domain. Current Anthropology, 10, 359-412.

Holloway, R.L. (1970). Neural parameters, hunting and the evolution of the human brain. In: Advances in Primatology, Vol. 1. ed. C. R. Noback \& W. Y. Montagna, pp. 299-309. New York: Appleton-Century-Crofts.

Holloway, R.L. (1979). Brain size, allometry, and reorganization: toward a synthesis. In: Development and Evolution of Brain Size, ed. M.E. Hahn, C. Jensen \& B.C. Dudek, pp. 59-88. New York: Academic Press.

Holloway, R.L. (1981a). Cultural symbols and brain evolution: a synthesis. Dialectical Anthropology, 5, 287-303.

Holloway, R.L. (1981b). Revisiting the S. African australopithecine endocasts: results of stereoplotting the lunate sulcus. Am. J. Phys. Anthrop., 56, 43-58. 
Holloway, R.L. (1983a). Cerebral brain endocast pattern of A. afarensis hominid. Nature, 303, 420-22.

Holloway, R.L. (1983b). Human paleontological evidence relevant to language behavior. Human Neurobiology, 2 : 105-14.

Holloway, R.L. (1984). The Taung endocast and the lunate sulcus: a rejection of the hypothesis of its anterior position. Am. J. Phys. Anthrop., 64, 285-88.

Holloway, R.L. (1985). The past, present, and future significance of the lunate sulcus in early hominid evolution. In: Hominid Evolution: Past, Present, and Future, ed. P.V. Tobias. pp. 47-62. New York: Alan R. Liss.

Holloway, R.L. (1988). 'Robust' australopithecine brain endocasts: some preliminary observations. In: Evolutionary History of the 'Robust” Australopithecines, ed. F.E. Grine. pp. 97-105. New York: Aldine-deGruyter.

Holloway, R.L. (1992). The failure of the gyrification index (GI) to account for volumetric reorganization in the evolution of the human brain. J. Human Evol., 22, 163-70.

Holloway, R.L. (1995). Toward a synthetic theory of human brain evolution. In: Origins of the Human Brain, ed. J.P Changeux \& J. Chavaillon. pp. 42-55. Oxford: Clarendon Press.

Holloway, R.L. (1996) Evolution of the human brain. In: Handbook of Human Symbolic Evolution, ed. A. Lock \& C. Peters. Chapter 4: 74-116. Oxford: Clarendon Press.

Holloway, R.L. \& Kimbel, W.C. (1986). Endocast morphology of Hadar hominid AL 162-28. Nature, $321,536$.

Jerison, H.J. (1984). Fossil evidence on the evolution of the neocortex. In: Cerebral Cortex, ed. E. Jones \& A. Peters. Vol. 8A Comparative Structure and Evolution of Cerebral Cortex, Part I. pp. 285-309. New York: Plenum.

Jerison, H.J. (1991). Brain Size and the Evolution of Mind. James Arthur Lecture on the Evolution of the Human Brain. New York: Amer. Mus. Nat. Hist.

Kheck, N.M., Gannon, P.J., Hof, P.R., Braun, A.R., Erwin, J.M., Broadfield, D.C., Yuan, M., \& Holloway, R.L. (1998). Human-like pattern of hemispheric asymmetry in planum temporale of chimpanzees. Society for Neuroscience, 24, 64.16, p. 160 (Abstract).

Klekamp, J., Reidel, A., Harper, C, Kretschmann, H.J. (1994). Morphometric study on the postnatal growth of the visual cortex of Australian Aborigines and Caucasians. J. of Brain Res., 35, 541-548.

Stephan, H., Frahm, H. \& Baron, G. (1981). New and revised data on volumes of brain structures in insectivores and primates. Folia Primatologia, 35, 1-29. 


\section{Harry J. Jerison}

Department of Psychiatry \& Biobehavioral Sciences, University of California at Los Angeles, USA

Keywords: language, Hominid evolution, neurology

\section{Adaptation and Preadaptation in Hominid Evolution}

Language as we know it could not have evolved, initially, as an adaptation for communication. Human language is peculiarly ambiguous and subject to error when compared to adaptations for communication in other animal societies. Furthermore, it encumbers an enormous mass of neural machinery, a characteristic of perceptual and cognitive neural control and not of the control of vertebrate communication systems. Finally, most mammalian communication systems are truly universal within a species, whereas isolated human populations speak in unique tongues. Human language is better understood as having begun as a way to generate perceptual/cognitive imagery, a mammalian adaptation that always depends on extensive neural networks. The issue then is to determine features in hominid evolution that required language as a novel adaptation for such imagery. My model for the adaptation is the territorial behavior of wolves, which is based on scent marking and olfactory codes and is supported by a brain system specialized for making cognitive maps. The hominid path in primate evolution exploited a wolf-like niche, but the severe reduction of normal mammalian olfactory capacity in all anthropoids had to be overcome. I will argue that human language began as a perceptual and cognitive adaptation for knowing and 'marking' a territory by non-chemical means to map an extended range. An adaptation of a perceptual/cognitive system, it has to be 'learned,' a typical feature of such a system. Language eventually evolved into the adaptation for human communication, because, despite its ambiguities, language could enable humans to share their elaborated knowledge of the external world.

\section{Introduction}

The evolution of a prehominid anthropoid into a hominid species occurred perhaps 4 or 5 million years ago, and present evidence is that we humans share our prehominid ancestor with living chimpanzees. This provides some clues about our mental origins, since we know a fair amount about the mental capacities of chimpanzees (Kummer \& Goodall, 1985; Passingham, 1982; Premack \& Woodruff, 1978). We know, for example, that we share with chimpanzees the conservation of mass as discussed by Piaget (Premack \& Kennell, 1978); the ability to make, use, and train others to use primitive tools (Boesch \& Boesch, 1983); and educability in the use of languagelike symbols (Savage-Rumbaugh et al., 1985). We also share the ability to learn to distinguish ourselves from others on the basis of fairly abstract information, such as that provided by a reflection in a mirror (Gallup, 1979), which indicates that, like us, chimpanzees have a knowledge of self.

These shared behavioral traits were presumably in the repertoire of our common ancestor, which means that we evolved from a species that had the mental capacities required by those traits. Some, but not all, of these capacities are shared with the other two great ape genera, the orangs and gorillas, as well 
as with chimpanzees, but no one has yet demonstrated that any other anthropoid primates, that is, monkeys and gibbons, possess them. The evidence is not all in on just how much is shared, nor does everyone agree on how to interpret the behavioral data as evidence of cognitive capacities, but we and the great apes appear to be closer relatives with respect to those capacities than either of us are to other anthropoids.

Among the more spectacular recent discoveries on our shared capacities has been the educability of chimpanzees and other great apes in the use of 'language.' I am as impressed as everyone else is by the remarkable performance, but I believe that the extraordinary performance of chimpanzees in languagelike activities involves different cognitive capacities than the ones we humans developed. My reactionary view (contradicting that of my friends in the ape-language field) is that our use of language is uniquely human, and I hold it on the basis of the logic of an evolutionary analysis and scenario. That is my theme.

\section{Selective Pressures for a Large Neurolinguistic System}

It begins very simply with the neurological status of language, namely that it is controlled by an enormous neocortical system. I have argued many times and can document the notion that very large neocortical systems evolved in mammals to control activity that should be described as perceptual and cognitive (e.g., Jerison, 1991, 1994). I distinguish these from three other major categories, namely learning, social behavior, and communication, which occur in all vertebrates and can be controlled by very small nervous systems. When their neural control is large, I think of perceptual-cognitive dimensions as having been added to, say, social behavior, or communication. Human language is, therefore, a priori a perceptual-cognitive adaptation.

To identify selection pressures that were effective during the prehominid-hominid transition and that were met by a language-like adaptation, I sought to identify problems of adaptation that required unusual perceptual-cognitive capacities. I recognized, of course, that those capacities would not necessarily have resembled language as we know it, although they had to evolve into such a language capacity. The role of language in human communication had to be secondary both in time and in importance according to this evolutionary analysis, since pressures for improved communication would have led to a different kind of initial adaptation, which would not have required much expansion of the brain for its control. But even in its beginnings, language may have been preadaptive for present human language and its place in communication, and it was, according to my scenario.

The first step in this evolutionary narrative is to suggest for the ancestral species an environmental niche characterized by adaptive requirements that would put unusual demands on the already large perceptual-cognitive brain system of a pre-hominid or early hominid. The environmental requirements, I propose, were in the climatic change in the Mediterranean basin, which reduced the size of the normal forest habitat for a chimpanzee-like primate species - the prehominid of my scenario. As I imagine them, some individuals of the prehominid populations were adapted to live in the desert-like or savanna region at the forest edge and were able to shift to a more carnivorous diet than that typical for primate species (cf., Pilbeam, 1984). It was in the neurogenetics of those individuals that I would identify the precursors of language.

\section{The Adaptation for Social Predation}

The niche that was available was for a carnivorous predator, but the animals that invaded it successfully were social vocal primates similar to living chimpanzees, and not members of the order Carnivora. The model of a species adapted for such a niche is the well-studied timber wolf (Peters \& Mech, 1975), a proper social carnivore, with a proper profile of morphological, neural, and behavioral adaptations for life in this niche. There are information-processing requirements for the adaptations that are fulfilled easily by wolves, which are average mammals in encephalization. But meeting those 
requirements would strain the neural processing capacity of an anthropoid primate species, despite its being more than twice as encephalized as wolves, because anthropoid primates lost the capacity to use certain critical information during the course of their evolution. My view is that the specialized information processing requirements were met in our hominid ancestors by a new adaptation that eventually evolved into human language.

The special demand of this niche is that it involves the navigation of a very large territory and range by a socially integrated group of predators to harvest prey in sufficient numbers to support the predators. In living wolves a typical territory is of the order of several hundred $\mathrm{km}^{2}$. In contrast, a typical daily range of living gorillas and chimpanzees for normal foraging may be only a few hundred square meters (Pickford, 1988). A successful predator must 'know' its territory, and this means that it must have a good cognitive map of it and remember the map's history and status. The sensory and neural equipment of wolves, in contrast to that of apes, provides the clue for the new anthropoid adaptation that was required and which appeared in our hominid ancestors.

For their adaptations as social predators, wolves have an elaborate scent-marking system coupled with 'normal' olfactory bulbs (more than 50 times the size of the almost vestigial human olfactory bulbs). Wolves are, therefore, properly recognized for their excellent olfactory sensation and perception. The brain systems receiving the olfactory information include the piriform lobes and schizocortex, and eventually the hippocampus. We know very little about how olfactory information is used in cognition, partly, of course, because we humans are peculiarly deficient in that sense modality. Our intuitions about how olfaction would work in 'normal' mammals are bound to be inadequate. Olfactory information in living carnivores is known to be sufficient to enable individuals to identify other animals individually (Brown \& Macdonald, 1985; Rasa, 1973; Roeder, 1983), and we probably should think of it as having

a role comparable to that of vision in our lives. This means that it could be used to create maps formed with edges and borders and so forth, and populated by animals and other objects - at least we should imagine this as something that can be constructed from olfactory data.

The fate of these maps in controlling action would be comparable to that of a well-remembered map in our own lives. Mapping and memory about maps are among the functions that involve important hippocampal control (Horn, 1985; Squire, 1987), and the system for wolves presumably involves significant sensory analysis of scent marks, coupled with the establishment of appropriate cognitive maps. The system would have access to all of the mapping and memory functions in which hippocampal control occurs. We should imagine the real world constructed by a wolf from olfactory information to involve input from olfactory bulbs coupled with appropriate analysis by hippocampal, paleocortical, and neocortical structures to produce a 'model of reality' that corresponds more to the one we can build from visual information than to the one we humans build (or fail to build) from odors.

\section{A Primate as a Social Predator}

There is a neurobiological problem for an anthropoid species adapting to a social predator's niche. An anthropoid primate has the right central neural machinery for the adaptation - appropriately large hippocampus and related structures. But because the system as a whole in all mammals is normally coupled peripherally to the olfactory bulbs, it would be unlikely to work as well when coupled with the almost vestigial olfactory bulbs of anthropoids. (The adaptational problem is like that of a species with vestigial eyes and retina, evolving under selection pressures to have access to the central visual system.) A solution to the adaptational problem could take advantage of the fact that the hippocampus, which may be thought of as a neural central processing unit in the brain's control of the required cognitive adaptation, is a polysensory structure that can be accessed by other senses. My idea is that the transition to the hominid grade was correlated with the evolution of other peripheral access to the cognitive system that controls a predator's mapping of its range. The other access, I propose, was primarily by the use of the auditory-vocal channel, which is highly developed in anthropoid primates. 
It is an odd picture, but I think it works. Instead of urinating and sniffing (the scent-marking and sensing that wolves do), we can imagine our ancestor as marking with sounds and sensing the sounds talking to itself, as it were, but in primitive tongues. The picture is odd, but no odder than another use of an auditory-vocal channel that evolved in some cetaceans and in insect-eating bats, in which echoes from vocalizations are used in the elaborate sonar system that evolved in these species, and from which they construct and know the external world. The picture for our ancestors would be adequate for access to the cognitive systems for mapping and remembering important features of the external world, that is, for knowing that world. The vocalizations could be with a very small vocabulary. A model for that might be the three 'word' vocabulary of vervets to signal the presence of eagles, or leopards, or snakes. The hominid vocabulary would have to be larger to encode relevant environmental features, and less frenetic, not a 'danger signal' that commanded escape but a 'knowledge signal' that helped construct a map of the world.

The suggestion is, in summary, that an auditory-vocal system was established for marking and knowing a territory or range, that this system sent information to appropriate old-brain and neocortical systems, and that the information was integrated with other knowledge of the external world. (An important peculiarity of the system, only interjected here but worth much more discussion, would be that even at its 'sense-data' stage, this system would be neocorticalized, because it would appear in a species in which the sensing and marking 'vocabulary' was already neocorticalized.) It would be a new perceptual-cognitive system. This new 'language-sense' would interact with the very elaborate older mammalian systems that are based on vision and touch and other senses. The older systems enable chimpanzees to be so much like humans in so many ways, but we humans probably know only in a distorted way the perceptual world that is generated by those systems. Our own knowledge of the external world is elaborated by the language dimension - built not only from sensory mappings that we share with other anthropoids as well as most mammals, but by important inputs to the mapping that comes from our language 'sense' as it has evolved in Homo sapiens.

This scenario offers a solution to an adaptational problem: how an anthropoid can succeed as a social predatory mammalian species without normal olfactory bulbs. It also has implications for other aspects of hominid evolution, because it describes a new cognitive system that is obviously usable for communication with conspecifics. Communication with the auditory-vocal channel is common in primates, as warning calls and other social messages that elicit a variety of behaviors. The communication by hominids using their range-marking system would be of a new kind, however, because the information transmitted by the auditory-vocal channel would be incorporated directly into the listener's knowledge of the external world rather than act as a releaser or elicitor of specialized behavior. Let me elaborate on this odd notion.

\section{Language as a Knowledge-System Available for Communication}

As I have pointed out before, animal communication is normally a system of commands to other animals that can be thought of as having co-evolved with the system of responses to those commands. The vervet calls are good examples of what I mean. We can think of the calls as danger signals that elicit appropriate escape action as the normal response. The cognitive dimension of this interaction could be completely absent; it probably is absent in most danger signals in most species, although for other reasons we can assume that it is present in vervets. In any case, normal animal communication need have no cognitive dimension.

The feature of human language that my scenario would emphasize is that it began as a cognitive rather than communicational adaptation. That it evolved into the characteristic communication system of our species implies that our communication is not like that of other mammals. Once the adaptation of using auditory and vocal signs to label the geographic environment had appeared, its utility for communication compared to normal communication with sign stimuli that release 'instinctive' behaviors 
in other members of the species is fairly obvious. This cognitive system for knowing an extended range, when used to communicate with another animal, could communicate the knowledge of the range, or other knowledge. What individual A knew could become part of what individual B knew if B merely listened while A vocalized. The only other species in which something close to this is believed to occur are echo-locating bats, which can intercept one another's calls and their echoes, and, in that sense, experience one another's worlds. I have speculated that this sort of thing could have developed in dolphins as well, and that the additional neural machinery in the dolphin's brain might process such information into something more nearly like human language (Jerison, 1986).

I should state this conclusion about language more dramatically. Since language contributes to our knowledge of reality in the same general way as information received by the conventional senses, such as the eye and ear, when we communicate with language we communicate information that contributes to our reality. The listener or reader receiving the message incorporates it into his or her reality and then knows the same world that we know as we communicate. Communication with language is, thus, a sharing of awareness or consciousness. We literally read minds when we read a realistic text and enter the minds of the characters as if we were living their fictional lives. This very common experience is really very odd, and it is one of the stranger features of the human mind.

\section{Consciousness}

This view of language leads to an unusual view of the nature of human consciousness in an evolutionary framework. There are two aspects of consciousness. The first, and biologically most important, is in connection with one's knowledge of the external world and should be thought of as the problem of awareness, or representation, or imagery. Why do we know a pictorial world with solid objects and so on? This is the more important biologically, because the evidence is overwhelming that all birds and mammals are conscious in this sense, and this may also be true for other vertebrates. Herrnstein (1985) has shown that pigeons can identify faces that people miss, presumably from pictorial cues. Griffin (1976) has argued for a universality for this kind of consciousness, or awareness, in a completely persuasive way. From my perspective, this means that in most vertebrates, certainly in birds and mammals, the work of the brain includes the construction of a possible real world from sense data, and that 'possible world' is the reality that the animal knows. The function of this construction is to make sense of an otherwise overwhelming mass of neural data that refers to the external world.

The other kind of consciousness involves an awareness of self that is unusual. It is not only the self as an object, which is really the same as any other object of which one may be aware or conscious in the first sense. It is the knowledge that the self is different from other objects in that it generates knowledge and knows that it knows. Why would this kind of self be created by a brain? A functional explanation is that this kind of self is necessary if one is to have human language as a dual adaptation for both perceptual/cognitive uses and for communication. Our knowledge of the external world is too important to be compromised by confusion about where it came from. If we can know another's external world simply by hearing (or reading) some statements, it is important that we be able to distinguish this known world from the reality that we know when our information comes through the usual sensory channels, e.g., when we see, hear and touch the external world. We can also know an external world by remembering it, and if our memories are verbalized that information, too, can enter into our awareness of the moment as information about the external world. The point is that language is so potent a medium for knowledge that it may be essential that knowledge carried by that medium be distinguished from other knowledge. By being self-conscious, we can distinguish images generated by the spoken or written word from images generated at the sensory and motor surfaces of the body in interaction with nonverbal external information. We can distinguish image from reality. It is another oddity about the mind that we don't always succeed in making the distinction, as any schizophrenic and many mystics and dreamers can tell us. 


\section{Acknowlegement}

I wish to thank my colleagues at the Hanse-Wissenschaftskolleg in Delmenhorst, Germany, where, as a Fellow, I prepared the final text for this contribution.

\section{References}

Boesch, C. \& Boesch, H. (1983). Optimization of nut-cracking with natural hammers by wild chimpanzees. Behaviour, 34, 265-86.

Gallup, G. G. (1979). Self-awareness in primates. American Scientist, 67, 417-21.

Griffin, D.R. (1976). The Question of Animal Awareness. New York: Rockefeller University Press.

Herrnstein, R.J. (1985). Riddles of natural categorization. Philosophical Transactions of the Royal Society (London), B 308, 129-44.

Horn, G. (1985). Memory, Imprinting, and the Brain. Oxford: Clarendon Press.

Jerison, H.J. (1986). The perceptual worlds of dolphins. In: Dolphin Cognition and Behavior: a comparative approach, ed. R.J. Schusterman, J. Thomas \& F.G. Wood, pp. 141-66. Hillsdale, N.J.: Erlbaum.

Jerison, H.J. (1991). Brain size and the evolution of mind: 59th James Arthur Lecture on the Evolution of the Human Brain. New York, American Museum of Natural History.

Kummer, H. \& Goodall, J. (1985). Conditions of innovative behaviour in primates. Philosophical Transactions of the Royal Society (London), B 308, 203-14.

Passingham, R. E. (1982). The Human Primate. San Francisco: Freeman.

Peters, R.P. \& Mech, L.D. (1975). Scent-marking in wolves. American Scientist, 63, 628-37.

Pickford, M. (1988). The evolution of intelligence: A palaeontological perspective. In: Intelligence and Evolutionary Biology, ed. H.J. Jerison \& I.L. Jerison, pp. 175-98. Heidelberg, Berlin, New York: Springer-Verlag.

Pilbeam, D. (1984). The descent of the hominoids and the hominids. Scientific American, 250(3), 84-96.

Premack, D. \& Kennell, K. (1978). Conservation of liquid and solid quantity by the chimpanzee. Science 202, 991 994.

Premack, D. \& Woodruff, G. (1978). Does the chimpanzee have a theory of mind? Behavioral and Brain Sciences, 4, 515-26.

Rasa, O.A.E. (1973). Marking behaviour and its social significance in the African Dwarf Mongoose, Helogale undulata rufula. Zeitschrift für Tierpsychologie, 32, 293-318.

Roeder, J.-J. (1983). Mémorisation des marques olfactives chez la Genette (Genetta genetta L.): durée de reconnaissance par les femelles de marques olfactives de males. Zeitschrift für Tierpsychologie, 61, 311-14.

Savage-Rumbaugh, E.S., Murphy, J., Sevcik, R.A., Brakke, K.E., Williams, S.L. \& Rumbaugh, D.M. (1993). Language comprehension in ape and child. Monographs of the Society for Research in Child Development, 58 (3-4), 1-254.

Squire, L.R. (1987). Memory and the Brain. New York \& Oxford: Oxford University Press. 


\section{Christoph P. E. Zollikofer \& Marcia S. Ponce de León}

\author{
Anthropological Institute \\ Institute of Computer Science/MultiMedia \\ Laboratory, University of Zurich-Irchel, \\ CH-8057 Zurich, Switzerland
}

Keywords: brain mapping, brain morphology, computerized fossil reconstruction, computer tomography, endocast, fossil hominids, Homo sapiens, medical imaging, MRL

\section{The Brain and its Case: Computer-based Case Studies on the Relation between Software and Hardware in Living and Fossil Hominid Skulls}

\begin{abstract}
Inferring brain function from the endocast morphology of a fossil skull involves three conceptually different steps: (1) reconstructiong the braincase from fossil fragments, (2) deriving the form of the brain from the braincase, and (3) iplying brain function from external brain morphological relationship between the brain and its case is generally limited.

We investigate the brain-bone relationship in modern human subject on the basis of clinical medical imaging data, using direct morphology. Basing on this evidence, we discuss possible implications for the inference of brain morphology and function from fossil hominid skulls.
\end{abstract}

\section{Introduction}

The evolutionary history of vertebrates, and especially that of hominids, is characterized by a general trend towards larger brain size and extensive cortical folding. While it is generally acknowledged that expansion of brain mass relative to body mass is an indicator of increased behavioural complexity, more specific issues such as the inferring of the functional significance of evolutionary changes in brain morphology remain a matter of continuous discussion (Holloway, 1991; Gannon et al., 1998). In hominid palaeoneurology, the analysis of brain evolution and function faces difficulties that originate from two distinct areas. First, brain shape has to be inferred from fossil evidence that is restricted to fragmentary remains of the hard tissue adjacent to the brain. Secondly, functional brain mapping, i.e. the correlation between morphology and functional regionalization of the brain, has to be performed by reference to extant species.

\section{Functional brain mapping}

In a long series of classical studies combining clinical and anatomical evidence of sensory-motor deficits, specific regions of the human brain, notably of the cortex, could be associated with specific cognitive and behavioural capacities. In areas directly related to sensory input or motor output, structurefunction relationships are traditionally described by maps, such as the well-known maps of somatotopic and retinotopic projection. The advent of new imaging technologies, notably functional magnetic resonance imaging (fMRI) and positron emission tomography (PET), has led to significant advances in non-invasive functional brain mapping (Roland \& Zilles, 1998). Originally designed for human test subjects, this approach has recently been extended to monkeys (Stefanacci et al., 1998) and steadily yields new insights into the functional relevance of various cortical and subcortical areas (Sereno, 1998). However, besides difficulties arising from the large intra-individual and inter-individual variability of fMRI and PET data sets, functional brain mapping has one major principal limitation. Many brain regions - notably those with particular phyletic significance, e.g. the frontal cortex - can only loosely be correlated with specific functions. This is mainly because complex brain functions are not necessarily confined to specific brain structures (Van Essen et al., 1998). 


\section{Fossil brain mapping}

While functional brain mapping in living subjects relies on both structural and behavioural data from one and the same individual, in fossil specimens, the sources of evidence are severely restricted. The cortical morphology is not preserved, and indirect evidence - the remains of the braincase or fossilized endocasts - is scarce, fragmentary and potentially distorted. Given the phylogenetic importance of brain morphology, however, it is tempting to infer brain function from the fossil evidence, using analogous information from extant species. In a fossil skull, this task involves three conceptually distinct steps: (1) reconstructing the braincase/endocast from fragmentary fossil remains, (2) inferring the external cerebral morphology from the endocast and (3) extrapolating brain function from external brain morphology, using analogies with extant species.

Using medical imaging procedures, it is possible to complete fragmentary fossil endocasts and to obtain estimates of cranial capacity (Conroy et al., 1990; Conroy et al., 1998). With the aid of dedicated graphics software and morphing algorithms, it is further possible to reconstruct endocasts from disarticulated and distorted fossil fragments (Zollikofer et al., 1995; Ponce de León \& Zollikofer, 1999).

This paper deals with the second step, establishment of a morphological link between the brain and its case. The question of how the braincase is related to the brain plays a central role in the interpreting of endocranial features in almost all studies dealing with hominid brain evolution. In his classical work on the external morphology of the primate brain, Connolly (1950) provided detailed information on endocranial versus brain morphology in a large number of primate species. With the advent of new technologies, it is now possible to tackle these problems in a quantitative and non-invasive way. Applying dedicated computer graphics procedures to medical imaging data sets from extant primate species, specifically from living human subjects, the in situ brain morphology can be directly related to the morphology of the surrounding braincase. From a palaeoneurological perspective, evidence provided by these studies can be used to extrapolate external brain morphology from the structure of a fossil endocast.

\section{Methods}

The morphology of endocranial structures was derived from serial cross-sectional images obtained by Computer Tomography (CT), Magnetic Resonance Imaging (MRI) and cryosections. The analyses were based on the Visible Male data set (cryosections, CT and MRI, see http://www.nlm.nih.gov/research/visible/visible_human.html) as well as on cranial CT data from patients not exhibiting brain-related disorders $(N=2)$. Using the special-purpose software toolkit FoRM-IT (Fossil Reconstruction and Morphometry Interactive Toolkit; Zollikofer et al., 1995; Zollikofer \& Ponce de León, 1995), various automated and semi-automated segmentation procedures were applied to extract and reconstruct three-dimensional geometric representations of (1) the external surface of the brain, (2) the internal surface of the braincase (i.e. the virtual endocast), and (3) the external surface of the bony cranial vault (Fig. 1). Typically, each surface structure consisted of $\sim 50$ 000-100 000 3D-data points connected to a polygon mesh. For every structure, the Gaussian surface curvature was evaluated at each point. Furthermore, distances between the brain and the endocast, as well as between the internal and external surfaces of the braincase (i.e. the bone thickness, see Fig. 1) were evaluated. Following these procedures, four different endocranial maps were generated for each individual, external brain curvature, endocranial curvature, brain-to-endocast distance, and cranial vault thickness (Fig. 2). The surface data were visualized on a high-performance graphics workstation (Silicon Graphics Onyx), local values of the morphometric parameters (curvature, distance) were visualized by applying grey-scale and false color transformations. Within each individual, the various maps were compared with each other, whereas between individuals, homologous maps were compared. 


\section{Results}

\section{The relation between the brain and its endocast}

Endocasts reflect external brain morphology on different levels of detail. Unless unrestrained by artificial or pathologic causes, the bones of the cranial vault adapt to the growing brain and therefore tend to reflect its overall shape. On a smaller scale, imprints of the cortical gyri and sulci are present on most endocasts. These structures are of major palaeoneurological interest as they convey information about the relative size of functional sub-units of the cortex. However, a variety of anatomical structures interfere with the direct mapping of brain shape and cortical surface structures onto the endocranium. The following effects have to be taken into account (Fig. 1):

- The cerebrospinal fluid pervading the space between the internal and external parts of the meninges keeps the brain in hydrostatic equilibrium. Given the fact that the brain is not fixed within its containment and that the thickness of the liquid-filled gap is variable, it can be expected that the match between cortical surface structures and endocranial imprints is rather loose.

- Structures associated with the cerebral and meningeal systems of blood supply and drainage, notably the venous sinuses and the meningeal arteries, hide or overlay external brain structures and therefore interfere with sulcal/gyral imprints.

- Dynamic responses of the cranial vault bones to stresses and strains evoked by the action of the masticatory apparatus as well as the postural musculature of the neck may modulate its overall shape.

These considerations show that the endocast is shaped by a variety of factors and therefore conveys information from diverse endocranial organs. As a consequence, the morphology of the cerebral surface can be recovered only partially from the endocast.

\section{Endocranial maps}

Using the concept of endocranial maps, it is possible to study more specifically which endocranial regions convey information about brain morphology. In this preliminary study, we report on comparisons between the four different endocranial maps that were created for each individual, namely brain curvature, endocast curvature, brain-to-endocast distance, and thickness of the brain case. Interindividual comparisons showed that the maps highlight distinct morphometric properties of the brain and/or the endocast (Fig. 2).

The brain curvature map quantifies the folding pattern of the cortical surface. As curvature measures local changes in surface orientation, this map represents the relative rather than the absolute volume of the cortical folds.

Following similar arguments, the endocranial curvature map shows the relative importance of imprints present on the surface of the bone.

Many aspects of the bone thickness map correspond to the former map for the following reasons: In all test subjects, the outer surface of the cranial vault bones turned out to be evenly curved, while the inner surface exhibited irregularities. Therefore, local fluctuations of bone thickness predominantly reflect local properties of the endocranial surface. Compared with endocranial curvature, the bone thickness map represents the absolute (volumetric) rather than the relative dimensions of the endocranial imprints.

The brain-to-endocast distance map represents dissimilarities between the shapes of the brain and of the endocranium, respectively. This can easily be verified by the following consideration: If the endocast surface followed the brain surface in detail, the distance map would exhibit a uniform distribution, regardless of the local curvature of the surfaces. Conversely, any fluctuation in the distance map corresponds to those parts of the external brain morphology that are not mapped onto the endocast.

The intra-individual comparison of the curvature maps of the brain and the endocast showed that there is considerable incongruence between the respective shapes of these structures. As a general rule, 


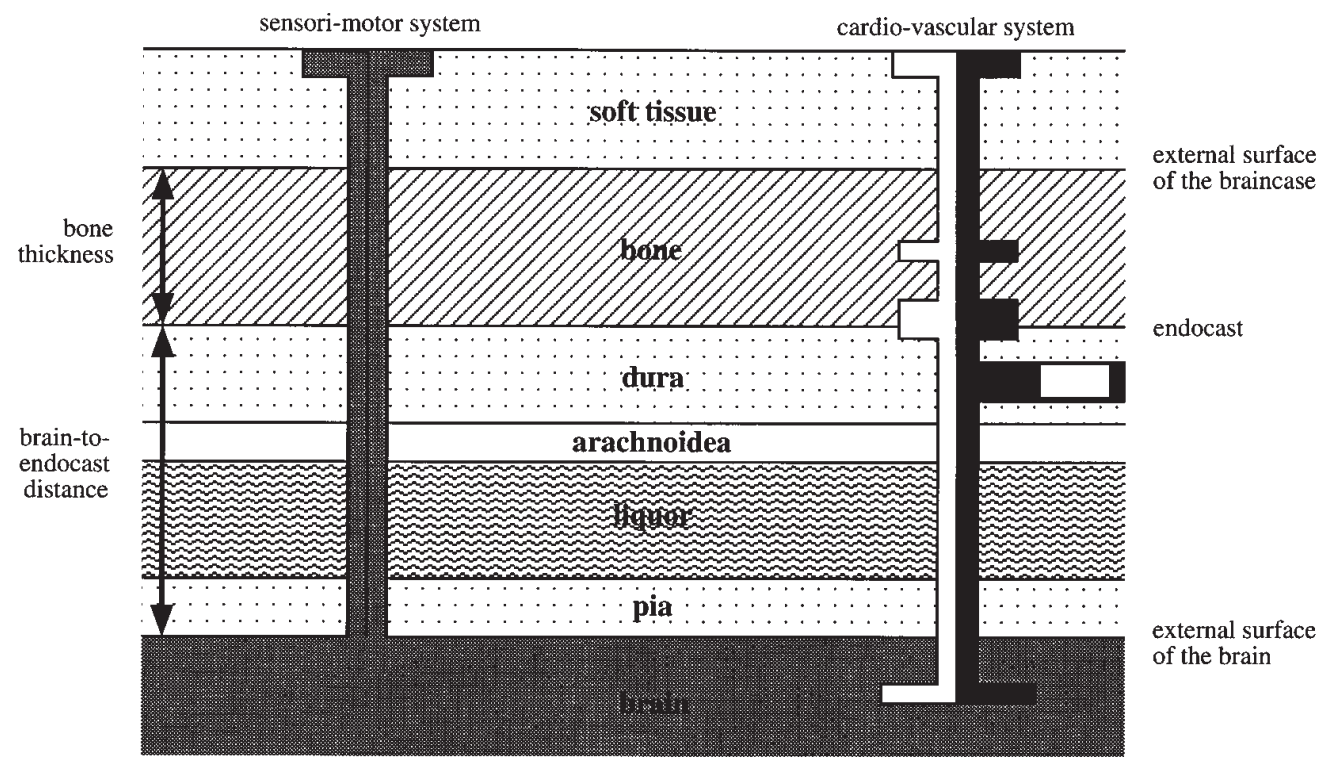

Figure 1. Schematic cross section through the outer region of a vertebrate skull.

it is possible to state that the imprints of meningeal vessels and venous sinuses dominate over cortical imprints on the endocast.

In all test subjects that we have examined so far, the distance maps reveal marked deviations between endocranial and cortical shapes in the regions of the larger cerebral fissures. On the other hand, details of the cortical folding pattern are comparatively weakly expressed on these maps. Following the above considerations, this signifies that larger brain structures are underrepresented on the endocranial surface while the smaller gyral-sulcal patterns are followed more closely by the endocast.

\section{Discussion}

How reliably can external brain morphology be extrapolated from endocast morphology? Our preliminary results show that the computer-generated endocranial maps presented in this study convey information on how different brain regions are represented on the endocranium and permit one to derive quantitative data about the relationship between the surface of the brain and the endocast in modern humans.

Although, in fossils, only two of these maps (the endocast curvature map and the bone thickness map) can be retrieved, they are of high palaeoneurological interest, because more complete data from extant species can serve as a reference against which possible implications of brain morphology from endocast morphology can be checked.

Our data on the correlation between endocranial curvature and brain surface curvature suggest that prominent cortical structures (such as the dominant fissures) are underrepresented relative to smaller structures (such as the local folding pattern). These findings can be explained by the fact that larger cerebral grooves tend to be filled by a variety of anatomical structures, many of which are related to blood supply and drainage. On the other hand, imprints of smaller cerebral structures such as the local 

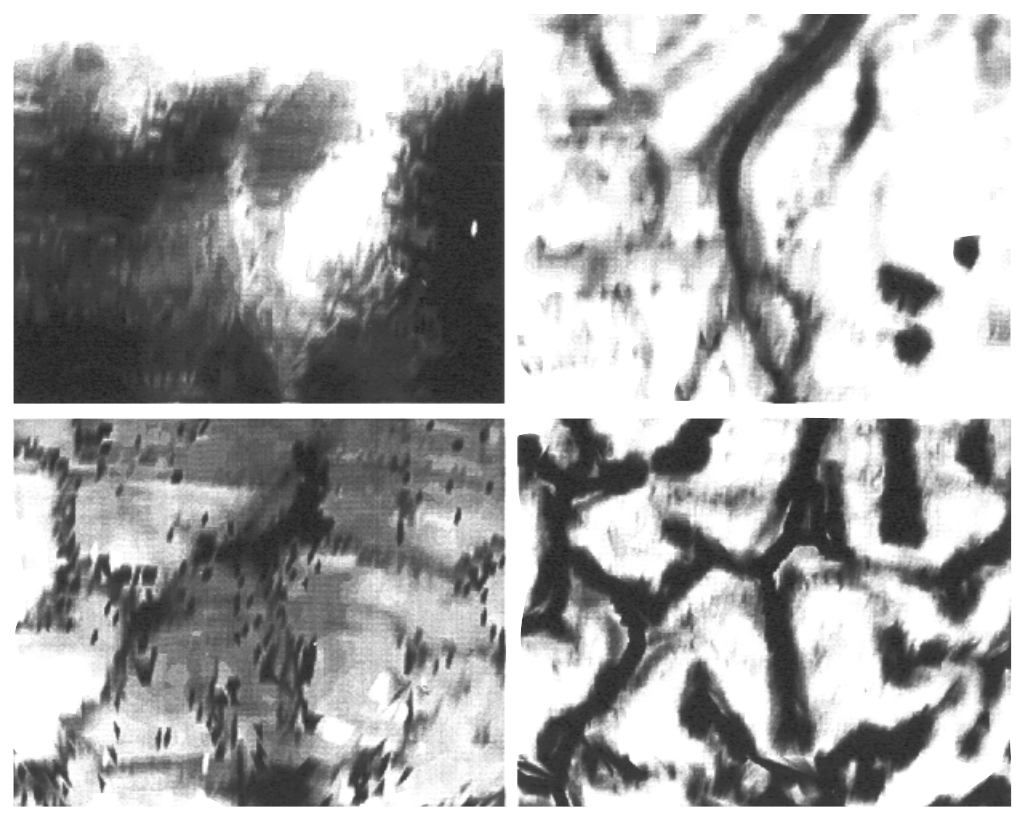

Figure 2. Grey-scale maps of brain curvature (top left), brain-to-endocast distance (top right), endocast curvature (bottom left) and bone thickness (bottom right). All maps comprise the same area of the left hemisphere around the central fissure (Visible Male data set).

cortical folding pattern tend to be over-represented because in these regions relatively little tissue is intercalated between the brain and the endocast. Similar inferences can be drawn from the brain-toendocast distance maps. The disparities between the external surface of the brain and the internal surface of the braincase are most pronounced in the region of the larger sulci, whereas the endocast appears to follow smaller cerebral structures more tightly. This point needs further investigation. Nevertheless, it can be stated that the 'goodness of fit' between endocast and brain morphology shows large regional differences.

Furthermore, our data show extended inter-individual and intra-individual variability of sulcal and gyral cortical patterns. Variability of the folding pattern of the cortical surface in modern humans is welldocumented and forms a major problem in localizing specific functional regions, notably with respect to concordance of neuroanatomical atlases and neurosurgical applications. The situation is even more complex, as recent studies on human test subjects demonstrate significant individual variability in the retinotopic mapping in the region of the calcarine fissure (Aine et al., 1996). Recent studies suggest that similar patterns of variability are also present in chimpanzees (Holloway et al., this volume).

With respect to palaeoneurology, the above results have the following consequences. If we consider the tendency of endocasts to enhance small-scale cortical folding patterns and take into account the individual variability of these structures, it can be expected that any inferences drawn from endocast morphology on external brain morphology are biased towards individual patterns. In extant species, this problem can be overcome by large sample sizes. In palaeoanthropology, however, sample sizes are small and inferences drawn are often far-reaching with respect to both phylogeny and behavior. It is therefore 
important to consider which endocranial structures reflect individual variation and consequently do not bear a phylogenetic signal and which can be used to draw phylogenetic and/or functional inferences.

One of the principal aims of paleoneurology consists in deriving brain function from brain morphology. Here, we have presented a quantitative approach that utilizes the indirect evidence of the endocast morphology to extrapolate brain function via cortical morphology. While further work is necessary to find specific quantitative surface parameters that permit one to gather correlative information about the endocast and its brain, it appears that endocast morphology is only one of many possible indicators of brain function. Fortunately, various complementary sources of information are available, from direct behavioural traces such as tools and footprints, to anatomical structures reflecting the sensorimotor or vascular system such as the foramina of the cranial base or the structures of the inner ear. A synopsis of the gathered evidence will lead to a better understanding of fossil brain function and evolution.

\section{Acknowledgement}

This work was supported by Swiss NSF grant \#31-42491.94.

\section{References}

Aine, C., Supek, S., George, J., Ranken, D., Lewine, J., Sanders, J., Best, E., Tiee, W., Flynn, E. \& Wood, C. (1996). Retinotopic organization of human visual cortex: departures from the classical model. Cerebral Cortex, 6, 354-61.

Connolly, C. J. (1950). External Morphology of the Primate Brain: Springfield, Ill.: Thomas.

Conroy, G. C., Vannier, M. W. \& Tobias, P. V. (1990). Endocranial features of Australopithecus africanus revealed by 2D and 3D computed tomography. Science, 247, 838-41.

Conroy, G., Weber, G., Seidler, H., Tobias, P., Kane, A. \& Brunsden, B. (1998). Endocranial capacity in an early hominid cranium from Sterkfontein, South Africa. Science, 280, 1730-31.

Gannon, P. J., Holloway, R. L., Broadfield, D. C. \& Braun, A. R. (1998). Asymmetry of chimpanzee planum temporale: human-like pattern of Wernicke's brain language area homolog. Science, 279, 220-22.

Holloway, R. L. (1991). On Falk's 1989 accusations regarding Holloway's study of the Taung endocast: a reply. American Journal of Physical Anthropology, 84, 87-91.

Ponce de León, M. S. \& Zollikofer, C. P. E. (1999). New morphometric evidence from Le Moustier 1: Computerassisted reconstruction and morphometry of the skull. Anat. Rec., 254, 474-89.

Roland, P. \& Zilles, K. (1998). Structural divisions and functional fields in the human cerebral cortex. Brain Research - Brain Research Reviews, 26, 87-105.

Sereno, M. I. (1998). Brain mapping in animals and humans. Current Opinion in Neurobiology, 8, 188-94.

Stefanacci, L., Reber, P., Costanza, J., Wong, E., Buxton, R., Zola, S., Squire, L. \& Albright, T. (1998). fMRI of monkey visual cortex. Neurotechnique, 20, 1051-57.

Van Essen, D., Drury, H., Joshi, S. \& Miller, M. (1998). Functional and structural mapping of human cerebral cortex: solutions are in the surfaces. Proceedings of the National Academy of Sciences of the United States of America, 95, 788-95.

Zollikofer, C. P. E. \& Ponce de León, M. S. (1995). Tools for rapid prototyping in the biosciences. IEEE Computer Graphics and Applications, 15, 48-55.

Zollikofer, C. P. E., Ponce de León, M. S., Martin, R. D. \& Stucki, P. (1995). Neanderthal computer skulls. Nature, 375, 283-85. 